\title{
REGIONAL SEISMIC ATTRIBUTE ANALYSIS AND TECTONO- STRATIGRAPHY OF OFFSHORE SOUTH-WESTERN TARANAKI BASIN, NEW ZEALAND
}

by

Jan Robert Baur

\begin{abstract}
A thesis
submitted to the Victoria University of Wellington in fulfilment of the requirements for the degree of Doctor of Philosophy in Geophysics
\end{abstract}

Victoria University of Wellington 


\begin{abstract}
This study investigates the nature, origin, and distribution of Cretaceous to Recent sediment fill in the offshore Taranaki Basin, western New Zealand. Seismic attributes and horizon interpretations on $30,000 \mathrm{~km}$ of $2 \mathrm{D}$ seismic reflection profiles and three $3 \mathrm{D}$ seismic surveys $\left(3,000 \mathrm{~km}^{2}\right)$ are used to image depositional systems and reconstruct paleogeography in detail and regionally, across a total area of $\sim 100,000 \mathrm{~km}^{2}$ from the basin's present-day inner shelf to deep water. These data are used to infer the influence of crustal tectonics and mantle dynamics on the development of depocentres and depositional pathways.
\end{abstract}

During the Cretaceous to Eocene period the basin evolved from two separate rifts into a single broad passive margin. Extensional faulting ceased before $85 \mathrm{Ma}$ in the present-day deep-water area of the southern New Caledonia Trough, but stretching of the lithosphere was higher $(\beta=1.5-2)$ than in the proximal basin $(\beta<1.5)$, where faulting continued into the Paleocene ( $\sim 60 \mathrm{Ma})$. The resulting differential thermal subsidence caused northward tilting of the basin and influenced the distribution of sedimentary facies in the proximal basin. Attribute maps delineate the distribution of the basin's main petroleum source and reservoir facies, from a $\sim 20,000 \mathrm{~km}^{2}$-wide, Late Cretaceous coastal plain across the present-day deep-water area, to transgressive shoreline belts and coastal plains in the proximal basin.

Rapid subsidence began in the Oligocene and the development of a foredeep wedge through flexural loading of the eastern boundary of Taranaki Basin is tracked through the Middle Miocene. Total shortening within the basin was minor (5-8\%) and slip was mostly accommodated on the basin-bounding Taranaki Fault Zone, which detached the basin from much greater Miocene plate boundary deformation further east. The imaging of turbidite facies and channels associated with the rapidly outbuilding shelf margin wedge illustrates the development of large axial drainage systems that transported sediment over hundreds of kilometres from the shelf to the deep-water basin since the Middle Miocene.

Since the latest Miocene, south-eastern Taranaki Basin evolved from a compressional foreland to an extensional (proto-back-arc) basin. This structural evolution is 
characterised by: 1) cessation of intra-basinal thrusting by 7-5 Ma, 2) up to $700 \mathrm{~m}$ of rapid (>1000 m/my) tectonic subsidence in 100-200 km-wide, sub-circular depocentres between 6-4 Ma (without significant upper-crustal faulting), and 3) extensional faulting since 3.5-3 Ma. The rapid subsidence in the east caused the drastic modification of shelf margin geometry and sediment dispersal directions. Time and space scales of this subsidence point to lithospheric or asthenospheric mantle modification, which may be a characteristic process during back-arc basin development.

Unusual downward vertical crustal movements of $>1 \mathrm{~km}$, as inferred from seismic facies, paleobathymetry and tectonic subsidence analysis, have created the present-day Deepwater Taranaki Basin physiography, but are not adequately explained by simple rift models. It is proposed that the distal basin, and perhaps even the more proximal Taranaki Paleogene passive margin, were substantially modified by mantle processes related to the initiation of subduction on the fledgling Australia-Pacific plate boundary north of New Zealand in the Eocene. 


\section{ACKNOWLEDGEMENTS}

First of all, I would like to thank my advisors Tim Stern, Beate Leitner, and particularly Peter King for their guidance and support during the last four years. Peter's in-depth knowledge about the basin and thorough reviewing has greatly improved the consistency of this thesis. I am grateful for Tim's scientific input and facilitating my attendance of local and overseas conferences. Thanks to Beate for the opportunity to work in New Zealand and her continued involvement in the project.

Throughout the course of this thesis, I have benefited from the encouraging and openminded research culture at GNS Science. I have very much appreciated collaborating on projects with Rupert Sutherland, Andy Nicol, and Chris Uruski, and I would like to thank them for sharing their time, data, and impressive expertise. Many thanks go to Kyle Bland and Dom Strogen for thought-provoking discussions, reviewing parts of the thesis, and teaching me various aspects of geology and software usage. I am indebted to many of my colleagues for their invaluable technical and scientific support and I would like to particularly thank Mike Milner, Lucia Roncaglia, Rob Funnell, Vaughan Stagpoole, Brad Ilg, Brad Field, Hugh Morgans, Miko Fohrmann, Eva Reid, Hai Zhu, Craig Jones, Malcolm Arnot, Matt Hill, Karsten Kroeger, and Paul Viscovic. Cheers to Deanne Houghton for the painstaking task of formatting this manuscript. This thesis could have not been brought to completion without the financial support provided by the Ministry of Science and Innovation and GNS Science, and I am grateful to Mike Isaac and Kevin Faure for promoting my scientific work. I acknowledge Schlumberger Petrel, Midland Valley, and especially Paul de Groot from DGB Earth Sciences for the provision of academic software licenses and training.

Thanks to my fellow students and good mates Yannik, Micko, Erik, and Nico for the great times both inside the office and outside. There may not be many better ways for relieving thesis pressure than a little Wairarapa surfing mission, an educational rulerbeating, or a healthy serving of smack-talk with you guys. I would also like to thank my other friends that have sweetened my time in New Zealand over the last four years. Special thanks go to my parents and sisters for being so supportive of my studies and escapades in far-away countries. Finally, I owe the most to my partner and best friend Karly Christ for her persistent love, patience, and support during times of long working hours. 


\section{TABLE OF CONTENTS}

ABSTRACT

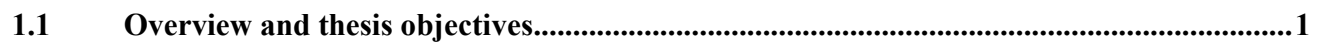

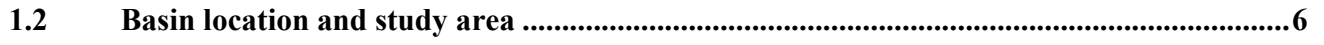

1.3 Previous work and contributions of this thesis ....................................................................6

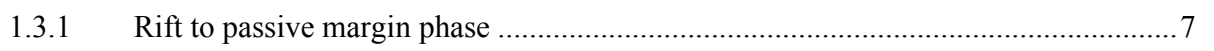

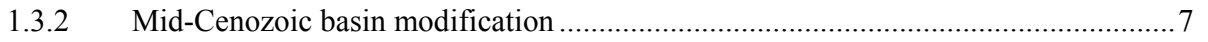

1.3.3 Miocene regressive phase ............................................................................ 8

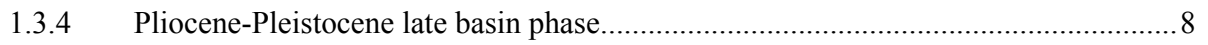

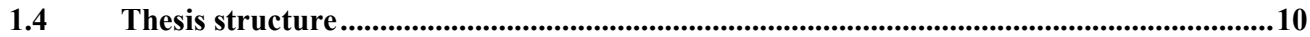

CHAPTER 2 DATA AND METHODS _ 13

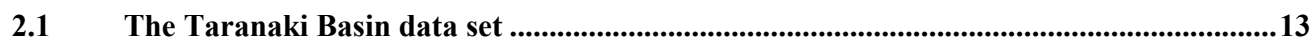

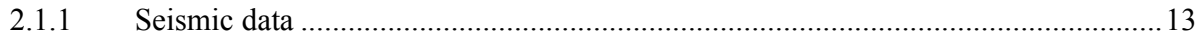

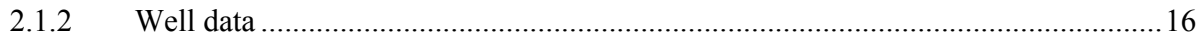

2.1.3 Time-to-depth curves and seismic-to-well ties .................................................... 18

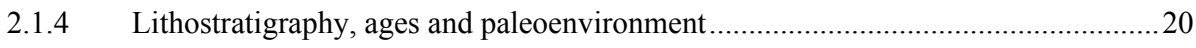

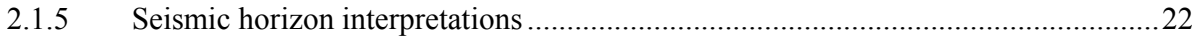

2.2 Methods and their application in Taranaki Basin................................................................27

2.2.1 Seismic stratigraphy, seismic facies and seismic geomorphology............................27

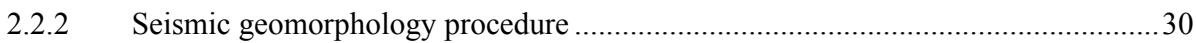

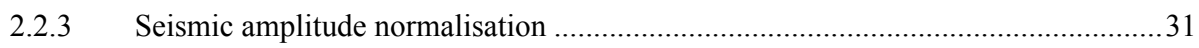

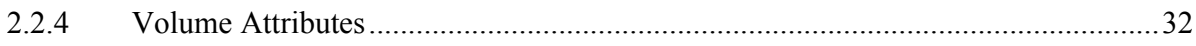

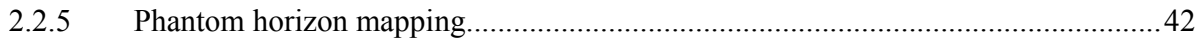

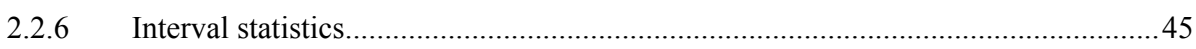

2.2.7 Attribute gridding and map normalisation.......................................................... 47

2.2.8 Tectonic subsidence and back-stripping ............................................................. 49

CHAPTER 3 TECTONO-STRATIGRAPHIC EVOLUTION OF SOUTHERN OFFSHORE TARANAKI BASIN: CONSTRAINTS FROM REGIONAL 2D-PALINSPASTIC RESTORATION OF SEISMIC REFLECTION DATA

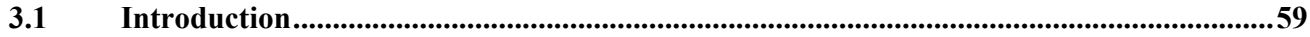

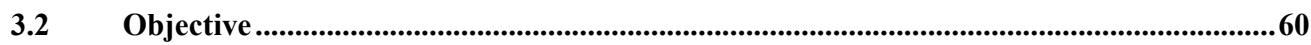

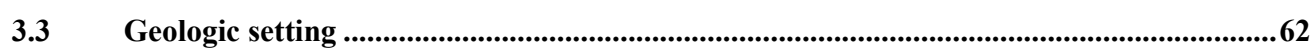

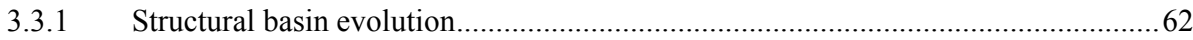

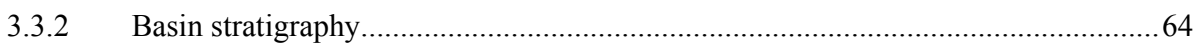

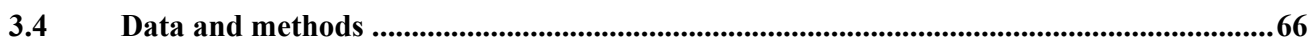




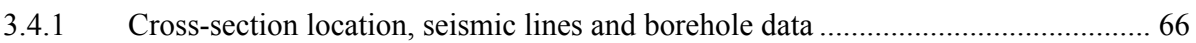

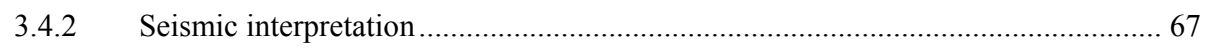

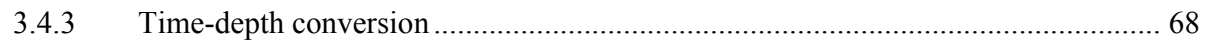

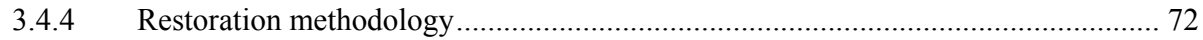

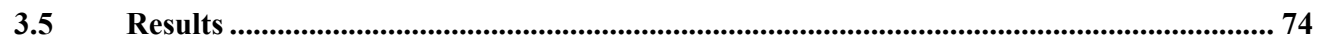

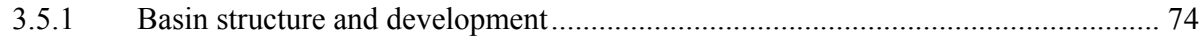

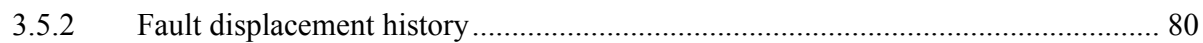

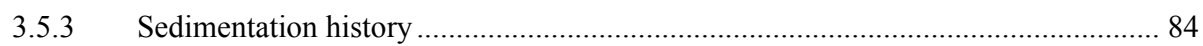

3.5.4 Neogene structural modification of Cretaceous strata …........................................ 87

3.5.5 Neogene structural development of the Western Platform ....................................... 88

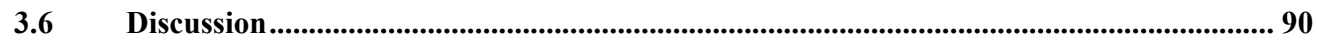

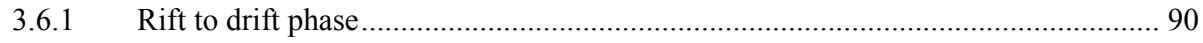

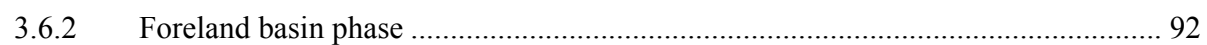

3.6.3 Formation of the Toru Trough and western Wanganui Basin................................... 95

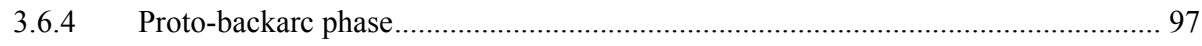

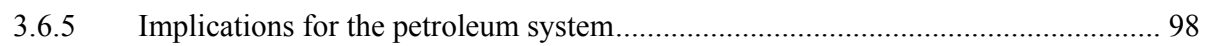

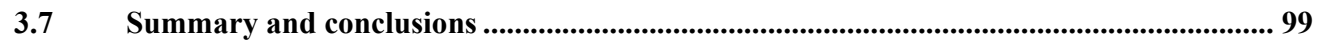

CHAPTER 4 CRETACEOUS TO EOCENE SEISMIC FACIES AND PALEOGEOGRAPHIC DEVELOPMENT: FROM TWO RIFTS TO A PASSIVE MARGIN

Introduction ............................................................................................................................101

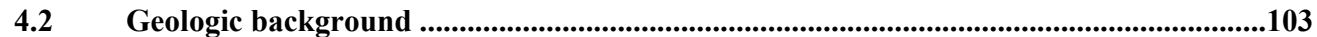

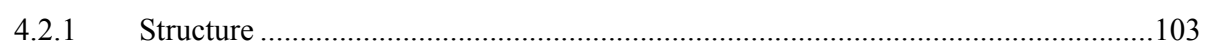

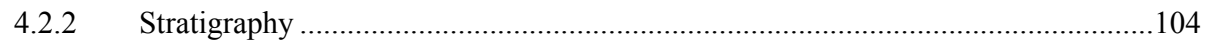

4.3 Boreholes, seismic data, and seismic horizon interpretations .........................................109

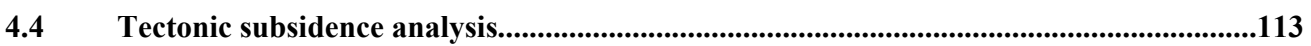

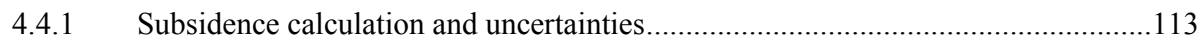

4.4.2 Cretaceous to Eocene tectonic subsidence history ..............................................113

4.5 Seismic stratigraphy and facies interpretation .................................................................117

4.5.1 Well data interpretation and seismic facies characteristics ...................................117

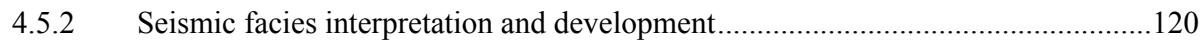

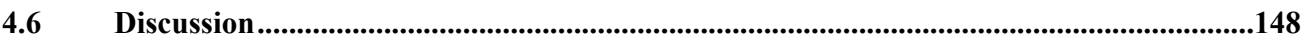

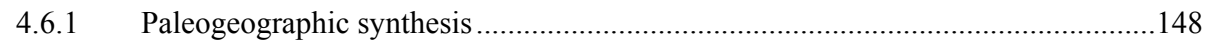

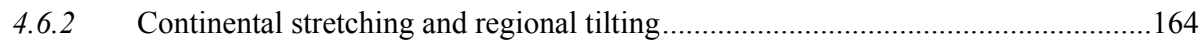

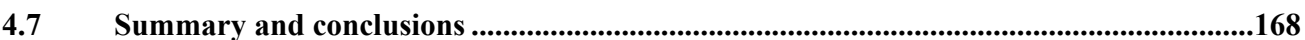


$5.1 \quad$ Introduction

5.2 Subsidence signatures of basin-forming processes ........................................................172

5.3 Geologic background on the New Caledonia Trough .........................................................174

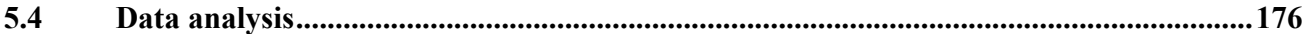

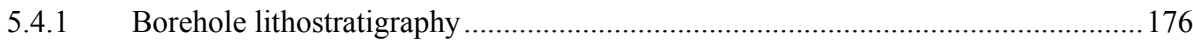

5.4.2 Biostratigraphic age and paleobathymetry ........................................................ 179

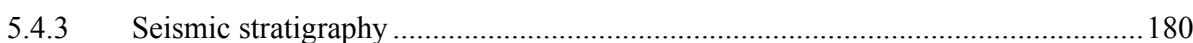

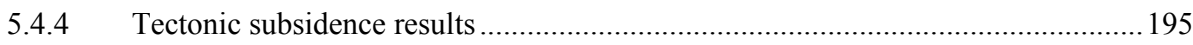

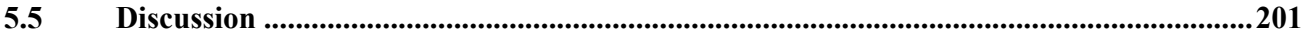

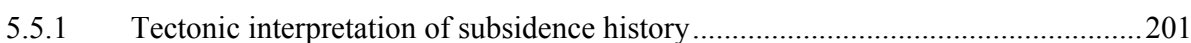

5.5.2 Tectonic processes that created the NCT deep-water basin...................................204

5.5.3 Sedimentary architecture of deep-water basins ….................................................208

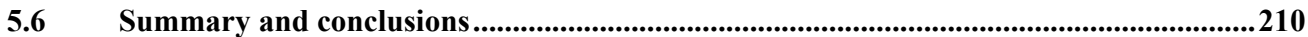

CHAPTER 6 DEVELOPMENT OF SHELF TO DEEP-WATER SEDIMENTARY SYSTEMS IN THE MIOCENE TARANAKI FORELAND BASIN

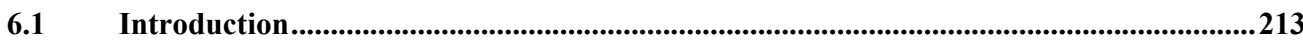

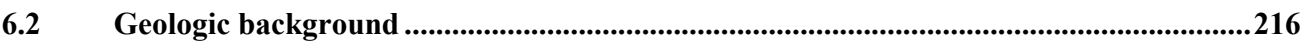

6.2.1 Depositional systems, turbidites and sub-marine fans ........................................2. 216

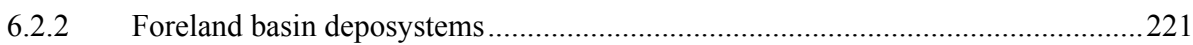

6.2.3 Review of Miocene Taranaki Basin stratigraphy …............................................22

6.2.4 Miocene paleogeographic development of Taranaki Basin ...................................224

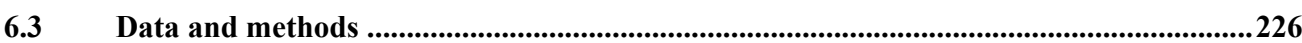

6.3.1 Seismic data, interpreted horizons and stratal slicing .........................................226

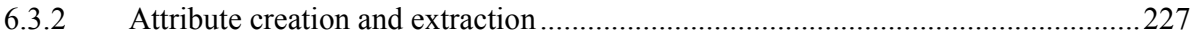

6.3.3 Subdivision of intervals and biostratigraphic stage boundaries.............................228

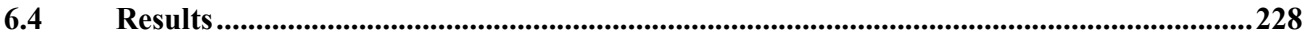

6.4.1 Well lithostratigraphy and paleo-environment …..................................................228

6.4.2 Basin evolution from $2 \mathrm{D}$ and 3D seismic reflection data .....................................2 231

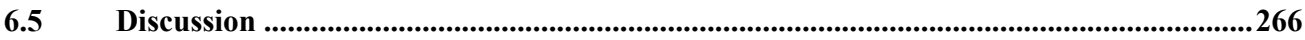

6.5.1 Characteristics of slope to basin floor channels.....................................................266

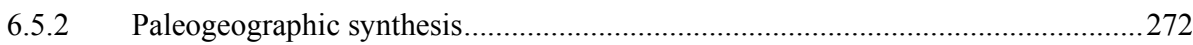

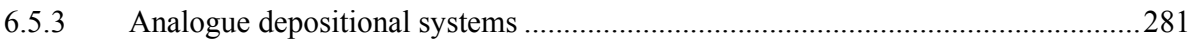

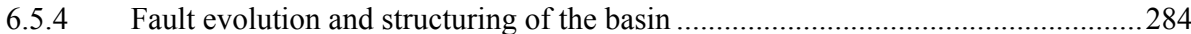

6.5.5 Controls on sedimentation and turbidite deposition ...............................................2. 285

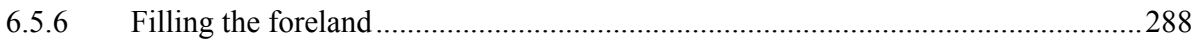

6.5.7 Implications for hydrocarbon prospectivity.......................................................2. 290 


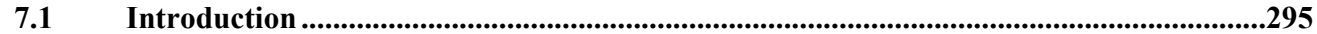

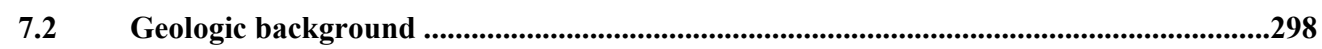

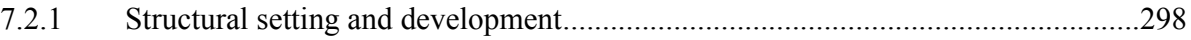

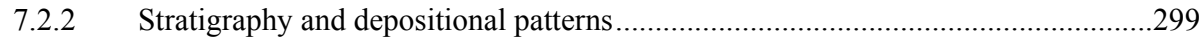

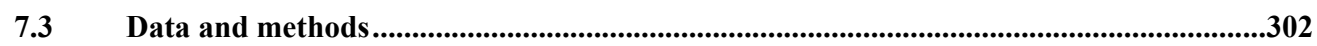

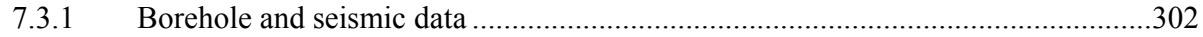

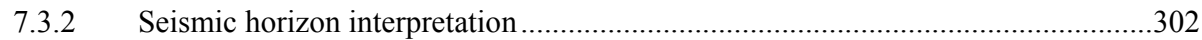

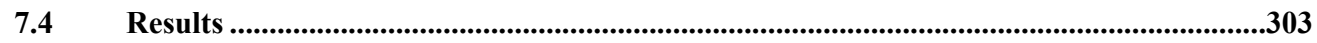

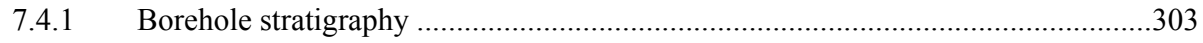

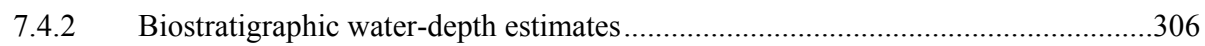

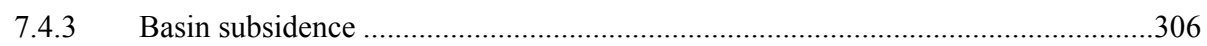

7.4.4 Structural basin evolution from seismic isochron maps.........................................309

7.4.5 Seismic facies overview and lithology interpretation ............................................311

7.4.6 Seismic facies distribution and development of depositional systems......................315

7.4.7 Chronostratigraphy and sequence stratigraphy of Plio-Pleistocene

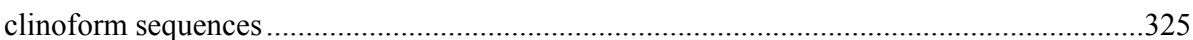

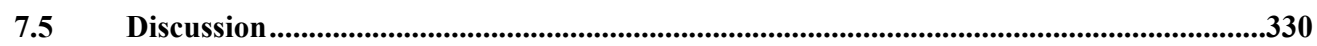

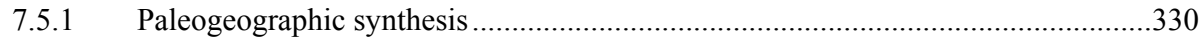

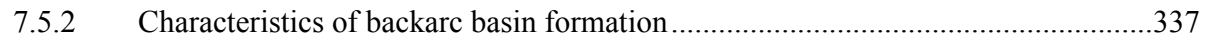

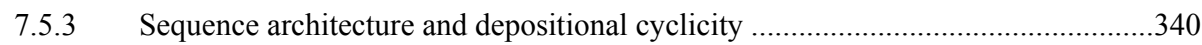

7.6 Summary and Conclusions …....................................................................................................344

CHAPTER 8 SYNOPSIS

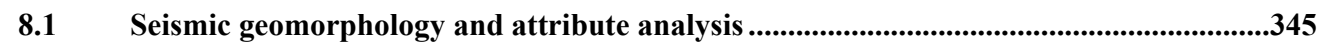

8.2 Taranaki Basin development ...................................................................................................346

\section{SUPPLEMENTARY CD}

SUPPLEMENT 1 Summary of seismic and well data.

SUPPLEMENT 2 Tectonic subsidence calculations.

SUPPLEMENT 3 Basin structure and development 


\section{LIST OF FIGURES}

Figure 1.1

Figure 1.2

Figure 1.3

Figure 2.1

Figure 2.2

Figure 2.3

Figure 2.4

Figure 2.5

Figure 2.6

Figure 2.7

Figure 2.8

Figure 2.9

Figure 2.10

Figure 2.11

Figure 2.12

Figure 2.13

Figure 2.14

Figure 2.15

Figure 2.16

Figure 2.17

Figure 3.1

Figure 3.2

Figure 3.3

Figure 3.4

Figure 3.5

Figure 3.6

Figure 3.7

Figure 3.8

Figure 3.9

Figure 3.10

Figure 3.11

Figure 3.12

Figure 3.13

Figure 4.1
Structural and physiographic overview of North Island and surrounding basins. 4

Seismic and well data coverage of Taranaki Basin and surrounding regions. .5 Overview map of sedimentary outcrop localities, general basin structure, and petroleum accumulations within the basin. 9

Overview map of the seismic and well data set used in this study. 15

Maps of Taranaki Basin showing the location of wells used in this study... 18

Example of available well data 19

Stratigraphy of the central southern Taranaki Basin. 21

Marine paleoenvironment classification scheme .22

Correlation of seismic horizon interpretations and well data ..........................................26

Schematic nature of seismic reflection terminations.......................................................30

Seismic facies expression on the different attributes used in this study.............................34

Schematic representation of the Unsupervised Vector Quantiser (UVQ) ...........................37

Schematic concept of dip-steered reflector auto-tracking ...................................................41

Schematic depiction of different phantom horizon mapping techniques ............................43

Example of mapped horizons and stratal slices..................................................................4

Example of stratal slicing in progradational sedimentary systems....................................45

Interval attribute extractions and seismic profiles.............................................................

Example of regional 2D attribute map creation ...........................................................48

Theoretic compaction diagram of Taranaki Basin lithologies .........................................52

Back-stripped subsidence curves of Taranaki Basin .........................................................56

Overview map of the composite seismic line used for restoration and wells.....................61

Tectonostratigraphic summary of the Taranaki Basin........................................................66

Comparison between depth-converted horizons and formation tops .................................69

Composite cross-section with well locations .................................................................71

Structurally balanced cross-sections for intervals between $85-34 \mathrm{Ma}$................................76

Structurally balanced cross-sections for intervals between 24-11 Ma ...............................77

Structurally balanced cross-sections for intervals between 7-4 Ma ...................................79

Structurally balanced cross-sections for intervals between 3-1 Ma.Error! Bookmark not defined.

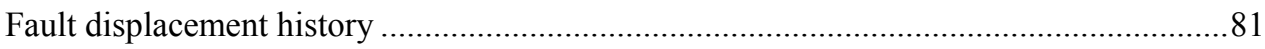

Sedimentation history of decompacted formation thicknesses..........................................86

Structural evolution of the Top Cretaceous horizon since the Early Miocene ....................88

Structural evolution of the Base Oligocene horizon on the Western Platform....................89

Summary map of relative horizontal shortening and extension across the basin ...............92

Map of Taranaki Basin showing Cretaceous structural elements and sub-basins

102 
Figure 4.3 Chronostratigraphic framework of Late Cretaceous to Oligocene strata

Figure 4.4 Basemap of seismic lines used to display the seismic facies development.

Figure 4.5

Regional isochron maps calculated over Cretaceous to Eocene intervals.

Figure 4.6

Back-stripped subsidence calculated for selected wells.

Figure 4.7

Back-stripped subsidence plots in different regions within the basin.

Stratal interval attribute maps showing the development from terrestrial to marine conditions during the Early to Middle Eocene......

Stratal interval attribute maps showing the development of shoreline systems from the Middle to Late Eocene. 
Figure 4.37 Tectonic setting during the two rifting phases evidenced in Taranaki Basin

Figure 5.1

Map of western New Zealand and the study area

Figure 5.2

Summary chart of tectono-stratigraphic evolution of the Taranaki Basin region. 176

Figure 5.3 Correlation panel of wells used in this study

Figure 5.4

Seismic composite line from well Tane-1 to the northwest. 182

Figure 5.5

Seismic line DTB01-20. 182

Figure 5.6

Root mean square amplitude extracted from three formation subintervals. 183

Figure 5.7 Isochron maps calculated from gridded horizon interpretation. 184

Figure 5.8

Figure 5.9

Figure 5.10 Isopach maps calculated from depth-converted horizon interpretations 185

Figure 5.11 Seismic composite line from well Ariki-1 to Waka Nui-1 187

Seismic line DTB01-04. 188

Figure 5.12

Paleobathymetry indicators from seismic data..... 190

Figure 5.13

Summary of paleobathymetry indicators 193

Figure 5.14

Gridded paleobathymetry interpretations

Figure 5.15

Tectonic subsidence history from back-stripped well data and seismic grids

Figure 5.16

Calculated tectonic subsidence from seismic horizon interpretations.

Figure 5.17

Tectonic subsidence history extracted from back-stripped seismic grids 200

Figure 5.18 Eocene to Miocene tectonic subsidence profile across Deepwater Taranaki Basin .202

Figure 6.1 Satelite gravity map of the offshore area

Figure 6.2 Overview map of Taranaki Basin.

Figure 6.3

Figure 6.4

Figure 6.5

Figure 6.6

Figure 6.7

Schematic models of depositional and structural elements of continental margins.

Gross depositional environments and log responses of deep-water clastic systems .221

Chronostratigraphic panel of Oligocene to Recent strata in central Taranaki Basin........223

Paleogeographic interpretations from previous studies. 225

Well panel showing selected boreholes with representative facies content 230

Figure 6.8 Isochron maps calculated from gridded seismic horizon interpretations

Figure 6.9

Regional EW-seismic composite line across the basin

Figure 6.10

Altonian to Clifdenian depositional systems

Figure 6.11

Attribute maps of Clifdenian to lower Lilburnian depositional systems.

Figure 6.12

Three-dimensional perspective views of Miocene facies distribution 240

Figure 6.13

Lillburnian and Clifdenian channel systems on Maui 3D attribute maps

Figure 6.14 RMS amplitude extractions between the N40 and N30 reflectors

Figure 6.15 Depositional systems of inferred Waiauan age

Figure 6.16 Stratal interval attribute maps and seismic sections from the Maari 3D survey........

Figure 6.17 
Figure 6.19 Regional attribute maps extracted between the N40 and N50 horizons.

Figure 6.20 Attribute maps and seismic profile from the Maui 3D survey showing characteristics of Late Miocene channel systems.

Figure 6.21

Upper Tongaporutuan- to Kapitean-aged depositional systems. 255

Figure 6.22 Attribute map extracted from meta-attribute volume of 2D survey..... .257

Figure 6.23 Slope channel mega-systems.on composite attribute maps 260

Figure 6.24 Seismic profiles of Middle and Late Miocene slope channel mega-systems.

Figure 6.25

Schematic illustration of procedure to measure clinoform foreset heights. 263

Figure 6.26 Decompacted heights of Miocene to Recent foresets. 265

Figure 6.27 Location of clinoform measurements on perspective view of Taranaki Basin 265

Figure 6.28 Characteristics of Miocene channel systems in Taranaki Basin . 267

Figure 6.29

Outlines of Miocene channel systems mapped in the Maui 3D data set...... 268

Figure 6.30 Sinuosity and width of Miocene channel systems imaged in the Maui 3D survey....... 271

Figure 6.31

Figure 6.32 Paleogeographic legend and Altonian to Clifdenian paleogeographic interpretation

Figure 6.33 Clifdenian and Lillburnian paleogeographic interpretations.

Figure 7.7

Seismic composite profiles across the Western Platform and the Toru Trough

Figure 7.8 Seismic profile of Late Miocene to Recent strata in the Toru Trough

Figure 7.9 
Figure 7.18 Latest Miocene-Early Pliocene and Early Pliocene paleogeographic interpretations .......332

Figure 7.19 Early Late Pliocene and latest Pliocene paleogeographic interpretations .......................333

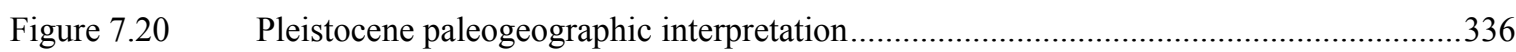

Figure 7.21 Profiles across the North Island, Wanganui, and Taranaki Basin ................................339

Figure 7.22 Summary of global sea-level estimates and base-level changes in Taranaki Basin.........343

Figure 8.1 Summary of the tectono-sedimentary evolution of Taranaki Basin ..............................349

\section{LIST OF TABLES}

Table 2.1 List of wells used in this study. .17

Table 2.2 cont. $\quad$ List of 17 seismic horizons interpreted on local seismic grids......................................25

Table 2.3 Seismic facies character and geologic interpretation .29

Table 2.4 Examples of training results from an unsupervised neural neural network classification . .39

Table 2.5 Lithology parameters after Funnell et al. (1996) ..........................................................51

Table 3.1 Seismic reflection profiles used for the construction of the composite cross-section ........67

Table 3.2 Seismic horizons and formation parameters used in this chapter....................................68

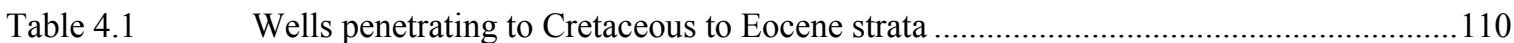

Table 4.2 Seismic facies, simplified wireline log character, and environmental facies ..................120

Table 5.1 Tectonic subsidence calculated from borehole stratigraphy .......................................197

Table 5.2 Tectonic subsidence history extracted from back-stripped seismic grids .....................200

Table 6.1 List of seismic horizon interpretations used in this chapter. ........................................227

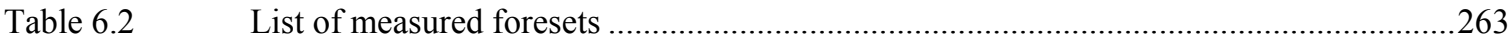

Table $7.1 \quad$ List of seismic horizon interpretations used in this chapter. ........................................303 



\section{CHAPTER 1 INTRODUCTION}

\subsection{OVERVIEW AND THESIS OBJECTIVES}

This thesis examines the geologic evolution of the greater Taranaki Basin, within an area that is located beneath shelf to deep marine waters west of New Zealand's North Island (Figure 1.1). Taranaki Basin is part of a series of neighbouring and interconnected Cretaceous and Cenozoic sedimentary basins that are presently situated in the western hinterland of the Australia-Pacific convergent plate margin. With a surface area of about $300,000 \mathrm{~km}^{2}$, Taranaki Basin represents one of the country's largest sediment repositories (Stagpoole et al., 2002) and contains a nearly complete record of Late Cretaceous and Cenozoic terrestrial to deep-water strata (King \& Thrasher, 1996). Taranaki Basin represents a favourable laboratory for studying basin formation and sedimentary processes because:

- The basin bestrides the western limit of Cenozoic plate boundary deformation, but is located beyond the influence of destructive uplift and erosion that is found closer to the plate boundary. The preserved sedimentary succession of Taranaki Basin thus holds vital information about the geologic evolution of the New Zealand sub-continent (now increasingly referred to as Zealandia), from the break-up of Gondwana through to the progressive development of the AustraliaPacific plate boundary.

- The basin has had a dynamic and episodic history of extension and compression, providing information about tectono-stratigraphic character and relationships in both rift and convergent margin settings.

- $\quad$ More than 400 petroleum exploration and production wells have been drilled and high-quality seismic reflection data sets cover the basin from the western shores to deep-water marine environments (Figure 1.2). Collectively, these data represent the country's densest offshore subsurface geologic and geophysical data set, and provide the basis for a comprehensive analysis of the basin's development. 
A series of studies conducted between the late 1970s and middle 1990s in the area of the modern continental shelf have significantly contributed to regional understanding of the structural and sedimentary basin evolution (Pilaar \& Wakefield, 1978; Knox, 1982; Shell Oil Company, 1987; Stern \& Davey, 1990; King \& Thrasher, 1992; Palmer \& Andrews, 1993; Holt \& Stern, 1994; King \& Thrasher, 1996). While some studies have drawn on seismic data to infer regional sedimentary facies character (Shell Oil Company, 1987; Thrasher, 1991a), much of the subsurface sediment distribution is inferred from extrapolation of sparse borehole data (e.g., King \& Robinson, 1988; King \& Thrasher, 1996). Seismic attribute images of 3D seismic reflection data sets have significantly improved the understanding of local sedimentary and paleogeographic development of individual stratigraphic formations (Voggenreiter, 1992; Bryant et al., 1994; Bussell, 1994; Matthews, 2010), but the limited availability of these highresolution data sets has restricted such detailed insight to small parts of generally much larger depositional systems. Available two-dimensional (2D) seismic reflection data, on the other hand, cover the whole basin and, when used together with $3 \mathrm{D}$ data, offer the opportunity for reconstructing these ancient sedimentary environments almost in their entirety. Although only few studies have investigated seismic attributes on a broader scale (Matthews et al., 1998; Matthews, 2008), they have shown that the seismic griddensity in Taranaki Basin is sufficient to map regional sedimentary facies fairways from attribute extractions of 2D seismic data.

This study aims to improve the understanding of the subsurface structure and sedimentary development of Taranaki Basin through combined analysis of seismic facies, basin subsidence, and palinspastic reconstruction. By incorporating seismic data beyond the present-day shelf edge, this thesis provides the first integrated study of the combined shelf and deep-water area of the basin. A basin-wide grid of seismic horizon interpretations together with updated and coherent lithostratigraphic and biostratigraphic borehole data is used to provide better constraints on the timing and character of basin evolution than was previously possible. A particular focus of this study is the integration of post-stack seismic attributes from high-spatial density 3D surveys and a basin-wide grid of 2D data to characterise the evolution of depositional systems through geologic time. Seismic attribute analysis is not commonly conducted on a basin scale and this thesis aims to develop approaches usable for studying regional seismic geomorphology in other basins elsewhere in the world. 
By combining data across such a large area and employing quantitative structural and sedimentary basin analysis techniques, the study is able to address the interaction between crustal tectonics, mantle dynamics, and sediment deposition. There are three main objectives:

1) Imaging and characterisation of ancient depositional systems, including the delineation of facies belts, depositional environments, and sediment transport pathways,

2) Constraining and quantifying the timing and magnitude of structural basin deformation,

3) Reconstruction of paleogeography based on seismic facies constraints, borehole strata, biostratigraphy, and structural deformation. 

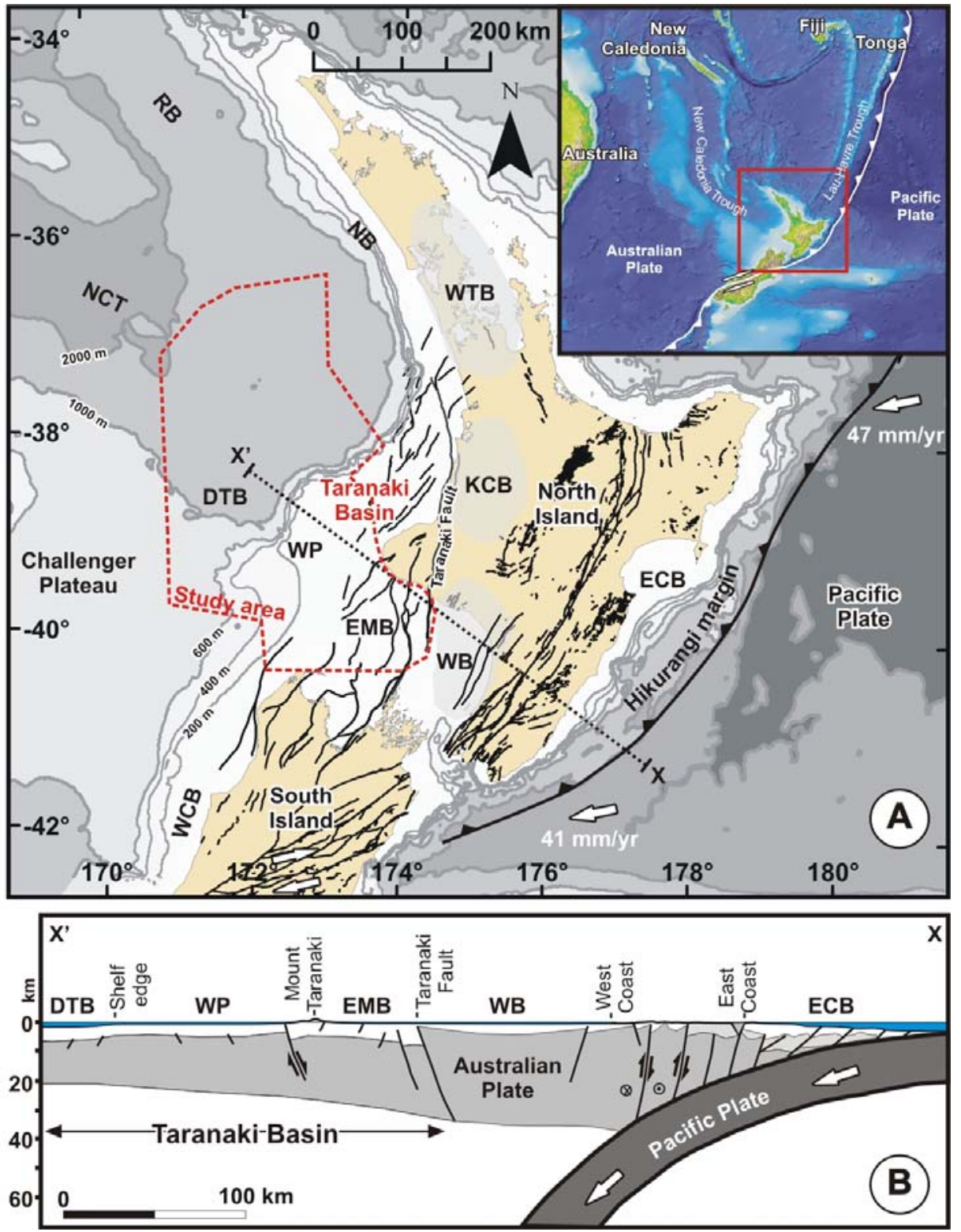

Figure $1.1 \quad$ A) Structural and physiographic overview of North Island and surrounding basins, where the Pacific plate presently subducts obliquely underneath the Australian continental plate. The map shows the offshore bathymetry (grey scale, contours in metres; relative blue scale in inset map) and major faults associated with Australia-Pacific plate boundary deformation (black lines). Taranaki Basin is defined as the area west of the Taranaki Fault and is contiguous to the north and south with the Northland Basin (NB) and the West Coast Basin (WCB), respectively. The basin extends into Deepwater Taranaki Basin (DTB), which marks the southern embayment of the New Caledonia Trough (NCT, see inset for overview). To the east it extends into a series of small basins that have successively formed during the Neogene (WTB-Waitemata Basin, KCB-King Country Basin, WB-Wanganui Basin). The study area (dashed red polygon) encompasses the area of Cenozoic plate boundary deformation (EMB-Eastern Mobile Belt) and tectonically quiescent Western Platform (WP). The forearc basin on the east coast (ECB) and relative plate motion vectors (white arrows) and rates from Beavan et al. (2002) are shown for reference. B) Structural cross-section X-X' from the Hikurangi subduction margin to DTB (modified from Nicol et al. (2007), see location in A). Continental crust of the Australian Plate is shown in light grey, sediment cover is shown in white, and water depth is indicated in blue. Mount Taranaki (see Figure 1.2) is projected southwards onto this cross-section. 


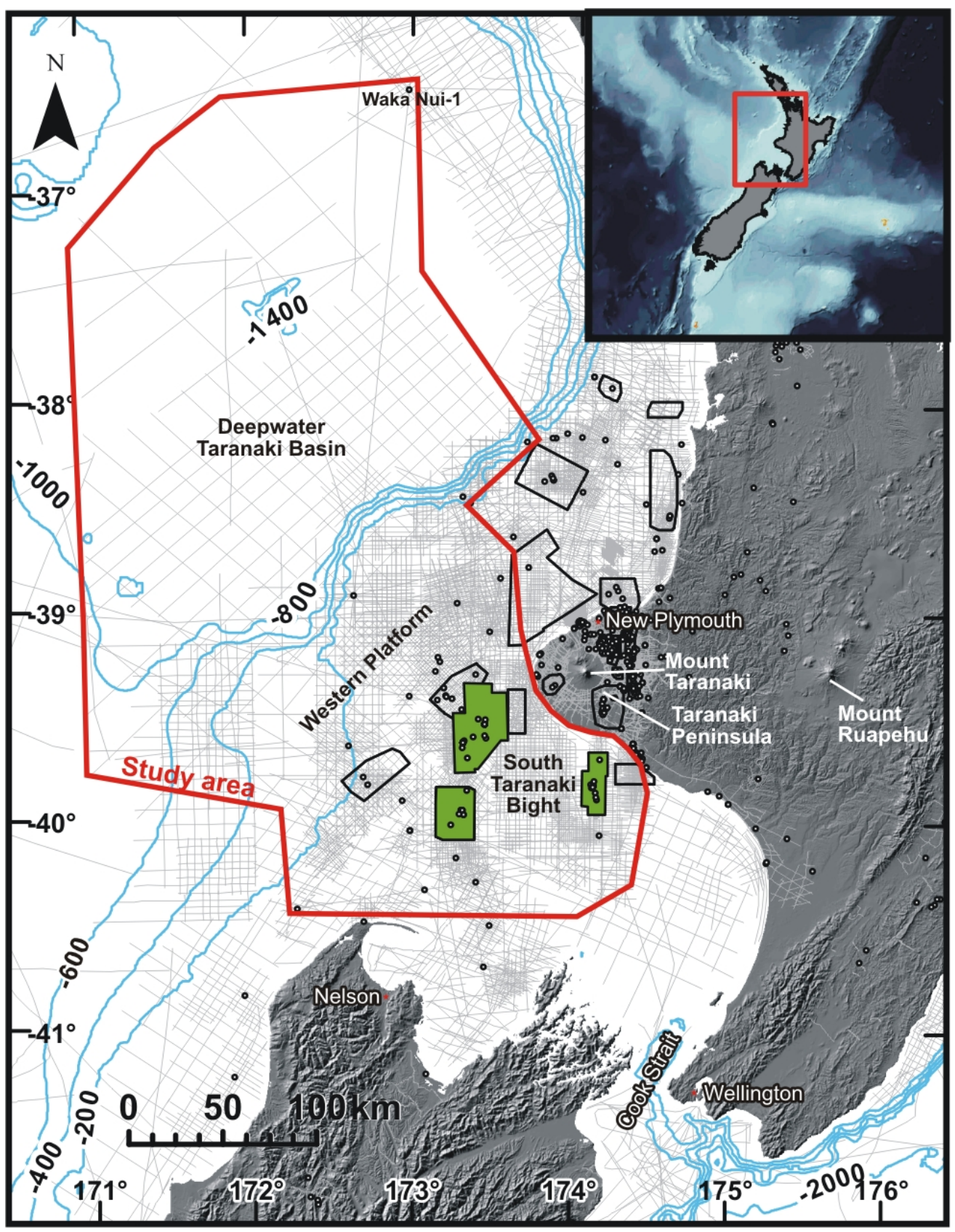

Figure 1.2 Seismic and well data coverage of Taranaki Basin and surrounding regions. Wells (black circles) are distributed across the onshore (Taranaki Peninsula) and offshore basin, but are sparser towards the outer shelf (shelf edge marked by $200 \mathrm{~m}$ bathymetry contour). 3D seismic surveys (black polygons) are limited to areas of increased exploration or production focus, whereas 2D seismic surveys (grey lines) cover the entire shelf and deep-water area. The red polygon outlines the study area and green polygons show the 3D seismic surveys used in this study. The data shown here is mostly derived from New Zealand's open file petroleum report archive that was compiled and loaded into geographic information systems by GNS Science. 


\subsection{BASIN LOCATION AND STUDY AREA}

Taranaki Basin predominantly occupies the offshore area of the western continental shelf, but also comprises the south-easternmost limit of the $2000 \mathrm{~km}$ long New Caledonia Trough, as well as onshore areas of the Taranaki peninsula and the northern South Island (Figure 1.1, Figure 1.2). The lateral extent of the basin has varied through geologic time and there are no formal boundaries with the surrounding basins. The informal eastern basin boundary coincides with the Taranaki Fault, which represents a remnant antithetic back-thrust to the Hikurangi subduction margin (Stagpoole \& Nicol, 2008). This boundary has been buried since the Late Miocene and younger strata are contiguous with the adjacent Wanganui and King Country basins to the east. To the south, the basin merges with ridges and basins surrounding the northern South Island, whereas to the north and west sedimentary systems are contiguous with the Northland Basin and the New Caledonia Trough, respectively. This thesis concentrates on the south-western offshore area of the basin from the hanging wall of the Taranaki Fault in the southeast $\left(\sim \mathrm{E} 174.3^{\circ}\right)$ to Deepwater Taranaki Basin in the northwest $\left(\sim \mathrm{E} 171^{\circ}\right)$, and from the northern tip of the South Island $\left(\sim \mathrm{S} 40.5^{\circ}\right)$ across the South Taranaki Bight to Waka Nui-1 $\left(\sim \mathrm{S} 37.5^{\circ}\right)$, which is the northernmost exploration well tied to seismic profiles in Deepwater Taranaki Basin (Figure 1.2). The study area encompasses the structural provinces of Cenozoic plate boundary deformation (the Eastern Mobile Belt), undeformed outer continental shelf (the Western Platform), and more distal Deepwater Taranaki Basin (southern New Caledonia Trough, Figure 1.1).

\subsection{PREVIOUS WORK AND CONTRIBUTIONS OF THIS THESIS}

Existing knowledge of basin history is built from limited outcrop exposure around the basin peripheries (Figure 1.3) and constraints from seismic and borehole data. This study uses offshore subsurface data to improve the understanding of basin dynamics, addressing questions and providing new insights that pertain to particular phases of basin evolution. 


\subsubsection{Rift to passive margin phase}

Previous studies have established that Taranaki Basin formed as an extensional basin during the Late Cretaceous and was marked by regional subsidence into the Paleogene (Pilaar \& Wakefield, 1978; Knox, 1982; Hayward \& Wood, 1989). The amount of lithospheric stretching and resulting post-rift thermal subsidence has not been rigorously documented. The character of Cretaceous to Eocene sedimentary strata is constrained by limited outcrop exposure on the southern basin margins (e.g., Wizevich et al., 1992; Browne et al., 2008) and description of borehole data across the basin (Palmer, 1985; King \& Thrasher, 1996; Higgs et al., 2010). The distribution of Late Cretaceous seismic facies across the basin has been constrained from manual mapping of paper sections more than 20 years ago (Thrasher, 1991a), whereas the Paleogene seismic facies character has hitherto only been determined from digital data in local areas of the basin (Voggenreiter, 1992; Bryant et al., 1994; Matthews et al., 1998). Previous studies were limited to the present-day shelf area, but more recent seismic data has shown that depositional systems extend beyond the shelf and into the present-day deep-water area (Uruski et al., 2002b). This study defines the distribution of Cretaceous to Eocene sediments from seismic facies mapping across the proximal shelfal and distal deepwater basin and quantifies the timing and amount of lithospheric stretching and subsidence that has occurred in the respective basin areas (Chapter $3 \& 4$ ).

\subsubsection{Mid-Cenozoic basin modification}

The formation of Deepwater Taranaki Basin and the New Caledonia Trough has long been attributed to lithospheric stretching and post-rift thermal subsidence associated with the Cretaceous break-up of Gondwana (Burns \& Andrews, 1973; Uruski \& Wood, 1991). More recently, based on limited seismic data, it has been proposed that much of the bathymetric expression of the New Caledonia Trough (NCT) is due to unusual downward crustal deflections that occurred along its length during the middle Cenozoic (Sutherland et al., 2010a). Several authors have previously documented evidence for Oligocene to Miocene rapid long-wavelength subsidence of the present-day shelf area of Taranaki Basin (Hayward \& Wood, 1989; Stern \& Holt, 1994) that followed the onset of convergence across the Australia-Pacific plate boundary. This study uses seismic facies constraints from a high-quality data set across the southern fringes of the 
NCT together with biostratigraphy data to assess the origin of deep-water basin formation northwest of New Zealand (Chapter 5).

\subsubsection{Miocene regressive phase}

Taranaki Basin evolution in the Miocene is characterized by widespread convergence, foreland basin subsidence, and increasing sediment influx (King \& Thrasher, 1992; Holt \& Stern, 1994). Miocene deep-water sedimentary facies have been described in detail from outcrop along the northern Taranaki Coast (Browne \& Slatt, 1999; Browne et al., 2005a; Arnot et al., 2007; Browne et al., 2007a; King et al., 2007a), whereas reconstructions of the Miocene depositional systems evolution from seismic data have received limited attention (Bussell, 1994; de Bock, 1994). This study reconstructs and characterises the development of sedimentary systems across the evolving foreland basin, constrains sediment dispersal pathways, and delineates the distribution of Miocene turbidite deposits. Due to the good preservation of sedimentary strata in the basin, this study is able to provide a rare example of shelf to deep-water sediment transport systems in a convergent basin (Chapter 6).

\subsubsection{Pliocene-Pleistocene late basin phase}

Throughout the Neogene, a series of small basins have successively formed adjacent to Taranaki Basin alongside the western proto-North Island, culminating in the formation of the neighbouring Wanganui Basin during the Plio-Pleistocene (Anderton, 1981; Stern et al., 1992; Kamp, 1999; Lamarche et al., 2005; Proust et al., 2005). Owing to pervasive basin subsidence and commensurately high sediment supply, terrestrial to shallow marine strata exposed on the southern Taranaki peninsula contain an excellent record of fluctuating Plio-Pleistocene eustatic sea-level signals (Abbott \& Carter, 1994; Naish \& Kamp, 1997; Naish et al., 2005). In the offshore area, large clinoform reflectors record the development of the modern shelf (Beggs, 1990), but studies of their sequence stratigraphic architecture and timing of slope advancement have mainly focused on areas north of the Taranaki peninsula (Hansen \& Kamp, 2004; Scott et al., 2004; Hansen \& Kamp, 2006). This study furthers the understanding of geodynamic processes of sub-basin formation in western North Island by constraining the timing and character of vertical crustal movements in eastern Taranaki Basin. It illustrates how these movements affected sediment dispersal and timing of shelf progradation and 
shows the influences of sea-level fluctuations on shelf margin architecture. The study thus documents the relative effects of tectonism and eustasy during Plio-Pleistocene sedimentation (Chapter 7).

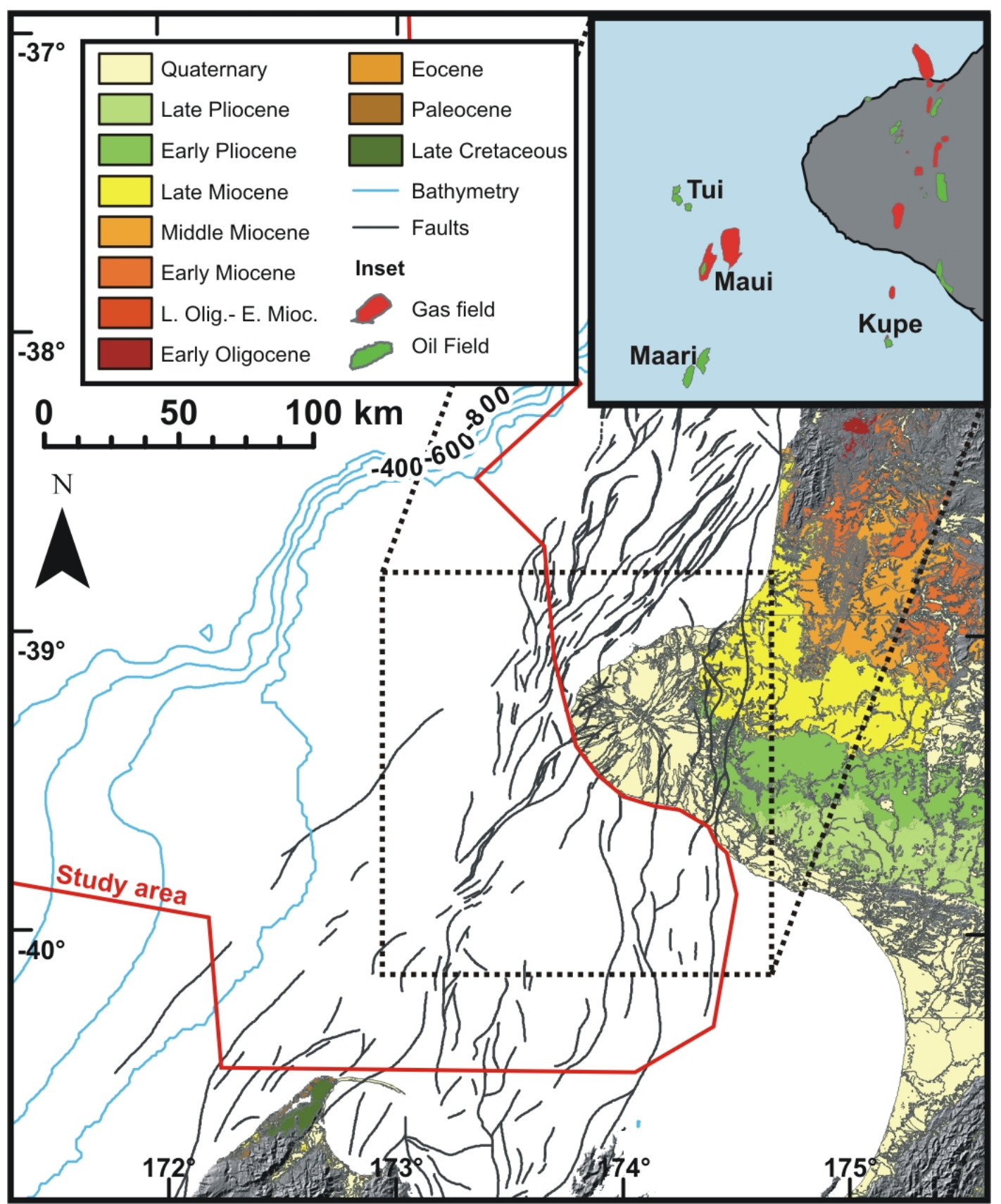

Figure 1.3 Overview map of Taranaki Basin showing the sedimentary outcrop localities, general basin structure, and petroleum accumulations within the basin (see legend for colour explanation). Due to varying modes of Cenozoic uplift, Cretaceous to Early Miocene strata are exposed on the South Island, whereas Oligocene to Pleistocene strata are exposed on the North Island. The faults depict the subsurface structure in proximal Taranaki Basin and are shown at their location on the top of the Eocene stratigraphic level (after Thrasher \& Cahill, 1990). 


\subsection{THESIS STRUCTURE}

The first three chapters of this thesis provide the requisite background to the study and an overview of the Taranaki Basin. Thereafter, each of the specific phases of basin evolution referred to above is investigated in a stand-alone chapter. These chapters are arranged in quasi-chronologic order and together provide a comprehensive analysis of the basin history. While overall emphasis of this thesis is the use of seismic attributes to unravel the depositional history, these individual chapters also address the structural evolution of the particular period to a varying extent. Each chapter introduces the relevant previous work and presents results from this study. The results are then discussed in relation to the paleogeographic basin evolution, sedimentary processes, and general geodynamic context. The self-contained character of chapters was chosen to facilitate publication of individual topics but, due to chronologic overlap of some of the scientific questions addressed, some repetition between chapters is unavoidable.

Chapter 2 describes the data used in this study and the approaches taken for seismic attribute and tectonic subsidence analysis. It provides a brief background on the methods, reasoning for their use, their application to the Taranaki Basin data set, and initial results.

Chapter 3 presents a palinspastic reconstruction of a $340 \mathrm{~km}$ long composite profile across the basin that extends from the Taranaki Fault in the southeast to the New Caledonia Trough in the southwest. This chapter investigates the timing, style and magnitude of basin deformation and erosion, while providing a general context of basin evolution and sedimentary geometries for later chapters. General implications on the petroleum systems are discussed.

Chapter 4 investigates the Cretaceous to Eocene evolution of the basin and shows the development from dominantly terrestrial rift graben-bound facies to broad shallow marine passive margin facies belts. The main petroleum source rock and reservoir fairways are outlined on attribute maps and their evolution is put into context with the tectonic subsidence history of the basin. 
Chapter 5 examines the geodynamic origin of deep-water basin systems northwest of New Zealand. Seismic facies and biostratigraphic data from wells are integrated to constrain changes in basin water depth, and seismic horizon isopachs and well data are back-stripped to reconstruct the basin subsidence history. This chapter consists of the main body of a journal paper that has been prepared for publication (Baur et al., in prep.) and contains some introductory material and concepts that are discussed in the other chapters.

Chapter 6 investigates the Miocene development of the shelf margin across an evolving foreland basin and focuses on the distribution and character of associated turbidite systems. The detailed nature of submarine channel systems is characterized from 3D data and neural network-based multi-attribute volumes are used to image shelf to deep-water sediment transport networks. Some results of this chapter have been published in a conference proceedings paper (Baur et al., 2010).

Chapter 7 investigates the Plio-Pleistocene basin history and uses seismic attributes and back-stripped stratigraphic data from wells to characterise the timing, wavelength, and magnitude of sub-basin formation in western North Island. The sequence architecture of large clinoforms on the Western Platform (Giant Foresets Formation) is analysed using automated horizon tracking and sequence stratigraphic interpretation methodologies.

Chapter 8 provides a brief summary of the main results and conclusions of this thesis. 



\section{CHAPTER 2 DATA AND METHODS}

\subsection{The TARANAKI BASIN DATA SET}

New Zealand's Crown Minerals Act 1991 requires that all New Zealand exploration and production license permit holders keep a detailed record of all their prospecting, exploration, and mining activities. This information has to be submitted to the Ministry of Economic Development under the Crown Minerals Act 1991 Section 90 and the Crown Minerals (Petroleum) Regulations 2007 after a) the expiry of 5 years after the date on which the information was obtained, or b) relinquishment of the permit. These data are available to the public through the Ministry of Economic Development open-file petroleum report system (www.med.govt.nz).

GNS Science has compiled a large amount of this publically available data and confidential data (provided by the industry under data sharing agreements) for a regional mapping study and stratigraphic re-assessment of the Taranaki Basin (the 4D Taranaki project). The compilation of this data is funded as part of the public good funding provided through the Ministry of Science and Innovation (previously Foundation of Research Science and Technology) research programme "Towards self-sufficiency: the geological basis for increasing New Zealand's petroleum reserves" (contract number C05X0302). A sub-set of this larger data set was used in this $\mathrm{PhD}$ study.

\subsubsection{Seismic data}

The seismic data used in this study consists of stacked, multi-channel seismic reflection data, most of which has been acquired across individual petroleum exploration licenses within the basin. The seismic data set comprises $\sim 8402 \mathrm{D}$ seismic lines with a total line length of $\sim 30,000 \mathrm{~km}$ and three 3D surveys (Kerry-3D, Maui-3D, and Maari-3D) with a surface area of $2676 \mathrm{~km}^{2}$ (Figure 2.1). These data sets encompass a total area of some $100,000 \mathrm{~km}^{2}$ from the Wanganui Basin in the southeast to Deepwater Taranaki Basin in the northwest. The lateral density of seismic reflection data varies considerably across the basin. Areas of active 
hydrocarbon production are covered by $3 \mathrm{D}$ surveys and dense $2 \mathrm{D}$ data with down to $0.5 \mathrm{~km}$ line spacing, whereas less explored areas such as the outer shelf and deepwater area have a line spacing of $5 \mathrm{~km}$ to $>10 \mathrm{~km}$ (Figure 2.1).

Acquisition vintages span more than 25 years from 1973 (PR624, Shell BP Todd Oil Services Ltd., 1973) to 2001 (PR2847, TGS-NOPEC, 2001), and some surveys (or parts of them) were reprocessed multiple times. Due to the large range of age, acquisition and processing parameters, the data quality, amplitude and frequency content vary noticeably amongst the different surveys. Whenever possible, the most recent processing versions was obtained and thus the database is considered the bestpossible compilation of available seismic data without undertaking seismic reprocessing of the entire data set (Milner et al., 2010; Roncaglia et al., 2010). A list of the seismic data used in this study is provided in Supplement 1.

To ensure that timing and seismic phase content of the entire seismic database are consistent among the different surveys, mist-ties and phases were analysed and adjusted using the Schlumberger IESX 'Well-Tie' and 'Mis-tie' analysis modules (Milner et al., 2010). The 2D survey SUNZ91 was selected as the master reference survey for matching of the entire Taranaki Basin offshore dataset (Figure 2.1), as it has a large regional extent, excellent data quality, and sufficient tie points with adjacent surveys. In addition, the HZT82A survey was used as a local reference survey for the south-eastern basin after being matched to SUNZ91. Where possible, phase-polarity information was obtained from processing reports or SEGY file text headers. The phase character and match between surveys was assessed via crosscorrelation of seismic traces, while the line-match was visually inspected to assess if bulk shifts were required. Phase rotations and/or bulk time shifts were performed to align seismic target events and systematically match all seismic data across the basin. For further details relating to this data set and phase-matching procedure, the reader is referred to the associated reports (Milner et al., 2010; Roncaglia et al., 2010) 


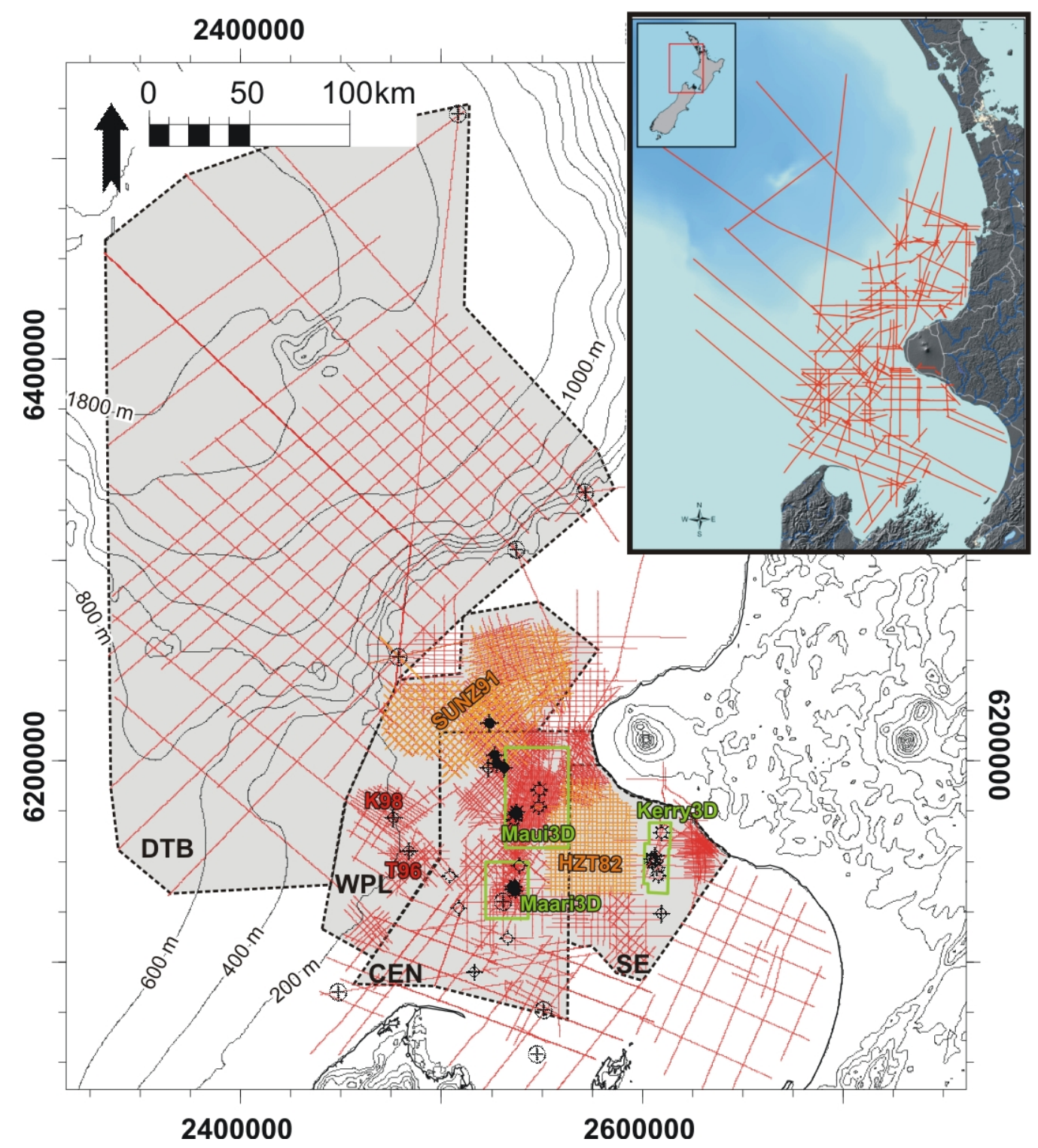

Figure 2.1 Overview map of Taranaki Basin showing the seismic and well data set used in this study. Seismic data locations are outlined by red/orange lines (2D seismic profiles) and green polygons (3D surveys), respectively. Orange lines show the locations of 2D surveys used as reference for phase-matching (see text for description). Well locations are shown as circular black symbols. The New Zealand coastline is shown as thick black line and elevation contours are shown as thin black lines. Note the decreasing density of seismic and well coverage in the distal basin area. The inset shows the location of seismic profiles (red lines) on which the regional horizon framework was mapped before horizons were mapped on all seismic lines in individual sub areas (grey polygons with dashed outlines, SE-southeast, CEN-central, WPL-Western Platform, DTB-Deepwater Taranaki Basin). A detailed map and list of surveys is provided in Supplement 1. The map is projected in metric New Zealand Map Grid coordinates. 


\subsubsection{Well data}

Open-file data from 36 exploration wells and one production well were used for the correlation of seismic horizon interpretations and calibration of seismic facies and paleo-environment interpretations (Table 2.1, Figure 2.2). Most of the well data were compiled as part of the 4D Taranaki project (Roncaglia et al., 2010), while wells Ariki-1 (Shell BP Todd Oil Services Ltd., 1984), Wainui-1 (Shell BP Todd Oil Services Ltd., 1981b), Tane-1 (Shell BP Todd Oil Services Ltd., 1976), Waka Nui-1 (Uruski \& Stagpoole, 2004) were included in the data set to provide constraints in the outer shelf and deep-water area of the basin. The well selection was aimed to provide a representative regional overview of the distribution of sedimentary strata and the author is aware of the availability of additional wells in the study area. The well data used in this project includes:

- $\quad$ Header information (ID, location, reference depths etc),

- Deviation surveys,

- Checkshot surveys,

- Wireline logs (primarily gamma-ray, calliper, spontaneous potential, acoustic, resistivity, neutron and density $\operatorname{logs}$ ),

- Mudlog, cutting descriptions and final wellsite lithology interpretation,

- Biostratigraphic and paleobathymetric data from benthic and planktic foraminifera, dinoflagellates, and spores and pollen (GNS Science Fossil Record Electronic Database, FRED).

These data were quality checked and loaded into the software WellCAD. Wireline logs of individual wells were spliced together and mudlogs, cutting descriptions, and lithology interpretations were converted into simple lithology logs. The lithology logs were updated in cases where inconsistencies with respect to available wireline logs were apparent. Some of these well compilations have been published as well sheets in GNS Science reports (Roncaglia et al., 2007; Roncaglia et al., 2008). The quality-controlled well data was then loaded into Schlumberger's Petrel software for seismic horizon and facies correlation (Figure 2.3). 
Table 2.1 List of wells used in this study. The column values refer to: the longitude (Lon) and latitude (Lat) values referenced in New Zealand map grid in metres, kelly bushing height in metres above mean sea level, total depth (TD) as true vertical depth in metres below mean sea level, the spudding date (Spudded), the operator (Op.), hydrocarbon shows (Shows, Con=Condensate) as reported in the associated petroleum report (PR-petroleum report number). The operator abbreviations refer to New Zealand Overseas Petroleum (NZOP), Shell BP Todd Oil Services (SBPT), New Zealand Acquitaine Petroleum (NZAP), New Zealand Oil and Gas (NZOG), NZ TCPL Resources (TCPL), Österreichische Mineralöl Verwaltung (OMV), Tricentrol Exploration overseas (TEO), Marathon Petroleum NZ (MP), Conocco Phillips (CP).

\begin{tabular}{|c|c|c|c|c|c|c|c|c|}
\hline Name & Lon (X) & Lat (Y) & KB & TD & Spudded & Op. & Shows & PR \\
\hline Amokura-1 & 2527914 & 6198528 & 25 & 3995 & $23 / 03 / 2004$ & NZOP & Oil & 2920 \\
\hline Ariki-1 & 2571264 & 6333608 & 19.8 & 4831 & $9 / 12 / 1983$ & SBPT & None & 1038 \\
\hline Cook-1 & 2448975 & 6084752 & 34.1 & 8821 & $8 / 10 / 1970$ & NZAP & None & 513 \\
\hline Fresne-1 & 2516730 & 6095021 & 9 & 2504 & $14 / 01 / 1976$ & NZAP & None & 674 \\
\hline Hochstetter-1 & 2476241 & 6171779 & 22 & 3274 & $2 / 09 / 2000$ & NZOG & Gas & 2524 \\
\hline Kea-1 & 2539037 & 6148016 & 22 & 3138 & $15 / 12 / 1984$ & TEO & Gas & 1089 \\
\hline Kiwa-1 & 2484171 & 6155161 & 11.3 & 3859 & $28 / 04 / 1981$ & SBPT & None & 880 \\
\hline Kiwi-1 & 2523361 & 6196781 & 25 & 4238 & $22 / 08 / 2004$ & NZOP & None & 2995 \\
\hline Kupe South-1 & 2605335 & 6149519 & 33 & 3503 & $30 / 10 / 1986$ & NP & Oil/Gas & 1284 \\
\hline Kupe South-2 & 2604714 & 6151130 & 34 & 3250 & $7 / 04 / 1987$ & TCPL & Oil/Gas/Con & 1285 \\
\hline Kupe South-3B & 2606386 & 6150529 & 32.6 & 3447 & $8 / 12 / 1987$ & TCPL & Gas & 1368 \\
\hline Kupe South-4 & 2607414 & 6146631 & 33.1 & 3806 & $16 / 01 / 1989$ & TCPL & Gas/Con. & 1483 \\
\hline Kupe South-5 & 2608030 & 6142944 & 31.3 & 3200 & $20 / 09 / 1990$ & TCPL & Oil & 1678 \\
\hline Kupe-1 & 2606506 & 6152695 & 9.4 & 3682 & $6 / 08 / 1975$ & SBPT & None & 662 \\
\hline Maari-1 & 2535853 & 6137531 & 25.4 & 2200 & $30 / 10 / 1998$ & SBPT & Oil & 1572 \\
\hline Maari-2 & 2535855 & 6136290 & 25 & 1483 & $1 / 10 / 2003$ & OMV & Oil/Gas & 2772 \\
\hline Maui-1 & 2536620 & 6170696 & 7.3 & 3512 & $27 / 01 / 1969$ & SBPT & Oil/Gas & 540 \\
\hline Maui-2 & 2548630 & 6177085 & 34.1 & 3572 & $10 / 05 / 1969$ & SBPT & Gas/Con & 541 \\
\hline Maui-3 & 2548843 & 6185566 & 34.1 & 3383 & $25 / 12 / 1969$ & SBPT & Oil/Gas/Con & 542 \\
\hline Maui-4 & 2530569 & 6129715 & 34.1 & 3919 & $5 / 11 / 1970$ & SBPT & Oil & 543 \\
\hline Maui-7 & 2537550 & 6174455 & 26.8 & 3139 & $15 / 08 / 1986$ & SBPT & Oil/Gas & 1218 \\
\hline MB-P(8) & 2537125 & 6173343 & 39.4 & 3697 & $23 / 02 / 1994$ & SBPT & Oil/Gas & 2018 \\
\hline Moki-1 & 2536653 & 6137540 & 26 & 2625 & $24 / 10 / 1983$ & TEO & Oil/Gas & 987 \\
\hline Moki-2A & 2537179 & 6135130 & 22 & 1822 & $26 / 01 / 1985$ & TEO & Oil/Gas & 1100 \\
\hline Motueka-1 & 2550984 & 6075905 & 32 & 1567 & $11 / 03 / 1990$ & MP & None & 1685 \\
\hline N. Tasman-1 & 2533188 & 6111919 & 31.5 & 2735 & $26 / 10 / 1978$ & NZAP & None & 736 \\
\hline Pateke-2 & 2526698 & 6202893 & 25 & 3861 & $8 / 01 / 2004$ & NZOP & Oil & 2995 \\
\hline Pukeko-1 & 2504649 & 6142715 & 25 & 4190 & $28 / 04 / 2004$ & NZOP & None & 2928 \\
\hline Surville-1 & 2547786 & 6053899 & 9 & 2200 & $3 / 03 / 1976$ & NZAP & None & 677 \\
\hline Tahi-1 & 2609297 & 6124052 & 26 & 1776 & $2 / 01 / 1984$ & PCRP & None & 1030 \\
\hline Takapou-1 & 2523842 & 6219015 & 25 & 4186 & $6 / 08 / 2004$ & SBPT & Oil & 3032 \\
\hline Tane-1 & 2478753 & 6251981 & 31.1 & 4532 & $9 / 10 / 1976$ & SBPT & None & 698 \\
\hline Te Whatu-2 & 2508922 & 6126612 & 27 & 3542 & $10 / 11 / 1987$ & PCRP & None & 1345 \\
\hline Toru-1 & 2609521 & 6164337 & 32.2 & 4151 & $17 / 07 / 1990$ & TCPL & Gas/Con & 1668 \\
\hline Tui-1 & 2531255 & 6196740 & 25 & 3889 & $24 / 01 / 2003$ & NZOP & Oil/Gas & 2784 \\
\hline Wainui-1 & 2537047 & 6304629 & 11.7 & 3880 & $25 / 08 / 1981$ & SBPT & None & 869 \\
\hline Waka Nui-1 & 2508520 & 6521648 & 24 & 3666 & $30 / 04 / 1999$ & $\mathrm{CP}$ & None & 2436 \\
\hline
\end{tabular}



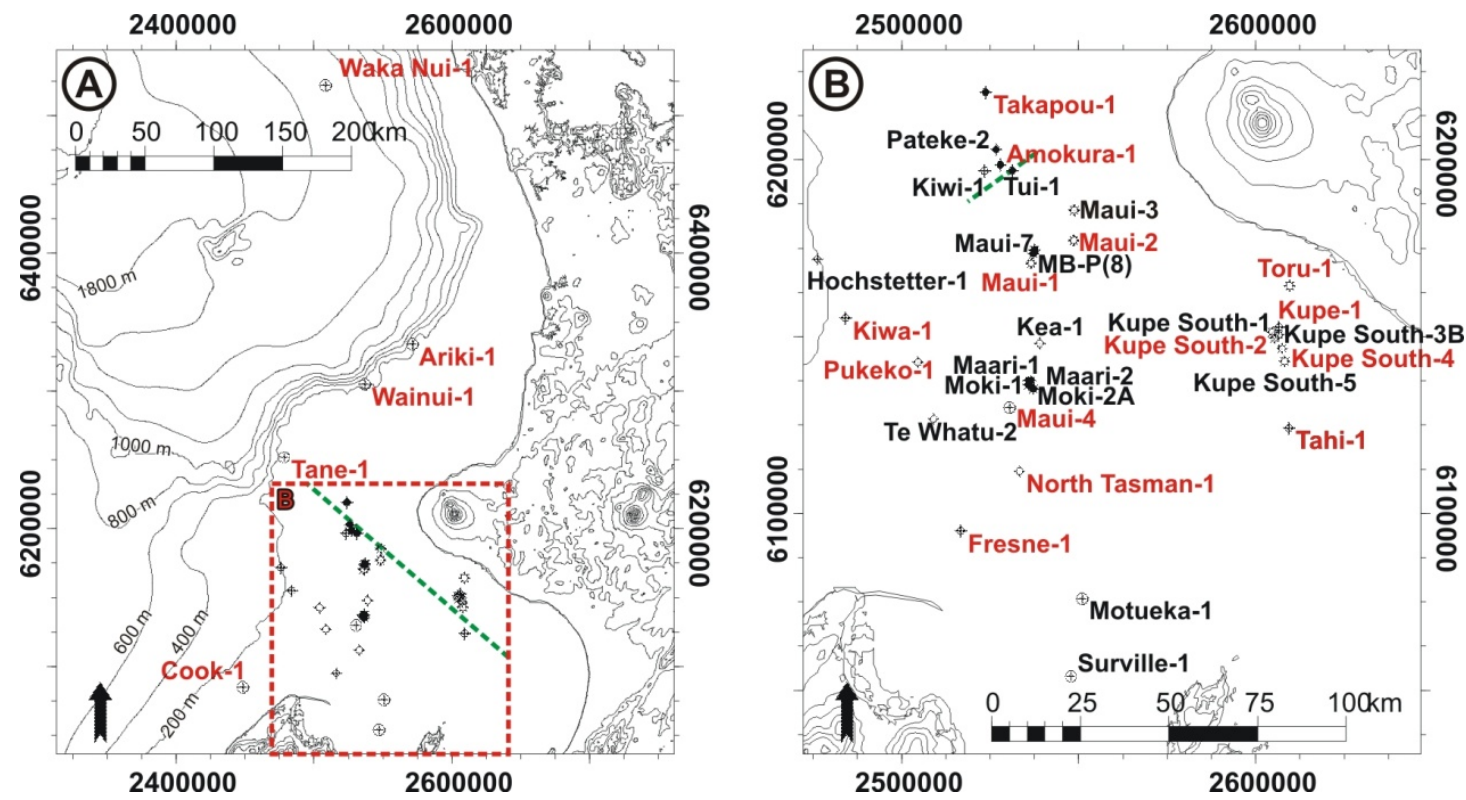

Figure 2.2 Maps of Taranaki Basin showing the location of wells used in this study. Well locations are shown as black circular symbols. A) Overview map of the basin with annotation of the wells in the outer shelf and deep-water areas of the basin (depth contours shown in black). B) Close-up view of wells in the proximal basin. The location of (B) is show as dashed orange polygon in (A). Wells that have been back-stripped as part of this study are annotated in red. The green dashed lines in (A) and (B) show the approximate locations of the chronostratigraphic panel in Figure 2.4 and seismic line shown in Figure 2.8, respectively. Maps are projected in metric New Zealand Map Grid coordinates.

\subsubsection{Time-to-depth curves and seismic-to-well ties}

Time-to-depth relationships and synthetic seismograms were derived from available check shot data, acoustic and density logs by the 4D Taranaki project (Juniper et al., 2010; Zhu, 2010). Deviation surveys, depth reference data, check shots, stratigraphic markers, and wireline logs for each of the selected wells were checked for internal consistency. Rapid variations in checkshot and log data were compared to variations in the underlying geology and discarded if indicative of internal errors. Acoustic impedance and reflection coefficients were calculated from the available acoustic (sonic) and density logs. High-frequency noise in the data, due to the higher sampling of logs with respect to available seismic data, was reduced by applying a block filter with a spacing of 1-3 $\mathrm{m}$. The time-depth correlations represent the best endeavour to minimise mis-ties between the variable seismic data and borehole information (e.g., formation tops, wireline logs) along the entire length of individual wells. 


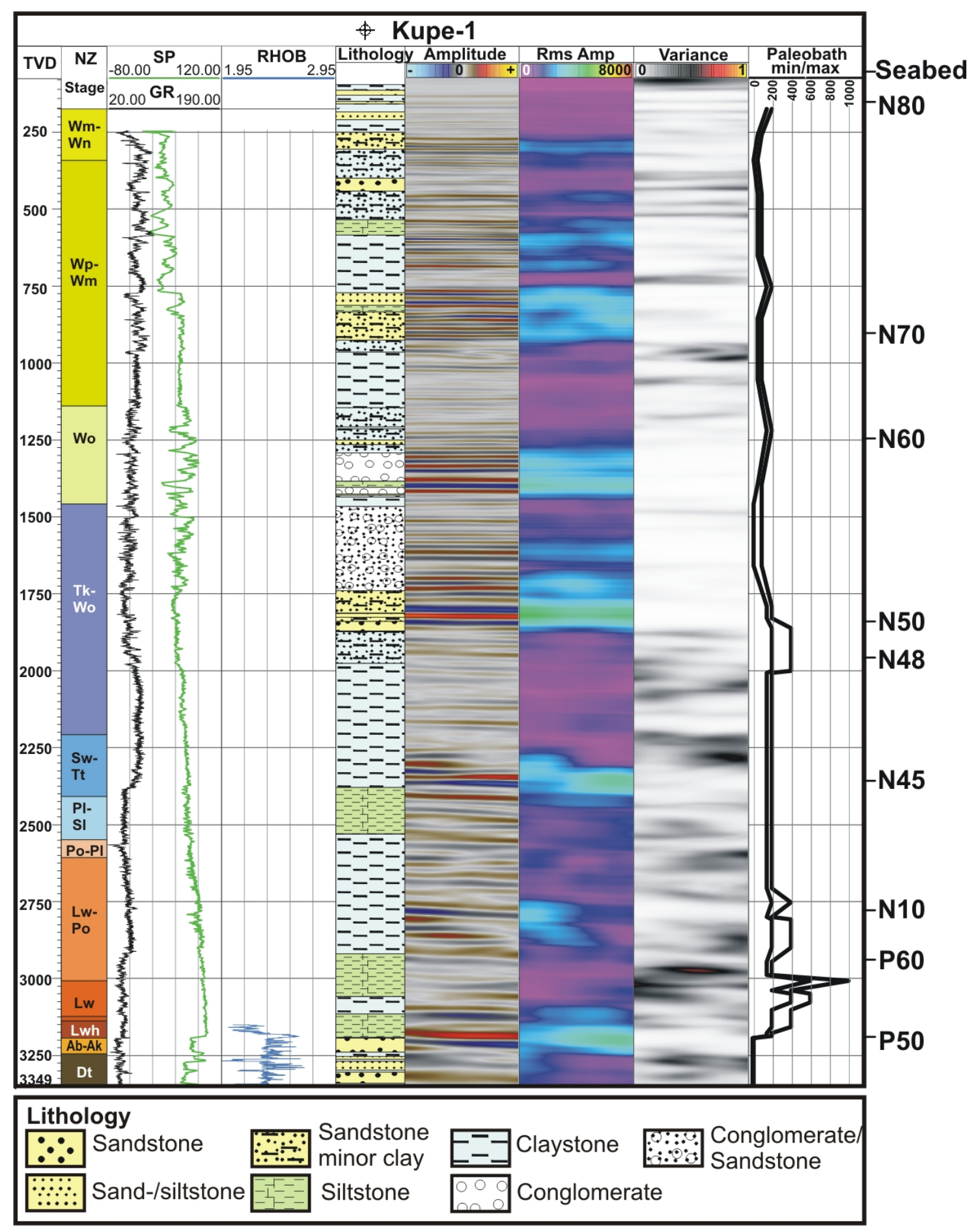

Figure 2.3 Example of available data in the well data set from Kupe-1 in south-eastern Taranaki Basin (see Figure 2.2 for location). The panel shows the biostratigraphic age estimates in New Zealand stage codes, wireline logs (gamma-ray -GR, spontaneous potential-SP, neutron density-RHOB), interpreted lithologies from cuttings (see legend at base for colour code), and the range of paleobathymetry estimates (right, in metres). Seismic amplitude RMS amplitude (calculated over a $20 \mathrm{~ms}$ window), and variance extracted over ten traces from the Kerry 3D data set are illustrated to show the correlation between seismic attributes, litho-, and wireline logs. The depth of mapped seismic horizons at the well location is annotated in with alphanumeric code names on the right (see Table 2.2 for further detail). Note that elevated amplitudes frequently occur in the vicinity of courser-grained lithologies, although the direct correlation is highly variable. 


\subsubsection{Lithostratigraphy, ages and paleoenvironment}

The lithostratigraphic nomenclature used here (Figure 2.4) is adapted from Palmer (1985), King (1988b; a) and King and Thrasher (1996), with modifications after Kamp et al. (2004) and Vonk and Kamp (2008). Age estimates and paleoenvironmental associations of lithostratigraphic units are based on biostratigraphic samples from well cuttings and core data. Key biostratigraphic events from palynology and micropaleontology encountered in these units are calibrated to the standard New Zealand chronostratigraphy (Cooper, 2004; Hollis et al., 2010). In Taranaki Basin, Late Cretaceous to Pleistocene biostratigraphic zonations are based on the distribution of planktonic and benthic foraminifera, dinoflagellates, spores and pollen. Paleoenvironmental and paleobathymetry associations are guided by the occurrence of planktic foraminifera (Figure 2.5) and follow an updated assessment scheme initially developed by Hayward (1986; Hayward et al., 2010). For further description of litho- and biostratigraphic correlations and interpretations of the data set the reader is referred to publications by the 4D Taranaki project (Roncaglia et al., 2008; Bland et al., 2010; Roncaglia et al., 2010; Strogen et al., 2010; Strogen et al., 2011). 


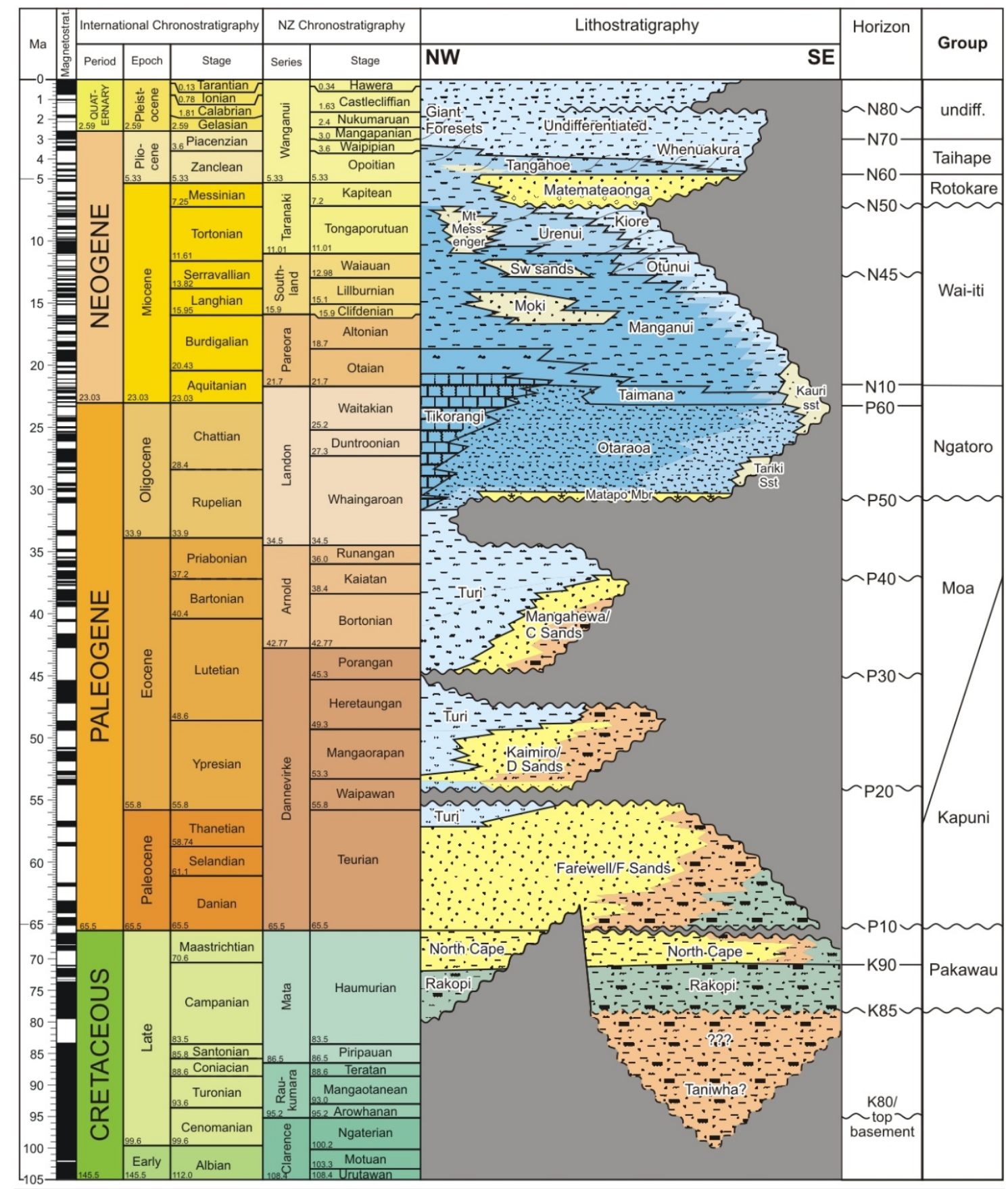

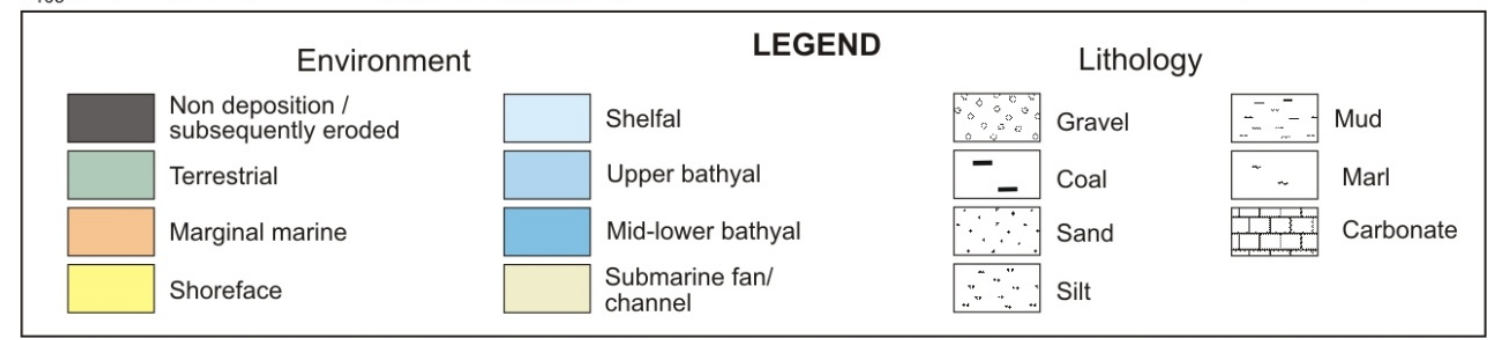

Figure 2.4 Stratigraphy of the central southern Taranaki Basin (modified after King \& Thrasher (1996)). The central panel illustrates lithostratigraphic formations distributed along a northwest to southeast transect as shown by green dashed line in Figure 2.2. The chronostratigraphic age associations in international and New Zealand time reference (Cooper, 2004; Hollis et al., 2010) are shown on the left. Seismic horizons (shown with alphanumeric names) mapped as part of this study and their associations with Late Cretaceous to Pleistocene stratigraphic and lithostratigraphic groups are shown on the right. 


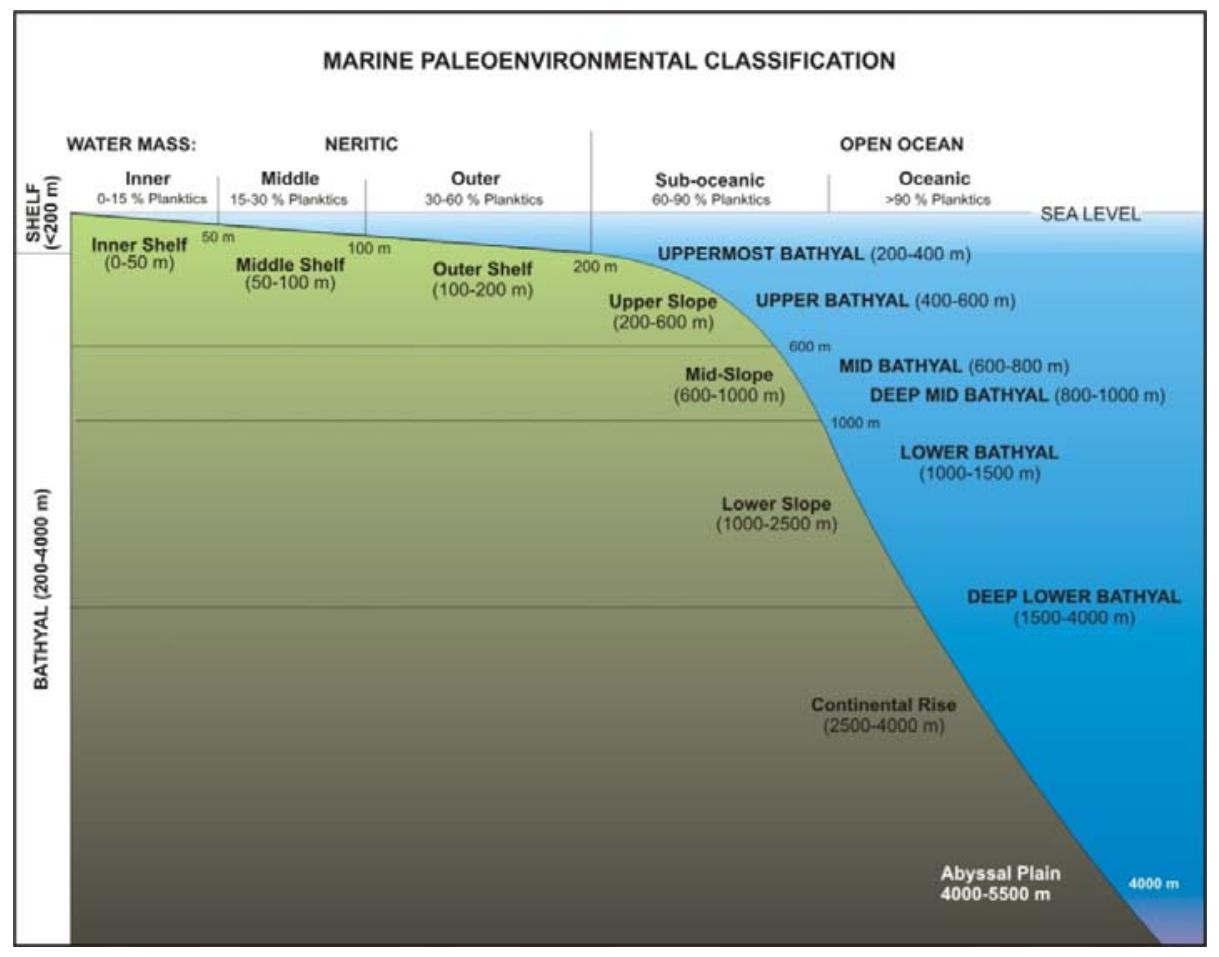

Figure 2.5

Marine paleoenvironment classification scheme based on foraminiferal assemblages (after Hayward et al., 2010).

\subsubsection{Seismic horizon interpretations}

The interpretation of seismic reflection data presented in this study was conducted by the 4D Taranaki project over a period of four years, beginning in late 2006. Seismic horizon interpretation was initially conducted across a regional 2D seismic line grid to establish a basin-wide framework of the basin stratigraphy (inset in Figure 2.1). This regional horizon framework was subsequently mapped on all available seismic 2D lines and selected 3D surveys within the smaller sub-regions of the basin (Figure 2.1). Local mapping was first conducted in the south-eastern part of Taranaki Basin (SE) and subsequently in the central (CEN) and western parts of the basin (WPL).

The approach for interpreting seismic horizons was to identify prominent seismic reflections, seismic facies changes or sequence boundaries and to associate these with stratigraphic markers in adjacent wells. The seismic events were correlated with distinct biostratigraphic ages wherever possible, while some horizons were correlated with lithostratigraphic formation tops and encompass small biostratigraphic age ranges (Table 2.2). The reflectors where interpreted from the well locations across the seismic grid and 
continuously back into previously interpreted areas to check the consistency (loop-tie method).

An alphanumeric naming scheme was developed (Figure 2.3 and Table 2.2) to avoid inconsistencies arising from the time-transgressive nature of certain surfaces, correlation with varying lithostratigraphic units, and areas of missing or eroded strata (Bland et al., 2010). In this naming scheme individual horizons within given time periods (KCretaceous, P-Paleogene, N-Neogene) were named numerically from the base of the stratigraphic sequence upwards $(10,20,30$ etc.). Seventeen seismic horizons were mapped in total, and, depending on their lateral distribution within respective areas a smaller number was correlated across the south-eastern (SE) and the central basin (CEN). On the Western Platform (WPL) only two horizons (P50 and N50) were mapped across three surveys (SUNZ91, K98, and T96). In order to provide coverage of depositional systems in the deep-water area of the basin (DTB), interpretations of eight seismic horizons from Uruski et al. (2002b) were used, which closely resemble the sequence subdivision by the 4D Taranaki project (DTB, Figure 2.1). The seismic horizon data set encompasses key stratigraphic events that demarcate major, second-to third-order sequences (1-10 my duration). In sub-areas in which certain horizons were not mapped (e.g, WPL, DTB), phantom horizons were calculated based on major seismic markers below and above the sequence to aid the interpretation of the internal facies character. A general description of the horizon database is provided in Table 2.2 and the correlation of horizons with well data in respective areas is shown in Figure 2.6. The detailed character of individual sequences is discussed in subsequent chapters.

The N40 horizon in the south-eastern basin and the P50 and N50 horizon on the Western Platform were mapped by the author. All other horizons were quality controlled by the author and revised by the 4D Taranaki project if internal inconsistencies were observed. 


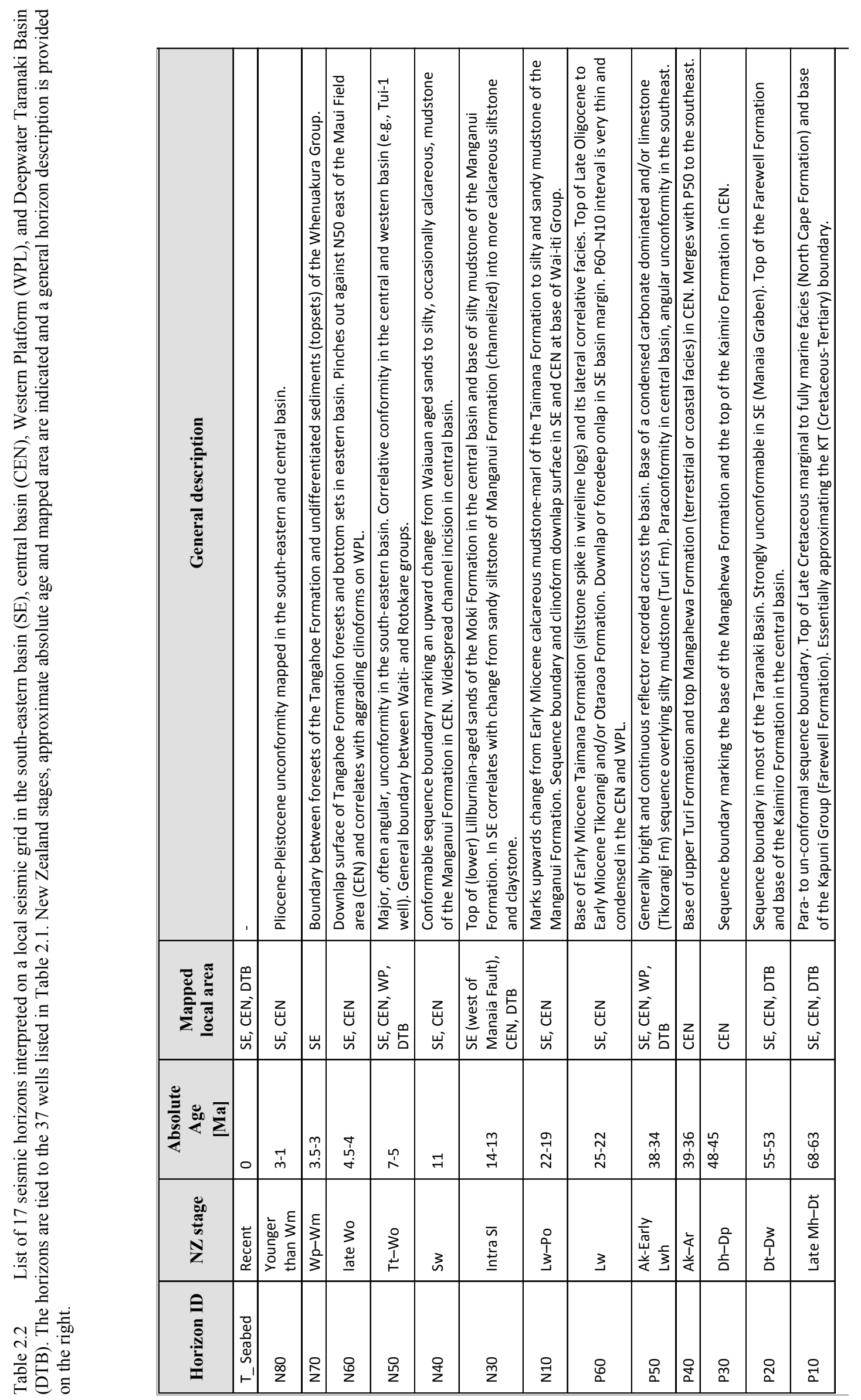




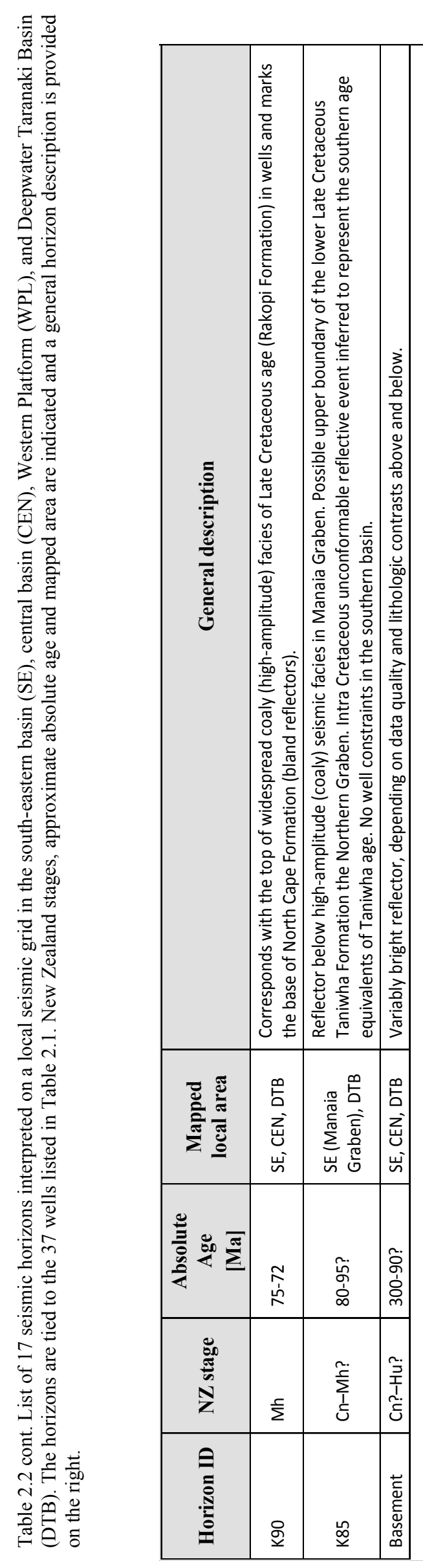



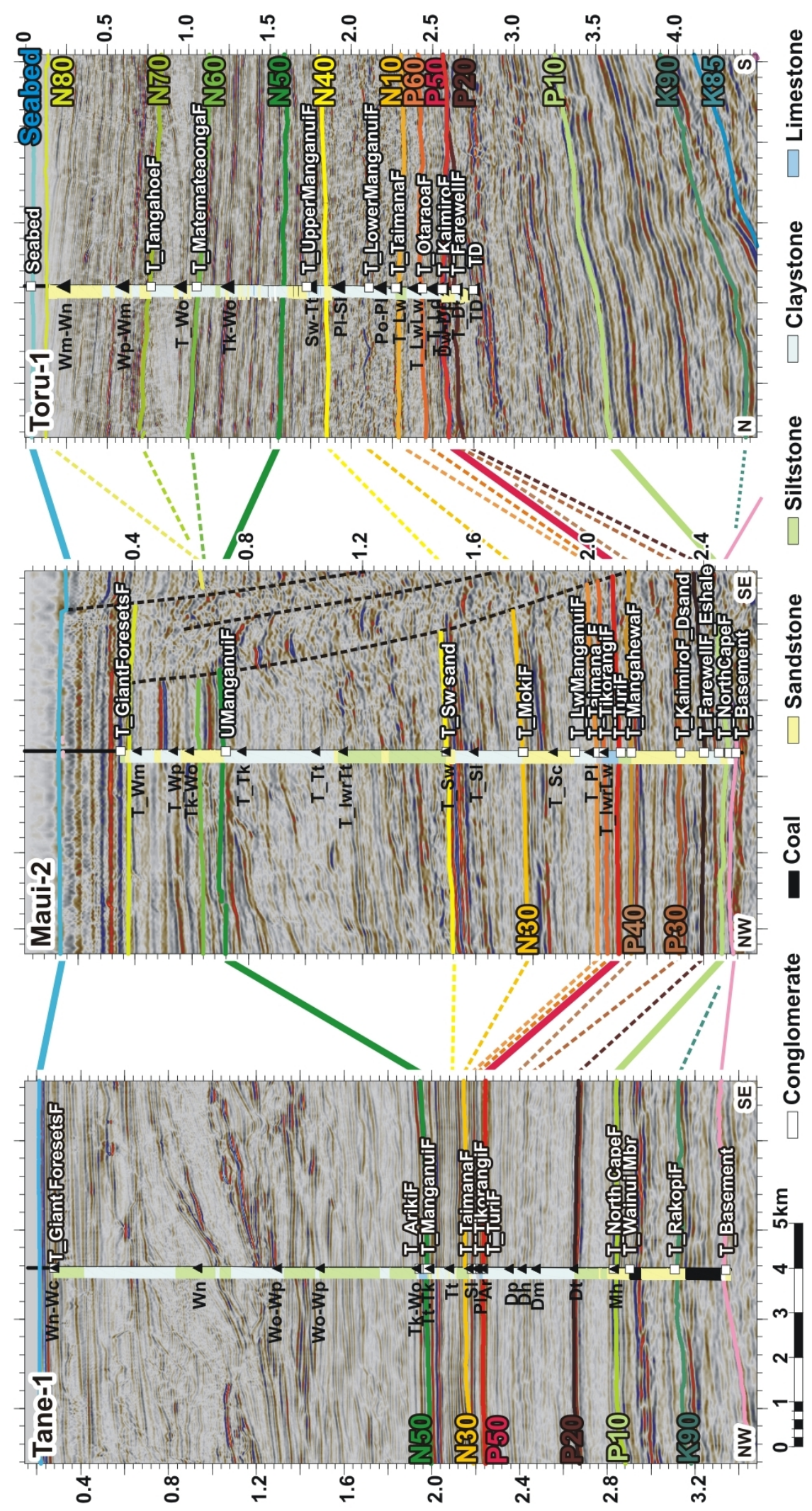

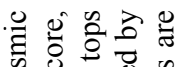

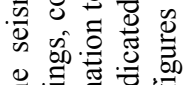

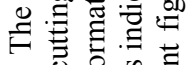

원월

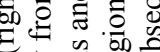

盛言卷

踏 응

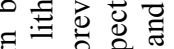

卷

1 .

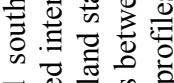

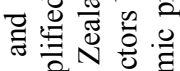

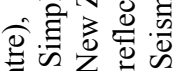

을

.

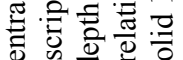

0 o

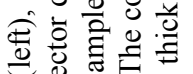

政

的宫.

ㄱ. 하웡

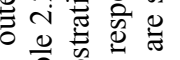

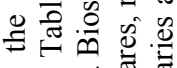

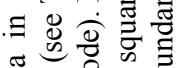

荧 品 $0.0 \%$

혀을

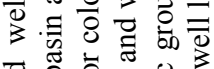

동

政

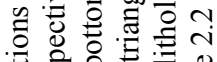

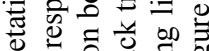

.

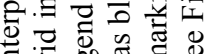

$\exists$ 的政

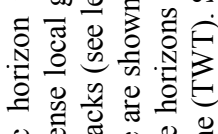

.

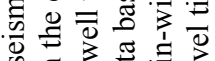

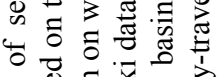

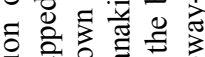

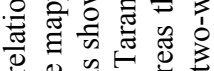

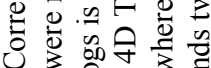

긍 능

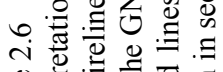

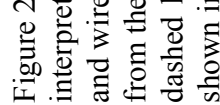




\subsubsection{Seismic stratigraphy, seismic facies and seismic geomorphology}

Seismic stratigraphy is the science of interpreting or modelling stratigraphy, sedimentary facies, and geologic history from seismic reflection data (Vail et al., 1977b; Vail, 1987; Van Wagoner et al., 1987). Fundamental to seismic stratigraphic approach is the observation that seismic reflections from sedimentary strata approximate geologic timelines and represent a short time interval of similar depositional environments (Vail \& Sangree, 1971; Vail et al., 1977c). Seismic reflection packages of time-equivalent, genetically related depositional systems can be grouped into depositional sequences or systems tracts (Mitchum et al., 1977b; Van Wagoner et al., 1987). These groups can be delineated based on reflection geometries, angular reflection terminations (unconformities, Figure 2.7A), and their laterally time-equivalent paraconformities (Mitchum et al., 1977b; Vail et al., 1977b; Vail, 1987). Depositional sequences are commonly composed of a series of systems tracts and characterisation of such groups provides insight into depositional character, sea-level history, and geologic evolution of a basin.

Since seismic reflections represent timeline approximations, they may extend laterally across different depositional environments and incorporate a variety of lithofacies units. Spatial variations in sedimentary architecture, lithofacies, and associated impedance character (impedance=velocity * density) are expressed in seismic data by changing reflection character and geometry (Figure 2.7). Such seismic facies are defined as groups of seismic reflections whose parameters (configuration, continuity, frequency and interval velocity) differ from adjacent groups (Mitchum et al., 1977a; Sangree \& Widmier, 1979). Each depositional sequence contains a suite of seismic facies with a particular regional distribution, stratal geometry, thickness pattern, and geologic history. Knowledge of the spatial distribution and correlation of seismic facies with information from borehole data allows geologic information (such as sedimentary facies or physical rock properties) to be propagated into adjacent areas.

In the classic procedure, the spatial distribution of seismic facies within a sequence is manually assessed and mapped across a grid of seismic profiles. The advent and 
proliferation of digital three-dimensional seismic data in the 1980's and 1990's provided the possibility for direct extraction of seismic patterns and their display in map view (Sonneland et al., 1989; Rijks \& Jauffred, 1991; Bahorich et al., 1992). By providing clearer images of the lateral continuity of seismic facies, this approach reduced the subjectivity of manual seismic facies interpretation and avoided the additional task of transferring features observed in profile-view to map-view. The plan view investigation and interpretation of seismic data evolved into the discipline of seismic geomorphology (Posamentier et al., 2000; Posamentier \& Kolla, 2003; Posamentier et al., 2007; Wood, 2007), which, besides study of basin structure, entails analysis and reconstruction of ancient landforms.

Seismic geomorphology (plan-view investigation) complements traditional seismic stratigraphy (vertical profile investigation) and has become an integral part of seismic interpretation (Carter, 2003; Zeng, 2004; Hadler-Jacobsen et al., 2007; Cross et al., 2009; Wood \& Mize-Spansky, 2009; Burton \& Wood, 2010; Sarkar et al., 2010). The study of seismic geomorphology usually comprises a series of steps that involve:

1) Identification of seismic facies types within a depositional sequence and association with geologic data (e.g., via well data),

2) Highlighting and characterisation of identified seismic facies from seismic data (e.g., via seismic attributes),

3) Display of spatial distribution of these facies on a surface that represents a specific point in or phase in geologic time (e.g., time-slices, mapped horizons, phantom horizons).

Fundamental to the study of seismic geomorphology is the characterisation of seismic facies via seismic attributes (Table 2.3). Seismic attributes represent quantitative measures of specific constituents of the seismic signal such as reflection amplitude or continuity (Sheriff et al., 1978; Taner et al., 1979; Haskell et al., 1995; Chopra \& Marfurt, 2007).

Traditionally, the plan view investigation of seismic attributes is limited to 3D data sets due to the superior lateral density and resolution compared to $2 \mathrm{D}$ seismic reflection surveys. Few published studies have investigated seismic attributes of sparser $2 \mathrm{D}$ data to constrain seismic facies distribution and basin development (e.g., Baaske et al., 2007). A 
shortcoming of 3D seismic geomorphology studies is the usually limited spatial extent and availability of 3D data sets, from which only small parts of the paleo-landscapes and their depositional components can be constrained. While providing inferior lateral resolution, 2D seismic data are usually more widely available across basins and cover larger parts of associated sedimentary systems. In New Zealand, several conference publications by the petroleum industry have shown the applicability of simple attribute maps created from sparse 2D seismic data to delineate regional facies fairways of specific petroleum source rock- or reservoir intervals (Matthews et al., 1998; Matthews, 2008; Mogg et al., 2008). This study aims to improve on previous studies by applying seismic geomorphology workflows to the Cretaceous to Pleistocene sedimentary basin fill of Taranaki Basin and extend these to a regional scale.

Table 2.3 Seismic facies character and geologic interpretation (modified from Sangree \& Widmier, 1979). General attribute examples and approach used in this study are shown on the right.

\begin{tabular}{|l|l|l|l|}
\hline \multicolumn{1}{|c|}{$\begin{array}{c}\text { Seismic facies } \\
\text { parameters }\end{array}$} & \multicolumn{1}{|c|}{$\begin{array}{c}\text { Geologic } \\
\text { interpretation }\end{array}$} & $\begin{array}{c}\text { General seismic } \\
\text { attribute examples }\end{array}$ & \multicolumn{1}{c|}{$\begin{array}{c}\text { Example from this } \\
\text { study }\end{array}$} \\
\hline $\begin{array}{l}\text { Reflection } \\
\text { configuration }\end{array}$ & $\begin{array}{l}\text { Depositional processes, } \\
\text { erosion, and } \\
\text { paleotopography }\end{array}$ & $\begin{array}{l}\text { Coherency, Dip, lateral } \\
\text { amplitude variations }\end{array}$ & $\begin{array}{l}\text { Delineate paleo-slope } \\
\text { geometry from amplitude } \\
\text { variations on phantom } \\
\text { horizon attribute maps (2D } \\
\text { and 3D) }\end{array}$ \\
\hline Reflection continuity & $\begin{array}{l}\text { Bedding continuity, } \\
\text { depositional processes }\end{array}$ & Coherency & $\begin{array}{l}\text { Delineate channel } \\
\text { orientation variance maps } \\
\text { from 3D data }\end{array}$ \\
\hline Reflection amplitude & $\begin{array}{l}\text { Velocity-density contrast, } \\
\text { bed spacing, fluid content }\end{array}$ & $\begin{array}{l}\text { RMS amplitude, } \\
\text { Instantaneous amplitude }\end{array}$ & $\begin{array}{l}\text { Map relatively coarser- } \\
\text { grained, carbonate-rich, or } \\
\text { cemented facies on interval } \\
\text { amplitude maps (2D and 3D) }\end{array}$ \\
\hline Reflection frequency & $\begin{array}{l}\text { Bed spacing, layer } \\
\text { thickness, and fluid } \\
\text { content }\end{array}$ & $\begin{array}{l}\text { Instantaneous } \\
\text { frequency, Dominant } \\
\text { frequency }\end{array}$ & $\begin{array}{l}\text { Differentiate bedding } \\
\text { character between channel } \\
\text { and surrounding sheet } \\
\text { deposits in meta-attribute } \\
\text { volumes }\end{array}$ \\
\hline $\begin{array}{l}\text { External form and areal } \\
\text { association }\end{array}$ & $\begin{array}{l}\text { Gross depositional } \\
\text { environment, sediment } \\
\text { source, geologic setting }\end{array}$ & Curvature, Dip & $\begin{array}{l}\text { Dip-steering and horizon } \\
\text { auto-tracking to constrain } \\
\text { continental margin } \\
\text { architecture }\end{array}$ \\
\hline
\end{tabular}



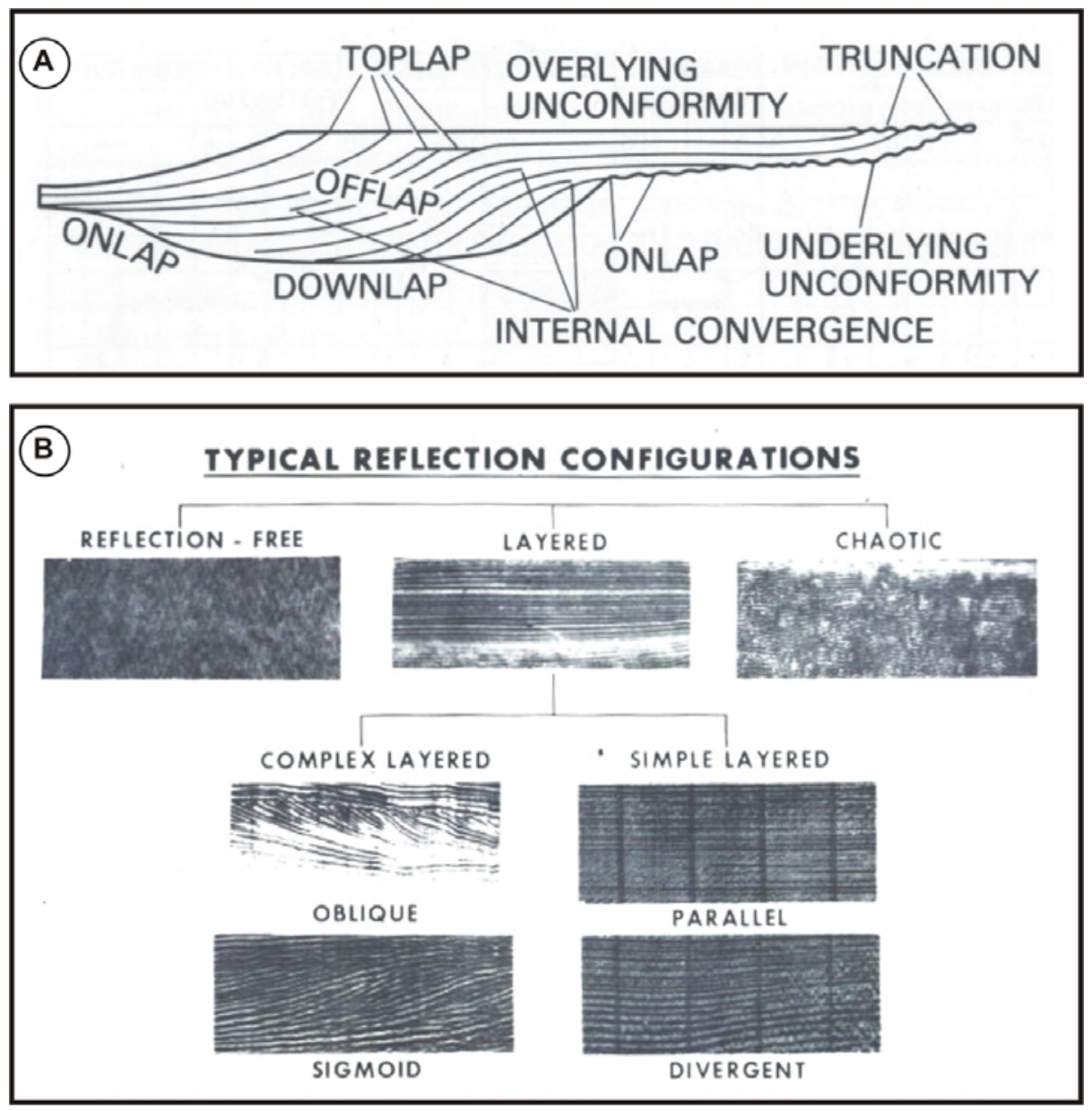

Figure $2.7 \quad$ A) Schematic nature of seismic reflector terminations and geometry of seismic facies units modified after Mitchum, et al. (1977b)). B) Typical reflection configurations on seismic reflection data from Sangree and Widmier (1979).

\subsubsection{Seismic geomorphology procedure}

One of the key objectives of this study is to apply post-stack seismic attribute and seismic geomorphology workflows commonly used in the analysis of $3 \mathrm{D}$ seismic reflection data on sparser but regionally extensive $2 \mathrm{D}$ seismic data set to capture the regional character of depositional systems. The general procedure used to analyse seismic facies and their attributes from 2D and 3D seismic reflection data in this study comprises a series of steps:

1) Normalisation of the seismic amplitude content between individual surveys to facilitate the regional extraction of seismic attributes,

2) Calculation of seismic attributes directly on the seismic data (volume attributes) to highlight and distinguish between specific facies and their characteristics, 
3) Calculation of phantom horizons to facilitate the investigation of internal facies character within manually mapped sequences,

4) Calculation of interval statistics to extract attribute information onto manually mapped seismic horizon interpretations or phantom horizons (horizon attributes),

5) Gridding and normalisation of attribute surfaces to display the seismic facies distribution in map view.

\subsubsection{Seismic amplitude normalisation}

In order to minimise the amplitude differences amongst the various seismic surveys and provide the basis for regional attribute extraction, the amplitude content in respective seismic surveys was normalised in two steps.

First, the amplitude content of individual seismic lines was normalised by applying a scalar to individual seismic lines to match the root mean square amplitude values of the line to a specified value (set to 1000 in Schlumberger's Geoframe software). In the second step, remaining amplitude mis-ties at seismic line intersections were assessed and minimised in the 'Gain Mis-Tie' analysis tool in Schlumberger's Petrel software. The amplitude content of individual lines at 2D-line intersections was cross-correlated over a vertical window between 0.2-3 s two-way-travel time, chosen to encompass the time interval in which sedimentary strata are predominantly present. The correlation coefficients of respective amplitudes at line intersections, which were mostly $>0.8$ after the first normalisation step, were further improved by applying a scalar that matched the intersections to the amplitude content of the HZT82A survey (Figure 2.1). Since the latter step only involved 2D line intersections, differences with respect to 3D surveys remained somewhat higher. In order to alleviate these differences individual attribute maps from 3D data were further normalised after careful investigation to match the surrounding $2 \mathrm{D}$ attribute data.

An attempt was undertaken to minimise the differences in frequency content between the surveys. The seismic data were band-pass filtered with a high- and low-pass cut-off of $40 \mathrm{~Hz}$ and $5 \mathrm{~Hz}$, respectively. While not significantly improving the coherency of 
resulting attribute maps, this filter significantly reduced the higher frequency content of most data. Thus, this step of data preparation was not employed on the final data set.

\subsubsection{Volume Attributes}

Volume attributes represent mathematic manipulations of the seismic trace, performed to highlight stratigraphic features in the seismic data. They can be subdivided into singleand multi-trace attributes. The former of which represents mathematical operations on individual traces, whereas the latter represent statistical comparisons of a trace with respect to adjacent traces (e.g., Chopra \& Marfurt, 2007). These attributes can be combined to meta-attributes to further define multiple characteristics of seismic facies (e.g., Schultz et al., 1994; de Rooij \& Tingdahl, 2002).

In this study, volume attributes were calculated to target three objectives:

1) Delineation of geomorphologic features and faults on 3D surveys via derivation of coherency attributes (multi-trace);

2) Imaging of Miocene channel networks in areas of sparse $2 \mathrm{D}$ seismic coverage via combination of several single- and multi-trace attributes to meta-attributes via artificial neural networks;

3) Derivation of a pseudo-chronostratigraphic model of the Plio-Pleistocene Giant Foresets Formation via calculation of reflector dip estimates and automated tracking of seismic reflectors.

The following section provides the background on single-trace attributes, multi-trace attributes, and neural network multi-attribute analysis and their application to the Taranaki Basin data.

\section{Single-trace attributes: instantaneous amplitude and frequency}

Single trace attributes used in this study are instantaneous attributes (Taner et al., 1979), which are derived through analysis of the complex seismic trace characteristics. These attributes provide quantifications of the seismic waveform (or character) at any sample point without dependency on the phase polarity (White, 1991; Barnes, 1996). 
The complex seismic trace, $\boldsymbol{c}$, can be expressed as a combination of the original seismic trace, $\boldsymbol{s}$, and its Hilbert transform, $\boldsymbol{h}$, as:

$$
c=s+i h
$$

where $i=\sqrt{-1}$. These harmonic signals at a given time $t$ can be expressed in terms of the amplitude $\boldsymbol{A}$, and their phase $\boldsymbol{\varphi}$, where the amplitude original (real) seismic trace is:

$$
s(t)=A(t) \cos \varphi(t)
$$

and the Hilbert transformed $\left(90^{\circ}\right.$ phase shifted) seismic trace is:

$$
h(t)=A(t) \sin \varphi(t)
$$

The amplitude of the complex trace (also known as the instantaneous amplitude, trace envelope, or reflection strength) can then be calculated by binomial addition from the real and Hilbert transformed amplitude values:

$$
c(t)=\sqrt{s^{2}(t)+h^{2}(y)},
$$

The instantaneous frequency $\omega$ represents the time derivative of the phase $\varphi$ :

$$
\varphi(t)=\tan ^{-1}\left(\frac{h(t)}{s(t)}\right)
$$

and can be expressed as:

$$
\omega(t)=\frac{d \varphi(t)}{d t}
$$

Thus, amplitude information can be separated from phase and frequency information in seismic data. Calculation of these measures commonly results in sudden inflections or discontinuities in the resulting trace, which is alleviated by application of a smoothing function. The function used in this study to smooth instantaneous attributes was a $20 \mathrm{~ms}-$ long triangle window function. 
Examples of these attributes calculated on Taranaki Basin data are shown in Figure 2.8. Although direct relationships between instantaneous attributes and lithology have been proposed, the physical basis for such correlations is not always clear (e.g., Russell et al., 1997). Thus, these attributes are used primarily for fingerprinting seismic facies and attribute responses were constantly cross-checked with available well data and seismic sections to substantiate geologic interpretations. Amplitude-related attributes show a tendency to highlight coarser-grained facies, but also highlight compaction related effects (e.g., in marl and limestones) or unconformites. Instantaneous frequency provides a measure for varying reflector loop duration that highlights sedimentary thickness variations (Taner et al., 1979), and is used here as a secondary seismic facies indicator. Combinations of instantaneous attributes such as sweetness (instantaneous amplitude divided by the square-root of instantaneous frequency, e.g., Radovich \& Oliveros, 1998; Hart, 2008) were tested to improve the imaging of relatively coarser-grained (sandy) intervals, but the resulting maps were found to not improve significantly on the insight gained from simple amplitude extractions and did not warrant further investigation.
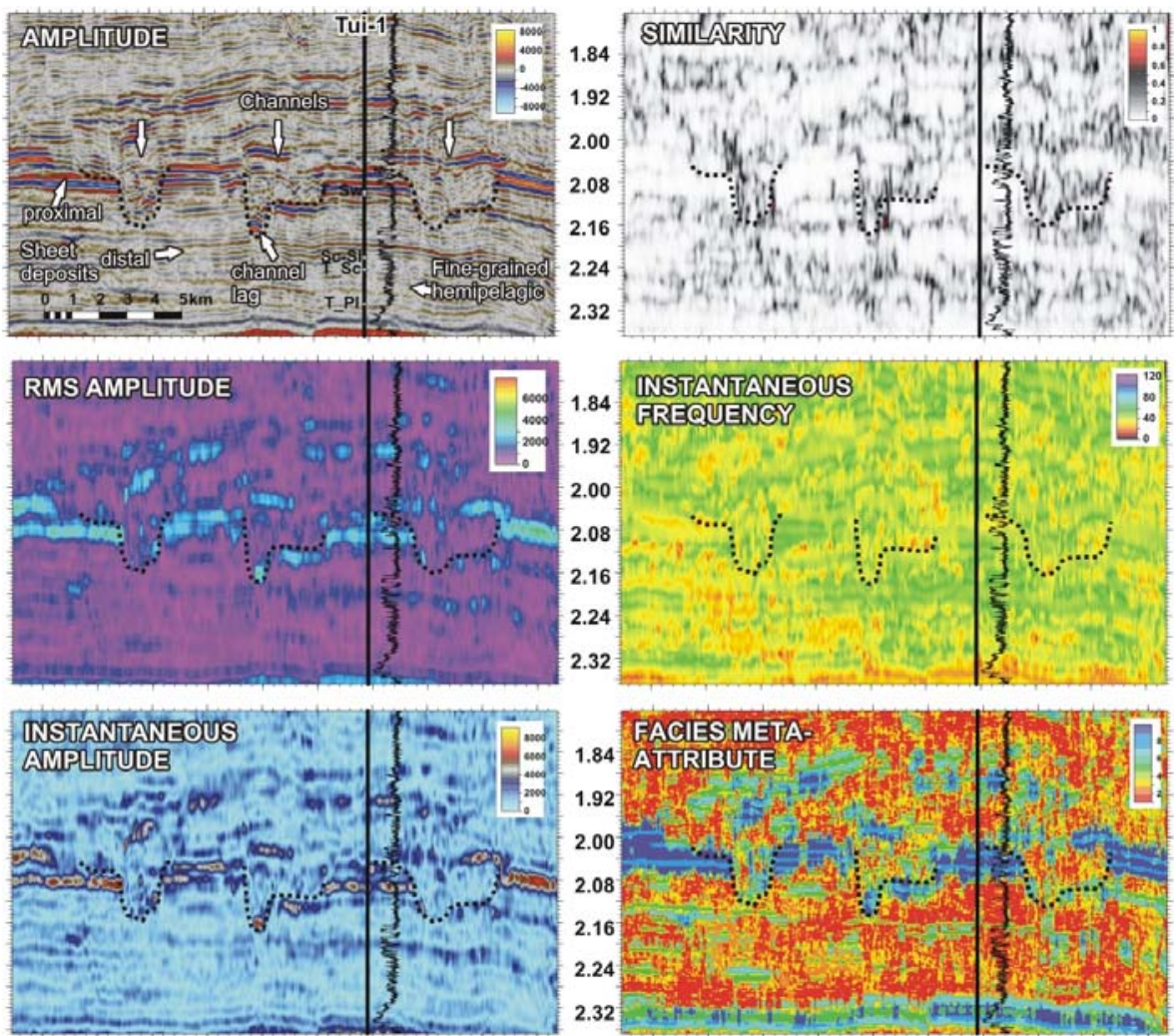

Figure 2.8 Seismic facies expression on the different attributes used in this study. Attributes were calculated from a 2D seismic amplitude profile in Taranaki Basin (stos95-110). The seismic line shows an example of varying facies types, such as sheet-like turbidite fan deposits and marine channel systems. Facies types are annotated on the seismic amplitude profile (top left) and the channel facies are outlined in all attribute panels for reference (black dashed lines). The bottom right panel shows a meta-attribute derived by combination of instantaneous amplitude, instantaneous frequency, and similarity (see text for description of the derivation). The location and gamma-ray log of well Tui-1 are shown in each panel. Note the similar response of the RMS and instantaneous amplitude panels, which is attributed to the similar window length used for calculation of these attributes $(20 \mathrm{~ms})$. 
Coherency attributes were developed in the 1990s to image discontinuities of the seismic data related to faulting or stratigraphy (Bahorich \& Farmer, 1995; Marfurt et al., 1998). These types of multi-trace attribute algorithms attempt to measure the similarity of waveforms or traces adjacent over given lateral and/or vertical windows and a multitude of algorithms have been developed to quantify such variations (see Chopra \& Marfurt, 2007 for review). They can be calculated across short lateral and vertical windows to image abrupt changes (edges or discontinuities) or over increased window size to compare the distribution of seismic energy in a sequence (texture). Since, especially for the analysis of sedimentary strata, it is important to compare seismic reflections along the stratigraphic dip, these algorithms contain functions to determine the prominent dip of adjacent reflectors by determining the direction of most coherent energy over a specified time window. The choice of coherency attributes was constrained by the software used in this study ('variance' in Schlumberger Petrel, 'similarity' in DGB Opendtect). The attribute used in this study for the delineation of edges such as faults and channel margins on $3 \mathrm{D}$ data measures the variance between adjacent traces. The variance attribute (Petrel) is a patented method used to isolate discontinuities in the lateral direction from the input data set (Van Bemmel \& Pepper, 2002). In this attribute, the normalised variance at time $\boldsymbol{t}$ is calculated as:

$$
\delta_{t}^{2}=\frac{\sum_{i=t-L}^{i=t+L} w_{i-t} \sum_{i=1}^{l}\left(x_{i j}-\overline{x_{i}}\right)^{2}}{\sum_{i=t+L}^{i=t+L} w_{i-t} \sum_{i=1}^{l}\left(x_{i j}\right)^{2}},
$$

where $\boldsymbol{x}_{\boldsymbol{i} \boldsymbol{j}}$ is the sample value at the horizontal position, $\boldsymbol{j}$, and the vertical sample, $\boldsymbol{i}, \bar{x}_{\boldsymbol{i}}$ is the mean value calculated over the lateral trace window, $\boldsymbol{l}$, along a calculated dip and $\boldsymbol{w}_{\boldsymbol{i}-\boldsymbol{t}}$ is the vertical smoothing term over a vertical window with half-length, $\boldsymbol{L}$. The variance algorithm is similar to the semblance method (Marfurt et al., 1998), with the difference that the vertical smoothing term is substituted by a vertical average. In this study variance values were calculated across two adjacent in-lines and cross-lines in each direction from the target trace (four traces). A triangular window function with $32 \mathrm{~ms}$ length was used for vertical smoothing. 
The coherency attribute used to fingerprint seismic facies, similarity (Opendtect, Figure 2.8), calculates how similar two traces are along the direction of reflector dip in a slightly different manner. The similarity, $\boldsymbol{s i m}_{\boldsymbol{t}}$, of adjacent traces over a vertical time window of length $2 \boldsymbol{L}$ along the estimated dip is calculated as the Euclidian distance of the two data points (expressed as vectors in 2D space) divided by the RMS values (length, L2 norm) of individual vectors as:

$$
\operatorname{sim}_{t}=1-\frac{\sqrt{\sum_{i=t-L}^{i=t+L}\left(x_{i}-y_{i}\right)^{2}}}{\sqrt{\sum_{i=t-L}^{i=t+L} x_{i}^{2}}+\sqrt{\sum_{i=t-L}^{i=t+L} y_{i}^{2}}},
$$

where $\boldsymbol{x}_{\boldsymbol{i}}$ and $\boldsymbol{y}_{\boldsymbol{i}}$ are the samples at a given time with offset determined a-priori during step one. This measure is then smoothed over a pre-defined lateral window along the stratigraphic dip, which was set to four in each direction of 2D dimensional seismic profiles (a total of eight traces). The difference between the variance and similarity methods is that variance measures the difference of a sample value from a mean, whereas similarity compares individual traces values and averages over an interval.

While being a very effective tool for the delineation of seismic facies in 3D surveys, the creation of 2D maps from coherency attributes yielded little insight into the facies distribution. This is because the relatively narrow edges that these attributes highlight are usually laterally more limited than amplitude trends and thus less visible when contoured on a larger grid size. However, the usage of similarity was important in the characterisation of facies with seismic meta-attributes (see below).

\section{Neural network multi-attribute analysis}

Artificial neural networks (ANNs) are used in seismic interpretation to reproduce physical log properties (supervised ANNs) or to find groups with similar seismic responses in the data based on multiple attributes (unsupervised ANNs) (Ronen et al., 1994; Schultz et al., 1994; Srivastava et al., 2004; Baaske et al., 2007). Neural network algorithms are used in this context due to their ability to resolve non-linear relationships between different seismic attribute responses (Ronen et al., 1994; Schultz et al., 1994). This study uses unsupervised ANNs to improve the visibility of seismic facies on attribute maps from sparse 2D data, by finding clusters in a set of seismic attributes. This type of ANNs was chosen due to their superior robustness in cases of sparse borehole 
sampling of the target seismic facies, which is the case for Miocene channel facies in Taranaki Basin.

The neural network algorithm used in this study is termed Unsupervised Vector Quantiser (UVQ, available in the software Opendtect), which represents a competitive learning application used for data encoding or compression (Haykin, 1994). The algorithm aims to find structure in an attribute data set and segments (cluster, classify) the input data (seismic attributes) into a pre-defined number of classes of similar character (meta-attribute of seismic facies classes) via a set of weighting functions for each attribute ( $w$, Figure 2.9). The class into which a specific data point falls is defined by calculating the Euclidian distance between the data vector and a set of protype vectors. The algorithm consists of a two-layer vector quantiser with data input layer and one hidden layer, and a post-processing part with an output layer.

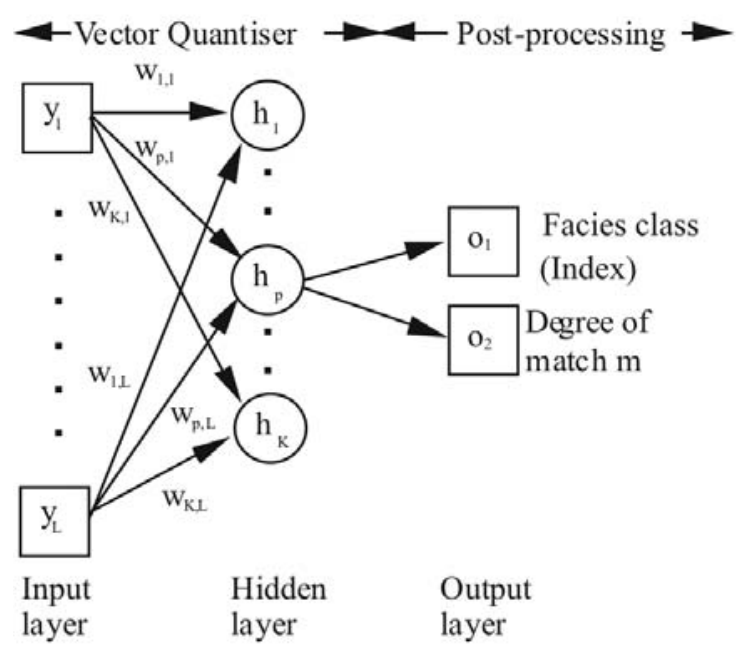

Figure 2.9 Schematic representation of the Unsupervised Vector Quantiser (UVQ) used in this study. The network consists of a vector quantiser part and a post-processing part. Two outputs are generated: the index of the winning hidden node (i.e. the class) and a degree of match, which indicates how close the input vector is located near the centre of the example facies class.

The input layer consists of seismic attribute data, in which each data sample location forms a vector, $\boldsymbol{y}$, of length, $\boldsymbol{L}$, representing the number of individual attribute values. The vector quantiser connects a single layer of hidden nodes of length equalling the number of pre-defined classes, $\boldsymbol{h}_{\boldsymbol{i}}$, with the input nodes via weighted attribute excitation functions (vectors), $\boldsymbol{w}_{i, j}$. The output for each hidden node is calculated as the Euclidean distance to the input:

$$
h_{i}(y)=\sqrt{\sum_{j=1}^{j=L}\left(y_{j}-w_{i j}\right)^{2}} \boldsymbol{i}=1, \ldots, \boldsymbol{K} .
$$


Initially, a random sample set of prototype vectors has to be defined from the data to train the network and find the relationship between the input data points. During this learning phase output values for a given weighting function are compared amongst each other and the hidden node with the smallest net differences is designated a attribute group. The weighting vector, $\boldsymbol{w}_{\boldsymbol{p}, j}$, associated with the winning node, $\boldsymbol{p}$, is then updated according to:

$$
w^{\prime} i j=\left\{\begin{array}{l}
w_{i j} \quad i=1, \ldots, p-1, p+1, \ldots, K \quad j=1, \ldots, L \\
w_{p j}+\eta\left(y_{i}-w_{p j}\right) \quad i=1, \ldots, L
\end{array},\right.
$$

where $\boldsymbol{w}_{t j}^{t}$ is the updated weighting matrix and $\boldsymbol{\eta}$ is an empirically determined learning rate parameter. The updating process is continued until prototype vectors cease to show noticeable changes.

This prototype data set is then used to classify the remaining data points. In addition to associating each input vector with a class through weighting functions derived in the first step, the match, $\boldsymbol{m}$, of individual data point with respect to the prototype vectors is quantified as:

$$
m=1-\left(\frac{h_{p}(y)}{r \sqrt{L}}\right)
$$

where $\boldsymbol{r}$ is the variation range for the training data. The attribute values of the input data set are scaled such that the match results range between 0 (no match) and 1 (perfect match). The influence of each attribute on the resulting multi-attribute can be inferred from their contribution in the weighting functions. For further detail on the method, the reader is referred to the background literature (Haykin, 1994; de Rooij \& Tingdahl, 2002; Aminzadeh \& De Groot, 2004; Meldahl et al., 2004; Chopra \& Marfurt, 2007).

\section{Multi-attribute facies classification on the Taranaki Basin data set}

Unsupervised facies classification was conducted on four surveys: 86MA (Western Geophysical Company, 1986; OMV New Zealand Ltd., 2002), STOS95 (RobertsonResearch, 1997), SUNZ91(GECO-PRAKLA, 1991), and DTB01 (TGS-NOPEC, 2001). Neural network facies classifications were derived for each of these data sets independently to avoid biases that arise from differences in the acquisition and 
processing character of each survey. A suite of single and multi-trace attributes were calculated and visually assessed in terms of their sensitivity with respect to channels and other facies types (Figure 2.8). Although a series of attributes showed a visible sensitivity with respect to these facies, a small number of these attributes were chosen to avoid bias due to linear correlation amongst individual attributes and to facilitate reproducibility of the outputs (e.g., Barnes, 2007). Attributes used in the procedure to fingerprint the seismic facies were instantaneous amplitude, instantaneous frequency, and similarity (Figure 2.8).

Within each survey, a set of 500-2000 randomly located points was created at the depth interval of Miocene strata (limited at the top and base by manually interpreted horizons) to provide a prototype data set. Attribute values were extracted onto these points for training the neural network. The neural network was trained to subdivide the data vectors (each point containing 3 attribute values) into a set number of output classes until no additional improvement of the weighting functions was observed. These trained weighting networks were applied to the seismic data to investigate the resulting facies classes. A low number of output classes was chosen initially and this number was iteratively increased until no additional improvement in facies definition was detected. The resulting meta-attributes of individual surveys contain 8-10 classes (Figure 2.8, Table 2.4). The resulting match between the input vectors and the facies classes in the final meta-attributes was commonly between 0.75-0.95. Most classes in the resulting meta-attributes are strongly influenced by amplitude, while frequency is found to be of subordinate importance in defining facies (Table 2.4).

Table 2.4 Examples of training results from an unsupervised neural network classification of the STOS95 survey. The top shows the contribution of each attribute in separating individual facies classes. The bottom shows the number of final facies classes, the number of data points (nodes or attribute vectors) associated with each class, and the average match achieved between the data and prototype vectors.

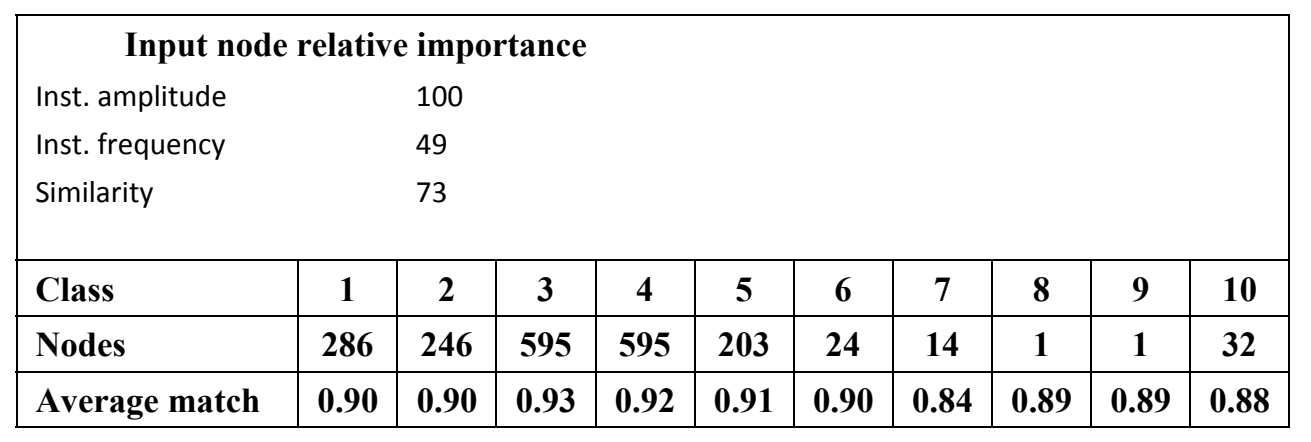




\section{Dip-steered horizon auto-tracking and development of chronostratigraphy}

The sequence stratigraphic interpretation system (SSIS) of DGBs Opendtect software was used to derive a chronostratigraphic, depositional, and sequence stratigraphic model of the Plio-Pleistocene Giant Foresets Formation. In this approach, individual seismic reflectors of a seismic sequence are automatically tracked between manually mapped sequence boundaries (unconformities). Auto-tracking of seismic reflectors is facilitated by a process named 'dip-steering' (Tingdahl et al., 2001; Tingdahl \& De Groot, 2003), which estimates the apparent reflector dip of individual reflectors along a seismic line (Figure 2.10, top). The dip of a given reflector is calculated using a sliding Fourier analysis technique, which aims to find the direction of most coherent energy within a given time window. The vertical and lateral calculation windows determine the resolution and smoothness of the estimated dip results and can be manually adjusted.

This process was applied to seismic line DTB01-31 that extends in a southwest northeast direction from the Western Platform to Deepwater Taranaki Basin (Figure 2.10, see chapter 7). A set of 16 unconformities or paraconformities were manually mapped on the line DTB01-31 to encompass major sequence boundaries and define the reference horizons for auto-tracking. The dips were calculated over three adjacent traces and then smoothed over a six-trace window. This dip information was used to automatically track individual reflectors towards their lateral truncation surfaces within individual sequences (Figure 2.10). The auto-tracking process started at the maximum thickness of each sequence and the minimum and maximum space between the auto-tracked horizons was specified to 2 and $8 \mathrm{~ms}$ two-way-traveltime, respectively. Auto-tracked horizons were then placed in stratigraphic order and a relative geological time was assigned to derive a chronostratigraphic model. Despite minor problems associated with seafloor multiples in the seismic data, the fit of the auto-tracked horizons was satisfactory and facilitated the detailed analysis of internal reflector truncations and sequence stratigraphic analysis (see chapter 7). 

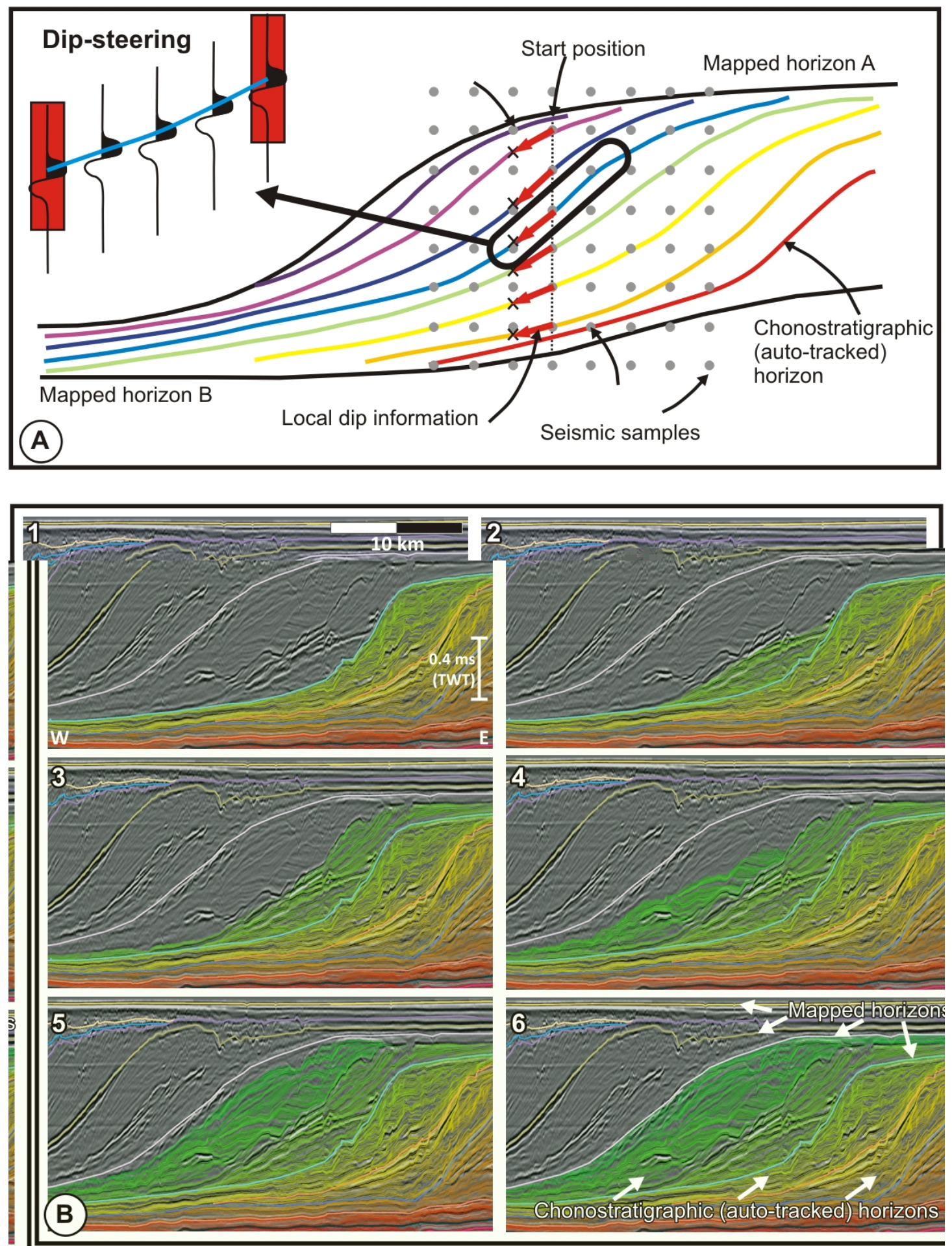

Figure 2.10 Schematic concept of dip-steered reflector auto-tracking and example from the application to the Taranaki Basin data set. Panel (A) shows how stratigraphic dips are calculated along a seismic profile and how reflectors are auto-tracked towards their lateral terminations. B) Dip-steered auto-tracking results from seismic line DTB01-31 within the Plio-Pleistocene Giant Foresets Formation in the outer shelf area of Taranaki Basin. The seismic profile shows the manually mapped (thick coloured lines) and auto-tracked horizons (thin lines, coloured from red /oldest to green/youngest). 


\subsubsection{Phantom horizon mapping}

In order to provide insight into the distribution of seismic facies between the seismic horizon interpretations, seismic attributes were extracted over sub-intervals based on calculated phantom horizons. Such interval and formation attributes combine several thin discontinuous units to generate an image of the overall facies character can help reduce the effects of small horizon reflector mismatches (Chopra \& Marfurt, 2007). The most basic slicing technique represents the shifting of the time datum of a seismic horizon, $\boldsymbol{H}$, by a certain time interval $\Delta t$ :

$$
\text { horizon_slice }=H(x, y, t)+\Delta t \text {. }
$$

This technique works well in areas where reflectors are parallel and thicknesses uniformly distributed. For cases in which the thickness and internal reflector geometries vary within a given sequence, the stratal slice has been developed (Zeng et al., 1998), which subdivides a given sequences between two seismic horizons, $\boldsymbol{H} \mathbf{1}$ and $\boldsymbol{H} 2$, into proportional sub-intervals (Figure 2.11). The depth of the $\boldsymbol{i}^{\text {th }}$ stratal slice in a total number, $\boldsymbol{k}$, proportional subdivisions can be calculated as:

$$
\text { stratal_slice }_{i}=H 1\left(x, y, t_{1}\right)+i\left(\frac{H 1\left(x, y, t_{1}\right)-H 2\left(x, y, t_{2}\right)}{k}\right) .
$$

Zeng et al. (1998) has shown that, when based on well-defined reference horizons, this approach is often more robust in developing time parallel sub-intervals than manually mapped intermediate horizons through sequences with low lateral reflector continuity. An advantage of this method is that reflector cross-cutting is avoided (Figure 2.11). Problems with proportional sub-division occur in the presence of strong faulting, angular unconformities and reflector offlaps, if insufficient bounding reflectors are available (Zeng et al., 1998). 


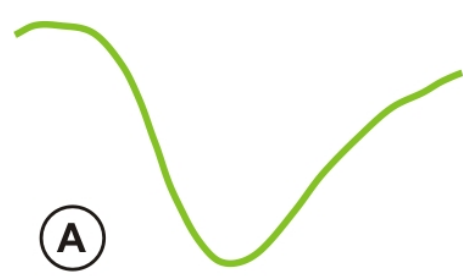

Geologic situation

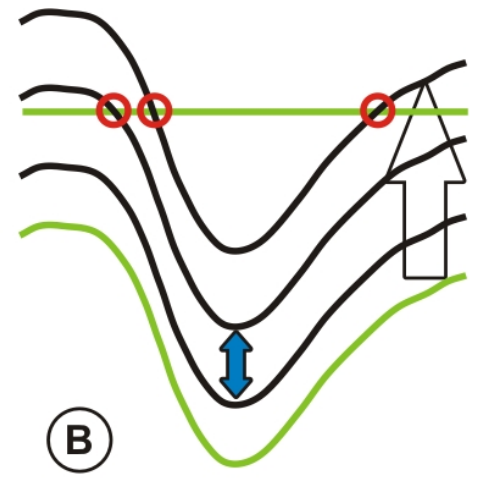

Horizon slicing (time shift)

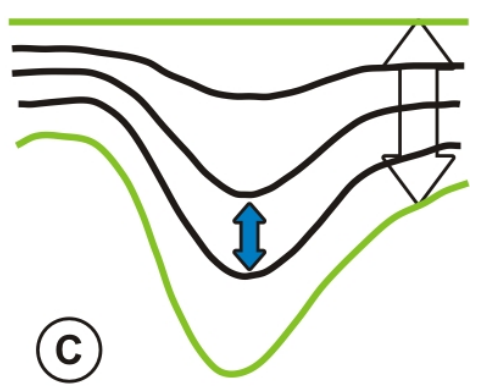

Stratal slicing (proportional shift)

Figure 2.11 Schematic depiction of different phantom horizon mapping techniques and their pitfalls. A) Shows the thickness distribition of a geological formation. B) Shows how phantom horizon creation through simple time shifting of mapped horizons results in reflector crosscutting, which can be alleviated through stratal slicing (C).

Stratal slicing was the most commonly used approach to create phantom horizons in this study, and has generally produced satisfying results (Figure 2.12). In cases of minor reflector cross-cutting, successive stratal attribute extractions were superimposed on each other and carefully investigated to map the continuity of facies within a sequence, while attribute responses from older or younger sequences were discarded. Substantial crosscutting between seismic reflectors and phantom horizons is observed in strongly progradational units within the Taranaki Basin (Figure 2.13). While not being able to produce time-parallel horizon sub-divisions for such sequences, cross-cutting interval extractions were used to delineate shelf margin and slope geometries for paleogeographic reconstructions (Figure 2.13).

The number of subdivisions stratigraphic analysis was chosen dependent on the isochron thickness (in TWT) of the interval and the number of loops (frequency) of the seismic wavelets within this interval. As the seismic resolution and frequency decrease with increasing depth (TWT), fewer subdivisions were applied at deep stratigraphic levels for a given two-way-travel time thickness. The general procedure was to create a high number of sub-intervals to investigate the facies in a given interval. The number of subintervals was then reduced to display the most characteristics facies of a given sequence. 

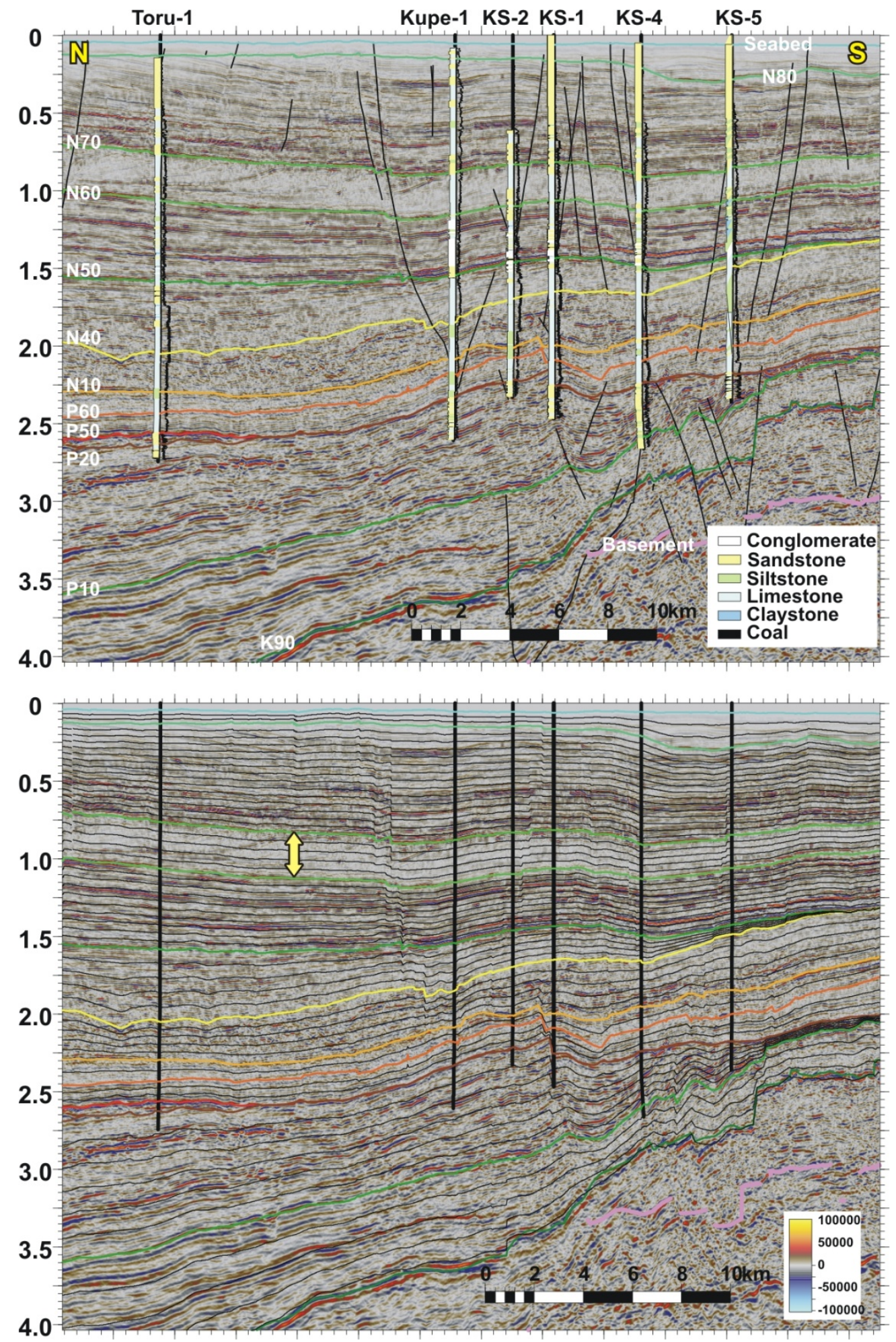

Figure 2.12 Example of mapped horizons and stratal slices used for sub-dividing the seismic-stratigraphic sequence on a north-south-oriented seismic line in the Kerry 3D data set (in s TWT). The stratal slices were calculated by proportionally subdividing the mapped seismic horizons sequences. Well paths (black lines) are shown in both panels and the well names are shown above the top panel (KS-Kupe South). The top panel shows gamma-ray logs and simplified versions of the lithology logs for individual wells (see legend on the right for colour code). Mapped horizons are shown in colour and are annotated, faults are shown as black lines in top panel and stratal slices are shown as black lines in bottom panel. The sequence shown in Figure 2.13 is indicated by a yellow arrow in the top panel. 

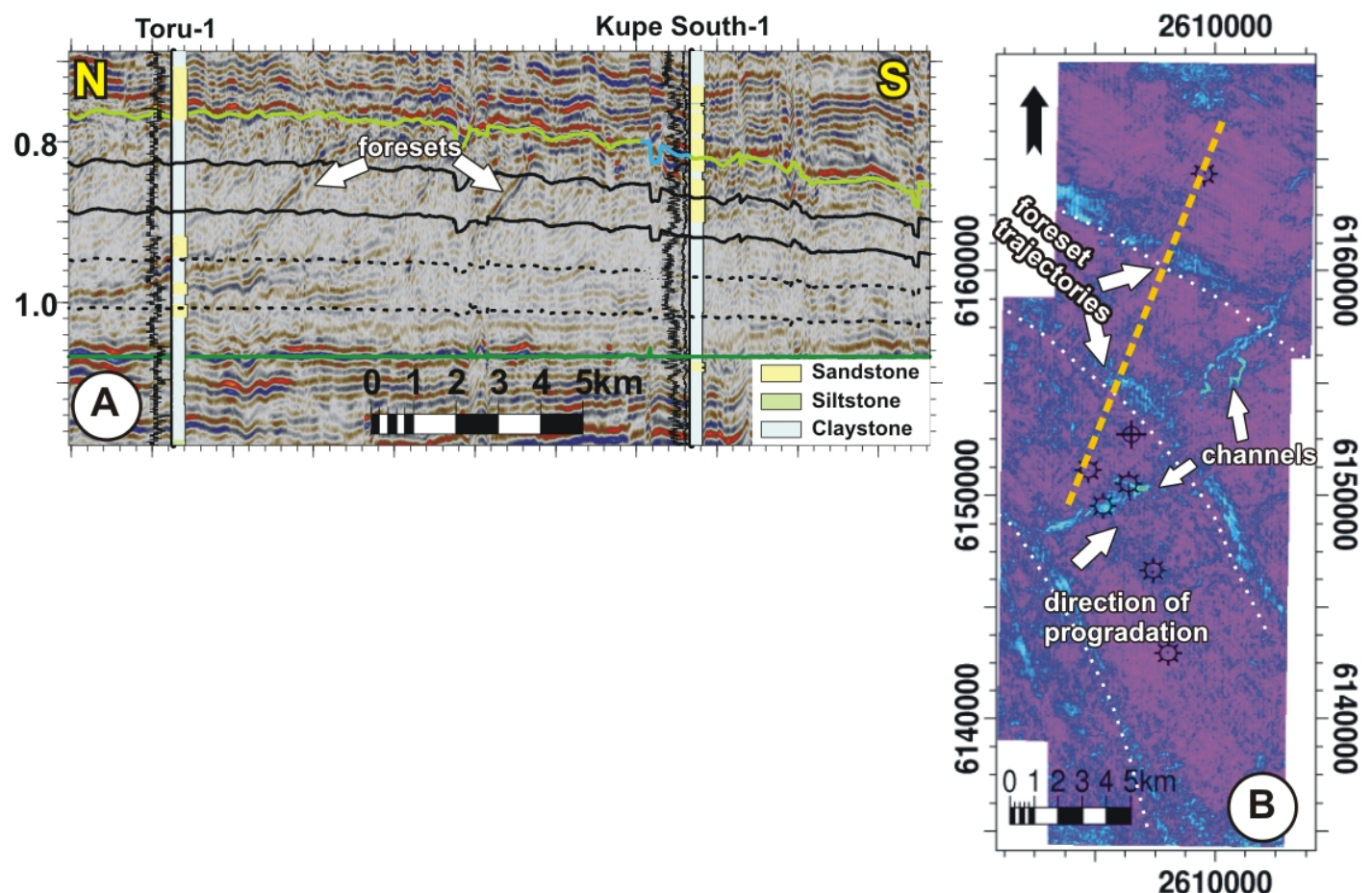

Figure 2.13 Example of stratal slicing in progradational sedimentary systems. A) Seismic profile from the Kerry 3D survey magnified over the interval indicated by the yellow arrow in Figure 2.12 (N60-N70, Tangahoe Formation) flattened on the N60 horizon (in s TWT). Stratal slices are shown as dashed and solid black lines. The paths of well Toru-1 and Kupe South-1 are shown with gamma-ray (black lines) and lithology logs (see legend). B) Root-meansquare (RMS) amplitude map over the stratal interval indicated by the solid black horizontal lines in (A). Note the continuity of lateral foreset geometries and channel facies (blue colours = higher amplitudes) from which the direction of progradation can be inferred. The location of the seismic line in (A) is shown as dashed orange line in (B).

\subsubsection{Interval statistics}

A series of statistics were calculated over the derived sub-intervals to extract, and best represent, seismic attribute information on mapped and phantom horizons. A large number of different statistics available in Schlumberger's Petrel software were calculated for individual sequences. The resulting attribute maps were investigated together with seismic profiles and a small number of statistics were chosen that provided the best discrimination between seismic facies. For interval amplitude extractions of 2D and 3D data, the most effective statistic was the root- mean-square (RMS) of the original trace amplitude (Figure 2.14A), as it represents a simple measure to separate areas of differing amplitude signature. The RMS amplitude is calculated as:

$$
R M S=\sqrt{\frac{\left(\sum_{i}^{i=n} x_{i}^{2}\right)}{k},}
$$

where $\boldsymbol{x}_{\boldsymbol{i}}$ is the amplitude of individual samples, $\boldsymbol{i}$, in the interval containing a total of $\mathbf{k}$ samples. 
Other measures used for amplitude extraction were the sum of absolute amplitude values (sum of magnitudes, Figure 2.15) or average peak values between zero crossings (average of maximum absolute values between individual pairs of zero crossings). For interval extraction of coherency attributes (e.g., variance) the median was chosen as the most stable window statistic (Figure 2.14C), due to its lower sensitivity to extreme values (outliers). Interval extractions from meta-attributes were summarised by the most commonly occurring value within the extraction window (most of-attribute), which allows for interval attribute representation without averaging to values that may not exist in the attribute volume.
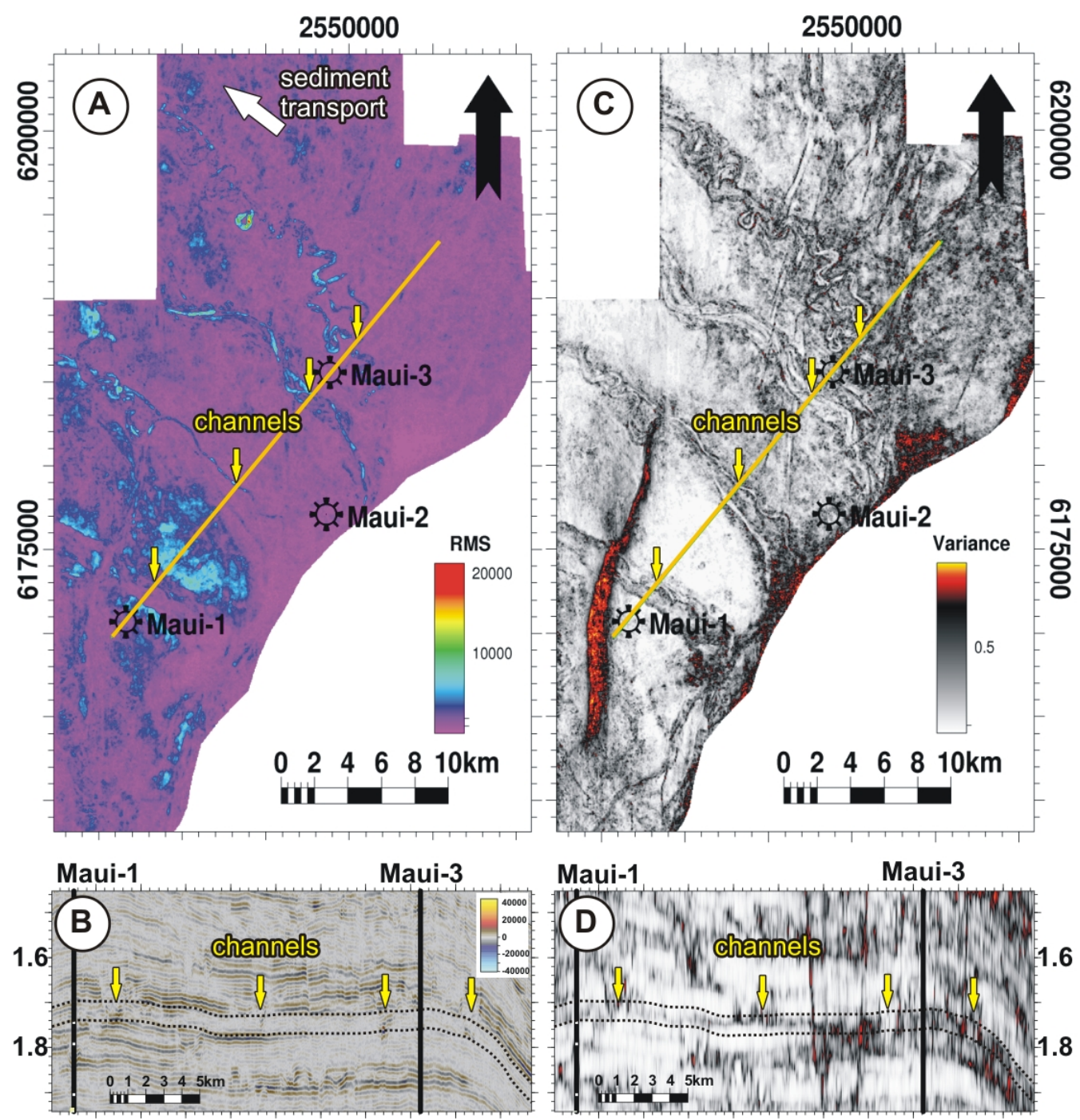

Figure 2.14 Interval attribute extractions and seismic profiles showing the variable expression of seismic facies on different attributes. The data shows Middle Miocene submarine channels in the Maui 3D data set (see Figure 2.1 for location). A) RMS amplitude extraction over a stratal interval indicated by dashed black lines in (B). C) Variance attribute map of the same interval created through calculating the median of the variance attribute shown in profile D). The location of the profiles in (B) and (D) are shown in (A) and (C) as orange lines, respectively. Well paths are shown as vertical black lines. Submarine channel facies are annotated with yellow arrows. Note that the amplitude-based attribute highlights the differences of the channel fill relative to surrounding reflectors, whereas the variance attribute highlights the discontinuities at channel margins. 


\subsubsection{Attribute gridding and map normalisation}

Seismic attributes from 2D data were extracted at the location of seismic horizon interpretations and then gridded to create attribute maps (Figure 2.15). For 3D data sets, seismic horizon interpretations were first gridded and attributes were extracted onto the resulting surfaces to maximise the usage of seismic traces from the $3 \mathrm{D}$ data set (Figure 2.14). Seismic horizon interpretations and attribute extractions from $2 \mathrm{D}$ and $3 \mathrm{D}$ data were contoured using a minimum curvature algorithm in Schlumberger's Petrel software. The grid size for contouring was $50 \mathrm{~m}^{2}$ for $3 \mathrm{D}$ data sets and $150 \mathrm{~m}^{2}$ for attributes of 2D data, respectively, while structural maps were contoured at $250 \mathrm{~m}^{2}$. The significantly smaller grid size of 2D attributes maps compared to the 2D line spacing (500-10,000 m) was chosen to maximise attribute information and to minimise the extrapolation of values into adjacent areas. A linear extrapolation operator (full tension) was used in the gridding algorithm, which imposes a flat trend in areas of no data and further reduces extrapolation artefacts. For display purposes, some of the maps were additionally smoothed with filters of up $1 \mathrm{~km}^{2}$ radius after facies investigation.

Due to the varying processing parameters and amplitude scaling functions (e.g., automatic gain control) that have been applied to the individual seismic data sets during seismic processing, minor differences remained between certain surveys or depth intervals. In order to alleviate these problems and delineate regional facies trends on single displays, attribute maps were further normalised between respective areas (e.g., Deepwater Taranaki Basin, central Taranaki Basin) after careful investigation of the seismic data and facies continuity. The attribute analysis of this heterogeneous seismic data set thus required the constant verification of observed attribute patterns on seismic profiles. Due to the multiple amplitude normalisation steps, final attribute maps are able to highlight relative amplitude differences in respective areas, but are not expected to provide quantitative rock property information such as acoustic impedance. 

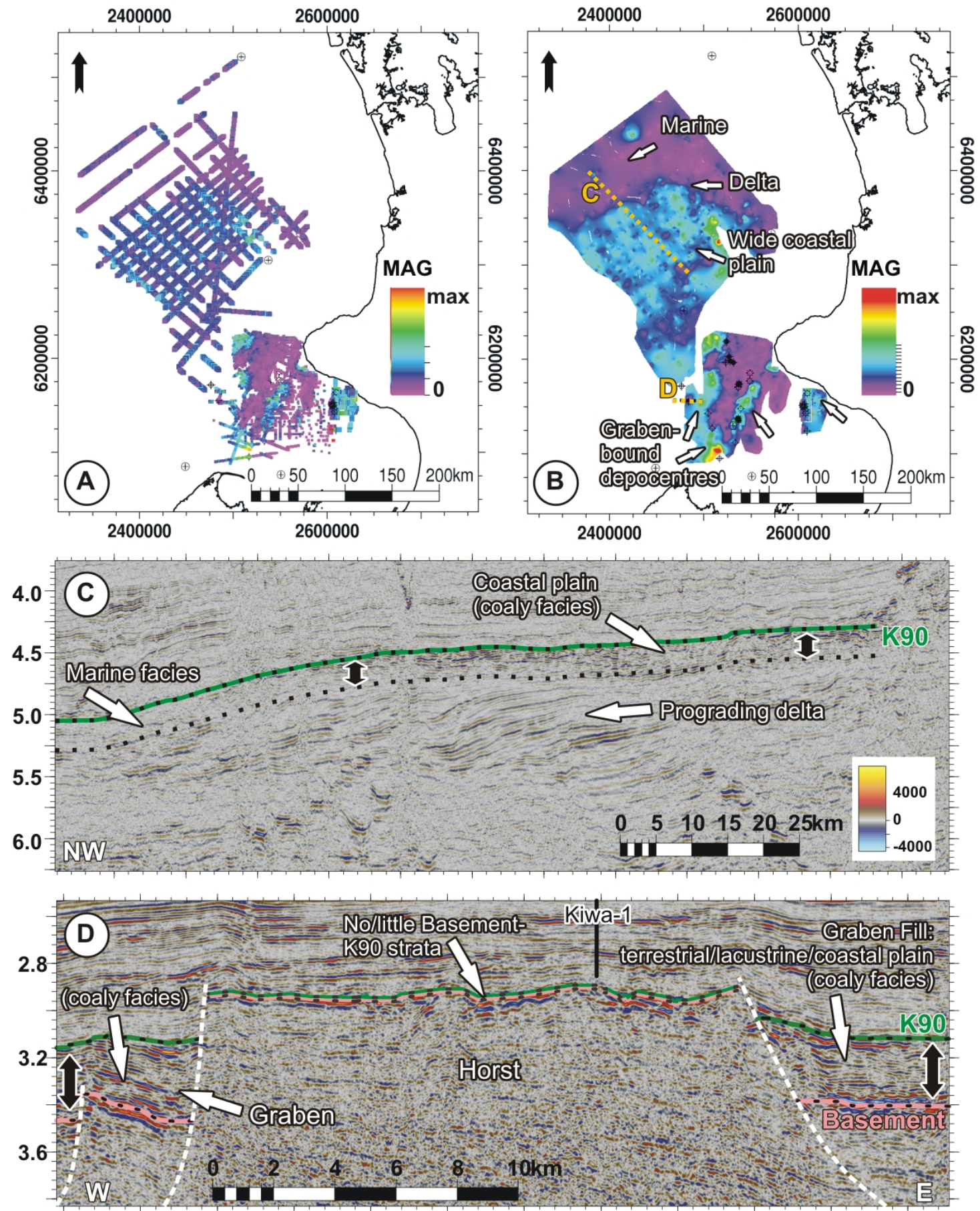

Figure 2.15 Example of regional 2D attribute map creation and expression of associated seismic facies on seismic profiles. In this example the maps were constructed to delineate the distribution of high-amplitude, humocky seismic facies associated with coaly sediments of the Late Cretaceous Rakopi Formation (see Figure 2.4). A) Attribute values (sum of amplitude magnitude) extracted between seismic horizon interpretations. B) Normalised attribute map gridded from attribute values shown in (A). C) Seismic profile in Deepwater Taranaki Basin (DTB01-17) showing the distribution of coaly facies above a prograding Late Cretaceous delta. D) Seismic profile in central Taranaki Basin (T96-14) showing coaly facies of similar age. Faults are shown as white dashed lines. Note the different depositional setting of these facies in respective areas indicating a wide coastal plain in the distal area (A, C) and laterally limited extensional graben systems (A, D). 


\subsubsection{Tectonic subsidence and back-stripping}

\section{Background}

Vertical crustal movement are recorded by basin strata and reflect lithospheric thickness changes, thermal evolution, isostatic adjustments to tectonic, water or sedimentary loads, or dynamic topography associated with mantle flow beneath the basin, (McKenzie, 1969; Watts \& Ryan, 1976; Parsons \& Sclater, 1977; McKenzie, 1978; Le Pichon \& Sibuet, 1981; White \& McKenzie, 1988; DeCelles \& Giles, 1996; Burgess et al., 1997; Burgess \& Moresi, 1999; Gögus \& Pysklywec, 2008). Tectonic subsidence is defined as the basement rock subsidence that would take place if the isostatic response to sediment and water loading was removed (Watts \& Ryan, 1976; Parsons \& Sclater, 1977; McKenzie, 1978; Sclater \& Christie, 1980). Compilations of worldwide stratigraphic basin data show distinctive commonalities of basin fill and subsidence patterns in given tectonic settings (Dickinson, 1976; Angevine et al., 1990; Xie \& Heller, 2009). If magnitude, timing, and extent of tectonic subsidence can be determined, then inferences can be made about basin-forming mechanisms and sedimentary sequence architecture (Steckler et al., 1993).

Watts and Ryan (1976) have first shown that the effects of tectonic driving force can be isolated by removing the isostatic effects of sediment/water load, which they termed back-stripping. The simplest way to separate the effects of sedimentary loading from tectonic driving mechanisms is by assuming that any vertical column of load is compensated locally (Airy isostasy) and the crust has no lateral strength to support the load (Watts \& Ryan, 1976; Allen \& Allen, 1990). Depending on the load distribution and the strength of the lithosphere however, stresses and deformation may be transmitted laterally by regional flexure (Watts \& Ryan, 1976; Watts, 1992). In the case of local sedimentary or tectonic loading, and regional strength of the lithosphere, the crust will subside by a smaller amount than predicted by Airy-isostatic assumptions. Despite the variations due to the lateral strength of the lithosphere, compilations of global basin subsidence histories has shown that the tectonic origin of a basin can be identified from simple 1D-back-stripping (Airy isostasy), even if eustatic sea-level changes are ignored (Angevine et al., 1990; Xie \& Heller, 2009). 


\section{Tectonic subsidence calculation method}

The tectonic driving forces involved in sedimentary basin formation can be quantitatively estimated by constraining the hypothetical depth of the basement in the absence of sediment and water loading. In order to reconstruct the subsidence history the stratigraphic record has to be incrementally removed (back-stripped). Back-stripping of the stratigraphic column requires several corrections to be applied to the present stratigraphic thickness in order to account for: 1) the progressive porosity loss during sediment burial (compaction), 2) the depth of the surface at the time of sediment deposition (paleobathymetry) with respect to a known datum (e.g., present-day sea level), and 3) changes in water loading effects due to oscillating sea level through geologic time (Allen \& Allen, 2005).

Subsidence due to sediment loading is a consequence of replacement of water or, less commonly, air. Assuming replacement of water, the local (Airy) isostatic effects due to the additional load can be calculated by comparison of the density difference (between water and sediment) to the buoyancy force provided by the underlying mantle material. Following Sclater and Christie (1980), the Airy isostatic effects of the sediment load can be calculated as:

$$
Y=S\left[\frac{\rho_{m}-\rho_{s}}{\rho_{m}-\rho_{w}}\right]
$$

where $\mathrm{Y}$ is the depth of the basement corrected for sediment load, $\mathrm{S}$ is the decompacted sediment height, $\rho_{m}$ is mantle density $\left(3300 \mathrm{t} / \mathrm{m}^{3}\right), \rho_{s}$ is the average density of the sediment column, $\rho_{w}$ is water density $\left(1030 \mathrm{~kg} / \mathrm{m}^{3}\right)$.

The tectonic component of subsidence can then be calculated by incorporating the effects of paleobathymetry, changing sea level and sediment loading:

$$
Y_{t}=S *\left[\frac{\rho_{m}-\rho_{s}}{\rho_{m}-\rho_{w}}\right]+\Delta s l\left[\frac{\rho_{w}}{\rho_{m}-\rho_{w}}\right]+\left(D_{w}-\Delta s l\right),
$$

where $Y_{t}$ is the tectonic subsidence for a given time, $\Delta s l$ is the paleo-sea level relative to the present and $D_{w}$ is the assumed paleobathymetry. The average density of the sediment column can be calculated as:

$$
\rho_{s}=\sum_{i} \frac{\left[\phi_{i}^{*} \rho_{w}+\left(1-\phi_{i}\right) * \rho_{s g i}\right] * z_{i}^{\prime}}{S}
$$


where $\phi_{i}$ is the porosity, $\rho_{s g i}$ is the grain density, and $z_{i}$ the thickness of the ith sediment layer. Following Sclater and Christie (1980), it is assumed that the porosity decreases with increasing depth according to:

$$
\phi=\phi_{0}\left(e^{-c z}\right)
$$

where $\phi$ is the present day porosity at depth, $\phi_{0}$ is the initial porosity at the surface, $c$ is the compaction coefficient, and $z$ is the depth. Consequently the porosity of a given sediment layer can be calculated as:

$$
\phi_{i}=\frac{\phi_{0}}{c} *\left[\frac{e^{-c z_{1}{ }^{\prime}}-e^{-c z_{2}{ }^{\prime}}}{z_{2}{ }^{\prime}+z_{1}{ }^{\prime}}\right] \text {, }
$$

where $\phi_{0}$ is the surface porosity, $\mathrm{c}$ the compaction coefficient and $\mathrm{z}_{1}{ }^{\prime} / \mathrm{z}_{2}$ ' the top/bottom of the formation corrected for compaction. The decompacted sediment thickness of each interval is solved for numerically (Sclater \& Christie, 1980; Allen \& Allen, 2005)

Taranaki Basin specific lithology parameters from Funnell et al. (1996) were used for the decompaction of sedimentary strata in this study. The surface porosity, compaction coefficient and bulk density values for generalised lithologies are listed in Table 2.5 and the compaction characteristics are shown in Figure 2.16. It is noted that, despite expected differences in surface properties, the mud and coal curves are identical in order to match the porosity development at greater depth (Funnell, personal communication). Individual formations were parameterised by estimating the percentages of individual lithologies from borehole cuttings and wireline logs and calculating their fractional contribution to the total formation thickness.

Table 2.5 Lithology parameters after Funnell et al. (1996) (top). Por0 is the surface porosity, c the compaction coefficient in $\mathrm{km}^{-1}$, and rho is the sediment grain density in $\mathrm{kg}^{*} \mathrm{~m}^{-3}$.

\begin{tabular}{|c|l|l|l|l|l|}
\hline Lithology & \multicolumn{1}{|c|}{ sand } & \multicolumn{1}{c|}{ silt } & \multicolumn{1}{c|}{ mud } & \multicolumn{1}{c|}{ marl } & \multicolumn{1}{c|}{ coal } \\
\hline por0 & 0.45 & 0.49 & 0.54 & 0.7 & 0.54 \\
\hline c & 0.000333 & 0.0004 & 0.0005 & 0.000714 & 0.0005 \\
\hline rho & 2650 & 2680 & 2720 & 2710 & 2500 \\
\hline
\end{tabular}




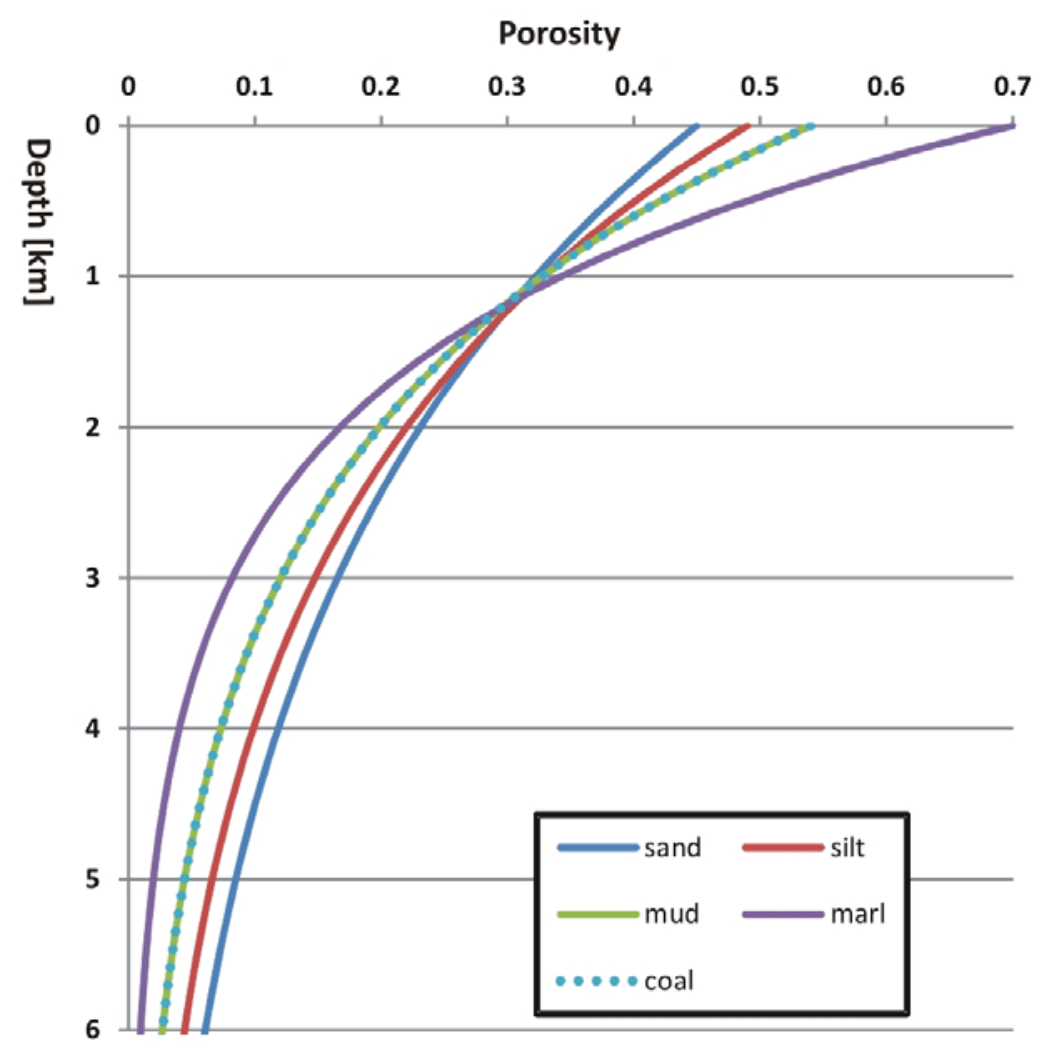

Figure 2.16 Theoretic compaction diagram of Taranaki Basin lithologies calculated with compaction coefficients from Funnell et al. (1996) using the method of Sclater and Christie (1980). Note the relatively rapid compaction of marl and the identical compaction behaviour of coals and mudstones.

Estimates of paleobathymetry used in this study are based on the updated biostratigraphic data set provided by the 4D Taranaki project (see above). These data were cross-checked for consistency amongst the different wells and assessed together with bathymetry indicators from seismic data (e.g., paleo-shelf breaks).

Uncertainties of paleo-water-depth estimates vary considerably in association with respective depositional environments. Rapid faunal changes on the continental shelf often provide the means of tightly constraining paleo-water depths, while the broad ranges of most bathyal taxa substantially limit their value for estimating paleo-depths beyond the shelf break. Expected uncertainty ranges proposed by Hayward and Wood (1989) are:

\section{Estimated paleobathymetry $[\mathrm{m}]$}

$\begin{array}{cc}0-100 & \pm 30 \\ 100-200 & \pm 50 \\ 200-400 & \pm 100 \\ 400-3000 & \pm 500\end{array}$


Estimates of the amplitude of sea-level fluctuations through geologic time vary considerably amongst different studies and there is no consensus on a global eustatic curve (e.g., Allen \& Allen, 2005). General agreement exists about a general long-term sea-level lowering since the Cretaceous (Kominz, 1984; Haq et al., 1987; Miller et al., 2005). However, estimates derived from global seismic reflection data and derivative onlap curves (Haq et al., 1987) suggest substantially higher paleo-sea levels than estimates from borehole data that include lithospheric cooling models (Kominz, 1984; Miller et al., 2005). The former estimates suggest up to $300 \mathrm{~m}$ higher sea levels during the Cretaceous (65 Ma), whereas the latter are on the order of 150-200 m. Similarly, estimates of short term sea-level changes vary considerably and, due to the high frequency signal in proxy curves such as oxygen isotope records (Lisiecki \& Raymo, 2005), are more difficult to extract and apply in the back-stripping procedure.

The approach taken here follows the proposition of Allen and Allen (2005) to ignore sealevel changes during the initial back-stripping and then apply justifiable corrections. These authors advise against a-priory invoking sea-level corrections by Haq et al. (1987) due to consistently higher estimates by a factor of about 2 with respect to other studies (Kominz, 1984; Miller et al., 2005). Eustatic corrections based on relatively conservative sea-level estimates of Miller et al. (2005) were applied to back-stripping results in chapter five due to reviewers comments about this publication. Results shown in Supplement 2 and chapters four and seven do not include eustatic corrections to minimise the assumptions incorporated into the calculation. The effect of changing sea level $(\Delta s l)$ on basin subsidence is $\sim 0.69 \Delta s l$ (Allen \& Allen, 2005). Uncertainties of this order mostly lie within the resolution of paleobathymetry estimates and interpretations made based on the back-stripping results are considered robust in spite of uncertainties arising from eustatic loading effects.

Erosion estimates were not included in the calculation of tectonic subsidence since they were not reconstructed in a consistent manner across the basin. Effects of erosion would accentuate the uplift estimates in southern and south-eastern basin, but would be of no primary significance to the interpretation drawn in this study. 


\section{General subsidence patterns of Taranaki Basin}

Stratigraphic data from 20 boreholes (Figure 2.2) were back-stripped to improve constraints of the tectonic evolution of the basin and to provide a context for observed sedimentary patterns from seismic data. The results of these calculations are discussed in detail within the individual chapters of this thesis and are listed in supplement 2. A selection of the results from this thesis in different basin areas is shown in Figure 2.17 to highlight the basins tectonic subsidence characteristics since the Late Cretaceous, which can be broadly subdivided into three phases of basin evolution:

1) A Late Cretaceous to Late Paleogene concave upward signature with a steep Late to latest Cretaceous segment and gradually decreasing incremental subsidence. This signature is interpreted as the result of rifting and post-rift thermal subsidence (passive margin phase).

2) A late Paleogene to Late Miocene phase of varied subsidence and uplift patterns in different parts of the basin, with an early rapid subsidence phase common to all wells. This signature is interpreted as the manifestation of the change to compression and development into a retroarc foreland basin. The common pattern of rapid subsidence during the early phases of foreland development shows the long-wavelength character of this event, which has been previously interpreted as dynamic topography driven by viscous coupling between the asthenospheric mantle wedge and the overriding plate during subduction initiation (Stern \& Holt, 1994). Differential subsidence and uplift in south-eastern and southern wells is interpreted to be due to thrust sheet loading and thickening of the crust, respectively.

3) A latest Miocene to Recent phase with varied subsidence characteristics across the basin, which is interpreted as a manifestation of differentiation of the basin into individual tectonic environments. Uplift in the southernmost basin, is interpreted as the effect of continued convergence, whereas subsidence in the southeast is attributed to crustal down-warp and extension. The western basin is interpreted as tectonically quiescent. Since seismic data indicates a lack of contemporary faulting or large-scale tilting, uplift of the north-western part of the basin (Tane-1 and Ariki-1 in Figure 2.17) is interpreted to be an artefact resulting from the calculation approach. The calculation assumes that the system is in Airyisostastic balance and that sediment compaction is completed. Investigations of 
the rapidly deposited Plio-Pleistocene sedimentary sequence has shown that the load is regionally (flexurally) compensated (Holt \& Stern, 1991) and the rapidly deposited sediment may not be fully compacted.

The general subsidence patterns and geodynamic interpretations are broadly consistent with interpretations of Taranaki Basin evolution that have improved during the last four decades (e.g., Pilaar \& Wakefield, 1979; Knox, 1982; King \& Robinson, 1988; Hayward \& Wood, 1989; Thrasher, 1990c; King \& Thrasher, 1992; Holt \& Stern, 1994). However, the usage of an updated and coherent stratigraphic data set provides additional constraints on the timing, magnitude and spatial distribution of tectonic events, which will be further developed and discussed in subsequent chapters. 

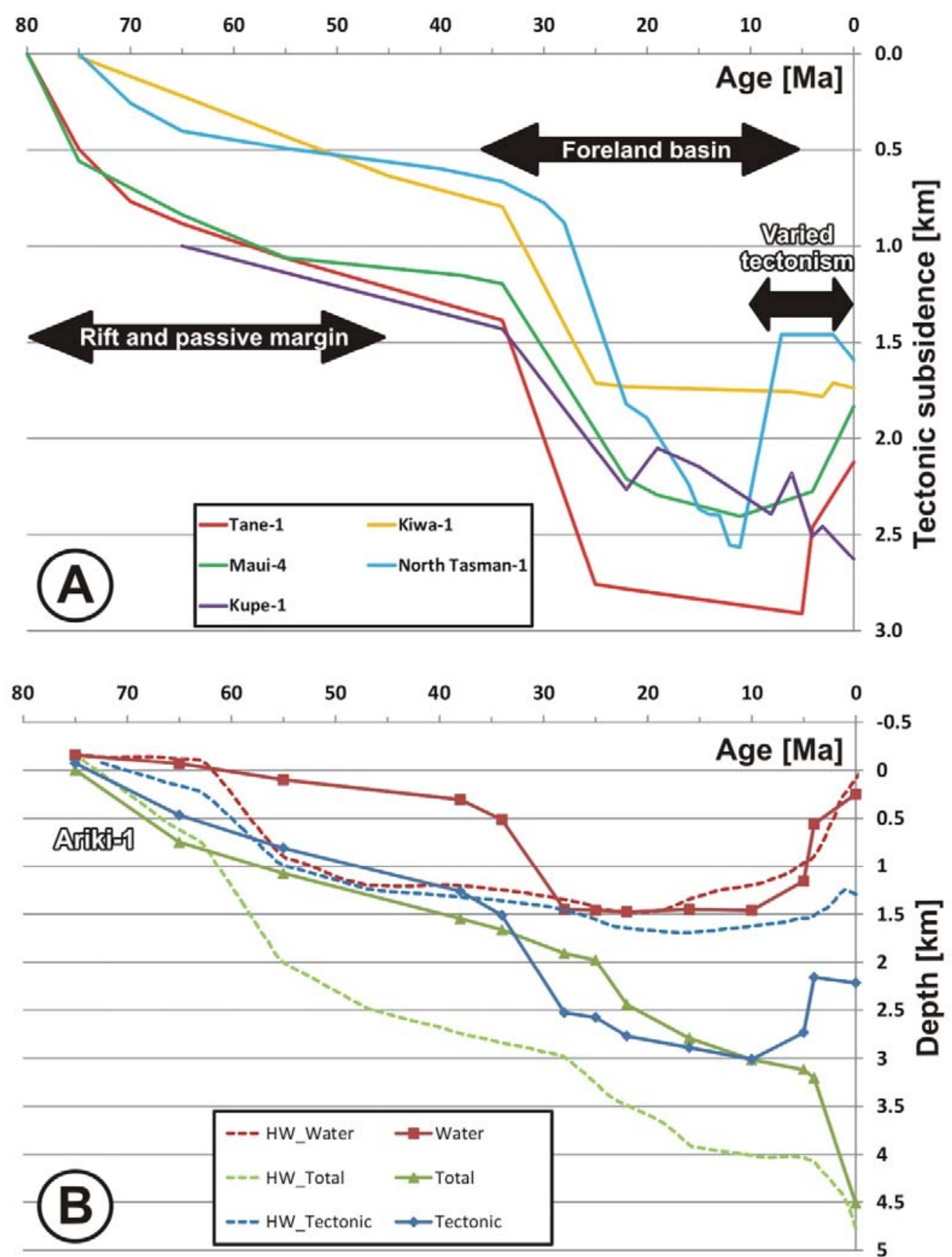

Figure 2.17 Back-stripped subsidence curves of Taranaki Basin. A) Selection of tectonic subsidence curves from five wells calculated in this study, illustrating the different phases of basin development. The curves in (A) were not corrected for eustatic sea-level fluctuations. B) Comparison of input parameters and back-stripping results for well Ariki-1 from this study (solid lines) with a previous study by Hayward \& Wood (1989, dashed lines). Individual curves show assumed paleobathymetry (Water), total subsidence with loading effects of decompacted sediment and without water depth (total), and the tectonic component of subsidence (tectonic). For the purpose of comparison, the results from this study were corrected for eustatic sea-level fluctuations according to estimates by Haq et al., (1987). Note the significance of assumed paleobathymetry (red lines) in the tectonic subsidence results (blue lines). See Figure 2.2 for well locations. 


\section{Comparison to previous investigations of tectonic subsidence}

Comparisons of results from this study with previous investigations show the influences of individual parameters on subsidence results (Figure 2.17, bottom). Hayward and Wood (1989) calculated subsidence histories of 40 wells by assuming 1) mostly terrestrial basin character, 2) compaction coefficients based on constraints from few boreholes, 3) assumption of high sea-level fluctuations since the Cretaceous after Haq et al., 1987. The assumption of a dominantly terrestrial basin omits the density of water in the back-stripping calculation and leads to systematically smaller tectonic subsidence values (30\%). Differences in decompaction algorithm and updated lithology parameters (Funnell et al., 1996) result in a $\sim 5 \%$ difference in total subsidence values. While showing a similar pattern of late-stage uplift, the somewhat higher negative subsidence indicates that some of this signal is attributed to overestimated compaction of shallow strata by the usage of Funnel et al. 's values. The biggest impact on the general shape of subsidence curves, and thus tectonic interpretation is associated with assumed paleobathymetry. Based on previous paleobathymetry estimates, the tectonic subsidence curve could be interpreted as Paleocene rifting and subsequent tectonic quiescence, while the rapid Oligocene subsidence event is not resolved. Rapid Paleocene water-depth increase is not substantiated in updated biostratigraphic paleobathymetry estimates, which are consistent with well and seismic analysis that suggest the development of a shoreline system near the well location at that time (see subsequent chapters). The Oligocene subsidence event is well established in other wells around the basin (King \& Thrasher, 1992; Stern \& Holt, 1994; King \& Thrasher, 1996), which further exemplifies the improved robustness of results from this study. 



\section{CHAPTER 3 TECTONO-STRATIGRAPHIC EVOLUTION OF SOUTHERN OFFSHORE TARANAKI BASIN: CONSTRAINTS FROM REGIONAL 2D- PALINSPASTIC RESTORATION OF SEISMIC REFLECTION DATA}

\subsection{INTRODUCTION}

The stratigraphic record of Taranaki Basin captures New Zealand's changing plate tectonic history since its Cretaceous break-up from Gondwana through to the Cenozoic evolution of the Australia-Pacific plate boundary. Outcrop, borehole and seismic reflection data document the basin's complex history and have revealed a poly-phase tectonic evolution of extension and compression (Pilaar \& Wakefield, 1978; Knox, 1982; Hayward \& Wood, 1989; Schmidt \& Robinson, 1990; King \& Thrasher, 1992; Palmer \& Andrews, 1993; Holt \& Stern, 1994; King \& Thrasher, 1996; King et al., 1999; King, 2000b; Nicol et al., 2007; Stagpoole \& Nicol, 2008). The geometry of sedimentary packages and structural styles have been depicted in structural cross-sections across parts of Taranaki Basin (Knox, 1982; Pilaar \& Wakefield, 1984) and several studies have presented assessments of the structural development of individual fault structures or local basin areas (Thrasher, 1991b; Voggenreiter, 1993; Funnell et al., 2004; Nicol et al., 2004). A small number of regional palinspastic basin restorations have provided a general overview of timing and style of deformation (Bishop \& Buchanan, 1995; Thrasher et al., 1995). However, the detail and quantitative value of these studies was limited to few stratigraphic sub-divisions of the Cretaceous to Recent basin fill and the manual restoration on paper sections.

Quantitative, digital cross-section balancing is now routinely conducted in academia and the petroleum industry to improve the understanding of structural and stratigraphic evolution of given basins and assess the quality of seismic horizon interpretations (e.g., Masini et al.; Thomas \& Bayona, 2002; Tanner et al., 2003; Tanner et al., 2011). By using a variety of restoration algorithms, stratigraphic boundaries can be transformed into a less deformed state at an earlier time in the structural history, while accounting for specific deformational styles, sediment compaction, and isostatic adjustments of the crust to sedimentary or tectonic loads. 


\subsection{OBJECTIVE}

This chapter aims to improve previous constraints on the characteristics and timing of the structural basin development via decompaction and palinspastic restoration of a $340 \mathrm{~km}$ long NW-SE-trending composite seismic cross-section. The regional transect crosses the structural trend of Taranaki Basin from the basin's eastern boundary in the western Wanganui Basin to the southern head of the New Caledonia Trough (NCT) in the northwest, incorporating previously unavailable seismic data in the deep-water basin area (Figure 3.1) and regionally tied seismic horizon interpretations (see Chapter 2).

The geological cross-section is restored to assess the viability of geologic assumptions inherent in seismic horizon interpretations and to reconstruct the representative twodimensional basin geometry through geologic time. Timing and magnitude of tectonic events, associated fault displacements, and subsidence are investigated to 1) constrain the time-space relationships of faulting in the NCT and proximal Taranaki Basin, 2) provide further constraints on the onset and character of convergent plate motion in New Zealand, 3) quantify the amounts of relative horizontal shortening in the basin and involvement of individual faults, and 4) quantify intra-basinal uplift and subsidence and investigate the tectonic controls on changing paleo-water depth. Sediment volumes and sedimentation rates are estimated from the cross-section to improve on constraints from well data and provide insight into the balance between the amounts of strata removed and re-deposited during major erosion events. The structural development of strata in specific parts of the cross-section is discussed in relation to highlight general implications for petroleum systems in the basin. 


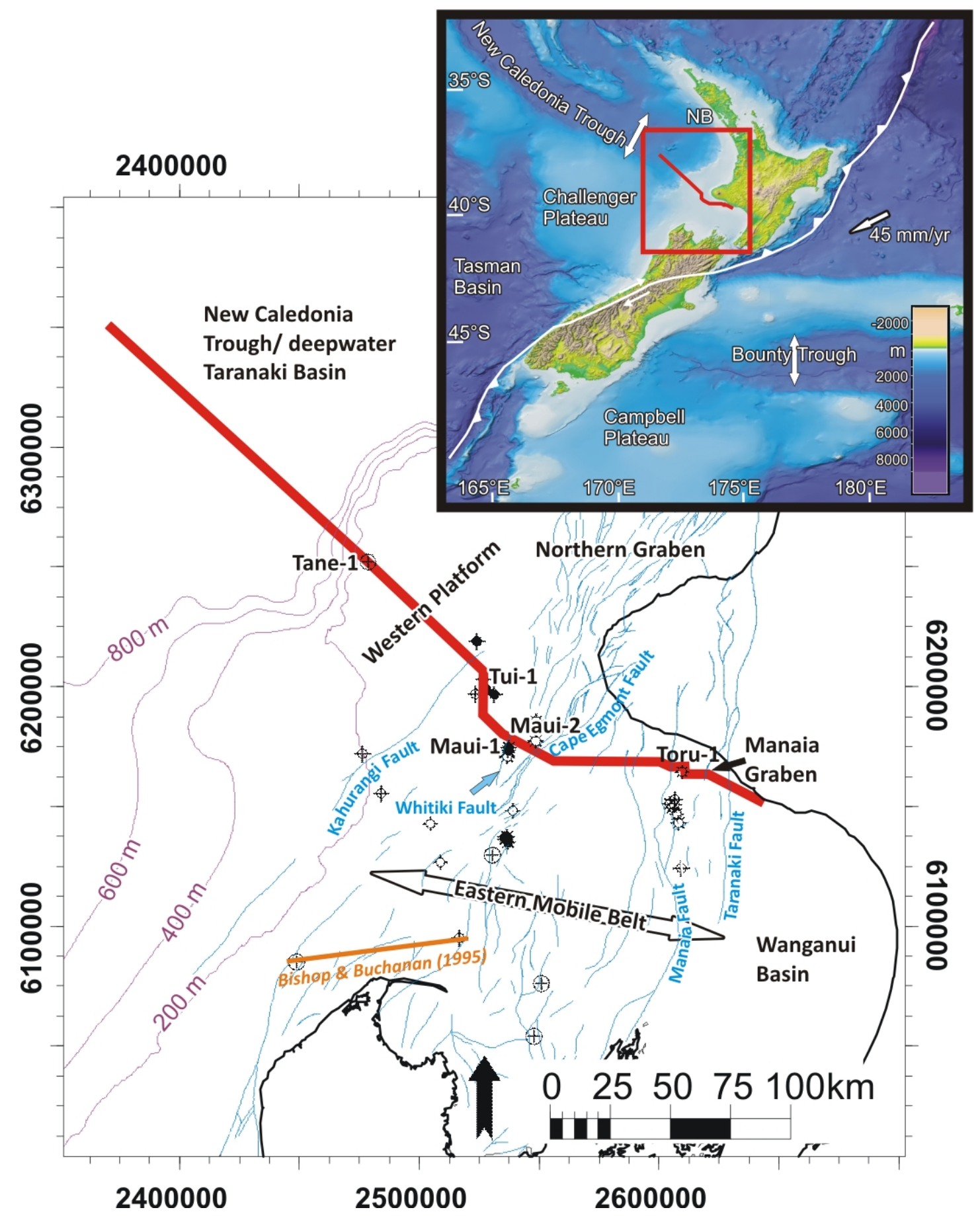

Figure 3.1 Overview map of Taranaki Basin showing the location of the composite seismic line used for restoration (red) and wells located nearby. Fault traces mapped at the top of the Eocene stratigraphic level are shown in blue (after Thrasher \& Cahill, 1990). Structural provinces and names of major faults are annotated. The location of the structural restoration published by Bishop and Buchanan (1995) is shown in orange. The map is projected in metric New Zealand Map Grid coordinates. The inset shows the profile as well as regional physiography of New Zealand and surrounding basins (see scale for water depth and topography). The inferred orientations of Cretaceous extension in the New Caledonia Trough and the Bounty Trough, and the rate and direction of relative Australia-Pacific plate convergence are indicated by white arrows. 


\subsubsection{Structural basin evolution}

Taranaki Basin occupies a large area from New Zealand's western North Island across the western continental shelf and continues westwards into deep-water areas of the NCT (Figure 3.1). While the deep-water part of the basin (hereafter referred to as distal Taranaki Basin) is thought to have been tectonically quiescent since the Cretaceous (e.g., Burns \& Andrews, 1973; Uruski \& Wood, 1991; King \& Thrasher, 1996), the proximal basin (hereafter referred to as the area of the present-day shelf) has been affected by deformation associated with the adjacent Australia-Pacific plate boundary during the Cenozoic (Stern \& Davey, 1990; King \& Thrasher, 1992; Stagpoole \& Nicol, 2008; Giba et al., 2010).

The northwest-southeast-oriented NCT (Figure 3.1, inset) has been previously interpreted as a Cretaceous failed rift (Burns \& Andrews, 1973; Uruski \& Wood, 1991). Basin formation was possibly initiated in response to slab roll-back along the previous Gondwana subduction margin prior to seafloor spreading in the Tasman Sea ( 105-100 Ma, Collot et al., 2009). During subsequent break-up from Gondwana and opening of the Tasman Sea between 85-55 Ma (Gaina et al., 1998; Laird \& Bradshaw, 2004), extension in proximal Taranaki Basin led to the formation of a series of along NNE-SSW striking sub-basins (Thrasher, 1990c), the orientation of which is partly preserved in the presentday structural trend (Figure 3.1). Based on the assumption of contemporary rifting in the Taranaki Basin and NCT, the high angularity between fault systems has been interpreted as a transform zone that accommodated oblique extension between the Tasman Sea and the NCT (Thrasher, 1990c). Extension in the proximal basin was assumed to be small, with estimates ranging from $\sim 5 \%$ to $\sim 10 \%$ in the southern and central basin, respectively (Thrasher, 1992; Bishop \& Buchanan, 1995). Following cessation of rifting, the basin developed into a passive margin that was characterised by thermal subsidence and marine transgression during the Paleocene and Eocene (King \& Thrasher, 1992).

Evidence for compression north and extension south of New Zealand indicate the onset of Australia-Pacific plate boundary deformation since the Middle Eocene (Sutherland, 1995; Lamarche et al., 1997; Collot et al., 2008). Estimates on the timing of plate 
boundary propagation through New Zealand are controversial, ranging from the Middle Eocene (43-40 Ma, Stagpoole \& Nicol, 2008) to the early Miocene ( 24-20 Ma, Ballance, 1976; Furlong \& Kamp, 2009). In Taranaki Basin, the effects of plate convergence are manifested in the development into a foreland basin with asymmetric subsidence, reverse faulting and inversion of previous extensional structures (Stern \& Davey, 1990; King \& Thrasher, 1992; Palmer \& Andrews, 1993; Holt \& Stern, 1994). The age estimates of this change in tectonic character are also variable and whether first signs of convergence in the basin were recorded during the Miocene (Bishop \& Buchanan, 1995), Oligocene (Schmidt \& Robinson, 1990; King \& Thrasher, 1992), or Eocene (Palmer \& Andrews, 1993; Voggenreiter, 1993; Stagpoole \& Nicol, 2008), is a matter of ongoing debate. Recent seismic mapping of the Taranaki Fault (Figure 3.1) has identified evidence for pre-Oligocene initiation of convergence in its northern parts and it has been suggested that this fault has been activated simultaneously in the southern basin (Nicol et al., 2004; Stagpoole \& Nicol, 2008).

Following the onset of convergence, biostratigraphic borehole data suggest a period of rapid subsidence during the Oligocene and early Miocene that affected wide parts of the basin (Hayward \& Wood, 1989). The regional, long-wavelength signal of this subsidence event $(>200 \mathrm{~km}$ ) could not easily be explained by thrust sheet loading of the basin edge alone and has thus been attributed to subduction-induced flow in the mantle (Holt \& Stern, 1994; Stern \& Holt, 1994). Inversion of previous normal faults and thickening of the crust in the eastern basin culminated in basement uplift and widespread erosion during the Late Miocene (King \& Thrasher, 1996). Estimates of the total amount of horizontal shortening within the basin are $<10 \mathrm{~km}$ or $3-5 \%$ (Thrasher, 1992; Bishop \& Buchanan, 1995), while estimated shortening across the combined Taranaki and Wanganui basin system is $\sim 35-75 \mathrm{~km}$ (Stern et al., 2006; Nicol et al., 2007).

Volcanism, subsidence and extensional faulting are evidenced in the north of the basin since the Late Miocene (Northern Graben, Figure 3.1), while the south has remained under compression (King \& Thrasher, 1996). Late Miocene-Pleistocene crustal extension estimates from interpretations of seismic reflection data indicate 2-3 km of horizontal extension in the north-eastern and $\sim 1 \mathrm{~km}$ in the south-eastern basin since the Miocene, respectively (Thrasher, 1992). The smaller amount of extension in the southern basin and apparent southward migration of the boundary between compression and extension through time (Giba et al., 2010), has been attributed to roll-back of the subducted slab 
and southward migration and counter-clockwise vertical axis rotation of the Hikurangi subduction margin (King \& Thrasher, 1992; Wallace et al., 2004; Nicol et al., 2007).

A similar north-to-south progression is expressed in the Late Miocene to Recent subsidence history of the basin. Late Miocene subsidence of sub-basins northeast of the basin was followed by uplift of the North Island in the Pliocene and Pleistocene (Kamp et al., 2004; Pulford \& Stern, 2004). The southern basin subsided during the latest Miocene, Pliocene, and Pleistocene, which led to the expansion of the basin beyond its previous eastern limits and formation of Wanganui Basin (Anderton, 1981; King \& Thrasher, 1996; Kamp et al., 2004; Lamarche et al., 2005; Proust et al., 2005). Subsidence of the Wanganui Basin has initially been attributed to distributed flexural shear between the subducting Pacific plate and the overriding Australian plate (Stern et $a l .$, 1992), while the apparent north-to-south progression of initial subsidence and uplift has been interpreted in terms of a southward migrating gravitational (Rayleigh-Taylor) instability and subsequent replacement of a $100 \mathrm{~km}$ thick mantle lid by asthenosphere (Pulford \& Stern, 2004; Stern et al., 2006).

\subsubsection{Basin stratigraphy}

The Cretaceous to Quaternary sedimentary succession of Taranaki Basin (Figure 3.2) resembles the general $1^{\text {st }}$-order (100 my) transgressive-regressive megacycle common to stratigraphic sequences in other New Zealand Basins (King et al., 1999). While Jurassic coal measures have been drilled in the adjacent Northland basin (Milne \& Quick, 1999), the oldest sedimentary strata confirmed from well data in north-eastern Taranaki Basin are terrestrial sequences of the Middle Cretaceous Taniwha Formation (Shell BP Todd Oil Services Ltd., 1986). The first widespread basin fill are the dominantly terrestrial sands and coal measures of the Late Cretaceous Rakopi Formation and the more marine influenced strata of the latest Cretaceous North Cape Formation (Pakawau Group, Thrasher, 1992; Wizevich et al., 1992), from which most hydrocarbon accumulations in the basin are sourced (Sykes, 2001). Paleocene to Eocene strata consist of terrestrial to shallow marine coals and clastic sediments of the Kapuni Group (and their marine age equivalents of the Moa Group), which represent the secondary petroleum source- and primary reservoir rocks, respectively (King \& Thrasher, 1996; Sykes et al., 2010). The increasing marine influence recorded in these strata reflects the gradual foundering of the basin and south-eastward marine transgression, which is accompanied by a general 
decrease in sediment thicknesses in boreholes (Hayward \& Wood, 1989; King \& Thrasher, 1992).

Maximum foundering of the basin and its hinterland during the Oligocene to Early Miocene (Hayward \& Wood, 1989) is expressed in the widespread deposition of calcareous muds, limestones, and limited clastic detritus of the Ngatoro Group (King, 1988 b; a). Increasing occurrence of clastic sediments marks the onset of the regressive sequence, which eventuated in the westward outbuilding of the shelf margin since the middle Miocene (King \& Thrasher, 1992). The regressive sequence has been broadly sub-divided into the dominantly Miocene Wai-iti and the Plio-Pleistocene Rotokare Group (King \& Thrasher, 1992; 1996) based on their separation by a widespread unconformity in the southern basin (Figure 3.2), although other subdivisions of this sequence have been proposed (e.g., Kamp et al., 2004). Sedimentation rates of $>400$ $\mathrm{m} / \mathrm{my}$ in the Late Miocene and $>700 \mathrm{~m} / \mathrm{my}$ in the Plio-Pleistocene derived from boreholes record the increasingly rapid northwest-ward outbuilding of a sedimentary wedge (King \& Thrasher, 1992) and deposition of large clinoform sequences of the PlioPleistocene Giant Foresets Formation (Beggs, 1990). The dominantly fine-grained lithologies of this sedimentary wedge are punctuated by coarser-grained gravity-flow deposits of the late Early-Middle Miocene Moki, Late Miocene Mount Messenger, and Pliocene Mangaa formations, which represent secondary hydrocarbon reservoir targets in the basin. Late Miocene- to Recent volcanics and volcaniclastic sediments are found outside the study area in the north-eastern and central parts of the basin, while Pliocene and Pleistocene strata in the south-eastern study area consist of shelf muds, silt- and sandstones, and shell- and gravel-lag deposits (King \& Thrasher, 1996; Vonk et al., 2002; Kamp et al., 2004). 


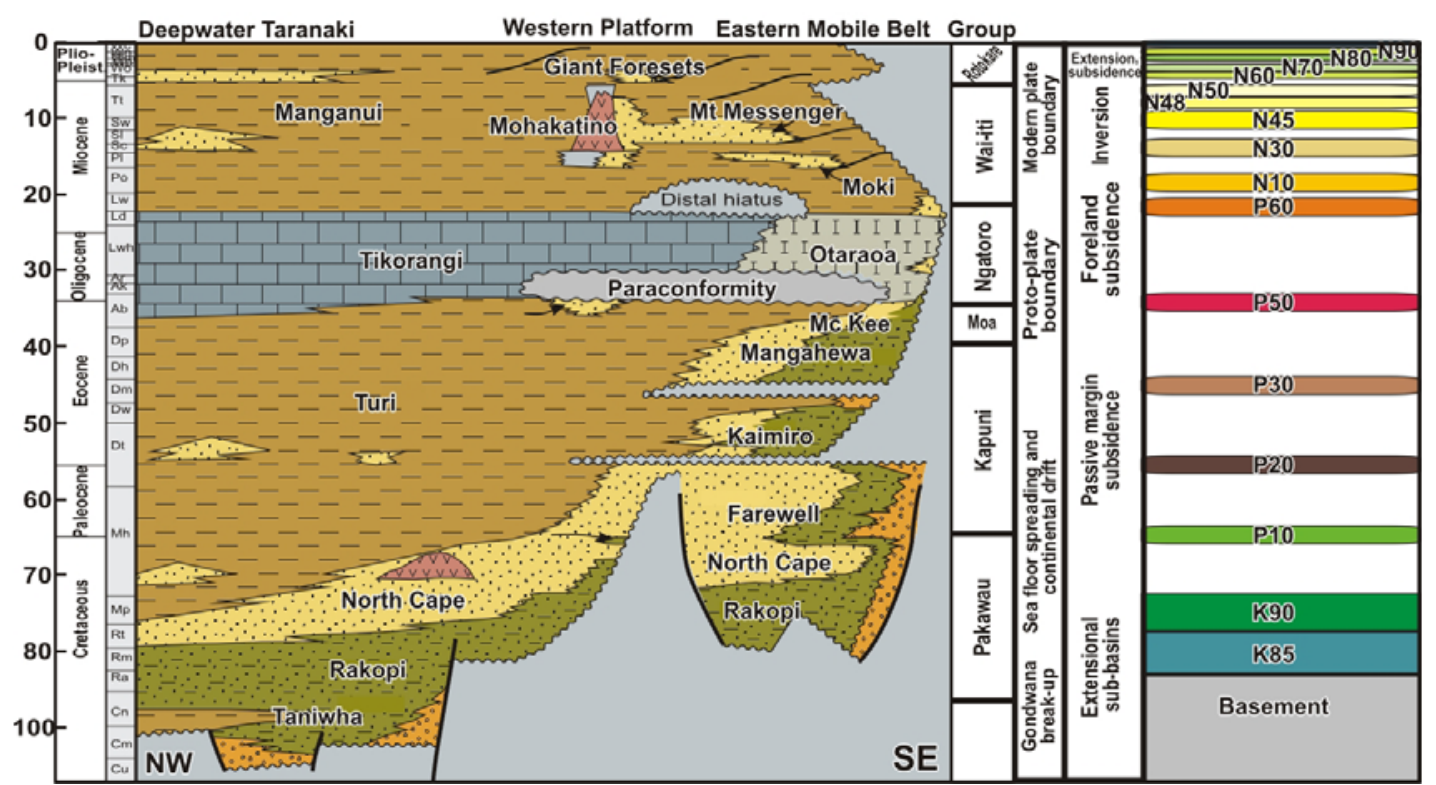

Figure 3.2 Tectonostratigraphic summary of the Taranaki Basin showing (from left to right): absolute time, international epoch, New Zealand stage abbreviation, chronostratigraphic panel of Taranaki Basin (modified King and Thrasher, 1996), stratigraphic group names, regional tectonic setting, intra-basinal tectonism, and age relation of seismic horizons used in this study with horizon name and colours used in the restoration. See text for description of the stratigraphy and tectonic events and Table 3.2 for seismic horizon details.

\subsection{DATA AND METHODS}

\subsubsection{Cross-section location, seismic lines and borehole data}

The composite cross-section was created from ten individual seismic lines that together extend some $340 \mathrm{~km}$ in an ESE-WNW direction across the basin (Table 3.1, Figure 3.1). The cross-section location was chosen to adequately capture the structural and sedimentary evolution of the proximal basin by including significant faults and representative sediment thicknesses, while providing sufficient stratigraphic well control. Wells in the vicinity of the profile include Toru-1 (Crocker, 1991), Maui-1\&2 (Shell BP Todd Oil Services Ltd., 1969; 1970b), and Tane-1 (Shell BP Todd Oil Services Ltd., 1976). In the Maui area, the profile is located up to $10 \mathrm{~km}$ from well locations to facilitate the modelling of faults in the central part of the cross-section (i.e., Whitiki Fault, Figure 3.1). 
Table 3.1 Seismic reflection profiles used for the construction of the reconstructed composite cross-section, showing the year of data acquisition and respective petroleum report numbers as listed in the Ministry of Economic Development's data archive.

\begin{tabular}{lcc} 
Seismic Line & Year & Petroleum Report \\
\hline wm51-627 & 1979 & 627 \\
86ma_034 & 1986 & 1219 \\
sunz91-165 & 1991 & 1948 \\
p95-500 & 1995 & 2261 \\
p116-81-23 & 1996 & 2304 \\
stos95-190 & 1997 & 2403 \\
wm-51e & 1997 & 2308 \\
phm02 & 2001 & 2664 \\
dtb01-23 & 2001 & 2847 \\
sk14e & 2002 & 2992
\end{tabular}

\subsubsection{Seismic interpretation}

Eighteen horizons were used in the palinspastic cross-section restoration to capture significant changes in the basin development (Figure 3.2, Table 3.2). Sixteen basin-wide correlated seismic horizons and fault interpretations from the GNS 4D Taranaki project were used to provide regional consistency with available well data (Roncaglia et al., 2010). The author checked these interpretations for internal consistency and modified them in cases where structurally simpler interpretations were possible. Two seismic horizons were added to the data set: 1) an intra-Plio-Pleistocene Giant Foresets Formation horizon (N90) was mapped to facilitate depth conversion of this thick sedimentary package and 2) a Late Miocene reflector (N48) to aid constraining the amount of missing section and infer the history of the Cape Egmont Fault Zone (Figure 3.1).

Fault offsets smaller than the duration of one seismic wavelength, especially in the deeper section of the seismic data ( $>3 \mathrm{~s}$ TWT), were not considered of particular structural significance, and were discarded. Fault zones consisting of multiple fault slivers (primarily the Manaia and Taranaki overthrusts), were simplified to one fault plane, while cumulative fault throws were honoured.

The seismic data, horizon and fault interpretations as well as borehole formation tops were loaded into Midland Valley's software 2D Move for depth conversion and palinspastic restoration. The section was projected onto a straight line with $124^{\circ}$ azimuth. 
Table 3.2 Seismic horizons and formation parameters used in this study. Seismic horizon names are shown with the colour code used in the restoration, correlative formation tops and age relations in boreholes (New Zealand stage code and approximate absolute age), and parameters used for depth conversion and decompaction (velocity $=\mathrm{v}_{0}$, surface porosity $\left.=\varphi_{0}\right)$. See text for further description and Figure 3.2 for stratigraphic relationships.

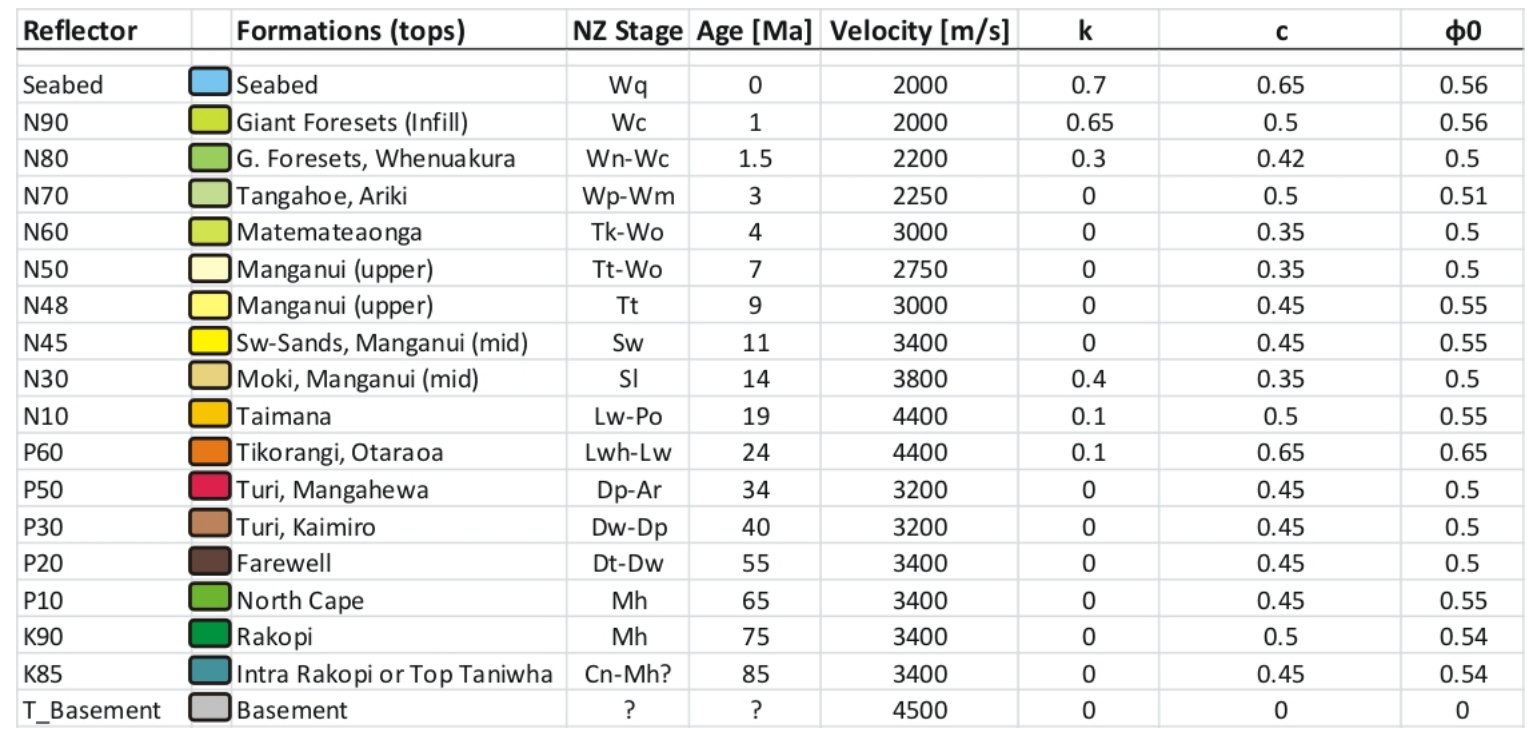

\subsubsection{Time-depth conversion}

The seismic data, horizon and fault interpretations were depth converted in 2D Move using simple interval velocity values based on previous studies (Thrasher, 1988; Stagpoole, 1998). The time/depth relationship for each formation was calculated using a horizon velocity method, which calculates individual layer thicknesses according to:

$$
\mathbf{z}=\frac{v_{0}\left(e^{k t}-1\right)}{k}
$$

where $\mathbf{z}$ is the thickness of the layer in metres, $\mathbf{v}_{\mathbf{0}}$ is the velocity at the top of the formation in metres per second, $\mathbf{k}$ is the rate of change in velocity with increasing depth, $\mathbf{t}$ is the one way travel time for layer thickness in seconds. If $\mathbf{k}$ equals zero, the equation simplifies to:

$$
z=v_{0} t
$$

Velocity values derived by previous authors were modified by trial-and-error to minimise any misfits with respect to well formation tops (Table 3.2). The k-value (rate of velocity change) was set to zero for most formations unless otherwise required to match the well tops. Compaction related effects within the young, thick, and possibly under-compacted 
sedimentary wedge of the Giant Foresets Formation were accounted for by using high kvalues of $0.3-0.7$, while values of $\sim 0.1$ were used to best match the Oligocene-Early Miocene section.

Shallow formations (Late Miocene- seafloor) were matched to well tops to within $\sim 50 \mathrm{~m}$, while deeper horizons (Basement-Paleogene) exhibit slightly larger disparities of up to $200 \mathrm{~m}$ (Figure 3.3). Largest discrepancies are observed with respect to formation tops in well Maui-1, which is interpreted to be due to the projection of the line over more than 5 $\mathrm{km}$ in an area of northward structural and stratigraphic dip (Figure 3.3). Artefacts from the depth conversion process, such as distortions below basement over-thrusts, were assessed and smoothed, whereas other structures were left as is wherever possible in order to honour potentially real geologic features. The final depth profile is considered the best endeavour to convert geologic formations from the time domain across this large area without using laterally varying interval velocity functions.

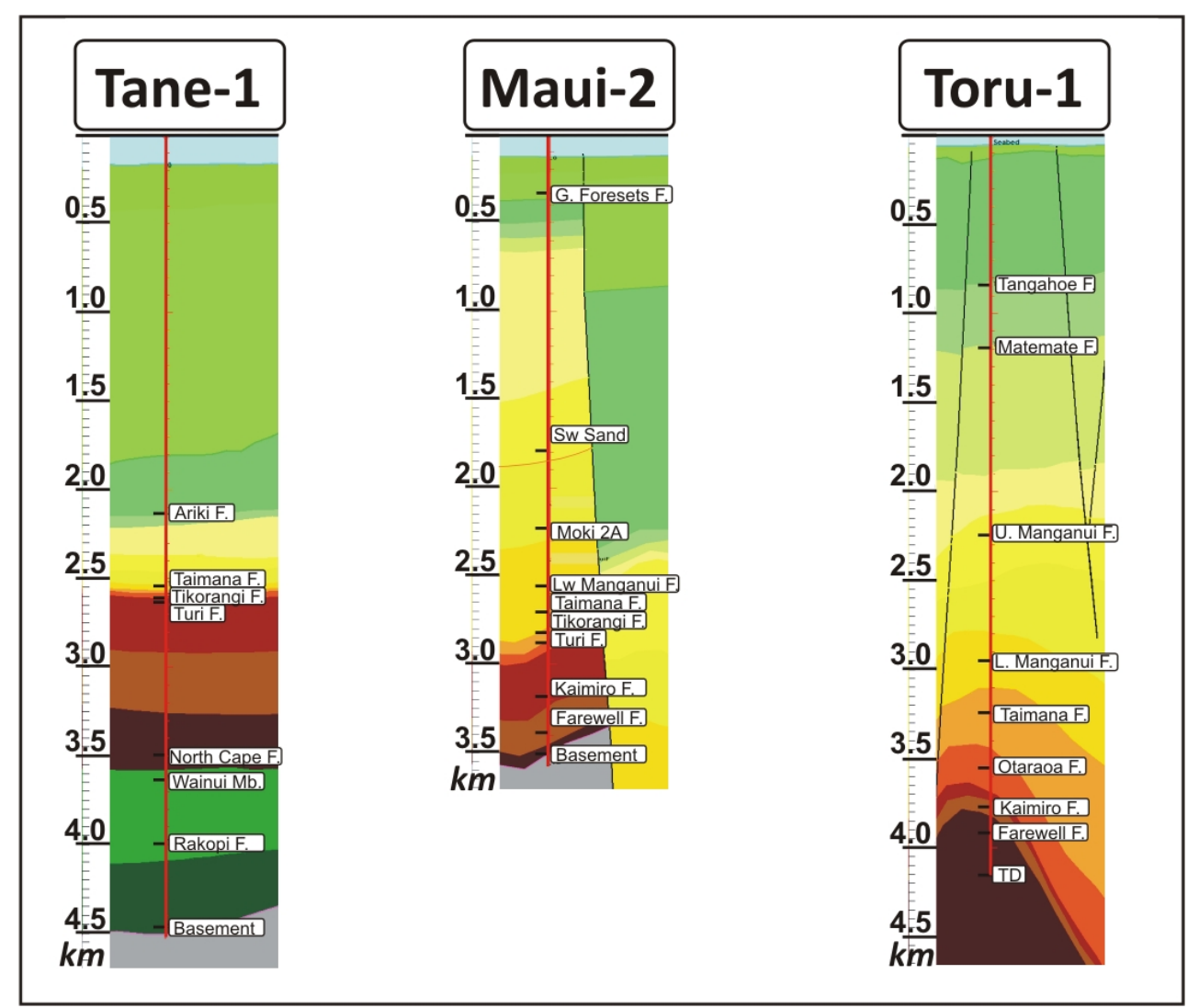

Figure 3.3 Comparison between depth-converted horizons and formation tops at closest well locations to the cross-section. See Figure 3.1, Figure 3.2, and Table 3.2 for well locations, formation descriptions, and colour codes, respectively. 
The modern continental slope exhibits a lower gradient on the depth-converted section than evident on the TWT profile (Figure 3.4), which is due to the increasing thickness of water (slower velocity) in the west compared to the sediment sequences in the east (faster velocitiy). Largest total sedimentary thicknesses of about $8.3 \mathrm{~km}$ are observed in the Manaia Graben in the east of the basin (Figure 3.4), and up to $7.2 \mathrm{~km}$ in the distal deepwater part of the basin. Thinnest total sediment cover of $1.3 \mathrm{~km}$ is observed above the basement overthrust of the Taranaki Fault, while, within the basin, smallest sedimentary thicknesses of $\sim 3.5 \mathrm{~km}$ are observed in the Maui Area. Overall, the depth values are comparable to previous estimates in the respective areas (King \& Thrasher, 1996; Uruski et al., 2002b). In the Manaia Graben, basement values are a few hundred meters $(<500$ m) higher than results of King and Thrasher (1996). The higher values in this study are attributed to a deeper basement interpretation made herein on the grounds of better imaging of deep structure on newer seismic data. 


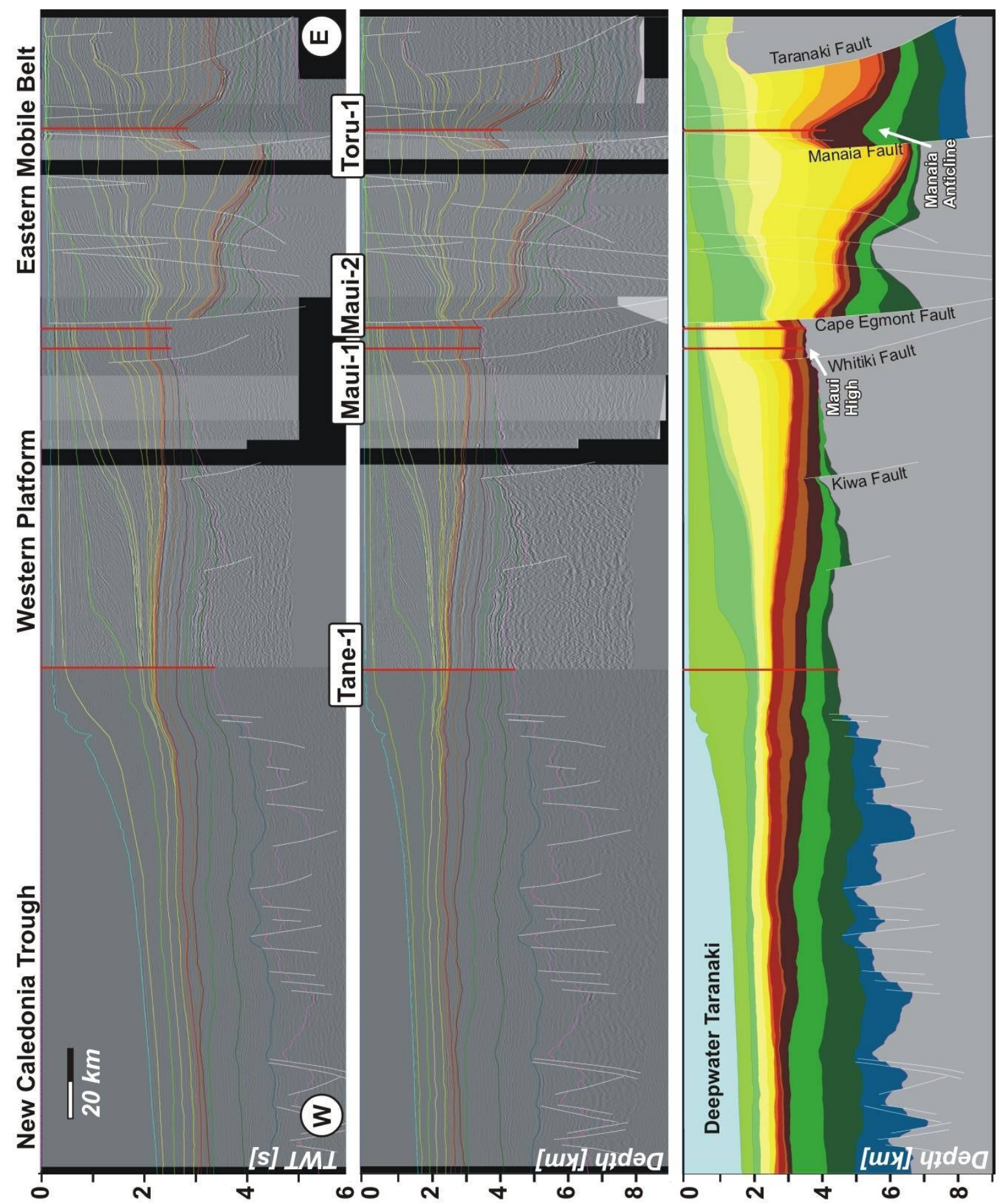

Figure 3.4 Composite cross-section with well locations and structural provinces. The top panel shows the composite seismic profile in seconds two-way travel time as well as horizon and fault interpretations. Centre panel shows the depthconverted version of the seismic profile (in $\mathrm{km}$ ) and interpretation with well locations. Bottom panel shows the present-day geologic depth model used for palinspastic reconstruction with names of selected faults (vertical exaggeration $=10$ ). The present-day bathymetry is shown in light blue at the top of the bottom panel. See Table 3.2 and Figure 3.2 for colour codes and formation descriptions. 


\subsubsection{Restoration methodology}

The section was sequentially restored from youngest to oldest strata. The restoration of a given formation was conducted in a sequence of restoration steps:

1) Removal of the highest formation, decompaction of underlying strata and isostatic adjustment of the basement for decrease in sedimentary load

2) Estimation and reconstruction of missing (eroded) strata based on assessment of truncated seismic reflectors

3) Restoration of fault offsets and folds based on the observed deformational style

4) Reconstruction of paleobathymetry

While the restoration sequence was generally performed in the above order, formations were individually assessed and restoration steps were adjusted or repeated with varied parameters to find the most viable solution.

The decompaction and isostatic correction routine in Midland Valley's 2D move follows the approach by Sclater and Christie (1980) and is described in Chapter 2. The average density of the sediment column and isostatic response between respective time steps is calculated for a densely distributed series of points along the section. Formation parameters were adopted from a previous Taranaki Basin studies (see Chapter 2) and individual formations were parameterised to reflect the most representative lithology compositions in boreholes and seismic facies interpretations.

In cases where significant erosion is apparent from reflector truncation on the seismic section, the thickness of missing strata was inferred based on several assumptions made about the underlying reflector geometries before erosion. While angular truncations are frequently observed in individual formation packages, restoration of missing strata was only attempted when the eroded thickness was considered more than the estimated accuracy of the depth conversion (i.e., $>100 \mathrm{~m}$ in the shallow and $>200 \mathrm{~m}$ in the deep section, respectively). Seismic profiles were included in the depth conversion in order to enable the reconstruction of missing sections from the seismic data and to allow for assessment of the viability of varying erosion scenarios. Multiple interpretations of the possible amount of eroded sediment were derived by extrapolating the geometry of 
reflectors sub-cropping the erosion surface (see Supplement 3 for details on reconstructions of erosion surfaces).

The fault throws and folding of individual formations were reconstructed to represent the geometry before the deformation event or deposition of the ensuing formation by using a selection of structural restoration algorithms dependent on observed deformational style. In most cases, displacements on faults were restored using a fault parallel flow algorithm (Egan et al., 1999), while folds were restored via flexural slip unfolding (Tanner et al., 1998). Fault-parallel flow assumes particle flow parallel to the fault surface and plane of the cross-section (plane strain assumption) and is often used for restoration of compressional structures such as (fault-bend fold) ramp structures (Suppe, 1983; Savage $\&$ Cooke, 2003). Flexural-slip and line-length unfolding allows horizons to be unfolded about a manually chosen fold axis and underlying horizons can be unfolded according to the deformation observed in the uppermost horizon. The length and thickness of individual horizons and formations are preserved in the process.

After restoring erosion and deformation, horizon and formation geometries were investigated for consistency, and paleo-water depths of the top surface were compared to biostratigraphic environment estimates (Shell BP Todd Oil Services Ltd., 1969; 1970b; 1976; Roncaglia et al., 2008). Smoothed water depth curves were constructed based on these biostratigraphic estimates and water depth indicators evident on seismic data (e.g., clinoform roll-overs, coastal onlaps). Respective upper horizons were then restored to this water depth surface via vertical simple shear ("flattening"), while restoring formations below this horizon accordingly. This restoration step was conducted to account for vertical crustal movements related to tectonism (e.g., thermal subsidence) and smoothing of small-scale artefacts introduced by the decompaction and restoration algorithms.

Discrepancies between the top of decompacted and isostatically adjusted formations and the paleobathymetry surface were generally minor, but were further investigated before the interpretation was considered valid. Some discrepancies were related to glitches in the restoration algorithms that caused unlikely geometries, and required multiple iteration steps. Other differences with respect to paleobathymetry were related to larger tectonic events such as rapid Oligocene subsidence or Late Miocene uplift, which are not simply accounted for by upper crustal faulting. Besides minor adjustments of local geometries, 
no unreasonable geometries or voids were encountered during restoration of the crosssection. The final seismic horizon interpretations were considered internally consistent and robust despite the non-uniqueness of the seismic horizon interpretation.

\subsection{RESULTS}

\subsubsection{Basin structure and development}

The cross-section (Figure 3.4) shows the character of structural provinces defined by previous authors (Pilaar \& Wakefield, 1978; Knox, 1982; King \& Thrasher, 1996; Uruski et al., 2002a), namely the Eastern Mobile Belt, the Western Platform and Deepwater Taranaki Basin. The faults in the cross-section can be subdivided into three groups: 1) Cretaceous to Paleogene normal faults, 2) Late Paleogene to Neogene reverse faults, and 3) Late Neogene normal faults. Dominant faults represented are (from east to west) Taranaki, Manaia, and Cape Egmont fault zones as well as the Whitiki Fault, the latter of which represents the western boundary of the Maui High and the Eastern Mobile Belt (Figure 3.1, Figure 3.4). The anticline associated with the Manaia Fault in the east represents an inverted rift feature.

The Taranaki Fault shows a dip of about $45^{\circ}$ in its upper parts $(<4 \mathrm{~km})$, but flattens at depth to less than $20^{\circ}$ below depths of about $6 \mathrm{~km}$. The Cape Egmont and Manaia faults show steeper dips of about $60-70^{\circ}$, flattening to as much as $45^{\circ}$ in the deeper parts $(>6$ $\mathrm{km}$ ). The relative steepness of these faults is typical for inverted normal faults (e.g., Lowell, 1995; Cooper \& Warren, 2010) and the lack of flat thrust slivers indicates the relative thick-skinned nature of convergent deformation observed by previous authors in this area (e.g., Stern \& Davey, 1990; Holt \& Stern, 1994; Stagpoole \& Nicol, 2008). The gradual flattening of these structures at depth is taken as an indicator that compression was mostly accommodated by dip-slip displacement. While a strike-slip component of displacement cannot be ruled out, the likely sub-ordinate importance of this transverse motion is in contrast with early interpretations of significant strike-slip motion within the basin (e.g., Pilaar \& Wakefield, 1978)

Other faults interpreted on the section include Cretaceous to early Paleocene normal faults in Deepwater Taranaki Basin and the Western Platform (e.g., the Kiwa Fault) and Plio-Pleistocene faults in the eastern part of the basin. Older, non-inverted, normal faults 
generally exhibit lower dips $\left(\sim 50^{\circ}\right)$ and higher dip variability $\left( \pm 25^{\circ}\right)$ than PlioPleistocene faults $\left(60^{\circ} \pm 5^{\circ}\right)$ observed in the eastern basin. The differences in fault dip and dip-variability may be related to the greater uncertainties associated with constraining the geometry and velocity structure of deeply buried formations.

The structural and stratigraphic basin development is reconstructed and depicted in a series of time steps (Figure 3.5-Figure 3.8). The details relating to the restored basin evolution, including decompacted sedimentary thickness distributions and reconstructions of missing strata are described in Supplement 3. 


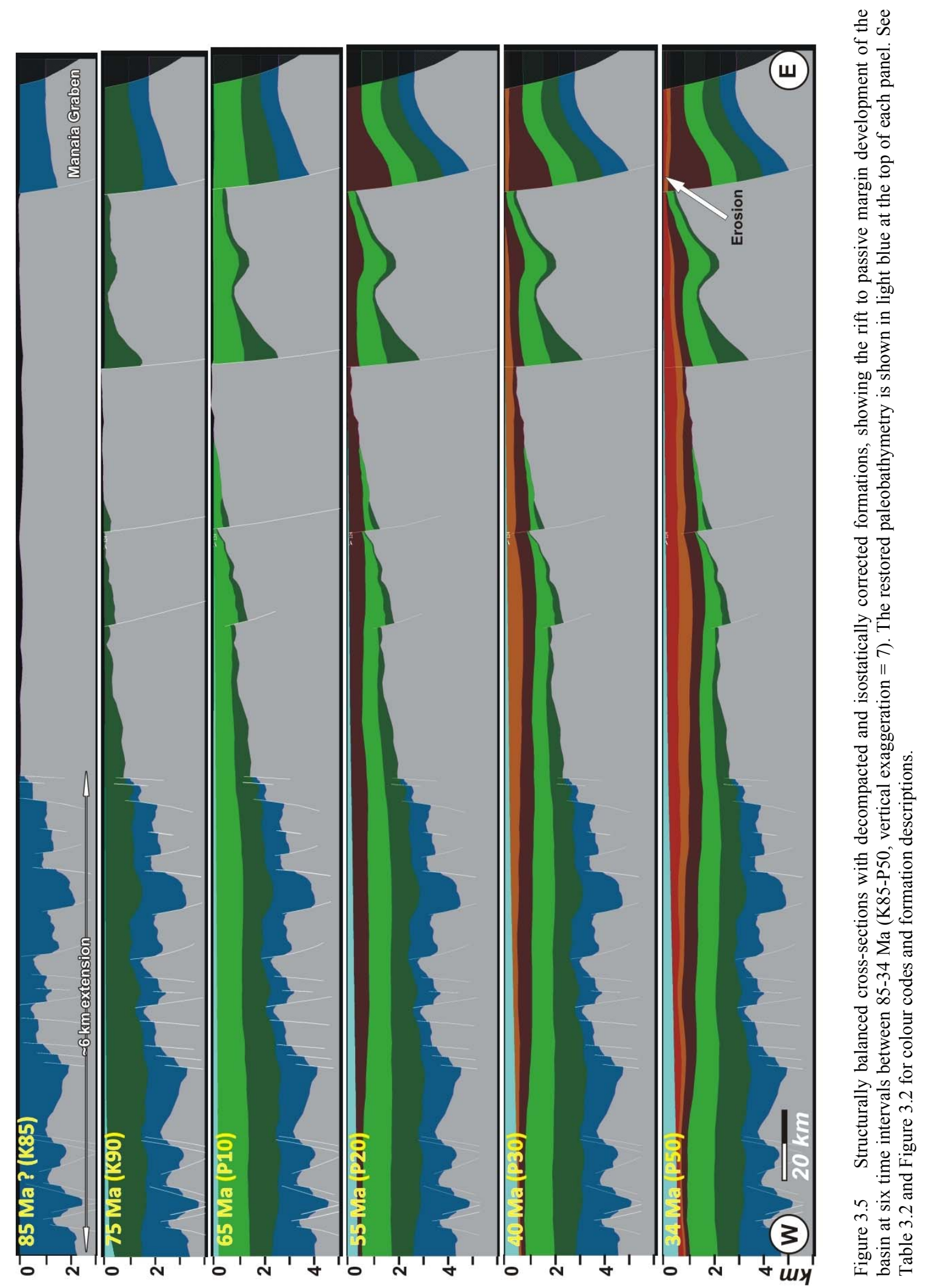




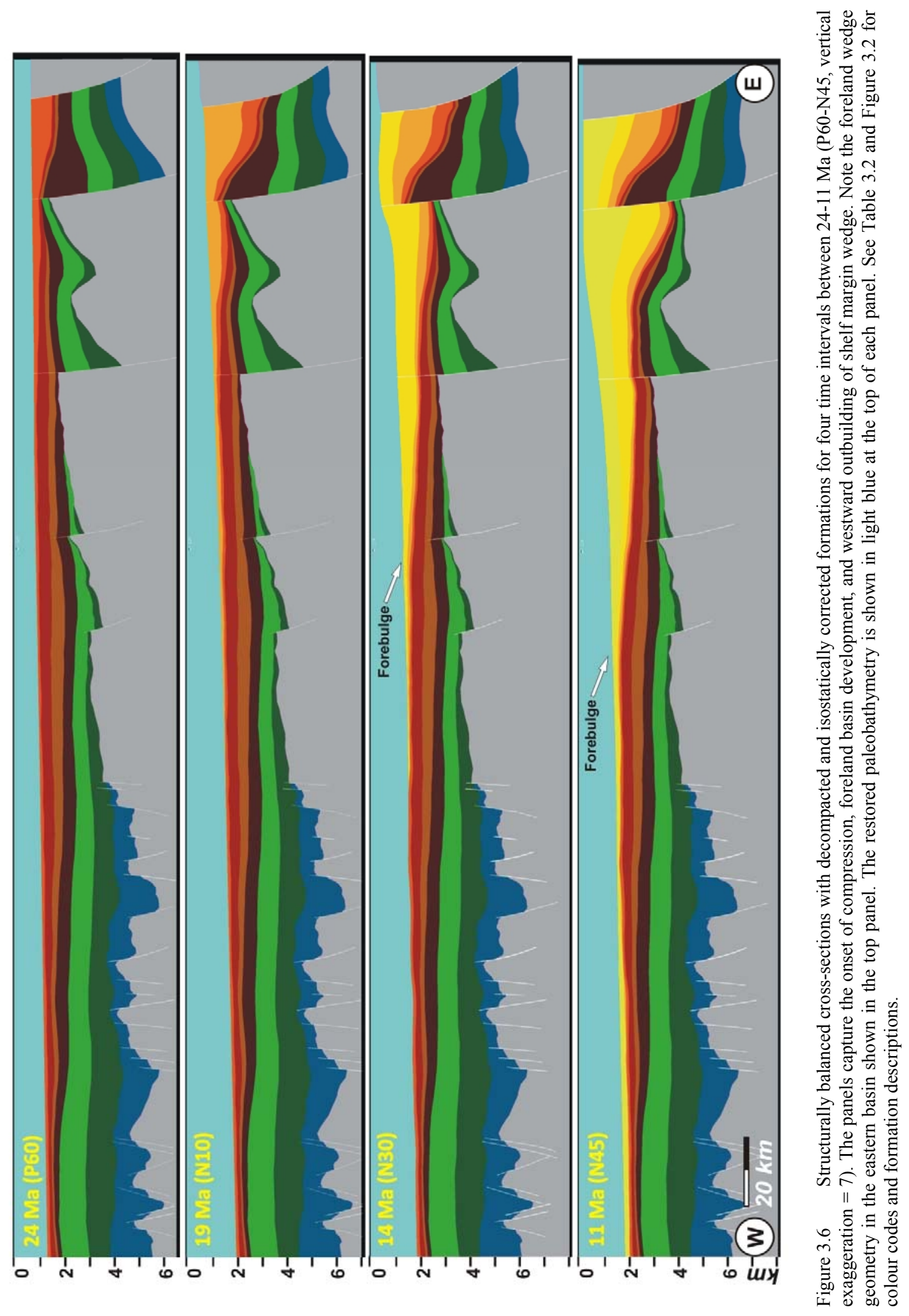




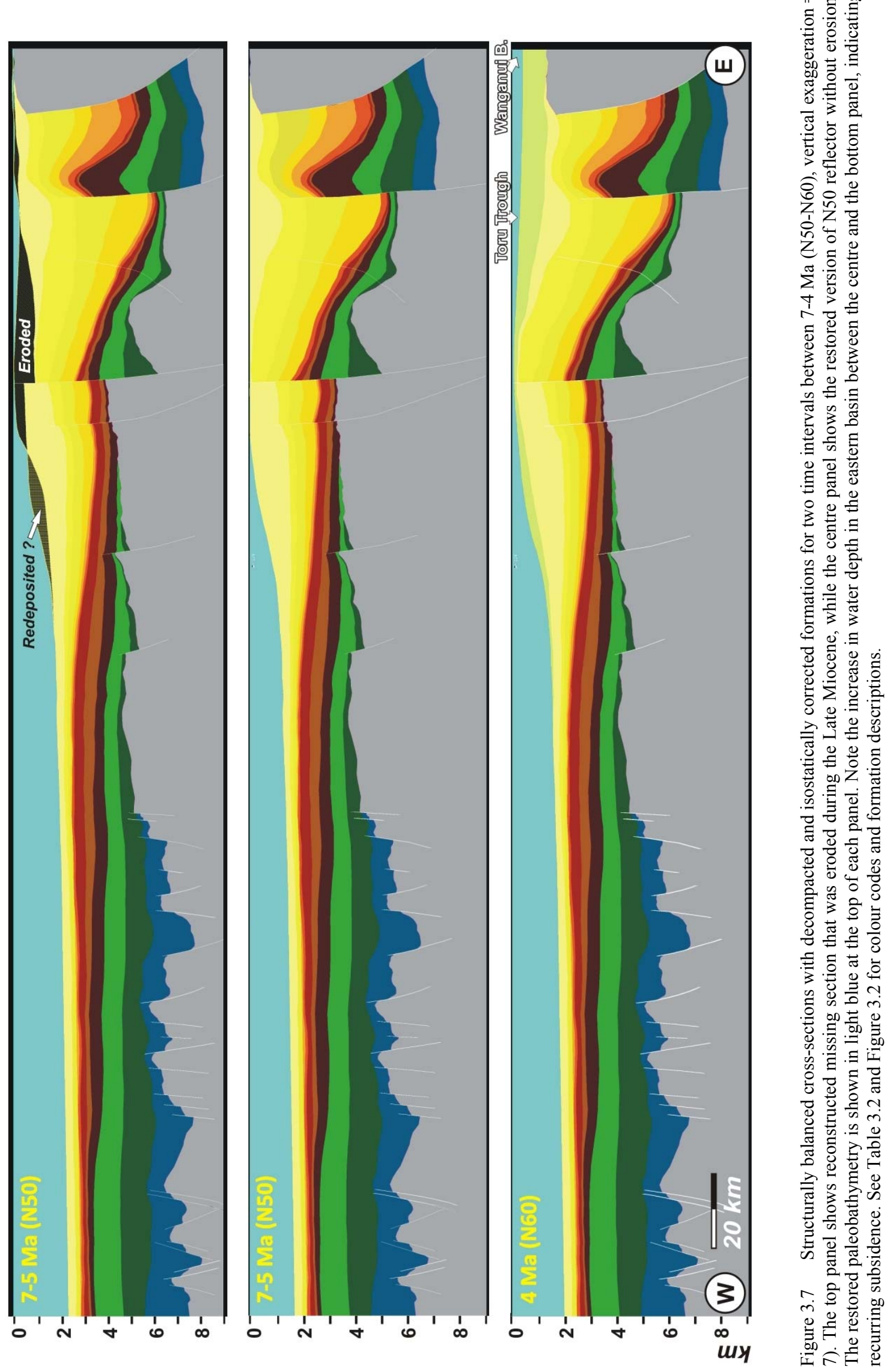




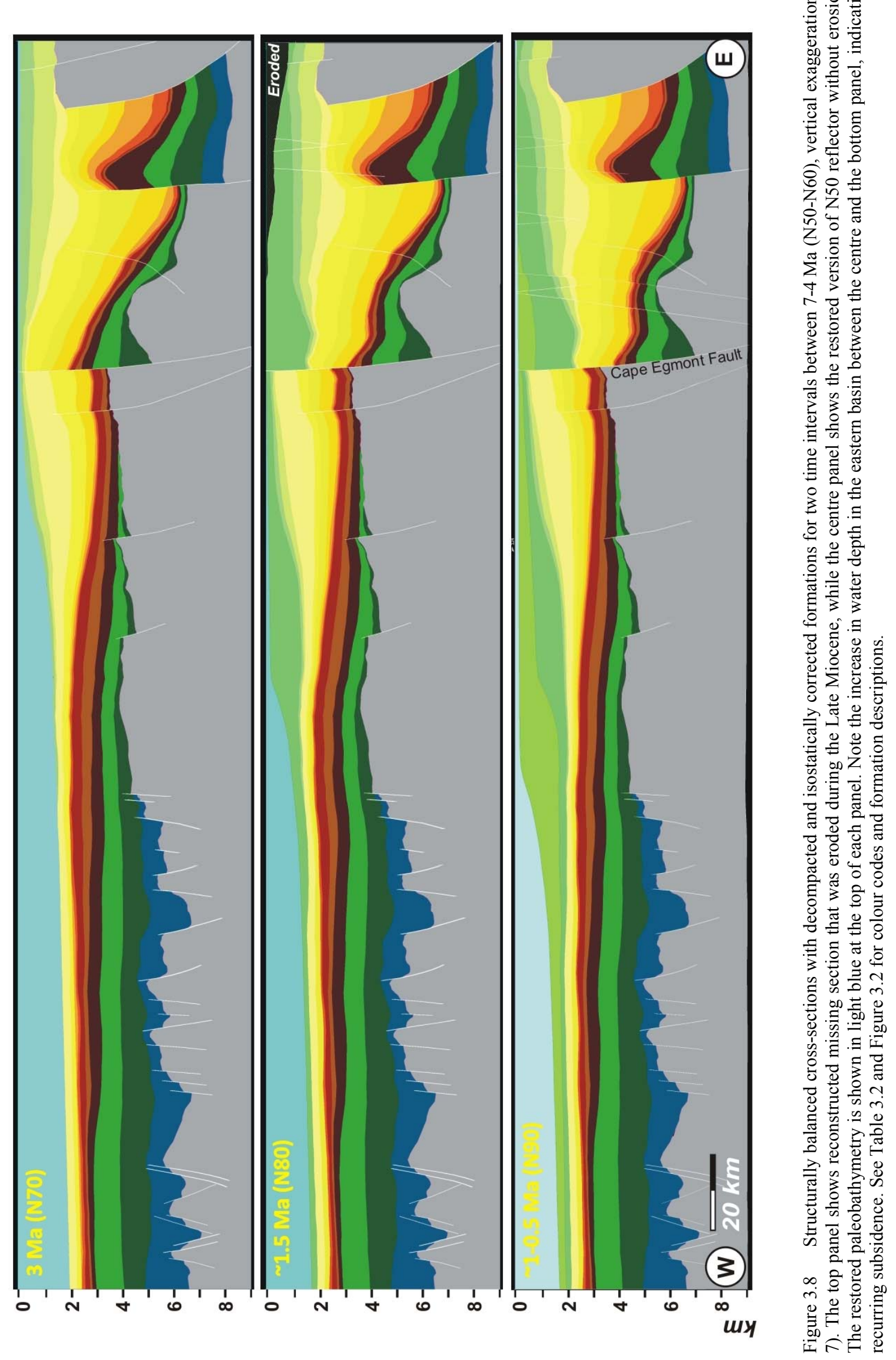




\subsubsection{Fault displacement history}

The structural evolution and deformation history of the basin was constrained by measuring the relative horizontal shortening across the cross section and vertical fault displacements on individual faults at incremental time steps. The amount of relative horizontal shortening was measured across the section whenever possible. However, due to uncertainties regarding the contact between horizons and individual faults, horizontal values were found to be less robust to constrain than vertical displacements. Thus vertical displacements were used as the proxy to quantify the deformation history. The vertical horizon offsets were measured from decompacted sections at representative locations few kilometres away from the faults to avoid bias by local artefacts in the fault vicinity. Figure 3.9 shows measured values of displacement, cumulative displacement and inferred displacement rate, displaying the characteristics of basin deformation with Cretaceous-Paleocene extension (>85-55 Ma), Paleogene quiescence (55-34 Ma), Late Paleogene to Miocene compression (34-7 Ma), Early Pliocene quiescence (6-3 Ma), and Late Pliocene-Pleistocene extension (3-0 Ma). The displacement rate was derived by dividing individual measurement by the time duration of deposition inferred for individual formations (Table 3.2), while the cumulative displacement was calculated by summation of vertical displacement values.

Uncertainties in these values are primarily associated with the depth conversion process $(\sim \pm 100-200 \mathrm{~m})$, estimates of formation age ( $\sim 1-5 \mathrm{Ma})$, and the projection of the seismic profiles onto a straight line of a distance $>5 \mathrm{~km}(\sim 100 \mathrm{~m})$. Additional uncertainties are associated with sediment decompaction $( \pm 100 \mathrm{~m})$ and amount of Miocene missing section across the Cape Egmont and Whitiki Faults $( \pm 100 \mathrm{~m})$. Due to the lack of prePliocene strata in the hanging wall of the Taranaki Fault, displacements on the fault were estimated from the decompacted thickness of adjacent strata in the footwall and are thus not well constrained for individual time intervals. 

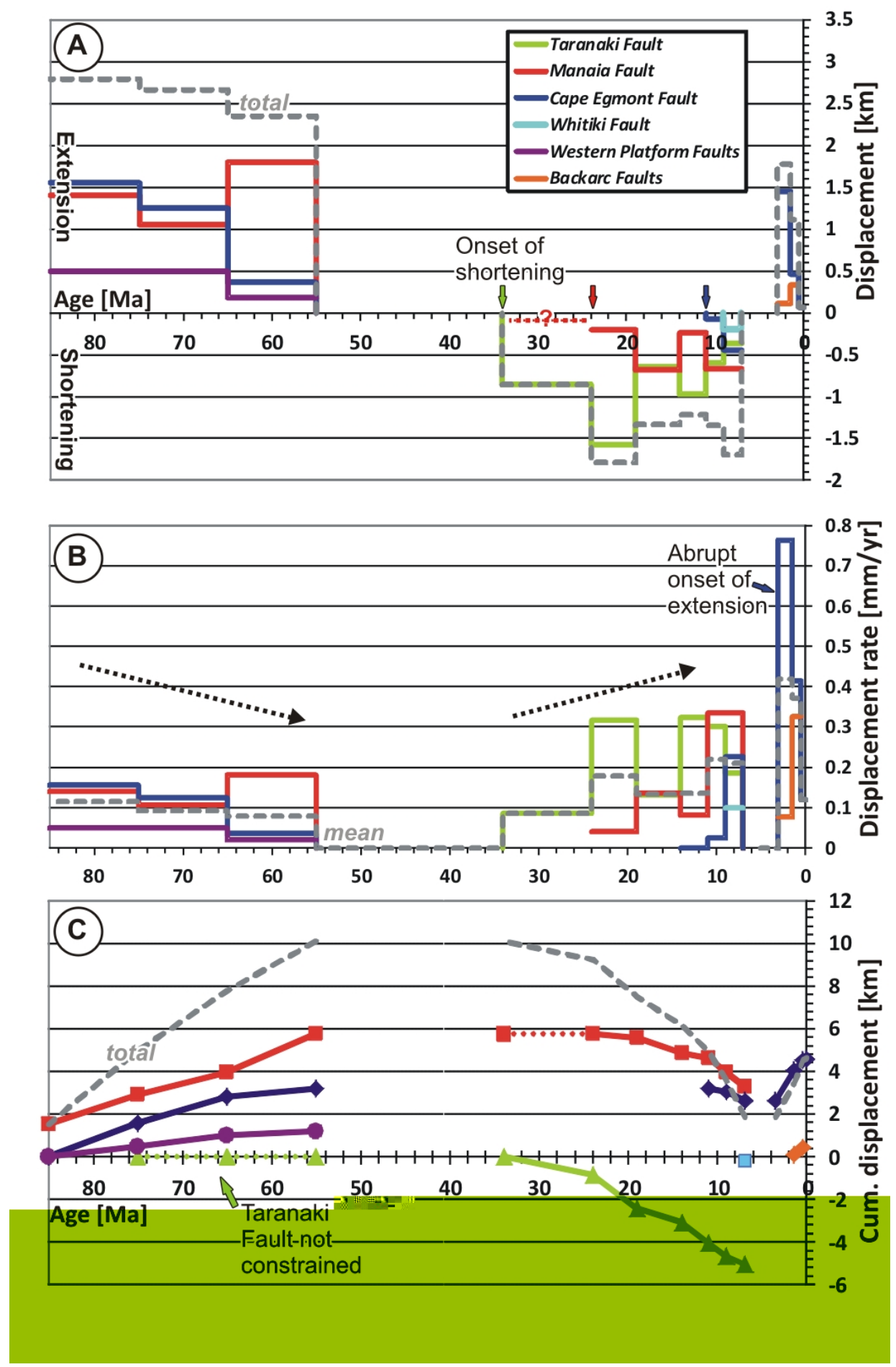

Figure 3.9 Fault displacement history measured from vertical offsets of decompacted horizons across the profile faults: A) Measured vertical horizon offsets, B) displacement rate derived by dividing the vertical horizon offsets by the time duration of individual formations (see Table 3.2), and C) cumulative displacements derived by summation of vertical fault throws. The total and mean values derived values are shown as grey dashed lines in panels. Displacement measurements of early extensional faults in the western and Plio-Pleistocene faults in the eastern cross-section are combined into Western Platform faults and backarc faults, respectively. Displacement on the Taranaki Fault is not constrained before the onset of compression. Note the general decrease of extensional displacement during the Late Cretaceous and Paleocene, increase in reverse displacements during the Miocene with differential initiation of fault convergence, and abrupt start of Plio-Pleistocene extension on the Cape Egmont Fault. 
Prior to deposition of the Late Cretaceous Rakopi Formation ( $\sim 85 \mathrm{Ma})$, sedimentation and thus constrainable fault activity was limited to the present-day deep-water area and the Manaia Graben. Restoration of intra-Cretaceous fault throws in the NCT show about $6 \mathrm{~km}(\sim 5 \%)$ of horizontal extension (Figure 3.5). However, it is noted that the total amount of extension is expected to be significantly higher since the strike of this crosssection is oriented sub-parallel to the structural grain of the area (see general trend of NCT in Figure 3.1). Formation thicknesses indicate that the Manaia Fault accrued up to $1.5 \mathrm{~km}$ of vertical displacement during this interval, suggesting that this structure may have developed contemporaneously with formation of the NCT. Because of the uncertainties regarding the age of the pre-Rakopi Formation sequence and the subparallel strike of the cross-section with respect to the structural grain of the NCT, these values are not represented in the diagrams shown in Figure 3.9.

Extension in the NCT ceased mostly prior to deposition of the Rakopi Formation ( $>85$ $\mathrm{Ma}$ ), and extension increasingly developed on a series of faults in the proximal Taranaki Basin. Vertical fault displacements related to this phase of extension are highest during the deposition of the Rakopi Formation and average displacement rates decrease to $<0.1$ $\mathrm{mm} /$ year during the Late Cretaceous and Paleocene (Figure 3.9). While most faults exhibit minor activity during the Paleocene, activity on the Manaia Fault increased and accounted for about $75 \%$ of the total displacement along the cross-section. Late Cretaceous to Paleocene horizontal extension between the Western Platform and the Taranaki Fault is about 4-5 km and, together with the $1.5 \mathrm{~km}$ of earlier extension on the Manaia Fault (Basement-K85) suggests $\sim 5-8 \%$ of crustal stretching across the proximal Taranaki Basin.

Fault displacement histories suggest the onset of convergence during the Oligocene with an east-to-west progression of convergent fault initiation and general displacement increase during the Oligocene and Miocene (Figure 3.9). Thickened strata in the footwall of the Taranaki Fault indicate up to $0.8 \mathrm{~km}$ of reverse movement on this fault during the Oligocene (34-24 Ma), while movement on the Manaia Fault is small and within the limits of uncertainty $(\sim 100 \mathrm{~m})$. Displacements increase during the Early Miocene with $>1.5 \mathrm{~km}$ displacement and $0.3 \mathrm{~km}$ on the Taranaki and Manaia Fault, respectively. The Cape Egmont and Whitiki Fault remained quiescent until the late Middle Miocene $(\sim 11$ 
Ma), after which they recorded relatively small amounts of displacements of about 0.5 $\mathrm{km}$ and $0.2 \mathrm{~km}$, respectively.

While being localised in the eastern basin during the early phases of convergence (34-11 $\mathrm{Ma})$, displacements were more evenly distributed across the Eastern Mobile Belt after convergent initiation of additional faults during the Late Miocene (Figure 3.9). Vertical displacements and displacement rates show an overall increase towards the Late Miocene with maximum displacement rates of $\sim 0.34 \mathrm{~mm} /$ year, which, given the observed fault dips of $20-70^{\circ}$ gives a horizontal shortening range of $0.12-0.93 \mathrm{~mm} / \mathrm{year}$. In addition to the overall increase in deformation during the Miocene, two phases of amplified convergence are observed. The earlier phase spans the interval between 24-19 Ma and the second phase was during the Late Miocene between 9-7 Ma, with average displacement rates of $0.18 \mathrm{~mm} /$ year and $0.22 \mathrm{~mm} / \mathrm{year}$, respectively. Total OligoceneMiocene horizontal shortening across the Eastern Mobile Belt is estimated at about 16-18 $\mathrm{km}$, of which at least $13 \mathrm{~km}$ are accommodated by slip on the Taranaki Fault.

Besides potentially small normal movement $(<100 \mathrm{~m})$ east of the Taranaki Fault, no fault activity is evident during the latest Miocene and early Late Pliocene (6-3 Ma). Abrupt onset of extension is observed from about $3 \mathrm{Ma}$ with large displacements of $\sim 1.5 \mathrm{~km}$ at rates of over $0.75 \mathrm{~mm} /$ year on the Cape Egmont Fault between 3-1.5 Ma. The significance of smaller faults in the overall displacement budget increases after this interval, while the amount of total extension may have decreased. Assuming an average fault dip of $60-70^{\circ}$ the total horizontal extension during the Plio-Pleistocene amounts to $\sim 1-1.6 \mathrm{~km}$.

Cumulative fault displacements suggest that the basin experienced an overall greater amount of extension than compression (Figure $3.9 \mathrm{C}$ ), but indicate that the amount of Late Cretaceous to Paleocene extension roughly equates to the amount of Cenozoic shortening. However, convergent deformation was distributed over a smaller area (Eastern Mobile Belt) than the earlier extension (Eastern Mobile Belt and Western Platform), leading to an overall higher percentage of relative shortening ( $\sim 16-18 \%)$ than extension $(\sim 5-8 \%)$. It is noted that these interpretations hinge on the uncertainties associated with the displacement history of the Taranaki Fault, which are due to the lack of pre-N50 strata in the fault's hanging wall. For this fault an early extension history is 
inferred but cannot be constrained, and convergent displacements represent a minimum estimate.

\subsubsection{Sedimentation history}

The thicknesses of individual formations shown in the cross-section provide insight into the sedimentation history of the basin. In order to estimate sediment input volumes in the study area, decompacted thicknesses of individual formations were summed across the cross-section (Figure 3.10). The resulting surface areas (formation area in Figure 3.10A) are considered a proxy for sediment input volumes throughout most of the basin history, since the cross-section covers representative parts of the proximal to distal part of the basin. From these values, average formation thicknesses were derived by dividing the formation surface area (integrated thicknesses) by the east-west extent over which the sediment was deposited (cumulative thickness in Figure 3.10B). Average sedimentation rates were then calculated by dividing the average formation thicknesses by the time duration of each interval as shown in Table 3.2.

The cumulative thickness curve shows characteristic signatures that can be associated with the different phases of basin formation. The Cretaceous to Paleogene upward concave part is characteristic of the Gondwana break-up rift to drift phase, while the Neogene to Recent upward convex part shows the sediment history during evolution of the Australia-Pacific plate boundary.

While average formation thickness show a general decrease during the Cretaceous (K85P10, Figure $3.10 \mathrm{~A}$ ) from $1.3 \mathrm{~km}$ to $<1 \mathrm{~km}$, sediment volumes increased and sedimentation rates remained relatively constant $(\sim 90 \mathrm{~m} / \mathrm{my})$. The latter two characteristics are due to the more widespread distribution of formations and have not been constrained from previous analysis of well data (e.g., Hayward \& Wood, 1989; King \& Thrasher, 1992). Sediment volumes and average thicknesses decrease from the Paleocene to Early Miocene (P10-N10, 65-19Ma), with declining sedimentation rates of $50 \mathrm{~m} / \mathrm{my}$ during the Paleocene (P20), $30 \mathrm{~m} / \mathrm{my}$ during the Eocene (P30-P50), and less than $20 \mathrm{~m} / \mathrm{my}$ in the Oligocene and Early Miocene (P60-N10), respectively. While most of the basin receives little sediment during the Oligocene, local interval thicknesses in the eastern basin suggest infilling of the foredeep at rates of up to $85 \mathrm{~m} / \mathrm{my}$ (Figure 3.6, Figure 3.10). 
Average sedimentation rates of $35 \mathrm{~m} / \mathrm{my}$ with localised maximum values of about 300 $\mathrm{m} / \mathrm{my}$ in the eastern part of the basin indicate increased sediment input in the Early Miocene. Between 19 and 5 Ma average sedimentation rates exponentially increase to $300 \mathrm{~m} / \mathrm{my}$, while localised depocenters west of the Manaia and Whitiki Faults exhibit rates of up to $500 \mathrm{~m} / \mathrm{my}$. Late Miocene sedimentation estimates have higher uncertainties due to incorporation of reconstructed missing strata. However, sediment volumes are significantly higher than previous values, even if potentially redeposited $\left(11 \mathrm{~km}^{2}\right)$ or eroded $\left(33 \mathrm{~km}^{2}\right)$ strata are not included.

During the latest Miocene to Early Pliocene (N60 \& N70), integrated thicknesses indicate a temporary decrease of sediment volumes deposited in the study area (Figure 3.10A). While sediment deposition was focused on the eastern basin, sedimentation rates continued to increase during deposition of the N60 interval ( 6-4 Ma) and show a sharp drop to rates of less than $250 \mathrm{~m} / \mathrm{my}$ during 4-3 Ma (Figure 3.10C). Following $3 \mathrm{Ma}$ sedimentation rates increased to average values of 400-450 $\mathrm{m} / \mathrm{my}$, with maximum values of $>700 \mathrm{~m} / \mathrm{my}$ in localised sediment depocentres in the hanging wall of the Cape Egmont Fault and on the Western Platform. During this time interval, sediment volumes in the cross-section area were smaller than during the Late Miocene. 

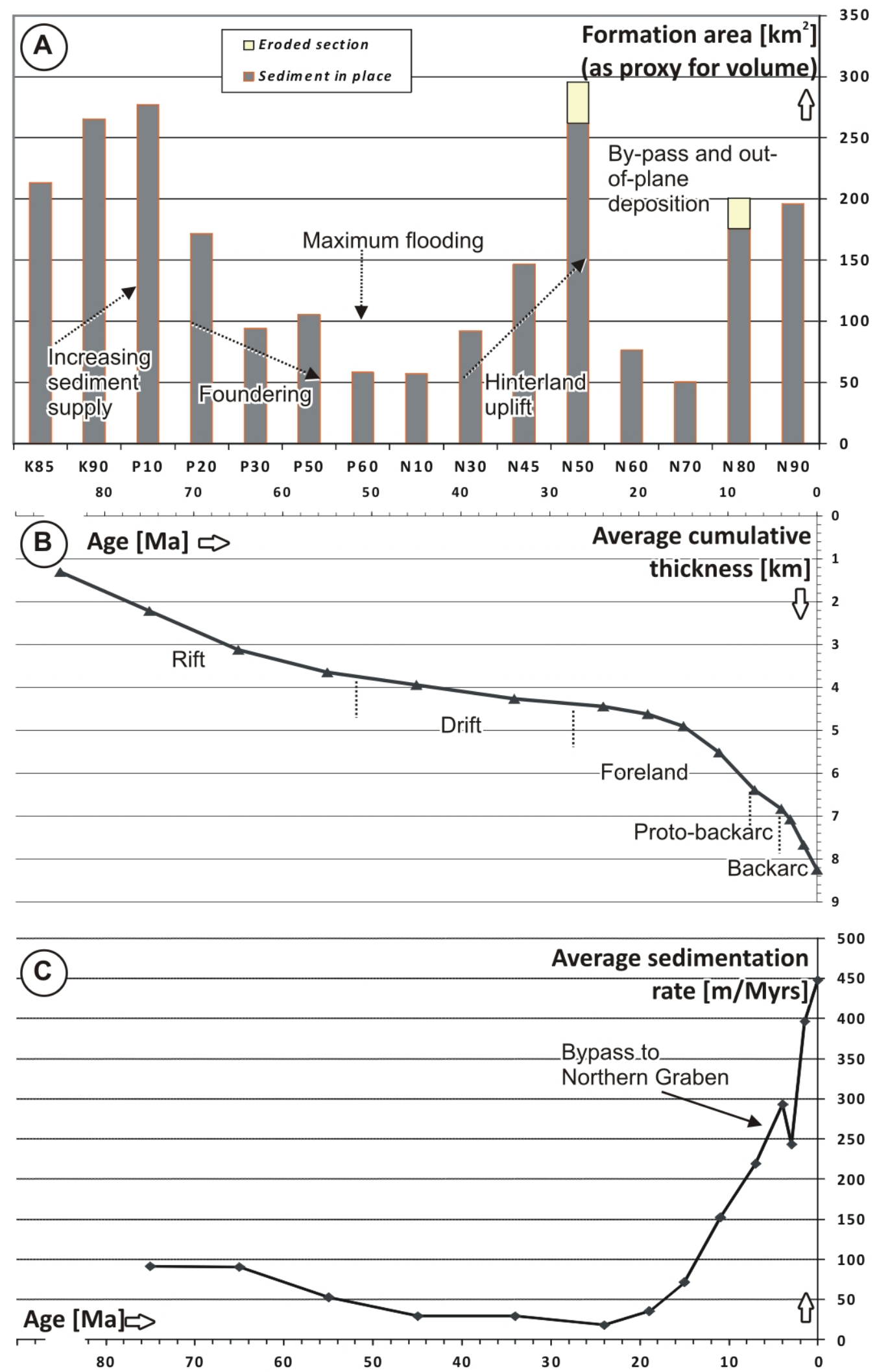

Figure 3.10 Sedimentation history calculated by integrating decompacted formation thicknesses across the profile: A) histogram of individual formation surface areas as proxy for deposited sediment volume, B) average cumulative sediment thickness, and C) inferred sedimentation rate. See text for description of details about derivation of these values. The amount of eroded section is included in plots (B) and (C). Note that the sedimentation rate was not derived for the K85 interval. 


\subsubsection{Neogene structural modification of Cretaceous strata}

The burial history and structural development of Cretaceous and Paleogene strata provide information about the petroleum source rock maturity and charge history in the basin. As mentioned above, coaly members of the Cretaceous Rakopi and North Cape formations (K85-P10) are regarded as the major source rocks for petroleum accumulations in the Taranaki Basin, with Paleocene coals and marine shales being considered secondary sources for hydrocarbons (Killops et al., 1994; Sykes \& Dow, 2000; Sykes, 2001). Although source rock-maturity is dependent on a wide range of factors such as organic content or heat flow histories (e.g., Allen \& Allen, 2005), generic threshold values for burial depth are commonly used to outline the window of hydrocarbon expulsion. For Taranaki Basin such generic burial thresholds for the onset of expulsion have been quoted as being a minimum of 4-4.4 km for oil expulsion and a minimum burial of $5 \mathrm{~km}$ for gas expulsion (e.g., Matthews, 2008). These threshold values have been plotted together with the evolution of the Base Paleocene horizon (P10) through the Neogene in Figure 3.11 to provide basic constraints on the potential maturity and charge history of hydrocarbon accumulations in eastern Taranaki Basin.

Assuming the thresholds above, the structural restoration suggests that Cretaceous source rocks in the Manaia Graben and, possibly, adjacent to the Cape Egmont Fault, were buried deep enough to expel hydrocarbons prior to the Early Miocene ( $>19 \mathrm{Ma}$ ). However, while a significant percentage of Cretaceous strata in the eastern basin passed through the oil and gas expulsion window during the Early and Middle Miocene, structural hydrocarbon-traps (i.e., Manaia Anticline) where not in place until the Middle to Late Miocene (14-11 Ma). During the Late Miocene, most of the Cretaceous isopach east and west of the Manaia anticline passed through the maturity window and generation from Paleogene source rocks may have started at about $11 \mathrm{Ma}$. The Manaia Anticline has since been significantly modified and early charge may have been redistributed during further convergence.

Immediately east of the Cape Egmont Fault, large parts of the Cretaceous isopach stayed within the threshold values for oil and gas maturity (mostly oil) during the Miocene and associated strata completely passed through the gas expulsion window. Late Miocene reverse movement on the Cape Egmont Fault led to juxtaposition of Cretaceous strata in the hanging wall with younger strata in the footwall between the Late Miocene and 
Pliocene (7-3 Ma). This juxtaposition may have provided a potential migration pathway from mature source rocks in the east into reservoirs in the adjacent Maui structure, which would be consistent with charge studies of the Maui oil and gas field (Funnell et al., 2004).

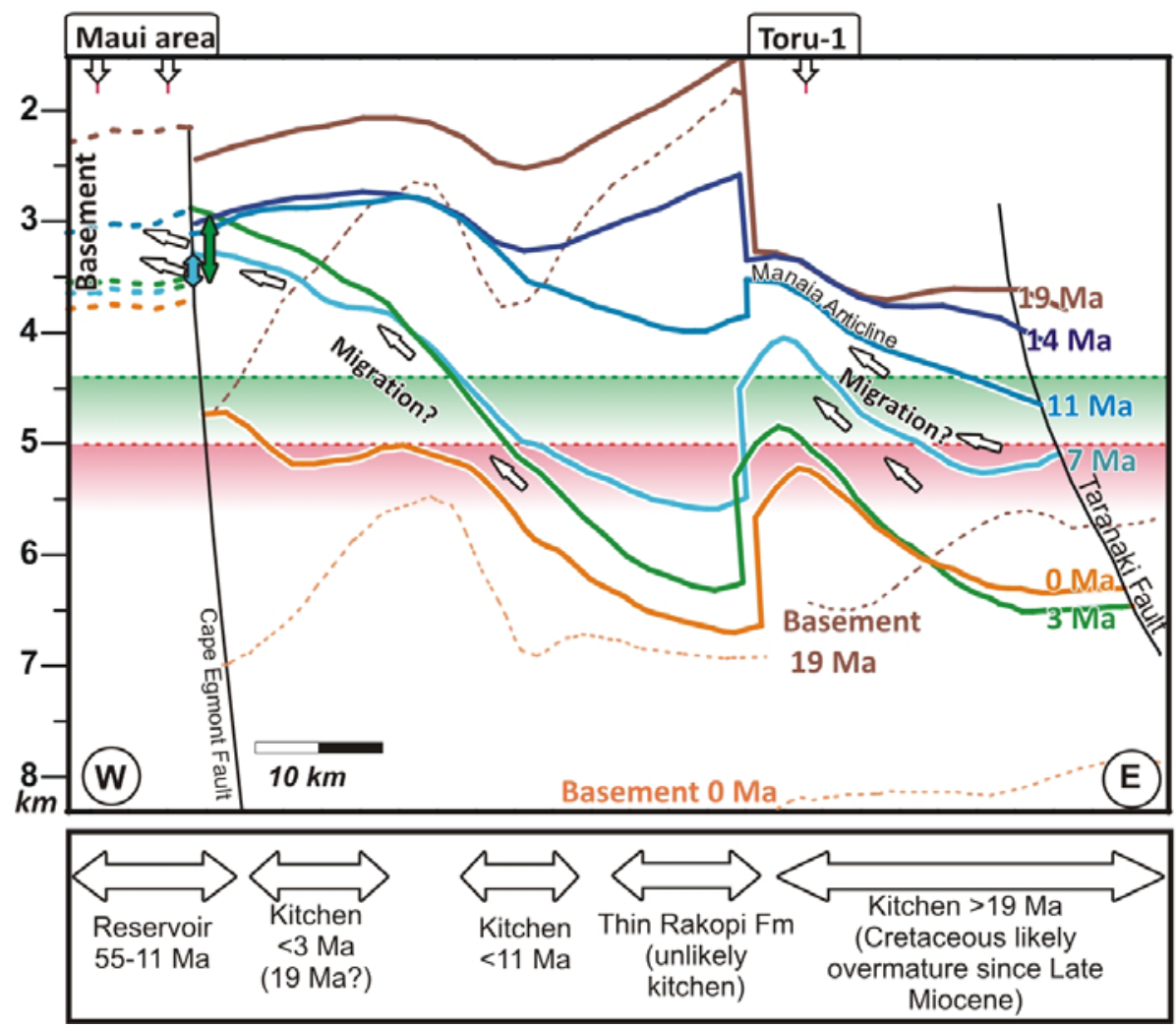

Figure 3.11 Structural evolution of the Top Cretaceous horizon (P10) since the Early Miocene (19 Ma) in the eastern part of the cross-section (vertical exaggeration $=10)$. Depth (in $\mathrm{km}$ ) is shown relative to the paleo-sea level at individual time periods. Rough approximations of the oil and gas expulsion window are shown as green and red dashed line, respectively. The Basement depth is shown at $19 \mathrm{Ma}$ and $0 \mathrm{Ma}$ as a reference for the Cretaceous isopach thickness, respectively, Horizons west of the Cape Egmont Fault correspond to the Basement reflector since no Cretaceous section is present in this area. White arrows represent the possible migration directions. Coloured arrows in the west indicate the vertical offset of the top Cretaceous reflector in the east above the basement reflector west of the Cape Egmont Fault to indicate the possible window of horizontal charge across the fault. Possible kitchen areas are shown with the inferred timing of possible earliest maturity.

\subsubsection{Neogene structural development of the Western Platform}

The lack of faulting in the western part of the profile suggests that the Western Platform has been tectonically quiescent since at least the Paleocene. However, incremental restorations indicate that the structure of the Western Platform has been modified through flexure and sediment loading following the cessation of extensional activity. The general characteristics of foreland basin formation and Neogene sediment loading on the Western Platform have been considered by previous authors (Holt \& Stern, 1991; 1994), but are 
here illustrated in greater detail by the development of the decompacted and structurally restored Base Oligocene horizon (P50) since the $24 \mathrm{Ma}$ (Figure 3.12).

At 24 Ma the P50 horizon exhibits a general westward dip, imposed by assuming a general increase in paleowater depth towards the NCT in the restoration. By the Middle Miocene (14 Ma) the horizon develops a broad dome structure roughly beneath the Tane1 well, which is interpreted as a flexural forebulge due to tectonic loading of the eastern basin margin. This feature became narrower, possibly migrated westwards, and increased in vertical amplitude to over $600 \mathrm{~m}$ underneath the present-day outer shelf during the Middle Miocene (14-11 Ma). During convergence on the Cape Egmont and Whitiki faults in the Late Miocene (11-7 Ma), formation of a smaller amplitude anticlinal structure in the Maui area modified by the eastern limb of this structure separated the Maui area from the long-wavelength dome structure in the west. Greater differential subsidence of the area immediately west of the Maui High between 7-3 Ma led to further modification and increase in vertical amplitude of the broad dome structure to as much as $\sim 1000 \mathrm{~m}$. During deposition and flexural loading by sediments of the Giant Foresets Formation, the crest of the broad dome structure migrated westwards and was depressed by up to $400 \mathrm{~m}$ due to subsidence associated with the advancing shelf margin wedge. Despite potential footwall uplift on the Cape Egmont Fault during Pliocene normal faulting, the Maui area exhibits little modification since the $3 \mathrm{Ma}$.

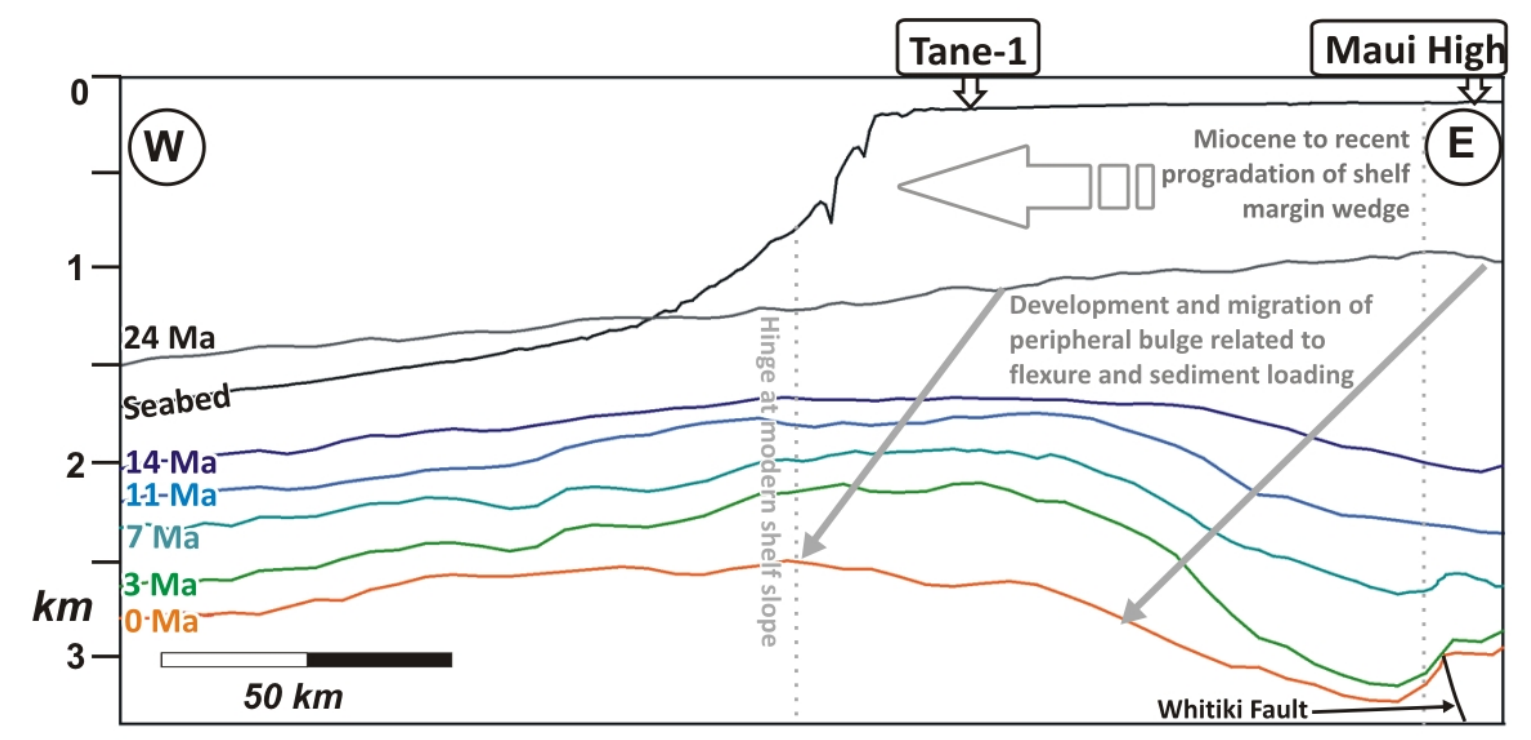

Figure 3.12 Structural evolution of the Base Oligocene horizon (P50) on the Western Platform. The geometry of the decompacted P50 horizon is shown as coloured lines at multiple times since the Oligocene (24-0 Ma, vertical exaggeration $=35$ ). Locations of the Tane-1 well and the Maui High are annotated and the depth of present-day seabed is shown in black. 


\subsection{DISCUSSION}

\subsubsection{Rift to drift phase}

Extension in the NCT was completed before or during deposition of the Rakopi Formation ( $>85 \mathrm{Ma}$ ), while subsequent Late Cretaceous to Paleocene extension was limited to proximal Taranaki Basin (Figure 3.5). The timing of these events in relation to the general development the greater New Zealand area indicates that rifting was related to 1) the precursors of Cretaceous Gondwana break-up (e.g., Laird \& Bradshaw, 2004) and 2) Late Cretaceous to Paleocene spreading of the Tasman Sea southwest of Zealandia (Gaina et al., 1998). This relationship is consistent with interpretations by previous authors (Thrasher, 1990c; Bishop \& Buchanan, 1995; King \& Thrasher, 1996), but the timing of extension across the basin highlights some differences with respect to previous studies.

The overall later timing of extension in the proximal Taranaki Basin, shift in deformation locus, and the switch in fault orientation from SE-NW to NS indicates that these rifting episodes were essentially two distinct events. As suggested by Thrasher (1990c), extension in proximal Taranaki Basin may have initiated as a rift transform system that connected contemporaneous extension in the NCT and the Tasman Sea during the Cretaceous (Basement-K85). However, since extensional faulting in the NCT ceased before $85 \mathrm{Ma}$, the development of proximal Taranaki Basin is here considered to have been independent since the Late Cretaceous (K85-K90) and directly related to Tasman Sea spreading ( $\sim 85 \mathrm{Ma}$, Gaina et al., 1998). Declining extension during the latest Cretaceous and Paleocene is here interpreted to reflect the increasing distance with respect to the spreading ridge and ultimate cessation of Tasman Sea spreading in the Paleocene (Gaina et al., 1998).

Since proximal Taranaki Basin extension is interpreted to have evolved in a rifttransform context distal to the Tasman Sea spreading ridge a small component of transtensional motion is considered likely. The gradual concave upward signature of Cretaceous to Paleocene average sediment thicknesses (Figure 3.10B) and small tectonic subsidence values (see Chapter 4) are characteristic of a dominantly dip-slip rift to passive margin sequence with little stretching (e.g., Allen \& Allen, 2005; Xie \& Heller, 2009), and thus trans-tensional motions are considered to have been minor. Generally 
minor stretching of the crust is also indicated by the estimated $\sim 5-8 \%$ of extension in proximal Taranaki Basin (between the Western Platform and the Taranaki Fault, Figure 3.13). This estimate is broadly consistent with earlier interpretations, but is somewhat smaller than the $\sim 10 \%$ by Thrasher (1992) and somewhat higher than the $\sim 5 \%$ estimated from reconstructions in the southern part of the basin (Bishop \& Buchanan, 1995).

Although not confirmed by well penetration, new seismic mapping conducted as part of this study suggests the presence of pre-Rakopi syn-rift strata in the Manaia Graben, possibly similar to Taniwha Formation strata penetrated in northern Taranaki Basin (Shell BP Todd Oil Services Ltd., 1986). The presence of such older strata suggests that this area of the proximal basin was to some degree affected by the earlier rifting period (Figure 3.5). While NW-SE-oriented 'Gondwana-margin'-faults are not well preserved in proximal Taranaki Basin, it is considered likely that this structural grain was present prior to the Late Cretaceous and may have connected the NCT in the northwest with the EW-oriented Bounty Trough in the southeast (inset Figure 3.1).

While extensional activity was low across the basin in the Paleocene, about $75 \%$ of the total displacement was accommodated by the Manaia Fault. The localisation of strain on a single fault structure (Manaia Fault) is a common phenomenon of mature faults and is observed in younger extensional systems such as the adjacent Taupo rift on the presentday North Island (Nicol et al., 2010). During the evolution of extensional systems, these processes result in the focussing of strain on large and mature faults at the expense and possible death of smaller faults (Cowie et al., 1993; Cowie et al., 2000). The localisation of strain may reflect the long history of this fault, which has been speculated to represent a boundary of Paleozoic-Mesozoic terrane accretion (Mortimer et al., 1997). In addition strain localisation may indicate the significant length of this fault or preferential orientation with respect to the paleo-stress field. The cross-section shows no evidence for Late Paleogene extension, which is in contrast to the Eocene extension observed in basins in the western South Island (Bishop \& Buchanan, 1995) and thus it is considered unlikely that a rift system extended through the study area during the Eocene or Oligocene (Kamp, 1986; Furlong \& Kamp, 2009). 


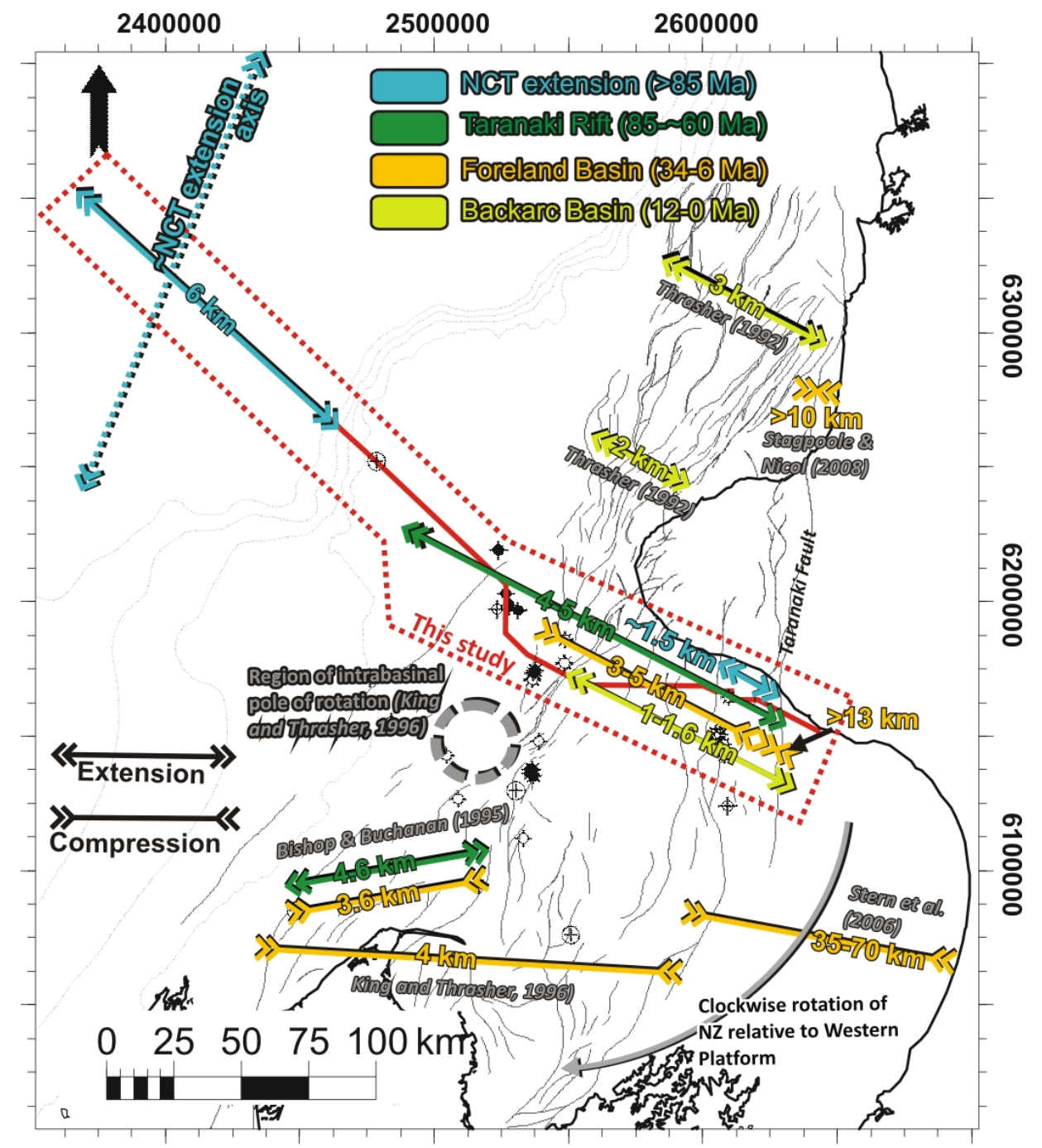

Figure 3.13 Summary map of relative horizontal shortening and extension across the basin from this and previous studies (Thrasher, 1992; Bishop \& Buchanan, 1995; King \& Thrasher, 1996; Stern et al., 2006; Stagpoole \& Nicol, 2008). The location of the reconstructed cross-section is shown as a red line. Results from this study are outlined by the dashed red polygon. The New Zealand coastline and faults at top Eocene level (after Thrasher \& Cahill, 1990) are shown as black and grey lines, respectively. Note the southward decrease in Late Neogene extension (light green) which may be related to clock-wise rotation of New Zealand (e.g., Wallace et al., 2004, schematically indicated by curved a grey arrow) relative to a schematic regional pole located in the Western Platform (after King \& Thrasher, 1996). Note also the high angularity between the cross-section and the inferred primary Cretaceous extension axis in the NCT, which inhibits accurate estimation of stretching in the NCT.

\subsubsection{Foreland basin phase}

The onset of convergence across the Taranaki Fault and, possibly, the Manaia Fault during the Oligocene $(\sim 34-28 \mathrm{Ma})$ is consistent with previous interpretations of Oligocene onset of foreland basin formation in this area (Schmidt \& Robinson, 1990; King \& Thrasher, 1992; Holt \& Stern, 1994). However, this estimate post-dates interpretations of convergent activity on the Taranaki and Manaia Fault from 43-40 Ma (Voggenreiter, 1993; Stagpoole \& Nicol, 2008) and pre-dates estimates for the southern Taranaki Basin and basins in the western South Island ( 22 Ma, Bishop \& Buchanan, 
1995). While angular truncations at the top of the Eocene sequence in the eastern part of the cross-section could indicate uplift and erosion related to pre-Oligocene convergence, the amount of convergence is likely to have been small given the geometry of Eocene strata in the foot- and hanging wall of the fault $(<200 \mathrm{~m})$. The interpretation of later onset of convergence in the southern basin by Bishop and Buchanan (1995) is considered to be due to the small lateral extent of their cross-section and the location of more than $100 \mathrm{~km}$ west of the inferred paleo-basin boundary.

Since convergence across the Taranaki Basin is considered to be a direct result of displacement transfer from the Australia-Pacific plate boundary into the overriding plate Australian plate (Stagpoole \& Nicol, 2008), inception of the plate boundary in the New Zealand sector might be placed into the Oligocene. However, evidence for Eocene onset of compression in the northern basin (Stagpoole \& Nicol, 2008) could indicate a general north-south progression of fault inception, which would be consistent with southeastward migration of the Australia-Pacific plate Euler pole away from southern Taranaki Basin since the Eocene (Sutherland, 1995; Cande \& Stock, 2004). Since numerical models of subduction initiation suggest that about 100-150 km of convergence has to occur before subduction zones become self-sustaining (Gurnis et al., 2004), it remains unclear whether the pre-Miocene convergent displacement occurred as a result of subduction, or if it recorded convergence that accrued before Pacific plate subduction started.

The general intensification of convergent displacements from the Oligocene to the Late Miocene suggests the increasing involvement of the Taranaki Basin in the plate boundary deformation, while smaller variations in the displacement history may be related to general changes in plate boundary characteristics. Increased reverse displacement across the Manaia and Taranaki faults during the Early Miocene (24-19 Ma) suggest a pulse of increased tectonic activity. This timeframe is concurrent with increased shortening in the East Coast region during onset of rapid subduction (Chanier \& Ferriere, 1989; 1991; Rait et al., 1991; Kamp, 1999).

Initiation of convergence across the Cape Egmont ( 11-9 Ma) and Whitiki Fault (9-7 $\mathrm{Ma}$ ) indicates a westward broadening of plate boundary deformation by over $60 \mathrm{~km}$ in the Middle to Late Miocene. The basin-ward migration of the deformation front has been evidenced in other compressional basins such as the Western Irish Numurian Basin 
(Tanner et al., 2011) and may be a general characteristic of similar basins during sustained shortening. In Taranaki Basin, this widening could be related to reorientation of the plate boundary and increase in vertical clock-wise axis rotation rates of the eastern Hikurangi margin (Nicol et al., 2007), which has also been interpreted to cause structural changes in deformation pattern in Northland during this time (Herzer, 1995). The ensuing pulse of tectonism, widespread uplift, and erosion in the Late Miocene can be attributed to thrust sheet uplift as well as concomitant thickening of the crust beneath eastern Taranaki Basin (Stern \& Davey, 1990; Holt \& Stern, 1994). Cessation of compression after development of a widespread unconformity in the Late Miocene ( 7-6 Ma) contrasts previous interpretations of convergent displacements on the Taranaki Fault in the Pleistocene (Proust et al., 2005).

Estimates herein of $>13 \mathrm{~km}$ horizontal shortening across the Taranaki Fault are slightly higher than estimates of $10 \mathrm{~km}$ proposed by Stagpoole and Nicol (2008), which may be attributed to the earlier cessation of Miocene convergence in the south compared to the north. The estimated amount of horizontal convergence within the Eastern Mobile Belt of about $16-18 \%$ is indiscernible from the $16.2 \%$ shortening determined from palinspastic restorations of seismic sections adjacent to the Alpine Fault on the western South Island (Bishop \& Buchanan, 1995). Despite displacements on the Taranaki Fault, the amount of shortening inferred from the cross-section $(3-5 \mathrm{~km}$ ) is similar to the $4 \mathrm{~km}$ (King \& Thrasher, 1996) or $\sim 4 \%$ (Bishop \& Buchanan, 1995) estimated in the southern basin (Figure 3.13), which shows the internal basin deformation was relatively minor compared to deformation further east.

Based on thickened crust underneath the eastern basin boundary Stern et al. (2006) estimated $70 \pm 35 \mathrm{~km}$ of shortening across the wider Taranaki-Wanganui basin area. Assuming a total Australia-Pacific plate convergence of about $670 \mathrm{~km}$ during the Miocene (given an average of 35 km/Myr over 19 Myrs from Cande \& Stock, 2004), horizontal shortening values of $20 \mathrm{~km}$ would imply that only $<3 \%$ of the total Miocene plate convergence was accommodated within the Taranaki Basin and a magnitude less west of the Taranaki Fault. The small amount of deformation generally agrees with interpretations of Nicol et al. (2007) that more than $90 \%$ of convergence was accommodated by the subduction thrust. In addition, the small values observed west of the Taranaki Fault indicate that this fault represented a main boundary which separated the substantial deformation in the east from minor deformation within the basin. 
Relative isolation from the plate boundary deformation is further indicated by the inferred maximum convergence rates of $\sim 1 \mathrm{~mm} / \mathrm{year}$, which are slower than the 3-4 $\mathrm{mm} /$ year observed across the North Island and an order of magnitude smaller than the inferred Miocene Australia-Pacific plate convergence (Nicol et al., 2007). The smaller rates of horizontal convergence can be partly reconciled by the relatively steep dip of inverted faults in the shallow section $\left(45-70^{\circ}\right)$. The downward flattening (listric) shape indicates that the Taranaki Fault, and possibly the Cape Egmont and Manaia faults, may sole into flat detachments $\left(<5^{\circ}\right)$ at depths of $12-15 \mathrm{~km}$. Assuming dips of 2-5 at depth, horizontal displacement rates of the Taranaki Fault may have been as high as 2-10 $\mathrm{mm} /$ year, which is more in line with rates of deformation further east.

The observed foreland basin geometry from at least $24 \mathrm{Ma}$ (Figure 3.6) is consistent with depictions by King and Thrasher (1996) in the onshore and central basin (their Figure 5.5). The location of the discernable forebulge from $14 \mathrm{Ma}$ on the Western Platform roughly agrees with interpretations of Holt and Stern (1994) for an elastic thickness (Te) of $\sim 25 \mathrm{~km}$. Infilling of the initial foredeep occurred during the Oligocene. Progradation across the foredeep during the Early Miocene (Figure 3.6) indicates that the rapidly increasing sedimentation rates (Figure 3.10) outpaced tectonic subsidence. Formation geometries suggest that the foredeep was filled to the forebulge by the Middle Miocene (14 Ma) after which sediment increasingly spilled beyond the forebulge and into the $\mathrm{NCT}$, representing the change from an underfilled to an overfilled foreland basin (DeCelles \& Giles, 1996). Inferred sediment volumes indicate continuous increase of sedimentation throughout the Miocene, in line with increasing amounts of sub-aerial exposure of the emerging New Zealand continent (King, 2000b; Wood \& Stagpoole, 2007). The derived sedimentation rates agree with the trends inferred from individual wells by previous studies (e.g., King \& Thrasher, 1992), but suggest that sedimentation rates were locally higher than previously inferred.

\subsubsection{Formation of the Toru Trough and western Wanganui Basin}

The virtual lack of upper crustal faulting until about 3 Ma suggests the existence of a transitional phase between convergence and extension. This transitional phase is marked by increased subsidence and sediment deposition in the eastern basin between 6-4 Ma (Figure 3.8). The location of this subsidence coincides with the circular depocentre outlined by Anderton (1981) and marks the formation of a contiguous depocentre (the 
Toru Trough and the western Wanganui Basin), which increased the extent of the Taranaki Basin eastwards beyond the Taranaki Fault. The observed increase in water depth of about 400-500 m between 4-6 Ma, decompacted sediment thicknesses of 1000 $\mathrm{m}$, and an average sediment density of $2500 \mathrm{~kg} / \mathrm{m}^{3}$, suggest tectonic subsidence of at least $500 \mathrm{~m}$ at rates of 350-450 m/my (Allen \& Allen, 2005). Previous authors have attributed the sudden increase in subsidence to frictional shear between the subducted Pacific and overriding Australian plates (Stern et al., 1992) or development of a gravitational instability (Rayleigh-Taylor instability) within the previously thickened mantle lid of the lithosphere (Stern et al., 2006). Although the data does not allow discrimination between these models, the high values of subsidence in absence of upper crustal faulting as well as the broad wavelength of this depression ( $200 \mathrm{~km})$, are in favour of such lithospheric-scale driving mechanisms.

The down-warp of the Toru Trough and Wanganui Basin resulted in an eastward shift of the depositional locus, causing a decrease in westward sediment transport and decelerated the advance of the western shelf margin. The clastic sediment starvation of the distal western part of the basin between 5-3 Ma, which is reflected in the deposition of Ariki Formation calcareous mudstones observed in well Tane-1 (Shell BP Todd Oil Services Ltd., 1976), can thus directly be related to the subsidence in the east. The sudden decrease in sedimentation rates in the eastern basin between 4-3 Ma (Figure 3.10) indicate either a temporary diversion of sediment sources or shift of depocentres to areas outside the plane of the study cross-section. Because sedimentation rates show an otherwise continuous increase since the Miocene and compression continued in the hinterland (Nicol et al., 2007), a decrease in sediment influx is considered unlikely. Seismic mapping of basin strata in the northern basin has shown the sedimentary infilling of the Northern Graben during active extension and subsidence in the early Pliocene (Hansen \& Kamp, 2004; Giba et al., 2010). Thus, bypass of sediment into this incipient backarc graben system located close-by (Giba et al., 2010) is considered a more plausible explanation for this sudden decrease in sedimentation rates and may have contributed to the paucity of clastic sedimentation in the distal western basin. 


\subsubsection{Proto-backarc phase}

Fault displacement history plots indicate onset of extension around 3 Ma (Figure 3.9), which may be related to the development of a backarc basin system. The total amount of 1-1.6 $\mathrm{km}$ of horizontal extension since $3 \mathrm{Ma}$ is consistent with earlier estimates of $1 \mathrm{~km}$ (Thrasher, 1992), while the slightly higher estimate herein can be attributed to faults that were not visible on seismic paper sections. The later onset and smaller amounts of extension compared to the Northern Graben (12-16 Ma, 2-3 km) are consistent with the interpretation of clockwise rotation and southward migration of the Hikurangi subduction margin since the Middle Miocene (King \& Thrasher, 1992; Wallace et al., 2004; Giba et al., 2010).

Between 3-1.5 Ma about $80 \%$ of the extensional strain is accommodated by slip on the Cape Egmont Fault ( $1.5 \mathrm{~km}$ of dip-slip displacement). Smaller faults increased in importance and have taken up about $30 \%$ of the strain since the Pliocene. The focussing of strain on a single fault (Cape Egmont Fault) appears to be a local phenomenon in this part of Taranaki Basin, since studies in the onshore Taranaki peninsula and the Northern Graben have shown more uniform distribution of extension across the eastern basin (Stagpoole, 1998; Mouslopoulou et al., 2009; Giba et al., 2010). A possible explanation for the importance of this fault during back-arc development could be given by the relative weakness of this zone compared to adjacent areas due to repeated previous structural activity. However, this does not provide an explanation for why this fault was favoured over large adjacent structures with similar displacement histories (e.g., Maiana Fault). A possible reason could be the more north-easterly strike of the fault, which is more parallel to the strike of the Northern Graben, and may have represented a preferred orientation with respect to the paleo-stress field. The increasing percentage of displacement accommodated on smaller faults suggests a widening of the backarc zone during the Late Pliocene and Pleistocene (Figure 3.9). The widening of this zone may be attributed to changing stress orientations during clockwise vertical axis rotation of the Hikurangi Trench and the North Island (Wallace et al., 2004). However, more detailed horizon mapping is needed to precisely date the development of smaller faults in this area.

Uplift of the eastern basin commenced significantly after $3 \mathrm{Ma}$ and possibly as late as 1.6 Ma, which is somewhat later than interpretations in northern Taranaki Basin of about 5 
Ma (Stagpoole, 1998). While the reconstructed $800 \mathrm{~m}$ of missing strata (Figure 3.8) is slightly lower than Stagpoole's (1998) estimates of 1-1.5 km, values agree well with inferred reconstructions of Pliocene rock uplift in the North Island (Pulford \& Stern, $2004)$ to within the limits of uncertainty $(\sim \pm 250 \mathrm{~m})$. Furthermore, the general eastward increase in exhumation is also consistent with concentric uplift of the North Island inferred by Pulford and Stern (1994). Possible causes of this uplift are related to replacement of lithosphere with less dense asthenospheric material due to slab roll-back or gravitational removal of the mantle lid as proposed by Stern et al. (2006).

\subsubsection{Implications for the petroleum system}

The burial history of strata in the eastern part of the basin suggests that Cretaceous source rocks were buried deep enough to expel hydrocarbons prior to the Early Miocene (19 Ma) and probably as early as the Eocene (Figure 3.10 and Figure 3.11). Early charge of adjacent structures such as the Kupe and Kapuni fields (offshore and onshore Manaia anticline) might have occurred during the Middle Miocene (14-11 Ma), but hydrocarbons have likely been re-distributed during Late Miocene deformation. The redistribution and charge from Paleocene source rocks is consistent with biomarker analysis of hydrocarbon produced from these fields (Sykes et al., 2010).

The reconstruction of Cretaceous strata (Figure 3.11) suggests that lateral charge of the Maui accumulation across the Cape Egmont Fault (Thrasher, 1990a) is generally feasible from the Late Miocene to the onset of extensional movement in the Pliocene. However, due to the high fault throw and shale gouge ratios (Funnell et al., 2004), charge would have had to occur through non-sealing fault relay structures.

In addition to charge of local structures, compression during thrust sheet loading might have enhanced fluid migration away from the deformation front and provided an early charge for structures further west (i.e., the Western Platform). Long distance fluid migration has been suggested as a model for charge of hydrocarbon accumulations in foreland basin settings of the USA, where fluid migration over hundreds of kilometres is expected to be driven by hydraulic pressure gradients imposed by orogenic loads (Oliver, 1986). While models of hydrocarbon generation and fluid flow indicate relatively late maturity (Late Miocene-Pliocene) on the Western Platform (McAlpine, 2000), hydrocarbons expelled earlier in the east during compression might have migrated a 
significant distance westward and could have been trapped by drape structures or the long-wavelength forebulge (Figure 3.6, Figure 3.12). However, the lack of hydrocarbon accumulations in the Tane-1 (Shell BP Todd Oil Services Ltd., 1976) or adjacent Hoki-1 (AWE New Zealand, 2010) wells suggest that if such long-distance migration occurred, it was diverted towards the north or south past the associated structures.

Whilst being a regional feature, the forebulge created on the Western Platform during convergence (Figure 3.6) is likely to have impacted the migration and entrapment of hydrocarbons. Initially representing a continuous structure west of the Cape Egmont Fault, the development of the discrete Maui structure in the Late Miocene disrupted the broad dome and separated the eastern part (Maui High) from areas further west. At the latitude of the Tui field further west (Tui-1 well, Figure 3.1), Matthews (2002) suggested that separation of the Tui and Maui structures was related to Pliocene uplift of the Maui area. Besides small amounts of footwall movement during Pliocene normal displacement of the Cape Egmont Fault, no significant uplift of the Maui area is observed in this study. Instead sediment loading by the Giant Foresets Formation (N70-Seabed) is considered the major driver of Pliocene modification of Western Platform structure (Figure 3.12). If hydrocarbon accumulations were present on the Western Platform before deposition of the Giant Foresets Formation, subsequent depression and reconfiguration of structural gradients through sediment loading could have led to re-dispersal of hydrocarbons into adjacent structures.

\subsection{SUMMARY AND CONCLUSIONS}

This chapter has provided the first fully quantitative structural restoration across the central structural grain of the Taranaki Basin from the proximal shelf to deep water. The Cretaceous to Recent stratigraphic column is mostly preserved and only $<3 \%$ of strata is estimated to have been eroded. Due to this complete sedimentary record of varied tectonism, the structural cross section provides a window into the tectonic and sedimentary evolution of this basin that is similar to the tectonic development of other New Zealand basins in which seismic and well data are sparse.

The cross-section shows the characteristics and spatial distribution of extensional basin formation associated with Gondwana break-up and Tasman Sea spreading, which are observed as two distinct events. Late Cretaceous to Paleocene fault displacements 
resulted in $<5-8 \%$ of regional horizontal extension across the present-day shelf. The amount of stretching in the NCT was likely higher, but could not be tightly constrained due to the sub-parallel strike of the cross-section with respect to the rift structure. Rifting in the NCT ceased before $85 \mathrm{Ma}$ and pre-Rakopi Formation sediment may be preserved in the proximal Manaia Graben.

The convergent overprint of the basin and the extent of Neogene convergent margin are clearly shown and provide insight into the effects of Australia-Pacific plate boundary deformation. Convergence during the Oligocene and Miocene resulted in about $17 \%$ of horizontal shortening across the Eastern Mobile Belt. About 75\% of this deformation was accommodated by slip on the basin-bounding Taranaki Fault, while the shortening within Taranaki Basin was minor ( $\sim 4 \%)$. The total amount of horizontal shortening recorded in Taranaki Basin is less than $3 \%$ of the total estimated Australia-Pacific plate convergence, suggesting that most displacement was accommodated by slip on the subduction thrust ( $>90 \%)$ and deformation in the overriding Australian plate east of the basin (i.e., Wanganui Basin and southern North Island).

Late Miocene to Pliocene formation of the Toru Trough and the western Wanganui Basin occurred without significant faulting in the upper crust. The long-wavelength signal $(100-200 \mathrm{~km})$ and rapid tectonic subsidence suggest the importance of subduction-, or mantle-related lithospheric processes in the formation of these basins. Since about $3 \mathrm{Ma}$ horizontal extension of about 1-1.6 km indicates the development of a young backarc basin, most of which was accommodated by slip on the Cape Egmont Fault.

Structural restoration and sediment decompaction highlight the importance of tectonic and sedimentary loading in reconfiguring hydrocarbon kitchens and migration pathways. Foreland basin tectonism may have caused the focusing of fluid migration on the Western Platform during the Miocene, while flexural bending due to the Giant Foresets sedimentary load may have led to a redistribution of accumulated hydrocarbons.

The restored deformation history and relative shortening estimates corroborate previous studies, but improve constraints on timing and magnitude and general character of tectonism and sediment deposition. These constraints provide further information critical to the assessment of petroleum charge in the basin or development of tectonic models for Taranaki Basin or the wider New Zealand area. 


\section{CHAPTER 4 CRETACEOUS TO EOCENE SEISMIC FACIES AND PALEOGEOGRAPHIC DEVELOPMENT: FROM TWO RIFTS TO A PASSIVE MARGIN}

\subsection{INTRODUCTION}

The Cretaceous to Eocene period encompasses the early stages of an independent New Zealand micro-continent and pervasive regression from active rift systems to passive margin development (King, 2000a; Laird \& Bradshaw, 2004). Sedimentary strata deposited during this phase of basin evolution contain the primary petroleum coaly source- and sandy reservoir rocks of Taranaki Basin (Ministry of Economic Development New Zealand, 2010). Despite the economic importance of these sediments, the regional facies and paleogeographic development during this interval is mostly constrained from lithofacies analysis and biostratigraphy of the relatively sparse distribution of outcrops and boreholes in the basin (Figure 4.1)(e.g., Robinson \& King, 1988; Wizevich et al., 1992; King \& Thrasher, 1996; Flores et al., 1998). Apart from a few regional studies (Shell Oil Company, 1987; Thrasher, 1990c; 1991a; Palmer \& Andrews, 1993; Matthews et al., 1998), previous investigations of seismic facies were focused on relatively small petroleum permit areas (e.g., Gresko et al., 1992; Voggenreiter, 1992; Bryant et al., 1994).

This chapter aims to improve the regional understanding of the Late Cretaceous to Eocene depositional and structural basin development by integrating seismic data sets across the greater Taranaki Basin. Seismic facies patterns are imaged and investigated via seismic attribute maps from 2D and 3D data with the aim to constrain the sedimentary development and delineate facies belts of rift and passive margin sequences. The sedimentary record of ten exploration boreholes is back-stripped to reconstruct the basin's subsidence history and constrain the variability of deformation across the basin. Seismic facies and subsidence information are combined to reconstruct the paleogeographic basin evolution at incremental time intervals. The study provides insights into the character of depositional systems that developed after New Zealand's break-up from Gondwana and demarcates the distribution of petroleum source rock and reservoir facies across the proximal and present-day deep-water basin. 


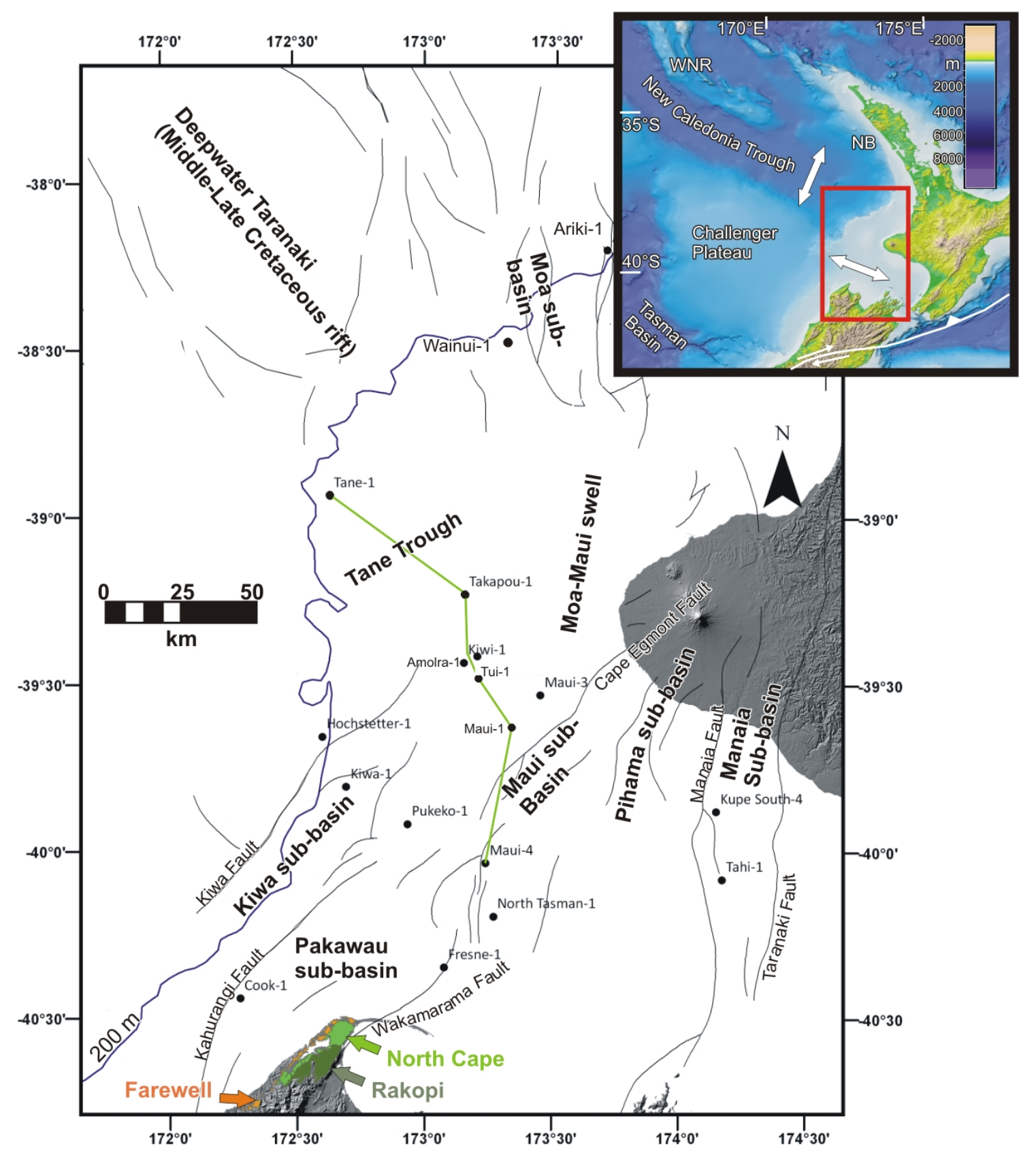

Figure 4.1 Map of Taranaki Basin showing Cretaceous structural elements and sub-basins (after Thrasher \& Cahill, 1990; Uruski et al., 2002b). Normal faults are shown as black lines at top Cretacteous level and major faults are annotated. Selected wells used in this chapter are shown as black dots and location of well panel in Figure 4.9 is shown as green line. The $200 \mathrm{~m}$ bathymetry contour is shown by the blue line to outline the approximate extent of the presentday shelf. Locations of Late Cretaceous to Paleocene outcrops on the northern South Island (NW Nelson) are shown in green and orange (Rattenbury et al., 1998a). The inset shows a physiographic overview map of the greater study area (see scale for water depth and topography). Generalized Cretaceous extensional directions in the proximal (present-day shelf) and distal basin (deep water) are shown as white arrows. 


\subsection{GEOLOGIC BACKGROUND}

\subsubsection{Structure}

Late Cretaceous extension related to the break-up of the Gondwana continent and opening of the Tasman Sea (Gaina et al., 1998; Laird \& Bradshaw, 2004) has led to the development of a horst and graben landscape in the greater Taranaki Basin (Thrasher, 1990c; Palmer \& Andrews, 1993; King \& Thrasher, 1996; Uruski et al., 2002a). Thrasher and Cahill (1990) have mapped a series of asymmetric, north-south to northeastsouthwest-oriented sub-basins in the proximal basin, which are dissected by basement highs such as the northward-trending Moa-Maui swell (Figure 4.1, Figure 4.2). The Cretaceous structure in the distal Taranaki Basin, on the other hand, is marked by fairly symmetrical, northwest-southeast-oriented rift systems (Uruski \& Wood, 1991; Uruski et $a l ., 2002 \mathrm{~b}$ ), the orientation of which is roughly outlined by the present-day bathymetry of the southern New Caledonia Trough (Figure 4.1, inset). Earlier studies have inferred that rifting occurred contemporaneously in the proximal and distal basin (Thrasher, 1990c).

More recent mapping has shown that rifting in the New Caledonia Trough (NCT) ceased before 85 Ma (Uruski et al., 2002a; Collot et al., 2009), significantly earlier than in the proximal basin, where extensional faulting continued until the Paleocene (King \& Thrasher, 1996). Cessation of faulting in the proximal basin coincides with the late stages of Tasman Sea spreading (Gaina et al., 1998) and Taranaki Basin developed into a passive margin marked by regional subsidence (King \& Thrasher, 1996). Based on facies trends in well data, the basin was interpreted to have developed into a northwest-facing marine embayment abutting the NCT (Leask, 1980; King \& Thrasher, 1996), while the remaining emergent landmasses were deeply weathered and peneplaned (King \& Thrasher, 1996). During the Paleocene and Eocene, general northward tilting of the proximal Taranaki has been inferred from the sedimentary facies distribution (King \& Thrasher, 1996), the cause of which has hitherto not been further investigated. 

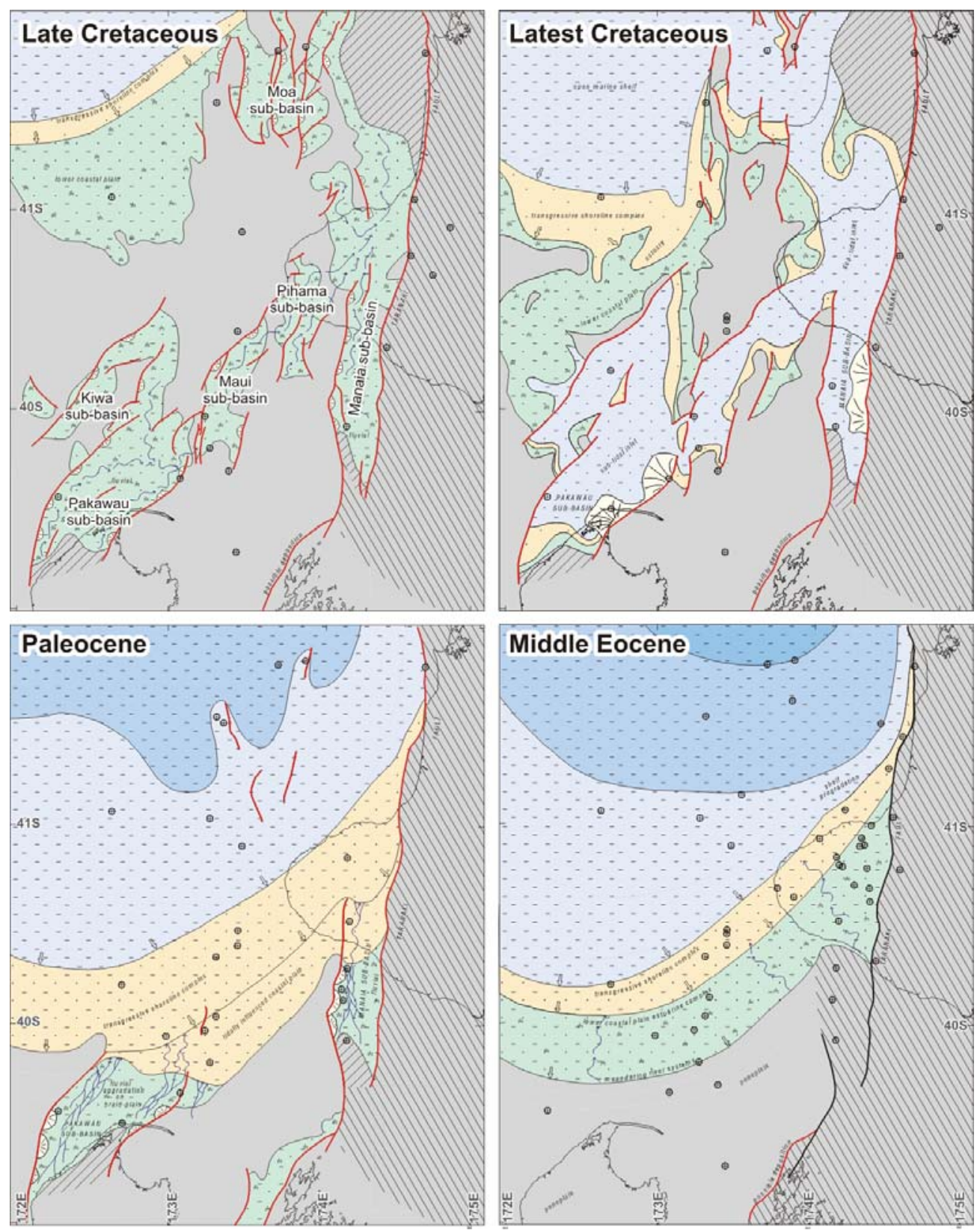

Figure 4.2 Late Cretaceous to Middle Eocene paleogeography maps compiled from well and seismic data by King and Thrasher (1996). See Figure 4.3 for lithology and environmental colour codes. Note that the Cretaceous paleogeography in the offshore area is largely based on seismic structure and facies mapping on paper sections (Thrasher, 1990c; 1991a; Thrasher, 1992), while Paleogene maps are derived mostly from borehole data.

\subsubsection{Stratigraphy}

Outcrop geology and petroleum exploration borehole data suggests that first widespread sediment deposition in proximal Taranaki Basin occurred during the Late Cretaceous (Thrasher, 1990c; Thrasher, 1990b). Early Late Cretaceous sedimentary strata of the Taniwha Formation have been locally encountered in north-eastern proximal Taranaki Basin (Shell BP Todd Oil Services Ltd., 1986) and seismic mapping and exploration drilling suggests that older deposits (Jurassic to early Late Cretaceous) may be 
widespread in the NCT and Deepwater Taranaki Basin (Milne \& Quick, 1999; Uruski \& Stagpoole, 2004; Collot et al., 2009). Due to the lack of borehole constraints on these earlier facies and their restricted distribution, the analysis is here limited to strata of the Late Cretaceous to Eocene Pakawau and Kapuni groups (King \& Thrasher, 1996). These strata record the general change from dominantly terrestrial to marine deposition and reflect the gradual foundering of New Zealand after break-up from Gondwana (Figure 4.3).

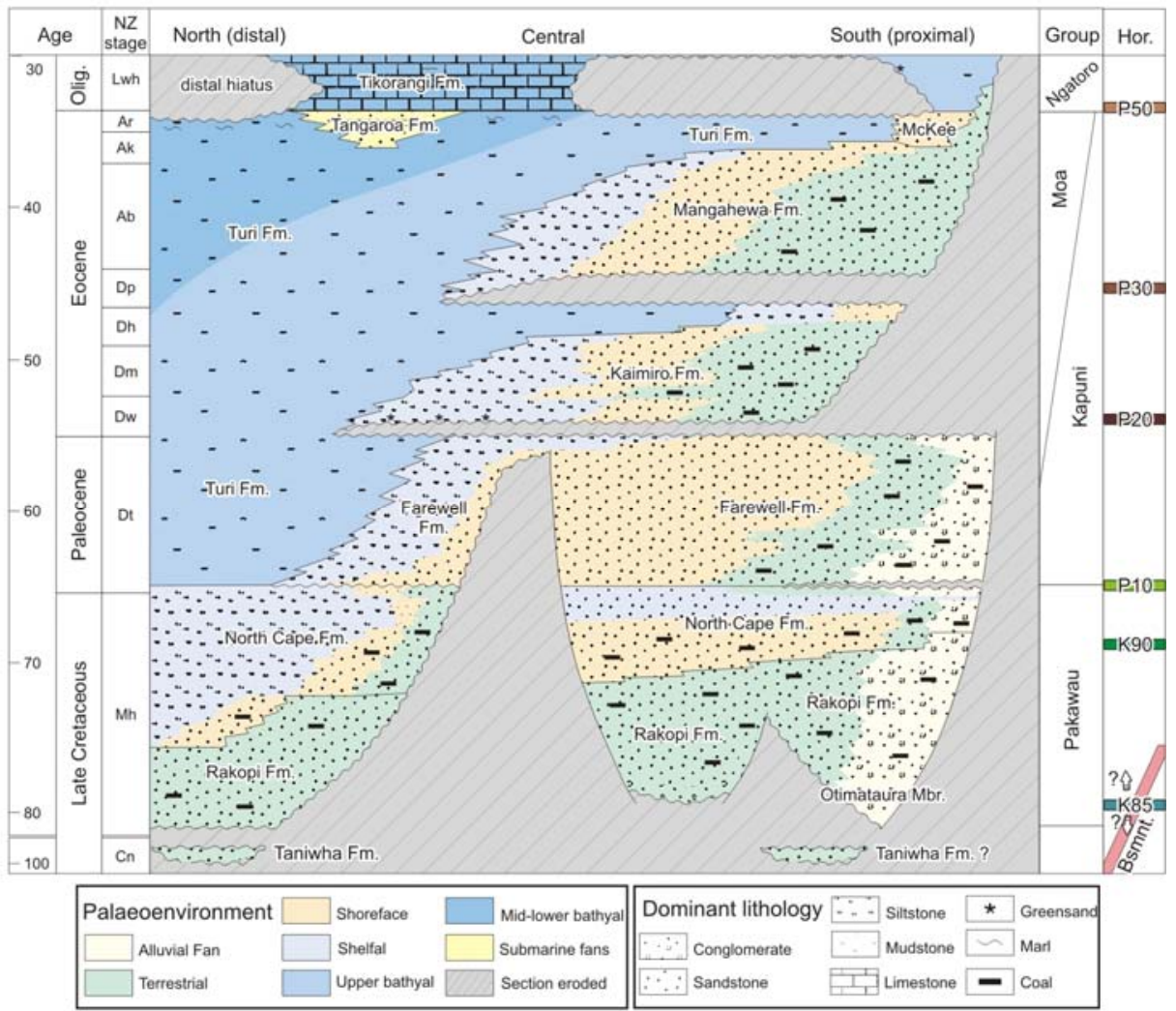

Figure 4.3 Chrono- and lithostratigraphic framework of Late Cretaceous to Oligocene Taranaki Basin strata under the present-day shelf after King and Thrasher (1996). Absolute age, international epochs and New Zealand stage abbreviations are shown on the left, lithologic group names and approximate stratigraphic age association of seismic horizons from this study are shown on the right.

\section{Pakawau Group}

The Late Cretaceous Pakawau Group has its name from outcrop type areas of Northwest Nelson (the Pakawau sub-basin, Figure 4.1) and has been grouped into the Late Cretaceous Rakopi Formation and latest Cretaceous North Cape Formation (Thrasher, 1991a; Thrasher, 1992). Coaly lithofacies of the Pakawau Group are considered the primary petroleum source rock in Taranaki Basin, whereas sandy members of this group are gaining increasing attention as potential reservoirs (Higgs et al., 2010), and have been the target of recent exploration efforts on the Western Platform (e.g., Matthews, 2008). 
Due to the limited outcrop area on the northern South Island (Figure 4.1), the understanding of the regional character and subsurface distribution of the Pakawau group was significantly influenced by seismic mapping conducted during the late 1980's to early 1990's (Shell Oil Company, 1987; Thrasher, 1990c; Thrasher, 1990b; Thrasher \& Cahill, 1990; Thrasher, 1992). While the Pakawau Group has long been considered as entirely non-marine (e.g., Titheridge, 1977; Pilaar \& Wakefield, 1978; Knox, 1982), it was expanded to include marginal marine facies of the North Cape Formation based on outcrop, borehole, and seismic facies character (Thrasher, 1991a; Wizevich et al., 1992). The Rakopi and North Cape formations are Campanian-Maastrichtian (83-65 Ma, Haumurian, Mh) in age, but their exact age differences are not easily distinguished from biostratigraphic dating.

The Rakopi Formation (Figure 4.3) was defined by Thrasher (1991a) as the first formation with widespread distribution in the basin and generally rests unconformably on Paleozoic meta-sedimentary or Cretaceous plutonic basement rocks. Within contemporaneous extensional graben systems in proximal Taranaki, the formation shows thicknesses of up to $1.5 \mathrm{~km}$ (Thrasher, 1990c). Besides the local occurrence of alluvial fan/braided river successions of the Otimataura conglomerate Member (Wizevich, 1994), the formation has been defined primarily as interbedded sandstone, carbonaceous siltstone and thin coal seams deposited in a series of coastal/fluvial floodplains and swamps (Thrasher, 1991a; King \& Thrasher, 1996). Lithofacies indicate a prevalence of terrestrial and lacustrine depositional environments (Figure 4.2), but episodical marine influence has been suggested based on the presence of dinoflagelates, glauconite, and elevated coal seam sulphur (Browne et al., 2008). The formation has been intersected by seven exploration wells in the basin, five of which are considered in this chapter (Cook1, Fresne-1, Maui-4, Tahi-1, and Tane-1, Figure 4.1).

The North Cape Formation has been penetrated by about twenty exploration wells and predominantly consists of shallow marine siltstones and coastal sandstones and silty sandstones (King \& Thrasher, 1996; Higgs et al., 2010). Several coal measures and conglomerate sequences have been locally encountered within the lower and upper formation and have been assigned to the older Wainui Member, and upper Puponga and Fresne members, respectively (Titheridge, 1977; Thrasher, 1992; Wizevich et al., 1992). These combined lithofacies of the North Cape Formation have been interpreted as being deposited in shallow marine, paralic, and localized terrestrial settings formed during a 
major southward transgression at the end of the Cretaceous (Figure 4.2). While the North Cape Formation is thought to be dominantly marine in the distal basin (Thrasher, 1990b; King \& Thrasher, 1996), local seismic facies mapping studies have suggested the presence of a number of estuarine systems and wide distribution of a coaly coastal plain within the formation (McAlpine, 1999).

\section{Kapuni and Moa groups}

The Kapuni Group encompasses Paleocene to Eocene terrestrial to marginal marine facies, while the Moa Group represents entirely marine time-equivalent sequences of mostly Eocene age (King \& Thrasher, 1996). In addition to the first-order marine transgressive character of the Kapuni Group, multiple higher-order base-level fluctuations have been inferred from internal facies variations in the various type localities (Pocknall \& Beggs, 1990; Schmidt \& Robinson, 1990; Beggs \& Pocknall, 1992; King \& Thrasher, 1996). This group is further subdivided into the Paleocene Farewell Formation, the Early to Middle Eocene Kaimiro Formation, Middle to Late Eocene Mangahewa Formation and the Late Eocene McKee Formation (Figure 4.3). Terrestrial to shallow marine sediments of this group represent the primary reservoir units in the basin (Ministry of Economic Development New Zealand, 2010) and recent petroleum biomarker analysis has indicated that virtually all hydrocarbon accumulations in the eastern basin are sourced from coals of this group (Sykes et al., 2010).

The Paleocene Farewell Formation (Figure 4.3) has been defined from the type section in the southern basin area of northwest Nelson (Figure 4.1) where it is dominated by coarse sandstones and conglomerates with fine sandstone to silt interbeds of Teurian (Dt) to Waipawan (Dw) age (Paleocene to earliest Eocene). In the Manaia sub-basin (Figure 4.1), the Farewell Formation consists of an up to $1.7 \mathrm{~km}$ thick sequence of fluvial and alluvial facies with coarse- to medium-grained sandstones and mud interbeds. (Schmidt \& Robinson, 1990). A series of 150-250 $\mathrm{m}$ thick, fining- and thinning-upward depositional packages in this formation have been interpreted as individual transgressive cycles in a dominantly regressive sequence (Schmidt \& Robinson, 1990). Marine time equivalents of the Farewell Formation in the central part of the basin consist of shoreface and shallow marine sandstones and shales. Shoreface facies have been broadly referred to as ' $\mathrm{F}$ '-sands in the literature, but stacked sand sequences encountered by recently drilled wells have been further differentiated, into older (' $\mathrm{G}$ '- or ' $\mathrm{F} 1$ '-sands) and younger 
members ('F'- or 'F0'-sands) in respective petroleum license areas (e.g., Pollock \& Crouch, 2005). Fine-grained members have been commonly grouped into the Turi Formation, or specifically named where they sub-divide sand sequences (e.g., 'E'-shale), while silty facies in the western parts of the basin which have been referred to as Tane Member.

Eocene strata are divided into several formations based on age, lithology, and environmental association. Similar to the Paleocene sequences, the geographic distribution of terrestrial to marine lithofacies varies in a southeast to northwest direction, with terrestrial lithofacies in the southeast and more marine lithofacies in the central and north-western basin, respectively (King \& Robinson, 1988; King \& Thrasher, 1996). The predominantly non-marine members of the Kaimiro and Mangahewa formations consist of coal, carbonaceous shale, shale, and fine- to coarse-grained siltstone and sand, which have been interpreted to be deposited in low-energy swamp, fluvial, and lacustrine environments. Marginal marine members of the Kaimiro Formation include stacked fining-upward cycles of sands and mud and have been interpreted as estuarine channel fill, lagoon, or tidal flat deposits (Flores, 1993). The marine members of the Kaimiro, Mangahewa, and McKee formations consist of shelf to lower shoreface mudstones with thin beds of glauconitic sandstone and inner shelf coarse-grained sandstone. The Early and Middle Eocene shoreface facies are commonly referred to as 'D'-sands and 'C'sands, respectively (e.g., Bryant et al., 1994; Bryant et al., 1995; Matthews et al., 1998), and form the main reservoir unit of the Maui gas and condensate fields. The Late Eocene to Early Oligocene Tangaroa Formation comprises a sequence of fine- to coarse-grained sandstones deposited between bathyal muds of the Turi Formation. Based on facies composition, fan lobe geometry, and internal channeling, the formation has been interpreted as a progradational wedge of slope to basin floor fans (Gresko et al., 1992). The top of the Eocene sequence is marked by a regional unconformity or disconformity (e.g., King \& Thrasher, 1996; Cooper et al., 2001) that might be related to the Marshall paraconformity found elsewhere in the country (Carter, 1985).

The regional paleogeographic development of the Kapuni Group (Figure 4.2) has been largely inferred from the analysis of sparse outcrop and exploration borehole data (Titheridge, 1977; King \& Robinson, 1988; Titheridge, 1992; Leask, 1993; Palmer \& Andrews, 1993; King \& Thrasher, 1996). Local investigations of seismic data in the basin focused on the depositional development along the Manaia sub-basin (Schmidt and 
Robinson, 1990), and provided the first detailed (3D) images of northwest-trending channel systems of Eocene age (Voggenreiter, 1992). Other studies showed the development of estuarine systems and NE-SW-trending shoreline systems from the Maui 3D data set (Bryant et al., 1994) and Eocene turbidite characteristics in the northwestern basin (Gresko et al., 1992). The first regional mapping effort of seismic facies on their quantitative attributes showed a broad Eocene northeast-southwest shoreface trend of the Kapuni 'D'- and 'C'-sand intervals (Matthews et al., 1998), which has previously been inferred from borehole lithofacies (Figure 4.2). These systems were imaged on amplitude maps based on acoustic impedance differences between generally bland shelfal facies (Turi Formation), medium- to high-amplitude shoreface facies ('C'-and 'D'sands), and high-amplitude coastal plain facies (terrestrial Mangahewa and Kaimiro formations).

\subsection{BOREHOLES, SEISMIC DATA, AND SEISMIC HORIZON INTERPRETATIONS}

This chapter uses wireline logs, mudlogs and biostratigraphic data from the 27 wells that penetrate the Cretaceous to Eocene stratigraphic section to guide the interpretation of seismic facies and constrain the subsidence history of the basin (Table 4.1). Thirteen of these wells penetrated the latest Cretaceous North Cape Formation and five penetrated the Late Cretaceous Rakopi Formation. While not encountering a Cretaceous section, the well Waka Nui-1 (Figure 4.4) penetrated coal measures and meta-sediments of Jurassic age (Milne \& Quick, 1999; Uruski \& Stagpoole, 2004).

While using an extensive array of 2D and 3D seismic data (see Chapter 2), a subset of characteristic seismic lines from this data set are shown in the following discussion to depict the Cretaceous to Eocene seismic facies character and stratigraphy (Figure 4.4). Interpretations of five seismic horizons (Figure 4.3) across the south-eastern, central and present-day deep-water basin are used here and Figure 4.5 shows the regional isochron thicknesses calculated between these horizons. In order to facilitate imaging of Eocene shoreface systems, the P50 horizon has been mapped on the Western Platform and used as a reference horizon for amplitude extractions. Reflectors demarcating the top Kaimiro Formation ('D'-sand, P30) and top Mangahewa Formation ('C'-sand, P40) have been interpreted in the area of the Maui 3D survey to allow detailed interpretation of the Eocene sequence. The basement horizon defines the base of the Late Cretaceous Rakopi Formation in most of the proximal basin, but is likely the base of older Mesozoic strata 
(>85 Ma) in the Manaia Graben and Deepwater Taranaki Basin. The details relating to the borehole, seismic, and horizon data sets are explained in Chapter 2 of this thesis.

Table 4.1 Wells penetrating to Cretaceous to Eocene strata that were used for log analysis and seismic correlation in this chapter. The columns show well name, location in New Zealand easting and northing in metric coordinates (meters), height of kelly bushing above mean sea level (in meters), spudding date, total measured depth (true vertical depth in meters below mean sea level), petroleum report (PR) number and operating company. Abbreviations of company names correspond to New Zealand (NZ), NZ Overseas Petroleum (NZOP), Shell Todd Oil Services (STOS, including BP in wells before 1995), NZ Aquitaine Petroleum (NZAP), Tricentrol Exploration Overseas LTD (TCPL), National Petroleum (NP), Petrocorp NZ (PCNZ), Conoco (UK) Ltd. (CON).

\begin{tabular}{|l|r|r|r|r|c|c|c|}
\hline \multicolumn{1}{|c|}{ Well } & \multicolumn{1}{|c|}{ Long } & \multicolumn{1}{c|}{ Lat } & \multicolumn{1}{|c|}{ KB } & TD (MD) & Spud date & PR Number & Company \\
\hline Amokura-1 & 2527913.8 & 6198527.51 & 25 & 3995 & $23 / 03 / 2004$ & 2920 & NZOP \\
Ariki-1 & 2571264.14 & 6333607.74 & 19.8 & 4831 & $12 / 09 / 1983$ & 1038 & STOS \\
Cook-1 & 2448974.88 & 6084752.35 & 34.14 & 8821 & $8 / 10 / 1970$ & 513 & NZAP \\
Fresne-1 & 2516730 & 6095021 & 9 & 2504 & $14 / 01 / 1976$ & 674 & NZAP \\
Hochstetter-1 & 2476240.8 & 6171779.17 & 22 & 3274 & $2 / 09 / 2000$ & 2524 & NZOG \\
Kea-1 & 2539036.87 & 6148015.83 & 22 & 3138 & $15 / 12 / 1984$ & 1089 & TCPL \\
Kiwa-1 & 2484171 & 6155161 & 11.3 & 3859 & $28 / 04 / 1981$ & 880 & STOS \\
Kiwi-1 & 2523360.84 & 6196781.49 & 25 & 4238 & $22 / 08 / 2004$ & 2995 & NZOP \\
Kupe South-1 & 2605335.48 & 6149518.78 & 33 & 3503 & $30 / 10 / 1986$ & 1284 & NP \\
Kupe South-2 & 2604714.28 & 6151130.01 & 34 & 3250 & $4 / 07 / 1987$ & 1285 & TCPL \\
Kupe South-4 & 2607413.7 & 6146630.7 & 33.1 & 3806 & $14 / 01 / 1989$ & 1483 & TCPL \\
Kupe South-5 & 2608030.41 & 6142944.21 & 31.3 & 3200 & $20 / 09 / 1990$ & 1678 & TCPL \\
Kupe-1 & 2606506.4 & 6152695.4 & 9.4 & 3682 & $8 / 06 / 1975$ & 662 & STOS \\
Maui-1 & 2536619.7 & 6170695.9 & 7.3 & 3512 & $27 / 01 / 1969$ & 540 & STOS \\
Maui-2 & 2548629.64 & 6177085.43 & 34.1 & 3572 & $10 / 05 / 1969$ & 541 & STOS \\
Maui-3 & 2548843.38 & 6185565.89 & 34.1 & 3383 & $25 / 12 / 1969$ & 542 & STOS \\
Maui-4 & 2530568.62 & 6129714.52 & 34.1 & 3919 & $5 / 11 / 1970$ & 543 & STOS \\
North Tasman-1 & 2533188.43 & 6111919.03 & 31.5 & 2735 & $26 / 10 / 1978$ & 736 & NZAP \\
Pukeko-1 & 2504649.15 & 6142714.56 & 25 & 4190 & $28 / 04 / 2004$ & 2928 & NZOP \\
Tahi-1 & 2609297.13 & 6124051.85 & 26 & 1776 & $2 / 01 / 1984$ & 1030 & PCNZ \\
Takapou-1 & 2523841.56 & 6219014.68 & 25 & 4186 & $6 / 08 / 2004$ & 3032 & STOS \\
Tane-1 & 2478752.73 & 6251980.86 & 31.1 & 4532 & $10 / 09 / 1976$ & 698 & STOS \\
Te Whatu-2 & 2508922.12 & 6126612.15 & 27 & 3542 & $10 / 11 / 1987$ & 1345 & PCNZ \\
Toru-1 & 2609521 & 6164337 & 32.2 & 4151 & $17 / 07 / 1990$ & 1668 & TCPL \\
Tui-1 & 2531255.1 & 6196739.8 & 25 & 3889 & $24 / 01 / 2003$ & 2784 & NZOP \\
Wainui-1 & 2537047 & 6304629 & 11.7 & 3880 & $25 / 08 / 1981$ & 869 & STOS \\
Waka Nui-1 & 2508520.45 & 6521647.62 & 24 & 3666 & $30 / 04 / 1999$ & 2436 & CON \\
& & & & & & & \\
\hline
\end{tabular}




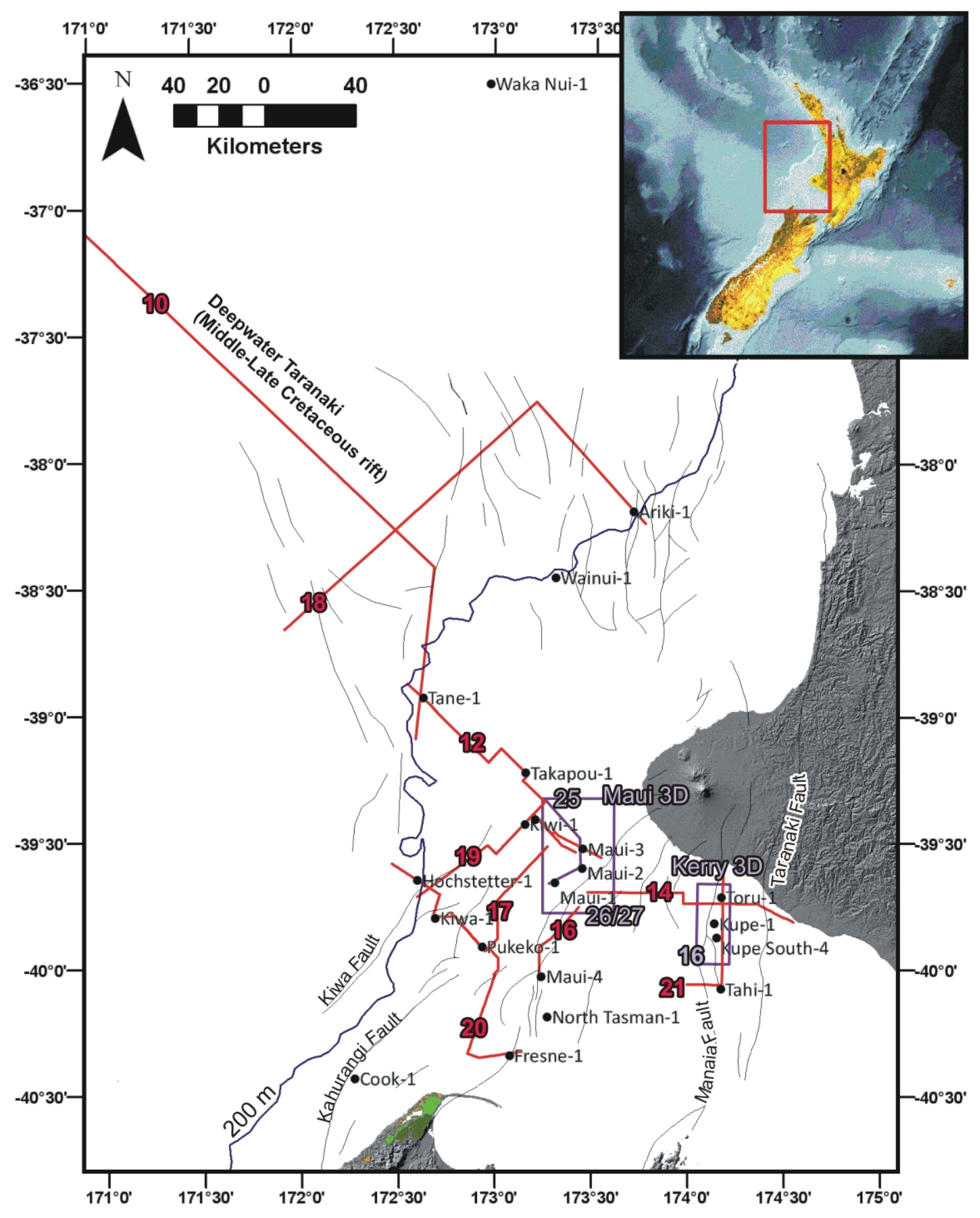

Figure 4.4 Basemap showing the location of seismic lines used to display the seismic facies development in this chapter. The locations of 2D seismic lines are shown in red, 3D survey outlines and profiles from 3D data are shown as purple polygons and lines, respectively. The numbers correspond to the respective figure numbers in this chapter. The locations of major Cretaceous to Paleocene Faults are shown as black lines (after Thrasher \& Cahill, 1990; Uruski et al., 2002b). Selected wells used in this chapter are shown as black dots and the $200 \mathrm{~m}$ bathymetry contour is shown as blue line show the approximate extent of the present-day shelf. 


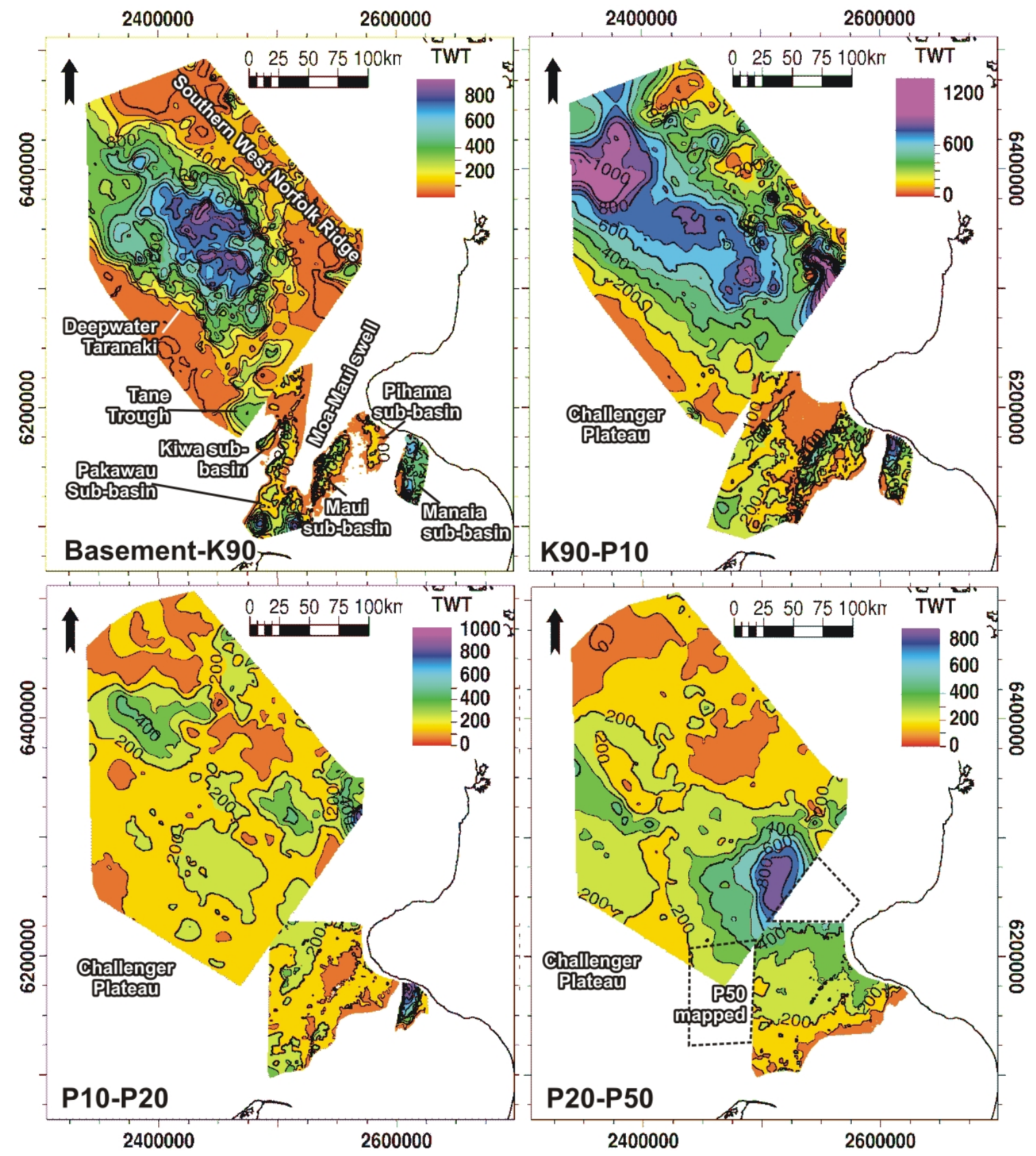

Figure 4.5 Regional isochron maps (in two-way-traveltime, TWT) calculated over Cretaceous to Eocene intervals discussed in this chapter. The north-western maps are based on seismic horizon interpretations of the Astrolabe survey (DTB01) in Deepwater Taranaki Basin (Uruski et al., 2002b), whereas the south-eastern maps are based on interpretations by the 4D Taranaki project. The names of Cretaceous sub-basins are annotated in the top left map. Note that this map includes pre-Late Cretaceous strata in the present-day deep-water area and, possibly, in the Manaia Graben (below K85). Note also the larger size and greater thickness of the Cretaceous graben in the present-day deepwater area compared to the relatively small grabens in the proximal basin. Areas where the P50 reflector was interpreted beyond the 4D Taranaki mapping region are outlined as black dashed polygons on the bottom right map. 


\subsection{TECTONIC SUBSIDENCE ANALYSIS}

\subsubsection{Subsidence calculation and uncertainties}

The stratigraphic record of ten wells that penetrate basement was back-stripped to reconstruct the Late Cretaceous to Eocene tectonic subsidence subsidence history. Age uncertainties are generally expected to be within $\pm 2-5$ million years, but may be somewhat higher for the Cretaceous interval $(\sim \pm 5 \mathrm{my})$, as there is no detailed biostratigraphic, intra-Late Cretaceous age distinction. While several surfaces of nondeposition are recognized from seismic data, estimated erosion during the CretaceousEocene time was relatively small $(<200 \mathrm{~m})$, and was not included in the calculation. In order to avoid bias due to age uncertainties and associated global eustatic sea-level estimates, no sea-level correction was applied. Global sea level is generally expected to have been higher than today during the investigated time range (80-34 Ma), but estimates vary amongst different authors. High estimates suggest a sea-level decrease from about $\sim 230 \mathrm{~m}$ in the Late Cretaceous to $\sim 170 \mathrm{~m}$ in the Late Eocene (Haq et al., 1987), whereas others suggest fairly constant values of $\sim 50 \mathrm{~m}$ above present-day sea level during the Cretaceous and Paleocene, with sea-level decreases to about $20 \mathrm{~m}$ by the Late Eocene (Miller et al., 2005). Assuming that the loading effect of water is $\sim 70 \%$ of the assumed water height (Allen \& Allen, 2005), the associated changes in tectonic subsidence would be $\sim 20-50 \mathrm{~m}$, which is within the limits of uncertainty of biostratigraphic paleobathymetry estimates (Hayward et al., 2010).

\subsubsection{Cretaceous to Eocene tectonic subsidence history}

Calculated tectonic subsidence curves (Figure 4.6) generally display an upward concave signature with more rapid Cretaceous subsidence followed by steadily declining subsidence into the Paleogene. This pattern is characteristic of rift and post-rift thermal subsidence in continental margin settings (e.g., McKenzie, 1978; Steckler \& Watts, 1978; Bott, 1979; Allen \& Allen, 2005; Xie \& Heller, 2009). Cumulative tectonic subsidence values observed by the Late Eocene (34 Ma) range between $0.8-2.1 \mathrm{~km}$ with a median value of $1.1 \mathrm{~km}$. Variations in Paleogene subsidence of $0.2-2.1 \mathrm{~km}$ (standard deviation = $0.6 \mathrm{~km})$ are somewhat higher than Cretaceous values that range between $0.1-1 \mathrm{~km}$ (standard deviation $=0.4 \mathrm{~km}$ ). The generally steepest subsidence signatures during the Late Cretaceous (80-75 Ma) suggests that most fault-related subsidence occurred during 
the Rakopi Formation interval (Basement-K90), which is in line the palinspastic restoration shown in Chapter 3.

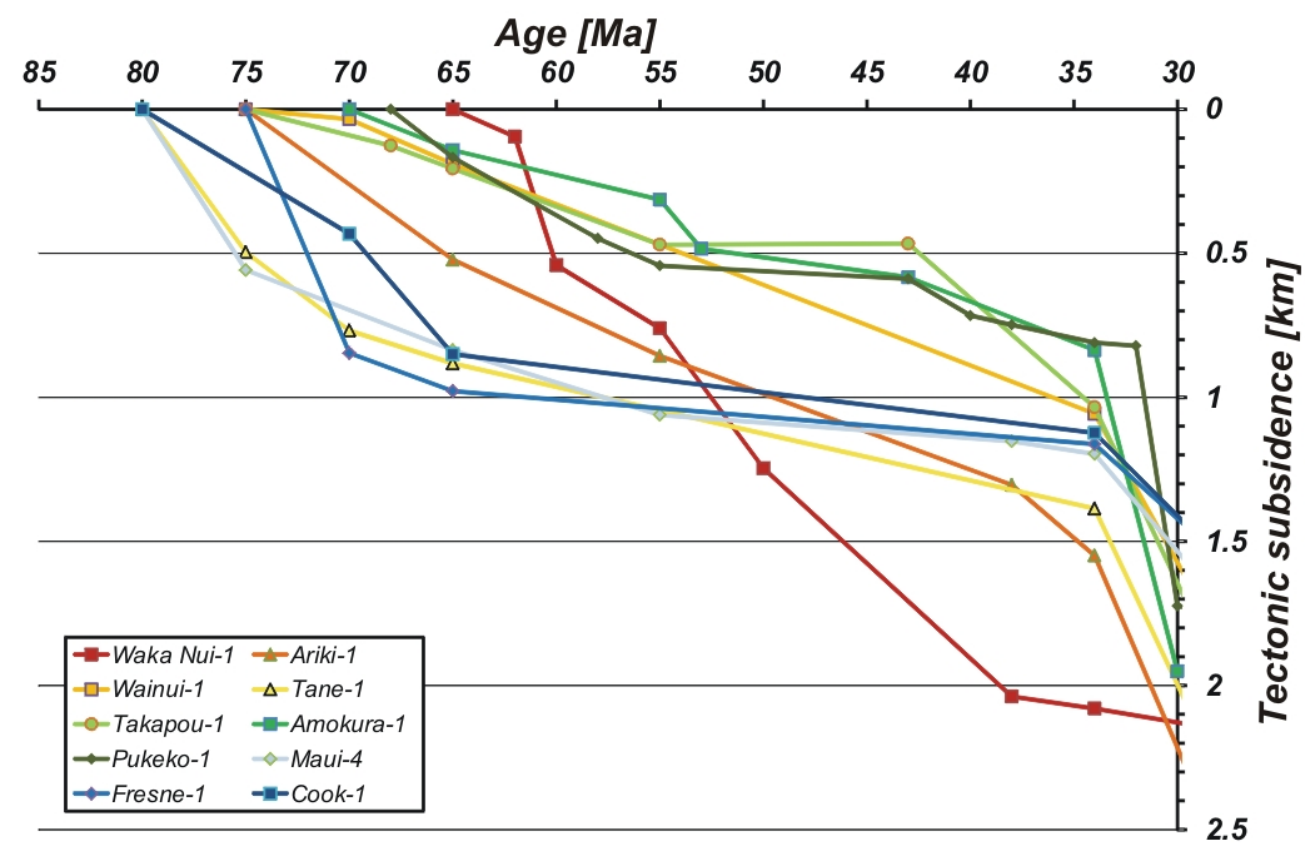

Figure 4.6 Back-stripped (tectonic) subsidence calculated for selected wells across the basin. Curves are colorcoded from red to green to blue from north to south, respectively. See Figure 4.1 and Figure 4.4 for well locations. Note the general upward concave Late Cretaceous to Paleogene subsidence signature characteristic for rift to passive margin sequences.

Variations in timing and character of individual parts of these curves suggest differences in basin development across the study area. These differences can be highlighted by grouping the wells into areas of the southern, central, and northern parts of the study area (Figure 4.7). Wells in the south show $0.9-1 \mathrm{~km}$ of tectonic subsidence between $85-65 \mathrm{Ma}$ and only little additional subsidence $(0.2-0.4 \mathrm{~km})$ until the Oligocene (34 Ma). Wells in the central part of the basin (Western Platform) did not penetrate the Late Cretaceous Rakopi Formation ( 80-75 Ma, Basement-K90) and show more gradually declining subsidence rates. By the Middle Eocene (43 Ma), only $0.4-0.5 \mathrm{~km}$ of tectonic subsidence is observed with small subsidence values during the Early Eocene. While the trend of decreasing subsidence rates continues to the Late Eocene in well Pukeko-1 and Amokoura-1, subsidence rates increase in the further northward located well Takapou-1. About $0.5 \mathrm{~km}$ additional subsidence are calculated for this well between 43 and $34 \mathrm{Ma}$ and the deviation from the exponentially declining curve may indicate renewed tectonic forcing (Figure 4.7). 
Highest variability in subsidence values is observed in the distal basin, which also encompasses the biggest area of the three geographic sub-divisions. Although the subsidence curves show a general upward-concave shape, well Ariki-1 and Wainui-1 lack the initially steep subsidence and subsequent values appear to decline less exponentially compared to southern areas, or almost at a constant rate during the Paleogene. However, only a few data points are available in the Paleogene, which may mask potential intermediate changes in subsidence due to mid-Cenozoic forcing. Total cumulative subsidence is somewhat higher than in the areas further south, with total Cretaceous-Eocene values of 1.1-1.6 km in the three southern wells and $2.1 \mathrm{~km}$ in the northern well (Waka Nui-1), respectively.

Figure 4.8 shows the general north-south trend of Cretaceous and Paleogene tectonic subsidence values (Figure 4.8). To allow comparison amongst the different well locations, subsidence that occurred before the latest Cretaceous $(75 \mathrm{Ma})$ is not included in this plot. Cretaceous subsidence values in excess of $0.5 \mathrm{~km}$ are limited to the southernmost area (wells Cook-1 and Fresne-1), while areas in the central and northern basin show constantly smaller values with a median of $0.2 \mathrm{~km}$. Paleogene values show an opposite trend, with values of less than $0.5 \mathrm{~km}$ south of well Pukeko-1 and increasing values to $1 \mathrm{~km}$ and $2 \mathrm{~km}$ in wells Ariki-1 and Waka Nui-1 respectively.

The higher latest Cretaceous subsidence values in the two southern wells may be due to later faulting in the area of the southern Pakawau sub-basin as suggested by King and Thrasher (1996). While some Paleocene fault activity is constrained from seismic data and palinspastic restoration in the southern basin (see Chapter 3), the generally lower subsidence gradients are suggestive of relative small amounts of fault-related subsidence and indicate that the Paleocene signals are dominated by post-rift thermal cooling. The apparent northward subsidence increase during the Paleogene may be a result of greater stretching and consequentially higher thermal subsidence (McKenzie, 1978) in the northern basin, and may be further influenced by Eocene tectonic forcing that is apparent in the central and northern basin. Whatever the geodynamic cause, the calculated trends represent the first quantitative documentation of basinal northward tilting, which has been qualitatively inferred from the distribution of sedimentary facies by previous authors (King \& Thrasher, 1996). 

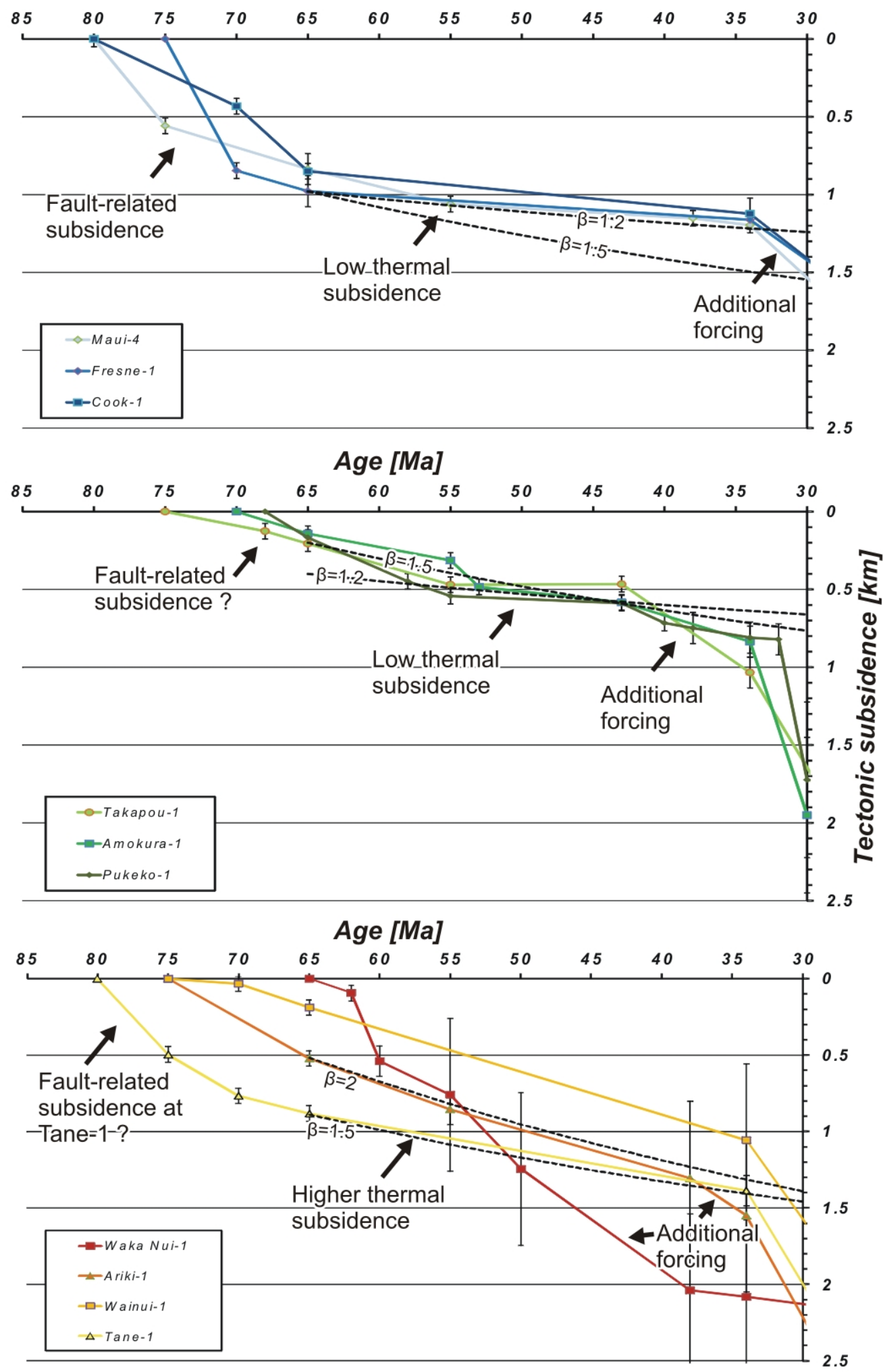

Figure 4.7 Back-stripped (tectonic) subsidence plots of selected wells shown separately for different regions within the basin. The panels show wells in the southern basin (top), on the Western Platform (centre), and on the periphery of the present-day deep-water part of the basin in the north (bottom). Error bars represent biostratigraphic paleobathymetry uncertainties (after Hayward and Wood, 1989, see Chapter 2). Theoretical curves for thermal subsidence assuming different stretching parameters, $\beta$ (black dashed lines), were calculated for an assumed lithosphere thickness of $125 \mathrm{~km}$ (after Steckler and Watts, 1980), whereby $\beta$ represents the fraction of crustal thickness before and after stretching. See Figure 4.1 and Figure 4.4 for well locations. 


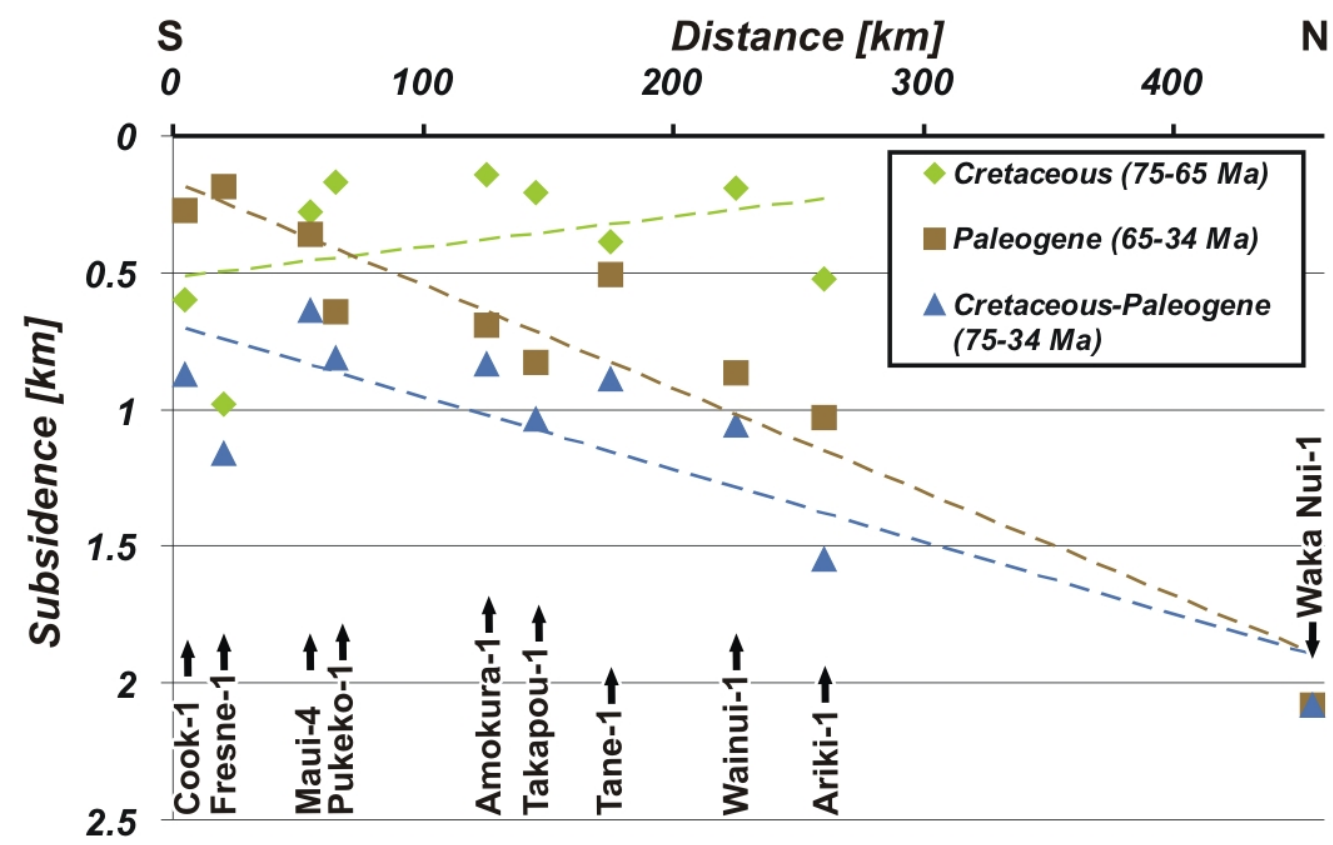

Figure 4.8 Back-stripped latest Cretaceous and Paleogene subsidence values of wells shown in Figure 4.6 and Figure 4.7 projected onto a NS transect to show variable character of tectonic subsidence across the basin. The dashed lines show the linear regression of respective subsidence values. Note the higher latest Cretaceous subsidence values of the two southern wells located in the Pakawau sub-basin and the overall northward subsidence increase, implying a northward tiliting of the basin during the Paleogene. Note also that there is no Cretaceous record for well Waka Nui-1. See Figure 4.1 and Figure 4.4 for well locations.

\subsection{SEISMIC STRATIGRAPHY AND FACIES INTERPRETATION}

\subsubsection{Well data interpretation and seismic facies characteristics}

Figure 4.9 shows characteristic features of Cretaceous to Eocene facies evidenced on well data from the Taranaki data set. The panel shows a SE-NW-oriented, proximal (Maui-4) to distal (Tane-1) paleoenvironmental trend that becomes more pronounced in the Paleogene. The predominant depositional paleoenvironment can be interpreted from the combined use of wireline logs, lithology, and biostratigraphic data. Facies with serrate, heterolithic wireline character, dominant or occasional coal content, and pollen and spore specimens are indicative of terrestrial, coastal or fluvial plain deposits. Mixed sand-silt lithologies, terrestrial and marine palynofacies and variable wireline character are interpreted to be deposited in an estuarine or paralic environment. Facies with a blockier wireline character, dominant sand lithology in mudlogs, and shallow marine microfauna are interpreted as shallow marine shoreface facies, while higher and relatively uniform gamma-ray signatures with dominantly fine-grained lithologies are interpreted to represent more marine, lower shoreface to shelfal deposits. In several 
wells, variable wireline signature and coarse-grained clastics are found with dominantly terrestrial palynofacies and are interpreted as fluvial and alluvial environments.

While a quantitative correlation between lithofacies and absolute seismic amplitude values is difficult due to the variability in seismic data quality, seismic processing parameters, and lithologic stacking patterns, general trends can be established that justify the interpretation of dominant lithofacies and/or depositional environment from the seismic record (Table 4.2). Terrestrial fluvial and coastal plain facies generally show elevated amplitude response, which can be attributed to the large impedance contrasts due to the superposition of coal, sand, and muddy lithologies. For example, the density contrast of coals with respect to mud or sand is about $6-8 \%$, whereas the contrast between sand-silt or sand-mud is only about 1-2\% for, respectively (Funnell et al., 1996). Sandy shoreface lithologies are often associated with semi-continuous, medium- to highamplitude responses, whereas more marine and finer-grained sequences show more continuous reflectors with generally bland (low amplitude) seismic character. Estuarine facies with frequent sand-silt interbeds show variable seismic character with semi- to discontinuous reflectors and low to medium amplitudes. Similar amplitude signature is observed for alluvial to fluvial facies, but these facies are characterized by generally lower reflector continuity, which is likely due to poor bedding of the coarse-grained alluvial facies. The top of the Turi Formation in the central and distal basin is marked by a continuous, high-amplitude response, which is attributed to superposition of Oligocene calcareous lithologies upon muddy lithologies of the Turi Formation (P50 horizon). Due to the significant overlap in correlation between seismic amplitude response and lithofacies, it is important to consider reflector geometries and lateral relationships with adjacent seismic facies in the paleo-environmental analysis. 


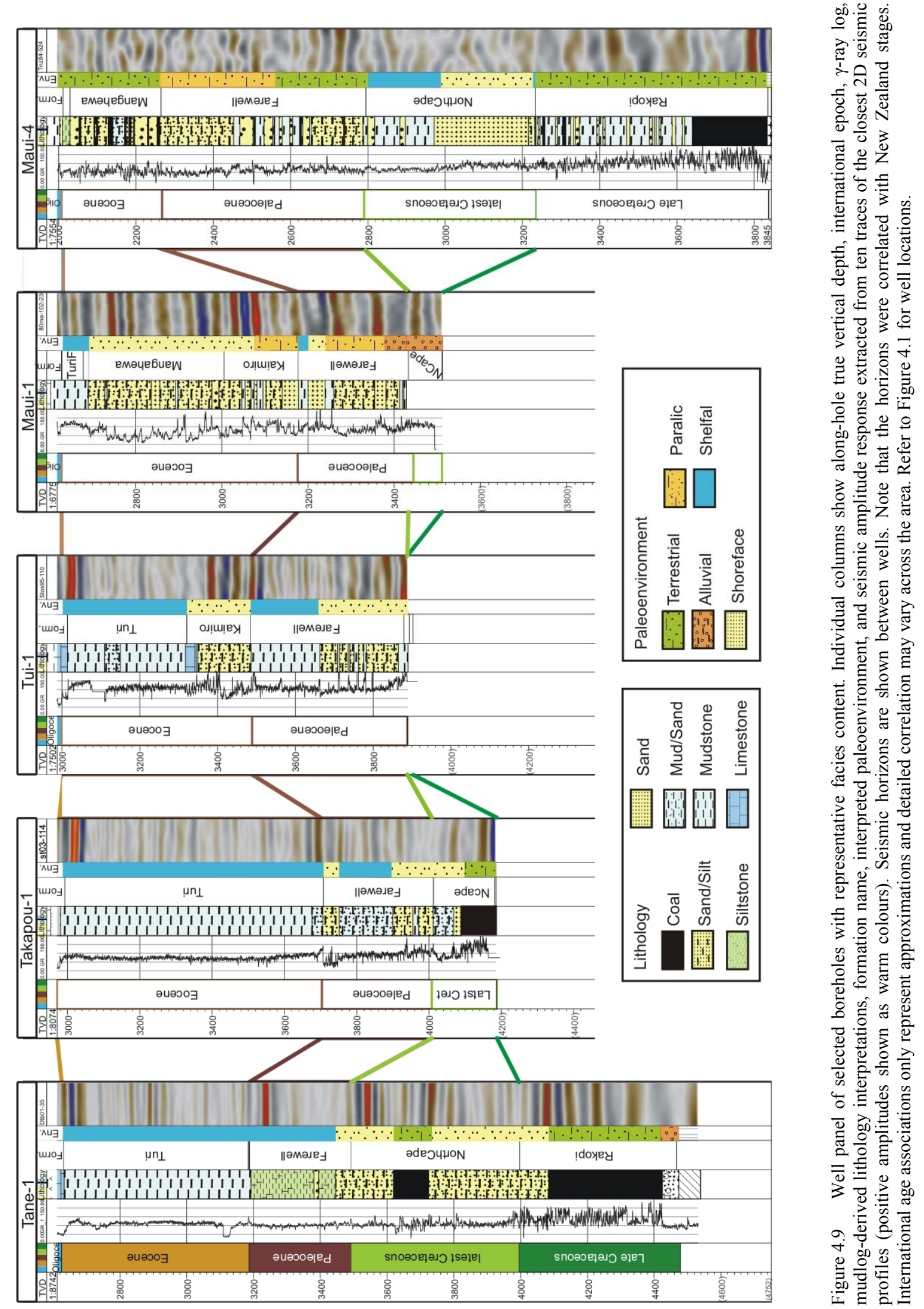


Table 4.2 Seismic facies, simplified wireline log character, and inferred environmental and lithofacies used as guidelines for paleo-environmental reconstructions.

\begin{tabular}{|c|c|c|c|c|c|}
\hline \multirow[t]{2}{*}{ Facies } & \multicolumn{3}{|c|}{ Seismic reflection character } & \multirow{2}{*}{$\begin{array}{c}\text { Log } \\
\text { Character }\end{array}$} & \multirow{2}{*}{$\begin{array}{l}\text { Inferred } \\
\text { lithology }\end{array}$} \\
\hline & Amplitude & $\begin{array}{c}\text { Lateral } \\
\text { continuity }\end{array}$ & Geometry & & \\
\hline Alluvial & low-medium & low & chaotic & variable & conglomerates \\
\hline $\begin{array}{c}\text { Terrestrial/coastal } \\
\text { plain }\end{array}$ & medium-high & $\begin{array}{l}\text { low-medium } \\
\text { (blocky) }\end{array}$ & $\begin{array}{l}\text { humocky, sub- } \\
\text { parallel }\end{array}$ & serrate & $\begin{array}{c}\text { sand, } \\
\text { carbonaceous } \\
\text { mud, coal }\end{array}$ \\
\hline Paralic & $\begin{array}{l}\text { variable, } \\
\text { medium }\end{array}$ & low-medium & $\begin{array}{l}\text { variable, sub- } \\
\text { parallel }\end{array}$ & variable & $\begin{array}{l}\text { interbedded } \\
\text { sand/silt }\end{array}$ \\
\hline Sandy shoreface & medium & medium & parallel & $\begin{array}{l}\text { serrate, } \\
\text { blocky }\end{array}$ & sand, silt \\
\hline $\begin{array}{c}\text { Lower shoreface- } \\
\text { shelf }\end{array}$ & low-medium & $\begin{array}{l}\text { medium- } \\
\text { high }\end{array}$ & parallel & $\begin{array}{l}\text { uniform, } \\
\text { high } \\
\text { gamma }\end{array}$ & $\begin{array}{l}\text { silt, muds, } \\
\text { minor sand }\end{array}$ \\
\hline Bathyal & low-medium & $\begin{array}{l}\text { medium- } \\
\text { high }\end{array}$ & parallel & $\begin{array}{l}\text { uniform, } \\
\text { high } \\
\text { gamma }\end{array}$ & mud, silt \\
\hline Bathyal & medium-high & $\begin{array}{l}\text { medium- } \\
\text { high }\end{array}$ & parallel & variable & $\begin{array}{l}\text { marls and } \\
\text { limestones }\end{array}$ \\
\hline Turbidite fans & low-high & low-medium & mounded, downlap & blocky & sand, silt \\
\hline $\begin{array}{c}\text { Fluvial/estuarine } \\
\text { channels }\end{array}$ & low-high & low & chaotic, contorted & variable & variable \\
\hline
\end{tabular}

\subsubsection{Seismic facies interpretation and development}

\section{Basement to K90 (Late Cretaceous)}

Late Cretaceous sediment deposition in the distal basin is marked by infilling of a $\sim 100$ $\mathrm{km}$ wide NW-trending graben system (Figure 4.5, Figure 4.10) that demarcates the early geometry of the southern NCT (Uruski, 2008; Collot et al., 2009). The base of the sequence comprises syn-rift strata deposited between faults that show throws on basement of up to $250 \mathrm{~ms}$ TWT (Figure 4.10). This syn-rift sequence can be subdivided into a lower part with low-continuity, medium-amplitude reflectors and an upper part with lower reflectivity. The change in seismic character may be attributed to a change 
from terrestrial to slightly marine sequences as noted by Uruski et al. (2002b), but is not investigated in any further detail herein.

Above the syn-rift sequence, a relatively undeformed sequence of prograding and aggrading clinoform reflectors indicate north-westward outbuilding of a shelf margin (Figure 4.10), which has been previously referred to as the Taranaki delta (Uruski et al., 2002a). The TWT-thickness between the upper and lower clinoform inclination points varies between about 0.3-0.5 s. Using simplified velocity and compaction parameters from Funnel et al. (1996), these values suggest decompacted foreset heights of 600-800 $\mathrm{m}$, and potential paleo-water depths of up to $1000 \mathrm{~m}$, respectively. Medium- to highamplitude, semi- to discontinuous seismic facies near the base of the more continuous clinoform reflectors indicate periodic channel incision and downslope turbidite deposition (Figure 4.10). A short distance landward of their upper inflection points, the clinoforms grade into discontinuous, hummocky, medium- to high-amplitude reflectors with internal variable-amplitude, chaotic reflections, which can be correlated with terrestrial sandy and coaly lithofacies (coastal plain) of the Late Cretaceous Rakopi Formation in Tane-1 (Figure 4.9, Figure 4.10). An interval amplitude extraction (average peak amplitudes between zero-crossings, APA) extracted over a $100 \mathrm{~ms}$ window below the K90 horizon highlights the distribution of these high-amplitude terrestrial facies (Figure 4.11A), over an area of about $20,000 \mathrm{~km}^{2}$ across the older graben and the area south of Tane-1 (Figure 4.12). The flat and, relatively uninterrupted character of this sequence indicates a vast, relatively flat-topography coastal plain across the southern NCT that developed landward of the prograding delta. Low-amplitude patches in the south of the attribute map in Figure 4.11A mark the location of basement highs near Tane-1 and younger magmatic intrusions (possibly latest Cretaceous, Figure 4.10). 

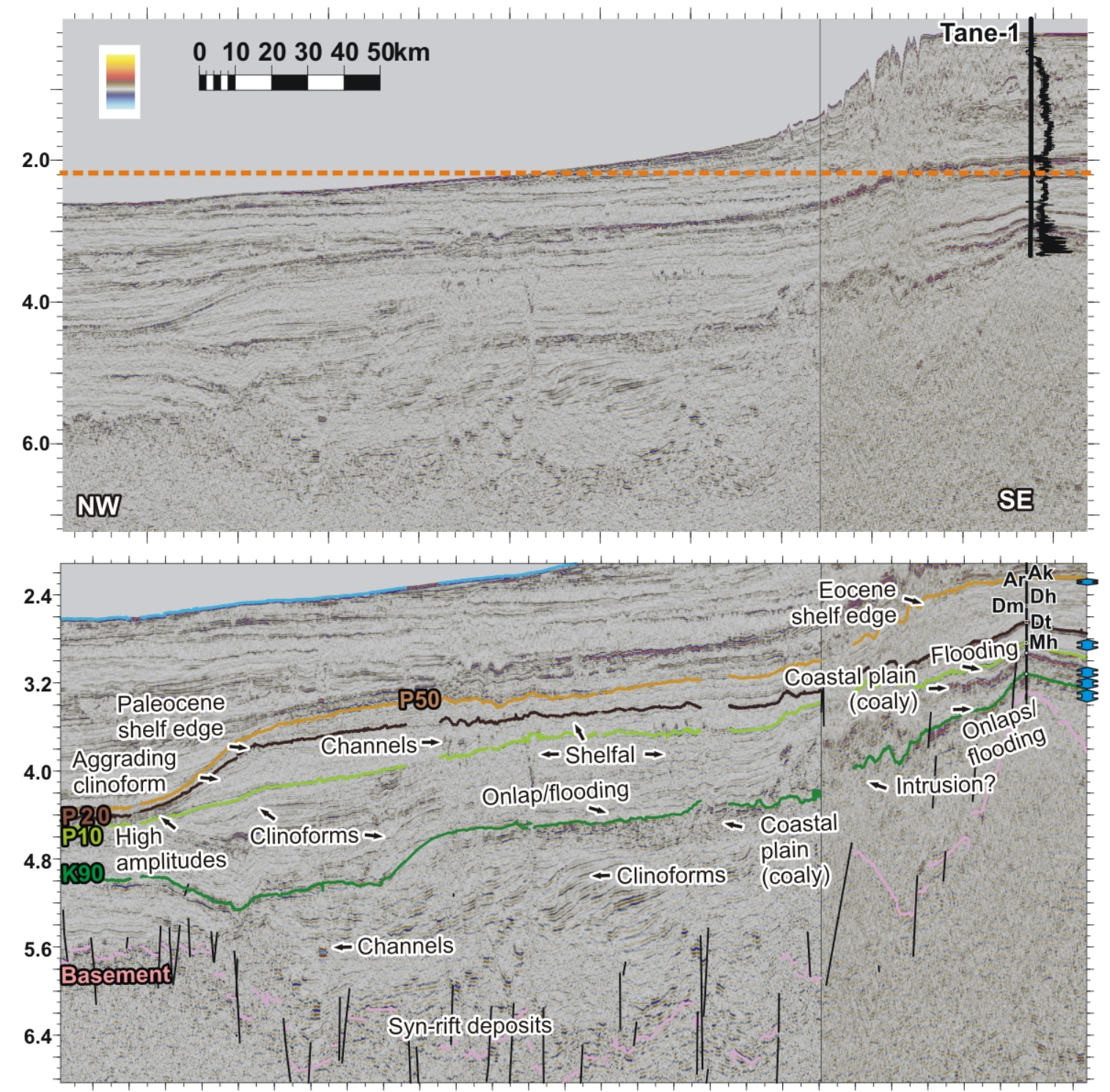

Figure 4.10 NW-SE composite seismic line across the distal, present-day deep-water basin. Bottom panel shows the lower part of the top panel (below dashed orange line) with seismic horizons and seismic facies interpretations. Faults are shown as black lines. Well trace of Tane-1 is shown as thick black line. Gamma-ray trace and New Zealand stage abbreviation are shown in the top and bottom panel, respectively. Location of line is shown in Figure 4.4 and marked as ' $\mathrm{D}$ ' in Figure 4.11A. Blue arrows on the right indicate the approximate intervals used for attribute extraction. Note the northwest outbuilding and aggradation of clinoform reflectors from the Late Cretaceous (below K90) to the Paleocene (P20). Seismic profiles here and in subsequent figures are shown in seconds two-way-travel time (TWT). 


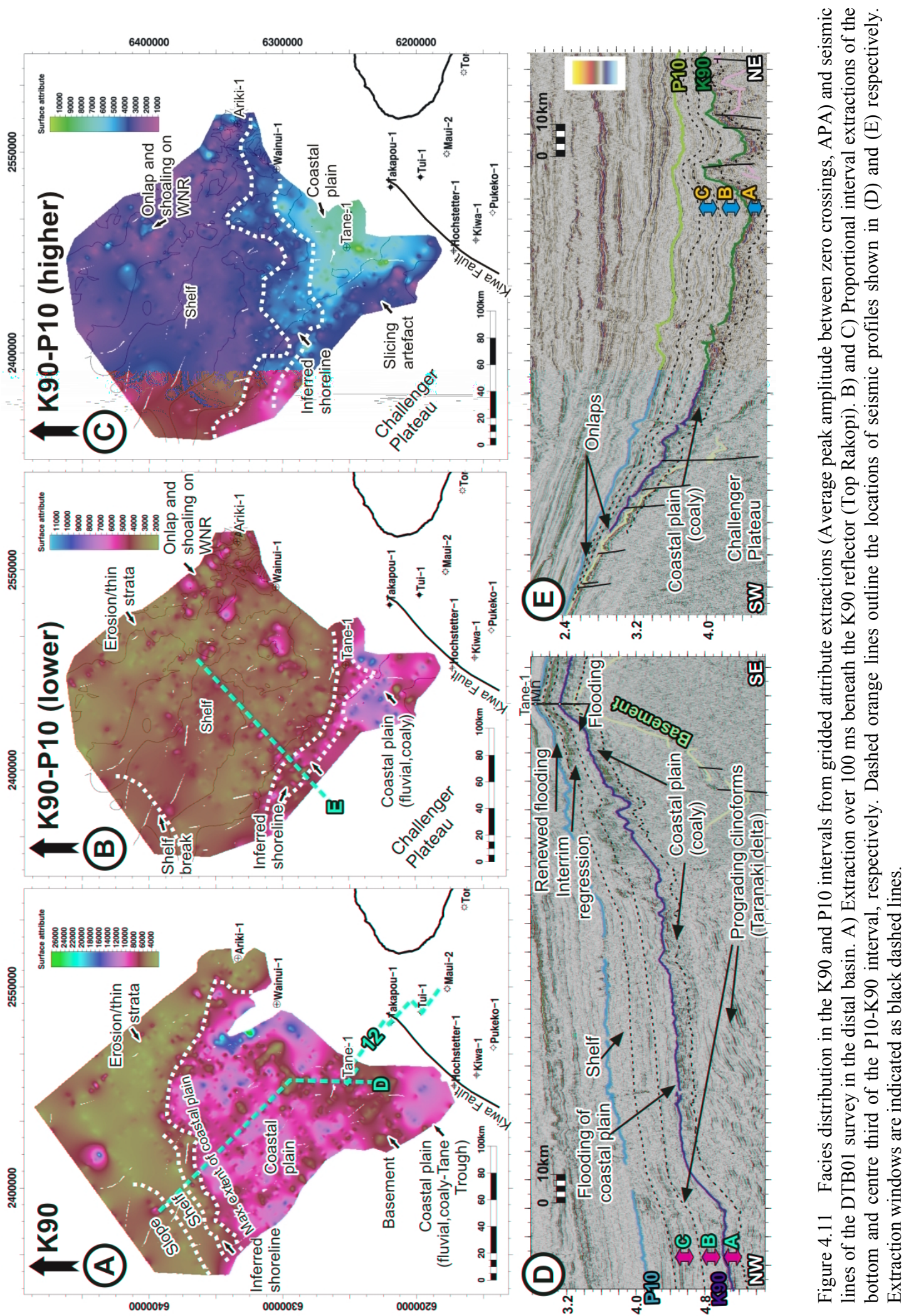



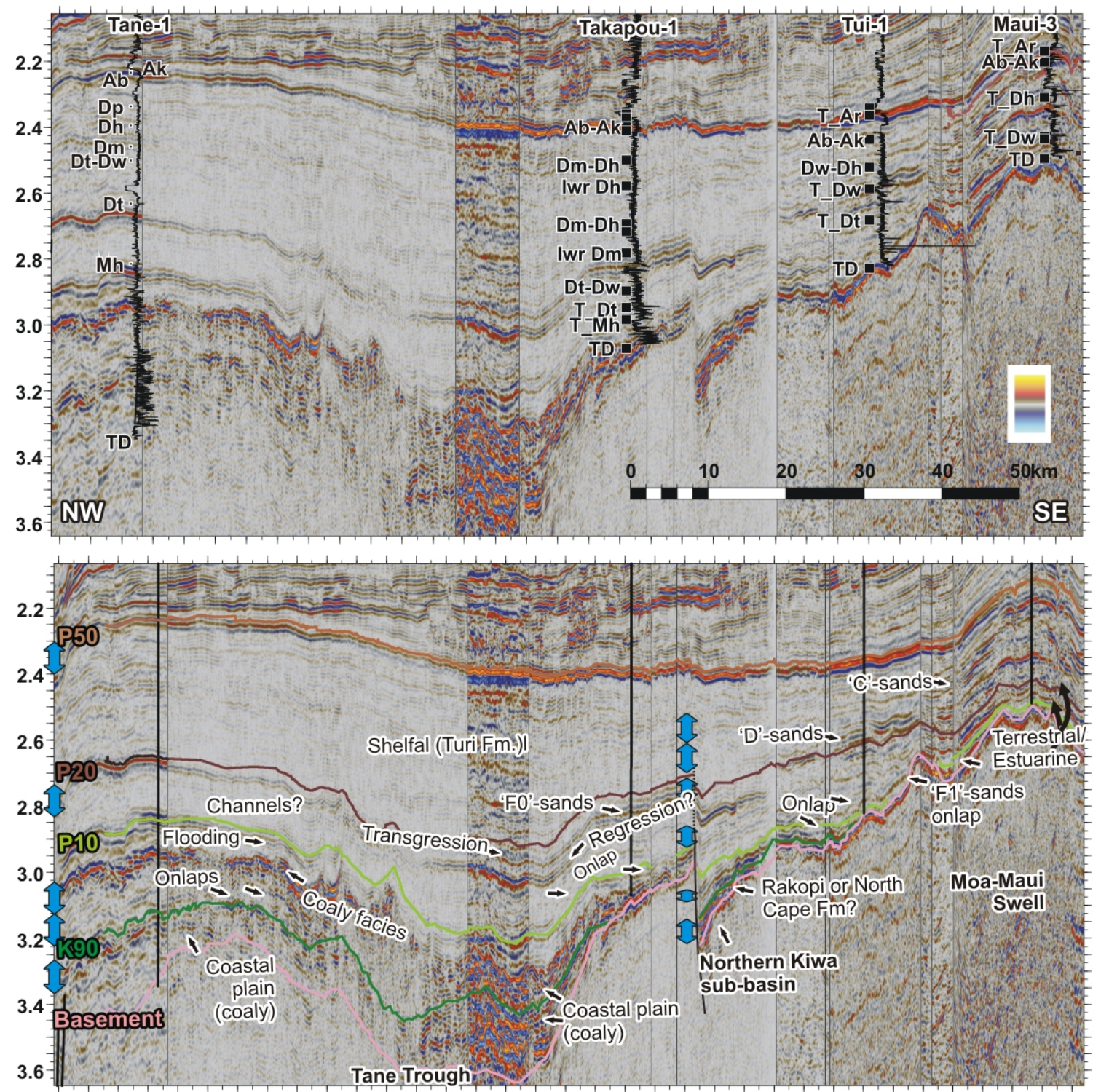

Figure 4.12 NW-SE composite seismic line across the Western Platform (Tane Trough) and the western part of the Moa-Maui swell. Bottom panel shows seismic horizons and seismic facies interpretations. Major faults are shown as black lines. Well traces are shown as thick black lines. Gamma-ray trace and New Zealand stage abbreviations are shown in the top panel. Location of line is shown in Figure 4.4 and individual attribute maps, respectively. Blue arrows indicate the approximate intervals used for attribute extraction for in the distal (left) and proximal (right) basin, respectively.

Southeast of the basement high in the area of well Tane-1, the sequence of blocky reflectors thickens to over $300 \mathrm{~ms}$ into the about $50 \mathrm{~km}$-wide, roughly NE-SW-oriented depression of the Tane Trough (Figure 4.12), from which they onlap onto the northern flank of the Kiwa Fault horst in the area of the Takapou-1 well. This area marks the approximate division of the basin's depositional systems into the generally flat, hardly faulted, and tectonically quiescent north-western part (present-day outer shelf and deepwater basin) and the south-eastern part (proximal Taranaki basin), where sedimentary wedge geometries in fault hanging walls indicate that deposition was accompanied and 
controlled by actively extending graben systems (Figure 4.5). In the proximal basin, the seismic facies character between the Basement and the K90 horizon is dominated by similar medium- to high-amplitude facies as observed in the distal basin, which is shown on an attribute extraction of the Basement-K90 interval (Figure 4.13A). The few wells that penetrate this sequence document the frequent occurrence of coaly lithofacies in well data (e.g., Maui-4 and Tahi-1) and suggest widespread coastal plain and lacustrine deposits. Two-way-time thickness (Figure 4.5) and amplitude character indicate that coaly facies are best developed in the large Pakawau sub-basin and the Maui sub-basin, whereas they do not appear to be well developed in the smaller Pihama sub-basin (Figure 4.13A, Figure 4.14).

Aside from the dominance of this coaly facies in the various sub-basins, seismic facies character indicates further facies differentiation in different localities. Discontinuous reflector packages of variable amplitude are frequently observed adjacent the graben margins and are interpreted as locally derived alluvium from the uplifting graben footwalls. Such alluvial facies are widely developed across the base of the K85-K90 sequence in Manaia sub-basin underneath more high-amplitude, coaly facies (Figure 4.14). The change in facies can be imaged on amplitude extractions from the Kerry 3D survey over the lower and upper part of the sequence (Figure 4.15), and is interpreted as occurring due to the development from an alluvial plain to a coastal plain, possibly resulting from subsidence-induced base-level rise. In the Maui sub-basin (Figure 4.16), slightly more continuous low-amplitude facies within the sequence correlate with the interval in well Maui-4 in which evidence for marine influence has been documented (Browne et al., 2008), possibly recording early periods of marine incursion. Furthermore, up to $1 \mathrm{~km}$-wide fluvial axial drainage systems in the northern part of the Kiwa sub-basin are interpreted from discontinuous reflectors within the overall high-amplitude sequences (Figure 4.17). The lateral continuity of marine sequences and fluvial systems, and their connection between individual sub-basins could not be mapped, which may be attributed to the deep burial, post-depositional deformation, and generally lower seismic resolution at depth. 

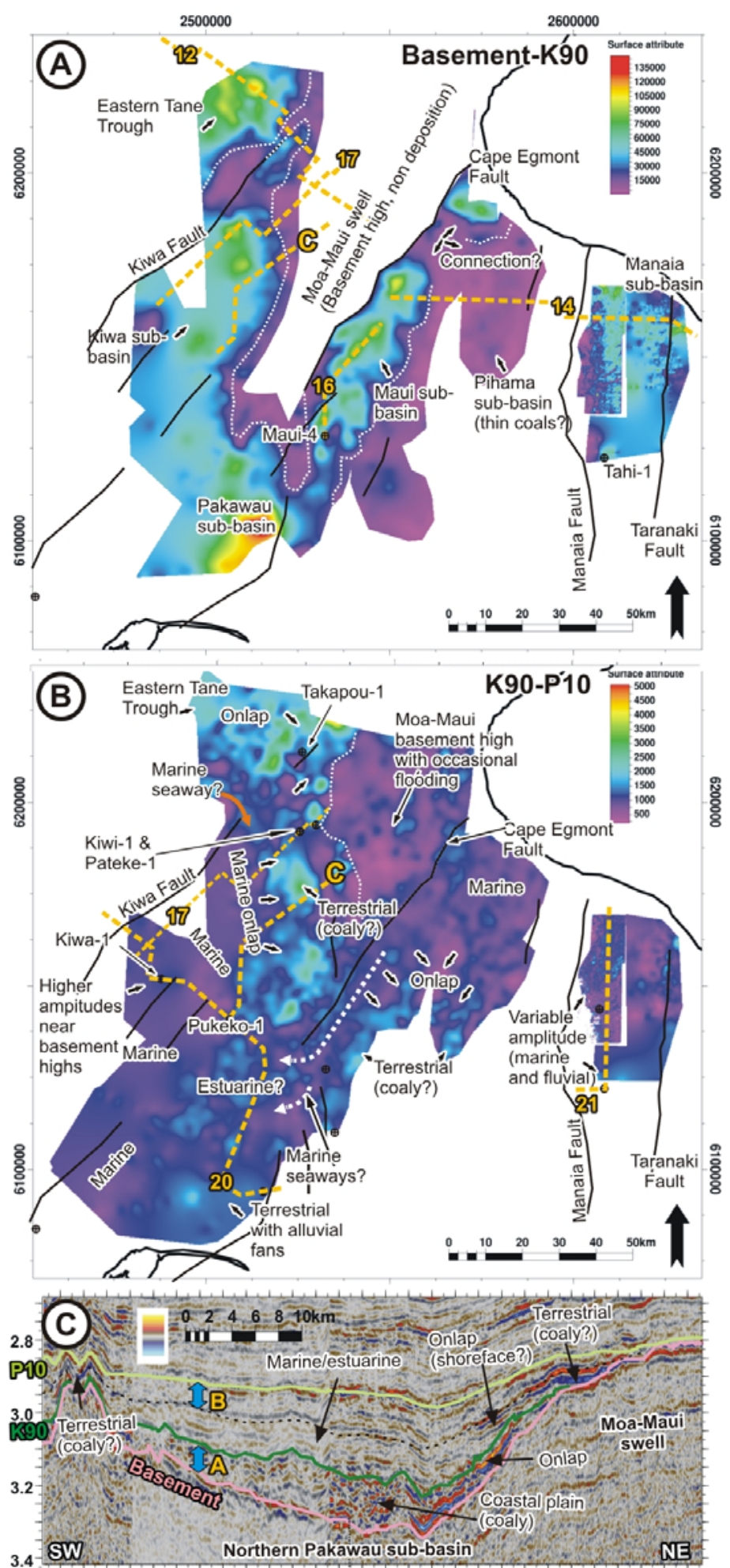

Figure 4.13 Late and latest Cretaceous seismic facies distribution in the proximal basin depicted on gridded attribute extractions from 2D and 3D data. A) Sum of magnitudes extraction over the entire Basement-K90 interval in the western part and the proportional upper half of the K85-K90 interval in the eastern part (Manaia sub-basin). Approximate sub-basin depocentres are outlined as white dashed lines. B) Stratal interval extraction (APA) over the lower half of the K90-P10. Locations of seismic profiles are shown as dashed orange lines. C) Seismic profile showing the facies characteristics and approximate extraction intervals used for attribute maps above (blue arrows, black dashed line). Note that the high amplitudes in (A) shows the approximate distribution of coaly source-rock facies of the Rakopi Formation, while variable amplitudes in (B) indicate the increased marine influence (low to medium) and onlap of sandy and coaly facies (medium to high) on remaining basement highs. 

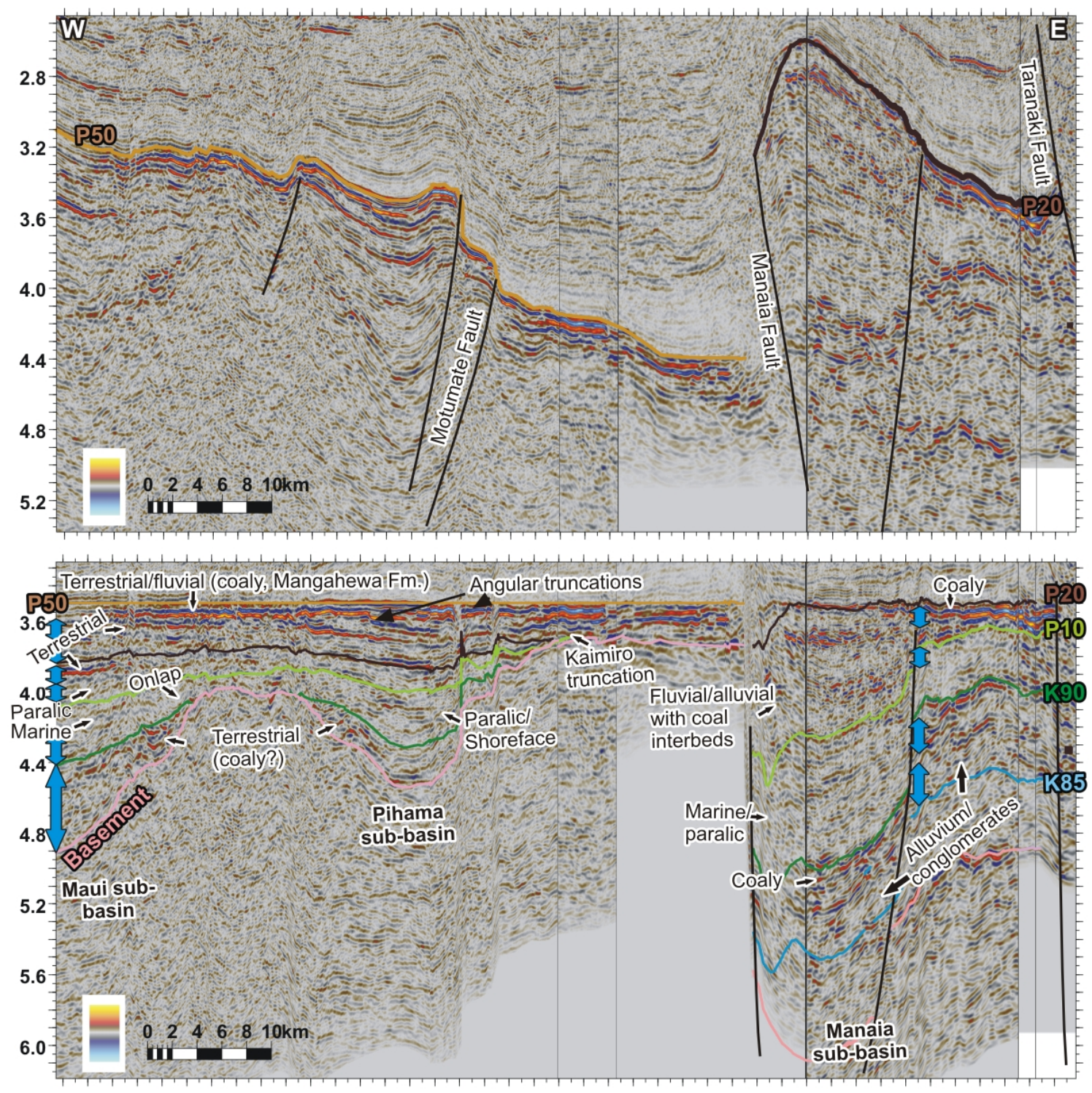

Figure 4.14 Seismic facies character on EW composite seismic line of the Maui, Pihama and Manaia sub-basins. Top panel shows the seismic line with interpreted base Oligocene horizon (P50 and P20) and prominent faults (black lines). Bottom panel shows flattened line with seismic horizons and seismic facies interpretations. Major faults are shown as black lines. Blue arrows indicate the approximate intervals used for attribute extraction. Location of line is shown in Figure 4.4 and individual attribute maps. 

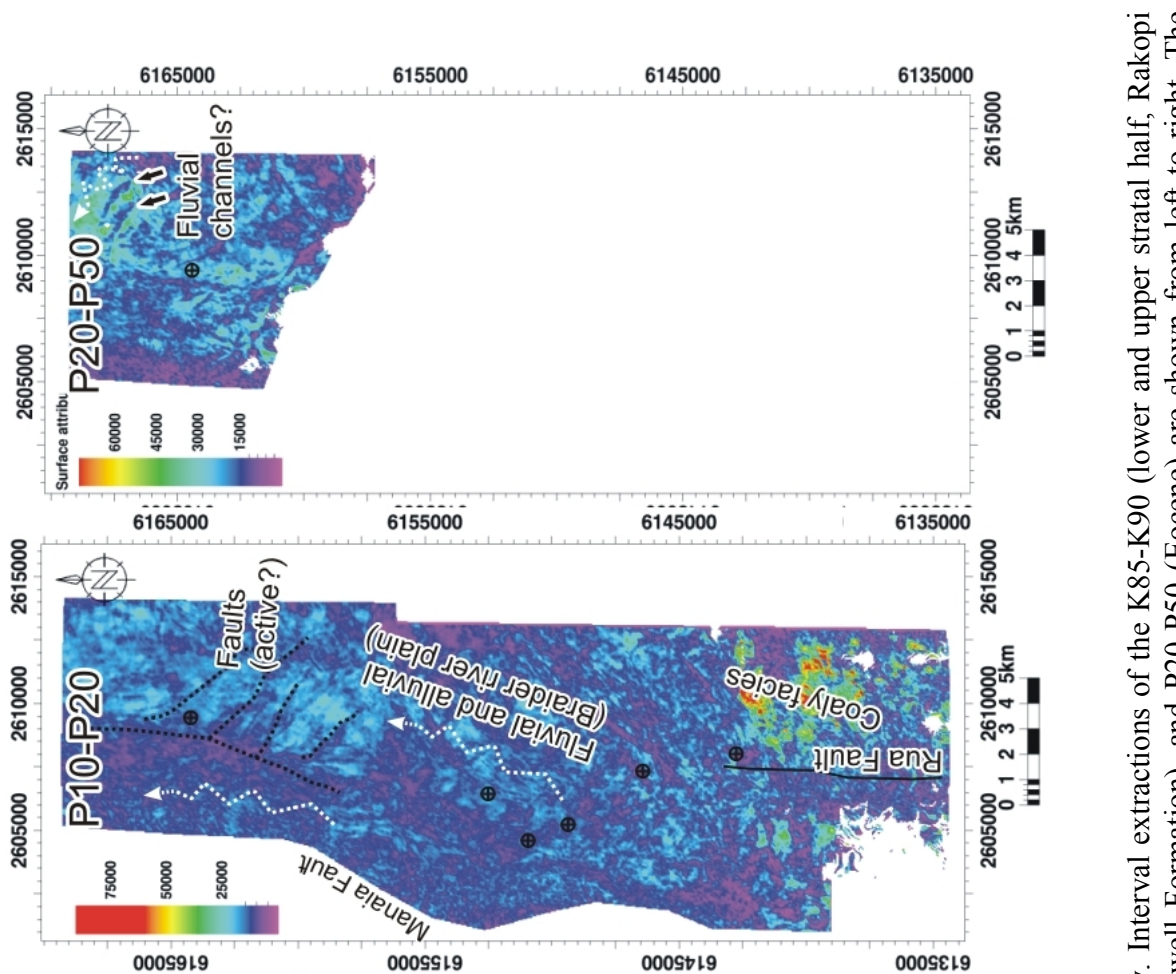

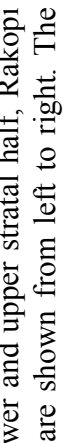

产㟔斻

จे ठ․

음

舟证

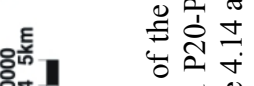

密

80 氖.

兽

옹

要号

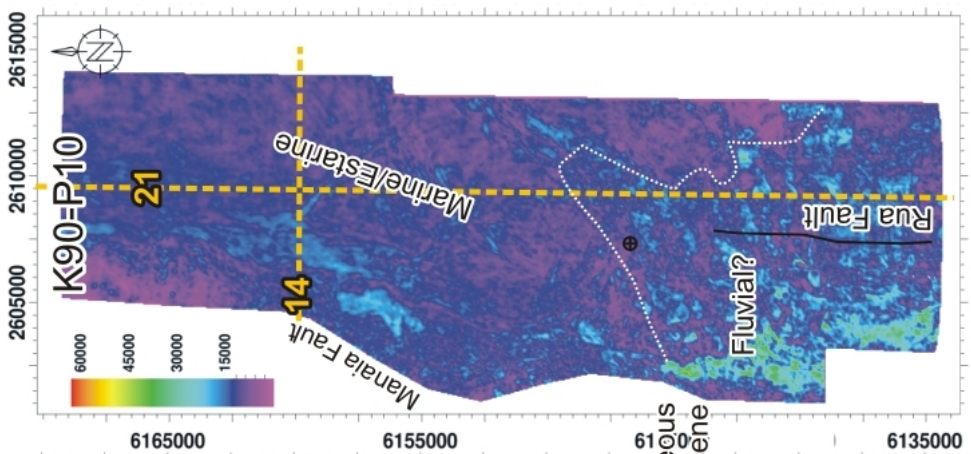

8 o

雚

है ले

然】

들 छ

용

বิ유을

这

w 0

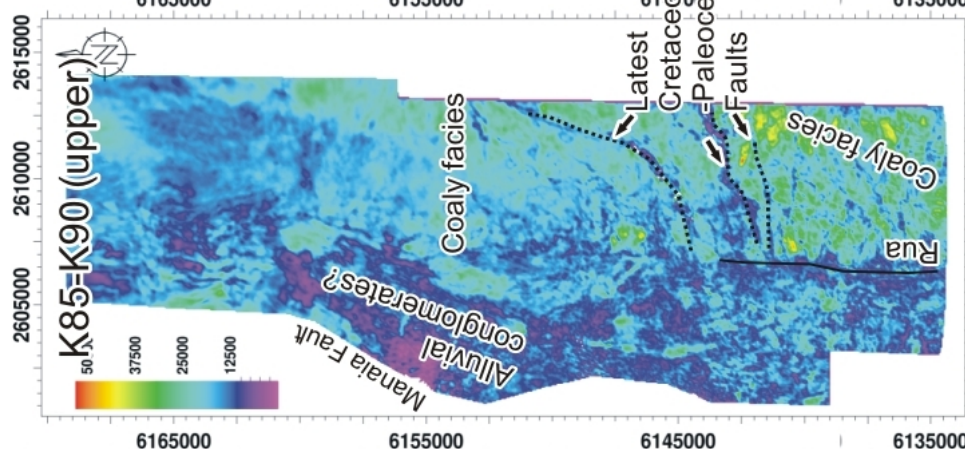

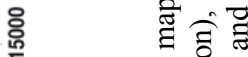

क

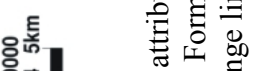

究

ก

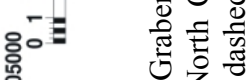

兽

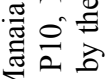

$\sum \overline{0}$

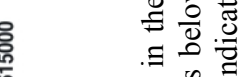

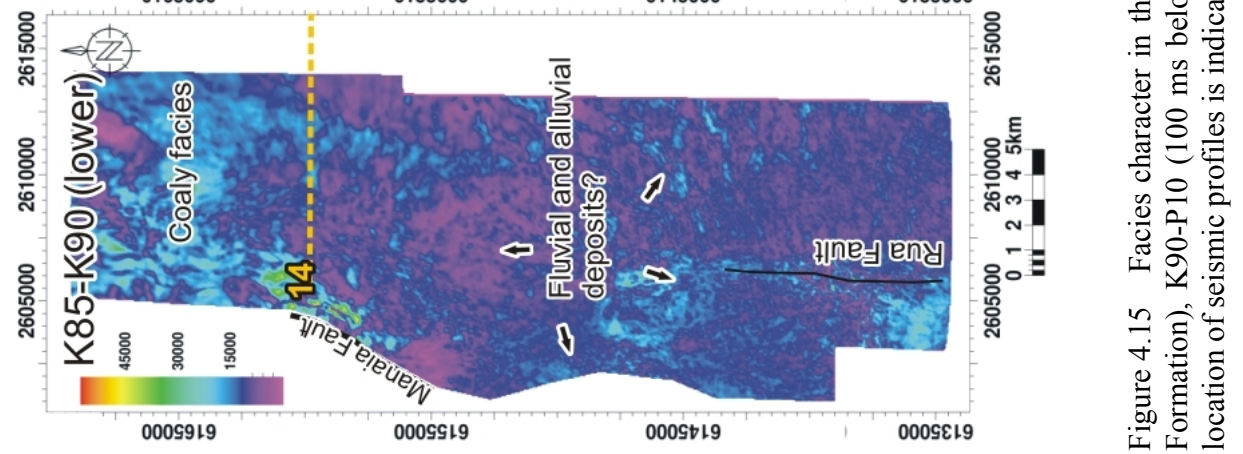



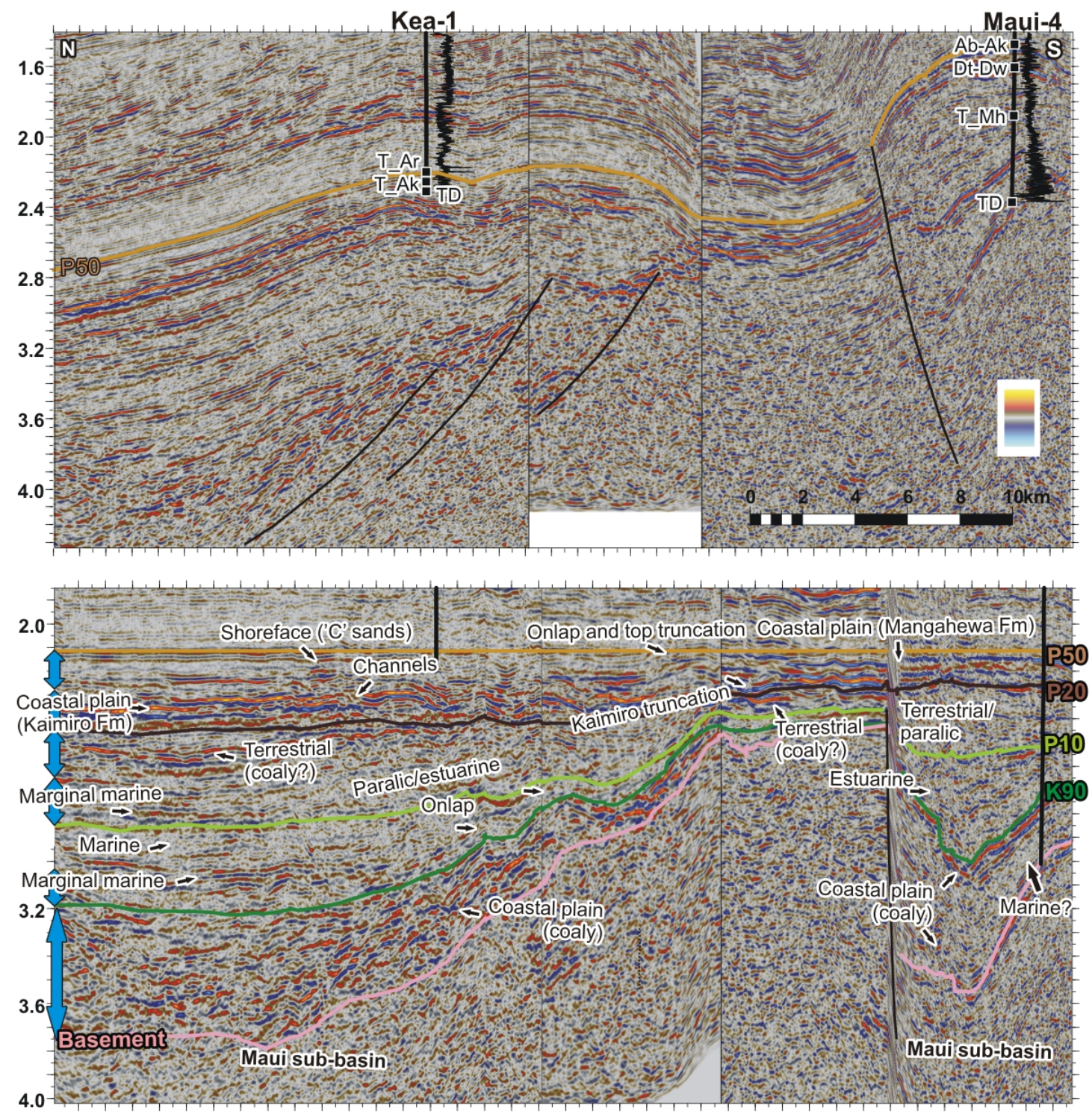

Figure 4.16 Seismic facies character on a NNE-SSW composite seismic line across the Maui sub-basin. Top panel shows the seismic line with interpreted P50 (base Oligocene) reflector. Centre panel shows the line flattened on the P50 horizon and bottom panel shows flattened line with seismic horizons and seismic facies interpretations. Major faults are shown as black lines. Well traces are shown as thick black line. Gamma-ray trace and New Zealand stage abbreviations are shown in the top panel. Blue arrows on the left indicate the approximate intervals used for attribute extraction. Location of line is shown in Figure 4.4 and individual attribute maps. 

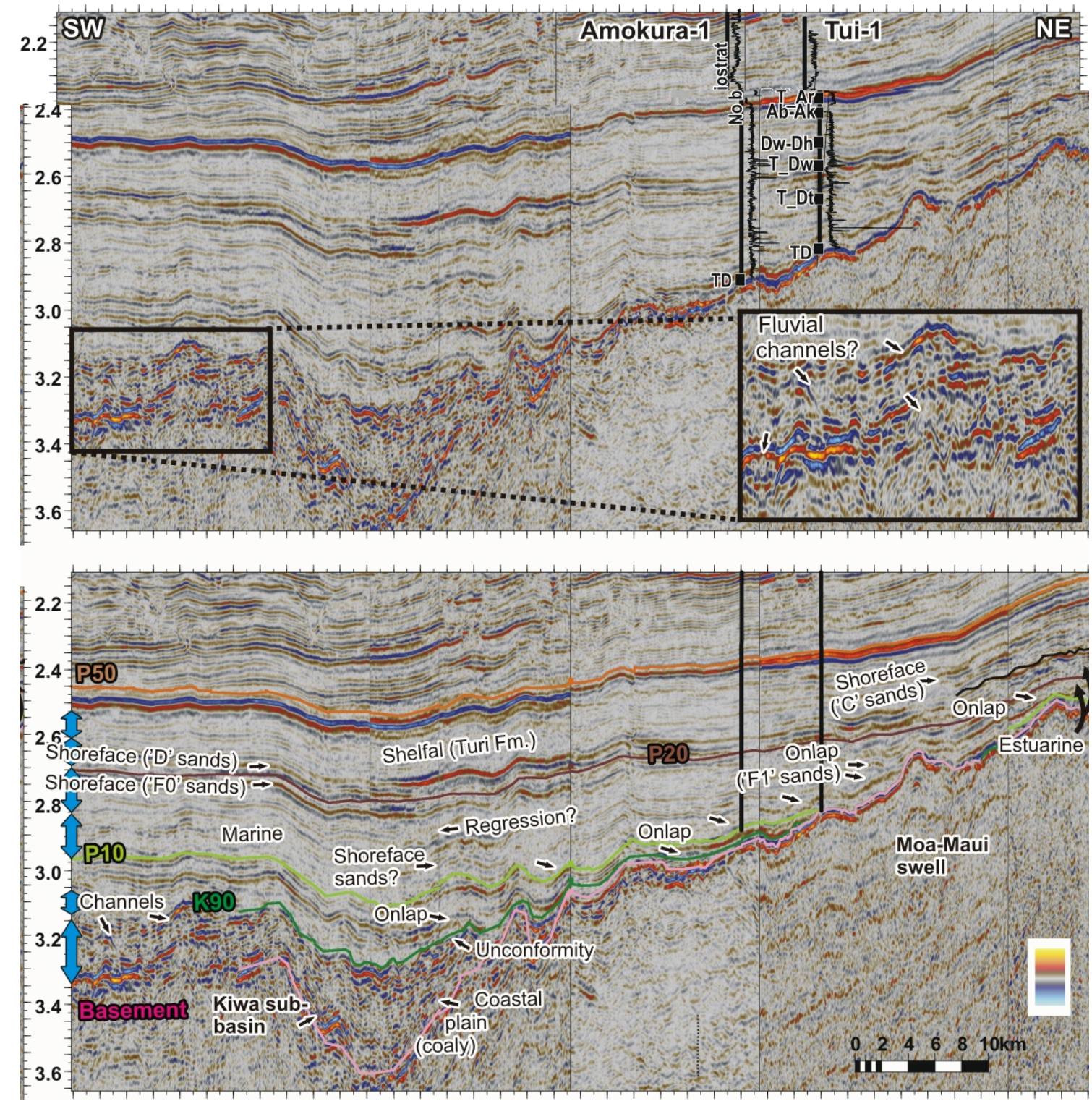

Figure 4.17 NE-SW composite seismic line across the Western Platform covering the western Moa-Maui swell and the Kiwa sub-basin. The bottom panel shows seismic horizons and seismic facies interpretations. Well traces are shown as thick black lines. Gamma-ray trace and New Zealand stage abbreviation is shown in the top panel. Location of line is shown in Figure 4.4 and individual attribute maps. Blue arrows indicate the approximate intervals used for attribute extraction. 
Increasing uniformity of TWT thickness and distribution of latest Cretaceous strata (K90-P10) compared to the previous interval indicates the waning control of the older rift systems on sediment deposition in the distal basin (Figure 4.5). In the north-western part of the deep-water survey (Figure 4.10), the sequence is marked by further outbuilding of clinoformal reflectors. Low- to medium-amplitude, semi-continuous reflectors suggest widespread marine deposits and flooding of the earlier coastal plain (below K90), which is confirmed by their correlation with shelfal silts and muds of the latest Cretaceous North Cape Formation in well Ariki-1 (Figure 4.18). These strata onlap and drape over adjacent basement highs and grade southward into higheramplitude, coaly facies south of well Tane-1 (Figure 4.12), where the same blocky facies character is observed since the Late Cretaceous (Basement-K90). Interval amplitude maps extracted over the lower part of the K90-P10 sequence outline a northwest-facing shoreline embayment and coastal plain facies belts on the northern parts of the Challenger Plateau (Figure 4.11B), which is corroborated by sandy facies in well Tane-1 and correlative coaly facies of the North Cape Formation in well Takapou1 (Figure 4.12). An intermittent base-level lowering within the K90-P10 sequence is indicated by renewed presence of terrestrial, coaly facies in Tane-1 (Figure 4.9, Figure 4.10), and the basin-ward shift of facies belts can be mapped on stratal interval attribute maps (Figure 4.11C). Onlapping reflectors of low or medium amplitude above these coaly facies indicate renewed flooding of this area towards the top of the K90-P10 sequence.

In the proximal basin, broadening of sediment depocentres (Figure 4.5) and widespread distribution of continuous low- to medium-amplitude reflectors are interpreted as marine sediments and indicate the increasing development of marine conditions (e.g., Figure 4.12, Figure 4.17). Figure 4.13B shows a general facies trends delineation on interval amplitude extractions from the sequence. Widespread reflector onlap, thinning, and drape of medium- to high-amplitude reflectors over basement mark the location of well-developed shoreline systems, which is confirmed by correlative marine sands or interbedded sand-silt facies in multiple wells that were drilled on the flanks of the paleo-basement highs. Furthermore, high-amplitude reflectors with decreased continuity near the basement highs and occasional coaly facies in wells such as Amokoura-1 and 
Pukeko-1 suggest the development of local terrestrial (coastal plain) sequences (e.g., Figure 4.17, Figure 4.19). A more widely developed shoreline system marks an about $50 \mathrm{~km}$-long, north-south-oriented trend on the north-western and western side of the Moa-Maui basement high (Figure 4.13). Thin correlative reflector sequences on this basement high as well as thin contemporary sediment in well Maui-3 suggest that this basement high was temporarily flooded near the upper part of the K90-P10 sequence (Figure 4.17).

A marine seaway connection between the Maui and the Pakawau sub-basin is inferred from a continuous low-amplitude trend on the eastern side of the Cape Egmont Fault (Figure 4.13B). These reflectors correlate with marine sands, silts, and muds in Maui-4 (Figure 4.9). Semi-continuous, medium-amplitude reflector packages in the area southwest of the Moa-Maui basement high and the Pakawau sub-basin could represent estuarine facies deposited within the connection of these sub-basins. In the southeastern part of the Pakawau sub-basin (Figure 4.20), relatively discontinuous reflectors indicate dominantly terrestrial conditions. Lower-amplitude, chaotic reflections are locally observed at the base of the formation in the southern Pakawau sub-basin (Figure 4.20), and correlation with sandy conglomerates in well Fresne-1 suggests the deposition of alluvial fans probably derived from the footwall of the adjacent Wakamarama Fault.

While increasing continuity of strata in the western part of the proximal basin suggests waning tectonic activity, the development of additional extensional faults with NE-SW to E-W orientation (Figure 4.15) suggests the continued structuring of the Manaia Graben in the eastern basin. Detailed reconstruction of depositional systems in this area is generally difficult due to substantial syn- and post-depositional deformation. Low- to medium seismic amplitudes, especially in the northern part of the Kerry 3D survey, may be interpreted as increased marine influence, but the variable continuity and amplitude of these reflectors are here interpreted to represent very marginal marine conditions with possible backward and forward migration of the shoreline. Reflectors with increased amplitude and decreased continuity become more frequent towards the upper parts of the sequence, especially in the southern part of the Kerry 3D survey (Figure 4.21). In this area, the temporal development from marine to more terrestrial facies is indicated by increasing occurrence of coal and terrestrial palynofacies up-section in the well Kupe South-4 (Crowley et al., 1989), culminating in an angular unconformity that marks the 
upper boundary of the formation. Reflector truncations and the presence of more marine facies sandstones without coaly facies drilled in well Tahi-1 suggests that the terrestrial sequence was eroded in this area (Figure 4.21).
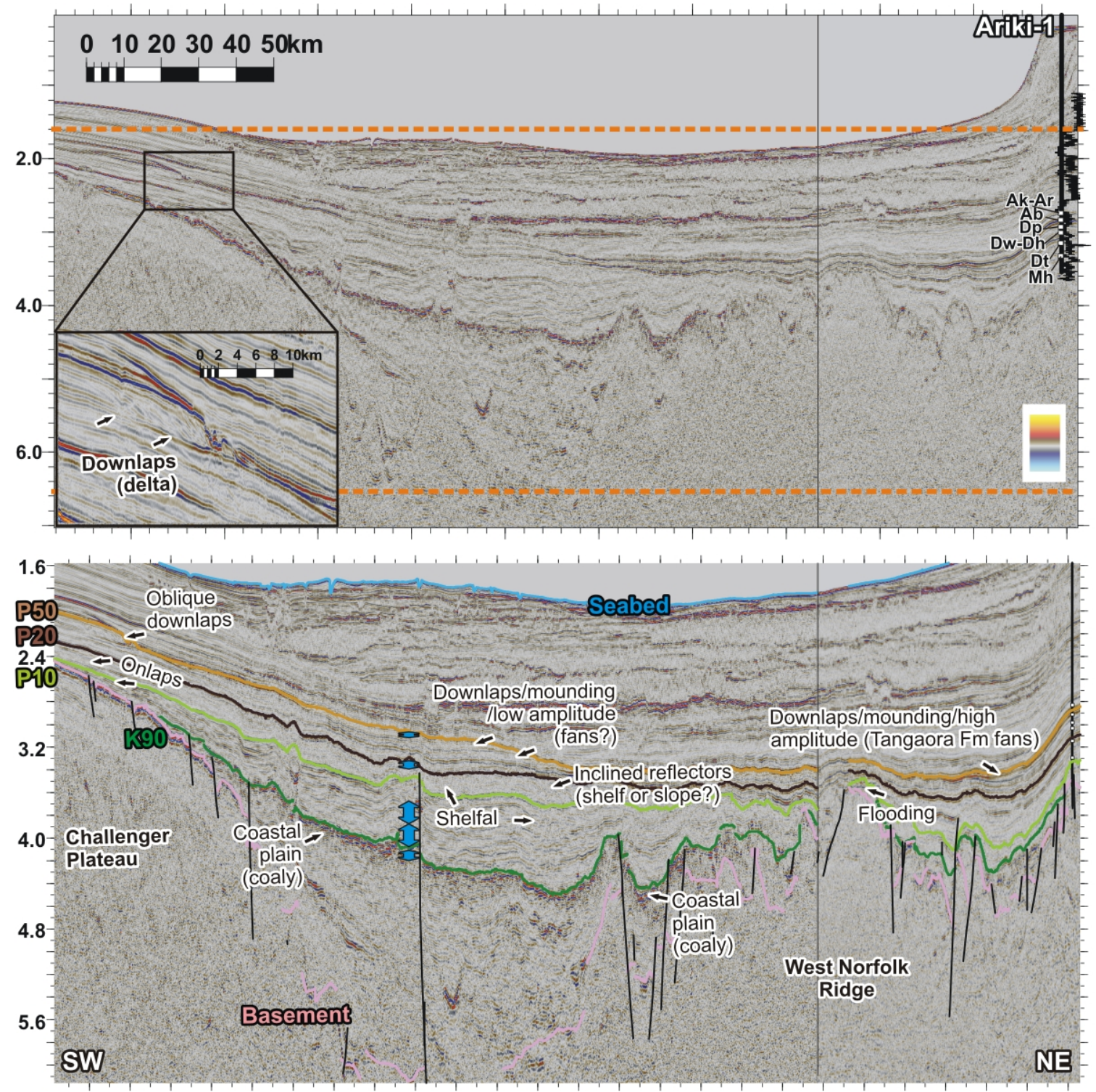

Figure 4.18 NE-SW composite seismic line across the distal basin. Bottom panel shows a magnified version of the top panel (indicated by the dashed orange lines) with seismic horizons and seismic facies interpretations. Faults are shown as black lines. Well path of Ariki-1 is shown as thick black line. Gamma-ray trace and New Zealand stage abbreviations of this well are shown in the top panel. Faults are shown as black lines. Location of line is shown in Figure 4.4 and individual attribute maps. Blue arrows indicate the approximate intervals used for attribute extraction. 

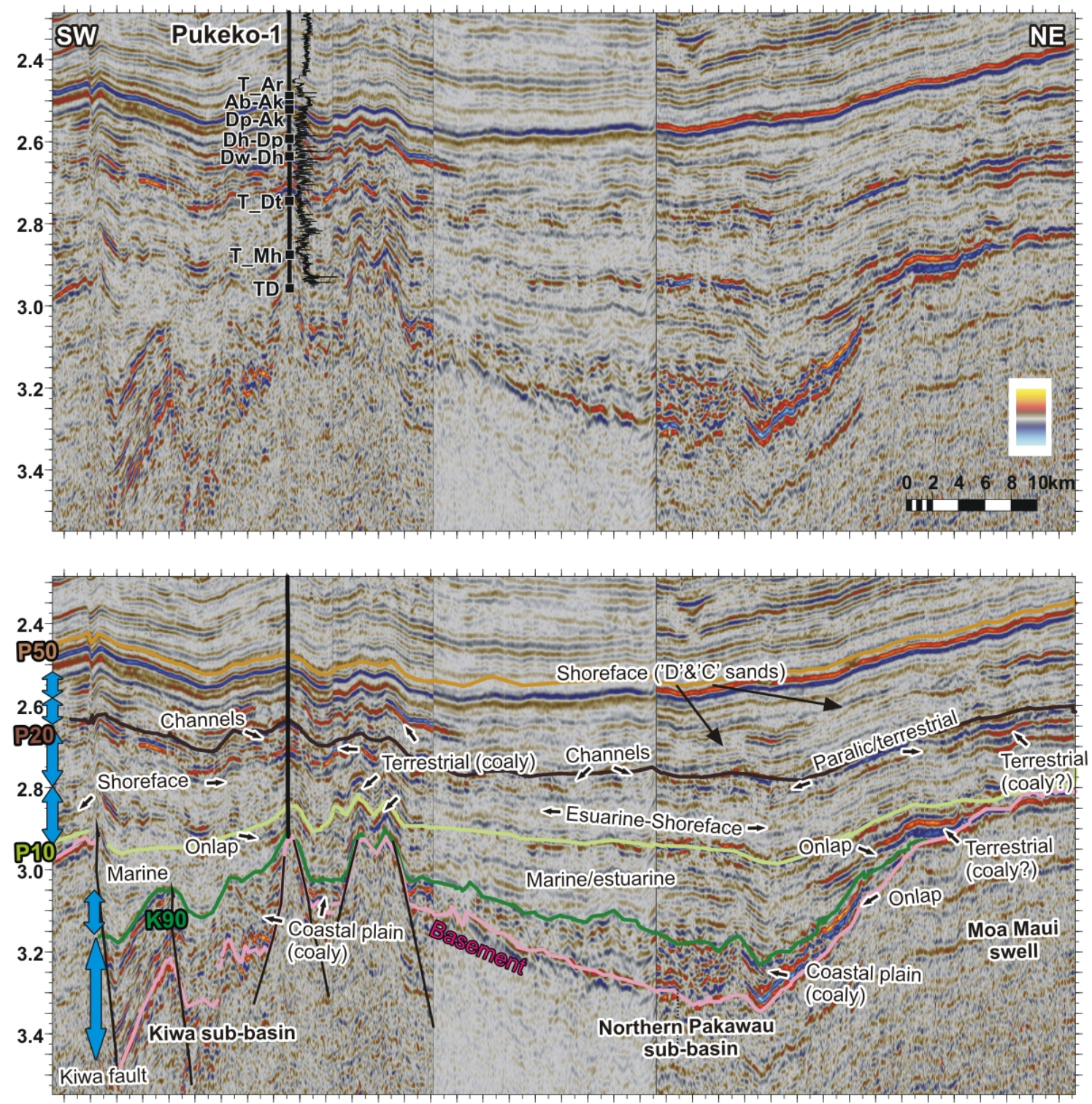

Figure 4.19 NE-SW composite seismic line across the Western Platform, covering the western part of the MoaMaui swell, the central Kiwa-, and the northern Pakawau sub-basins. Bottom panel shows seismic horizons seismic facies annotations. Major faults are shown as black lines. Well path of Pukeko-1 is shown as thick black line. Gammaray trace and New Zealand stage abbreviations are shown in the top panel. Location of line is shown in Figure 4.4 and individual attribute maps. Blue arrows indicate the approximate intervals used for attribute extraction. 

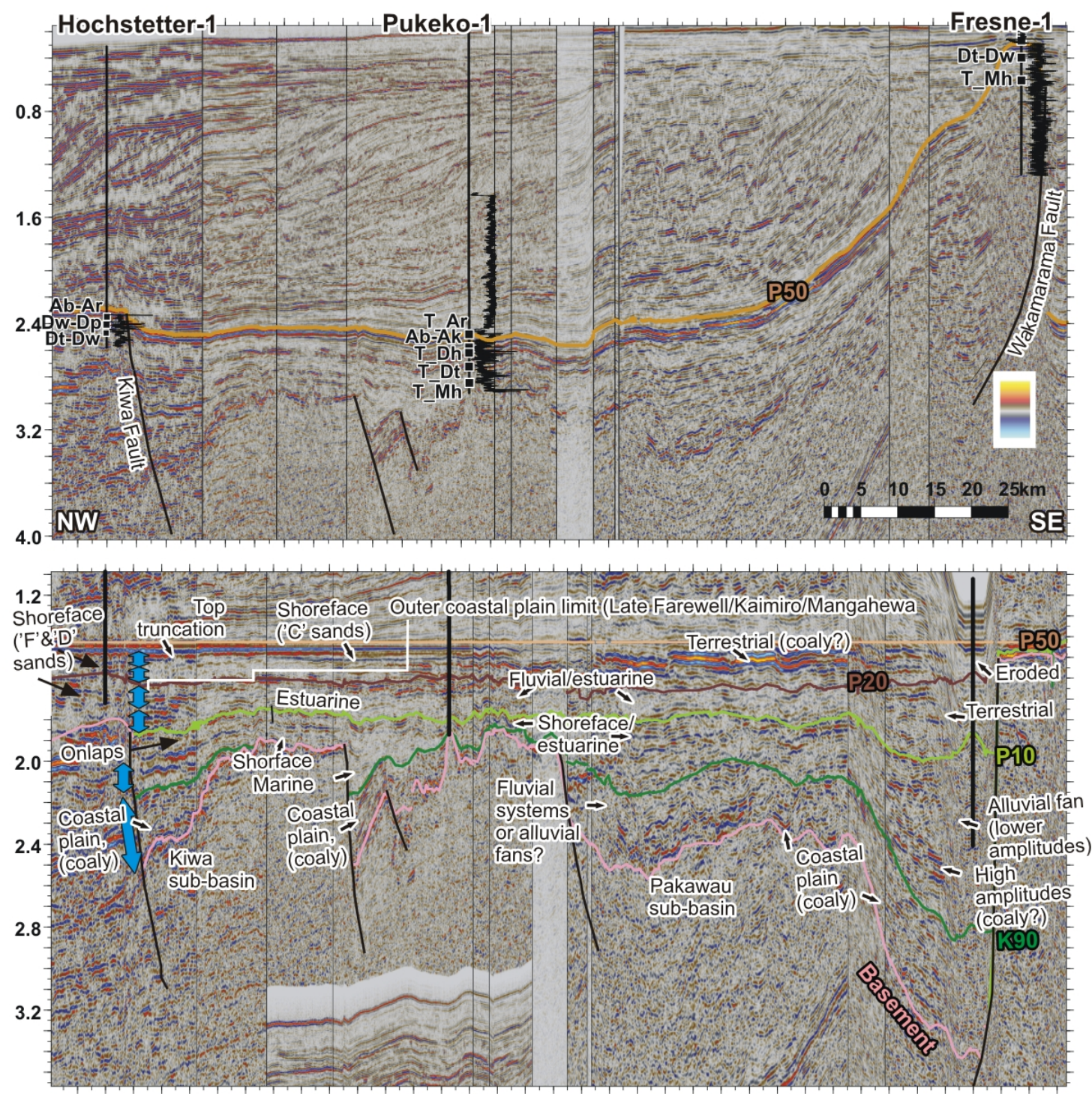

Figure 4.20 NE-SW composite seismic line across the southern Kiwa- and Pakawau sub-basins. Top panel shows the seismic line with interpreted P50 (base Oligocene) reflector. Bottom panel shows the seismic line flattened on the P50 reflector with seismic horizons and seismic facies interpretations. Major faults are shown as black lines. Well paths are shown as thick black lines. Gamma-ray trace and New Zealand stage abbreviations are shown in the top panel. Location of line is shown in Figure 4.4 and individual attribute maps. Blue arrows indicate the approximate intervals used for attribute extraction. 

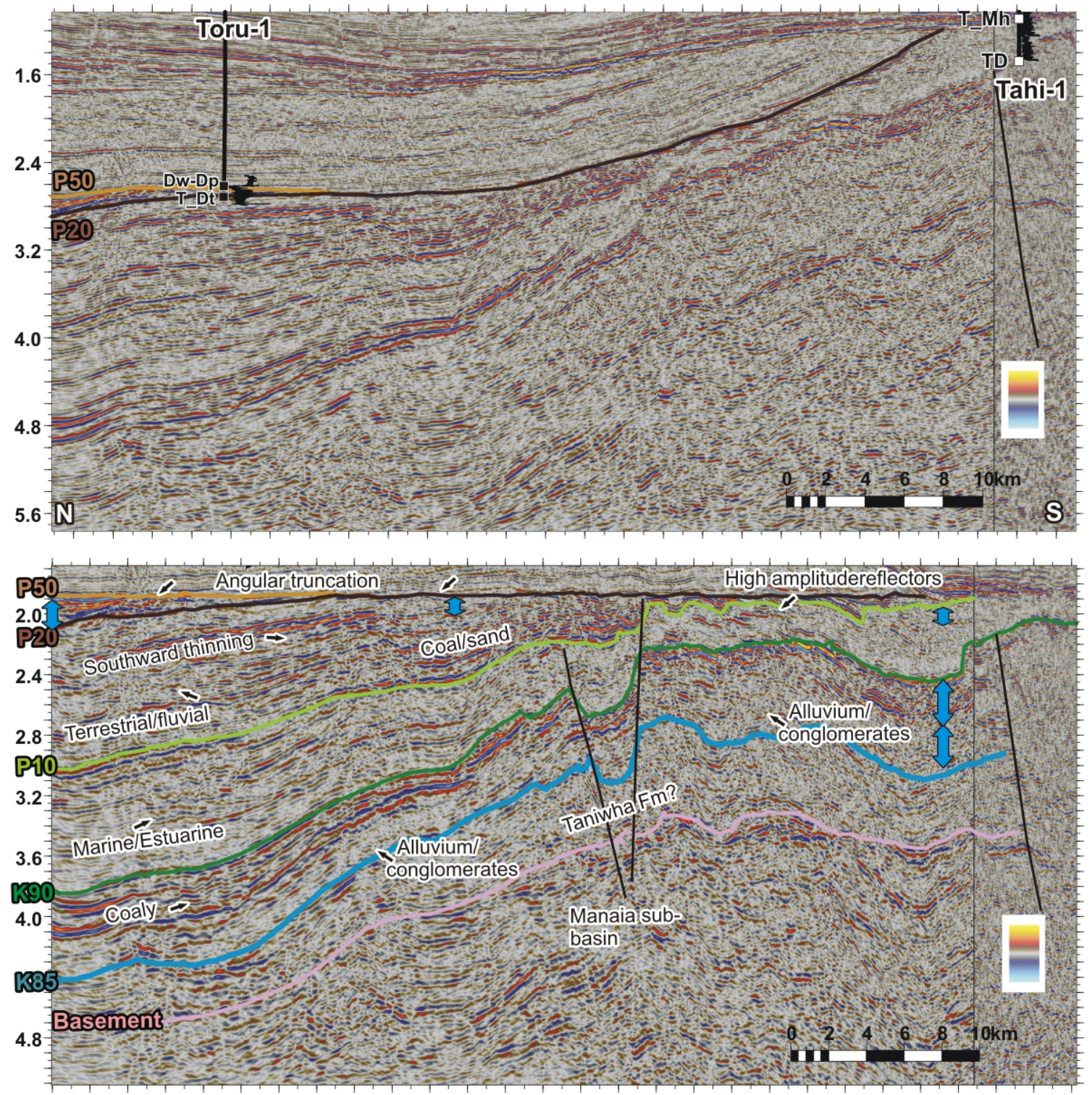

Figure 4.21 NS composite seismic line across the Manaia sub-basin in eastern Taranaki Basin. Top panel shows the seismic line with interpreted base Oligocene horizons (P50 and P20). The bottom panel shows the line flattened on the base Oligocene horizon with seismic horizons and seismic facies interpretations. Major faults are shown as black lines. Well paths of Toru-1 and Tahi-1 are shown as thick black lines and their associated gamma-ray trace and New Zealand stage abbreviations are shown in the top panel. Location of line is shown in Figure 4.4 and individual attribute maps. Blue arrows indicate the approximate intervals used for attribute extraction. 
Smaller isochron thicknesses mark a further decrease of sediment input into the distal basin and waning control of Cretaceous graben systems on sediment dispersal (Figure 4.5). In the proximal basin, Paleocene strata have relatively uniform thicknesses across faults, but show general thinning to the south (Figure 4.5), which suggest the healing of graben morphology and possible northward tilting of the basin. In contrast, fault-bound hangingwall thickening of strata in the south-eastern Manaia and southern Pakawau sub-basin (Figure 4.14, Figure 4.20) indicate active extension or, alternatively, more substantial topography created during Late Cretaceous faulting.

An aggrading clinoform structure in the north-western part of the distal basin indicates a stationary shelf edge (Figure 4.10). However, northeast-ward isochron thinning (Figure 4.5) and inclined reflectors further southeast (Figure 4.18) indicate the reorganisation of the shelf geometry to a more northward-trending slope (Figure 4.22A). The landward side of the inferred shelf edge is marked by generally bland seismic character that correlates with siltstones and mudstones of the Turi Formation in well Tane-1, whereas the basin-ward side shows highly variable-amplitude character that can be partly attributed to post-depositional magmatic intrusions (Figure 4.22A). The inferred shelf and slope strata are disrupted by multiple discontinuous, medium- to high-amplitude reflectors (Figure 4.10), which are interpreted as northward-trending continuous shelf channels and slope canyons (Figure 4.22A). Onlap and drape of medium-amplitude reflectors indicate further development of transgressive shoreline systems on the northern flanks of the Challenger Plateau and the footwall of the Kiwa Fault (Figure 4.22). Continuous, low- to medium-amplitude reflectors between the two shoreline systems in the south and southwest are interpreted as marine sediments and indicate the encroachment of a marine seaway across the Challenger Plateau within the Paleocene sequence.

Onlapping, medium-amplitude reflectors on the Western Platform can be correlated with sandy shoreface lithologies in well Tui-1 ('F1'-sands after Pollock \& Crouch, 2005), and attribute maps in the proximal basin delineate the development of a NESW-trending coastline in that area (Figure 4.23). The widespread distribution of onlapping shoreface facies across the western part of the proximal basin is locally 
interrupted by more continuous, low-amplitude facies (Figure 4.17, Figure 4.23), which may suggest low-energy marine embayments and periodical probing of seaway along the remnant topography of the Kiwa and Cape Egmont faults, respectively. Areas further south and southeast are dominated by medium- to high-amplitude, discontinuous facies, and together with correlative interbedded sand-coal sequences in well Pukeko-1 (Figure 4.19, Figure 4.23) indicate the development of a coastal plain. These facies are frequently dissected by chaotic, low- to medium-amplitude reflectors (Figure 4.19), which are interpreted as channel facies that show apparent north-westerly and northeasterly trends on attribute maps (Figure 4.23).

Marine onlap locations, seismic facies, and litho-facies successions indicate a temporary basin-ward facies-shift and base-level lowering within the upper part of the P10-P20 sequence (Figure 4.12). Amplitude extractions over the upper part of the sequence show the further northward distribution of high-amplitude facies, which may suggest aggradation of coal measures or widening of the coastal plain in the southern basin (Figure 4.23, lower panel). Similarly, shoreface sands ('F0'-sands) are encountered above finer-grained shelfal silts and sands in well Takapou-1 (Figure 4.12). The intermittent base-level lowering was succeeded by further rise towards the top of the sequence and the shoreline is interpreted to have migrated over most of the Moa-Maui swell during maximum flooding in the Late Paleocene (Figure 4.12).

Seismic facies patterns in the Manaia Graben are characterised by the intercalation of semi-continuous to discontinuous, medium- to high-amplitude reflectors and loweramplitude discontinuous reflectors (Figure 4.21). While correlative sand, silt, and coal interbeds in boreholes have been interpreted as high-energy braided stream deposits (Schmidt \& Robinson, 1990), seismic data quality of the Kerry 3D and derivative attribute maps are not conclusive enough to interpret such depositional systems (Figure 4.15). Multiple north-south and smaller east-west-trending faults dissect the sequence, indicating active faulting during Paleocene deposition in this area. 

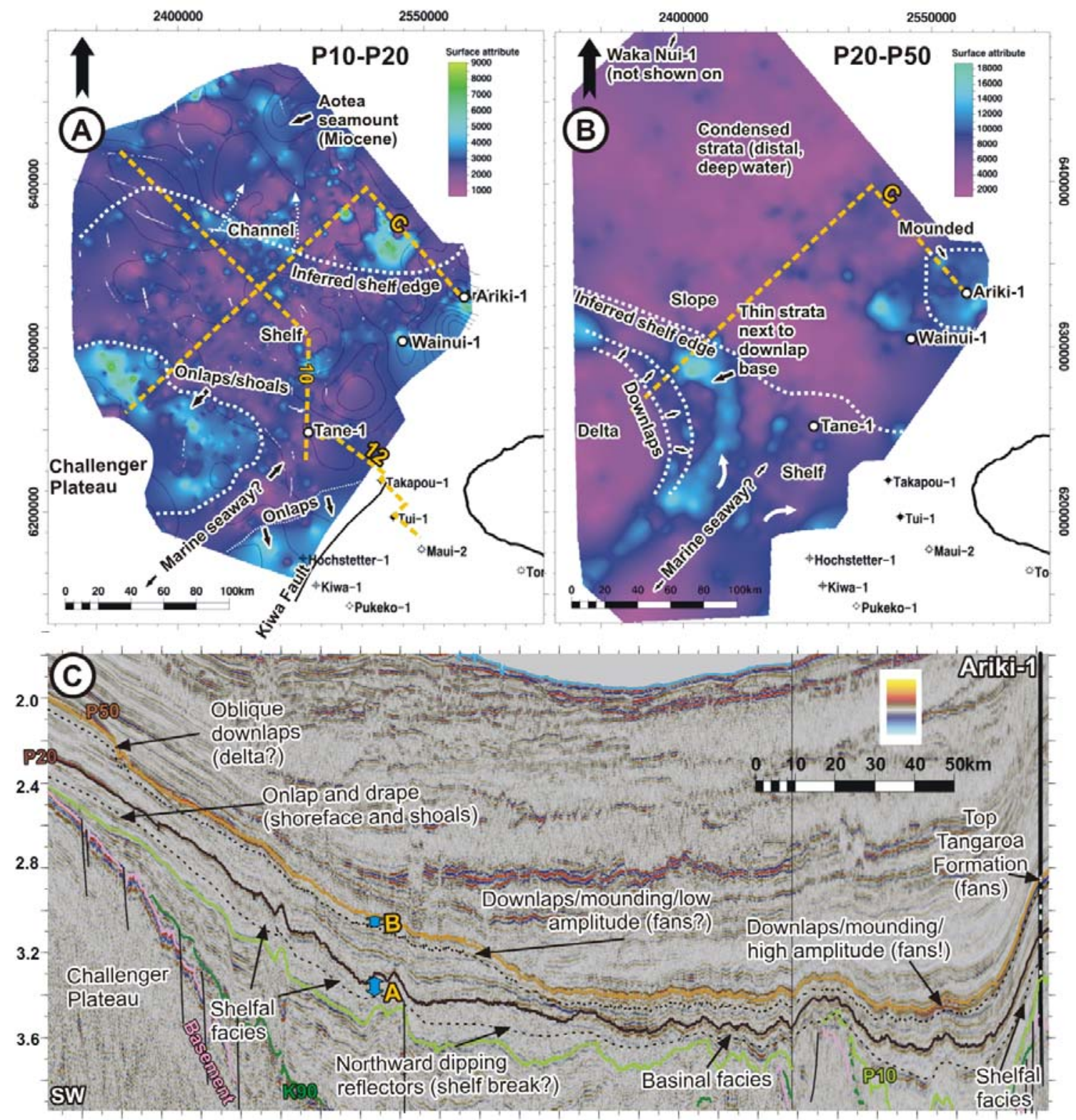

Figure 4.22 Paleocene and Eocene seismic facies distribution depicted on gridded attribute extractions (APA) of the DTB01 survey in the distal basin and their expression in profile view. A) Stratal interval extraction over the upper half of the P10-P20 interval. B) Interval extraction over a $50 \mathrm{~ms}$ window below the P50 horizon. C) Seismic profile with seismic horizon and facies interpretations, well path of Ariki-1, and extractions windows used for attribute maps shown above (dashed black lines and blue arrows). The location of seismic lines is shown as orange dashed lines in (A) and (B). 

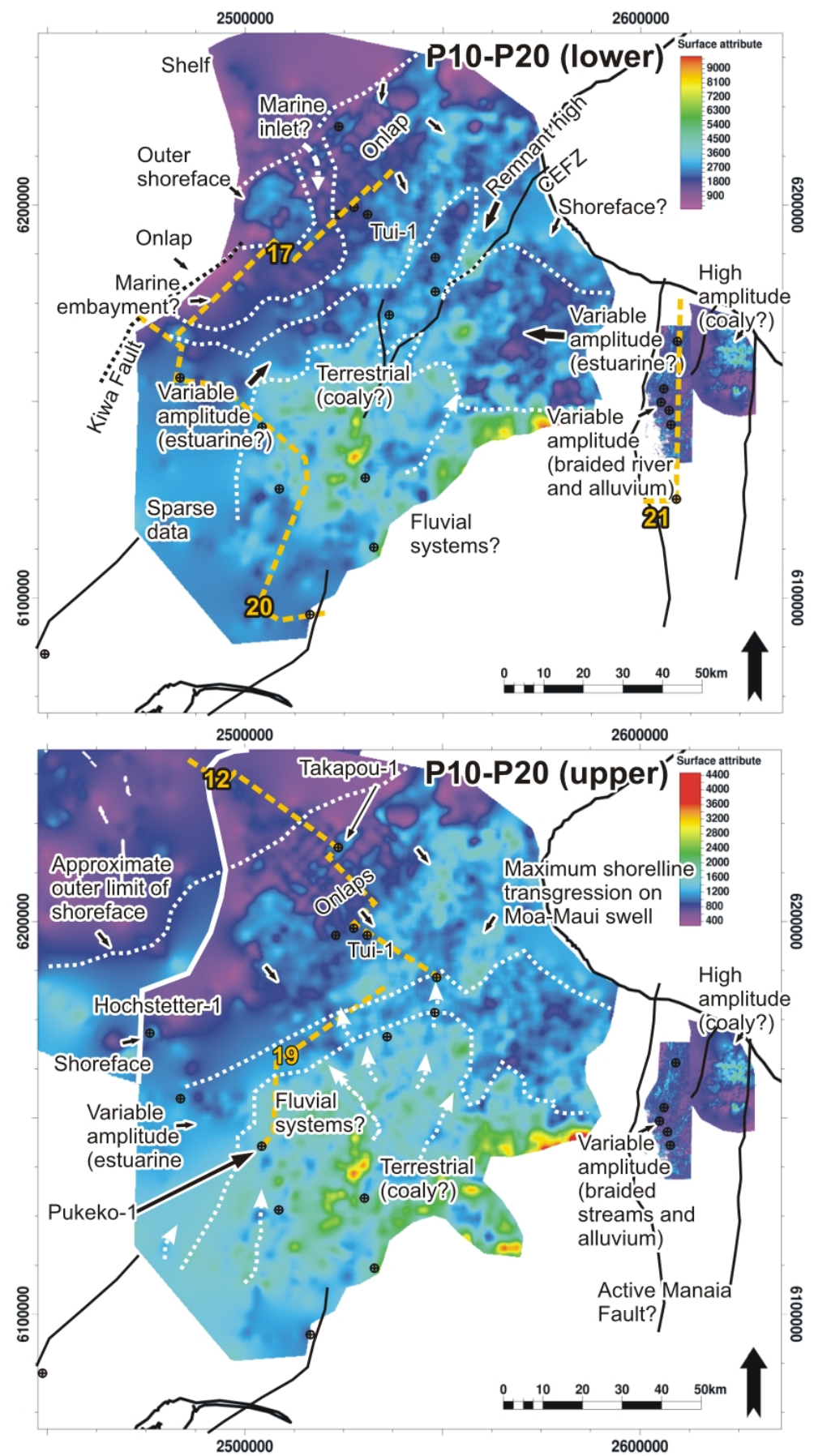

Figure 4.23 Paleocene facies distributions in the proximal basin depicted on gridded attribute extractions (APA) from $2 \mathrm{D}$ and 3D data. The maps were extracted over the lower (top panel) and upper half (bottom panel) of the proportionally subdivided P10-P20 sequence. Maps in the east show the upper $100 \mathrm{~ms}$ of the Paleocene sequence in both maps, since the creation of adequate sub-divisions was not possible. Approximate facies boundaries are outlined as dotted white lines. The location of seismic lines is shown as orange dashed lines. Major faults inferred to be active are shown as black lines. 
Generally thin Eocene strata across the present-day deep-water basin suggest further decrease of sediment supply to distal areas, while fault control on sediment deposition appears to have ceased entirely (Figure 4.5). The P20-P50 sequence is thickest in the present-day outer shelf area from where it thins towards distal areas in the north, the Challenger Plateau in the southwest, and into a northwest-facing embayment in the eastern part of the proximal basin (Figure 4.5).

Thinning of strata north of Tane-1 is interpreted to outline the east-west geometry of the contemporary shelf margin wedge (Figure 4.5, Figure 4.10), which appears to have retreated southwards with respect to the Paleocene. Some ten kilometres north of this feature, mounded and downlapping reflectors are interpreted as turbidite fan systems, indicating a northerly dip of the slope in this area (Figure 4.18, Figure 4.22). Similar facies geometries in the eastern part of the survey can be correlated with sandy slope or basin-floor fan deposits of the Late Eocene Tangaroa Formation in Ariki-1 (Gresko et al., 1992). The approximate distribution of the Tangaroa Formation is visible on amplitude extractions below the P50 horizon (Figure 4.22B). While the former turbidites are interpreted to be facies equivalents of the Tangaroa Formation, the timing of their deposition is unclear and could range from Early to Late Eocene. However, these features do not show an increased amplitude signature with respect to the surrounding media and are therefore not visible on amplitude maps from this sparse (10 $\mathrm{km}^{2}$ ) seismic data set. Seismic facies distal to these turbidites show a thin sequence of dominantly parallel, continuous low-amplitude reflectors with occasionally elevated amplitudes (Figure 4.10 Figure 4.18), which correlate with bathyal muds and marls in well Waka Nui-1 (Uruski \& Stagpoole, 2004) and indicate bathyal environments.

Landward of the inferred shelf margin (Figure 4.22B), reflectors of the lower part of the formation onlap and drape over the Challenger Plateau, while the upper part of the Eocene sequence shows a series of obliquely down-lapping reflectors (Figure 4.18). These down-lapping reflectors have a TWT thickness of about $100 \mathrm{~ms}$, show occasional incision (possibly channels), and are interpreted to be a low-topography delta that built out from the northern flanks of the Challenger Plateau. Downlapping reflectors can be traced over several seismic lines along strike and relatively higher amplitudes near their 
outer truncation outline this up to $100 \mathrm{~km}$ wide feature on attribute maps (Figure 4.22B).

The Western Platform is widely marked by continuous, bland or medium-amplitude reflectors that correlate with fine-grained shelf facies of the Turi Formation in wells (e.g., Takapou-1 and Tane-1, Figure 4.9), and indicate increased marine flooding across the Challenger Plateau. Shelfal reflectors grade south-eastwards into semi-continuous, medium- to high-amplitude facies that correlate with sandy shoreface lithologies of the Kaimiro and Mangahewa formations ('D'- and 'C'-sands, Figure 4.12). Amplitude extractions show a sharp boundary between the shelf and shoreface facies and outline the geometry of the NE-SW-trending coastline, while shifting facies belts depict the south-eastward transgression of the system during the Eocene (Figure 4.24). Loweramplitude facies landward of the main shoreface trend are interpreted to reflect marginal marine strata, such as lagoonal ponds or tidal flats, and correlate with strata that has been interpreted as terrestrial to estuarine in several wells (Pollock \& Crouch, 2005). Further south and southeast, medium- to high-amplitude reflectors with variable continuity (e.g., Figure 4.16, Figure 4.20) correlate with sandstone, mudstone, and coal interbeds in wells and are interpreted to demarcate the coeval coastal plain. On multiple seismic lines these facies show higher lateral continuity with respect to older coaly facies in this area (e.g., K90-P10), possibly indicating fairly uniform deposition or periodical marine flooding of a low-lying marsh environment. Terrestrial facies are frequently disrupted by chaotic reflectors of variable amplitude, which are interpreted as fluvial or estuarine channels (Figure 4.16). Longitudinal, relatively lower-amplitude patches between higher (coaly) amplitude responses on attribute maps may indicate the northwest orientation of these channels (Figure 4.15, Figure 4.24).

The top of the Eocene sequence shows angular truncation in several places across the southern basin. Angularity is most pronounced in the south-eastern basin (Figure 4.21), but is observed east of the Maui area (Figure 4.14) and possibly as far west as well Hochstetter-1, where medium-amplitude shoreface facies are top-truncated (Figure 4.20). Some angularity can also be inferred within the Eocene sequence, possibly indicating a change in basin geometry between deposition of the Kaimiro and the Mangahewa formations (Figure 4.14). Besides the widespread development of angular truncations within or atop the Eocene sequence, no evidence for localised compressional or extensional fault control is evident. 


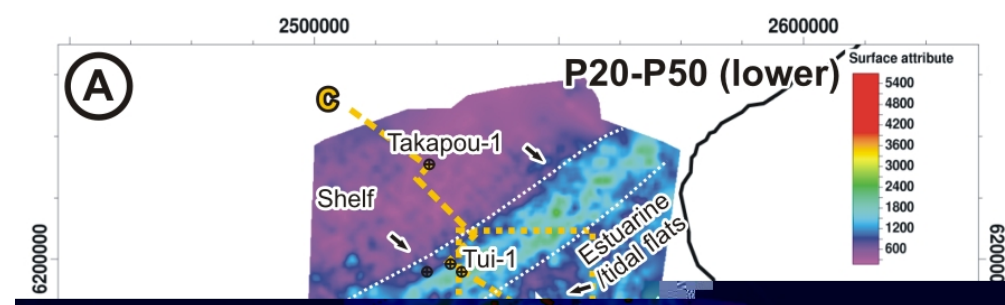

Figure 4.24 Facies distribution of the Eocene sequence (P20-P50) in the proximal basin from gridded interval attribute extractions (APA). Facies distribution of the (A) Kaimiro Formation ('D'-sands), and (B) the Mangahewa Formation ('C'-sands). C) Seismic reference profile from the Western Platform to the Moa-Maui swell showing horizon interpretations and well locations. The eastern parts of each attribute map (east of solid white line on attribute map) are based on stratal subdivisions indicated as dashed lines in (C), while the western parts were extracted between 100-150 ms (top) and 50-100 ms (bottom) beneath the base Oligocene reflector (P50), respectively. Approximate facies belts are outlined with white dotted lines and seismic profile locations are shown as orange dashed lines on attribute maps. 


\section{Detailed Eocene facies character in the Maui $3 D$ area}

The more detailed facies character and development of Eocene coastal systems is imaged by the Maui 3D survey (Figure 4.24). The base of the Eocene sequence (P20) in the Maui area is variably marked by a shale horizon or sandy shoreface facies of Late Paleocene to Early Eocene (Dt-Dw, 'E'-shale or sands), respectively (Figure 4.25), which indicates temporary flooding of Moa-Maui swell during the latest Paleocene. Above this horizon, 3D attribute maps show a number of sinuous, generally less than 200 m-wide channel systems with a northerly to north-westerly orientation and variableamplitude fill (Figure 4.26, left and centre). The high sinuosity of these systems, channel cross-cutting, and increased amplitudes in the overbank areas suggest frequent switching of channel pathways in a low-energy, low-gradient environment. An up to 400 m-wide, moderate-sinuosity channel just southeast of well Maui-3 can be traced in a northwesterly direction over more than $10 \mathrm{~km}$ (Figure 4.26, centre), and is interpreted as a major fluvial tributary towards the contemporary shoreline. Seismic amplitudes extracted over an interval higher in the sequence demarcate the inner (landward) limit of the contemporary shoreline. A northeast-southwest-oriented band of low amplitudes southeast of this feature (Figure 4.26, right) is interpreted as fine-grained, low-energy tidal flat or lagoonal facies. Near the top of the P20-P30 sequence, an isolated area of relatively continuous, medium to high amplitudes (Figure 4.26 right), can be correlated with sandy lithologies in wells Maui-1 and Maui-3, and could represent an estuarine mouth- or barrier bar that stretches between the locations of the two wells.

The base of the Mangahewa sequence (P30-P40) is marked by a relatively continuous, low-amplitude reflector that correlates with fine-grained deposits of the Turi Formation in wells (Kaimiro 'D'-shale, Figure 4.25). An amplitude extraction near the base of the formation shows a southwest-northeast-oriented band of increased amplitudes that could indicate the orientation of the coeval shoreline and distribution of relatively coarsergrained facies during maximum flooding (Figure 4.27, left). Further up-sequence, medium and high amplitudes indicate a subsequent basin-ward migration of this outer shoreline limit (Figure 4.27, centre), and intermittent base-level lowering. Subsequent transgression is indicated by the south-eastward migration of the shoreline system (Figure 4.27, right), which marks the top of the upper Mangahewa ' $\mathrm{C}$ 'sands interval in wells. Smaller features, marked by low-medium amplitude facies on attribute maps in the area of Maui-3, outline possible estuarine channels associated with this shoreline complex (Figure 4.27, right panel inset). 

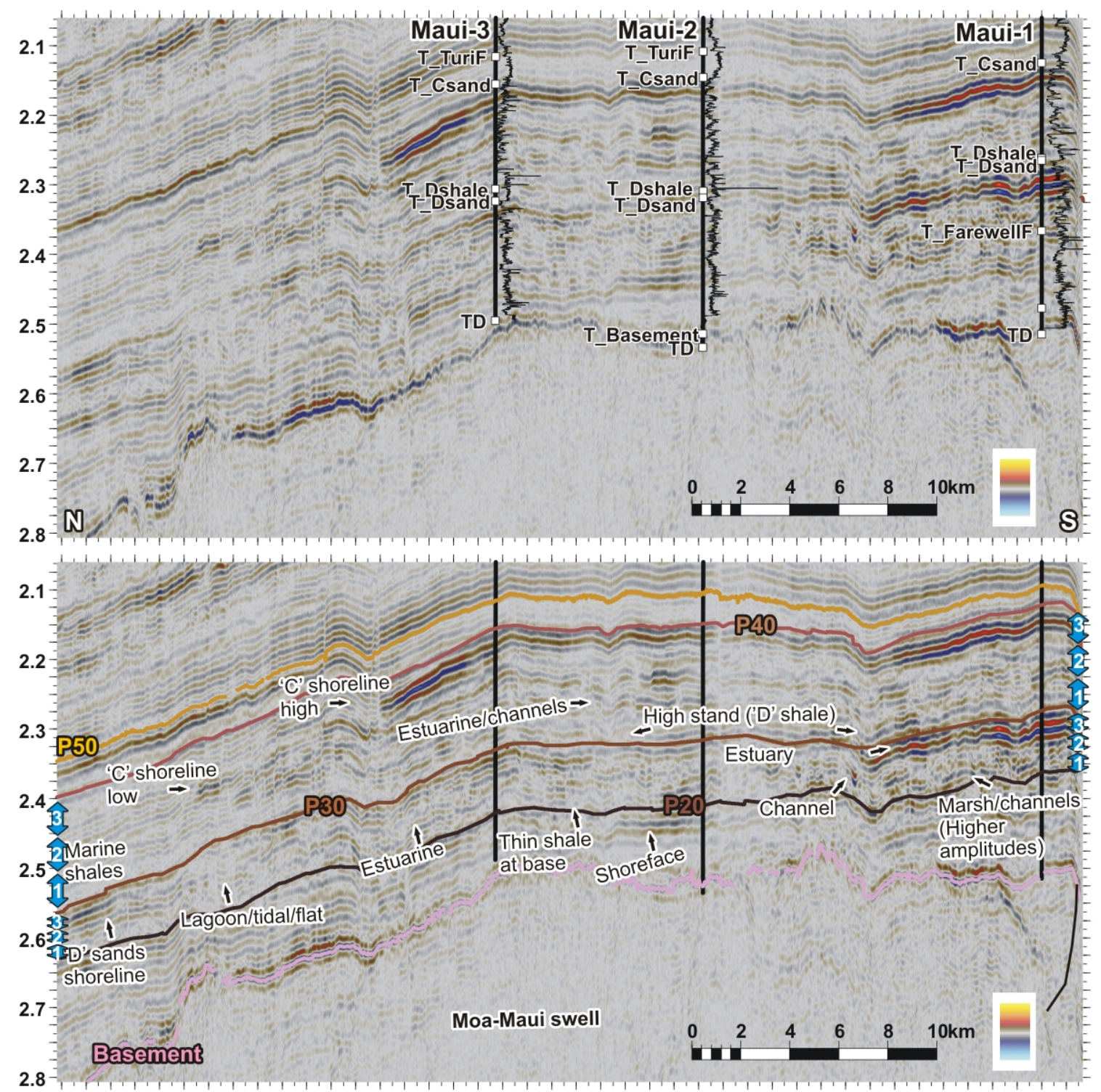

Figure 4.25 Composite seismic line of the from the Maui 3D survey magnified to show the facies character of the Eocene sequence (P20-P50). The top panel shows the seismic line with well paths (thick black lines), gamma-ray logs (thin black lines), and formation tops (white squares) of wells Maui-1, -2, and -3. Lower panel shows associated seismic horizon and seismic facies interpretations. Location of seismic line is shown in Figure 4.4, Figure 4.26, and Figure 4.27. Blue arrows indicate the intervals used for attribute extractions shown in Figure 4.26 and Figure 4.27. 


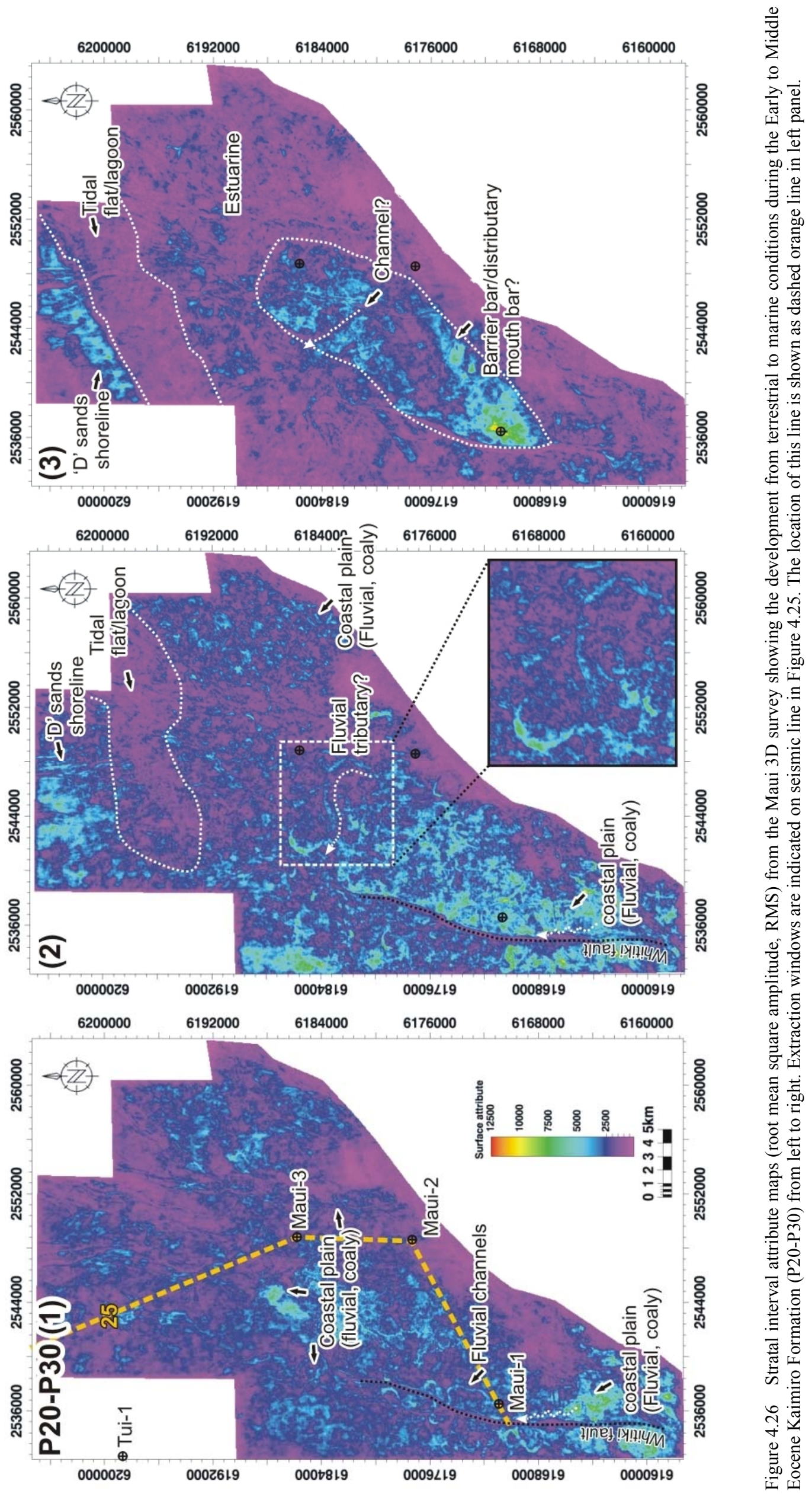



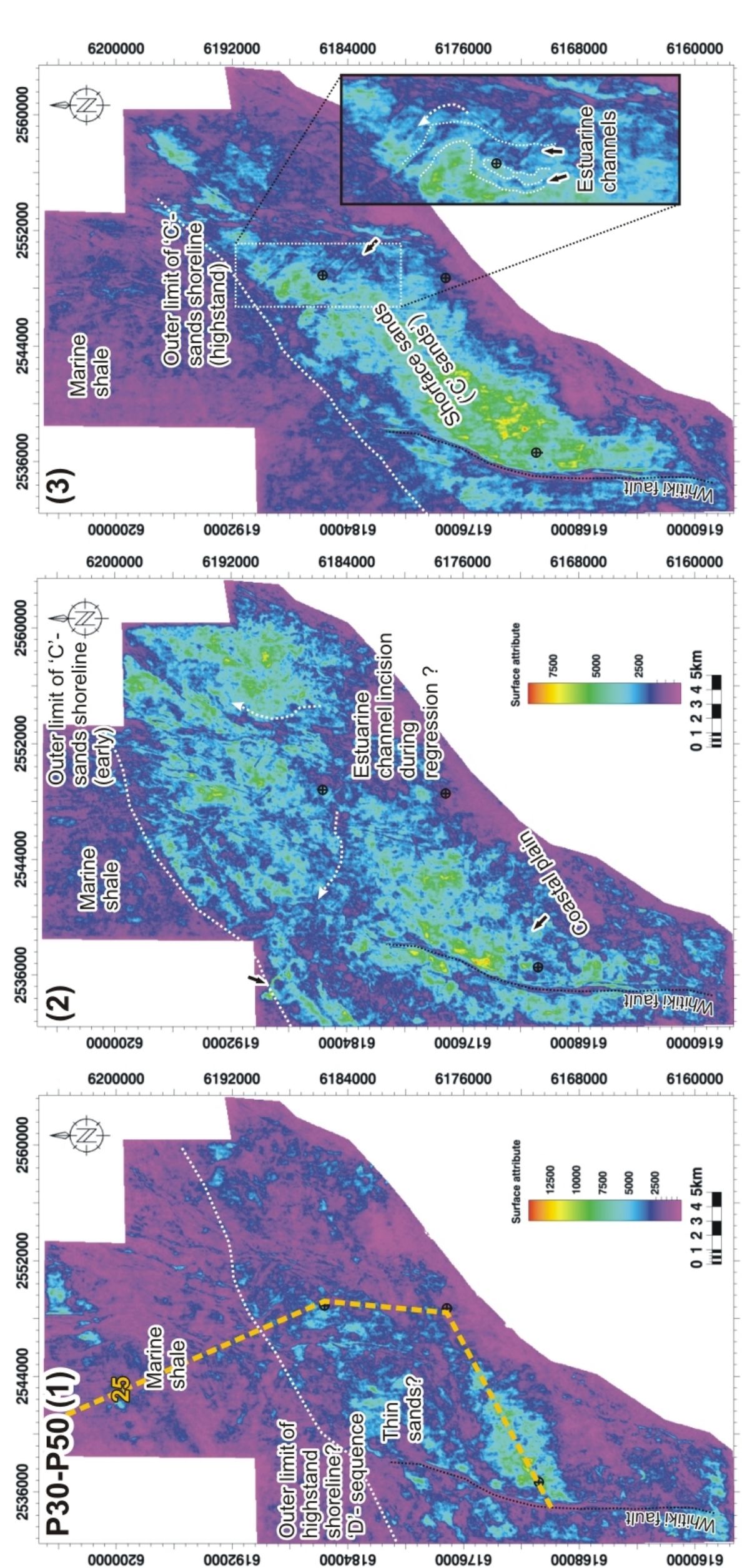

竞京 


\subsection{Discussion}

\subsubsection{Paleogeographic synthesis}

Observed facies patterns are combined into paleogeographic interpretations to depict the basin development at distinct phases of Cretaceous to Eocene basin evolution. Wherever possible these maps are based on quantitative differences in amplitude character and the nature of their spatial distribution derived from attribute maps. Attribute information was supplemented with observations of stratal geometries such as onlaps, downlaps, and angular truncations wherever observed, especially when attribute maps were inconclusive or adequate phantom horizon slicing to represent the chronostratigraphic development was difficult (e.g., Paleocene). Seismic facies information was augmented with environmental and lithofacies data from boreholes and reconstructions were aimed to be consistent with outcrop geology (e.g., Wizevich et al., 1992; Bal \& Lewis, 1994; Rattenbury et al., 1998a; Browne et al., 2008; Higgs et al., 2010).

\section{Late Cretaceous}

The Late Cretaceous paleogeographic map (Figure 4.28) in proximal Taranaki Basin is comparable to previous paleogeographic interpretations of the Rakopi Formation (Thrasher, 1991a; King \& Thrasher, 1996) and shows the widespread dominance of coastal plain and fluvial marsh environments. However, extension of seismic data analysis into the distal basin shows that the coeval shelf margin may have been located significantly further northwest than previously interpreted (see Figure 4.2). Foreset heights of the Late Cretaceous delta suggest temporary bathyal ocean conditions in the southern NCT and deposition of turbidite sequences into a possibly one kilometre deep basin. The considerable sediment thickness of this delta sequence indicates that this area may have been a major sediment sink of the detaching New Zealand landmass.

The maps outline a vast, relatively flat coastal plain and suggest the deposition of coaly sequences (Rakopi Formation) over an area of more $20,000 \mathrm{~km}^{2}$ in the southern NCT. The presence of the formation on basement highs such as the area near the Tane-1 well indicates a generally rising base-level during deposition of this sequence and frequent flooding of this broad, low-lying coastal plain is considered likely. Increased marine influence has been shown to lead to earlier petroleum expulsion and increased oil- 
proneness in Eocene coals (Sykes et al., 1999), and might have improved the petroleum source-rock potential of Late Cretaceous coals in the distal basin. Coal sequences in graben-bound depocentres of the proximal basin are likely to contain higher amounts of detrital components and alluvium derived from the graben footwalls (Gawthorpe \& Leeder, 2000). Widespread alluvial facies in the lower part of the Late Cretaceous sequence in the Manaia Graben are interpreted to be equivalent to conglomerates found in outcrop of northwest Nelson (Otimataura conglomerate, Wizevich, 1994).

General sediment transport was likely to the north because the area of the NCT was topographically lower than the proximal basin, and major drainage pathways are inferred through relay systems of the Kiwa Fault or the north-eastern basin (Moa subbasin by Thrasher, 1990) (Figure 4.1). Although fluvial systems and possibly marine periods can be inferred from the seismic data, major uncertainties in the interpretation pertain to the connection of sedimentary systems between the individual sub-basins and between the proximal and the distal basin. A problem arises from the inferred location of contemporary shoreline, the widespread distribution of coaly coastal plain facies, and evidence for marine influence in outcrop areas of the northern South Island (Browne et al., 2008), since minor base-level shifts would have had to eventuate in flooding of coastal plain area over more than $300 \mathrm{~km}$ in a north-south direction. The evidence of marine facies in the southern basin thus suggests that either 1) the entire area was extremely flat, allowing rapid translation of the sea during relative sea-level rises, 2) there was a marine connection towards the opening Tasman Sea in the south for which evidence has been destroyed during Cenozoic convergence, or 3) that mapped Cretaceous coal sequences are older in the distal basin compared to the proximal basin and that this time-transgressive nature has not been resolved in biostratigraphic data and seismic mapping. While a relatively flat topography is indicated by seismic data in the distal basin, it is considered likely that there was a certain topographic gradient in the horst and graben landscape of the proximal basin, making the $300 \mathrm{~km}$ of flooding an unlikely scenario. A marine seaway to the south could have existed along failed continental rifts on the western South Island (Laird, 1981; Laird \& Bradshaw, 2004), which may have represented the southern extension of Taranaki Basin. Recent analysis of biostratigraphic data in Tane-1 (I. Raine, pers. comm.) suggests that coals previously associated with the Rakopi Formation and North Cape Formation may be older ( $\sim 5-10$ Ma) than the age inferred for these formations in the proximal basin, and this uncertainty may be reflected in the paleogeographic reconstruction. 


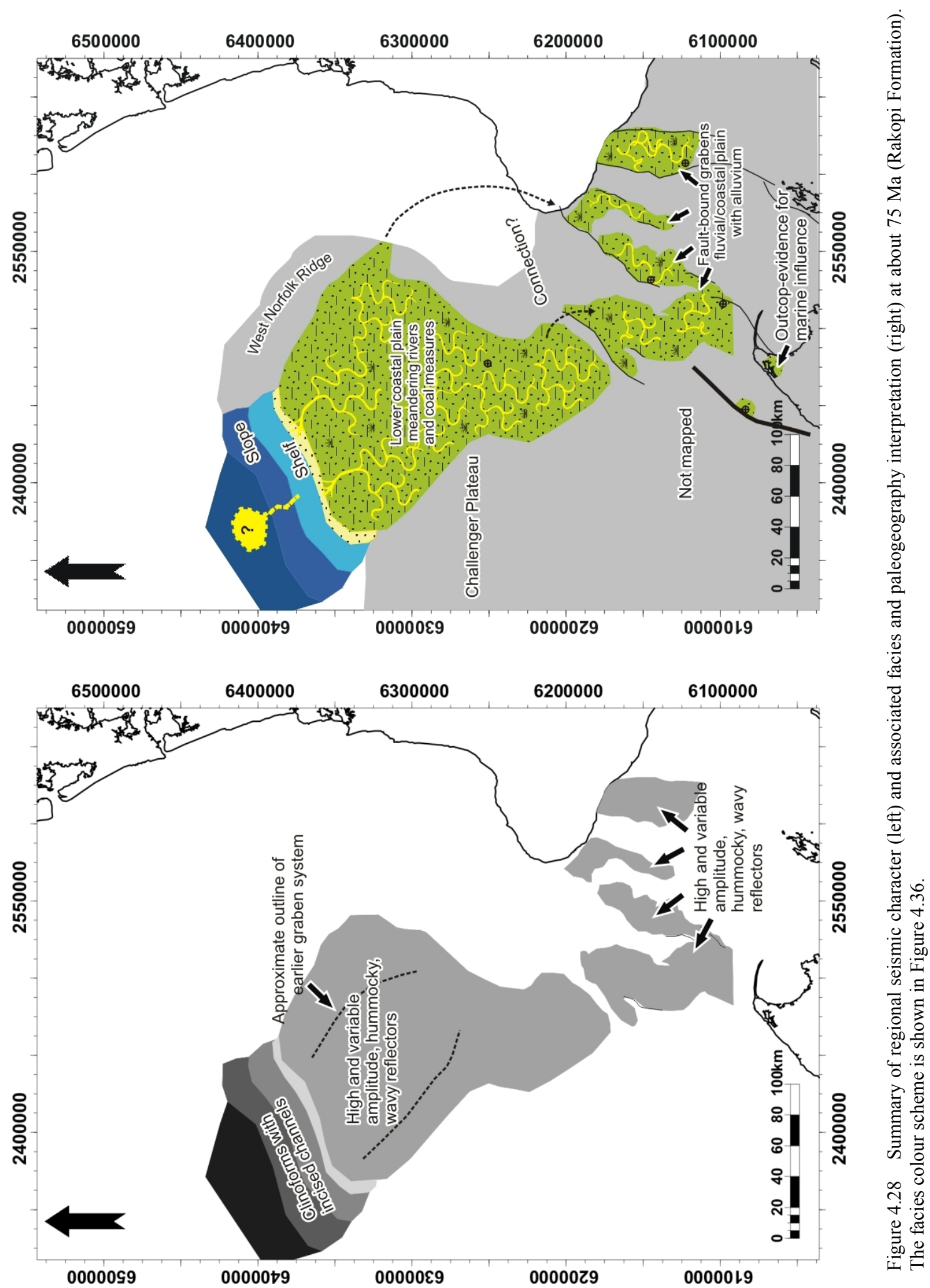




\section{Latest Cretaceous}

Three maps depict the time interval of the latest Cretaceous North Cape Formation, of which the first two are limited to the distal basin. The first map (Figure 4.29) depicts the facies distribution during initial flooding of the Taranaki delta coastal plain ( 75-70 Ma), and shows the development of a wide shelf area and shoreline systems across the remaining basement highs. Although not constrained in detail, it is considered likely that marine flooding reached the proximal basin during this time. While, based on few biostratigraphic age constraints, it has been suggested that deposition of the North Cape Formation in the proximal basin was restricted to the last 3 million years of the Cretaceous (Thrasher, 1992), flooding could have occurred earlier, but is not represented in samples that were drilled above paleo-basement highs. Alternatively, due to the insufficient intra-Cretaceous age differentiation, it is possible that this marine incursion is recorded by strata that is defined as Rakopi Formation in the proximal basin (Browne et al., 2008). However, the inability to confidently correlate seismic reflectors across the Kiwa Fault has not allowed deriving the appropriate time constraints.

The second map (Figure 4.30) depicts an interim lowstand, which, based on dinoflagellate data in well Wainui-1, is inferred to occur at about 72-68 Ma (Mildenhall et al., 1982). This lowstand may be attributed to an eustatic sea-level fall either at $71 \mathrm{Ma}$ or $68 \mathrm{Ma}$ (Haq et al., 1987) as previously inferred by Thrasher (1992), or, alternatively, may be attributed to decreasing tectonic subsidence (e.g., Tane-1, Figure 4.6) and filling of available accommodation space. If Cretaceous facies associations in Tane-1 are indeed older than in proximal Taranaki Basin (I., Raine, pers. comm.), this regression could represent the event that is evidenced as an unconformable surface at the base of the North Cape Formation in the proximal basin.

The third map depicts the upper part of the North Cape Formation close to maximum flooding in the late Cretaceous about $66 \mathrm{Ma}$ (Figure 4.31). Uncertainty is again associated with the location of marine pathways between the proximal basin and the distal basin. It is evident that the sea penetrated to the southern parts of the basin, but marine inlets might have been very narrow. The western basin is interpreted to have been tectonically quiescent with only minor extension on faults on the Western Platform. The development of new faults in the Manaia Graben and the deposition of alluvial 
conglomerates in the Pakawau basin indicate continued tectonic activity in the southern and south-eastern areas.

High-energy marine shoreline systems are inferred to have established in the distal basin, while the proximal basin was dominated by tidally-influenced shallow marine environments. Based on the more open-marine conditions in the distal basin, it is assumed that shoreface facies are well sorted and might have similar properties to Paleogene shoreline facies, which have shown typical average porosities of $\sim 20 \%$ and permeablities in the 2-10 Darcy range (e.g., King \& Thrasher, 1996; Matthews, 2000). In comparison, constricted marine conditions in the proximal basin are likely to have led to the deposition of finer-grained sands and frequent sand-silt interbeds (Higgs et al., 2010). However, elongated channels between the individual sub-basins may have been subjected to significant tidal currents, which may in turn have facilitated sorting of sandy facies along the narrow shorelines. Deposition of alluvial conglomerates is inferred to be localized adjacent to active graben systems in the south and southeast. Besides the relatively wide distribution of coaly facies within the depression of the Tane Trough (Wainui Member), the distribution of latest Cretaceous coal members is inferred to be laterally localized between remnant basement highs and within graben systems in southern and south-eastern margin of the basin (Moa-Maui swell, Manaia and Pakawau sub-basin), as inferred from limited outcrop by Higgs et al. (2010). The map of the proximal basin is consistent with earlier reconstructions based on seismic paper sections by Thrasher (1992). 

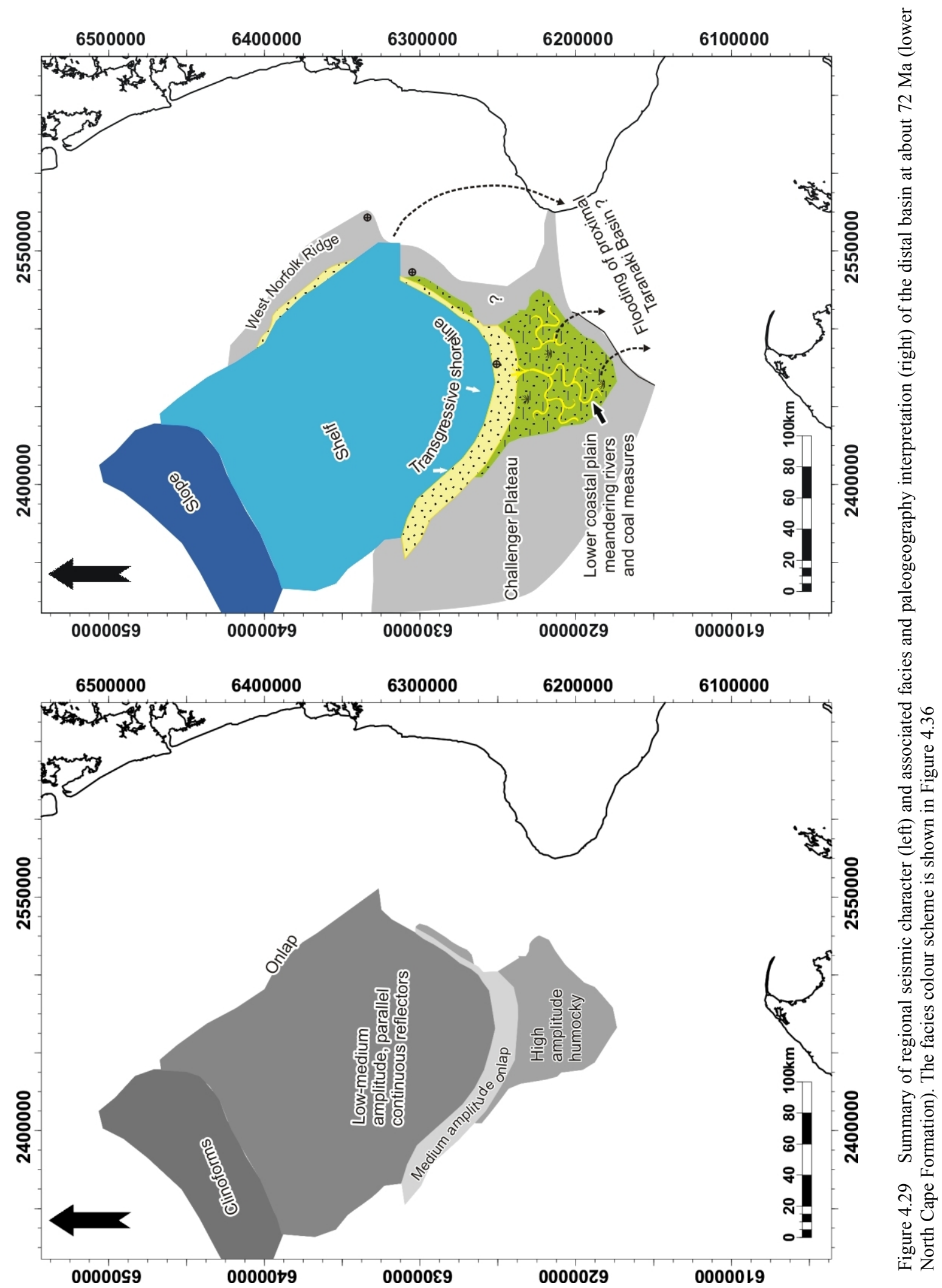


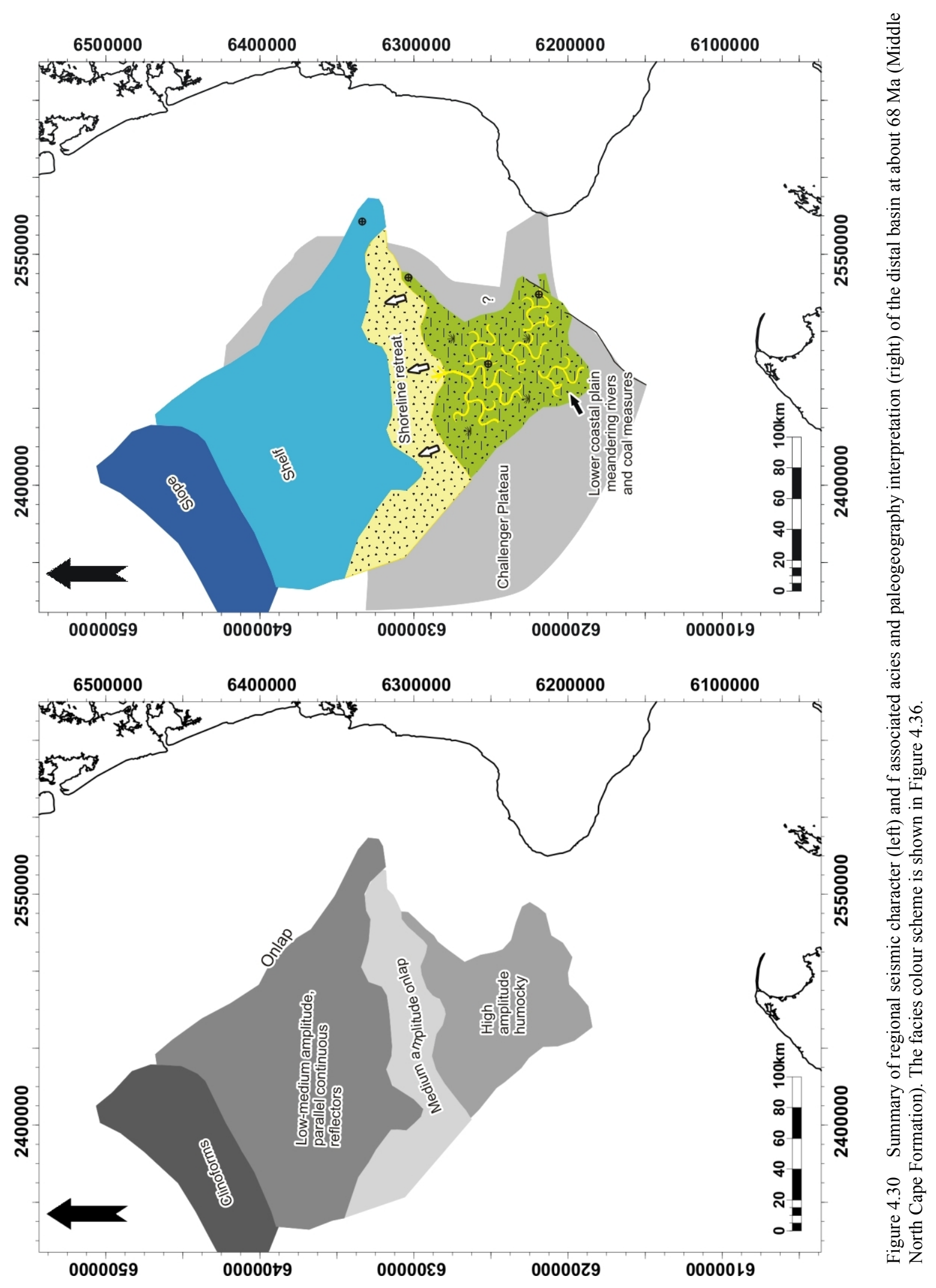




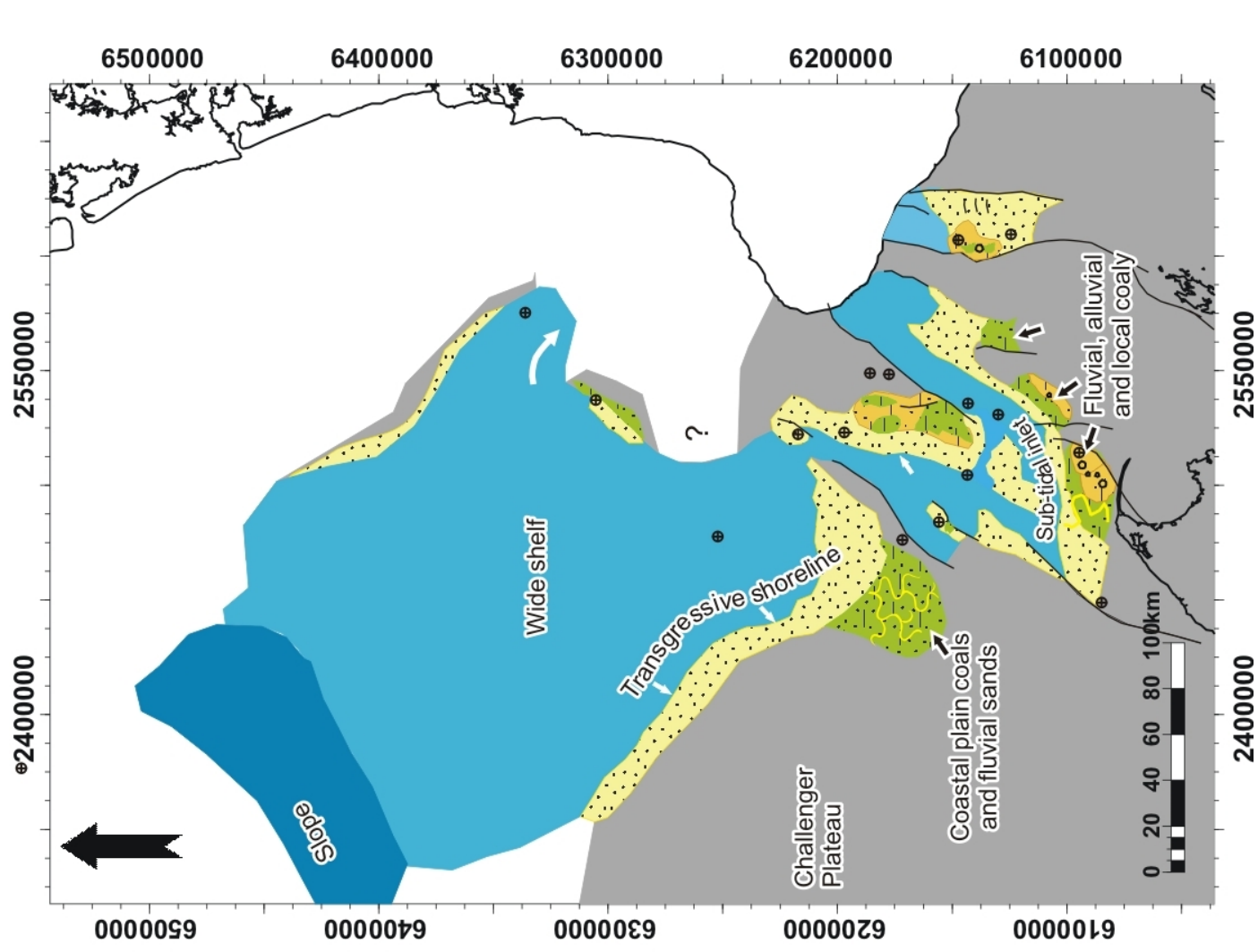

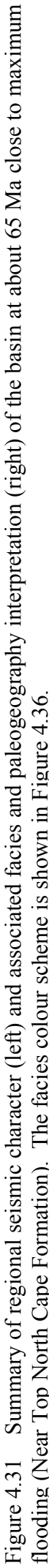

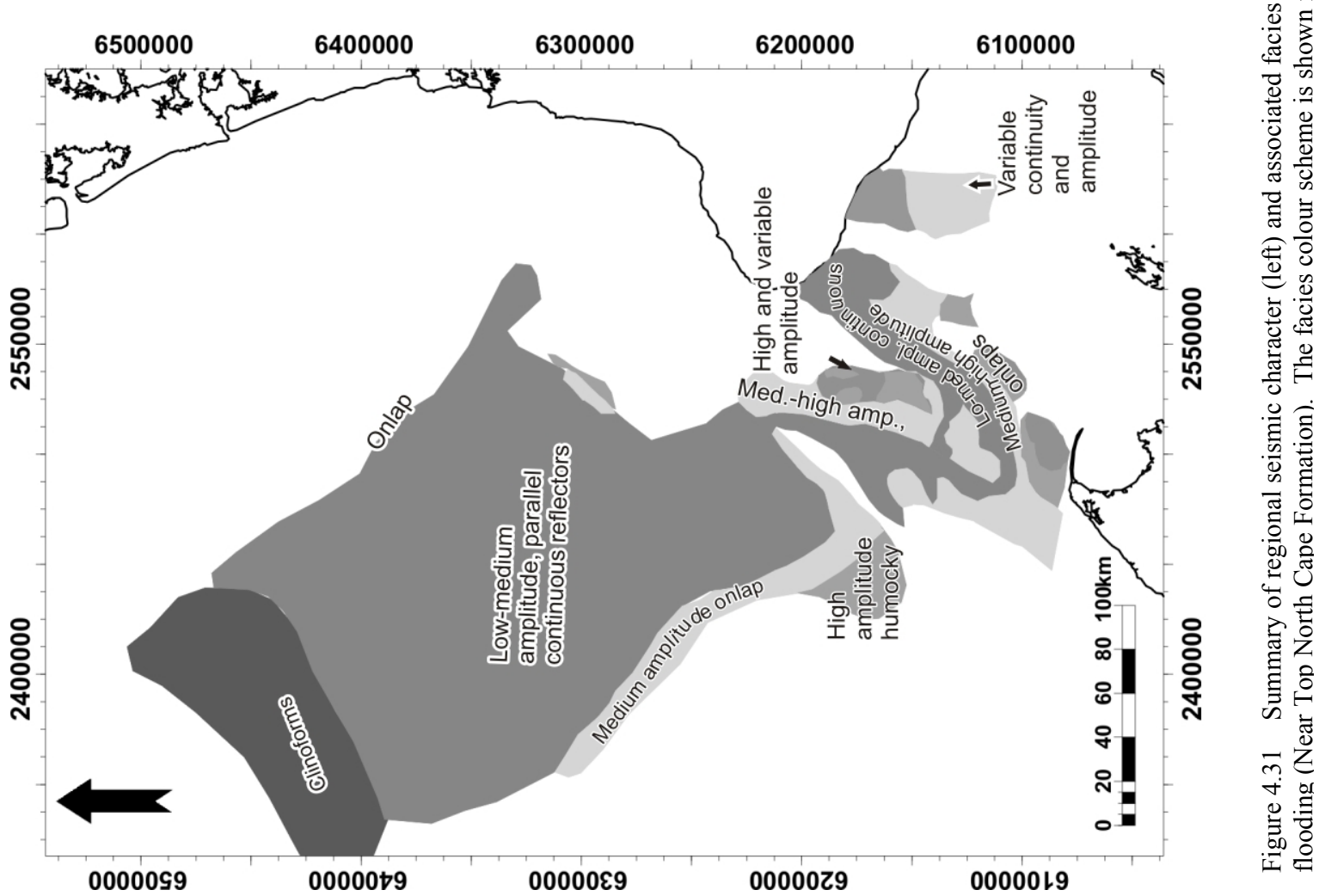




\section{Paleocene}

Two maps are presented for the Paleocene time interval, depicting the lower part of strictly Teurian age (Dt, $\sim 65-58 \mathrm{Ma}$ ) (Figure 4.32) and the upper part that may extend into the Waipawan (Dt-Dw, $258-53 \mathrm{Ma}$ ) (Figure 4.33). Occurrence of marine strata in well Waka Nui-1 (Uruski \& Stagpoole, 2004) indicate the development of entirely marine conditions in the north, which together with reorganization of the slope geometry may be a response to higher thermal subsidence in this area of the basin (Figure 4.8). The wide development of shoreface sequences on remaining basement highs in the central basin is interpreted to be an expression of generally flat topography and large shoreline shifts during minor base-level variations. Areas landward of these shoreface facies are interpreted to represent regions of episodic flooding, in which sandy facies may not be well developed or be frequently intercalated with finer-grained facies. Relatively thin, high-amplitude seismic sequences and the frequent occurrence of coal-sand interbeds in wells (Shell BP Todd Oil Services Ltd., 1970a; New Zealand Overseas Petroleum Ltd., 2004) suggest that the central basin area has developed into a broad, low-lying coastal and fluvial plain, which is in contrast to higher-energy braided stream deposits evidenced in outcrop (Rattenbury et al., 1998a) and boreholes (Schmidt \& Robinson, 1990) of the southern and south-eastern basin. The different nature of depositional environments in the south might be related to steeper topographic gradients in the graben systems that have remained tectonically active until at least the Early Paleocene.

The later map (Figure 4.33) depicts the waning control of graben morphology on sediment deposition. Due to total net subsidence a general base-level rise is inferred, but apparent widening of the coastal plain, deposition of the Tane siltstone member on the Western Platform (e.g., Shell BP Todd Oil Services Ltd., 1976), and channels in the outer shelf area (Figure 4.10) may indicate a base-level lowering during the upper Paleocene, which is in line with previous interpretations of regressive systems in the south-eastern basin (Schmidt \& Robinson, 1990). This regression could be a result of decreasing accommodation space due to declining subsidence rates despite constant sedimentation (King \& Robinson, 1988; King \& Thrasher, 1996) and could have been amplified by a global eustatic sea-level low during the late Middle Paleocene (58 Ma) as proposed by Haq et al. (1987). 


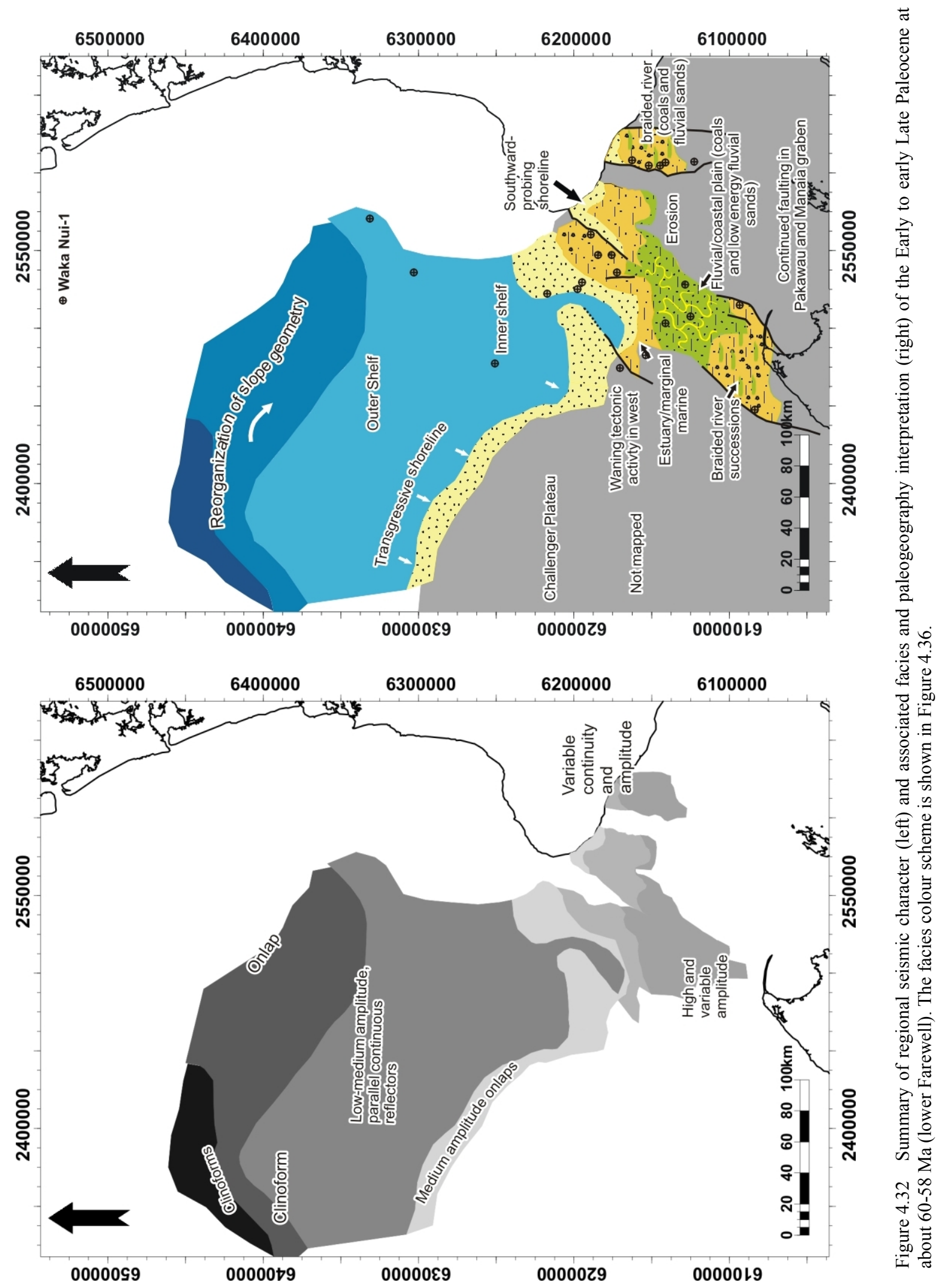




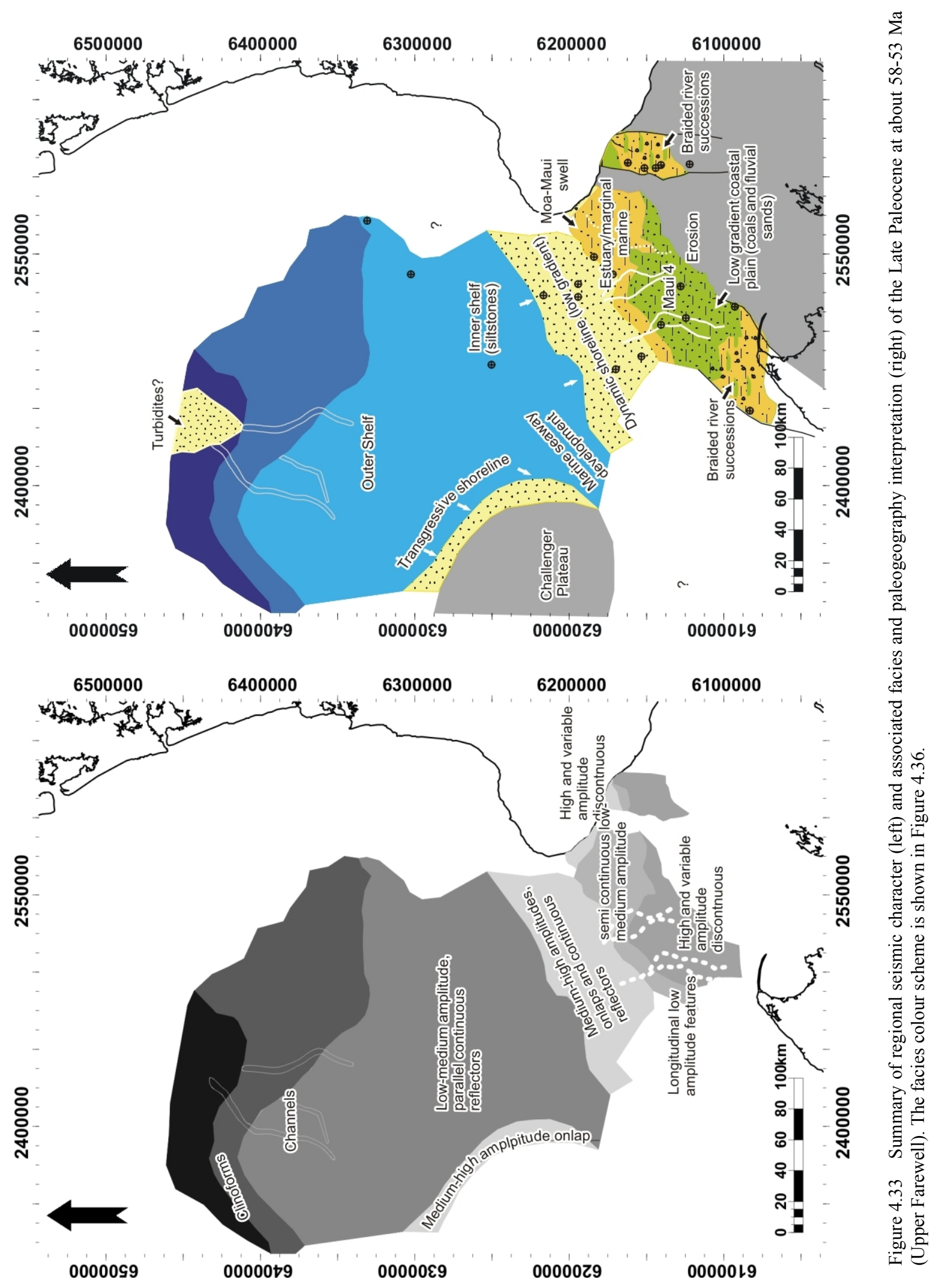




\section{Eocene}

Two maps are presented for the Eocene time interval, spanning New Zealand stages from the Mangaorapan to Kaiatan (Dm-Ak). The earlier map (Figure 4.34) captures the time interval of the Kaimiro Formation, during the Mangaorapan to Porongan (Dm-Dp, 53-45 Ma). The well-developed northeast-southwest-trending shoreline system evident from seismic data indicates predominantly wave-dominated coastal environments. Furthermore, the linear nature of this shoreline could be indicative of longshore drift along a marine seaway that developed south-westwards across the Challenger Plateau. Channels observed in the Maui 3D (Figure 4.27, centre) are interpreted to link basinward with a bigger channel mapped by Matthews (2010) in the area of Tui-1. The combined channel systems may represent sediment contributories towards the outer shelf areas and feeder systems of fan deposits north of well Tane-1 (Figure 4.18). The widespread development coastal plain environments and low-energy fluvial systems in the central and south-eastern basin suggests relatively small topographic gradients.

The later map (Figure 4.35) displays Middle to Late Eocene depositional systems of mostly Porongan to Bortonian age (Dp-Ab, 45-38 Ma), and shows the southeast advance of the shoreline systems (Mangahewa Formation, ' $\mathrm{C}$ '-sands). The inferred sediment transport direction of fluvial channel systems towards the coast is in line with similar features imaged in the onshore area (Voggenreiter, 1992). Wrench faulting and folding observed in the distal part of the basin (Uruski et al., 2002b) suggests the onset of tectonic activity from the Middle Eocene and is schematically depicted. Increasing subsidence rates observed in wells (Figure 4.6) suggest further deepening in the distal basin, while angular truncations in the southeast may indicate concurrent uplift in the southern area (Figure 4.14).

Although shoreface facies in wells Maui-4 (Shell BP Todd Oil Services Ltd., 1970a), Kea-1 (Tricentrol Exploration Overseas Ltd., 1985), and onshore Taranaki (e.g., Lock \& Adams, 1980) indicate further south-eastward migration of the shoreline during the Late Eocene, the development of shoreline sequences east of the Maui area cannot be confirmed from seismic facies analysis, but may have been subsequently eroded. Because the Late Eocene facies distribution is not constrained in detail in the proximal basin, fan systems of the Late Eocene Tangaroa Formation (Ab-Ar, 38-34 Ma) are included in the Mangahewa map (Figure 4.35). 


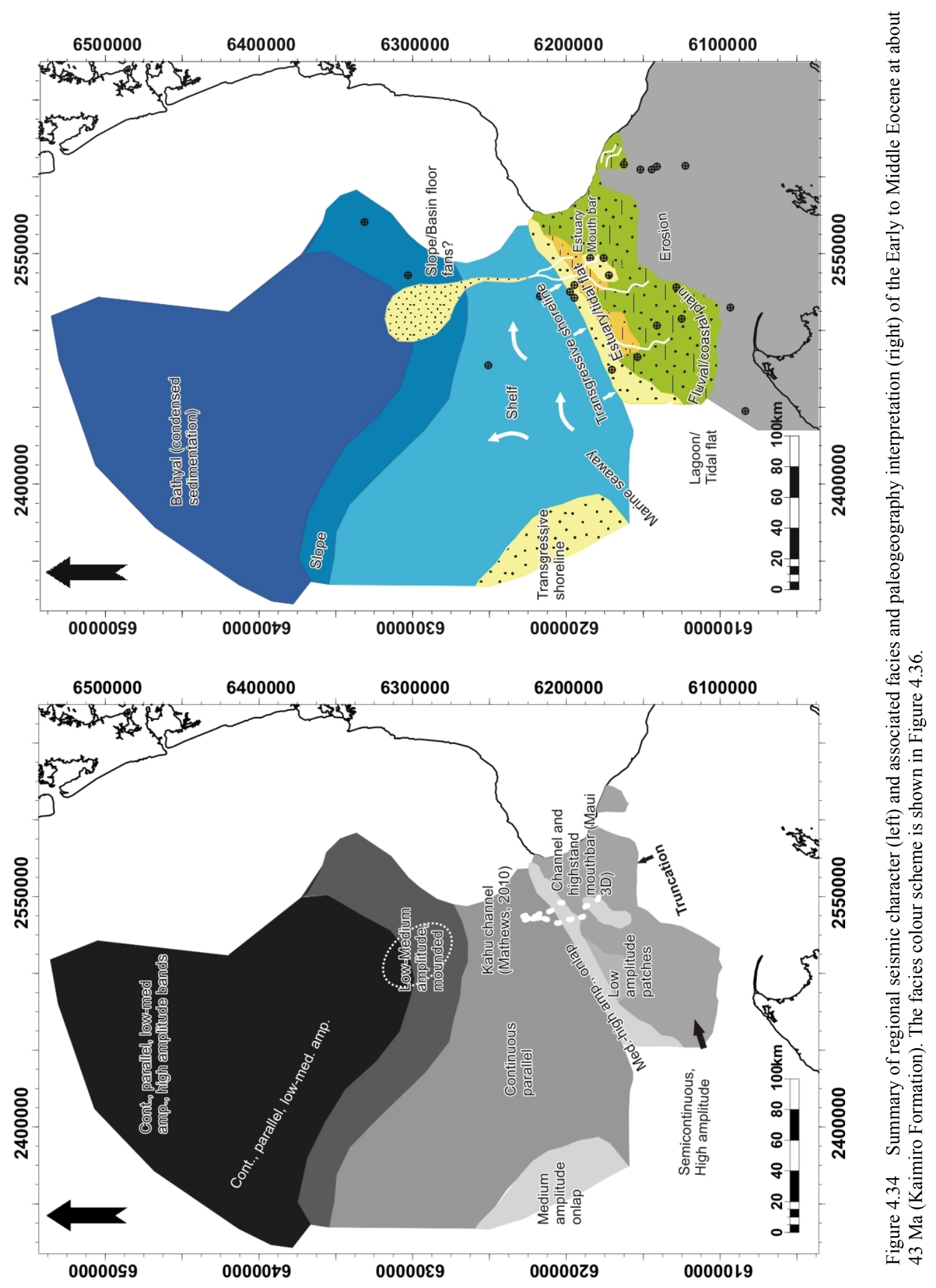




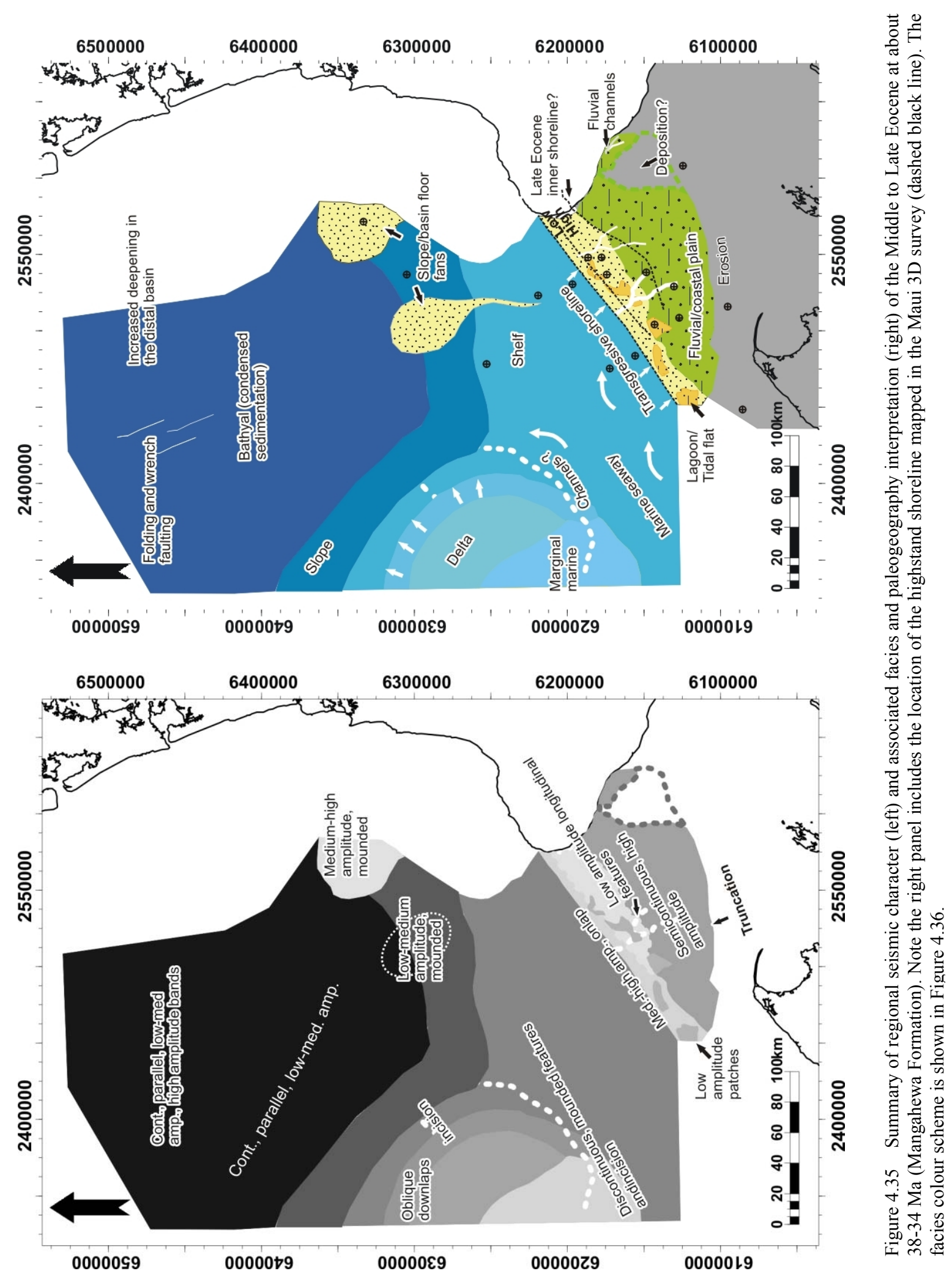




\section{Chronostatigraphic basin development and sequence character}

The facies and paleogeographic interpretations are presented along representative transects across the basin to illustrate the sequential development and distribution of sedimentary facies belts (Figure 4.36). In order to closely honour the facies interpretation from seismic data, the chronostratigraphic panels were directly projected from facies maps onto profiles. The time intervals between the maps were infilled based on trends seen on seismic data such as onlaps or migrating shoreline sequences.

The two transects show the first-order trangressive nature of the latest Cretaceous to Eocene sedimentary development with a general south and south-eastward migrating shoreline and provide improved detail compared to generalized chronostratigraphic columns from previous authors (e.g., Palmer \& Andrews, 1993; King \& Thrasher, 1996). At least five higher, $2^{\text {nd }}$ - to $3^{\text {rd }}$-order cycles can be inferred from the backward- and forward-stepping shoreline sequences and may record the influences of periodic baselevel changes. Although not well constrained in the Cretaceous sequence, Paleogene successions show characteristic facies superpositions indicative of cyclic changes in relative base-level. Each of these sequences shows a basal regression, basin-ward stepping of the shoreline, and channel incision in the near-shore to shelf area. Ensuing base-level rise within each successive sequence resulted in landward stepping shorelines marked by marine onlaps (e.g., 'F'-, 'C'-, and 'D'-sands). Each sequence is then bounded at the top by a shaly member that might represent maximum flooding and relative highstand of the sequence (e.g., 'E'-shale, 'D'-shale).

Higher-order cyclicity inferred from well data by Pocknall and Beggs (1990) is not resolved on seismic data. While mapping of high-quality 3D seismic data reveals more detail compared to regional attribute mapping, it is considered unlikely that higher-order cycles can be seismically resolved for the Paleocene-Eocene interval in the proximal basin. This is mainly due to the overall low subsidence rates and little sediment accumulation, making it hard to distinguish higher-order cyclity on seismic. 

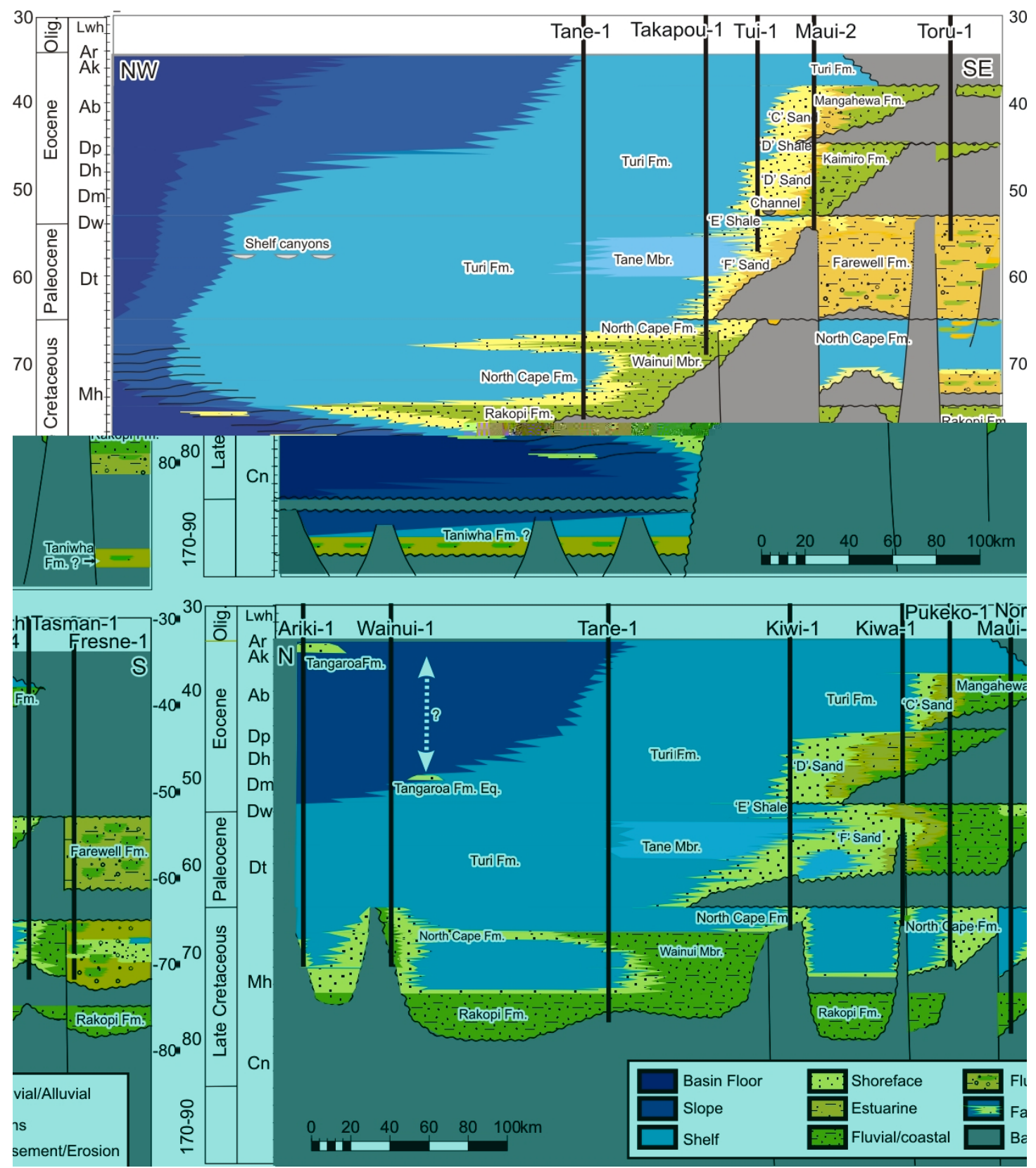

Figure 4.36 Chronostratigraphic panels showing the evolution of sedimentary facies from the Cretaceous to the Eocene in NW-SE (top) and NS direction (bottom). Legend of facies interpretations is shown at the base. Absolute ages are shown on the left and right and international epochs and New Zealand stage abbreviations are shown on the left. 


\subsubsection{Continental stretching and regional tilting}

Seismic facies patterns and palinspastic reconstructions (see Chapter 3) confirm that rifting in the present-day deep-water basin ceased before the development of the Cretaceous Taranaki delta ( $>85 \mathrm{Ma}$ ), while extensional faulting continued into the Late Cretaceous and Paleocene in the proximal basin (85-60 Ma). Differences in timing and angularity between extensional fault systems indicate that the two areas, though forming contiguous depositional systems during the Late Cretaceous and Cenozoic, evolved as the result of essentially two different tectonic rifting events (Figure 4.37).

Basin formation in the present-day deep-water area can be interpreted as a result of regional extension of the New Zealand area prior to Tasman Sea opening (Gaina et al., 1998; Sutherland et al., 2001), which was possibly initiated as a result of slab rollback after cessation of Mesozoic subduction around $105 \mathrm{Ma}$ (Collot et al., 2008; Collot et al., 2009). On the other hand, the plate tectonic origin of extension in proximal Taranaki Basin until the Paleocene is not easily explained, since deviatoric crustal stresses should have been accommodated on the spreading ridge in the southwest (Figure 4.37C). Due to the high angularity of faults with respect to the Tasman Ridge (Figure 4.37), it is considered possible that the proximal basin may have formed in the context of a transform system of the opening Tasman Sea as suggested by Thrasher (1990c). However, since rifting in the NCT may have ceased as early as $100 \mathrm{Ma}$ (Collot et al., 2009), significant overlap of these events and a transform link between contemporary rifting in the NCT and Tasman Sea, as suggested by Thrasher (1990c), is considered unlikely.

The effects of these different rifting events on the crustal structure can be further characterised by estimating the amount of lithospheric stretching from the slope of the post-rift tectonic subsidence signal (McKenzie, 1978; Steckler \& Watts, 1978). Comparison of Paleogene tectonic subsidence values with theoretical models of subsidence due to thermal re-equilibration of the lithosphere after crustal stretching (Figure 4.7) suggests that crustal thinning in proximal Taranaki Basin was likely significantly less than $33 \%(\beta=1.5)$. In southern Taranaki basin curves are better matched with an assumed $\beta$-value of 1.2 (17\% thinning), but, given that this signal might be influenced by activity on adjacent faults, values are likely smaller. Similarly, Paleogene 
subsidence values in the central basin roughly match theoretical stretching factors of about 1.5, but flat Early-Middle Eocene part of the curve indicate that stretching may have been on the order of $10-23 \%(\beta=1.2-1.3)$. Paleogene values in well Tane-1 can be approximated with a thermal subsidence caused by 33\% stretching of the lithosphere ( $\beta=1.5)$, while Wanui-1 and Ariki-1 require stretching factors of $>50 \%(\beta>2)$, possibly increasing from south to north. Since these signals may show the effects of minor Late Cretaceous fault-related subsidence in the adjacent Moa-sub-basin (Figure 4.1) and a lack of intra-Eocene stratigraphic markers in these boreholes hinders constraining the change from post-rift sag to additional forcing during the Late Eocene, stretching factors of 1.51.8 are considered reasonable estimates for these wells. Subsidence values in Waka Nui1 are too high to be explained by thermal contraction alone and this area is interpreted to have been severely affected by renewed tectonism during the Eocene. Given present-day crustal thicknesses of 25-30 km in proximal Taranaki Basin (Stern \& Davey, 1990) and 20-25 km on the outer continental shelf (location of well Tane-1, Wainui-1, and Ariki-1, Wood \& Woodward, 2002), estimated pre-stretching thicknesses $28-39 \mathrm{~km}$ ( $\beta=1.1-1.3)$ and 30-40 km ( $\beta=1.5-1.8)$ are inferred. The similar pre-rift crustal thickness would be consistent with neighboring locations and thickened crust in the hinterland of the Paleozoic to Mesozoic Gondwana subduction zone. However, uncertainties in the amount of crustal thickening during Neogene convergence in the proximal basin hinder the accurate estimation of pre-rift crustal thickness. Regardless of the uncertainties associated with Paleocene faulting and Late Eocene tectonic forcing, northward tilting of the basin during the Paleogene can be partly attributed to greater stretching and consequently higher post-rift subsidence in the NCT.

The slightly higher extension estimated from subsidence curves in proximal basin $(\beta=1.1-1.3)$ compared to the palinspastic reconstruction presented in Chapter $3(<5-8 \%$, $\beta=1.05-1.08)$ could be attributed to the distal effects of greater lithospheric thinning in the NCT. Alternatively, since some of the faults in proximal Taranaki Basin are estimated to sole into flat detachment systems at depths of 15-20 km (Thrasher, 1990c), the amount of horizontal extension may be somewhat higher than can be constrained by reconstructing fault throws at shallow depths (e.g., Lister et al., 1986). Furthermore, because proximal Taranaki Basin may have developed in the context of a transform system associated with Tasman Sea spreading ridge, a certain degree of trans-tensional motion is likely. Trans-tensional motion has been previously inferred (Thrasher, 1990c) and may have influenced the subsidence character, but upward-concave subsidence 
curves show little resemblance to classic strike-slip basins (Xie \& Heller, 2009), and suggest that strike-slip motion was minor.

Stretching factors on the order of 1.5-2 are common in basins of similar origin around the globe, such as the northern North Sea or east Africa (Swift et al., 1987; Hendrie et al., 1994; Roberts et al., 1995). The southern NCT can therefore be classified as a failed rift. These estimated amounts of extension suggest that stretching in the southern NCT was smaller than in the northern parts of this basin system, where crustal thinning has led to decompressional melting in the mantle lithosphere and creation of oceanic crust (Klingelhoefer et al., 2007). Stretching factors of $<1.5$ are more typical for basins located in distal areas of rift zones or minor intra-continental rifts (e.g., Allen \& Allen, 2005; Xie \& Heller, 2009). Thus, the Late Cretaceous-Paleogene history of proximal Taranaki Basin is consistent with being a small extensional feature located in the distal area of the opening Tasman Sea.

The timing of increasing subsidence in the northern and central basin and angular truncations in the southern basin during the Middle- to Late Eocene follows the initiation of the Australia-Pacific boundary north and south of New Zealand (Sutherland, 1995; Wood et al., 1996; Cluzel et al., 2006). While minor trans-pressional faulting has been observed in the distal areas of the deep-water basin and the northern Taranaki Fault (Uruski et al., 2002b; Stagpoole \& Nicol, 2008), no renewed extension in the central basin is evident during the Late Paleogene. Consequently, compression related to the onset of Australia-Pacific plate convergence is a more likely cause for additional tectonic forcing than renewed extension. The detailed character of this subsidence and possible tectonic driving mechanisms are further investigated in Chapter 5 of this thesis. 

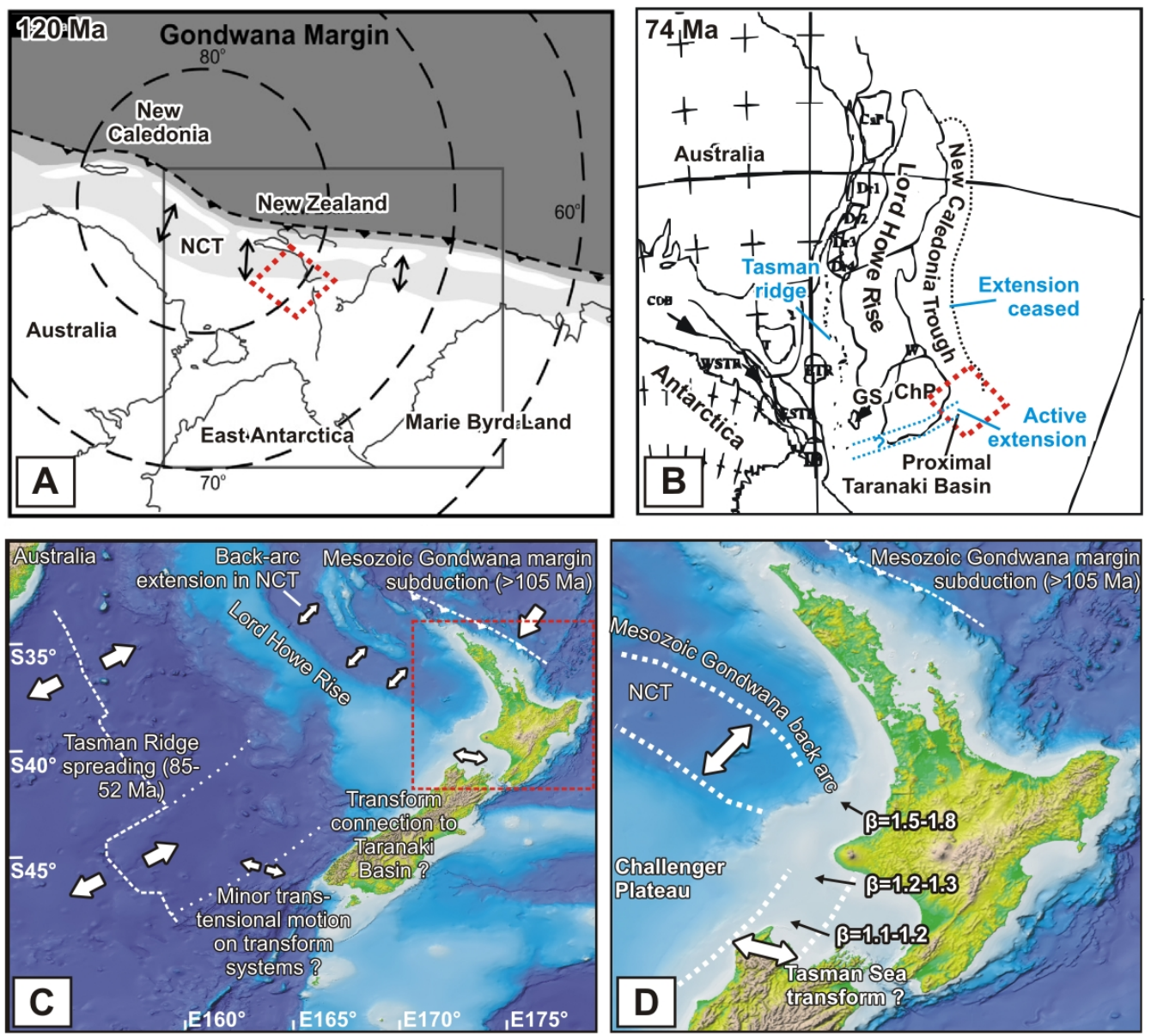

Figure 4.37 Tectonic setting during the two rifting phases evidenced in Taranaki Basin and present-day physiography of the greater New Zealand area. A) Plate tectonic reconstruction of the eastern Gondwana margin during the late Early Cretaceous (after Sutherland et al., 2001), showing the general setting of early NCT formation. B) Plate tectonic reconstructions during the early phases of Tasman Sea spreading and onset of waning tectonic activity in proximal Taranaki Basin (after Gaina et al., 1998). The approximate study area is outlined by the dashed red polygon. Abbreviations in maps refer to New Caledonia Trough (NCT), Challenger Plateau (ChP), and Gilbert Seamount (GS), which are shown for geographic reference. C) and D) Maps of the greater New Zealand area, showing the relation to between the Cretaceous-Paleogene tectonic features and present-day physiography. The red dashed polygon in (C) outlines the areas shown in (D). Note the inferred northward increasing stretching factors ( $\beta$ ) determined in this study (D). 


\subsection{SUMMARY AND CONCLUSIONS}

The greater Taranaki Basin comprises two juxtaposed rift systems that formed prior to ( $>85 \mathrm{Ma}$ ) and during Tasman Sea spreading (85-60 Ma). The present-day deep-water area represents a classic failed rift system $(\beta<2)$, whereas the proximal Taranaki Basin is best characterized as a minor continental rift $(\beta<1.5)$ that was a small tectonic feature compared to the New Caledonia Basin system. More significant thinning of the crust in the distal basin eventuated in greater amounts of post-rift subsidence, exacerbating a general northward tilting of the basin floor and influencing the basin geometry through the Paleogene.

The generally low stretching factors explain the well-developed terrestrial and shallow marine facies that are documented in both the proximal and distal basin. New mapping shows the character of large Late Cretaceous delta and coastal plain system that stretched over as much as $20,000 \mathrm{~km}^{2}$ into the southern head of the New Caledonia Trough and suggests the widespread development of latest Cretaceous shoreface systems. The geometries of these facies belts show resemblance to depositional systems of the Paleocene Kapuni sequence, and may have similarly good petroleum reservoir and source rock potential.

Paleogeographic reconstructions are in general agreement with interpretations from previous authors (Thrasher, 1990c; Thrasher, 1990b; Beggs \& Pocknall, 1992; Thrasher, 1992; Voggenreiter, 1992; Bryant et al., 1994; King \& Thrasher, 1996; Matthews et al., 1998; Uruski et al., 2002b), but this study extends previous analyses into a larger area. In particular, this study contributes a regional view of Cretaceous to Paleogene depositional systems based on seismic attribute mapping and delineation of the basin's main source rock and reservoir facies. Future seismic mapping and biostratigraphic dating will aid in further defining the detailed character of depositional systems and facies architecture, and may help to resolve the location of Cretaceous marine seaways between the distal and proximal basin. 


\section{CHAPTER 5 ANOMALOUS PASSIVE SUBSIDENCE OF DEEP-WATER SEDIMENTARY BASINS: AN EXAMPLE FROM THE SOUTHERN NEW CALEDONIA TROUGH AND TARANAKI BASIN}

\section{$5.1 \quad$ INTRODUCTION}

Faulting and volcanism patterns, combined with the time, length, and magnitude scales of subsidence are distinctive for different sedimentary basin-forming processes. As petroleum exploration moves into progressively deeper water there is an increasing interest in the processes that form deep-water sedimentary basins, and a growing dara volume ro investigate these issues. Are deep-water basins simply the more evolved products of processes that form shallow-water sedimentary basins, or are they influenced by different processes that inevitably lead to deeper water? The need for realistic models of these processes and hence accurate prediction of sedimentary, structural, and thermal evolution of these basins is increased by the sparseness of boreholes in deep-water.

This chapter presents an analysis of a deep-water sedimentary basin system northwest of New Zealand, where wells and high-quality seismic-reflection data allow determination of sedimentary facies and precise subsidence histories. Hence, the general issue of deepwater basin-forming processes and the consequential sedimentary architecture is addressed.

Taranaki Basin is located at the south-eastern end of the New Caledonia Trough (NCT), a $2000 \mathrm{~km}$ long submarine physiographic feature between New Zealand and New Caledonia (Figure 5.1). The seabed of the NCT is submerged in 1000-3500 $\mathrm{m}$ water along most of its length and shallows onto the Taranaki shelf at its southeast termination. Taranaki Basin is where most of New Zealand's petroleum has been produced, but the NCT remains sparsely-explored.

The evolution of the NCT-Taranaki Basin system is linked to the break-up of Gondwana and formation of the Tasman Sea during Cretaceous and Paleocene time (Burns \& Andrews, 1973; Uruski \& Wood, 1991; King \& Thrasher, 1996; Lafoy et al., 2005). Taranaki Basin has a relatively complex Neogene tectonic history, including foreland basin formation, thrust sheet uplift, and subsequent backarc extension related to the 
Australia-Pacific plate boundary (Pilaar \& Wakefield, 1979; Hayward \& Wood, 1989; Stern \& Davey, 1990; King \& Thrasher, 1992; Holt \& Stern, 1994; King \& Thrasher, 1996; Stern et al., 2006). The initial stages of foreland basin development during Oligocene and Miocene time is shown by borehole samples to be characterised by rapid subsidence over a width of $>200 \mathrm{~km}$ (Hayward \& Wood, 1989), which has been interpreted as dynamic topography created by viscous coupling between the subducted slab and mantle wedge during inception of the Hikurangi subduction zone (Stern \& Holt, 1994).

The distal location of the NCT from the active Australia-Pacific plate boundary, combined with a record of undeformed Late Cretaceous and Cenozoic siliceous and nannofossil oozes that were drilled during DSDP leg 21, led most previous authors to propose that the NCT has been tectonically quiescent since rifting ceased in the Late Cretaceous (Burns \& Andrews, 1973; Uruski \& Wood, 1991; King \& Thrasher, 1996; Lafoy et al., 2005). However, a recent review of sparse seismic-reflection data and dredge samples (Sutherland et al., 2010a) identified evidence for large values of Cenozoic subsidence along the length of the NCT, and suggested significant modification of the entire basin system during inception of the Tonga-Kermadec subduction system. Sutherland et al. (2010a) suggested a transient regional uplift was associated with mantle flow and accompanied by localised lithosphere delamination and foundering of the lower crust that led to permanent subsidence and created the topographic depression of the NCT.

In this chapter, tectonic subsidence histories in the southern NCT-Taranaki Basin system are precisely quantified and the observed timing and spatial relationships of subsidence are compared to predictions from basin-forming models. Detailed seismic-stratigraphic analysis techniques on a high-fold seismic-reflection survey acquired in 2001 (TGSNOPEC, 2001; Uruski et al., 2002a) are integrated with biostratigraphic analyses of samples from boreholes located on the outer Taranaki shelf (Shell BP Todd Oil Services Ltd., 1976; 1981b; 1984) and one that is in deep water (Milne \& Quick, 1999). These data are used to make inferences about the paleo-water depth at various stratigraphic levels of known age, and hence tectonic subsidence of the basin is mapped through time.

For rifted deep-water basins, a particular question of interest to petroleum explorers is at what point the basin subsided through shallow marine conditions $(0-200 \mathrm{~m})$. High 
stretching factors required by classical models (e.g., McKenzie, 1978) to produce large total subsidence and hence deep water predict a short period of shallow marine conditions near to the end of the rift phase, and early in the basin history.

This chapter describes the evolution of the southern NCT from Cretaceous rifting to its present-day configuration and shows that classical rifting models are unable to fit the observed subsidence history. Hence some alternate classes of mechanism are proposed that may apply more widely. The results demonstrate the need for new ways of thinking about how deep-water basins form, and they may have broad implications for understanding the sedimentary architecture, structure, and thermal evolution of deepwater basins in similar tectonic environments.

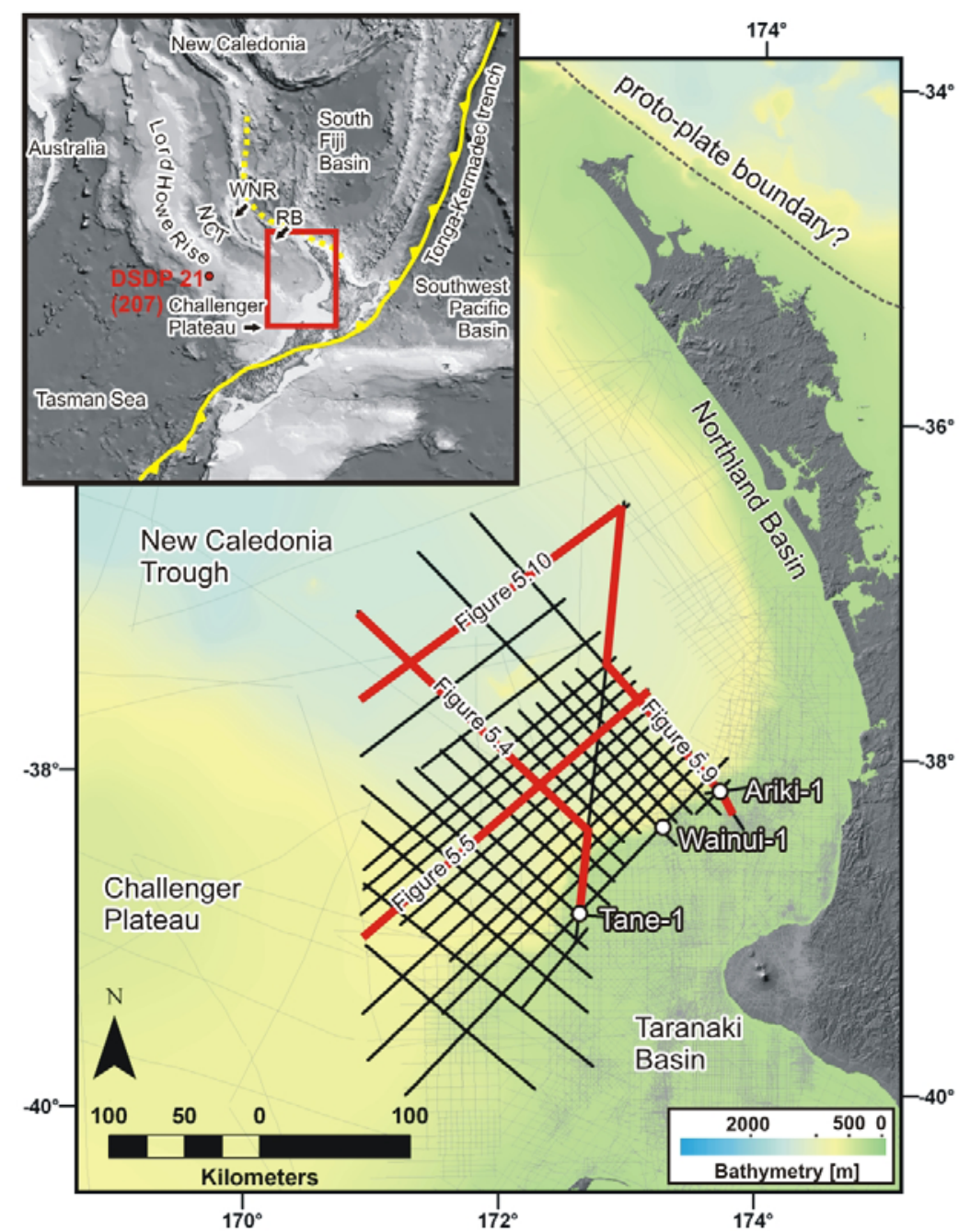

Figure 5.1 Map of western New Zealand and the study area showing the seismic survey DTB01 (black and red lines) and wells (white dots) used in the study. Other 2D seismic surveys are shown as grey lines and the bathymetry is shown in the background (see scale for water depth). Inset shows a physiographic map of the greater New Zealand area. The present-day location of the Australia-Pacific plate boundary (solid yellow line) and speculative location of the proto-plate boundary (dotted yellow line) is shown. Physiographic features are annotated and abbreviated as: NCTNew Caledonia Trough, WNR-West Norfolk Ridge, RB-Reinga Basin. 


\section{2}

\section{SUBSIDENCE SIGNATURES OF BASIN-FORMING PROCESSES}

Signals of vertical movement are recorded by basin strata and reflect lithospheric thickness changes, thermal evolution, isostatic adjustments to tectonic or sedimentary loads, or dynamic topography associated with mantle flow beneath (McKenzie, 1969; Parsons \& Sclater, 1977; McKenzie, 1978; White \& McKenzie, 1988; DeCelles \& Giles, 1996; Burgess et al., 1997; Burgess \& Moresi, 1999; Gögus \& Pysklywec, 2008; Spasojevic et al., 2009). Tectonic subsidence is defined as the basement rock subsidence that would take place if the local isostatic response to sediment loading was removed (Parsons \& Sclater, 1977; McKenzie, 1978; Sclater \& Christie, 1980). If the magnitude, timing, and extent of tectonic subsidence can be determined along with faulting patterns, then inferences can be made about basin-forming mechanisms, which in turn yield predictions about parameters such as thermal structure and ancient stress conditions. Alternately, if a tectonic model of basin formation is proposed in the absence of any knowledge of subsidence history, then predictions of parameters such as water depth through time and hence sedimentary architecture can be made. Reviews of worldwide basin subsidence histories derived using simple assumptions have shown that distinctive subsidence patterns can be matched to different tectonic settings, even if flexural loading and eustatic sea-level changes are ignored (e.g., Xie \& Heller, 2009).

The precision of any tectonic subsidence history critically depends upon the quantification of past vertical position relative to some known datum, usually sea level (Allen \& Allen, 2005). The period in a basin history during which it subsides relative to sea level from $+100 \mathrm{~m}$ to $-200 \mathrm{~m}$ is significant because the wide range of sediment facies and biological zones allow relatively precise $(<100 \mathrm{~m}$ in many cases) determination of vertical position. The precision of determination of past elevations outside this range is typically much worse, and may be $>1000 \mathrm{~m}$. It is a particular focus of this chapter to objectively address the issue of paleo-water-depth estimation in our region of interest and confidently identify paleobathymetric markers.

Rift basins and rifted continental margins are the result of stretching and thinning of the crust and sub-crustal lithosphere (Falvey, 1974; Steckler \& Watts, 1978; Bott, 1979). Stretching may occur uniformly by pure shear (McKenzie, 1978), by simple shear of the whole lithosphere (Wernicke \& Burchfiel, 1982; Lister et al., 1986), as a zone of laterally-variable and depth-dependent stretching (Rowley \& Sahagian, 1986; White \& 
McKenzie, 1988), or combinations of the above (Kusznir et al., 1991). The variety of models results from the need to explain discrepancies between observed faulting and synrift subsidence with post-rift subsidence patterns. Any model that involves thinning of the lithosphere predicts post-rift subsidence, as thermal conduction cools asthenosphere to return the lithosphere to a normal thickness. Post-rift subsidence continues after rifting at a rate that exponentially decreases as time passes, and with a total magnitude that depends upon the location and amount of thinning (McKenzie, 1978; Le Pichon \& Sibuet, 1981). Subsidence in passive-margin settings has been shown to continue for more than $150 \mathrm{Ma}$, and mid-ocean ridge topography shows that infinite extension results in c. $2600 \mathrm{~m}$ of post-rift subsidence that is mostly accomplished over the first c. $80 \mathrm{Ma}$ of cooling (Crosby et al., 2006). For continental basins, post-rift tectonic subsidence values are generally less than $1000 \mathrm{~m}$ (Xie and Heller, 2009).

Foreland basins are formed by flexure driven by thrust sheet loading (Beaumont, 1981; Lyon-Caen \& Molnar, 1985). The spatial geometry of subsidence, both in peripheral and retroarc foreland settings, is distinctly asymmetric, with greatest values located directly ahead and parallel to the thrust front (DeCelles \& Giles, 1996). The magnitude of subsidence depends on flexural parameters or tectonic load variations, but generally decreases away from the deformation front to less than a few hundred meters at few hundred kilometers distance from the topographic or tectonic load (Beaumont, 1981; DeCelles \& Giles, 1996). The characteristic signature of foreland basin subsidence is a convex-up accelerating segment in subsidence curves and the maximum magnitude of tectonic subsidence is generally smaller than at margins that have experienced extensive rifting, and is seldom $>3 \mathrm{~km}$ (Xie \& Heller, 2009).

Anomalous basin subsidence is documented in varied environments around the globe, and has been associated with forces within the lithospheric or deeper mantle acting on the shallow lithosphere. Numerical models of plate motions over regions of active mantle flow predict vertical deflections of up to several hundred metres $(300-500 \mathrm{~m})$ over large (typically $>1000 \mathrm{~km}$ ) length scales and long timeframes (20-100 Ma), and these predictions are confirmed by surface observations (Gurnis, 1990; 1993; Coakley \& Gurnis, 1995; Wheeler \& White, 2000; DiCaprio et al., 2009a; Spasojevic et al., 2009). Models of plate boundary inception and evolution (Mitrovica et al., 1989; Gurnis, 1992), and models of lithosphere instability (Houseman \& Molnar, 1997; Gögus \& Pysklywec, 2008), predict both permanent and transient vertical motions. The spatial wavelength and 
vertical magnitude of surface deflections associated with such models is dependent on factors like dip angle, age and depth of a subducted slab, flexural rigitidy, or viscosity and density structure of the mantle and crust. These models produce vertical crustal deflections with magnitude $>1000 \mathrm{~m}$ and rates of up to $150 \mathrm{~m} / \mathrm{my}$, and may affect regions of 1000-2000 km width (Burgess \& Moresi, 1999). In the southwest Pacific region, a mix of such mechanisms have been proposed to explain anomalous elevation of continental crust induced either by the Cenozoic (Australia-Pacific) or Cretaceous (Gondwana) subduction plate boundaries (Gurnis, 1993; Stern \& Holt, 1994; Billen et al., 2003; Stern et al., 2006; DiCaprio et al., 2009b; Sutherland et al., 2010a; Sutherland et al., 2010b).

\subsection{GeOlogic BACKGROUND ON THE NeW CALEdonia Trough}

The NCT is part of the SW-Pacific basin-and-ridge system, a series of backarc basins, continental fragments and volcanic arcs, interpreted as a product of Mesozoic trench rollback and backarc extension along the Gondwana eastern margin (Cluzel et al., 2001; Crawford et al., 2003; Schellart et al., 2006). Basement rocks in the southern part of the NCT represent a wide range of mostly continental rock types including, plutonic, metasediments, metamorphic and sedimentary rocks (Mortimer et al., 1997; Mortimer, 2004a; b), whereas seismic refraction data indicates thin $(10 \mathrm{~km})$ crust with high $(7.0-7.4 \mathrm{~km} / \mathrm{s})$ seismic velocities in the northern part of the NCT that is consistent with highly-thinned continental crust or oceanic crust (Klingelhoefer et al., 2007). Gravity models that include bathymetry and sediment thickness data indicate a crustal thickness of 10-15 km beneath the southern NCT and 15-30 km on adjacent ridges (Uruski \& Wood, 1991; Wood \& Woodward, 2002).

The NCT is believed to have formed during the Cretaceous (Lafoy et al., 2005; Collot et al., 2009), although sedimentary deposits of the Murihiku supergroup indicate localized deposition of terrestrial to shallow marine strata of Jurassic age (Milne \& Quick, 1999; Uruski \& Stagpoole, 2004). Rifting in the NCT possibly ceased during the middle Late Cretaceous (Collot et al., 2009; Uruski, 2010), substantially before cessation in the proximal Taranaki Basin. Occurrence of marine sediments and calcareous oozes in DSDP leg 21 (206 and 207) indicate flooding of lower lying ridges surrounding the NCT during the Cretaceous (Burns \& Andrews, 1973). 
During the Middle and Late Eocene, rifting of the Emerald Basin to the south of New Zealand (Sutherland, 1995; Wood et al., 1996; Lamarche et al., 1997; Veevers, 2000) was accompanied by subduction and convergent orogenesis in New Caledonia (Aitchison et al., 1995; Cluzel et al., 2001; Cluzel et al., 2006), indicating inception of the Cenozoic Australia-Pacific plate boundary. Convergence and subduction is assumed to have propagated southward towards New Zealand, with signs of convergence north of the Northland Plateau (Herzer et al., 2009), and north-eastern Taranaki Basin in the Middleto Late Eocene (Stagpoole \& Nicol, 2008).

The base of Oligocene strata is marked in most places by a para- or unconformity characterized by the absence of Late Eocene and Early Oligocene strata (Burns \& Andrews, 1973; King \& Thrasher, 1996; Cooper et al., 2001). In proximal Taranaki Basin (Figure 5.2), strata below this unconformity are as young as $34 \mathrm{Ma}$ (King \& Thrasher, 1996; Cooper et al., 2001) and terrestrial or shallow-marine Eocene rocks below the unconformity are separated from Oligocene distal muds and carbonates with bathyal microfaunal assemblages directly above (Figure 5.2). The difference in depositional environments suggests 1000-1500 m water-depth increase over a timespan of less than 10 my (Robinson et al., 1986; Hayward \& Wood, 1989). Within the NCT, the unconformity separates 43-47 Ma aged rocks below from 27-25 Ma strata above (Burns \& Andrews, 1973; Collot et al., 2009; Sutherland et al., 2010a). Previous authors (King \& Thrasher, 1996; Cooper et al., 2001) have noted similarities of this stratigraphic gap to the Marshall paraconformity (Carter, 1985), which is widely found across New Zealand. During the Neogene, most of the NCT is considered to have been significantly submerged, detached from clastic sediment sources and plate boundary deformation in areas to the east. 


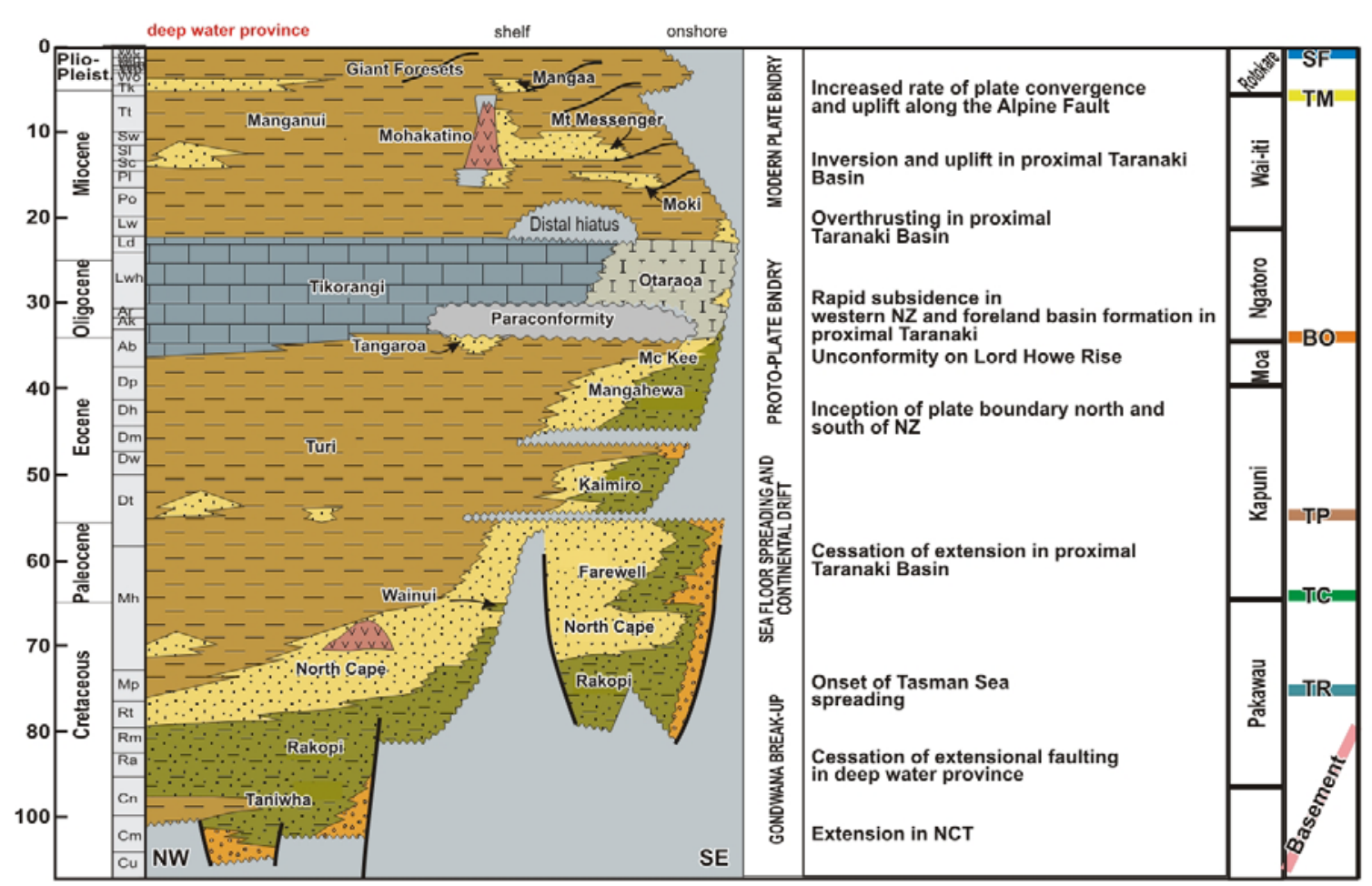

Figure 5.2 Summary chart of structural and stratigraphic evolution of the Taranaki Basin region. The panel shows age, international epochs and New Zealand stages, chronostratigraphy of Taranaki Basin with lithologic facies distribution and associated formation names, generalized plate tectonic environments, and key structural events. Stratigraphic group names after King and Thrasher (1996) and the approximate time association of seismic horizon interpretations is shown on the right and abbreviated as: SF-Seafloor, TM-Top Miocene, BO-Base Oligocene, TP-Top Paleocene, TC-Top Cretaceous, and TR-Top Rakopi.

\subsection{DATA ANALYSIS}

\subsubsection{Borehole lithostratigraphy}

Four petroleum exploration wells have been drilled adjacent to the deep-water region of Taranaki Basin. The wells Tane-1 (Shell-BP-Todd, 1976; van der Lingen \& Smale, 1990), Wainui-1 (Shell BP Todd Oil Services Ltd., 1981b), Ariki-1 (Shell BP Todd Oil Services Ltd., 1984) and Waka Nui-1 (Milne \& Quick, 1999; Uruski \& Stagpoole, 2004) serve as the primary lithostratigraphic control for this study. Lithostratigraphy is based on borehole cuttings, mud-, and wireline logs (Figure 5.3). The wells confirm a Cretaceous to Recent lithological sequence similar to that observed in the near-shore Taranaki Basin (Figure 5.2) (King \& Thrasher, 1996). All of these wells penetrated basement rock, which consists of granites in Tane-1, metamorphic rock in Wainui-1 and Ariki-1, and Jurassic volcaniclastic sediments in Waka Nui-1. 
Cretaceous strata are absent in Waka Nui-1 and the volcaniclastic sequence beneath a significant unconformity near the base of the borehole contained coals that were dated at c. $158 \mathrm{Ma}$ (early Late Jurassic). The oldest Cretaceous sediments are encountered in well Tane-1 and consist of non-marine sandy and coaly lithologies of the Late Cretaceousaged (Haumurian, 75 Ma) Rakopi Formation (Thrasher, 1991c; King \& Thrasher, 1996), interpreted from pollen flora to be deposited in a coastal plain environment. These strata are succeeded by latest Cretaceous shoreface sands, coastal silts and muds of the North Cape Formation (King \& Thrasher, 1996; Higgs et al., 2010) in the three south-eastern wells. Coeval coaly-sandy lithologies in Tane-1 and Wainui-1 (Wainui Member) indicate a coastal plain environment in the south.

Transgressive conglomerates and sandstone facies overlying Jurassic coal measures indicate marine flooding of the region near Waka Nui-1 during Paleocene time (Figure 5.3). The Paleocene and Eocence sequence is dominated by siltstone and mudstone of the Turi Formation (Palmer, 1985), but also includes bioclastic debris (flysch facies), and a unit with high (2-8\%) organic carbon content in Waka Nui-1 (Paleocene Waipawa black shale correlative, see also Moore et al. (1989)). Eocene strata consist of similar mudstone and siltstone facies, but increased calcareous content (marl) in Waka Nui-1 suggests decreased clastic sediment input during the Late to latest Eocene. A $\sim 100 \mathrm{~m}$ thick sequence of channel or fan sands of the Tangaroa Formation in Ariki-1 (Shell BP Todd Oil Services Ltd., 1984; Gresko et al., 1992; King \& Thrasher, 1996) indicates regression or the distal emergence of a new sediment source in the Late Eocene.

The basal unit of Oligocene strata is a 30-300 m thick limestone section of the Tikorangi Formation (King, 1988b). This unit conformably overlies Eocene strata in all wells, but an intra-Oligocene stratigraphic gap that could be equivalent to the Marshall paraconformity (Carter, 1985) has been identified in Tane-1 and Wainui-1 (Cooper et al., 2001). The Oligocene-Miocene section is mostly fine-grained calcareous mud, with an upwardly increasing content of siltstone facies, and the first occurrence of sandy sediment gravity-flow deposits in the Middle Miocene. Late Miocene volcaniclastic sediments of the Mohakatino Formation are found in wells Ariki-1 and Wainui-1. Calcareous mudstones and carbonates of the Ariki Formation mark the top Miocene in southern wells. The Plio-Pleistocene sequence reflects a shallowing upwards trend, with deep-water to slope to shelfal mud and siltstone facies represented. 


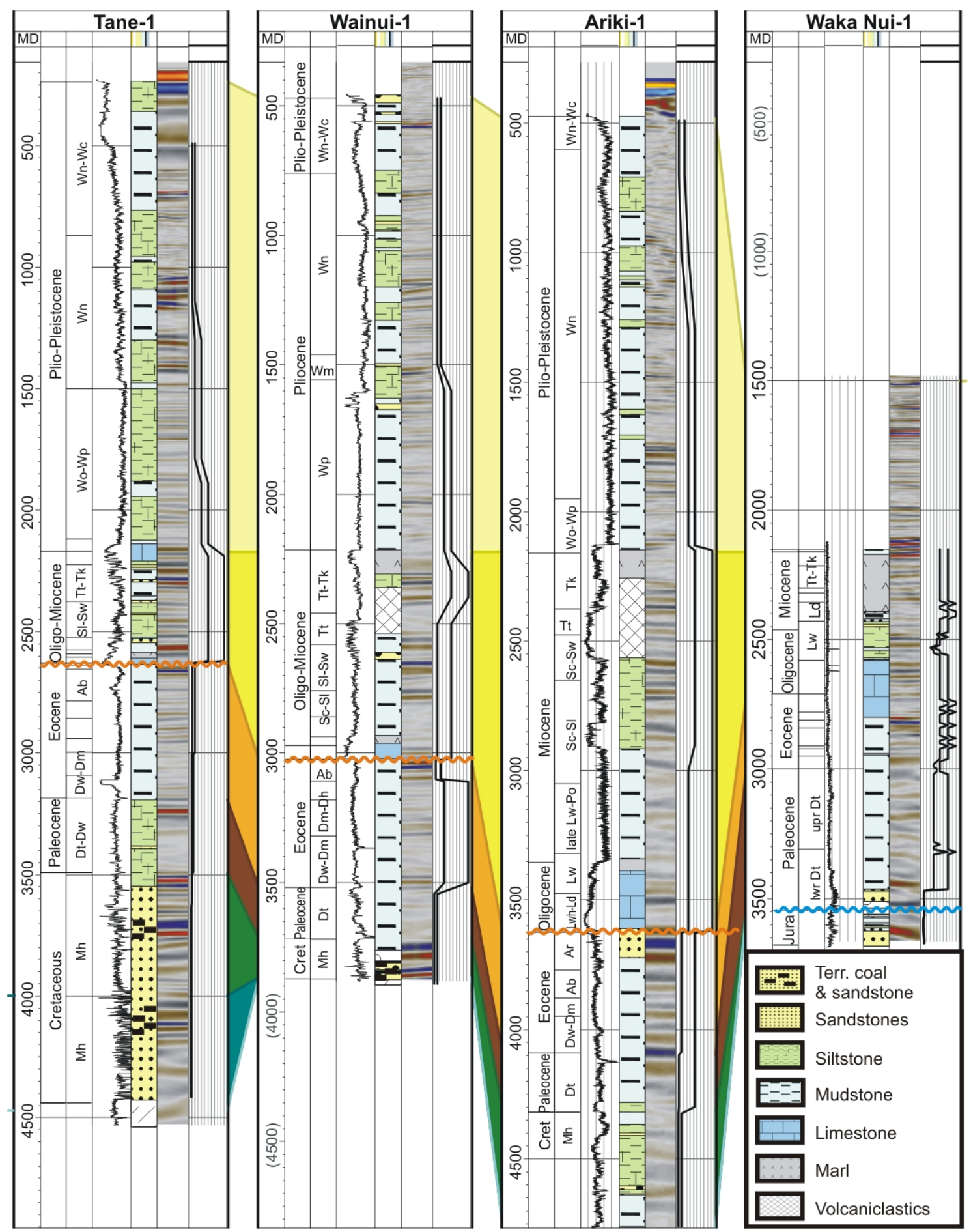

Figure 5.3 Correlation panel of wells used in this study aligned from south (left) to north (right) and flattened on the top Miocene (see Figure 5.1 for well location). Individual columns show (from left to right): 1) epochs with associated seismic horizon interpretation between the wells; 2) depth of biostratigraphic markers and interpreted New Zealand stage codes (see Figure 5.2 for comparison); 3) gamma-ray wireline logs; 4) simplified lithology interpretation from mud and wireline logs; 5) seismic amplitude extraction of ten traces from closest seismic line; 6) biostratigraphic paleobathymetry range estimates. Traces are scaled from left (minimum) to right (maximum) from 0150 for gamma-ray, blue-red for seismic amplitudes, and -100-2200 $\mathrm{m}$ for paleobathymetry. Lithology patterns are shown in the legend in bottom right. 


\subsubsection{Biostratigraphic age and paleobathymetry}

Biostratigraphic data are the primary basis for age evaluation of strata in this study and have also been extensively used to infer depositional environments and paleo-waterdepth history of the New Zealand continent (Ballance et al., 1985; Hayward, 1985a; Hayward \& Wood, 1989; Hansen \& Kamp, 2004; 2006). While coastal plain terrestrial and shallow marine microfauna and flora are sensitive to small changes in paleoelevation, bathyal samples provide only broad subdivisions of deep water (400-3000 m). Because the latter are outside the photic zone, they are strongly influenced by substrate type, slope, sedimentation rate, water mass character, etc., rather than depth alone (Hayward \& Wood, 1989). Although there is a recognisable succession of taxa with increasing depth, its calibration is imprecise. Consequently, conservative uncertainties are given for bathyal biostratigraphic water-depth estimates (Figure 5.3). Biostratigraphic paleo-depth estimates are grouped into: terrestrial, near-shore and shelf marine, and open or deep marine.

Late Cretaceous coal facies in Tane- 1 and Wainui- 1 contain abundant pollen and spores indicative of non-marine coastal plain environments. Latest Cretaceous and Paleocene samples in south-eastern wells are dominated by near-shore to shelfal foraminifera, with a northward proximal-to-distal trend from Tane-1 to Ariki-1 indicating shallow ocean conditions in the south of the study area (Figure 5.3). In Waka Nui-1, flooding, transgressive facies and shallow marine microfauna (e.g. Textularia plummerae, 0-50m) suggest the development of marine conditions during Early Paleocene time. Wainui-1 shows abundant shelfal $(<200 \mathrm{~m})$ foraminifera (e.g. Vagunilopsis waiparaensis, Cyclamina grangei) in rocks of Paleocene to Late Eocene ( $40 \mathrm{Ma})$ age, and small to moderate percentages of planktonic foraminifera $(<40 \%)$ in Tane-1 samples indicate shelf environments until the latest Eocene (34 Ma).

Foraminifera in Waka Nui-1 indicate the onset of open-marine conditions (estimated paleowater depth of 400-800 m; upper bathyal) in the late Paleocene. However, organic shales of latest Paleocene-Early Eocene age (Waipawa black shale) suggest deposition in restricted environments associated with water depths of only c. $25 \mathrm{~m}$ in adjacent basins (Schiøler et al., 2010). In southern wells, microfauna suggests the onset of open-marine conditions (e.g. Cibicides parki, Cyclamina grangei) in Ariki-1 in the Early-Middle Eocene (45-49 Ma) and Wainui-1 in the Late Eocene (40-38 Ma). 
First occurrences of deep bathyal indicators (e.g., Tritaxilina zealandica) are encountered in Middle-Late Eocene (40-36 Ma) samples in Waka Nui-1. In southern wells, similar assemblages are restricted to strata immediately above the unconformity that excludes latest Eocene and Early Oligocene strata (Cooper et al., 2001). The most likely water depth inferred from these assemblages is $1500-2000 \mathrm{~m}$, although the uncertainty in this value is large and poorly quantified (certainly $>500 \mathrm{~m}$ ). The Miocene-Recent sequence shows an upwardly increasing occurrence of slope facies indicative of decreasing water depths and final establishment of shelf environments during the Late Pliocene and early Pleistocene in the south.

\subsubsection{Seismic stratigraphy}

\section{Seismic reflection dataset and previous work}

Single-channel and low-fold seismic reflection surveys carried out in the 1970s and 1980s identified a region of thick sediment beneath the southern NCT (Mobil, 1972; 1979; Uruski \& Wood, 1991). The New Zealand government and the Australian Geological Survey collaboratively acquired the first high-fold seismic-reflection data in 1996. These data proved that the Taranaki Basin extends beyond the present-day shelf edge into the deep-water regions and that sediment thickness was as much as $9000 \mathrm{~m}$. In April 2001 TGS-NOPEC, in association with the Institute of Geological and Nuclear Sciences (GNS), acquired $6208 \mathrm{~km}$ of high-quality 2-D seismic-reflection data over the deep-water extension of Taranki Basin in the southern NCT (TGS-NOPEC, 2001). A 651 (4000 cubic inch) air gun array was used with a $6000 \mathrm{~m}$ streamer and a shot point interval of $25 \mathrm{~m}$ to record $8 \mathrm{~s}$ of high-quality data, within an area of approximately $80,000 \mathrm{~km}^{2}$ and water depths of 200-2000 $\mathrm{m}$. The data were processed and pre-stack time migrated and tied to synthetic seismograms from adjacent well logs (Uruski et al., 2002b).

Initial geological interpretations of the new seismic reflection data were depth-converted using interval velocities derived from optimal stacking of the seismic data (Uruski et al., 2002b). Uruski et al. (2002b) mapped seismic reflectors that were correlated with: basement, top Rakopi Formation (75 Ma, Late Cretaceous), top Pakawau Group (65 Ma, top Cretaceous), a prominent reflector of inferred top Paleocene age (55 Ma) that correlates with the top of the Waipawa Formation in Waka Nui-1, the base of the 
Ngatoro Group (c. $34 \mathrm{Ma}$, base Oligocene), and the top of the Wai-iti Group (5 Ma, top Miocene, Figure 5.2). The reflectors can be associated with five phases of basin evolution based on observed faulting patterns, seismic facies character, and geometry of sedimentary packages. The basal unit comprises the syn-rift and early drift sequence, the upper unit encompasses major flooding and regression, while other reflectors are described as part of the late drift phase.

\section{Early Rift (120?-100 Ma)}

The basal unit with coherent internal reflections, interpreted as sedimentary layering, has normal faults that exhibit throws on basement of up to $250 \mathrm{~ms}$ TWT and indicate deposition during active extension (Figure 5.4). Based on the dominant seismic character, this syn-rift unit can be subdivided into 1) a basal sequence with medium-amplitude, subparallel to parallel reflectors of medium or low lateral continuity, and 2) an upper sequence with slightly lower reflectivity but higher lateral continuity and locally interwoven chaotic reflections.

\section{Rift-drift transition ( 100-75 Ma)}

A sequence of stacked clinoformal reflectors indicates north-westward progradation of a shelf margin across the area during deposition of this unit (Figure 5.4). Lower parts of these clinoform reflectors are laterally continuous with low or medium amplitude, and grade up-dip towards the south and east into discontinuous, blocky, medium- and highamplitude reflectors (Figure 5.4, Figure 5.5). The latter reflectors correlate with sandy and coaly litho-facies of the Late Cretaceous Rakopi Formation in Tane-1 and define the top of the seismic stratigraphic unit (Figure 5.3, Figure 5.4). An extraction of RMS amplitude over a $100 \mathrm{~ms}$ window below the top Rakopi reflector outlines the distribution of coaly facies over some $20,000 \mathrm{~km}^{2}$, indicating the extent of a coastal plain across large parts of the survey area (Figure 5.6). The isochron and ispoach calculated between basement and the reflective top Rakopi horizon (amalgamated syn-rift and early drift sequences, Figure 5.7, Figure 5.8), outline a northwest-southeast-trending graben system with sediment thicknesses $>2.2 \mathrm{~s}$ TWT $(>4 \mathrm{~km})$. Sedimentation was controlled by this graben up to $75 \mathrm{Ma}$, although extension clearly ceased prior to deposition of the progradational unit. Within the main depocentre, the thickness of the early drift unit is 1.0-1.2 $\mathrm{s}$ TWT, which is depth converted to $2-2.4 \mathrm{~km}$. 


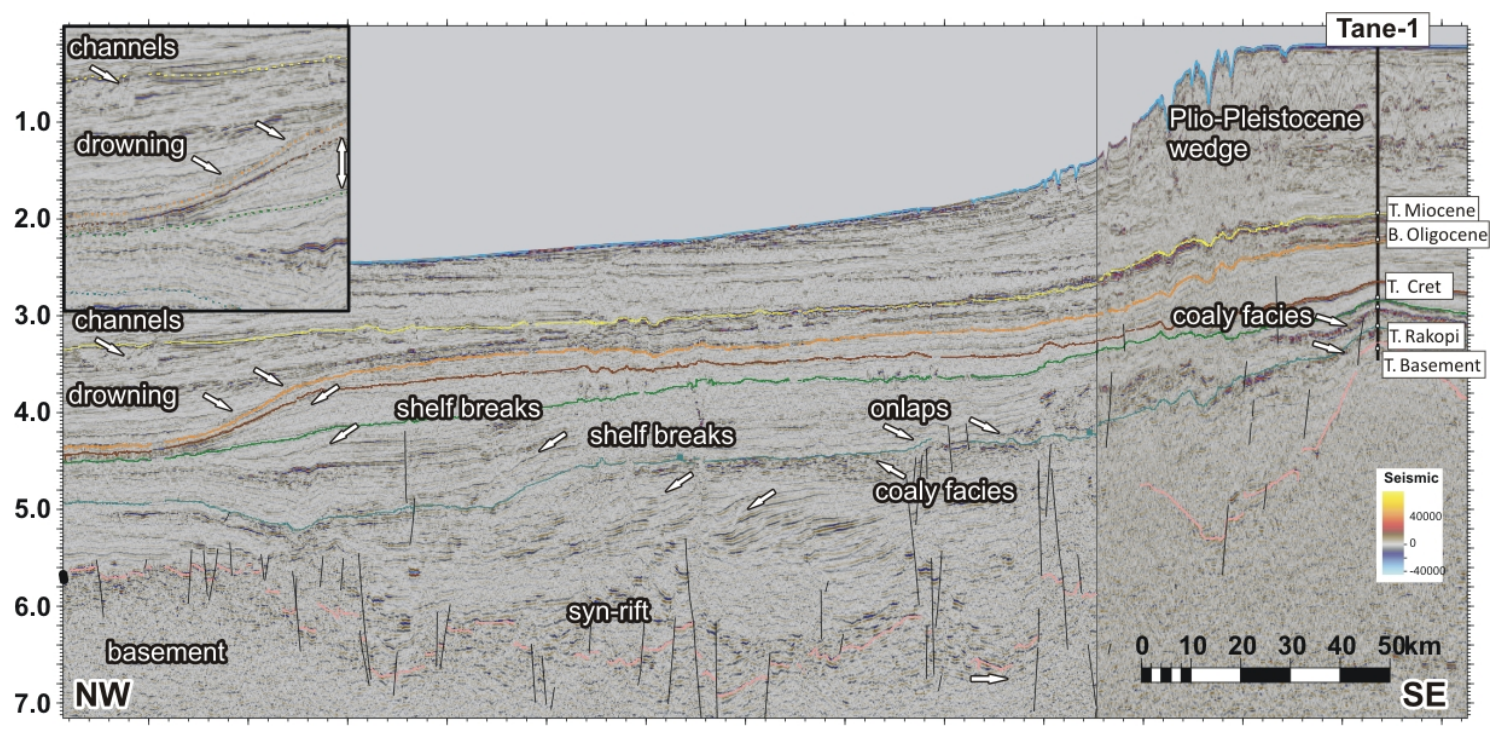

Figure 5.4 Seismic composite line from well Tane-1 to the northwest. The well path of Tane-1 is shown with age markers as black line and white squares, respectively. Colours of seismic horizon interpretations are shown as in Figure 5.2. Faults are shown as black lines. Annotations are discussed in the text. Inset shows magnification of the area outlined by black rectangle on seismic line. See Figure 5.1 for profile location. The seismic profile here and in subsequent figures is shown in seconds two-way-travel time (TWT).

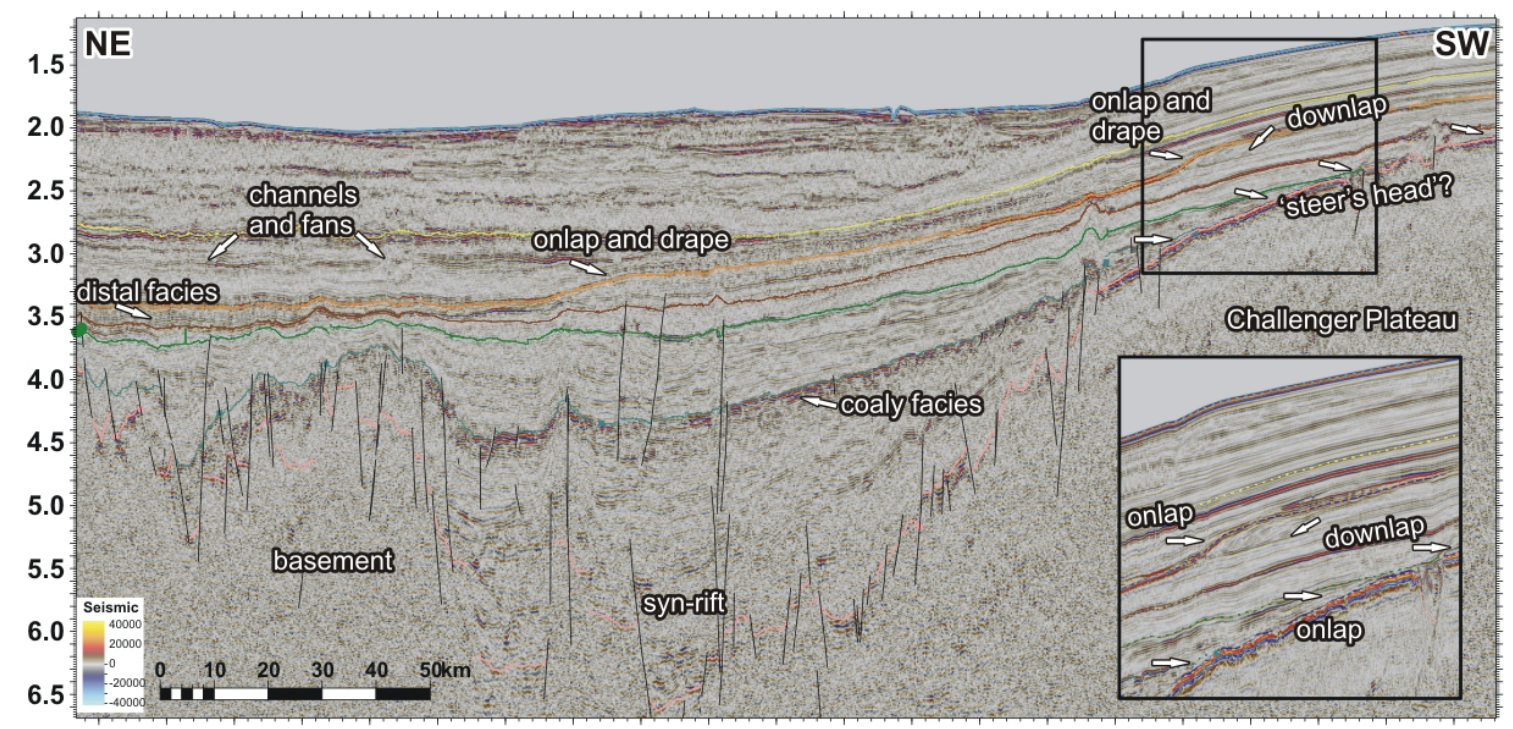

Figure 5.5 Seismic line DTB01-20 with seismic horizon interpretations in colour codes as shown in Figure 5.2 Faults are shown as black lines. Annotations are discussed in the text. Inset shows magnification of the area outlined by black rectangle on seismic line. See Figure 5.1 for location. 


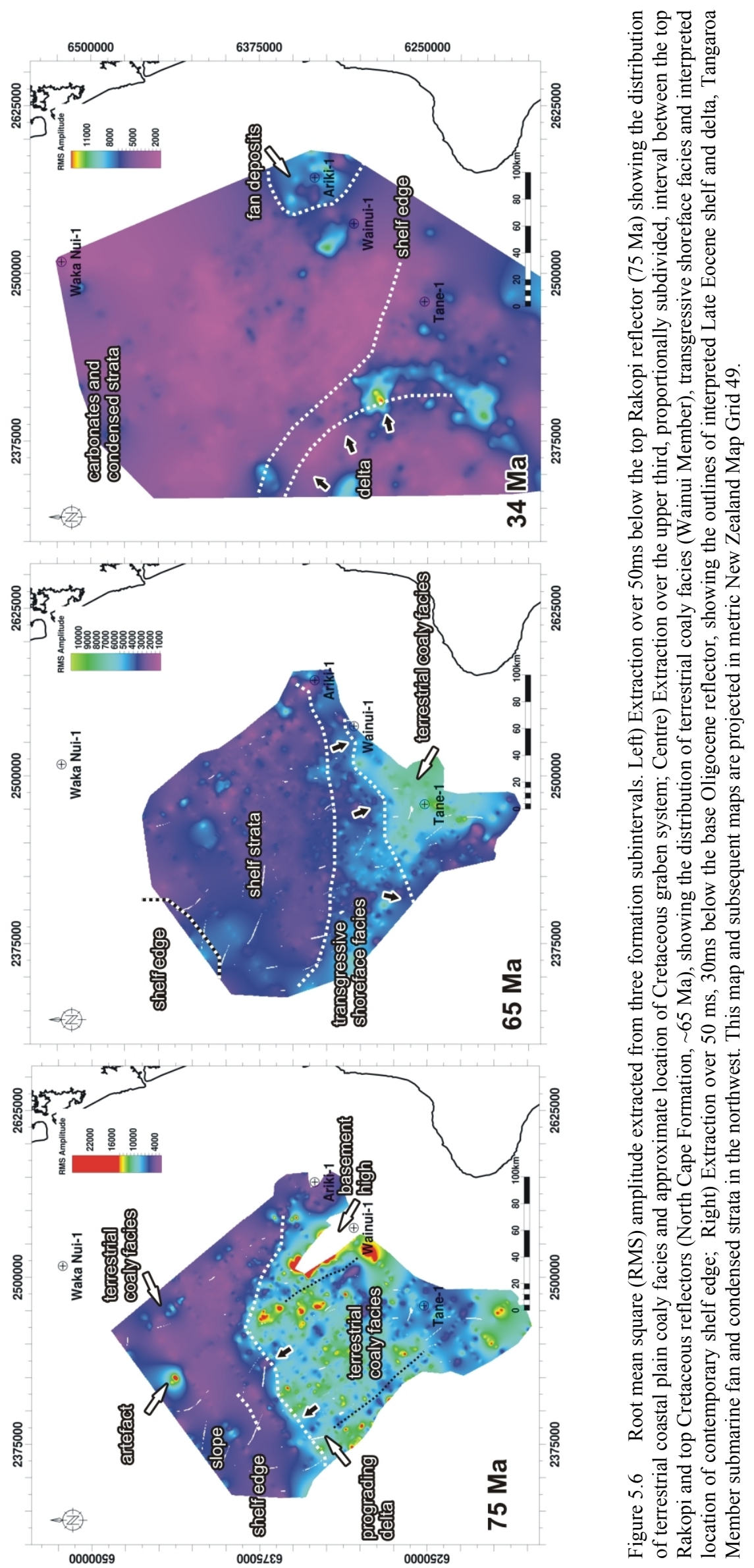



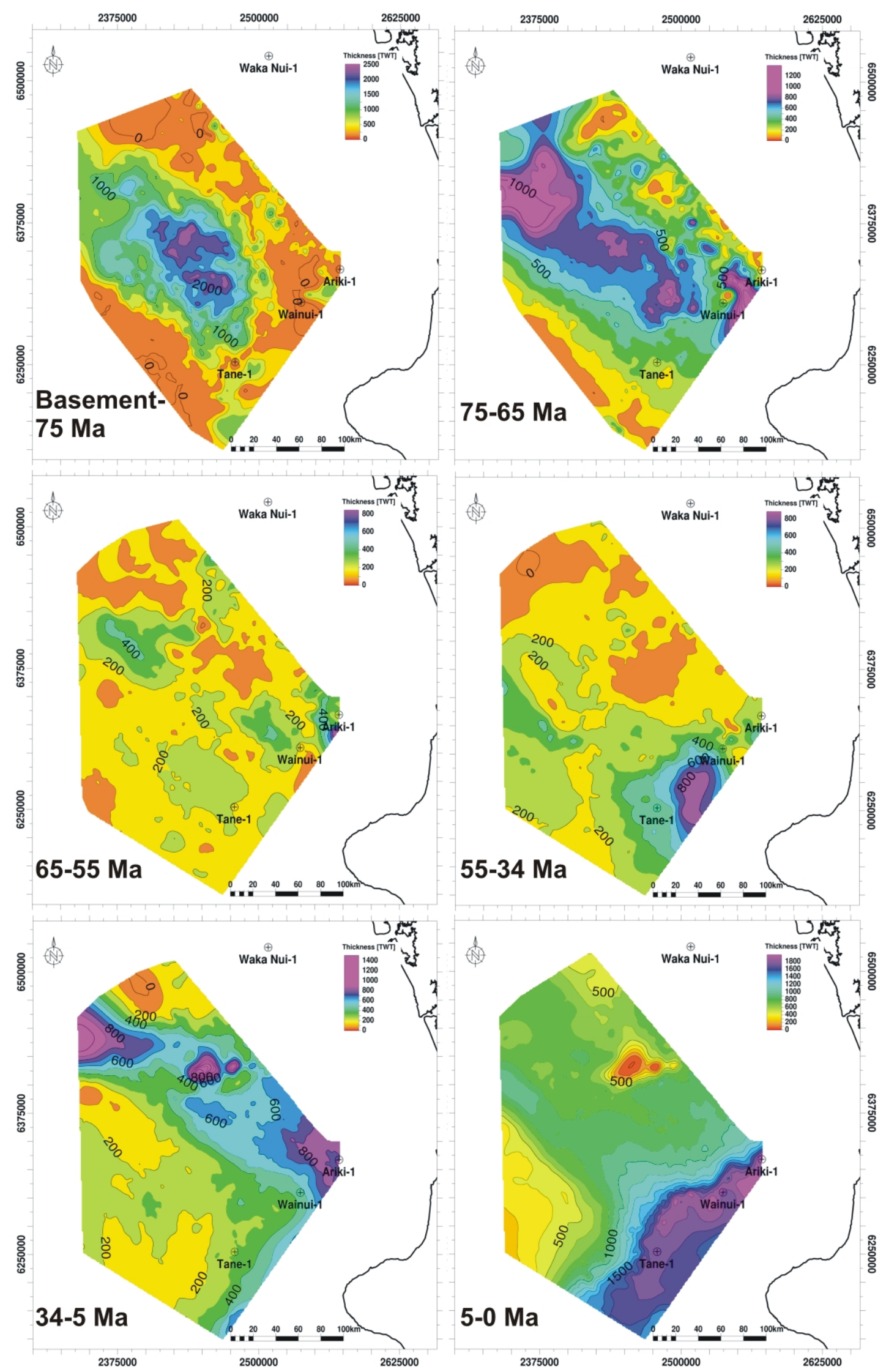

Figure 5.7 Isochron maps calculated from gridded horizon interpretation in milliseconds two-way-travel time. 

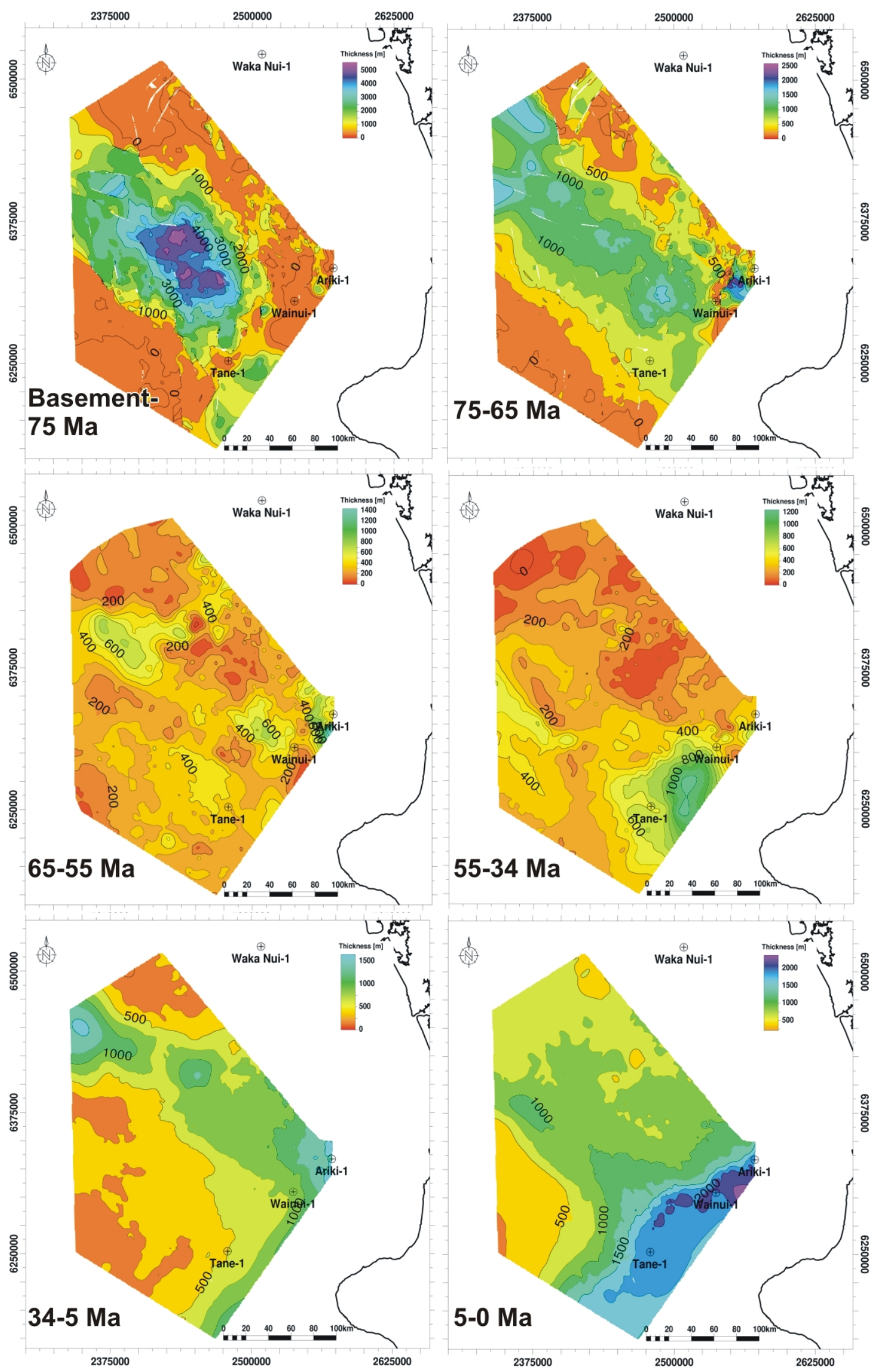

Figure 5.8 Isopach maps calculated from depth-converted horizon interpretations in metres (after Uruski et al., 2002b). 
Decreasing isochron and isopach thicknesses in maps calculated from latest Cretaceous (75-65 Ma), Paleocene (65-55 Ma), and Eocene (55-34 Ma) units suggest gradually decreasing sediment deposition from the latest Cretaceous through the Paleogene (Figure 5.7, Figure 5.8). Areas of thickest latest Cretaceous strata $(\sim 1 \mathrm{~s} T W T / 1.5 \mathrm{~km})$ in the northwest of the survey correlate with prograding and aggrading clinoform reflectors that indicate further north-westward outbuilding of the shelf across the older graben system (Figure 5.4). Up-dip (landward) of the clinoform roll-overs, the unit is characterized by low- to medium-amplitude, semi-continuous to continuous reflectors that correlate with shelfal silts and muds of the latest Cretaceous North Cape Formation in south-eastern wells. Reflectors with increased amplitudes onlap and drape over surrounding basement highs (Figure 5.5) and grade south-eastwards into blocky high-amplitude facies (Figure 5.4). The former facies correlate with shallow marine, sand and siltstones in Ariki-1, whereas the latter reflectors correlate with sandy and coaly coastal plain deposits of the latest Cretaceous Wainui Member in wells Tane-1 and Wainui-1 (Figure 5.3). RMS amplitude extractions over a stratal interval near the top of the latest Cretaceous sequence outline the facies distribution and approximate geometry and location of the shoreline, outer shoreface and shelf facies. The seismic attributes and manually mapped shelf break suggest widespread flooding with southwest migration of the shoreline and development of a wide shelf ( $<200 \mathrm{~m}$ depth) across most the survey area. Reflector geometries and continuity indicate minor to absent faulting during deposition of this unit.

Within the top Cretaceous to top Paleocene unit (65-55 Ma), aggrading clinoform reflectors in the northwest and down-lapping reflectors in the southeast are observed (Figure 5.4), and mark a northwest-southeast-oriented trend of thicker strata (0.2-0.4 s TWT) on isochron maps (Figure 5.7). Further onlap and drape is observed to cover the remaining basement highs of the study area (Figure 5.5, Figure 5.9, and Figure 5.10). The general lack of faulting indicates that the area was tectonically quiescent, although some graben systems continue to influence sediment distribution through the Paleocene (Figure 5.9).

Seismic amplitudes extracted over a $50 \mathrm{~ms}$ window below the basal Oligocence reflector show the facies distribution near the top of the Eocene unit (34 Ma, Figure 5.6). The dominant seismic reflector character of this unit is low- to medium-amplitude, relatively 
continuous reflectors that correlate with fine-grained shelf sediment in Tane-1 and bathyal facies in Wainui-1, respectively. The environmental difference implied by the biostratigraphy in these wells (Figure 5.3), northward decreasing isochron thicknesses (Figure 5.7), and offlapping reflector geometries are taken as indicators for the shelf edge location in this area. Westward along this thickened trend, obliquely downlapping reflectors indicate north-eastward outbuilding of a delta from the northern flank of the Challenger Plateau (Figure 5.5). This delta is about $0.1 \mathrm{~s}$ TWT thick and can be traced over several lines, indicating its extent over at least $100 \mathrm{~km}$ along strike of the Challenger Plateau. Reflectors with higher amplitudes in the north and northwest correlate with increased calcareous content of mudstones in Waka Nui-1 and might reflect diagenetic effects and/or condensed deposition (Figure 5.9). In the eastern part of the survey, the upper Eocene unit is marked by downlapping, medium- to high-amplitude reflectors that correlate with sandy lithology of the Tangaroa Formation in Ariki-1 (Figure 5.9), indicating slope to basin floor environments and fan deposition. In the northern part of the survey disruption and bending of reflectors indicate wrench or reverse faulting and some folding beneath the basal Oligocene reflector (Figure 5.10).

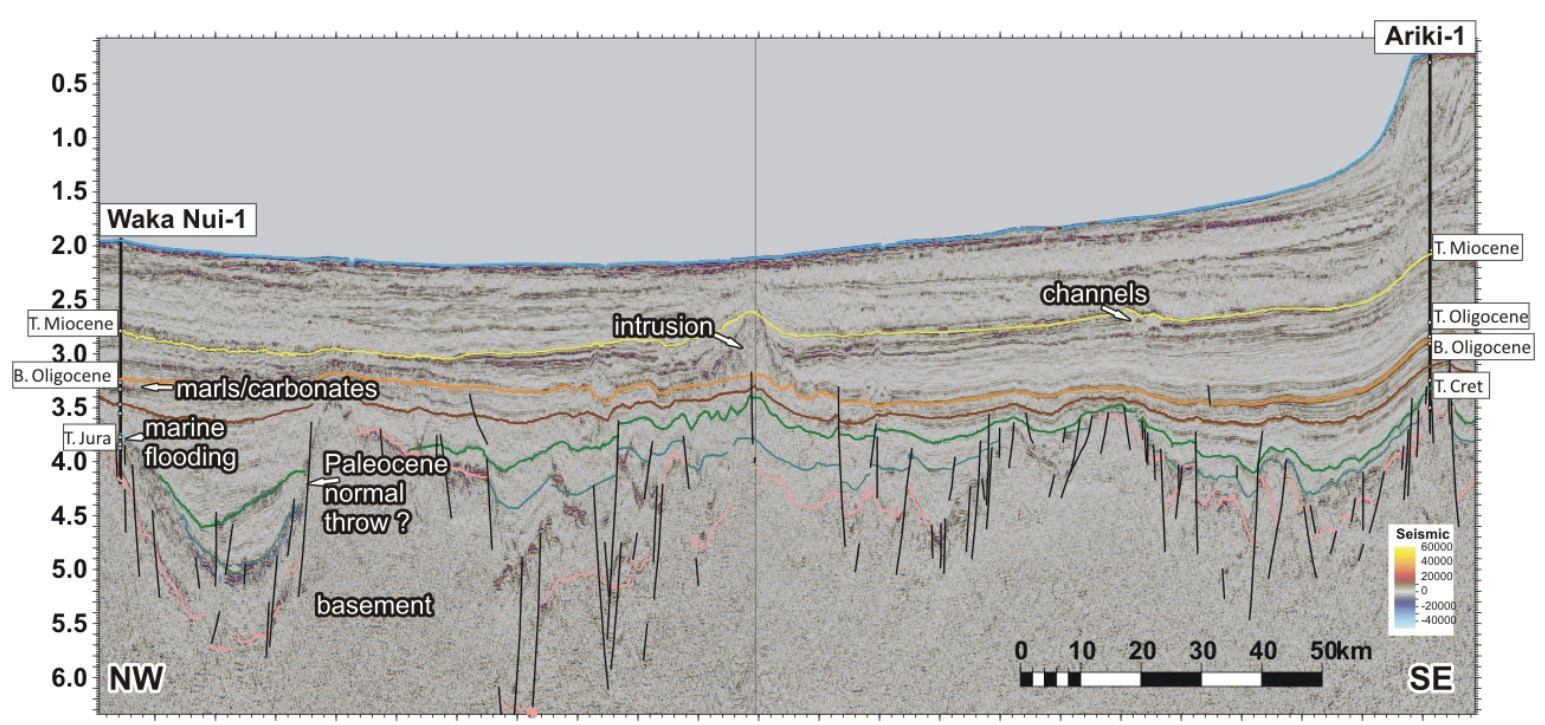

Figure 5.9 Seismic composite line from well Ariki-1 to Waka Nui-1 in the northwest. Well paths are shown with age markers as black lines and white squares, respectively. Colours of seismic horizon interpretations are as shown in Figure 5.2. Faults are shown as black lines. Annotations are discussed in the text. See Figure 5.1 for profile location. 


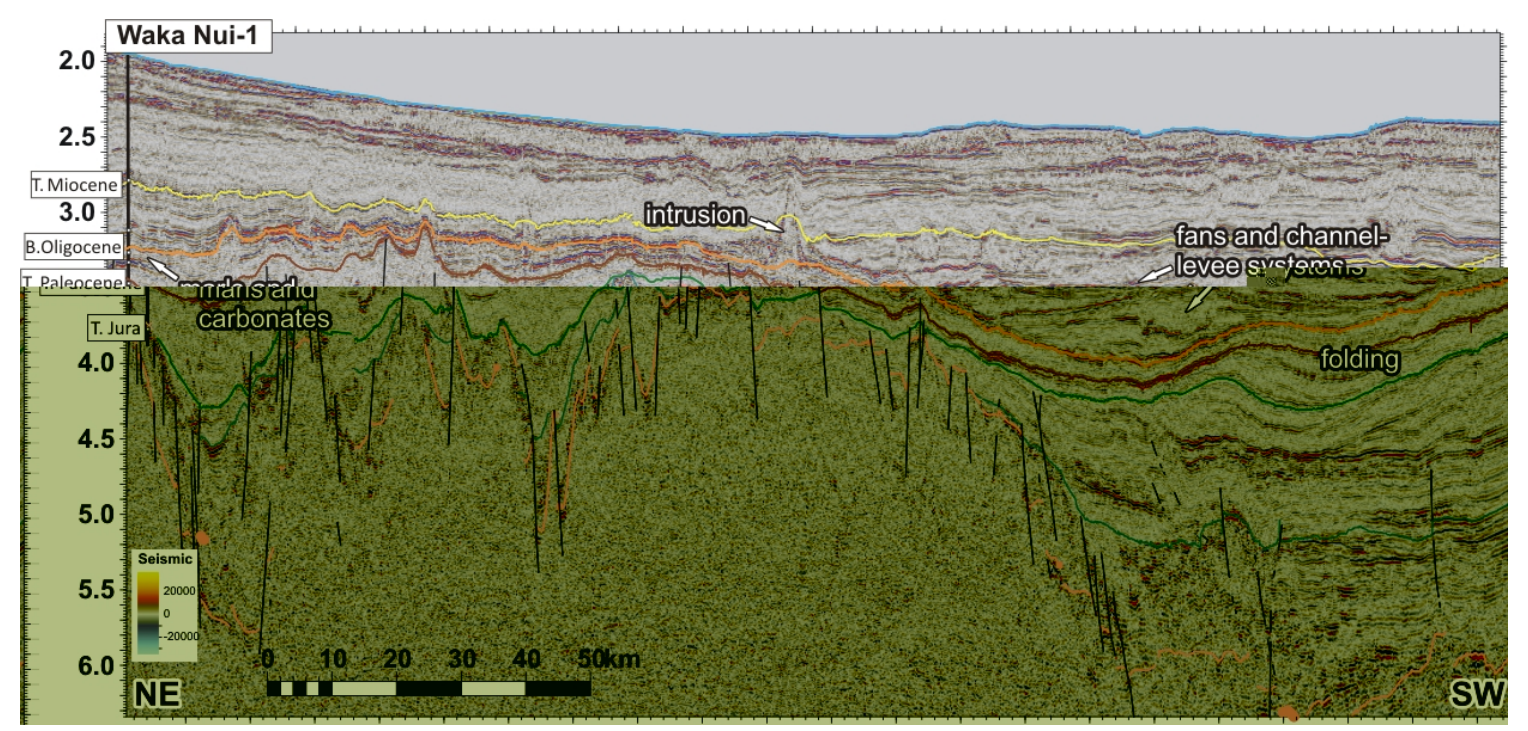

Figure 5.10 Seismic line DTB01-04 with seismic horizon interpretations in colour codes as shown in Figure 5.2. Well path of Waka Nui-1 is shown with age markers as black line and white squares, respectively. Colours of seismic horizon interpretations are as shown in Figure 5.2 Faults are shown as black lines. Annotations are discussed in the text. See Figure 5.1 for location.

\section{Drowning (34-19 Ma)}

Above the base Oligocene reflector, stratal relationships show onlap or drape over structures evident in previous sequences, indicative of drowning of the survey area (Figure 5.4). The lower part of the sequence has parallel, continuous, low- to medium-, or medium- to high-amplitude reflectors (Figure 5.4). At the wells, these reflectors correlate with limestones, marls, mud, and siltstones of the Tikorangi, Taimana and lower Manganui Formations, suggestive of low to absent input of clastic sediment through the Oligocene and Early Miocene.

\section{Regression (19-0 Ma)}

Medium- and high-amplitude, semi-continuous reflectors and correlative sand-silt interbeds in Wainui-1, indicate the onset of renewed clastic input and turbidite-related deposition during the Middle Miocene (Figure 5.5). Variable-amplitude, discontinuous and chaotic seismic facies indicate the development of 5-8 km wide channel systems (Figure 5.10) that can traced several hundred kilometres towards the proximal basin (Baur et al., 2010). Several areas of chaotic reflections with high-amplitude margins at the top indicate volcanism, with onlapping strata indicative of Middle to Late Miocene age (Figure 5.9). The Pliocene to Pleistocene part of the section is marked by large clinoforms (Figure 5.4, Figure 5.9) and together with the associated southwest-northeast 
trend of thick strata (Figure 5.7) indicates the north-westward progradation of the shelf into the survey area. This progradational unit correlates with deposits of the Giant Foresets Formation (Figure 5.2).

\section{Paleobathymetric estimates from seismic interpretation}

The seismic sequences described above contain facies from which paleo-waterdepth constraints can be derived. Specific examples of such water-depth indicators are illustrated in Figure 5.11 together with line drawings of associated stratal patterns.

The correlation of sandy and coaly sediments containing coastal flora and fauna in wells with high-amplitude, blocky reflectors on seismic sections provides tight constraints that an area was very close to sea level (within c. $30 \mathrm{~m}$ ). The seaward limit of this inferred coastal plain defines a paleo-shoreline position. Shorelines and coastal plain facies are identified for sediments with ages $75 \mathrm{Ma}$ (top Rakopi Formation) and $65 \mathrm{Ma}$ (top North Cape Formation). Onlapping reflector geometries with medium to high amplitudes seaward of this shoreline can be correlated with transgressive shoreface facies in wells and assumed to mark the limits of inner shelf and outer shoreface deposition. This interpretation is in line with studies of analogous Eocene facies in proximal Taranaki Basin (Matthews et al., 1998). The interpreted paleo-water-depth association of this facies is $0-50 \mathrm{~m}( \pm 50 \mathrm{~m})$, although it is realized that the deposition is dependent on the depth of effective wave base amongst other factors.

The upper rollover of clinoform reflections are commonly associated with the paleo-shelf break (e.g., Steckler et al., 1999). Such paleo-shelf breaks are identified in strata with biostratigraphic ages 75, 65, 55, and $34 \mathrm{Ma}$; and in strata older than $75 \mathrm{Ma}$ for which there is no age control. Modern shelf breaks in Taranaki Basin are located at water depths close to $200 \mathrm{~m}$ (Nodder, 1995), which is slightly deeper than the uniform global average of about $150 \mathrm{~m}$ (Gross, 1982). In this analysis, shelf breaks are assigned a depth of $200 \mathrm{~m}$ with an uncertainty of $\pm 100 \mathrm{~m}$. Since the water depth of the shelf break is controlled by the amplitude of eustatic sea-level fluctuations, the depth of this point could have been smaller before the development of permanent Antarctic ice sheets in the EoceneOligocene (Zachos et al., 2001). Medium-amplitude continuous reflectors landward of the shelf break are found to be characteristic of outer and inner shelfal strata at wells and, depending on the distance to the shelf break are assigned water depths between 50 and 
$200 \mathrm{~m}( \pm 150 \mathrm{~m})$. In cases of well-developed clinoform reflectors, the water depth basinward of the rollover can be estimated by restoration of the clinoform geometry via depth conversion and decompaction (Figure 5.11).
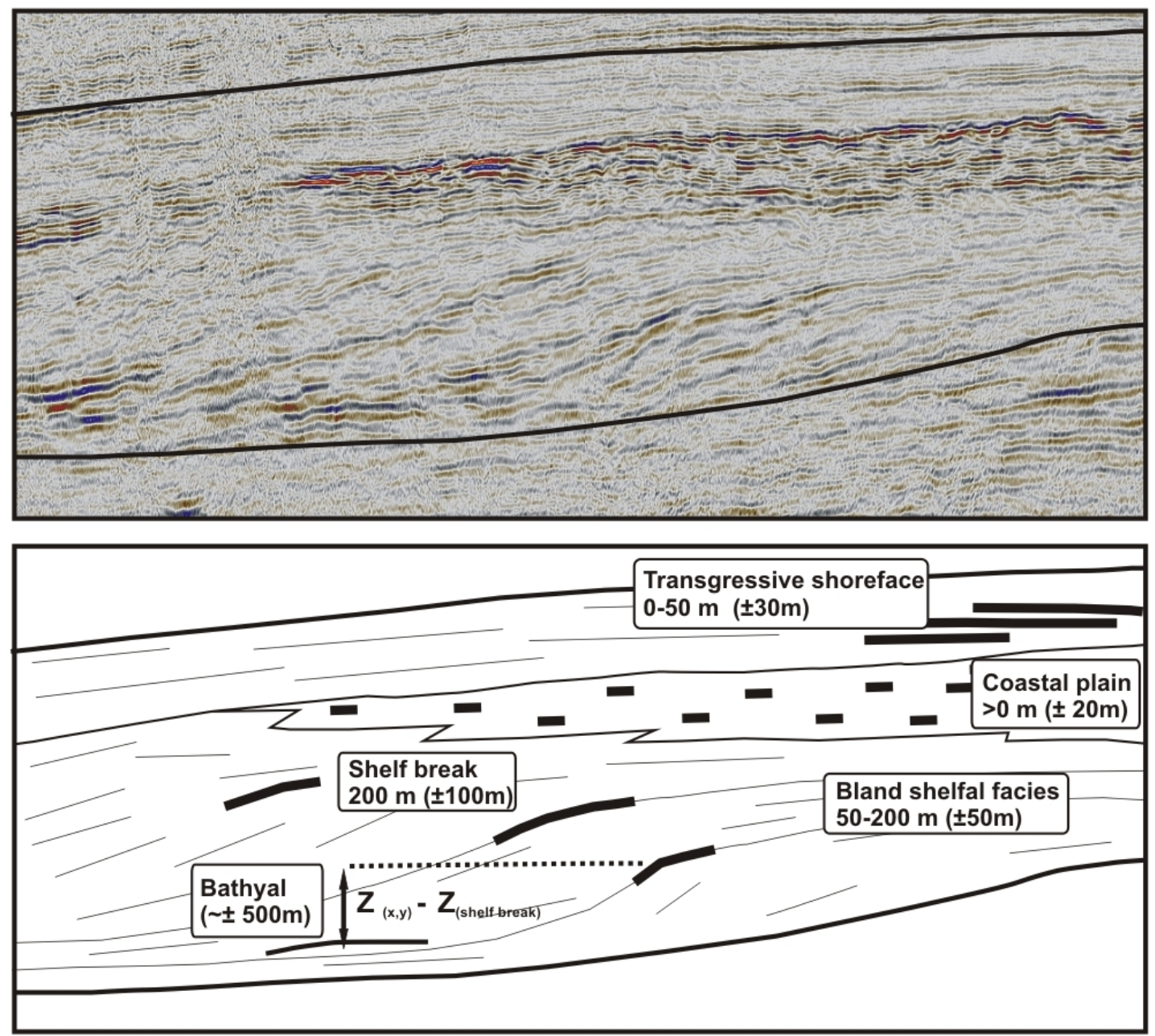

Figure 5.11 NW-SE seismic line from the DTB01 survey (top) and interpretation line drawing (bottom) illustrating seismic facies interpretations, interpreted paleo-bathymety association, and uncertainty estimates. 


\section{Paleobathymetry synthesis}

Constraints from microfossil samples of four wells, lithostratigraphic interpretation, Cretaceous and Paleocene coastal flooding surfaces, and seismic facies interpretations across the basin are integrated to derive paleobathymetry estimates at various stratigraphic levels throughout the basin evolution (Figure 5.12).

Constraints on terrestrial environments and sub-aerial exposure $(>0 \mathrm{~m})$ of large parts of the study area after cessation of rifting are well established by the absence of strata in wells and on basement highs and distribution of Late Cretaceous (75 Ma) coastal plain facies outlined on attribute maps (Figure 5.6). Latest Cretaceous water depths are constrained by clinoforms in the northwest $(200 \mathrm{~m})$, shelf $(200-50 \mathrm{~m})$ to shallow marine $(50-0 \mathrm{~m})$ and coastal plain facies $(<0 \mathrm{~m})$ constrained in wells and seismic facies and absence of contemporary strata in well Waka Nui-1.

The Paleocene bathymetric evolution is derived by a flooding surface in well Waka Nui1 , shelfal microfauna in south-eastern wells $(0-200 \mathrm{~m})$, and observed clinoform and downlap reflector geometries (Figure 5.4), which mark the development of an east-westtrending shelf margin. The flanks of the Challenger Plateau and the south-eastern survey area are interpreted to have had marginal marine $(0-50 \mathrm{~m})$ or inner shelf environments, based on onlapping strata and foraminifera in Tane-1. Water depths in the north and northeast of the survey are somewhat uncertain: biostratigraphy of Waka Nui-1 suggests water depths of $400-800 \mathrm{~m}$ by the late Paleocene, but these bathyal environmental indicators are less easily interpreted in terms of depth than the coastal and shelf facies beneath. Minimum estimates for the relief of the contemporary shelf margin are derived based on depth conversion and decompaction with generic Taranaki Basin values (Funnell et al., 1996; Stagpoole, 1998) suggest 300-600 $\mathrm{m}$ of topography in the northwest and closer to $150-300 \mathrm{~m}$ in the southeast.

Late Eocene downlap observed on the northern flanks of the Challenger Plateau is interpreted as a delta with maximum topography of $200 \mathrm{~m}$ and the eastward trajectory of the shelf margin is mapped from northward thinning strata and reflector geometries north of well Tane-1. The location and geometry of the shelf in this area is further constrained by inner or mid shelfal $(50-150 \mathrm{~m})$ water-depth indicators in Tane-1, location of the 
contemporary shoreline (King \& Thrasher, 1996; Matthews et al., 1998, see also previous chapter), and observation of fan facies north of the shelf trajectory. Fan facies in Ariki-1 and basin-ward continuous reflectors suggest a morphological break in slope and gradual northwest sloping basin floor, respectively, although the depth associations range from upper bathyal to lower bathyal-abyssal (400->1500 m, Shell BP Todd Oil Services Ltd., 1981a; Hayward, 1985b; 1986). Thin, medium- to high-amplitude reflectors, correlative marly lithologies, and abyssal foraminifera in Waka Nui-1 corroborate a northward distal deepening $(>1500 \mathrm{~m})$, although depth estimates are similarly uncertain.

Oligocene and Miocene water-depth indicators on seismic data are less distinct, although reflector onlaps, seismic-to-well correlations and biostratigraphic markers point to a rapid marine deepening in the area that has remained shallow to the Late Eocene. Reflectors associated with the Oligocene Tikorangi Formation (above base Oligocene horizon) can be mapped throughout the deep-water survey and into the proximal part of Taranaki Basin where biostratigraphic data consistently indicate bathyal conditions more than $100 \mathrm{~km}$ southeast of Tane-1 from the Late Oligocene (28-25Ma) (Hayward \& Wood, 1989; King \& Thrasher, 1996). Depositional depth of channel and fan facies within the Miocene sequence are uncertain, but observed deep-water channels of Middle Miocene age that delivered sediment from southeast (Baur et al., 2010) corroborate that the study area remained structurally lower than proximal Taranaki Basin. Furthermore, the height of Miocene to Recent foresets (Figure 5.4) suggests accommodation space well over $1000 \mathrm{~m}$ from at least the early Miocene. The herein inferred bathymetry distribution and development (Figure 5.13) is in good agreement with initial facies and paleogeographic interpretation of the survey (Uruski et al., 2002a; Uruski et al., 2002b; Uruski \& Stagpoole, 2004). 


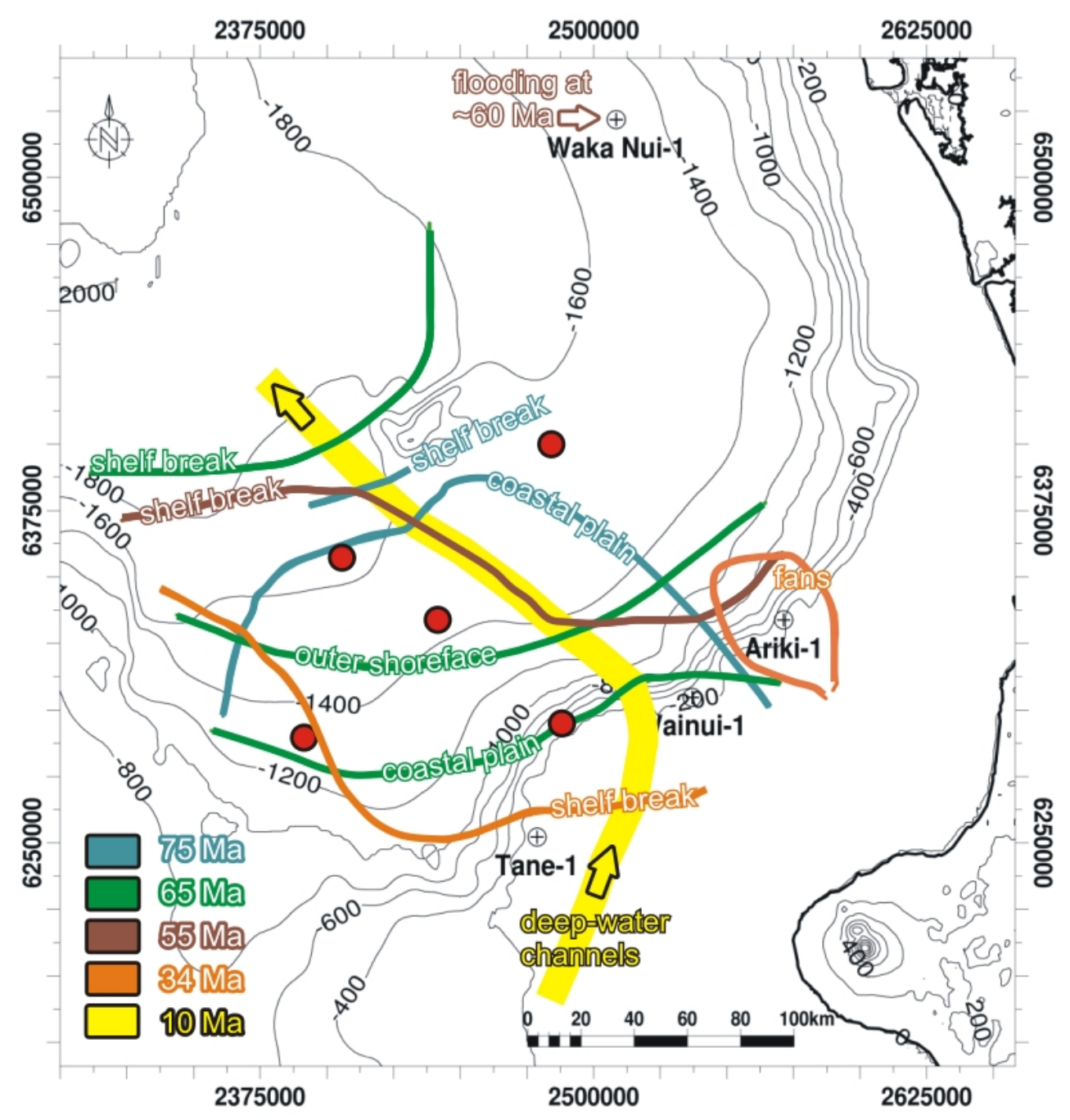

Figure 5.12 Summary of paleobathymetry indicators derived from seismic interpretation and facies analysis. Present-day bathymetry contours are shown as grey lines in metres. Pseudo-well locations used for the extraction of tectonic subsidence curves from back-stripped seismic horizon interpretations are shown as red dots. 

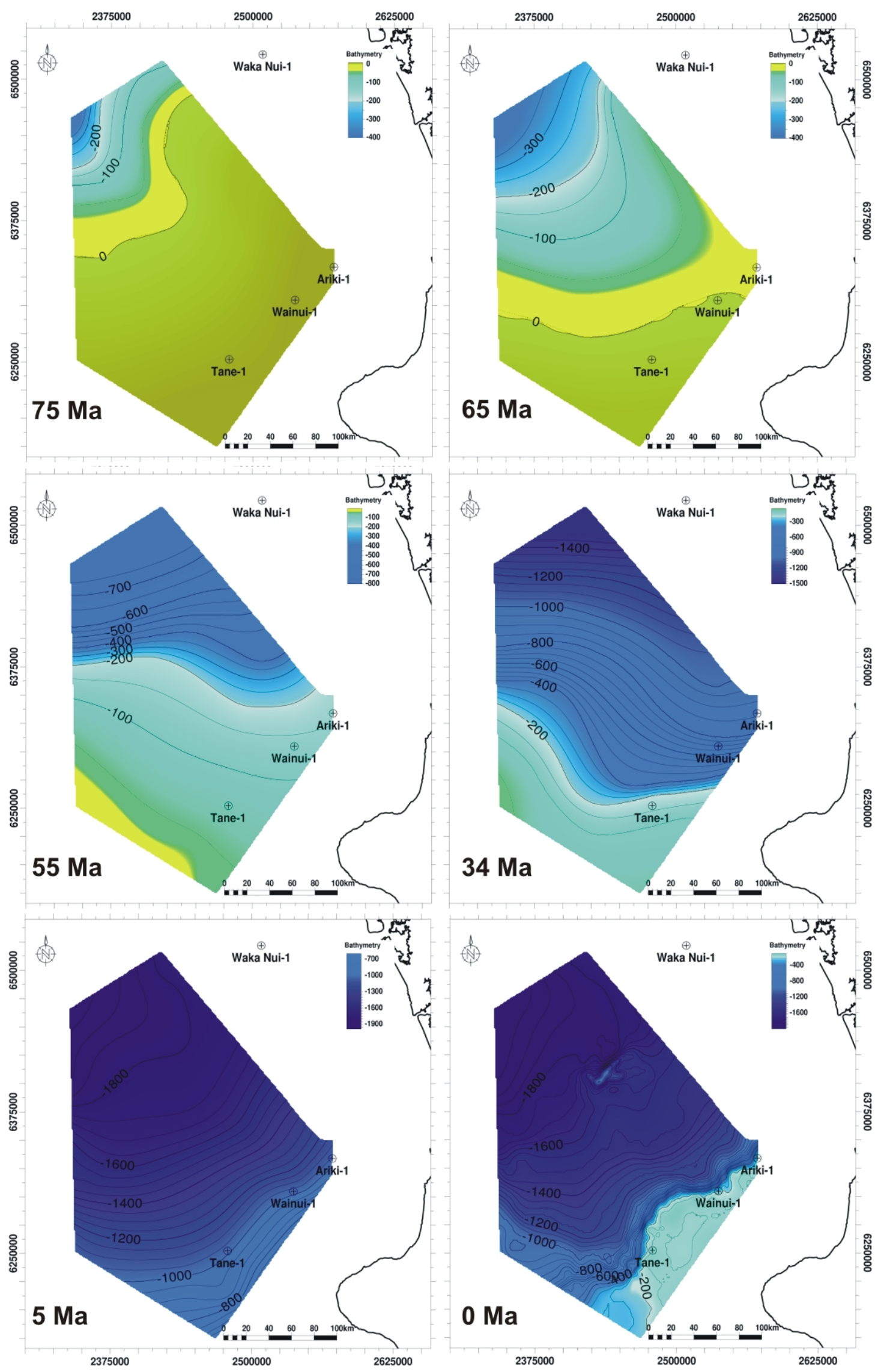

Figure 5.13 Gridded paleobathymetry interpretations based upon well information and seismic facies interpretations at incremental time steps, used for back-stripping of depth-converted seismic horizon interpretations. 


\subsubsection{Tectonic subsidence results}

Lithofacies, sedimentary thickness, and paleo-water-depth data are used to infer the tectonic subsidence history of the basin. Tectonic subsidence is calculated by removing the local isostatic effects of the sediment load and eustatic sea-level changes using a 1-D back-stripping method (Steckler \& Watts, 1978; Sclater \& Christie, 1980; Miller et al., 2005; see Chapter 2).

\section{Wells}

Tectonic subsidence values derived from borehole stratigraphy (Figure 5.14, Table 5.1) have a concave upward signature during the Late Cretaceous and Paleocene with 0.5-1.1 $\mathrm{km}$ of tectonic subsidence. In Waka Nui-1, $0.7 \mathrm{~km}$ of tectonic subsidence was accrued over less than $10 \mathrm{Ma}$, although uncertainties relating to water-depth estimates are high $(>500 \mathrm{~m})$. After initially rapid subsidence rates, southern wells show commonly low subsidence values of $0.2-0.3 \mathrm{~km}$ between $65-55 \mathrm{Ma}$. A change from decreasing to increasing subsidence rates is observed during the Eocene and further defined to occur during the Middle Eocene (45 Ma) and Late Eocene (38 and $34 \mathrm{Ma}$ ) in Waka Nui-1, Ariki-1 and Tane-1, respectively. Subsidence before the inflection point during the time between 55-34 Ma varies between 0.3-0.9 km with decreased subsidence rates compared to the Paleocene of 21-30 m/my. Tectonic subsidence rates increase to maximum values of $>130-150 \mathrm{~m} / \mathrm{my}$ between the Eocene and Oligocene and have a steep segment with additional $1.5-1.7 \mathrm{~km}$ in the south and $1.1 \mathrm{~km}$ in well Waka Nui-1, respectively. By the earliest Miocene (25 Ma), fauna sampled in wells indicate deep water and calculations show gradual subsidence through the Miocene $(0.1-0.6 \mathrm{~km})$. Wells on the present-day shelf show 0.6-0.9 $\mathrm{km}$ of basement uplift since the Late Miocene. Despite the uncertainties in deep-water settings, the total amount of tectonic subsidence is well constrained since the time of marine flooding in the Late Cretaceous (80-65 Ma) or Paleocene (62-58 Ma; Waka Nui-1) and falls in the range of 2.3-3.0 km (Table 5.1). 


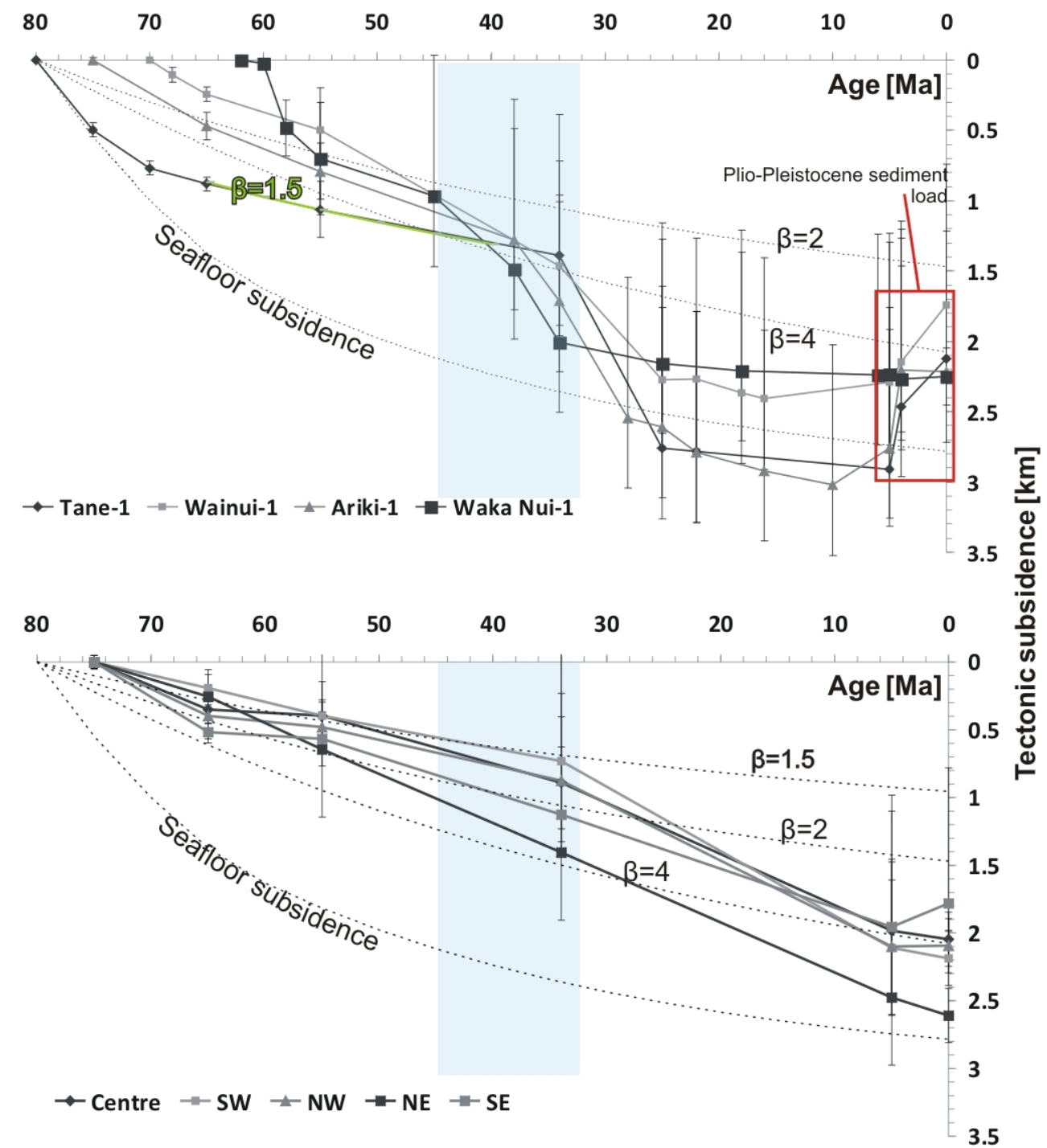

Figure 5.14 Tectonic subsidence history from back-stripped well data (top) and seismic grids at five locations shown as red dots in Figure 5.12 (bottom panel). Black dashed lines show the theoretical subsidence values of cooling seafloor (minus $2.6 \mathrm{~km}$, after Stein and Stein, 1992) and post-rift subsidence following continental stretching (for stretching factors $(\beta)$ of $1.5,2$ and 4 ). Theoretical curves for continental stretching were calculated using generic parameters for a lithospheric thickness of $125 \mathrm{~km}$ (after McKenzie, 1978). The green line in the top panel shows the slope of post-rift thermal subsidence with $\beta=1.5$ adjusted for assumed cessation of rifting at 65 Ma. The light blue area indicates the age range of possible Cenozoic Australia-Pacific plate boundary inception. 
Table 5.1 Tectonic subsidence calculated from borehole stratigraphy (TS) and inferred paleobathymetry (PB). Values are given in kilometres. See Figure 5.1 for well locations.

\begin{tabular}{|l|l|l|l|l|l|l|l|l|}
\hline \multirow{2}{*}{ Age [Ma] } & \multicolumn{2}{|c|}{ Tane-1 } & \multicolumn{2}{c|}{ Wainui-1 } & \multicolumn{2}{c|}{ Ariki-1 } & \multicolumn{2}{c|}{ Waka Nui-1 } \\
\cline { 2 - 8 } & TS & PB & TS & PB & TS & PB & TS & PB \\
\hline 80 & 0.00 & 0.00 & & & & & & \\
75 & 0.50 & 0.00 & & & 0.00 & 0.00 & & \\
70 & 0.77 & 0.00 & 0.00 & 0.00 & & & & \\
68 & & & 0.10 & 0.02 & & & & \\
62 & 0.88 & 0.02 & 0.24 & 0.10 & 0.47 & 0.04 & & \\
60 & & & & & & & 0.00 & 0.00 \\
58 & & & & & & & 0.02 & 0.02 \\
55 & & & & & & & 0.48 & 0.20 \\
45 & 1.06 & & 0.50 & 0.20 & 0.79 & 0.20 & 0.70 & 0.40 \\
38 & & & & & & & 0.97 & 0.60 \\
34 & & & & & 1.28 & 0.40 & 1.49 & 1.00 \\
28 & 1.39 & 0.15 & 1.46 & 0.80 & 1.71 & 0.80 & 2.01 & 1.50 \\
25 & & & & & 2.54 & 1.50 & & \\
22 & 2.76 & 1.50 & 2.27 & 1.50 & 2.61 & 1.50 & 2.16 & 1.50 \\
18 & 2.79 & 1.50 & 2.28 & 1.50 & 2.79 & 1.50 & & \\
16 & & & 2.37 & 1.50 & & & 2.21 & 1.50 \\
10 & 2.13 & 0.24 & 1.74 & 0.20 & 2.22 & 0.25 & 2.25 & 1.50 \\
6 & & & 2.41 & 1.50 & 2.92 & 1.50 & & \\
5 & & & & & 3.02 & 1.50 & & \\
4 & & & & & & & 2.24 & 1.50 \\
0 & & & & & & & & \\
\end{tabular}

\section{Seismic grids}

Tectonic subsidence maps derived from depth-converted seismic grids and interpolated paleobathymetry estimates indicate total tectonic subsidence values of up to $4.6 \mathrm{~km}$ in the centre of the Mesozoic graben system (Figure 5.15). The tectonic subsidence that occurred between $75 \mathrm{Ma}$ and the present-day is robustly constrained due to the welldefined bathymetry at these times, showing values of 2.5-3.2 km north of the Mesozoic graben and a soutward decrease to $\sim 1.5 \mathrm{~km}$ towards the Challenger Plateau. The inferred Eocene to Miocene component of subsidence is more than $1.5 \mathrm{~km}$ over most of the survey with peak values of $>1.75 \mathrm{~km}$ and low values of $\sim 1.25 \mathrm{~km}$ towards the southeast of the survey. 
Tectonic subsidence curves were extracted from these grids at four pseudo-well locations (Figure 5.14, Figure 5.16, Table 5.2) within areas of good paleobathymetry constraints during the Cretaceous and Paleogene, and a north-eastern pseudo well with lesser waterdepth control during these times (Figure 5.6, Figure 5.12). The curves extend the record back to the onset of Mesozoic basin formation (Figure 5.16), show large differences in subsidence within and outside the Mesozoic graben system prior to $75 \mathrm{Ma}(0.2-2.5 \mathrm{~km})$, and describe a general upward concave shape until 55 Ma. Late Cretaceous subsidence is 0.2-0.5 km and further decreases to 0.01-0.4 km during the Paleocene. Subsidence rates further decrease in the southwest between 55-34 Ma (34 Ma, 0.3 km, $16 \mathrm{~m} / \mathrm{my}$ ), but additional subsidence of $0.4-0.8 \mathrm{~km}$ suggest increasing rates of $19-36 \mathrm{~m} / \mathrm{my}$, at the other locations. During the 34-0 Ma time interval, tectonic subsidence values are 0.8-1.4 km which, together with the Eocene signal, amounts to $1.2-2.0 \mathrm{~km}$ of total subsidence since the Paleocene. Areas underlying the present-day slope show minor uplift of $0.2 \mathrm{~km}$ since $5 \mathrm{Ma}$, similar to adjacent wells.

In summary, two distinct phases are common to back-stripped tectonic subsidence curves from boreholes and seismic interpretation. Firstly, an early, concave upward phase with decreasing subsidence rates and associated subsidence values of up to $2.5 \mathrm{~km}$ during rifting and 0.4-1.0 km clearly identifiable concave up post-rift subsidence between the Late Cretaceous and Paleocene. The second, younger part, is characterized by a steep (or upward convex) segment followed by gradual subsidence with 1.2-2 km of tectonic subsidence. This part shows initially gradual increases in subsidence rates, while well data indicate that $80-90 \%$ of this signal occurred at high rates of $>130-150 \mathrm{~m} / \mathrm{my}$ during the Oligocene to Early Miocene within $\sim 10-16$ Ma. The timing of change between these two phases varies between the Early to latest Eocene and appears to be variable in different locations, but is not well defined by the stratigraphic age control. 


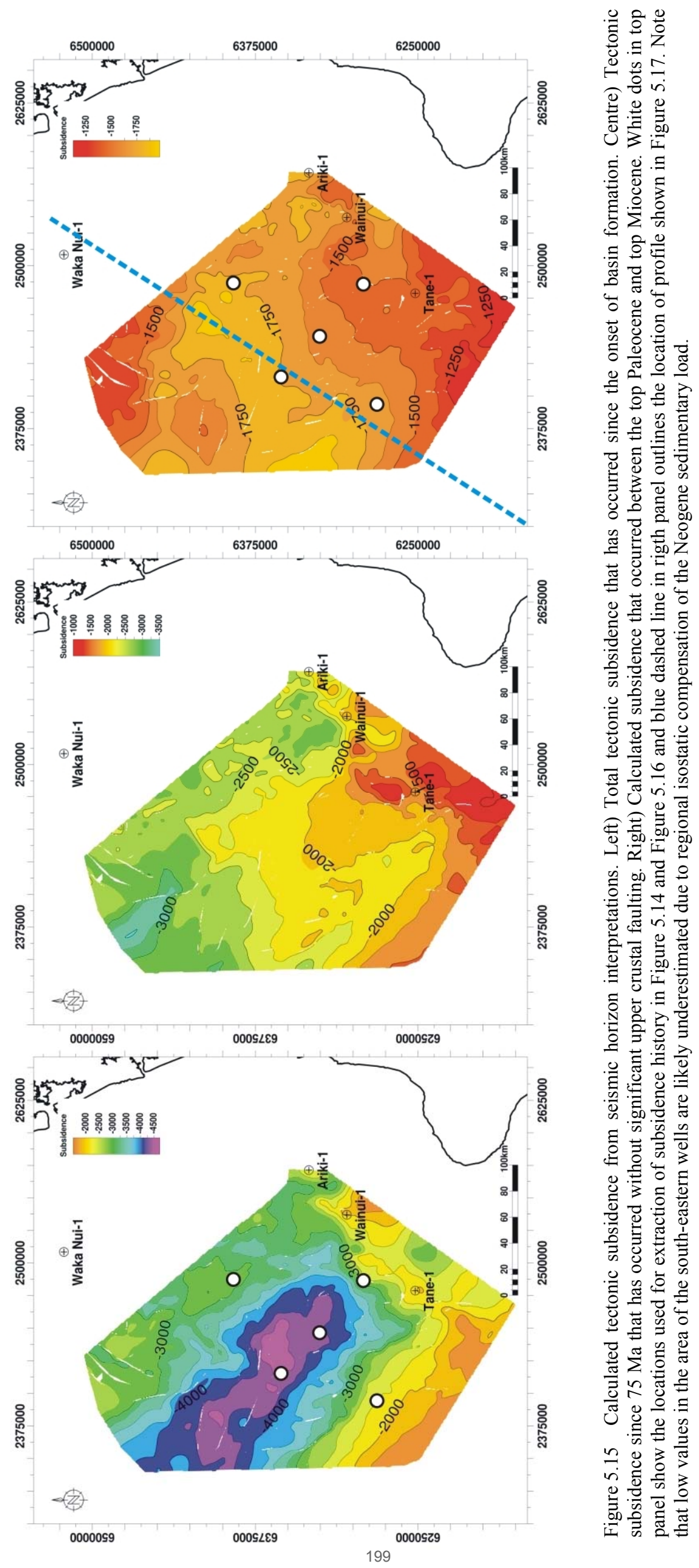




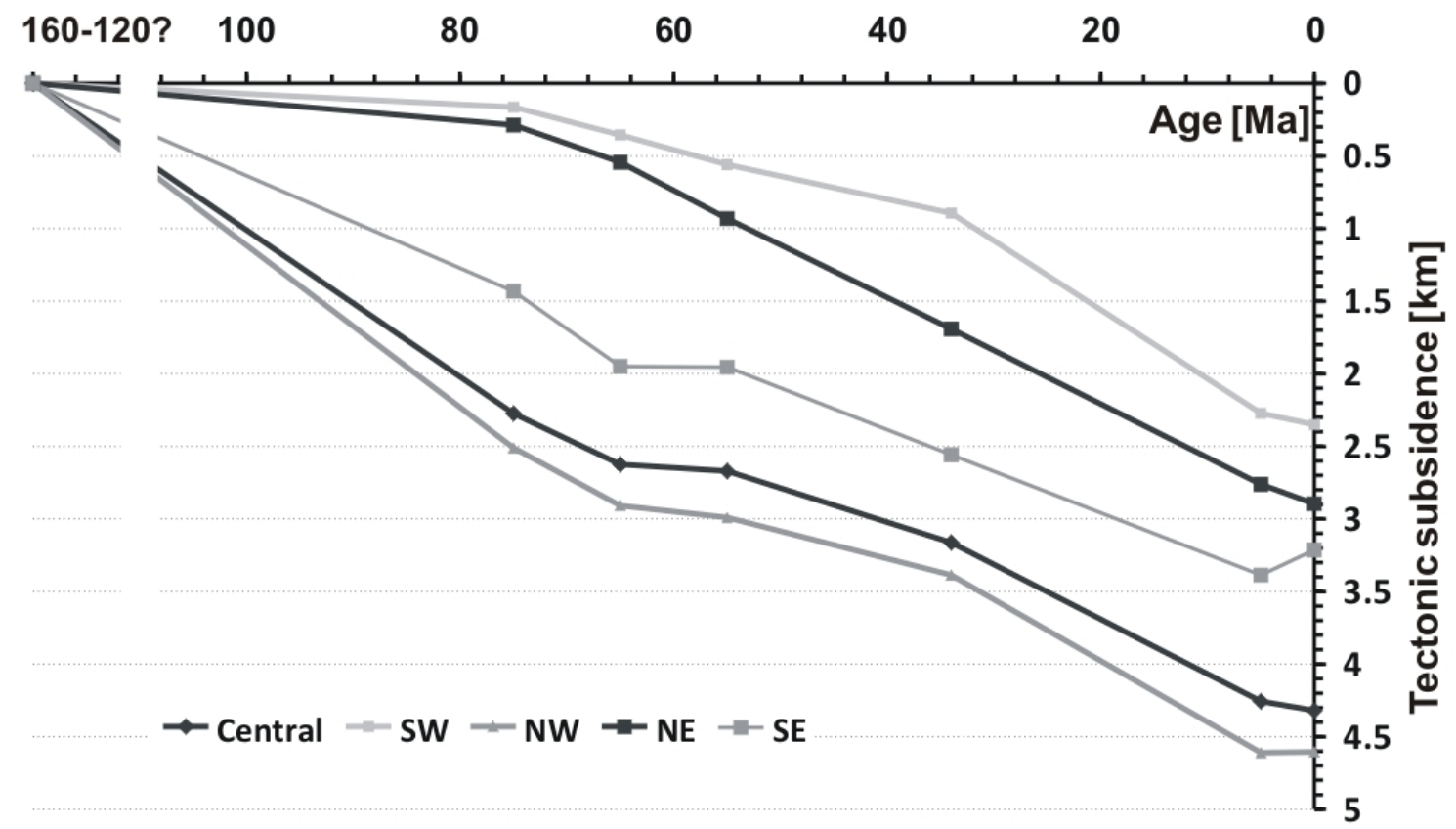

Figure 5.16 Tectonic subsidence history extracted from back-stripped seismic grids at five locations shown as white dots in Figure 5.15. Note the upward concave subsidence signature during the Cretaceous and early Paleogene, and deviation from this trend since the Eocene.

Table 5.2 Tectonic subsidence history extracted from back-stripped seismic grids at five locations shown as white dots in Figure 5.15. Values are given in kilometres. Note the distinct upward concave subsidence signature during the Cretaceous and early Paleogene, and deviation from this trend since the Eocene.

\begin{tabular}{|c|c|c|c|c|c|c|c|c|c|c|}
\hline \multirow[t]{2}{*}{$\begin{array}{c}\text { Age } \\
\text { [Ma] }\end{array}$} & \multicolumn{2}{|c|}{ Centre } & \multicolumn{2}{|l|}{ SW } & \multicolumn{2}{|l|}{ NW } & \multicolumn{2}{|l|}{ NE } & \multicolumn{2}{|l|}{ SE } \\
\hline & TS & PB & TS & PB & TS & PB & TS & PB & TS & PB \\
\hline 120 & 0.00 & 0.00 & 0.00 & 0.00 & 0.00 & 0.00 & 0.00 & 0.00 & 0.00 & 0.00 \\
\hline 75 & 2.27 & 0.00 & 0.16 & 0.00 & 2.51 & 0.00 & 0.29 & 0.00 & 1.43 & 0.00 \\
\hline 65 & 2.62 & 0.06 & 0.36 & 0.01 & 2.91 & 0.10 & 0.54 & 0.07 & 1.95 & 0.01 \\
\hline 55 & 2.67 & 0.14 & 0.56 & 0.06 & 2.99 & 0.15 & 0.93 & 0.43 & 1.95 & 0.12 \\
\hline 34 & 3.16 & 0.56 & 0.89 & 0.18 & 3.39 & 0.50 & 1.69 & 1.03 & 2.56 & 0.58 \\
\hline 5 & 4.26 & 1.55 & 2.27 & 1.38 & 4.61 & 1.72 & 2.76 & 1.71 & 3.39 & 1.18 \\
\hline 0 & 4.32 & 1.46 & 2.35 & 1.31 & 4.60 & 1.65 & 2.90 & 1.55 & 3.21 & 0.46 \\
\hline
\end{tabular}




\subsection{DISCUSSION}

\subsubsection{Tectonic interpretation of subsidence history}

Steep subsidence signals during the early basin history can be related to initial rifting and their subsequent decrease is consistent with cessation of faulting before or during the early Late Cretaceous in the southern NCT (Collot et al., 2009). Post-rift thermal subsidence is expected and consistent with the observed decreasing subsidence rates during the Late Cretaceous and Paleocene (Figure 5.14, Figure 5.16). The 0.4-1.0 km of Late Cretaceous and Paleocene subsidence is similar to global values for the thermal cooling phase of many continental, failed-rift basins (Xie \& Heller, 2009). Stretching factors of $<2$ are inferred based upon the rate and magnitude of post-rift subsidence, the amount of syn-rift subsidence, and the observation that the axis of maximum extension remained above sea level for at least 10-20 Ma after rifting ceased. The inferred stretching factors are comparable to rift systems in the North Atlantic and East Africa (Swift et al., 1987; Hendrie et al., 1994; Roberts et al., 1995), which are presently located in shallow water or above sea level. The distribution of syn-rift and post-rift subsidence suggests a significant component of extension via pure shear (McKenzie, 1978), as large-scale simple shear models predict post-rift thermal cooling that is offset from syn-rift subsidence (Klemperer, 1988). The importance of simple shear along midto lower- crustal detachment systems, as proposed for areas further north in the basin (Lister et al., 1991), cannot be confirmed due to the poor imaging of the fault character at depth. Drift-phase stratal onlap patterns on the northern Challenger Plateau exhibit some degree of 'Steer's Head' geometry (Dewey, 1982), which may indicate that the lithospheric mantle was stretched over a wider area than the crust (White \& McKenzie, 1988).

Several observations point to a change in tectonic driving mechanisms during the Eocene. Rapidly increasing subsidence rates in the north of the study area are inconsistent with post-rift thermal decay models (Figure 5.14, Figure 5.16). Minor wrench or reverse fault offsets and open folding of Eocene reflectors in the northern survey, also observed by previous authors (Uruski, 2008), indicate the Middle or Late Eocene onset of tectonic activity (43-38 Ma). The timing of deformation is similar to north-eastern Taranaki Basin (Stagpoole \& Nicol, 2008), and probably related to initiation of the Australia-Pacific plate boundary northwest of New Zealand (Sutherland, 
1995; King, 2000b). The largest Eocene subsidence is in the north and northeast of the survey area and may represent the early effects of gravitational loading and flexural depression from the north (Figure 5.17). The West Norfolk Ridge (Figure 5.1) is the only candidate for a major load that could have been emplaced at that time, since obduction of the Northland allochthon along the eastern margin of the study area did not occur until the Early Miocene (Isaacs, 1994). However, simple calculations of flexural bending using elastic thickness estimates $(\mathrm{Te}=25 \mathrm{~km})$ determined for Taranaki (Holt \& Stern, 1991) are not able to produce the long wavelength of subsidence that is observed during the Eocene (Figure 5.17).

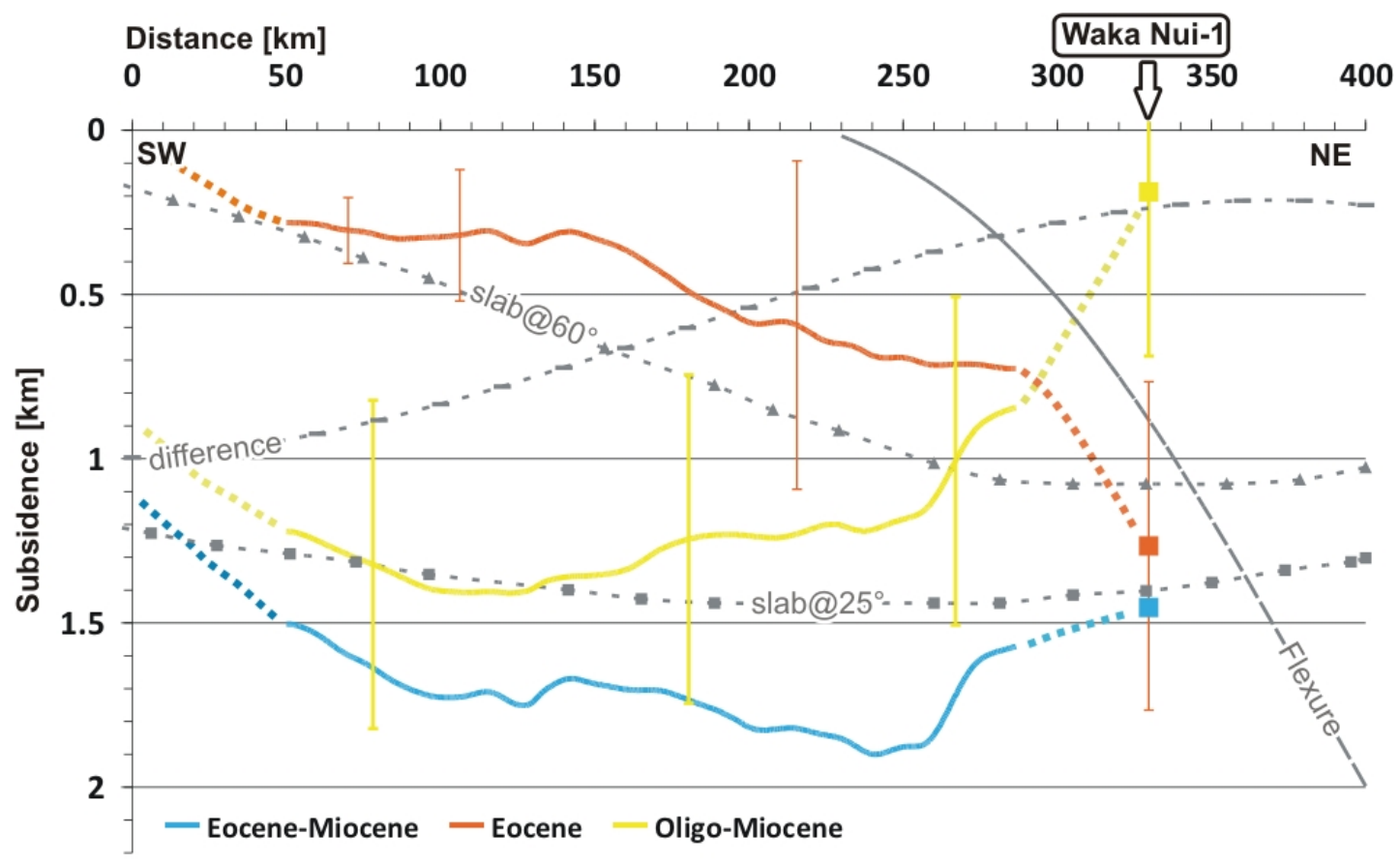

Figure 5.17 Eocene to Miocene tectonic subsidence profile across Deepwater Taranaki Basin and comparison to theoretical models of flexural loading and dynamic topography (see Figure 5.15 for transect location). The coloured curves show tectonic subsidence increments that were extracted from back-stripped seismic grids and well Waka Nui1. The blue line depicts the combined Eocene and Oligocene subsidence shown in the right panel of Figure 5.15 Stippled reference lines show flexural profiles calculated for loading on a free edge of discontinuous elastic plates with effective elastic thickness (Te) of $25 \mathrm{~km}$. Loading was assumed within a $50 \mathrm{~km}$ wide zone at the free edge and constrained to produce minimum $2 \mathrm{~km}$ deep depression at an imaginary loading point $80 \mathrm{~km}$ north of Waka Nui- 1 . This loading point was chosen to simulate the effects of tectonic forcing by a proto-plate boundary north of the study area. Dashed lines show subsequent stages of estimated surface deflection (corrected for water-loading) from a finite element model simulating the viscous coupling of a sinking slab that shallows after subduction initiation from $60^{\circ}$ (phase 1) to $25^{\circ}$ (phase 2, after Mitrovica et al., 1989) and differential subsidence (difference) between these two phases. 
Tectonic subsidence values of 1.4-2.0 km are calculated since the Eocene of which 80$90 \%$ is inferred to have occurred between 38 and $25 \mathrm{Ma}$ (Figure 5.14) at subsidence rates on the order of 130-150 m/my. While Eocene subsidence was higher in the north (in the southward extension of the Reinga Basin, Figure 5.1), the locus of maximum Oligocene subsidence is centred on the south-western part of the survey (Figure 5.17). The latter part defines a broad low between Waka Nui-1 and the Challenger Plateau with subsidence values in excess of $1.0 \mathrm{~km}$ over a distance of $220 \mathrm{~km}$, which is comparable to the width of the NCT along most of its length. There is no evidence for any significant structural boundary between the study area and the greater New Caledonia basin system (New Caledonia, Fairway, Aotea Basin), and the results are broadly consistent with the suggestion by Sutherland et al. (2010a) that the region to the north was also modified during this time interval.

The observations suggest a two-phase development of the NCT: Cretaceous rifting, followed by strong modification during the Cenozoic. Extensional faulting in the NCT was completed before $85 \mathrm{Ma}$ and was followed by post-rift subsidence typical for moderate stretching $(<2)$. Subsidence since the Eocene was in some way related to the onset of Australia-Pacific plate convergence and subduction, but the processes involved remain unknown. Any model of these processes must explain the timing, magnitude, and, wavelength of subsidence, and must not predict significant disruption of basin strata, because Cenozoic deformation is very slight. Late Miocene-Recent basement uplift shown on the subsidence plots (Figure 5.14) is likely an artefact of the assumption of Airy-isostatic compensation in the calculation, which underestimates the regional flexural support of the sedimentary load that was very rapidly and locally deposited during Plio-Pleistocene time (Holt \& Stern, 1991; Hansen \& Kamp, 2006). Positive freeair gravity anomalies associated with this sedimentary wedge (Wood \& Woodward, 1999) confirm that isostatic compensation is partly regional (Figure 5.18). 


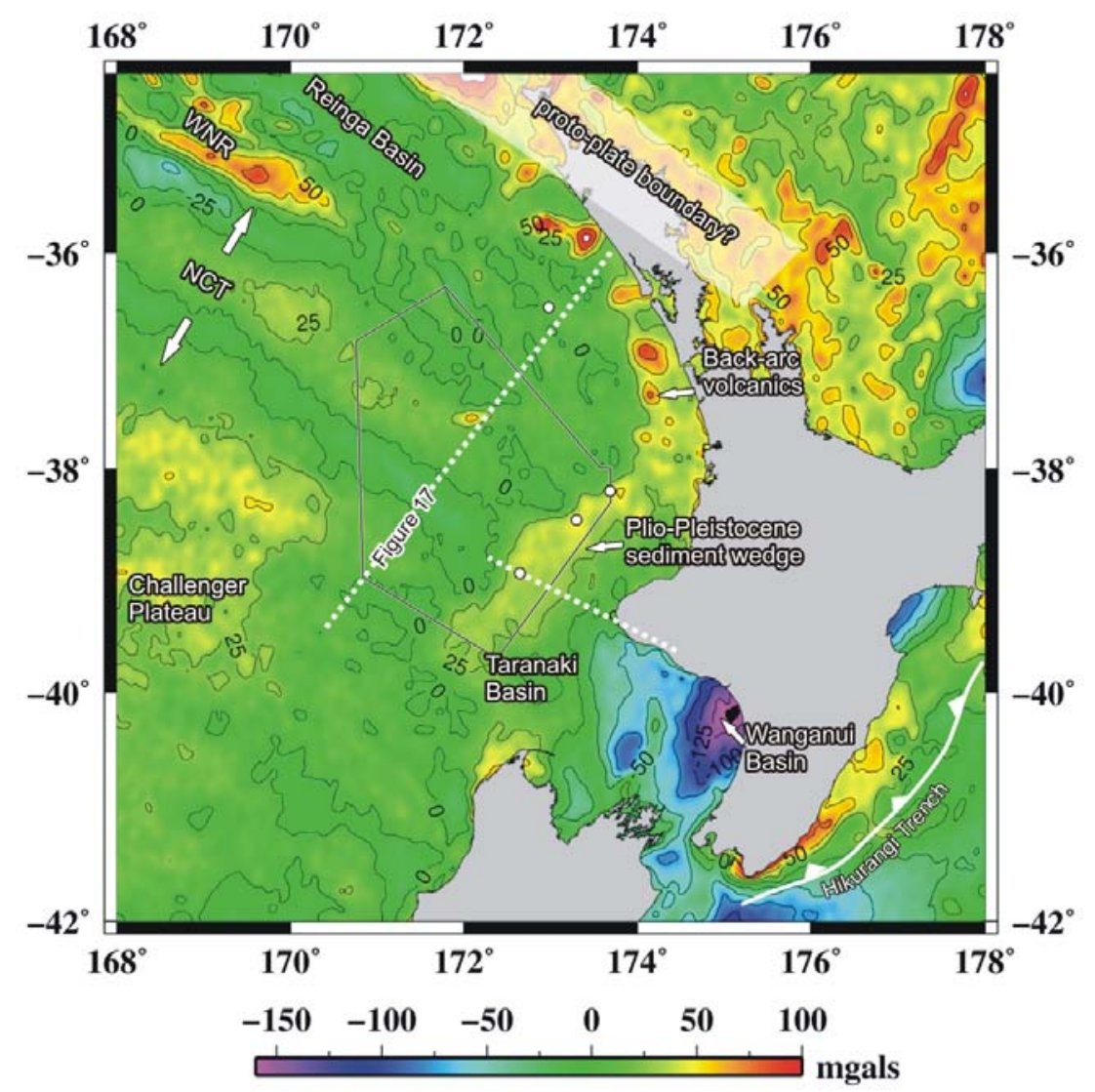

Figure 5.18 Satelite gravity map of the offshore area (after Wood and Woodward, 2002). The location of backstripped grids, well data, and transect shown in Figure 5.17 are displayed as black outline, white dots, and NE-SWtrending thin dashed white line, respectively. The NW-SE-trending white dashed line shows the location of transect shown by Stern and Holt (1994). The location of the inferred proto-plate boundary and the present-day surface location of Australia-Pacific plate subduction are shown as transparent white area and solid white line, respectively. Physiographic features are annotated and abbreviated as in Figure 5.1.

\subsubsection{Tectonic processes that created the NCT deep-water basin}

As introduced above, sedimentary basin subsidence may be an isostatic response to a change in buoyancy of the lithosphere, gravitational loading and flexure, or may be driven by dynamic forces associated with subduction or mantle flow beneath the lithosphere. The buoyancy of the lithosphere may be mechanically redistributed, changed by chemical or mechanical addition or subtraction, and altered by thermal processes. These different basin-forming processes have characteristic time and length scales.

Up to $2.5 \mathrm{~km}$ of tectonic subsidence are calculated to have occurred during Cretaceous rifting, with an additional $1.0 \mathrm{~km}$ of post-rift subsidence during the following $30 \mathrm{Ma}$ (Late Cretaceous and Paleocene, Figure 5.16). The magnitude and timing of this subsidence are consistent with predictions based upon lithosphere thinning by moderate factors of $<2$ (McKenzie, 1978). The total subsidence since deposition of post-rift Late 
Cretaceous and Paleocene strata can be precisely determined, because of the ability to map ancient coastal and shelf facies. The calculated amount of Cenozoic tectonic subsidence $(>2 \mathrm{~km})$ is more than can be explained by any realistic model of Cretaceous rifting, and the inferred subsidence rates do not have the characteristic exponential decay of passive thermal diffusion. Observed subsidence values are similar to environments where the continental crust has been completely rifted, e.g. the West Atlantic margin (Steckler \& Watts, 1978), or the thermal subsidence observed after formation of oceanic crust (Stein \& Stein, 1992), both of which define end members for thermal processes that occur after infinite extension.

These large values of tectonic subsidence are here documented across a region with width greater than $200 \mathrm{~km}$ in proximity to, but not at the surface manifestation of the Cenozoic Australia-Pacific plate boundary (King, 2000b; Herzer et al., 2009). Mechanisms related to minor shallow crustal faulting, supra-crustal loading, and thermal contraction are not able to explain the observed magnitudes, rates and subsidence profiles. A mechanism is required that produces little or no local surface manifestation, except subsidence. The observed subsidence rates, subsidence wavelength, and coincidence with the onset of plate convergence in the neighbouring area do point to mechanisms that involve the entire crust, lithosphere, or mantle, and are related to the subduction process.

If imposed by the plate boundary, lateral changes in subsidence patterns would be greatest in a perpendicular direction to the plate boundary (Burgess \& Moresi, 1999). Paleogeographic reconstructions of the New Zealand area predict a migration and clockwise rotation of the plate boundary by up to $90^{\circ}$ between the onset of convergence in the Eocene and its present-day location (King, 2000b). Stern and Holt (1994) presented evidence for dynamic 'platform subsidence' via rapid Oligocene water-depth increases along a profile perpendicular to the present-day plate boundary and thus subparallel to the possible proto-plate boundary strike. A cross section perpendicular to a speculative early-stage plate boundary location (Figure 5.17, Figure 5.18) confirms the general Oligo-Miocene subsidence signal, but shows the preceding history with large $(0.8-1.3 \mathrm{~km})$ Eocene subsidence values in the north and rapid to gradual southward decrease $(<0.3 \mathrm{~km})$. This early phase was followed by broad and possibly rapid subsidence of $>1 \mathrm{~km}$ over a width of $>200 \mathrm{~km}$ in the central and southern area, with little additional subsidence ( $200 \mathrm{~m}$ at Waka Nui-1) in the north (Figure 5.17). 
Theoretical basement deflection from an early finite element model for the western United States (Mitrovica et al., 1989) that incorporate shallowing of slabs from $60^{\circ}$ to $25^{\circ}$ during subduction evolution are used for comparison with the observations (Figure 5.17). For this purpose, the model plate boundary is positioned $80 \mathrm{~km}$ north of Waka Nui-1 and model deflections are corrected for water loading assuming sediment-loaded subsidence amplification by a factor of:

$$
\frac{\left(\rho_{m}-\rho_{w}\right)}{\left(\rho_{m}-\rho_{s}\right)}=2.84
$$

using average sediment densities $\rho_{s}$, of $2500 \mathrm{~kg} / \mathrm{m}-1$ and other densities as listed in Chapter 2 (see also Stern and Holt, 1994). Differential subsidence between the two steps is calculated by subtracting the topographic profiles of Mitrovica et al. (1989) between the two time-steps of the model.

Assuming initially steeper slab dips, the models predict an initial phase of continental tilting towards the deformation front. As the slab shallows, which is due to the development of a horizontal pressure gradient in the surrounding media (Gurnis \& Hager, 1988), the locus of subsidence shifts away from the deformation front and shows a broad wavelength deflection, while additional deflection close to the deformation front is fairly small. Following subduction initiation, similar models predict rapid (waterloaded) subsidence in excess of $100 \mathrm{~m} / \mathrm{my}$ over large area towards the continental interior during flattening of the slab (Gurnis, 1992).

The modelled pattern of continental tilting toward the deformation front followed by a continent-ward shift of subsidence locus is in general agreement with the observations derived here. Furthermore, high subsidence rates inferred for the Oligocene period are in good agreement with results from viscous flow models (Gurnis, 1992), as suggested by Stern and Holt (1994). It is noted that Base Oligocene unconformities in southern Taranaki Basin (King \& Thrasher, 1996) are observed at distances from the inferred Eocene-Oligocene plate boundary at which models of subduction initiation predict uplift (Mitrovica et al., 1989). The observed unconformities and paraconformities could thus be the composite expression of initial uplift and erosion followed by subsidence and nondeposition. Steeper Eocene geometries in the north could be related to flexural bending by imposed gravitational loads (Figure 5.17), while rapid long-wavelength Oligocene 
subsidence could be interpreted as a result of flattening of the down-going slab after subduction initiation.

On the contrary, the wavelength of modelled surface deflection at the base of the lithosphere is significantly (2-3 times) longer and, although Oligocene submergence is widely evidenced around New Zealand (King, 2000b), is not a good fit to patterns observed in the southern NCT. Despite high values predicted by numeric models, observed vertical deflections attributed to dynamic topography are often in the range of 300-500 m (Gurnis, 1993; Wheeler \& White, 2000), significantly less than the $>1 \mathrm{~km}$ observed here. Moreover, since dynamic topography is proportional to stresses applied at the base of the lithosphere, associated crustal deflections are restored to or above previous values when such forces diminish, (i.e., slab sinks into the mantle, Mitrovica et al., 1989; Gurnis, 1992; Burgess \& Moresi, 1999; Spasojevic et al., 2009). Areas in which anomalous subsidence has been explained by dynamic topography, such as the western North America (Mitrovica et al., 1989; Spasojevic et al., 2009), have recovered to previous elevations or have experienced significant uplift after the forces imposed by the slab diminished. Dynamic topography in the NCT should thus either have been restored, or depressing loads should still be present in the area. Satellite gravity maps (Wood \& Woodward, 2002) show a central gravity high within the NCT that may be related to the sedimentary loading of the stretched crust (Figure 5.18), but gravity lows that would point to a transient depression via lower crust or mantle loads, are not observed. Subduction underneath the North Island continues and is possibly able to suppress topography close to the plate boundary, as suggested for the present-day Wanganui Basin (Stern et al., 2006). However, earthquakes in the distal subduction zone underneath New Zealand's North Island (Anderson \& Webb, 1994) and tomographic images of the mantle (Hall \& Spakman, 2002), indicate that potential slab candidates northwest of New Zealand have sunk to depths of $800-1500 \mathrm{~km}$ and are too deep to depress the present-day basin topography by over $1 \mathrm{~km}$.

The observations suggest that the present-day basin topography is not dynamic but that deformation is instead permanent. For strata to permanently subside to over $3 \mathrm{~km}$ after being at or above sea level at 75 Ma however, buoyant material had to be removed 35-55 million years after rifting had ceased, which points to detachment of crustal material shortly after the onset of Australia-Pacific plate convergence. Assuming a stretching factor of 1.5-2, estimated present-day crustal thicknesses of 5-15 km (Wood \& 
Woodward, 2002; Klingelhoefer et al., 2007) suggest pre-rift crustal thicknesses of 15-30 $\mathrm{km}$, which appears thin for an area that is assumed to have constituted the Gondwana eastern margin (Davy et al., 2008). The observations support the view of Sutherland et al. (2010a) that the crust was additionally thinned either by vertical delamination or lateral translation of the lower crust along detachment faults, probably along the entire basin system. The wavelength of subsidence observed since the Eocene (Figure 5.15) and lack of any obvious loads in gravity data (Figure 5.18) is in support of such lithosphericscale processes. Both mechanisms however, lithospheric delamination and viscous coupling, provide models for the medium- to long-wavelength uplift, widespread development of paraconformities, and subsequent submergence in proximal Taranaki Basin and the wider New Zealand region in the Eocene-Oligocene (Carter, 1985; King, 2000b).

Based on the evidence described above, it is suggested that the present-day physiography of the NCT and the area underneath the Taranaki Basin shelf was modified by lithospheric-scale processes such as delamination of the lithosphere including the lower crust, possibly along chemically preconditioned detachment surfaces as proposed by Sutherland et al. (2010a). The effects of viscous drag by the subducting slab may have been superimposed, since the observed Eocene tilting and subsequent platform subsidence are characteristic features of numerical models of dynamic topography created during subduction initiation.

\subsubsection{Sedimentary architecture of deep-water basins}

It is here suggested that continental deep-water basin formation northwest of New Zealand reflects the composite signal of small-moderate lithospheric stretching $(\beta<2)$ and Cenozoic subduction initiation processes. The composite structural history and stratigraphic response is significantly different to deep-water environments formed as a result of extensive stretching of the lithosphere $(\beta=3-4)$, commonly attributed to the formation of deep-water continental margins (McKenzie, 1978; Le Pichon \& Sibuet, 1981). Subsidence in extensively rifted margins commonly outpaces sedimentation during the rifting stage (Prosser, 1993), in turn leading to a relatively short window of shallow marine deposition during the late rift and post-rift phase and gradual translation of clastic sediment sources away from evolving deep-water environments. In the lowmoderately stretched NCT, terrestrial to shallow-marine sediment deposition occurred 
during the rift and early post-rift phase, with well-developed shallow marine onlap sequences and maintenance of clastic sediment input during gradual late post-rift subsidence until the Eocene.

The example from the NCT shows that anomalous uplift or subsidence events significantly influence the supply of siliciclastic sediment and may rapidly change the general sedimentation character of basins in similar geodynamic settings. For example, it has been noted that the development and death of carbonate platforms in the South China Sea is intimately linked to subduction-related, long-wavelength mantle processes (Dorobek, 2008). In the NCT, rapid subsidence of more than $1 \mathrm{~km}$, led to the rapid creation of accommodation space, drowning of surrounding ridges, southward translation of the shelf margin $(>300 \mathrm{~km})$, and consequential instant demise of siliciclastic sediment input for more than 15 million years. At the present-day, most of the NCT is disconnected from prolific sediment sources and without the exceptionally high sediment supply during the Neogene (Wood \& Stagpoole, 2007), even the southern NCT would remain far removed from the shelf margin. The observations made here raise the possibility that remote basins in deep-water areas may have only experienced moderate stretching, contain well developed shallow marine facies sequences, and clastic sediment supply may have been sustained over long time periods.

Based on the history of basin formation in the NCT, it is suggested that deep-water basins are not necessarily the more evolved equivalents of shallow water basins, but that they may be rapidly formed due to processes in the lithosphere and mantle. There is little or no indication that the responsible process is transient and, in spite of subsequent uplift events, such basins may remain permanently depressed. As opposed to deep-water margins formed by extensive rifting in areas adjacent to moderately rifted areas, this group of deep-water margins is less easily identified and may be far away from presentday sediment sources. The more striking feature in the NCT/Taranaki Basin example is a para- or unconformity with differences in depositional environments above and below of $>1$ km (Hayward \& Wood, 1989; King \& Thrasher, 1992; Cooper et al., 2001), and similar basins may be identified by sudden uplift or subsidence events, temporary starvation of siliciclastic sediment input, or sudden demise of shallow water carbonates (Dorobek, 2008). In the NCT upper crustal faulting is clearly not able to account for the observed rapid subsidence, but more developed deformation of the shallow crust may have masked the recognition of such processes in other basins. 
Modifications of the lithosphere and the lower crust are expected to have significant effects on geothermal gradients and basin geometry, and are important to consider when assessing the thermal history and fluid migration of a basin. Late-stage thinning of the lithosphere via vertical or lateral delamination would cause additional heat input at the base of the crust, and temporarily increase geothermal gradients. In cases of dynamic topography, the heat input may be temporarily depressed, since the geothermal gradient will be perturbed downward by addition of a comparatively colder slab at the base of the lithosphere. However, compression in adjacent areas may facilitate long-distance heat transfer and fluid flow (Oliver, 1986), and may be exacerbated by regional crustal tilting. Numerical models of regional fluid flow in foreland basins suggest topographicaldriven heat advection from internal to peripheral basin areas (Garven \& Freeze, 1984; Gayer et al., 1998), where very high geothermal gradients and high surface heat flow develop.

\subsection{SUMMARY AND CONCLUSIONS}

On the basis of improved paleobathymetry data and back-stripped seismic horizon interpretations and well stratigraphy, a multi-phase evolution of deep-water environments of the New Caledonia Trough is suggested. The early history is marked by Mesozoic extension and subsequent thermal subsidence, in line with previous explanations for basin formation within the context of Gondwana break-up. During the second phase, subsidence is driven by far-field effects of Australia-Pacific plate convergence and subduction in the Eocene and Oligocene.

Total tectonic subsidence values of up to $4.6 \mathrm{~km}$ are observed, of which up to $2.5 \mathrm{~km}$ can be directly related to Mesozoic rifting. The remaining subsidence signal cannot be explained by thermal relaxation alone as it would require stretching factors large enough to eventuate in seafloor spreading. Subsidence curves indicate that thermal relaxation accounts for up to $1 \mathrm{~km}$ of the subsidence signal and suggest stretching factors of $<2$. Stretching factors of this order do not explain the present-day deep-water submergence of the NCT seafloor. Furthermore, simple rift-drift models fail to explain the presence of the widespread Eocene-Oligocene aged unconformities.

Remaining subsidence values of up to $2 \mathrm{~km}$ over a width of more than $300 \mathrm{~km}$ point to lithospheric and mantle effects of subduction initiation in the Eocene. The data shows 
evidence for long-wavelength tilting of the continental interior during the Eocene followed by broad platform subsidence in the Oligocene-Miocene, in line with numerical models simulating the effects of viscous coupling of the slab (Mitrovica et al., 1989; Gurnis, 1992) and previous interpretations in proximal Taranaki Basin (Stern \& Holt, 1994). However, lacking evidence for masses to subdue the present-day topography suggests that parts of the lithosphere have been removed by delamination and the crust additionally thinned in the process. Viscous coupling and lithospheric delamination provide mechanisms to explain the development of unconformities at the base of the Oligocene section in proximal Taranaki Basin, the Lord Howe Rise, and the West Norfolk Ridge. In addition, late stage thinning of the crust might be able to explain Miocene volcanism in an area where no backarc extension is observed in the upper crust. Further numerical models and sampling of volcanic edifices are needed to underpin the viability of suggested models, but the observation of large amounts of subsidence since the Eocene are incontrovertible.

The observation of a moderately rifted basin in a deep-water environment calls for a reassessment of ancient or present-day deep-water basins previously attributed to extensive stretching. Evidence for lithospheric-scale processes has been documented for a variety of areas, such as the western United States (Mitrovica et al., 1989; Spasojevic et al., 2009), western Mediterranean (Docherty \& Banda, 1992; Calvert et al., 2000), and Southeast Asia (Gurnis, 1993; Dorobek, 2008), and their involvement in the development of sedimentary basins may be widespread around the globe. It is crucial to understand the effects of such processes on sedimentary facies distribution, thermal history, and fluid flow, due to their controls on the presence of petroleum source- and reservoir facies, organic maturation, and fluid migration pathways. Terrestrial and shallow marine petroleum source- and reservoir facies may be better developed and present at shallower stratigraphic levels than predicted by extensive stretching. Silicilastic sediment flux may be rapidly muted during large-scale subsidence events, and such basins may be located considerable distance from present-day shelf margins. Ultimately, the sedimentary fill of deep-water basins may prove more prolific than previously thought. 



\section{CHAPTER 6 DEVELOPMENT OF SHELF TO DEEP-WATER SEDIMENTARY SYSTEMS IN THE MIOCENE TARANAKI FORELAND BASIN}

\subsection{INTRODUCTION}

Convergence across the Australia-Pacific plate boundary and emergence of the New Zealand landmass during the Miocene resulted in exhumation and transport of large sediment volumes into ocean basins surrounding New Zealand (Adams, 1980; King, 2000b; Stagpoole et al., 2002; Wood \& Stagpoole, 2007). In addition to near-shore deposition and consequential outbuilding of vast shelf areas that frame the country's landmass (Figure 6.1), large sub-marine channel systems observed on the present-day seafloor show that deep ocean sediment transport represents an important part of the sedimentary system (Carter et al., 1994; Lewis \& Barnes, 1999; Lewis \& Pantin, 2002). Up to a third of the total Neogene sediment volume that has been eroded from the uplifting New Zealand landmass is estimated to have been deposited into Taranaki Basin (Stagpoole et al., 2002). These large sediment volumes caused the rapid outbuilding of a shelf margin wedge across the evolving Taranaki foreland basin during the Miocene (King \& Thrasher, 1992; Holt \& Stern, 1994). Observations of concurrent shallowing in paleo-water depth are paralleled by a decrease in sand to mud ratio of deposited sediment (King \& Thrasher, 1996), but the character and timing of the evolving Miocene continental margin and spatial shift of bathyal depocentres have hitherto not been documented in detail.

Miocene turbidite deposits are of increasing exploration interest in Taranaki Basin, where the second largest proven oil accumulation is trapped in basin floor turbidite sandstones in the Maari field ( $\sim 50 \mathrm{mmboe})$ and similar facies have been proven prospective for oil and gas in a number of other fields, such as the Kaimiro, Ngatoro, and Cheal fields in onshore Taranaki peninsula (Crown-Minerals, 2010). Globally, some of the major oil and gas accumulations are trapped within sub-marine turbidite systems such as the Giant Barracuda and Roncador Fields in the Campos Basin of Brazil ( $\sim 4$ bbloe, 1.15 -2.6 bbloe recoverable, Rangel et al., 2005). In the light of increasing hydrocarbon exploration in deep-water areas and associated sedimentary facies, documentation of the sedimentary character and developmental in these deep-water basins controls is critical for local 
exploration and production success and to use these observations as meaningful analogue studies elsewhere.

Sedimentary deposits associated with Miocene turbidity flows are exposed on the northern Taranaki coast (Figure 6.1), in outcrop sections that have been recognized as some of the world's best for examining deep-water sedimentary processes (Jordan, 1994; King et al., 1994b; Browne et al., 2000; Browne \& Slatt, 2002; Arnot et al., 2007; Browne et al., 2007b; King et al., 2007b). In contrast, sub-crop investigations of associated seismic facies have been limited to few localized studies or investigations of specific formations (Bussell, 1994; de Bock, 1994; Dauzacker et al., 1996; Grain, 2008). These studies have shown that Miocene turbidite sequences are well imaged on seismic reflection data, but regional analysis of seismic facies distribution has hardly been attempted (e.g., Grain, 2008). The over-representation of outcrop and well geology with respect to seismic facies interpretation is a common phenomenon in studies of turbidite systems in actively deforming foreland basins world-wide (Covault \& Graham, 2008). While outcropping foreland basin turbidite systems represent some of the type examples of gravity-flow deposits (e.g., Mutti, 1985; Ricci Lucchi, 1990; Mutti \& Normark, 1991), the literature on their seismic characteristics is much sparser (e.g., De Ruig \& Hubbard, 2006; Covault et al., 2009).

This chapter focuses on using seismic reflection data to constrain the spatial and temporal evolution of Miocene shelf margin and associated deep-water sedimentary systems within their paleogeographic context. Specific attention is given to the delineation of turbidite depocentres through time and the characteristics of associated sediment conduits through which sediment was transported to deep-water environments. The regional Miocene depositional development is described from well data, sediment isochron maps and regional seismic profiles, while the detailed distribution of sedimentary facies is reconstructed from seismic attribute maps and facies interpretation of 2D and 3D seismic data. Multi-attribute volumes are used to image large sediment conduits from the proximal Taranaki Basin to the deep-water New Caledonia Trough (NCT). The paleo-basin morphology is reconstructed via decompaction of observed clinoform heights, and the detailed character of channels mapped from 3D data is investigated to improve on the current knowledge of these systems from outcrop studies. The results are synthesised and presented as paleogeographic maps to display the evolution of the shelf margin and distribution of turbidite facies in the basin and 
analogies are drawn to present-day deep-water sediment transport systems in New Zealand and elsewhere to better understand the observed facies patterns in Taranaki Basin. This study improves the previous knowledge of Taranaki Basin paleogeography and facies development, and provides some constraints for the petroleum prospectivity of Miocene turbidite systems. In so doing, it also presents an example of depositional patterns in a relatively well-preserved foreland basin.

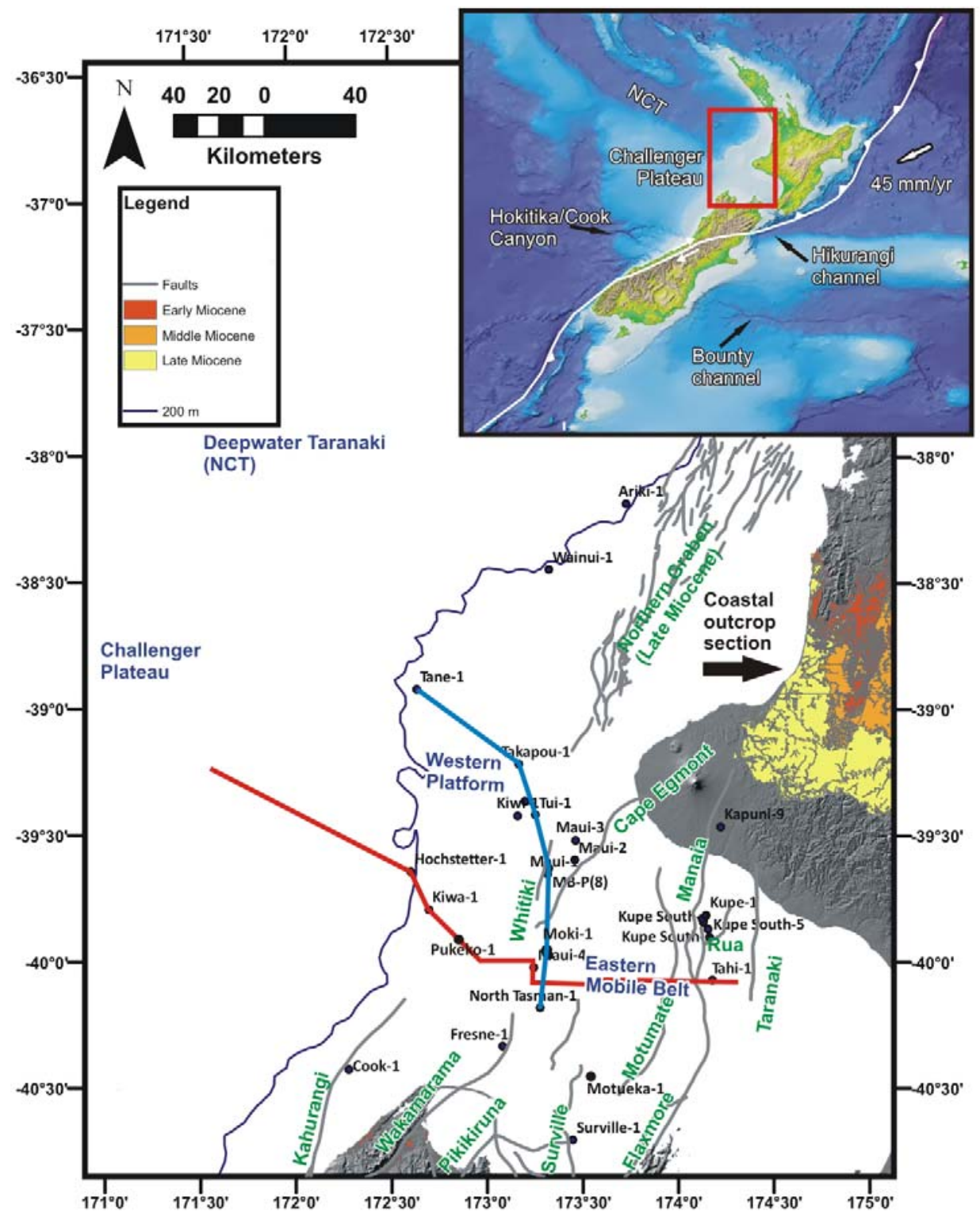

Figure 6.1 Overview map of Taranaki Basin. Faults inferred to be active during the Miocene are shown in grey (after Thrasher and Cahill, 1990). Selected wells used in this study are shown as black dots and the $200 \mathrm{~m}$ bathymetry contour is shown as dark blue line to show the approximate extent of the modern shelf. Locations of outcropping strata of Miocene strata in eastern Taranaki are shown in red orange and yellow, respectively. Blue and red lines delineate the locations of the well correlation panel shown in Figure 6.7 and the regional seismic line shown in Figure 6.8, respectively. The inset shows an overview map with annotations of major deep-water channels around New Zealand. 


\subsubsection{Depositional systems, turbidites and sub-marine fans}

Continental margins around the world show a series of common building blocks and sedimentary processes that vary in character depending on factors such as basin morphology, tectonic setting, sediment supply, and relative sea level (Reading \& Richards, 1994). In most basic terms, basin margin components are subdivided into shelf, slope, and basin floor (Figure 6.2A). Clastic sediment is supplied to the shelf by river systems or longshore drift (Piper \& Normark, 2001), the character of which is influenced by the nature of drainage systems and ocean currents. Density flows are considered by far the most common mode of coarse-grained, sediment transport downslope to deepwater environments (Weimer \& Slatt, 2004). These flows may originate from sediment slumps, sediment failure on a delta front or shelf break (Posamentier \& Walker, 2006; Moscardelli \& Wood, 2008), or through density undercurrents (hyperpycnal flows) in cases of increased sediment discharge from large rivers to the slope (e.g., Mulder et al., 1998). Remobilization of sediment from the shelfal staging area is often associated with exposure of the whole or parts of the shelf during relative base-level lowstands, which are controlled either eustatically or tectonically (Posamentier \& Vail, 1988; Reading \& Richards, 1994; Richards \& Bowman, 1998).

A spectrum of flow characteristics exists by which sediment is transported down the slope, which in turn affects the character of resulting deep-water deposits. The flows can occur as turbidity currents, fluidised flows, liquidised flows, grain flows and debris flows and vary in their density, support mechanisms, and sedimentation mechanisms (Shanmugam, 2006). Debris flows, for example, are very dense, matrix-supported, clayrich flows initiated on steep slopes and are generally unstratified, poorly sorted deposits (Pratson et al., 2000; Moscardelli \& Wood, 2008). Turbidity currents are the most documented mode of sediment supply to sub-marine fans and are of profound exploration importance due to the good sedimentary stratification and superior reservoir characteristics with respect to other types of flow (Bouma, 1962; Weimer \& Slatt, 2004; Shanmugam, 2006). These flows are characterised by turbulent suspension of sediments that is maintained until the speed is reduced below critical levels, usually due to flattening sea-floor topography (e.g., Lowe, 1982; Boggs, 2001). The coarser and heavier particles settle first as there is not enough energy in the flow to support them, while the 
smallest, lightest particles will remain in suspension until the flow stops (Posamentier \& Walker, 2006). These sedimentation characteristics lead to a well-established vertical stratification of the turbidite deposit with clear lateral thinning and upward fining (Bouma, 1962). Despite these commonly observed depositional sequence characteristics of turbidite deposits, significant variations in stratification and depositional character may exist based on flow characteristics, sediment grain size of the system, feeder systems (channels), and slope margin geometry (Reading \& Richards, 1994; Richards \& Bowman, 1998; Posamentier \& Walker, 2006).

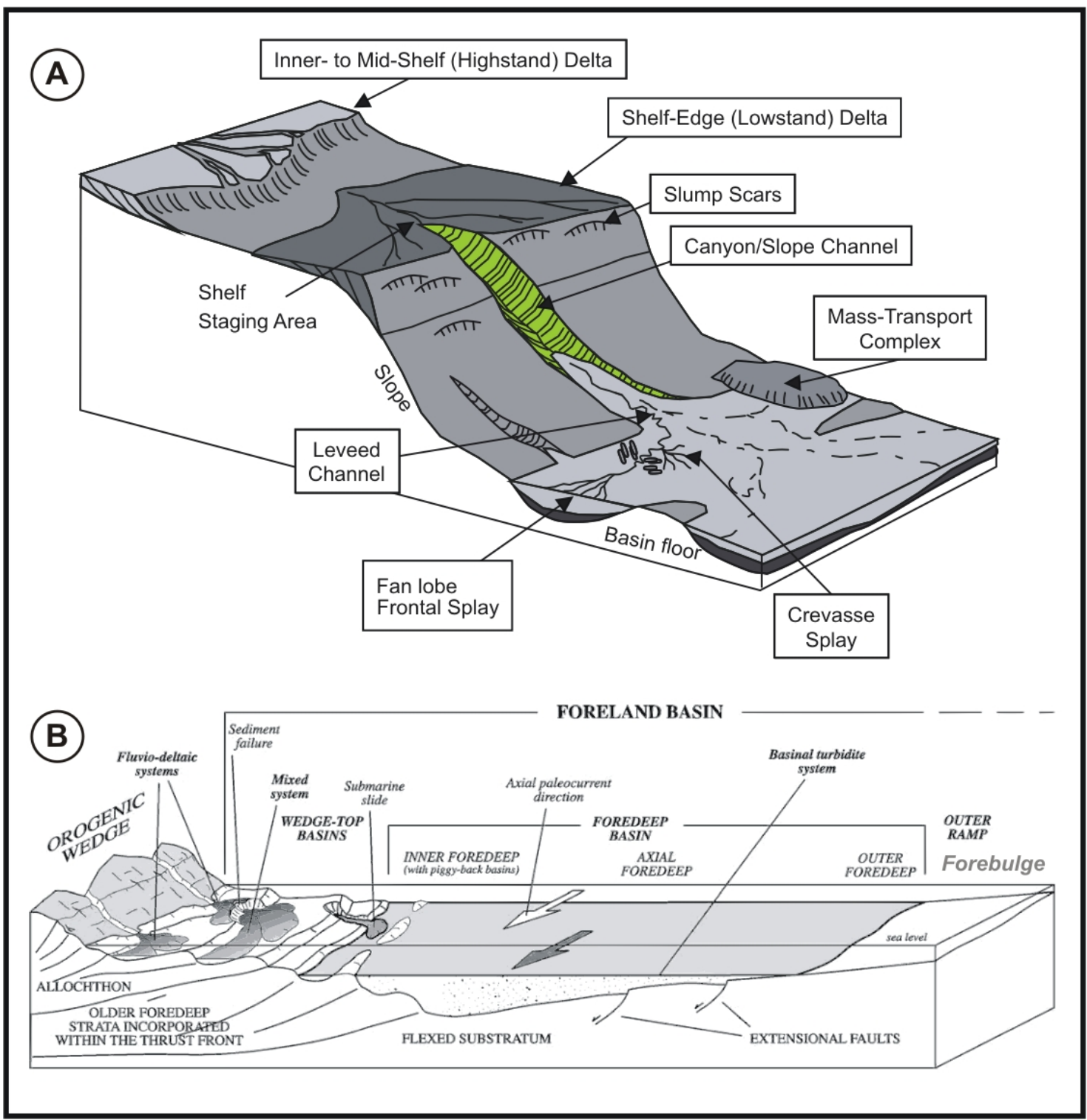

Figure 6.2 Schematic models showing depositional and structural elements of continental margins. A) Generalized summary of depositional elements in deep-water settings (after Posamentier and Kolla, 2003). B) Generalized structural elements, basin geometries, and depositional characteristics in foreland basin settings (after Mutti et al., 2009). 
Many authors have tried to identify the sedimentary elements common to modern and ancient turbidite systems. Mutti and Normark (1991) have defined such depositional elements as the basic mappable components of both modern and ancient turbidite systems that can be recognized in marine, outcrop, and subsurface studies. The five elements they identified were channels, overbank, fan lobes (sheets), channel-lobe transition and erosional features, but many other subdivisions of these elements have been proposed (e.g., Reading \& Richards, 1994; Posamentier \& Walker, 2006; Shanmugam, 2006). The prevalence, character, and location of these depositional elements depend on a series of factors such as the character of sediment supply systems, slope morphology and lithology of the transported material and substrate.

Channels can extend over distances of hundreds to several thousand kilometres in a down-dip direction, such as the Hikurangi Channel of New Zealand's East Coast $(>1000$ km, Lewis \& Pantin, 2002) or feeder systems of the Indus and Bengal fans (> $4000 \mathrm{~km}$, Emmel \& Curray, 1984; Prins et al., 2000). Channel characteristics vary from straight to highly sinuous, and can be erosional, depositional, or a combination of both processes (Mutti \& Normark, 1991). The geometries of channels change in response to sea floor gradient from confined, deep feeder channels or canyons on steeper slopes, to more unconfined shallower and broader channel systems in lesser gradient settings (Weimer \& Slatt, 2004). Their morphometric character is reflected in the sedimentary filling of the channel conduit and dictates the connectivity of sandy deposits in the channel architecture. For example, erosional channels may retain a coarse-grained (conglomeratic-sandy) basal lag, while the dominant fill is fine-grained hemipelagic sediment deposited after cessation of flow (Posamentier \& Walker, 2006). Consequently, these features often have medium to high seismic amplitudes near the erosive base, and relatively lower-amplitude, semi-continuous to chaotic reflectivity within the overlying fill (Posamentier \& Kolla, 2003). Depositional channels can show a variety of filling patterns, such as lateral accretion packages (LAPs, see Abreu et al., 2003) or vertical accretion, which is indicative of development of sinuosity of the system in a longitudinal ('sweep') and lateral direction ('swing'). The degree of sinuosity tends to be inversely related to the gradient of the slope (Weimer \& Slatt, 2004), although, due to contrasting observations in fluvial (Schumm \& Khan, 1971) and some deep-water systems (Wood \& Mize-Spansky, 2009), controls on channel sinuosity remain a matter of debate. 
As flows travel down system, relatively finer-grained sediment is preferentially stripped from the flow and contributes to the construction of levee walls, while the flow is progressively enriched in the denser, more coarse-grained part of the flow down-system. The levees thin away from the channel and may be identified by 'gullwing' shape on seismic reflection data (Posamentier \& Kolla, 2003). On burial, the bathymetric expression of the levees might diminish due to differential compaction between coarsergrained channel fill and finer-grained sediment in the levee/overbank systems (Weimer \& Slatt, 2004).

Ultimately, channels pass into depositional lobe/sheet deposits once the flow decelerates and sediment that has been transported through the channel confining spreads out and is deposited across the basin floor as sub-marine fan lobes (Figure 6.2). The plan-form appearance of these features has been documented as lobate to paddle shaped, but is highly dependent on the morphology of the receiving basin and sediment grain size (Reading \& Richards, 1994). Successive density currents preferentially fill areas of lower-lying morphology, thereby building complex bathymetric compensation geometries with coalescing and inter-fingering of individual fan lobes. Individual sand sheets have been documented to range within about 3-16 m thickness although sand bodies can be $>100 \mathrm{~m}$ thick where individual sheets or flows are amalgamated, and even thicker in semi-confined mini-basins (Weimer \& Slatt, 2004).

A host of definitions exist that further subdivide the different regions within a fan system. Classical fan models of sand-rich environments envisage a system fed by a single feeder channel that radially splits into distributary systems down-current, feeding an upper, middle, and lower fan (e.g., Normark, 1970; Walker, 1978). With decreasing energy in a distal direction, the sand content and the width of channels decrease towards the outer fan. On seismic reflection data, fan deposits (or lobes) can have a mounded appearance (Sangree \& Widmier, 1979) and are often marked by relatively continuous high-amplitude reflection packages (HARPs, e.g., Pirmez \& Flood, 1995). The upper fan has also been termed the channel-lobe transition (Mutti \& Normark, 1991), describing a region of variably unconfined deposition and further bypass onto the basin floor. While the reflection character is variable in the channel-lobe transition zone, reflectors may become more continuous in the distal fan, due to the reduction in channelling and the more distinct stratification of coarser-grained sediment and intervening hemipelagic units (Beaubouef \& Friedmann, 2000). 
Studies of continental margins around the world have shown that varying fan characteristics can be linked to factors such as dominant grain size, feeder systems and tectonic setting (e.g., Mutti, 1985; Mutti \& Normark, 1991; Reading \& Richards, 1994; Shanmugam, 2006). Mutti (1985) considered the importance of grain size and subdivided fan systems into sand-dominated, canyon-fed, low-efficiency systems with relatively short source-to-sink sediment transport distances and mud-dominated, delta-fed, highefficiency systems in which sediment is transported over longer distances, forming elongate fans. Reading and Richards (1994) subdivided depositional systems in deepwater margins into a spectrum of twelve classes, consisting of a combination of grain sizes (mud rich, mixed mud-sand rich, sand rich, gravel rich) and type of feeder systems (point-source fan, multiple source sub-marine ramp, line-source slope aprons). The size and stability of channels, organization of depositional sequences, and the length-to-width ratio of the system are all least in the line-source end-member, and greatest in the pointsource end member. These relationships have significant impact on the quality and connectivity of coarse-grained reservoir bodies (Figure 6.3). 


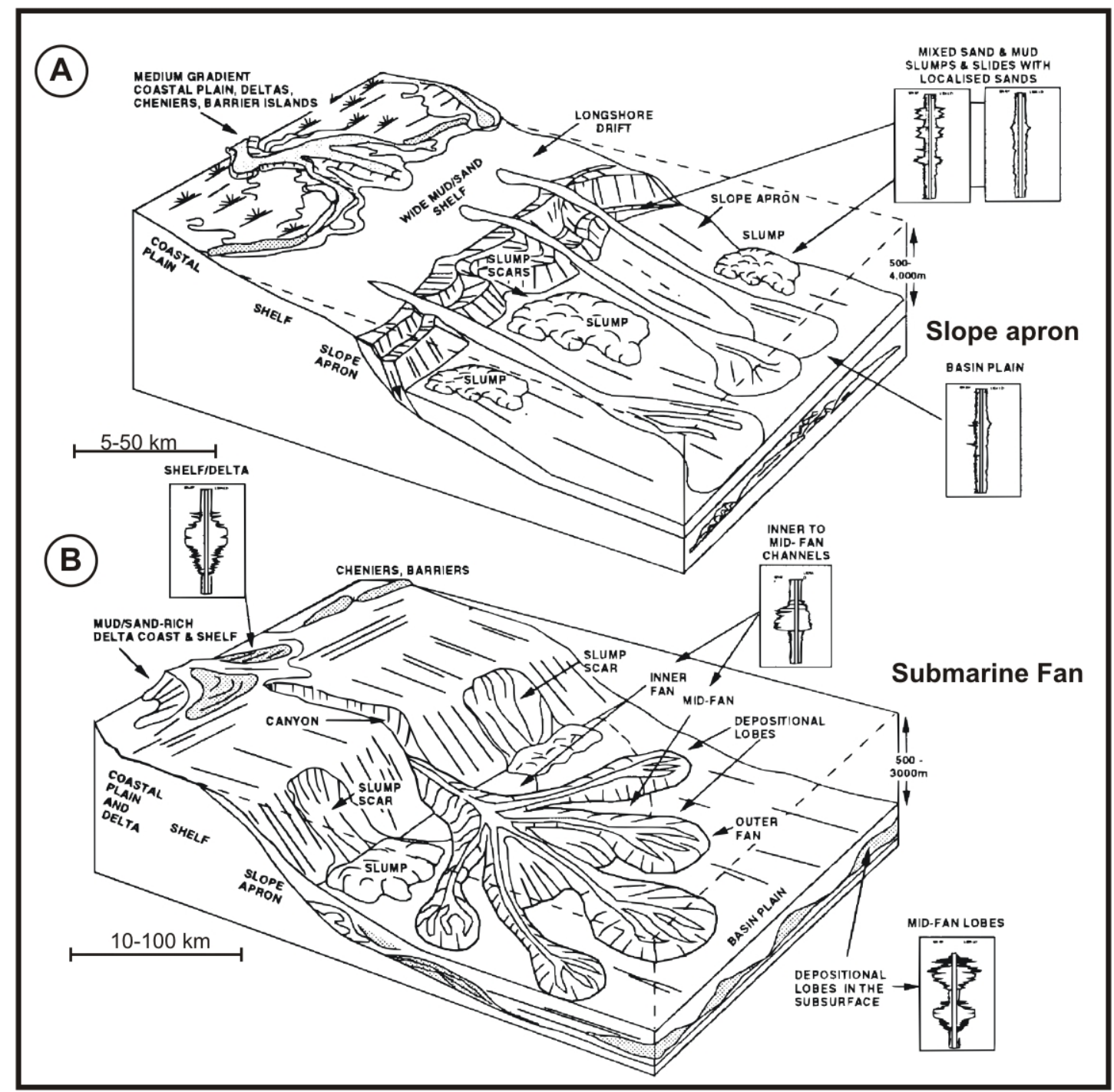

Figure 6.3 Gross depositional environments and log responses of mixed mud-sand rich deep-water clastic systems (after Richards and Bowman, 1998). The models illustrate two end member models of a line-source slope apron (A) and point-source submarine fan (B). Indicative responses from gamma-raylspontaneous potential and resistivity logs in differing submarine environments are shown and serve as a proxy for primary reservoir properties and fabric.

\subsubsection{Foreland basin deposystems}

Depositional systems and submarine topography in actively-deforming foreland basins frequently differ from passive margins, in turn leading to the development of sedimentary architectures unique to foreland settings (Covault \& Graham, 2008). Foreland basins are formed as a flexural response to orogenic or tectonic loading of lithospheric plates (Watts, 1992; DeCelles \& Giles, 1996) and are characterized by an asymmetric wedge geometry (Figure 6.2B). The width of these basins depends on the elastic thickness of the lithosphere, but is generally on the order of 100-200 km (Watts \& Ryan, 1976; Sinclair et al., 1991). Foreland basin depocentres can be divided into wedgetop, foredeep, forebulge, and backbulge depozones (Allen \& Allen, 2005). Tectonic 
deformation of the wedge-top depozones and foredeep margin slopes causes the creation of localized accommodation space, in turn leading to the deposition of slope fans and ponding of sediment (Ricci Lucchi, 1990; De Ruig \& Hubbard, 2006; Covault et al., 2009). The axial foredeep depozone has been focused on by most foreland basin system studies (Covey, 1986; Sinclair, 1997a; Mutti et al., 2003; De Ruig \& Hubbard, 2006; Hubbard et al., 2008; Hubbard et al., 2009) and is generally marked by large sediment bypass systems that tend to be oriented transverse to the deforming margin (De Ruig \& Hubbard, 2006; Hubbard et al., 2008). During basin evolution, peripheral foreland basins may change their character from an underfilled state, with deposition of dominantly deep marine strata in the foredeep, to filled and overfilled states with shallow-marine to fully continental facies (molasse deposits), and deposition of sediment beyond the forebulge depozone (Coakley \& Watts, 1991; DeCelles \& Giles, 1996; Sinclair, 1997a). Faults oriented transverse or oblique to the thrust front can facilitate the development of sediment conduits from the hinterland source area and local depressions along the foredeep margin slopes (Ricci Lucchi, 1990; Covault \& Graham, 2008). During evolution of the foreland basin, the foredeep may be successively incorporated into the thrust front and wedge-top, and become a piggy-back basin (Allen \& Allen, 2005).

\subsubsection{Review of Miocene Taranaki Basin stratigraphy}

The Miocene sequence has been mostly described from borehole and outcrop data (Lock, 1985; King, 1988a; de Bock, 1994; Browne et al., 2000; Browne \& Slatt, 2002; Browne et al., 2005b; Townsend et al., 2008) and is understood as an overall regressive sequence driven by local as well as regional convergent tectonics (King \& Thrasher, 1992). Within the succession of the Miocene Wai-iti Group (Figure 6.4), the litho-facies units are subdivided into basinal muds (Manganui Formation), lower slope to basin floor sanddominated fans and channels (Moki and Mt Messenger formations), upper slope mud and coarse clastic filled channels (Urenui Formation), as well as uppermost slope to shelf deposits of the Kiore and Otunui formations (King \& Thrasher, 1996; Kamp et al., 2004). Fine-grained mud and marl of the Ariki formation indicate a temporary muting of siliciclastic sediment input in Western Platform wells (Hansen and Kamp, 2004), while shallow marine facies of the Matemateaonga Formation that onlap onto a Late Miocene unconformity mark the top of the Miocene succession in the south-eastern basin (Vonk et al., 2002). 
The Moki Formation represents the earliest sand-dominated basin-floor fan sequence in the Miocene and is of Altonian to Lillburian age (Pl-S1, 17-13 Ma). It typically has a distinct wireline log signature of stacked tabular, sandstone packages with sharp upper and lower contacts with the marine mudstones of the Manganui Formation (King and Thrasher, 1996). A later phase of fan deposition has been recognized in the central basin area and previously been grouped with the Moki Formation (Bussell, 1994; Dauzacker et al., 1996), but, based on its New Zealand stage association, is here referred to as Swsands (Waiauan, 13-11 Ma). These strata have been described as combined sheet sands and channel deposits (Bussell, 1994; Dauzacker et al., 1996), and have shown excellent reservoir properties in the southern basin (26\%, Rogers et al., 2000). The Mount Messenger Formation is a fine-grained sand-dominated succession of Late Miocene age (lower Tt, 12.7- $7 \mathrm{Ma}$ ). The sequence is exposed along the northern coastline of Taranaki where stacked basin-floor fan, slope fan, and progradational slope deposits have been described (King et al., 1994b; King \& Thrasher, 1996; Browne et al., 2000; Browne \& Slatt, 2002; Browne et al., 2005b). The Urenui Formation overlies the Mount Messenger Formation and is described as characteristically fine-grained, middle to upper slope deposits, punctuated by 1-2 km wide and 30 and $60 \mathrm{~m}$ thick channel systems with coarse(sand and conglomerate) to fine-grained channel fill (King \& Thrasher, 1996).

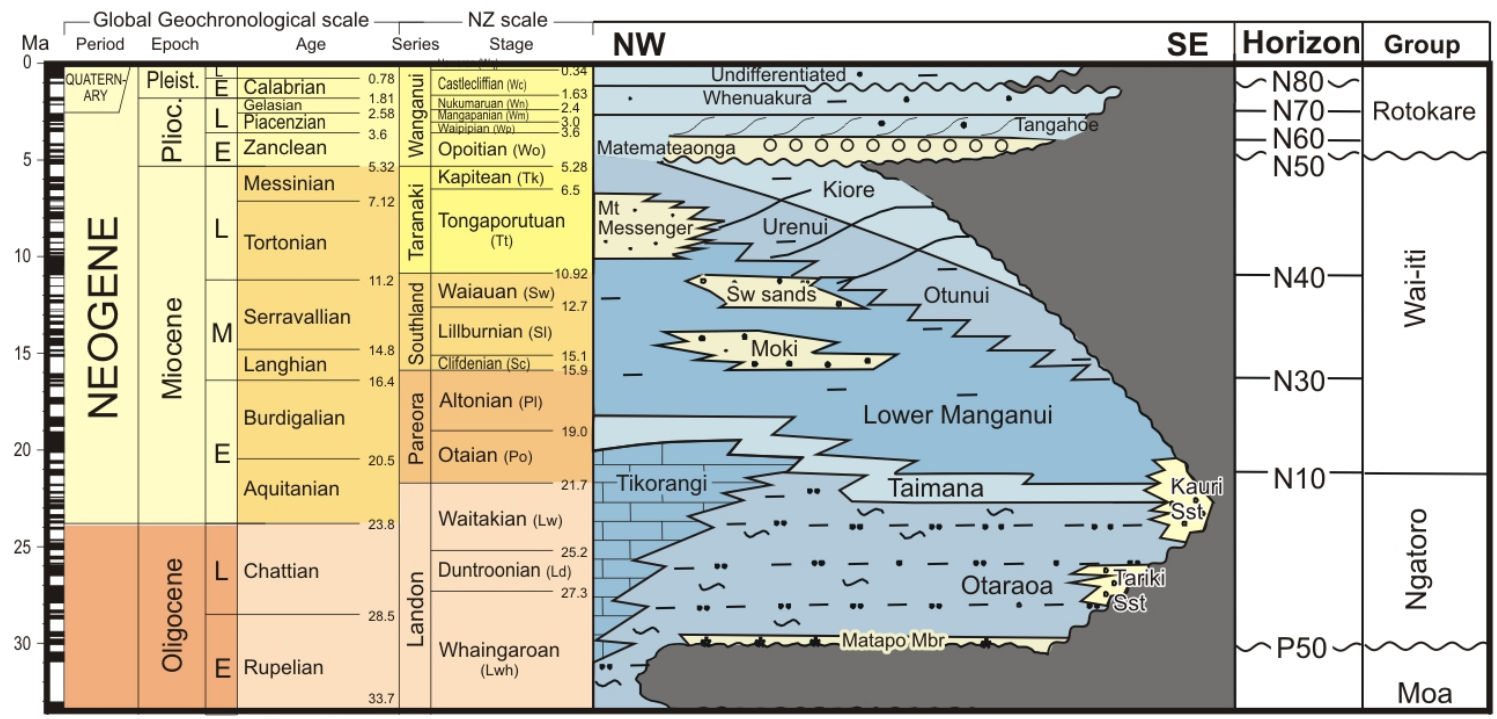

Figure 6.4 Chronostratigraphic panel of Oligocene to Recent strata in central Taranaki Basin (modified after King and Thrasher, 1996). Note the abbreviations of New Zealand stage names that are frequently used in the following discussion. The approximate age of seismic horizons used in the study is shown in the second column from the right. 


\subsubsection{Miocene paleogeographic development of Taranaki Basin}

Early paleogeographic reconstructions were based on paleobathymetry interpretations of biostratigraphic data (e.g., Hayward \& King, 1987), and have shown the development from widespread basin submergence to a northwest-facing marine embayment. Studies of facies distribution of the Middle Miocene Moki Formation (de Bock, 1994) have inferred an elongate fan system, fed from the south and directed towards the north-east on a trend parallel to the basin's eastern slope margin (Figure 6.5A). Based on the batholithic provenance and seismic mapping of channel systems in the Maui area (Bussell, 1994), this fan system was inferred to be sourced from the Separation Point Granite suite in Northwest Nelson (northern South Island). While confirming the provenance and southern sourcing in the central basin, petrographic reservoir quality studies of the Moki Formation suggest distinct provenance of sands in the eastern basin (Higgs, 2004). These latter, more lithic-rich, sands indicate a meta-sedimentary provenance that would be consistent with sourcing from eastern provinces (Mortimer et al., 1997). Other paleogeographic reconstructions (King \& Robinson, 1988; King \& Thrasher, 1996) incorporated easterly sourcing of Middle Miocene depocentres located in the onshore area. In addition to multiple depocentres along the base of a north-south-trending slope in the eastern basin, they inferred the widespread distribution of coalescing, balloon-shaped fan systems across much of the southern basin and east-west-trending slope in the south (King \& Thrasher, 1996).

The shelf geometry was inferred to change towards a more linear northeast-southwest orientation across the present-day onshore and offshore areas during the Late Miocene with generally smaller, prograding fan lobes developing in a northwest direction (Figure 6.5B). The main features in the Pliocene reconstruction of King and Thrasher (1996) consist of an unconformity that occupies large parts of the southern basin and a series of mapped and inferred channels on the western prograding margin that merge into an axial channel system with continuation into the NCT (Thrasher \& Cahill, 1990). Vonk and Kamp (2008) analyzed additional well data and a few seismic lines, concluding that the maximum northward development of this unconformity can be traced across large parts of the peninsula and occurred during the upper Tongaporutuan ( 7.5 Ma, Figure 6.5C). This unconformity represented an interim maximum regression and was followed by southward probing of marine facies towards the end of the Miocene (King \& Thrasher, 1996; Vonk et al., 2002; Vonk \& Kamp, 2008). 

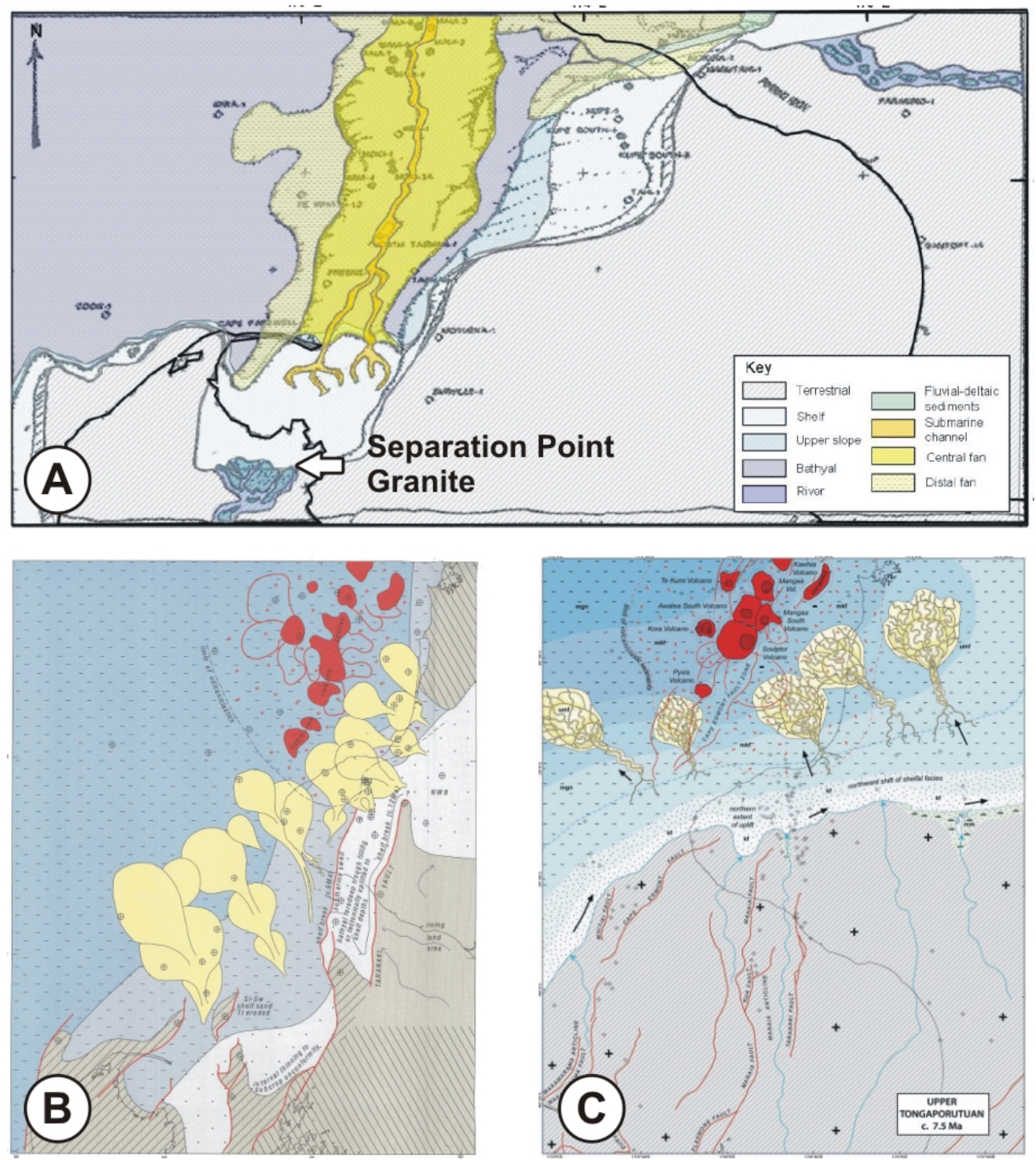

Figure 6.5 Paleogeographic interpretations from previous studies. A) Interpretation of depositional characteristics and facies distribution of the Moki Formation (modified after de Bock, 1994). B) Late Miocene paleogeographic interpretation from King and Thrasher (1996) and C) Late Tongaporutuan paleogeographic interpretation from Vonk and Kamp (2008). 


\subsubsection{Seismic data, interpreted horizons and stratal slicing}

The seismic data base investigated in this chapter consists of a basin-wide grid of phasematched 2D seismic reflection profiles and three 3D surveys that are located in the eastern (Kerry 3D), central (Maui 3D), and southern-central part (Maari 3D) of the basin. The seismic data base and phase-matching methodology is summarised in Chapter 2. Horizon interpretations from the GNS 4D Taranaki project were used as guidelines for seismic stratigraphy and facies interpretation and are listed in Table 6.1. Seismic horizon interpretations of the base Oligocene and Top Miocene horizons from Uruski et al. (2002b) were used to extend the analysis of depositional systems into the deep-water basin. These two dominant seismic markers were interpreted on the K98, SUNZ91, and T96 survey to constrain the facies distribution on the Western Platform and provide a reference for phantom horizon mapping. Additional seismic interpretation was conducted on selected regional lines to correlate approximate timelines across the basin.

The P50 horizon represents a regional unconformity or paraconformity marking the base of the Oligocene sequence (Ab-Lwh, $\sim 34 \mathrm{Ma}$ ) and the top of the underlying Kapuni Group. This horizon locally corresponds with base of the Matapo sandstone member, siltstones and muds of the Otaraoa Formation, or calcareous muds and limestones of the Tikorangi Formation. The P60 horizon approximates the top of Oligocene strata (LwhLd, 25-22 Ma), widely coincides with the top of calcareous facies of the Tikorangi Formation and, in places, represents the initial downlap surface for the prograding sediment wedge. The N10 horizon represents the top of a relatively thin package of bland, continuous reflectors in most of the basin that correlate with fine-grained muds of the lower Manganui Formation and silty lithology of the Taimana Formation (Ld-Lw, 19 $\mathrm{Ma}$ ). The N30 and N40 horizons are interpreted on relatively continuous medium- to high-amplitude reflectors that can be traced over wide areas in the central and western basin and their lateral age equivalents. In the central basin area the reflectors correlate with sandy deposits of lower Lillburnian and Waiauan age and represent intra Middle Miocene (Top Moki Sl) and Base Late Miocene reflectors (Top 'Sw'-sands), respectively ( 14 and $11 \mathrm{Ma})$. The N50 horizon represents a regional unconformity in the southeastern basin which, based on reflector truncations in the central basin, is interpreted as 
being of Late Tongaporutuan to Kapitean age. On the Western Platform, the reflector underlies marls of the Ariki Formation, while marking the base of the mostly Pliocene Rotokare Group in the east (Figure 6.4). The N60 horizon correlates with the top of the Ariki Formation in the western basin and is interpreted to coincide with the top of the Matemateaonga Formation in the eastern basin.

Table 6.1 List of seismic horizon interpretations used in this study. The columns show the alphanumeric horizon name, colour used on seismic profiles, horizon description with the reference to the base of the overlying sequences, the correlation with formation tops picked in wells, dominant biostratigraphic age association in New Zealand stage abbreviation and approximate absolute age.

\begin{tabular}{lllrr} 
Horizon ID & Horizon & Formation association (tops) & NZ stage & Age (top) \\
\hline & & & Wo & 4 \\
N60 & Base Tangahoe & Matemateaonga & Tk & 6 \\
N50 & Base Rotokare & Manganui, Kiore, Urenui & 11 \\
N40 & Base Late Miocene & Moki A, Sw Sands, Manganui, Otunui & Sw & 14 \\
N30 & Intra SI & Moki, Manganui & SI & 19 \\
N10 & Base Moki & Taimana, Lower Managanui & Lw-Po & 19 \\
P60 & Base Wai-iti & Otaraoa, Tikorangi & Lwh-Lw & 23 \\
P50 & Base Oligocene & Turi, Mangahewa & Dp-Ar & 34
\end{tabular}

\subsubsection{Attribute creation and extraction}

Single- and multi-trace attributes are extracted from seismic data to create $2 \mathrm{D}$ and $3 \mathrm{D}$ attribute maps based on manually mapped and artificially calculated (phantom) horizons. The strongly progradational character of the Miocene sedimentary succession poses certain problems with regards to the creation of phantom horizons. Stratal geometries in the bathyal to slope environments can be closely reproduced, whilst the presence of clinoforms and, in places, erosional character in the slope to shelf environment preclude the creation of reflector parallel phantom horizons. While it is not possible to approximate time-line equivalent horizons in these cases, the general depositional character of channels and canyons associated with these environments can still be appropriately imaged to allow examination of the depositional succession. In order to highlight channels on $2 \mathrm{D}$ data, multiple seismic attributes were combined to metaattributes using unsupervised neural networks (e.g., Aminzadeh \& De Groot, 2004) for four surveys in the areas of the Western Platform and Deepwater Taranaki Basin. Details relating to the attribute extraction, phantom horizon mapping, and meta-attribute creation are provided in Chapter 2. 


\subsection{3}

The biostratigraphic stage boundaries are derived from petroleum reports and were updated for several wells as part of the 4D Taranaki project (Roncaglia et al., 2007; Roncaglia et al., 2008; Roncaglia, 2010). Due to coarse biostratigraphic sample spacing, stage boundaries are often poorly defined. In most cases, the Miocene biostratigraphic stage differentiation is limited to a Waiatakian to Otaian (Lw-Po, 25.2-18.7 Ma), Altonian (P1, 18.7-15.9 Ma), Clifdenian (Sc, 15.8-15.1 Ma), Lillburnian (S1, 15.1-12.98 Ma), Waiauan (Sw, 12.98-11.01 Ma), lower Tongaporutuan (lwr Tt, 11.01-9 Ma), Tongaporutuan to Kapitean (Tt-Tk, 9-6 Ma), and Kapitean to Opoitian (Tk-Wo, 6-4.8 $\mathrm{Ma}$ ), although specific stages are ascertained in some wells (e.g., Tk, lower Sl). In certain instances, there is considerable disparity between stage boundary estimates and seismic correlations between the wells. Some of these disparities may be related to the vintage of the initial petroleum reports, since biostratigraphic age associations are constantly updated in accordance with increasing knowledge about the evolution of marine fauna. In cases of such disparities facies interpretations were associated with the most dominantly occurring age correlation across the basin.

\subsection{RESULTS}

\subsubsection{Well lithostratigraphy and paleo-environment}

A north-south-oriented correlation panel of selected wells shows the general character of Miocene stratigraphy and the progradational north-westward development of the sedimentary system into the basin (Figure 6.6). Thickest Miocene strata are found in the central basin (>2000 $\mathrm{m}$ in well Maui-1) and are thinning to the south (Moki-1) and the north to less than $500 \mathrm{~m}$ (Tane-1). The relatively thinner section in well Tane-1 indicates the more distal location of the north-western basin area, while missing upper Middle and Late Miocene strata show the erosional character of the upper boundary in the southern wells. Paleo-environmental interpretations from biostratigraphic data show the widespread distribution of bathyal environments across the basin during the Oligocene to Early Miocene and the subsequent shallowing throughout the Miocene. Furthermore, southern wells indicate a deepening from slope $(200-600 \mathrm{~m})$ to lower bathyal environments $(>600 \mathrm{~m})$ near the base of the Clifdenian $(\mathrm{Sc})$. 
Relatively high gamma-ray values and mudlog data indicate the limited coarse-grained terrigenous clastic input and widespread deposition of fine-grained muds, marls and limestones into Early Miocene bathyal environments. Decreasing gamma-ray values and sandy lithology in mud logs are observed within upper Altonian aged strata $(\mathrm{Pl})$ in several wells of the southern basin area and indicate the first localized input of coarser sediment. Distinct packages of sandstone are absent in southern-central wells (e.g., North Tasman-1) during the Altonian, but increasing fractions of sand in mud logs and blocky gamma-ray signatures in water depths of $>400 \mathrm{~m}$ suggest the increased deposition of sands associated with gravity flows during the Clifdenian (Sc) and, more widespread, during the Lillburnian ( $\mathrm{Sl}$ ). Individual sand-dominated sequences of these intervals are 250-300 m thick.

Similar, blocky gamma-ray signatures indicative of sandstone intervals are also evident in Late Lillburnian-Waiauan aged strata $(\mathrm{Sl}-\mathrm{Sw})$ in the central basin, although their thickness is generally limited to $<30 \mathrm{~m}$ for individual beds and $\sim 100 \mathrm{~m}$ for stacked intervals (e.g., Tui-1). A significant decrease in net to gross (sand to mud ratio) in Late Miocene strata is indicated by a general increase of gamma-ray values and decrease in grain-size in mud logs. Blocky wireline log signatures of lower Tongaporutuan (lwr Tt) strata indicate frequent thin sandy intervals, in the central, southern and western basin. The Late (upper $\mathrm{Tt}$ ) to latest Miocene (Tt-Tk, 8-6 Ma) section in the southern and central basin is dominated by high gamma-ray values, indicating relatively fine-grained sediment, although wireline signatures and mud log data indicate frequent sand and silt intervals. In the central basin, intervals with lower gamma-ray values show a serrate signature, are relatively thin $(10-50 \mathrm{~m})$ and are associated with middle slope environments. Intervals of this age in Western Platform wells display a blocky to serrate signature with thicknesses of over $200 \mathrm{~m}$ and were deposited in lower slope environments. In well Hochstetter-1 for example (Figure 6.1), a $233 \mathrm{~m}$ thick sandy unit of latest Miocene age has been interpreted as turbidite related but with a calcareous and argillaceous matrix and no visual porosity (Mills, 2000). 


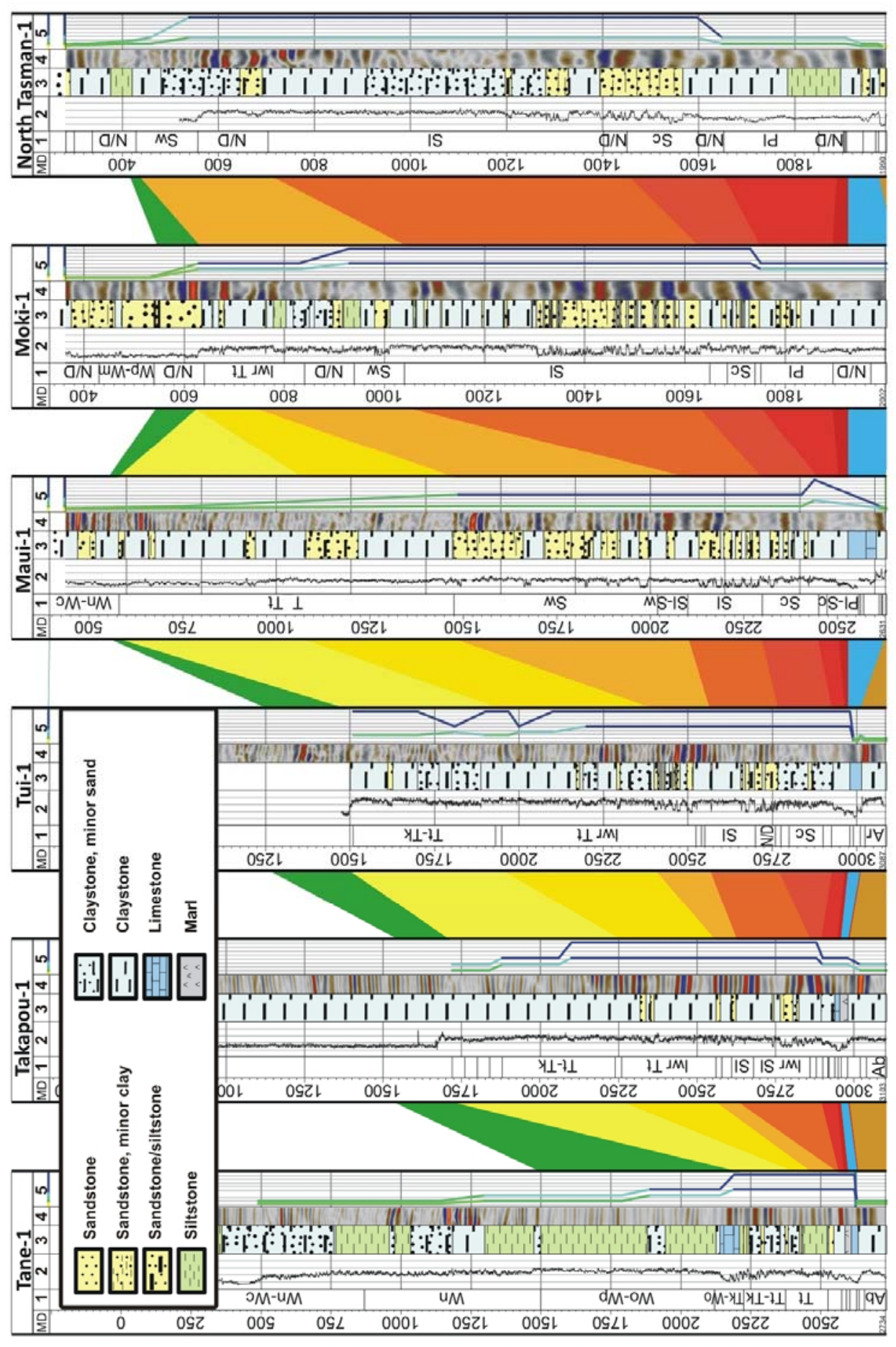

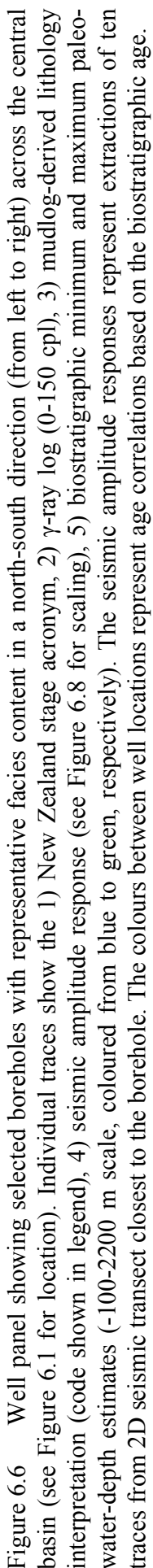




\subsubsection{Basin evolution from $2 D$ and 3D seismic reflection data}

\section{Isochron maps and structural development}

The regional Oligocene-Miocene isochron (P50-N60) shows the asymmetric structure of the basin fill, defining eastward thickening wedge geometry that is dissected into multiple asymmetric, 40-80 km wide depocentres (Figure 6.7A). Greatest sediment thicknesses in excess of $3.0 \mathrm{~s}$ two-way travel time (TWT) are observed in the footwalls of the Taranaki and Manaia Faults in the south-eastern basin. West of the Cape Egmont Fault thicknesses exceed $1.5 \mathrm{~s}$ TWT, decreasing to less than $0.1 \mathrm{~s}$ TWT towards the structurally elevated Challenger Plateau. North of the Challenger Plateau, an elongated, NW-SE-trending, 60-80 km wide area with sediment thicknesses of 0.5-0.8 s TWT outlines the depocentre in the distal basin (Figure 6.7A). The sediment thickness distribution shows the proximal to distal trend with inferred sediment sources in the east and south, and outlines the Oligocene-Miocene foreland basin geometry with a foredeep in the east and possible forebulge and backbulge development due to flexural bending in the west (see also Holt \& Stern, 1994; DeCelles \& Giles, 1996).

Further isochron subdivisions in the south-eastern basin depict the differences in lower and upper Miocene tectonic and sedimentary development of this foreland basin. The Early to Middle Miocene isochron (P60-N40, Figure 6.7B) shows thicknesses of up to $1.5 \mathrm{~s}$ TWT and $1 \mathrm{~s}$ TWT in the footwall of the Manaia and the Taranaki Fault, respectively, indicating inversion and folding in these structures. Isochron thicknesses decrease north-westwards into the central basin, outlining the orientation of the late Middle Miocene shelf margin. Isochron thickness variations by more than $50 \%$ across structures in the southern-central area suggest convergent fault activity on south-western faults. The comparatively smaller variations further north $(\sim 0.1 \mathrm{~s}$ TWT) suggest negligable tectonic activity in the central basin area (CEF) during most of the Middle Miocene.

Late Miocene (N40-N50) isochron thickness variations suggest increasing inversion and folding across the eastern and central basin (Figure 6.7C). In the hanging wall of the Manaia Fault thicknesses are limited to less than $0.5 \mathrm{~s}$ TWT, suggestive of a generally higher structural elevation and less accommodation space with respect to areas in the 
west. Thinning across the Cape Egmont Fault and the Whitiki Fault suggests that the central basin was tectonically active and has become part of a westward advancing thrust wedge, while the foredeep may have migrated westward onto the Western Platform (see also Chapter 3).

The latest Miocene to Early Pliocene (N50-N60) isochron outlines three major depocentre trends (Figure 6.7D). A southwest-northeast-trending area in the west can be linked with aggradation on the western shelf margin. This area thickens toward the southern part of the extending Northern Graben in the northeast. In the east, a circular depocentre with a thicknesses of over $0.6 \mathrm{~s}$ TWT and a radius of about $50 \mathrm{~km}$ defines the subsidence of the Toru Trough (King \& Thrasher, 1996) and onset of Wanganui Basin subsidence, which has been previously mapped by Anderton (1981).
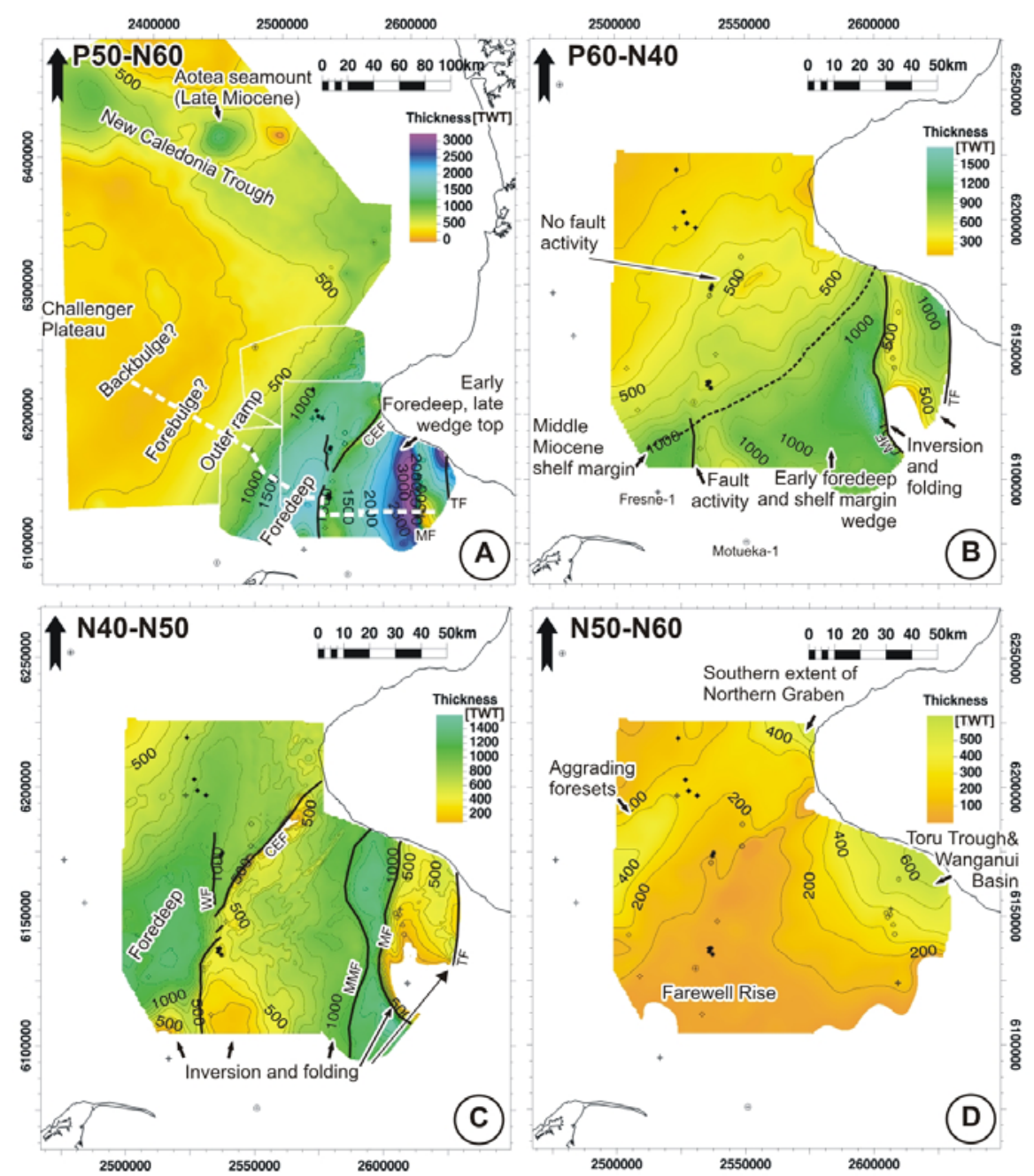

Figure 6.7 Isochron maps calculated from gridded seismic horizon interpretations (in milliseconds two-waytraveltime). A) Oligocene-Miocene isochron showing the combination of seismic interpretations in the south-eastern and central basin, Western Platform, and Deepwater Taranaki Basin (DTB01, Uruski et al., 2002b). B) Early to Middle Miocene, C) Late Miocene, and D) Late Miocene to Early Pliocene. Main faults are outlined (black lines) and annotated as CEF-Cape Egmont Fault, MF-Manaia Fault, MMF-Motumate Fault, TF-Taranaki Fault, WF-Whitiki Fault). 


\section{Regional evolution of depositional systems}

A composite seismic transect across the study area shows the regional development of depositional systems from the shelf margin to deep water and general north-westward progradational character of the Miocene sequence (Figure 6.8). Oligocene and Early Miocene (P50-N10, Lw-Po) strata are thin across the basin $(<100 \mathrm{~ms}$ TWT), marked by relatively continuous, low- to medium-amplitude reflectors that thicken into the footwall of convergent structures in the eastern basin, and converge westwards with the underlying reflectors. The westward truncation is interpreted as stratal onlaps onto the distal foredeep, or alternatively may represent the earliest progradational bottom sets of the shelf margin in the Otaian (Po, 22-19 Ma). Clinoforms above the N10 reflector in the southeast indicate the outbuilding of the shelf margin from the late Early Miocene to early Middle Miocene (Pl-Sc, $19-15 \mathrm{Ma}$ ). Further progradation and aggradation of clinoformal reflectors suggests the westward translation of the shelf edge from the central Eastern Mobile Belt during the Lillburnian to Waiauan (N40), to the western faulting limit by the end of the lower Tongaporutuan ( 11-9 Ma), and further onto the Western Platform by the latest Miocene (N50, Tt-Tk, 9-5 Ma).

Increasing obliqueness (steepness) of lower Tongaporutuan to upper TongaporutuanKapitean clinoforms in the central basin indicates an increasing pace of progradation. Intermediate down-stepping of shelf break rollovers below previous shelf edges suggests forced regression, which is corroborated by distinct angular truncations in the eastern and southern parts of the basin that indicate erosion of strata. Parallel reflectors underlying the unconformity in the eastern part of the basin suggest the deposition and late stage erosion of Late Miocene strata (possibly Tt-Tk). Angular truncations and erosion can be traced some ten kilometres west of the Eastern Mobile Belt. While the sequence thicknesses and pace of progradation indicate a general increase in sediment input in the Late Miocene, aggradation and decrease of clinoform slopes in latest Miocene to Early Pliocene sequences (below and above N50, Tt-Tk, Tk-Wo) may indicate a decrease in sediment delivered to the western margin, or possible bypass of sediments into the NCT (see also Chapter 3). 


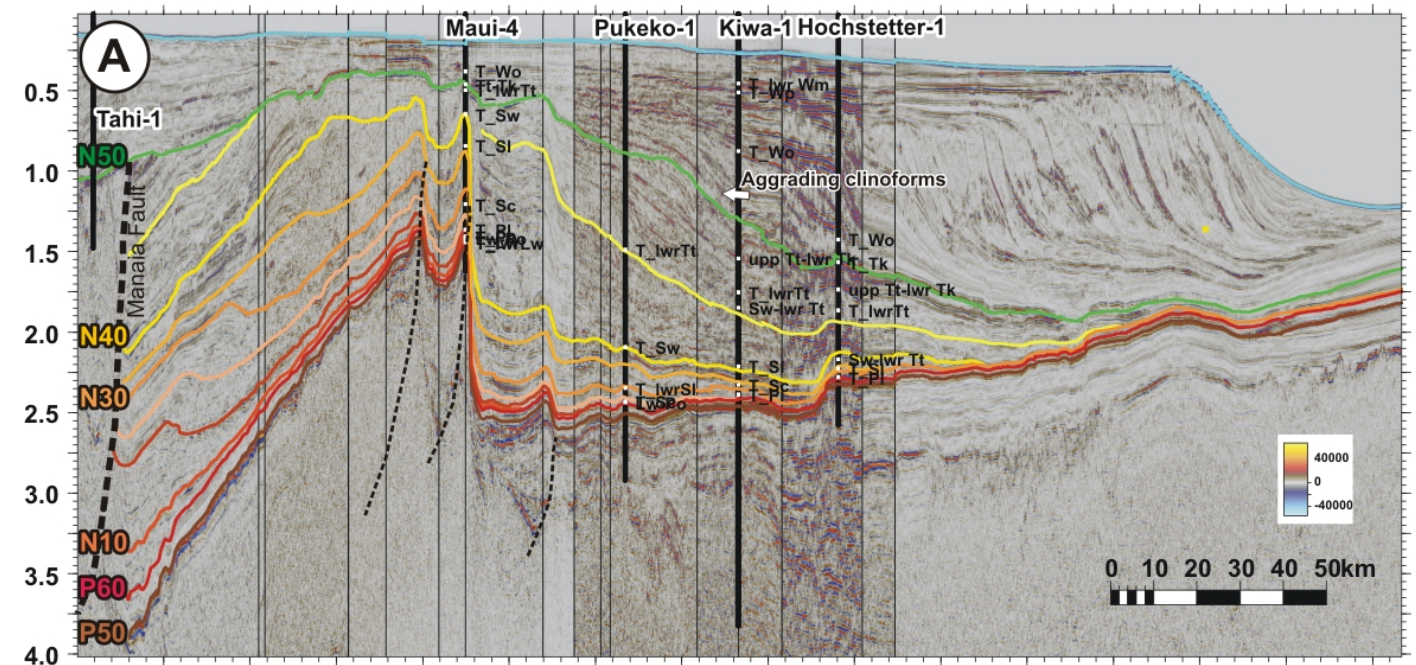

Eastern Mobile Belt Western Platform Challenger Plateau $\Rightarrow$

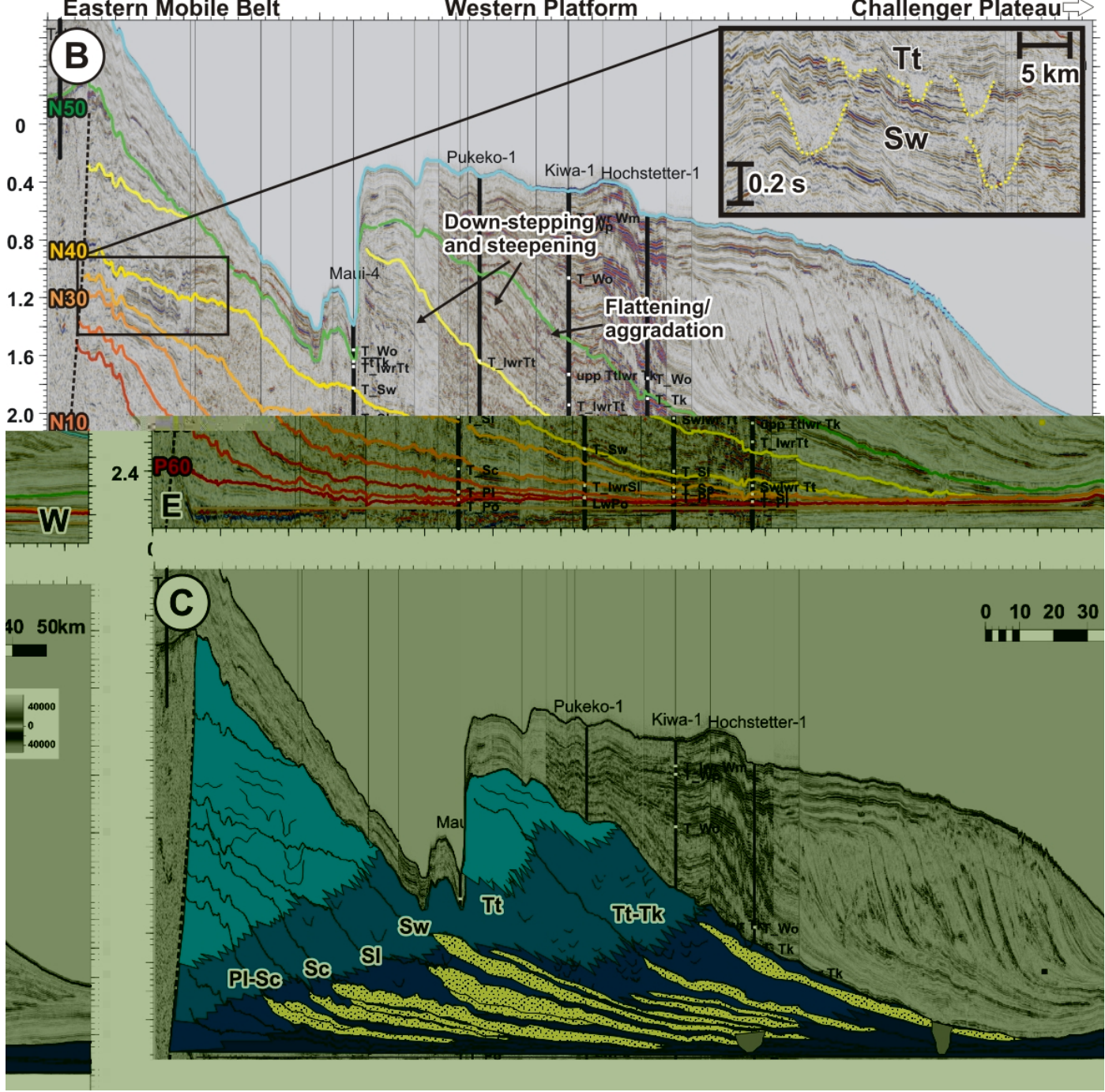

Figure 6.8 Regional EW-seismic composite line across the basin showing: A) present-day character of the Miocene depositional succession, B) line flattened on the Base Oligocene (P50) horizon (which takes out the effect of syn-or post-depositional uplift, but shows the effect of erosion in the SE), and (C) schematic paleoenvironment and facies interpretation (from dark blue/base of slope to light blue/shelf). Interpreted horizons are shown from red (base Miocene) to green (base Pliocene), respectively. The base Oligocene reflector is shown in brown. Well locations are shown as black lines and biostratigraphic age estimates are shown as white squares with black annotation. Interpretations of major faults are shown as black dashed lines. Note the large channels at the base of slope (grey) in (C). Seismic profiles here and in subsequent figures are shown in seconds two-way-travel time (TWT). 


\section{General sequence architecture and seismic facies character}

The seismic character of individual sequences shows certain commonalities that can be interpreted in terms of depositional elements and environment (Figure 6.8). Landward of the upper clinoform rollover (shelf strata), seismic facies are dominated by relatively continuous, sub-parallel reflectors with low to medium or medium to high amplitudes. In several instances, these continuous reflectors are interrupted by discontinuous facies, interpreted as indicating channel incision into the shelf (Figure 6.8B, inset).

The upper part of the slope in each sequence is characterized by discontinuous and chaotic reflectors with variable amplitudes and frequent upward concave features. The discontinuous character may be attributed to slope instabilities and slumping as well as channel incision. Towards the base of slope, or toe-sets, concave upward channel features become more distinct and the occurrence of more continuous reflectors increases in concert with an increase in amplitude content. This zone is interpreted to represent the channel-fan transition in the area of the lower slope, where sediment transport gradually changes from confined channel to unconfined sheet deposition.

Further down-slope, the seismic reflections increase in continuity with either low to medium or medium to high amplitudes. The lower-amplitude packages are interpreted to represent phases of relative depositional quiescence and fine-grained, hemipelagic sedimentation, whereas the higher-amplitude packages are interpreted as fan lobes with intercalated coarse and fine-grained sediment deposited during phases of sediment input from the shelf. In several places, the higher-amplitude facies appear as mounded structures and show downlap onto older surfaces, which is sometimes evidenced to be bidirectional in cross section view, and interpreted to represent submarine fan lobes. Middle and Late Miocene distal deposits are incised by 5-10 km wide channels systems, suggestive of further basin-ward sediment bypass (Figure 6.8, C). 


\section{Detailed Miocene facies development}

\section{Altonian to Clifdenian (19-16 Ma, lower N10-N30)}

Northward and westward prograding clinoforms can be identified on several seismic lines in the area between well Motueka-1 and Fresne-1 (Figure 6.1), and west of the Manaia Fault near well Tahi-1 (Figure 6.8). The preservation of these features is generally limited to the downthrown side of convergent structures due to postdepositional erosion on the upthrown side. On these seismic lines, the change from relatively flat continuous shelfal reflectors to dipping clinoformal slope reflectors outlines the shelf break of an embayment open to the northwest that is inferred to have persisted through the Altonian to Lillburnian age ( 19-13 Ma). Several kilometers downslope of the inferred shelf (Figure 6.9), semi-continuous reflectors of medium to high amplitude and bi-directional downlap are interpreted to indicate the first signs of basinfloor fan deposition of inferred upper Altonian age (P1, 17-16 Ma), and possibly older fans in the footwall of the Taranaki Fault (Po-Pl, 20-17 Ma). An interval amplitude map extracted near the base of the N30-N10 sequence (Figure 6.9) shows a northeastsouthwest-oriented, medium- to high-amplitude trend that decreases in amplitude towards the northwest, interpreted to outline the fan lobe depocentre in the early foredeep.

Several low-amplitude disruptions of this high-amplitude area show a NW-SE orientation and are interpreted as $0.5-2 \mathrm{~km}$ wide channel-levee systems that develop near the base of the inferred slope (Figure 6.9B). The fill of the channel systems is characterized by generally low-amplitude chaotic reflections and levees can be traced over about one kilometer away from the channel axis on several lines. A three-dimensional perspective view (Figure 6.9C) shows the fan outline and downlapping reflector geometry, interpreted as indicating sediment transport from elevated highs in the area of the deformation front in the east (Manaia Fault) down the slope. No well control is available in the main depocentre of these fans to confirm the presence of sandy fan lobe deposits, but fine-grained sandstones and siltstones of upper Altonian age in well Moki-1 (Figure 6.6) and Maui-4 (Tricentrol Exploration Overseas, 1984; Grain, 2008) could represent the distal fan equivalents of these facies. 


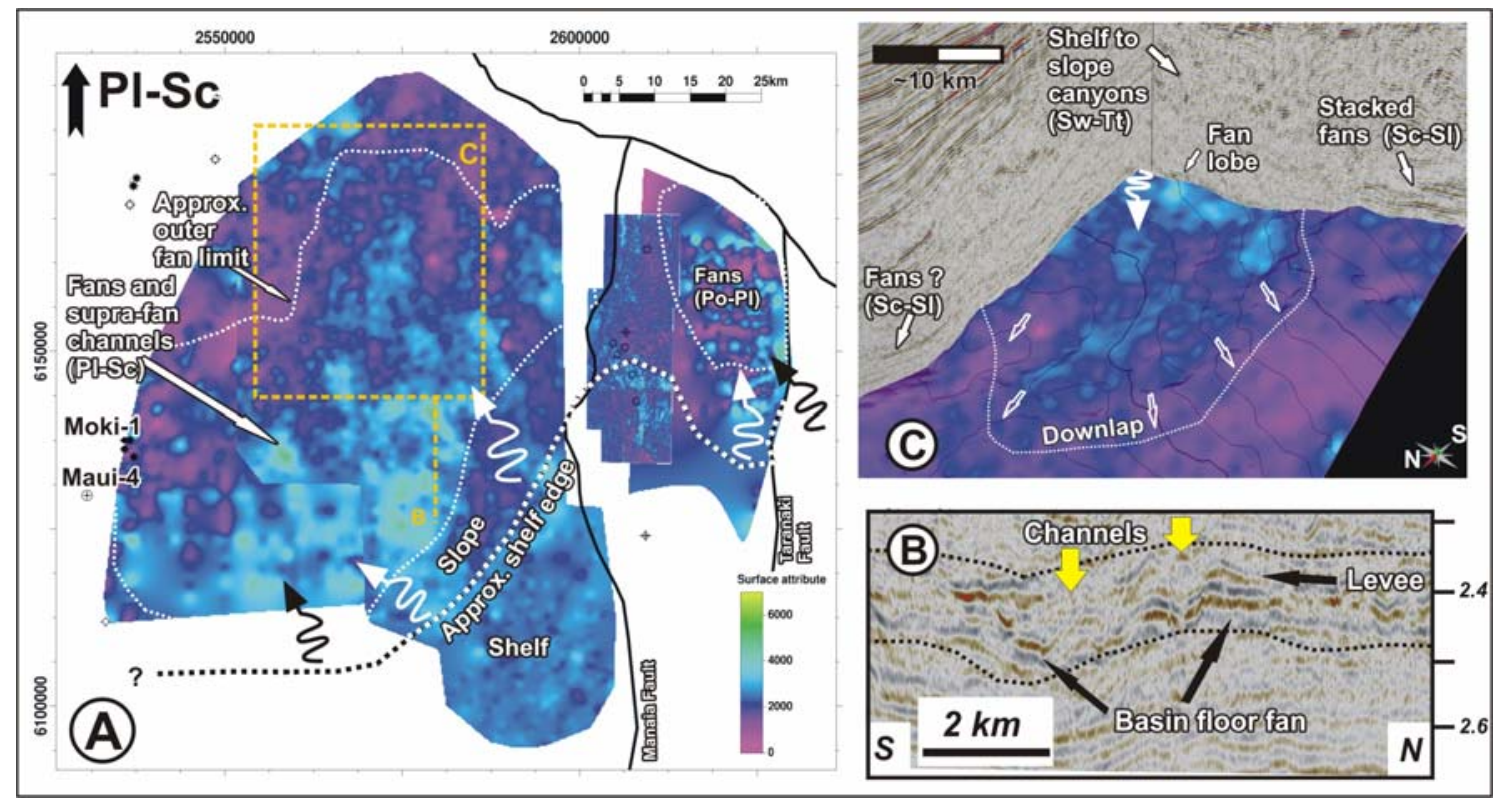

Figure 6.9 Altonian to Clifdenian depositional systems inferred from seismic sections and attribute maps. A) Combined 2D and 3D RMS amplitude maps based on stratal subdivision of the N10-N30 sequence with interpretation of facies distribution. B) Seismic section showing interpreted basin-floor fan and channel-levee facies with extraction window used to create attribute map in (A) shown as black dashed lines. C) 3D perspective view (from the northwest) showing the character of inferred basin-floor fan on parts of the attribute map draped over a stratal surface and seismic sections. Locations of (B) and (C) are indicated as orange dashed lines in (A). Seismic profiles in this and subsequent figures are shown in second two-way-traveltime (TWT).

\section{Clifdenian to Lillburnian (16-13 Ma, Middle to upper N10-N30)}

Two deep-water fan depocentres are inferred to develop during the Clifdenian and Lillburnian. One of them is fed with sediment from the east and southeast and located in the eastern part of the basin, whereas the other one is located in the central part of the basin and sourced predominantly from the south (Figure 6.10). Several channels demarcate the sediment entry points from the shelf and sediment transport direction into the eastern depocentre (Figure 6.10A). A 1-2 km wide channel system is imaged in the 2D survey just west of the Manaia Fault (HZT82a) and can be traced over several lines $(\sim 10 \mathrm{~km})$ in a north-westerly direction on attribute maps (Figure 6.10A, Figure 6.11A). This high-amplitude channel feature expands to the north into an apparently paddle shaped area of semi-continuous reflectors of medium to high amplitude (Figure 6.11A), which is interpreted as fan deposits. Further sediment entry points can be mapped in the eastern basin, where a $6 \mathrm{~km}$ wide canyon is interpreted to have eroded into the contemporary shelf edge (Figure 6.10B). In the Kerry 3D data set (Figure 6.10B and inset), a 2-3 km-wide low-sinuosity channel with similar azimuth, low-amplitude channel fill and high-amplitude basal lag may represent the associated down-system sediment bypass conduit through the slope. Thin sands found at the base of a smaller channel of 
same age in the nearby well Toru-1 indicate that some coarse-grained sediment was available for deposition into deeper water and biostratigraphic water-depth estimates of 200-600 m confirm the location within the middle to upper slope (Roncaglia et al., 2008). Due to the coarse time constraints from biostratigraphic data in well Toru-1 (P1S1, 19-13 Ma), the age of these channel and canyon systems is uncertain, but, based on the general location within the stratigraphic column, the system is inferred to be of Clifdenian or Lillburnian age.

In the central basin, seismic facies and widespread occurrence of sandy lithologies in wells indicate the development of a larger, northward-trending fan lobe system. Northward reflector downlaps, thinning of the sequence, decreasing amplitude content, in concert with decreasing sand content in well bores all indicate that sandy gravity flows were waning near the central Maui area during the Clifdenian, (Figure 6.10A). The fan system is delineated by lateral reflector downlaps and imaged on attribute maps to be about 40-50 km wide (Figure 6.10A). Higher up in the sequence (Figure 6.10B), widespread semi-continuous to continuous, medium- to high-amplitude packages indicate the northward development of this fan system during the lower Lilburnian $(\sim 15-$ $14 \mathrm{Ma}$ ). Associated sandy facies are observed as far north as well Takapou-1 (Figure 6.11B), and low- to medium-amplitude reflectors downlap in the distal part of this system in the area south of well Tane-1 (see also Figure 6.1 for location).

Detailed characteristics of channel morphologies associated with Clifdenian and Lillburnian fan systems in the central basin are delineated on attribute maps from the Maui 3D survey (Figure 6.12). In the distal areas of the Clifdenian system, northwardoriented, 200-300 m wide, 20-40 ms thick, moderate-sinuosity channel systems are imaged within low- to medium-amplitude reflectors of the lower sheet facies (Clifdenian to lowermost Lillburnian; Figure $6.12 \mathrm{C}$ ). The high amplitudes and north- to northeastward orientation of these channels could indicate coarse-grained sediment transport into the outer reaches of the fan lobe. The top of the younger, lower Lillburnian-aged fan system shows a highly sinuous, 5-8 km wide channel meander belt with few hundred meters wide individual channels. The channel fill is expressed as variable-amplitude, chaotic reflections with less frequent high-amplitude, discontinuous patches at the base (Figure 6.13). The high amplitudes in this system are strongly dissected due to meander loop migration and breaching of the channel walls. Levees are subdued and several highamplitude patches can be mapped that may be associated with sandy overbank deposits. 


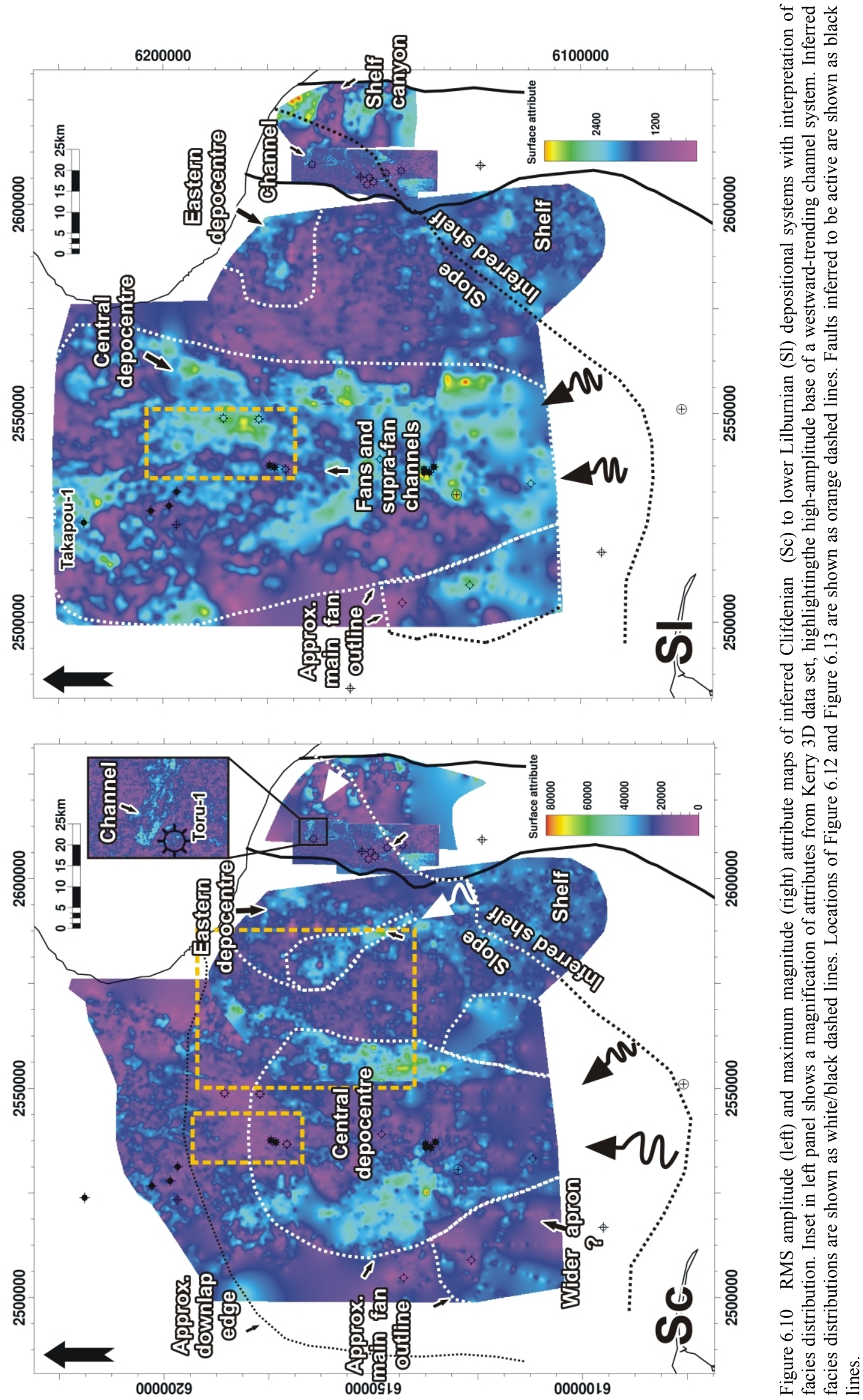



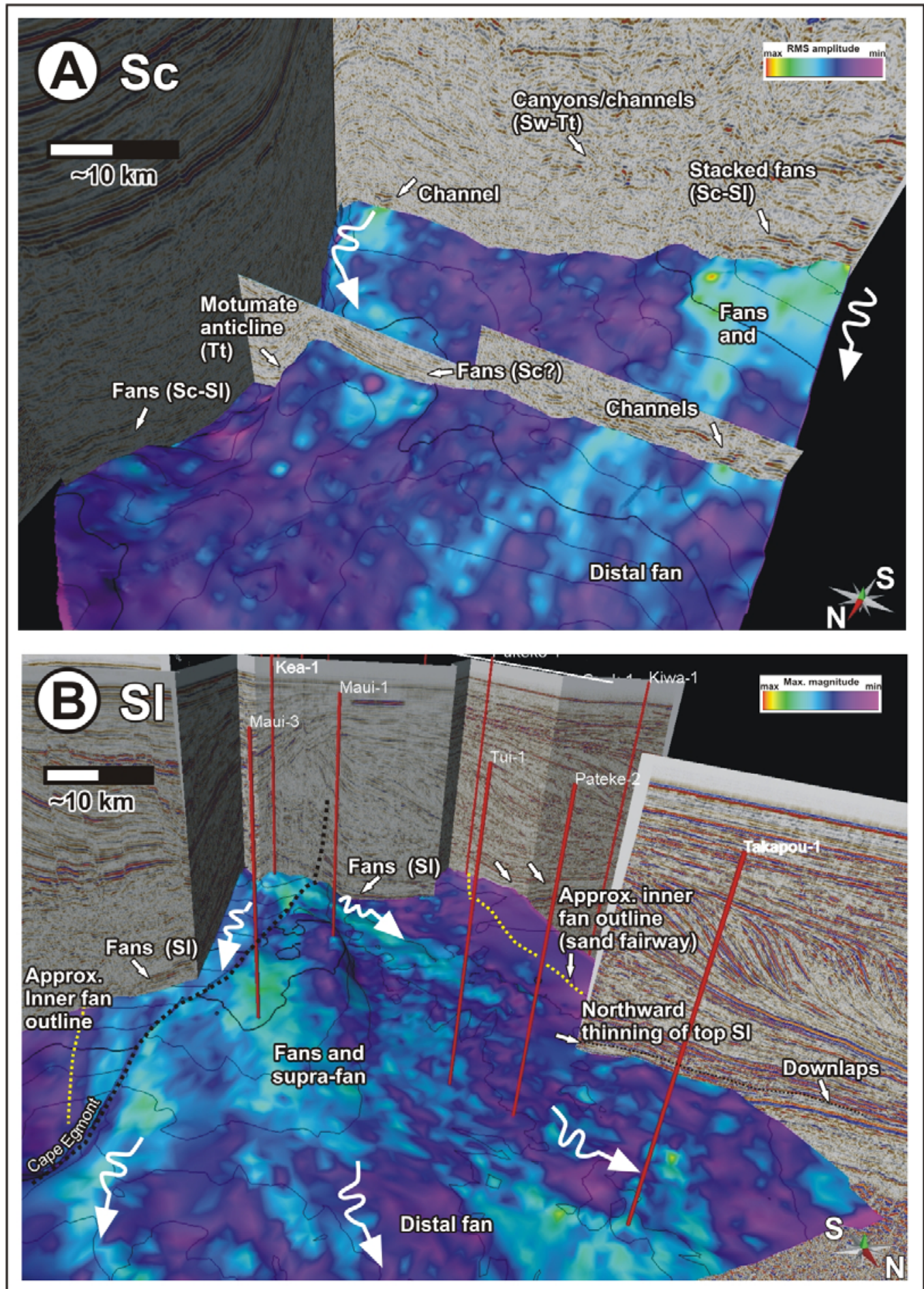

Figure 6.11 Middle Miocene facies distribution depicted on three-dimensional perspective views of gridded interval attribute maps (also shown Figure 6.10) and representative seismic profiles. A) Seismic facies distribution of inferred Clifdenian age in the south-eastern basin, and (B) Lillburnian-aged facies in the central basin. The attribute maps are draped over lower stratal surface used for extraction. Inferred sediment transport directions are indicated as white wavy arrows and facies interpretations are annotated. The red sticks in (B) show the path of wells that constrain the facies distribution and the yellow dashed lines outline the inferred fairway of sand deposition. The present-day trace of the Cape Egmont fault is shown, but continuity of facies across the fault indicates non activity during deposition. 

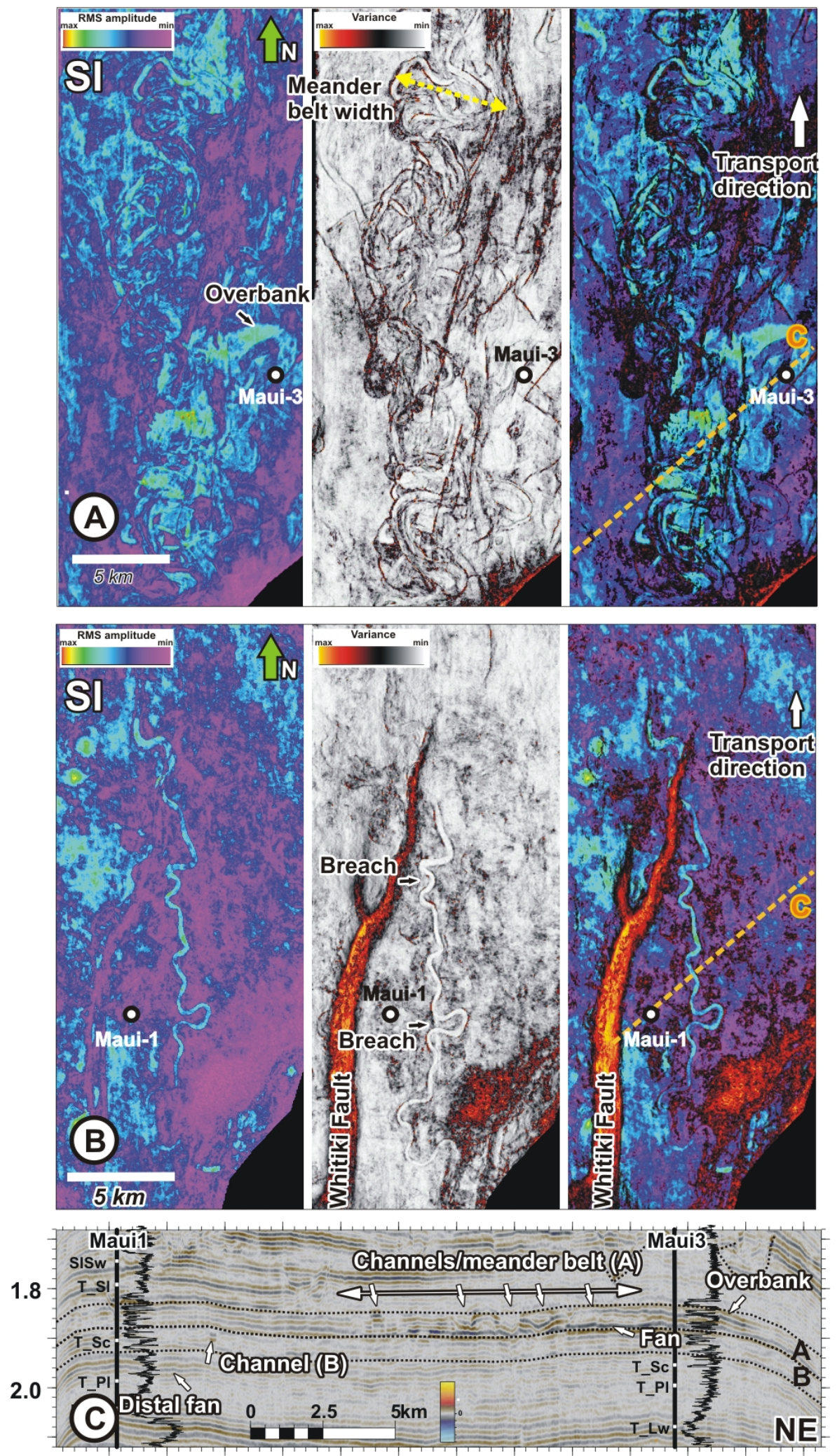

Figure 6.12 Attribute maps from the Maui 3D survey depicting the character of Lillburnian and Clifdenian channel systems (A) atop and (B) below the lower Lillburnian fan system shown in Figure 6.10 and Figure 6.11, respectively. Attribute maps in (A) and (B) represent extraction of RMS amplitude (left), variance (centre) and their composite overlay (low variance values are transparent). C) Seismic transect from the 3D survey at location indicated by orange dashed line in (A) and (B) with extraction windows for attribute maps shown as dashed black lines. Locations of well Maui-1 and Maui-3 are shown in (A) \& (B) with well traces, gamma-ray wireline response and biostratigraphic age estimates in $(\mathrm{C})$. 


\section{Waiauan (13-11 Ma, N30-N40)}

Prograding and aggrading clinoform reflectors between the N30 and N40 horizons (Figure 6.8) and shelfal microfauna in well North Tasman-1 (Figure 6.6) document the general north-westward development of the shelf during the Lillburnian to Waiauan. Continuous, parallel reflectors in the southern study area suggest the widening of the shelf, infilling of the earlier shelf margin embayment. The development of a more linear northeast-southwest-oriented shelf edge is outlined on stratal interval attribute maps extracted between the N30-N40 reflectors (Figure 6.13).

Regional attribute maps furthermore delineate the successive northward and westward migration of fan depocentres, and development of extensive sediment bypass systems (Figure 6.13). Semi-continuous, medium- to high-amplitude reflectors are interpreted to indicate the continued deposition of sheet deposits (fans) in the south-western study area during the upper Lillburnian and Early Waiauan (Figure 6.13A and B), after which the depositional locus shifted towards the north (Figure 6.13C). These reflectors can be tied to sandy lithologies in southern and central basin wells, where they have been previously referred to as M2A (Dauzacker et al., 1996) and Moki-A sands (Bussell, 1994), respectively. On the Western Platform these sheet deposits show westward downlap or onlap (Figure 6.14), which may indicate subtle ponding against the inferred eastward dipping seafloor that is evident on seismic lines (Figure 6.8).

Channel forms can be delineated and traced on attribute maps from inferred shelf areas into the distal basin and show the character and distribution of sediment entry points and basin-ward dispersal (Figure 6.14). Frequent disruptions of continuous reflectors in the southeast suggest severe incision of the shelf and development of multiple large sediment conduits. In the inner shelf, incision is generally shallow and laterally widespread, but becomes localized towards the inferred shelf edge. Their plan-view character is evident from the contrast of low-amplitude canyon fill and relatively higher-amplitude shelf reflectors (Figure 6.13C). Near the inferred shelf edge, these canyons are up to $10 \mathrm{~km}$ wide and incise over $400 \mathrm{~ms}$ into the shelf edge (inset in Figure 6.8B), which, using generic Taranaki Basin compaction and interval velocity values (Funnell et al., 1996; Stagpoole, 1998), suggests to $650-800 \mathrm{~m}$ of down-cutting. 


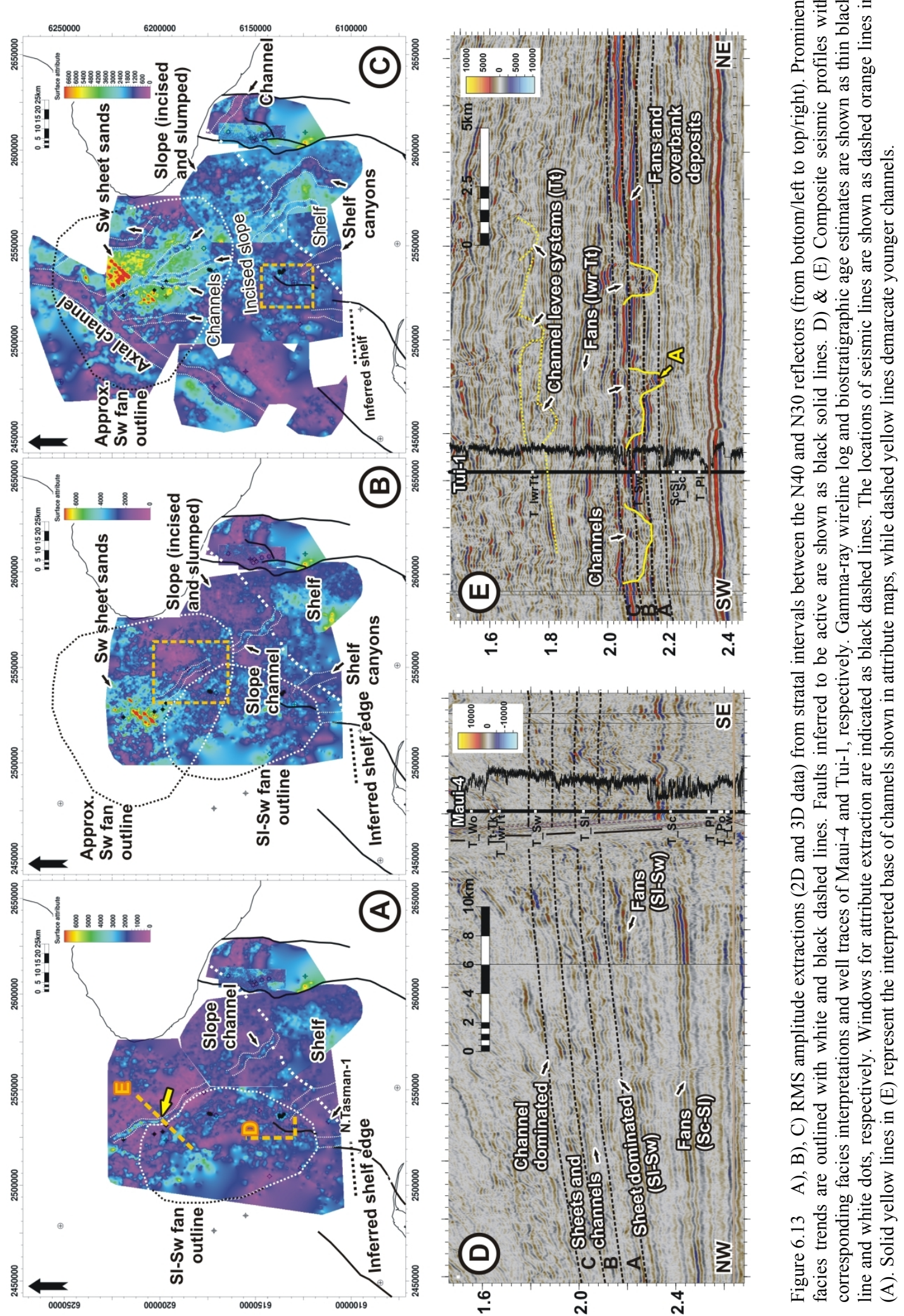


The higher-amplitude basal fill of one of these systems can be traced over some $100 \mathrm{~km}$ basin-ward of the inferred shelf edge on attribute extractions over the lower part of the N30-N40 sequence (Figure 6.13A and B). This channel has a moderately sinuous appearance in the inferred upper slope, where it is over $1 \mathrm{~km}$ wide up to $200 \mathrm{~ms}$ TWT deep. Common discontinuous, variable-amplitude, and chaotic reflections in the channel vicinity are interpreted to indicate frequent slumping within of the surrounding slope. Further downslope, increasing continuity and amplitude of surrounding reflectors suggests that this system fed sediment into proximal and distal reaches of sheet deposits in the central basin and the Western Platform (Figure 6.13B).

Lower-amplitude channel systems within medium- to high-amplitude sheet deposits in the central basin document the further sediment transport during the Waiauan (Figure 6.13C, Figure 6.14). On the Western Platform, multiple channel systems successively merge and lead into a large axial bypass system that transported sediment into the deeper reaches of the basin (Figure 6.14). This axial distributary is mapped to be about $6 \mathrm{~km}$ wide in the southwest and widens to the northeast to about 8-10 $\mathrm{km}$ with a relief of up to $200 \mathrm{~ms}$ TWT. The variable-amplitude channel interior of this channel correlates with mixed sand-silt deposits and multiple decreasing gamma-ray sequences (fining-upward) in well Hochstetter-1 (Mills, 2000), which may indicate the dynamic development of smaller sinuous channels within the broad axial master channel. Biostratigraphic age estimates variably indicate a latest Lillburnian to lowermost Tongaporutuan age, and a lack of further seismic reflection subdivision precludes more precise dating of the evolution of this system. 


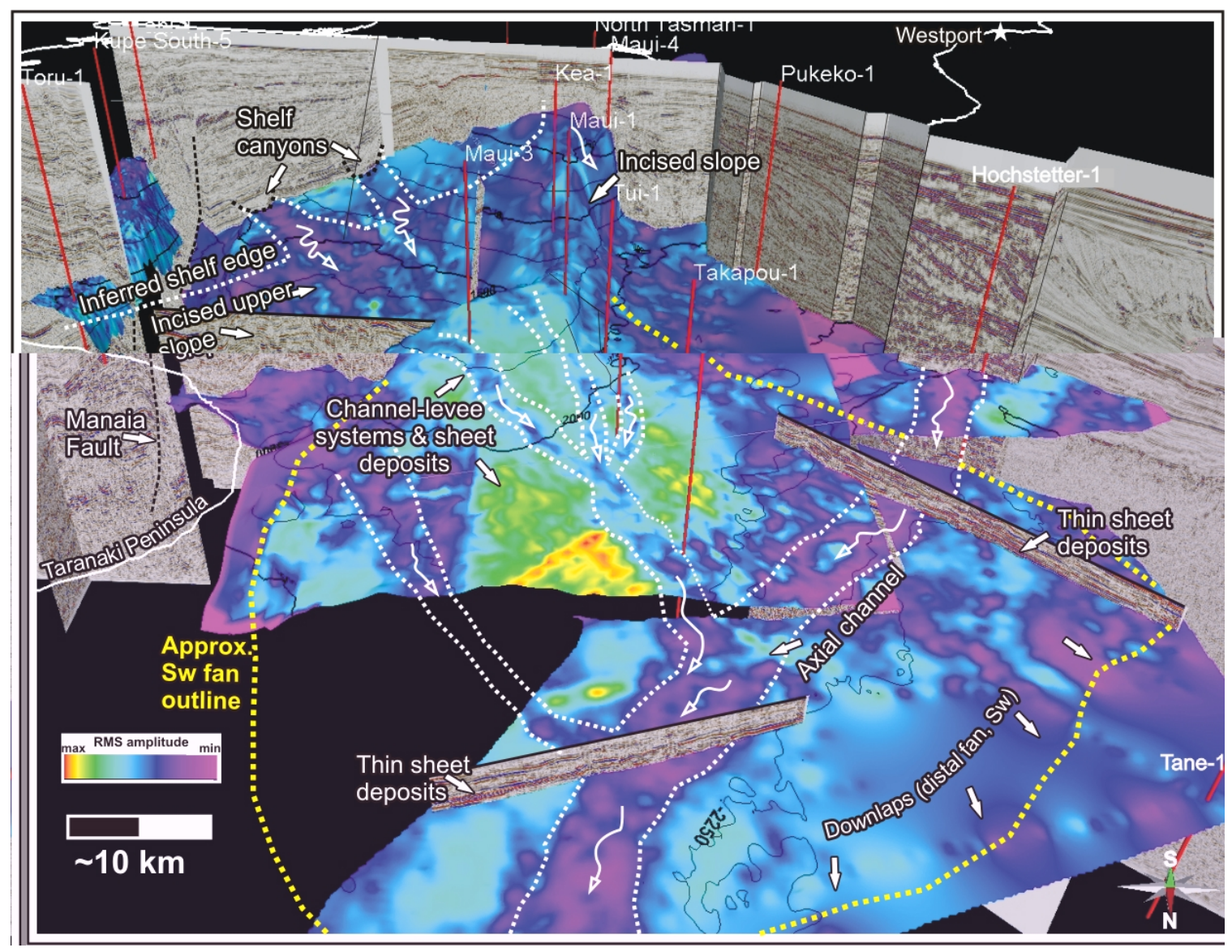

Figure 6.14 Depositional systems of inferred Waiauan age from the shelf to the intermediate base of slope shown on perspective view of attribute map (also shown in Figure 6.13C) and seismic profiles. The attribute maps are draped over the lower stratal surface used for extraction (black contours show depth of horizon in ms TWT). Seismic facies interpretations are outlined and annotated (white and yellow dashed lines). Inferred sediment transport directions are indicated as wavy white arrows. Wells are shown in red. The present-day shoreline is shown as white lines. The fault trace of the Manaia Fault is shown as black dashed line in the background. 
Attribute maps extracted from the Maari 3D (Figure 6.15) and Maui 3D surveys (Figure 6.16) show the detailed character of channel systems displayed on regional attribute maps and further document the successive north-westward shift of sediment depocentres. Channel occurrences in the area of the Maari 3D survey (Figure 6.15A and D) increase toward the upper part of the N30-N40 sequence. Based on their northwest trend and lowsinuosity (Figure 6.15A), these channels are interpreted as bypass systems that fed sediment into sheet deposits further north. Attribute maps from the Maui 3D survey (central basin) show clear dissimilarities between older channels with generally lower sinuosity and higher amplitude fill and younger channels with higher sinuosity and lower amplitude fill (Figure 6.16). The detailed attribute maps show that the prominent example displayed in Figure 6.13A consists of multiple, several hundred meter wide, anastomosing channels, which together form an up to $1 \mathrm{~km}$ wide channel network. In some cases, the channel fill appears to extend beyond the channel walls, indicating overfilling of the channel and unconfined sediment deposition. As channels with similar characteristics appear to be absent further northwest, the area of the Maui 3D survey is interpreted to mark the general channel-fan lobe transition zone at this particular time. The fault perpendicular channel orientations suggest non-activity of the Cape Egmont Fault. Younger channels are moderately to highly sinuous, show lateral accretion, meander belt migration, and up to $3 \mathrm{~km}$ wide master channels. Tabular low-gamma-ray responses indicate that some sandy facies were deposited at the base of the channels (Figure 6.16C). The low amplitude fill and relatively minor levee-relief indicates dominantly erosional confinement of these channels and bypass of coarse-grained sediment to the deeper basin. 

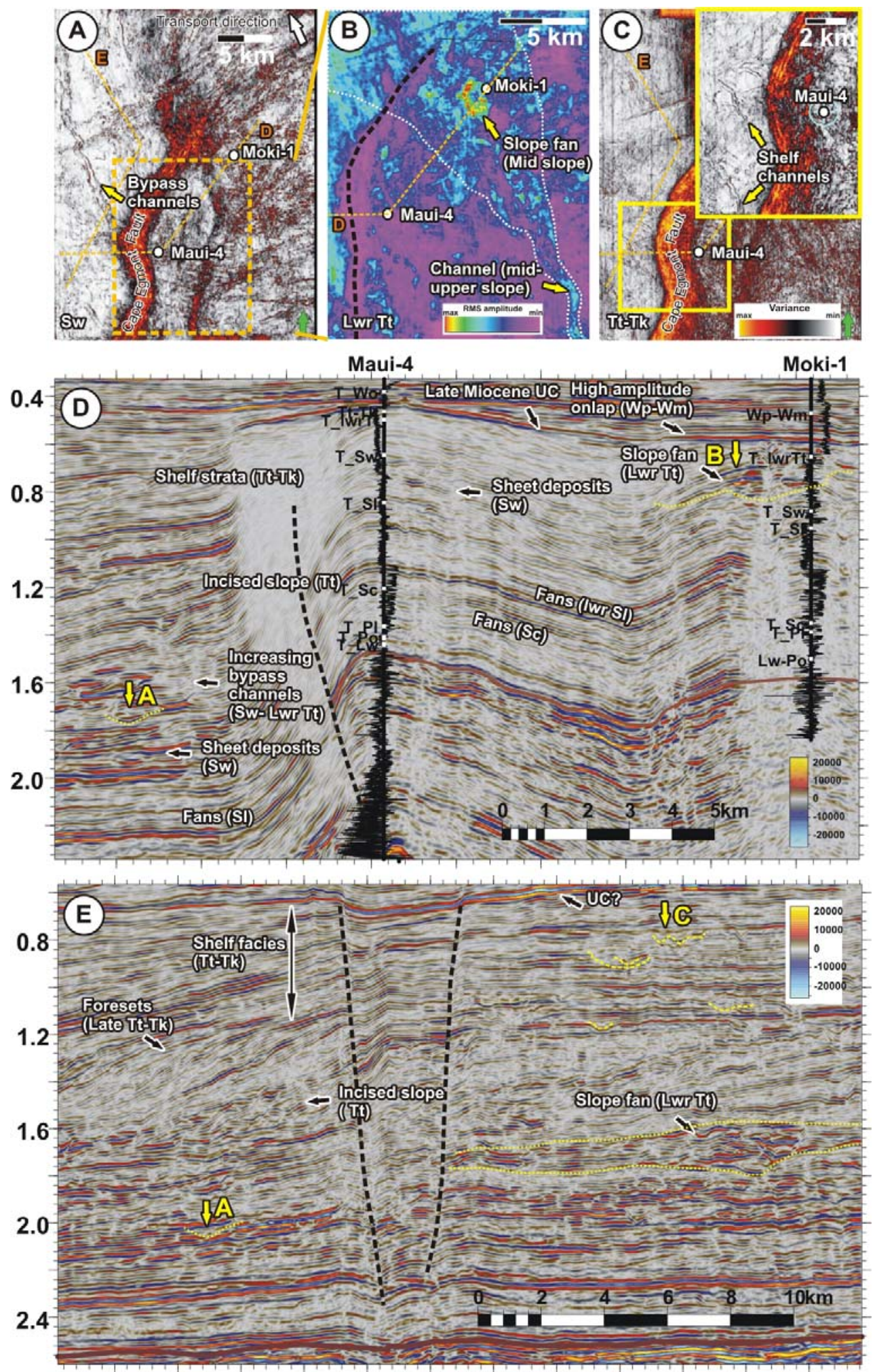

Figure 6.15 Stratal interval attribute maps and seismic sections from the Maari 3D area showing seismic facies of Waiauan to Kapitean age. A) Waiauan-aged channel system shown on variance attribute map. B) Tongaporutuan-aged channel and slope fan shown on RMS amplitude map (see orange dashed rectangle in (A) for location of map). C) Upper Tongaporutuan to Kapitean shelf to upper slope channel systems shown on variance attribute map (magnified view in yellow box). D) and (E) seismic profiles from the Maari 3D data set. Well paths are shown with gamma-ray $\log$ and biostratigraphic age estimates as black lines and white dots, respectively. Locations of seismic profiles are shown as orange dashed lines in (A), (B), and (C). Yellow arrows on seismic profiles point to features depicted on attribute maps. 

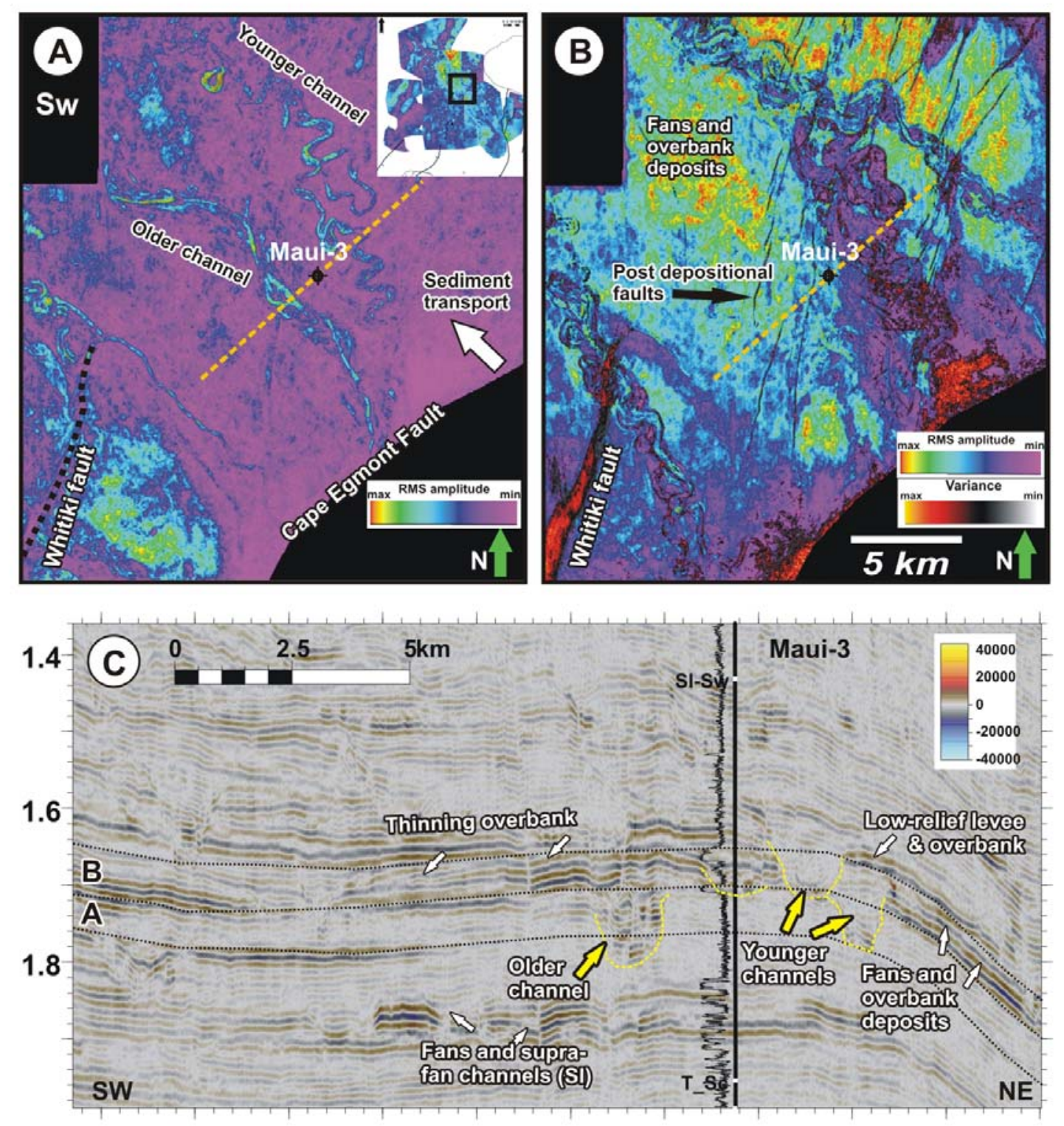

Figure 6.16 Stratal interval attribute maps and seismic profile from the Maui 3D survey showing the detailed facies and variable channel character of inferred Waiauan age. A) RMS amplitude extraction and (B) composite RMS amplitude and trace-to-trace variance (low variance values are transparent). Inset in (A) shows location of (A) and (B) as an black square on a replica of the regional attribute map shown in Figure 6.13C. Seismic line from Maui 3D survey with borehole trace (thick black line), gamma-ray wireline log (black), and biostratigraphic age estimates (white dots) of well Maui-3. Black dashed line shows the attribute extraction window in (A) and (B) and location of line is shown as orange dashed line in (A) and (B). Interpreted facies are annotated and channel systems are underlined with yellow dashed lines. Note the lower extraction window (A) captures the high-amplitude basal fill of a relatively younger sinuous channel in the north, while the dominantly low-amplitude fill of this channel is imaged in (B). 


\section{Lower Tongaporutuan (11-9 Ma, Lower N40-N50)}

Rapid progradation of the shelf margin and severe erosion of the southern and eastern basin areas together reflect increasing tectonic activity during the lower Tongaporutuan (Figure 6.8). Northward and westward advancing clinoform reflectors are identified east (Figure 6.17) and west (Figure 6.18A) of the Cape Egmont Fault, respectively, and outline the approximate geometry of the shelf margin A regional attribute map shows the trace of a large, northward-trending shelf canyon system in the south-eastern basin (Figure 6.19A), which may have been structurally controlled by convergent activity on the adjacent Manaia Fault. In the western part of this map semi-continuous, medium- to high- amplitude reflectors correlate with 40-50 m thick sandy intervals in Western Platform wells, and are interpreted to outline a local fan depocentre in the western basin. Multiple channel systems are observed amongst the more continuous fan facies, indicating lateral migration and aggradation (vertical stacking) of successive channel generations (Figure 6.18B). The fans thin to the northwest, where they cover older, Waiauan-aged fan deposits (Figure 6.18C).

The characteristics of the depositional elements in the slope are not easily imaged on regional attribute maps due to the cross-cutting of stratal intervals with clinoform sequences, but frequent chaotic seismic facies within the slope-sets suggest common channel incision and mass wasting (slumping) across the central basin. In the Maui 3D area a switch to more northerly channel orientations with respect to Waiauan-aged specimen suggests incipient reverse movement on the Cape Egmont Fault and Whitiki Fault, and onset of structuring of the Maui anticline (Figure 6.20A). Based on their location within contemporary clinoforms and biostratigraphic water-depth estimates, these channels are interpreted to have formed within the lower to middle slope (Maui-1, Figure 6.6). The channels are generally less than $1 \mathrm{~km}$ wide, low- to moderately sinuous, and their north- to north-westward orientation may indicate sediment transport into areas located north of the depocentre outlined in Figure 6.19A. The localised deposition of sheet facies in the middle to upper slope is imaged in the Maari 3D survey further south (Figure $6.15 \mathrm{~B}$ ), where a $\sim 0.5 \mathrm{~km}$ wide, high-amplitude channel leads into a more than 4 $\mathrm{km}$ wide area with semi-continuous reflectors. The temporary change from channel bypass to more sheet-like deposition in middle- to upper slope environments may suggest the influence of the local faulting on the basin floor topography. 

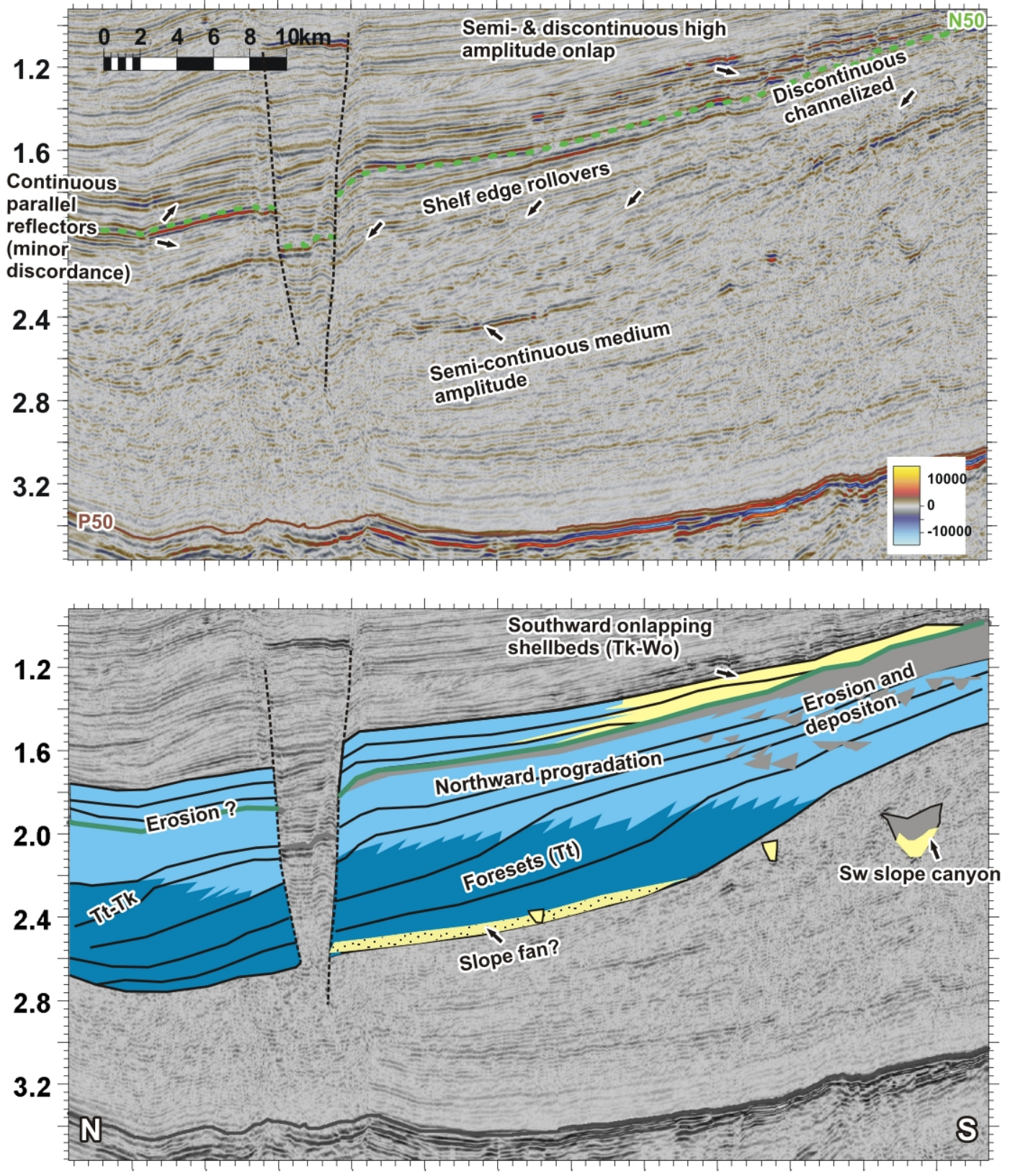

Figure 6.17 $\mathrm{A}$ A) North-south-oriented seismic line located east of the Cape Egmont Fault (HZT82a-123) with interpretations of the N50 and P50 horizons and late Neogene faults (dashed black lines). Interpreted seismic facies are annotated. B) Interpretation of Late Miocene to Early Pliocene (Tongaporutuan to early Opoitian) seismic facies development indicating the northward progradation of slope (dark blue) and shelf (pale blue). Erosion in the south (grey) is followed by southward transgression marked by onlapping strata (yellow). The location of the seismic profile is shown as orange dashed line in Figure 6.19. 

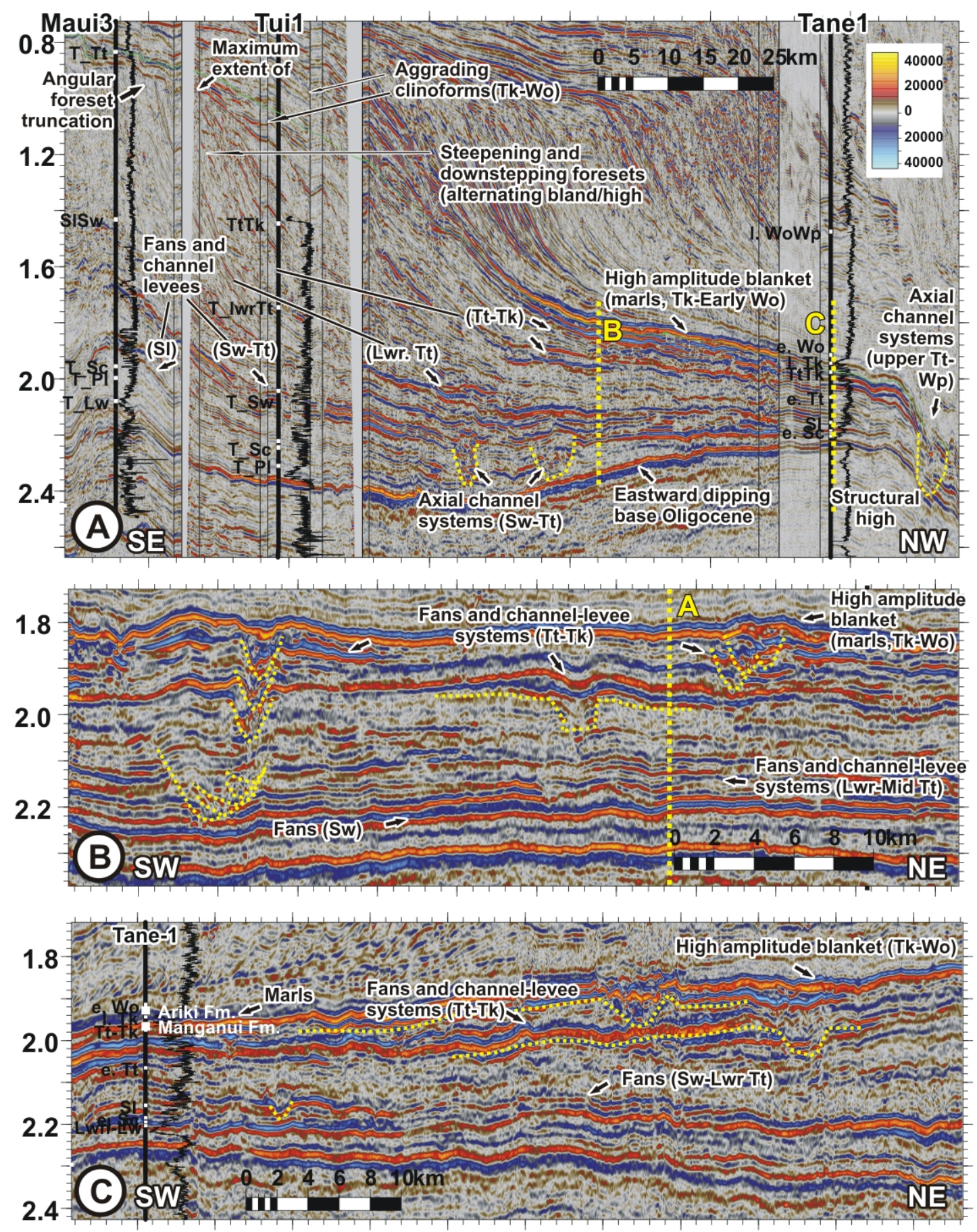

Figure 6.18 Seismic profiles across the central and western basin showing facies development of Middle to Late Miocene depositional systems. A) NW-SE seismic composite line from the central basin to the present-day outer shelf. Note the high-amplitude character and location of inferred Middle to Late Miocene sheet deposits as well as the location of large axial channel systems (marked by dotted yellow lines). Note also that the structural distortion in the northwest of the profile (near Tane-1) is related to the change in water depth outboard of the present-day shelf edge. B) and C) SW-NE seismic profiles from the SUNZ91 survey with annotated facies interpretations. The intersections of these lines are shown as yellow dashed lines in (A) and (B). Wells traces are shown with gamma-ray log and biostratigraphic age estimates as black lines and white dots, respectively. The location of seismic profiles is shown as orange dashed lines in the western parts of maps in Figure 6.19. 


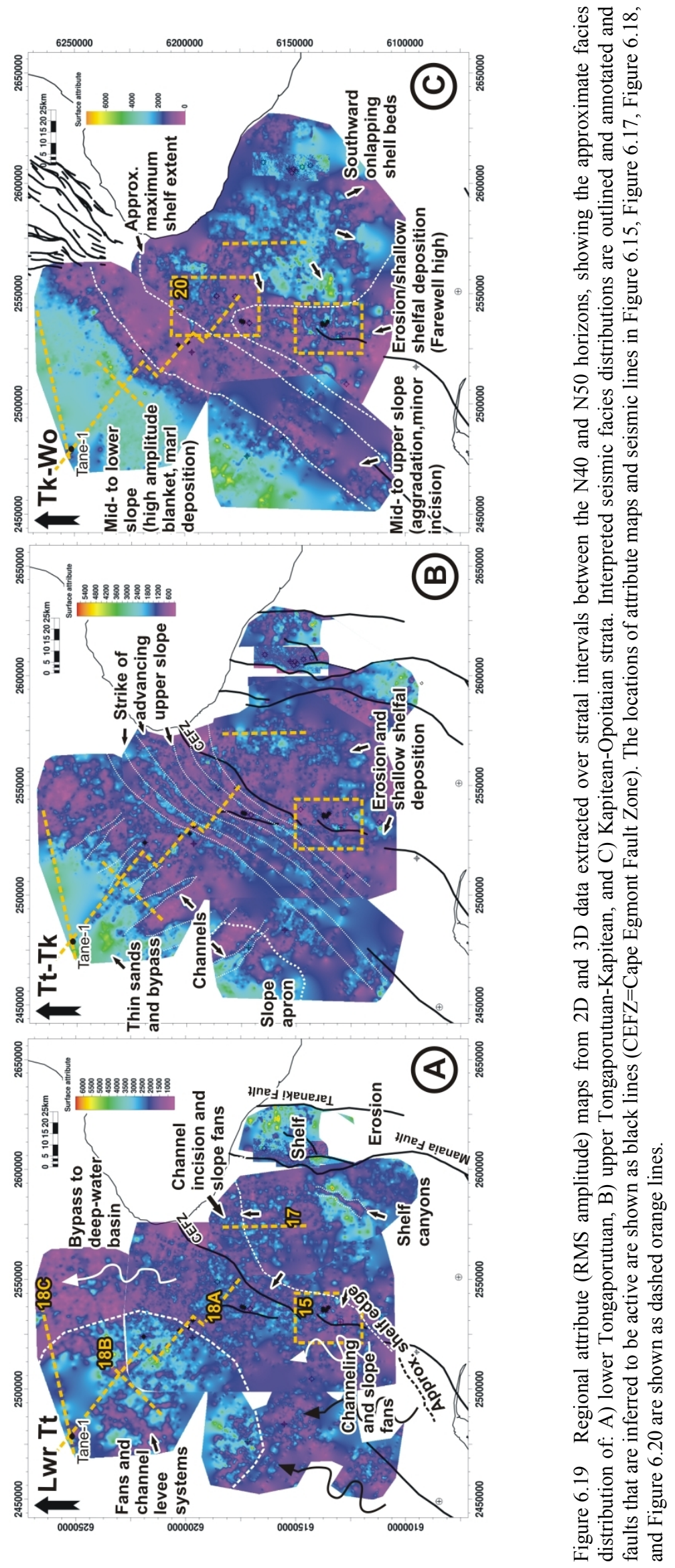



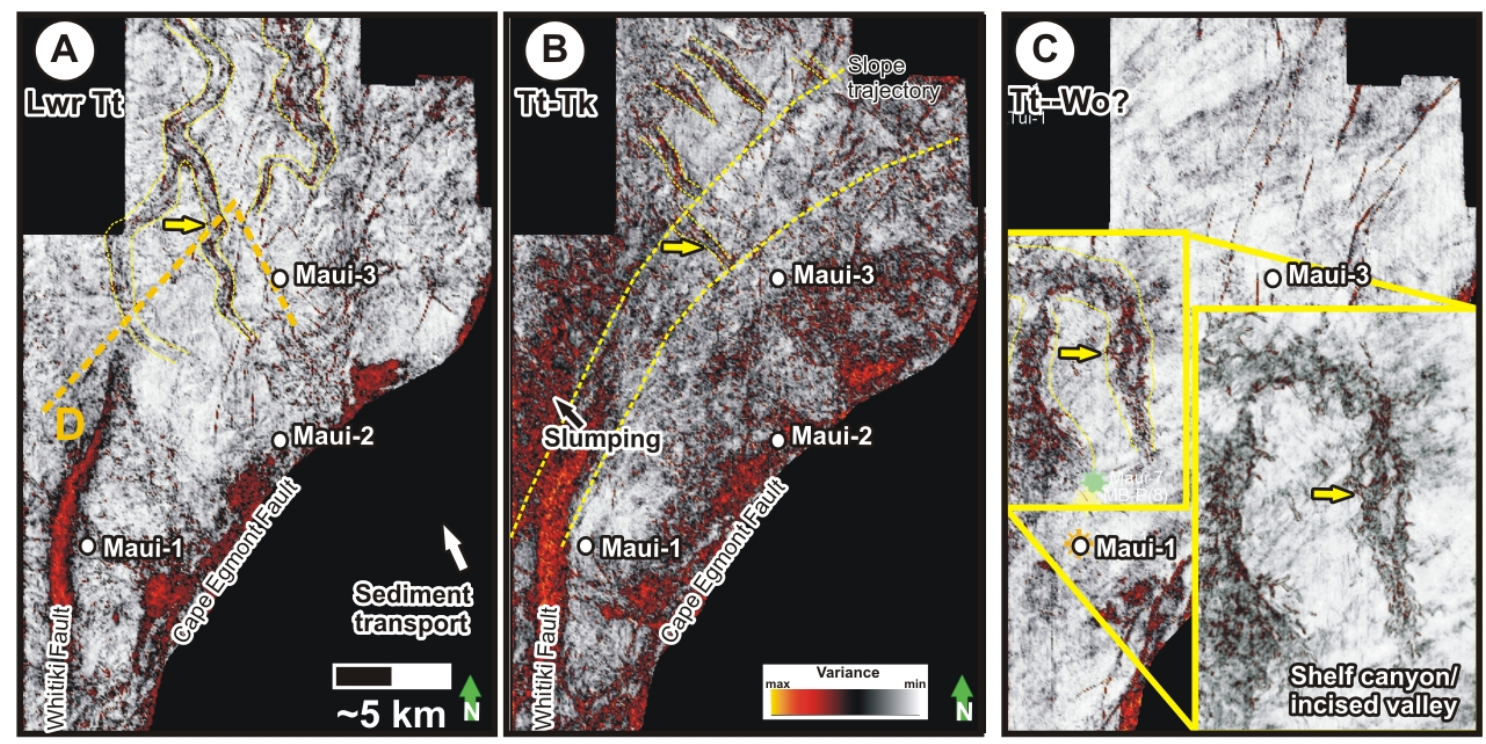

Maui-3

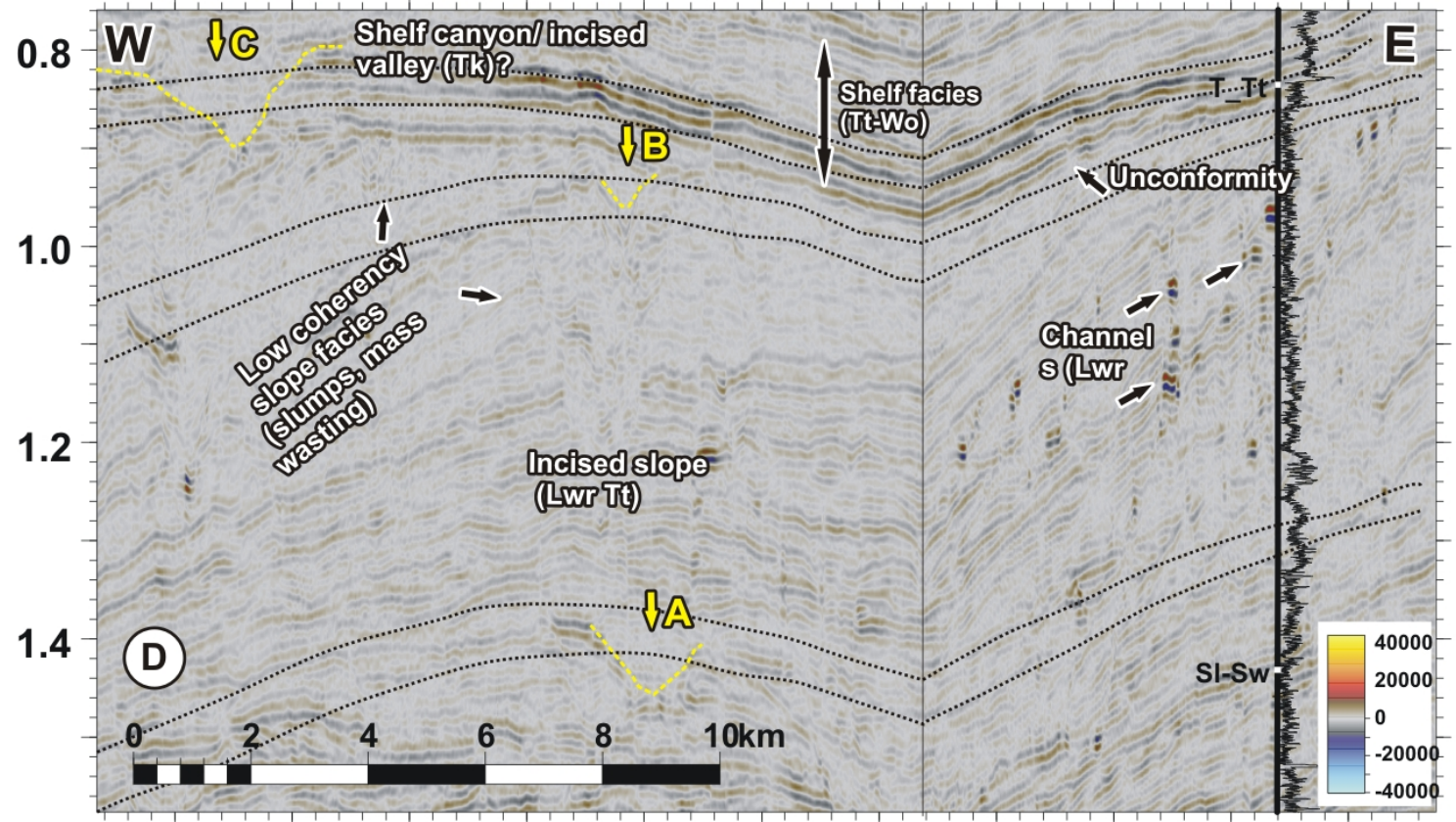

Figure 6.20 Attribute maps and seismic profile from the Maui 3D survey showing characteristics of Late Miocene channel systems. Attribute maps (median of variance) show channel systems of A) early-middle Tongaporutuan, B) middle Tongaporutuan, and C) late Tongaporutuan-Kapitean age, respectively. Inset in (C) shows a magnification of shelf canyon/incised valley systems. D) Seismic section from the Maui 3D survey with well Maui-3 and gamma-ray and biostratigraphic age estimates shown as black lines and white dots, respectively. Seismic facies interpretations are outlined and annotated. Location of seismic line is shown as orange dashed line on (A). Yellow arrows on seismic line point to channel features shown on attribute maps. Black dashed lines outline the intervals used for attribute extraction in maps shown above. 


\section{Upper Tongaporutuan to Kapitean (9-6 Ma, upper N40-N50)}

During the upper Tongaporutuan to Kapitean, the slope migrated beyond the Eastern Mobile Belt and across the Western Platform (Figure 6.8). Clinoforms, especially in the vicinity of the Cape Egmont and Whitiki Fault in the central basin, show increasing dip of slope-sets, down-stepping of shelf edge rollovers below the previous shelf edge, and erosion of landward shelfal strata (Figure 6.18).

The seismic character of the prograding upper slope is marked by packages of alternating amplitude intensity (Figure 6.18A), which suggests variations in sediment texture (fineror coarser-grained) and/or calcareous content. Stratal interval extractions that cut across the upper part of clinoformal reflectors show the lateral continuity of these rhythmic cycles and delineate the orientation and outward growth of a long and fairly linear slope front (Figure 6.19B , Figure 6.20B, and Figure 6.21). At least 5-8 of these cycles are observed in the upper Tongaporutuan to Kapitean stage, which may point to $<1$ my and $4^{\text {th }}$ - to $5^{\text {th }}$-order periodicity. Regions of low lateral seismic coherency indicate frequent failure events and slumping along the advancing slope. One such low coherency area is outlined on a variance attribute map in the area of the Whitiki Fault, where mass wasting could be directly related to reverse activity on the underlying fault (Figure 6.20B). In addition, a large number of relatively straight, low amplitude channels (0.3-0.5 km width) incise near the upper shelf edge rollover and outline the transport direction of sediment that was bypassed downslope.

In areas of decreasing slope gradient a series of longitudinal, high-amplitude features on regional attribute maps outline the distribution of regularly spaced channel systems (Figure 6.19B \& Figure 6.21). These channels widen down-slope into an area with a greater dominance of continuous medium- to high-amplitude reflectors. On seismic profiles these reflectors thin laterally and generally decrease in amplitude away from channel axes (Figure 6.18B), indicating the development of subtle levees and overbank deposition. High-amplitude continuous reflectors correlate with serrate gamma-ray values in well Tane-1 and indicate the unconfined deposition of inter-bedded thin sandstones and mudstone facies. In the outer parts of these sheet deposits, a large channel with northerly trend indicates further bypass of sediment towards the southern New Caledonia Trough (Figure 6.21). 


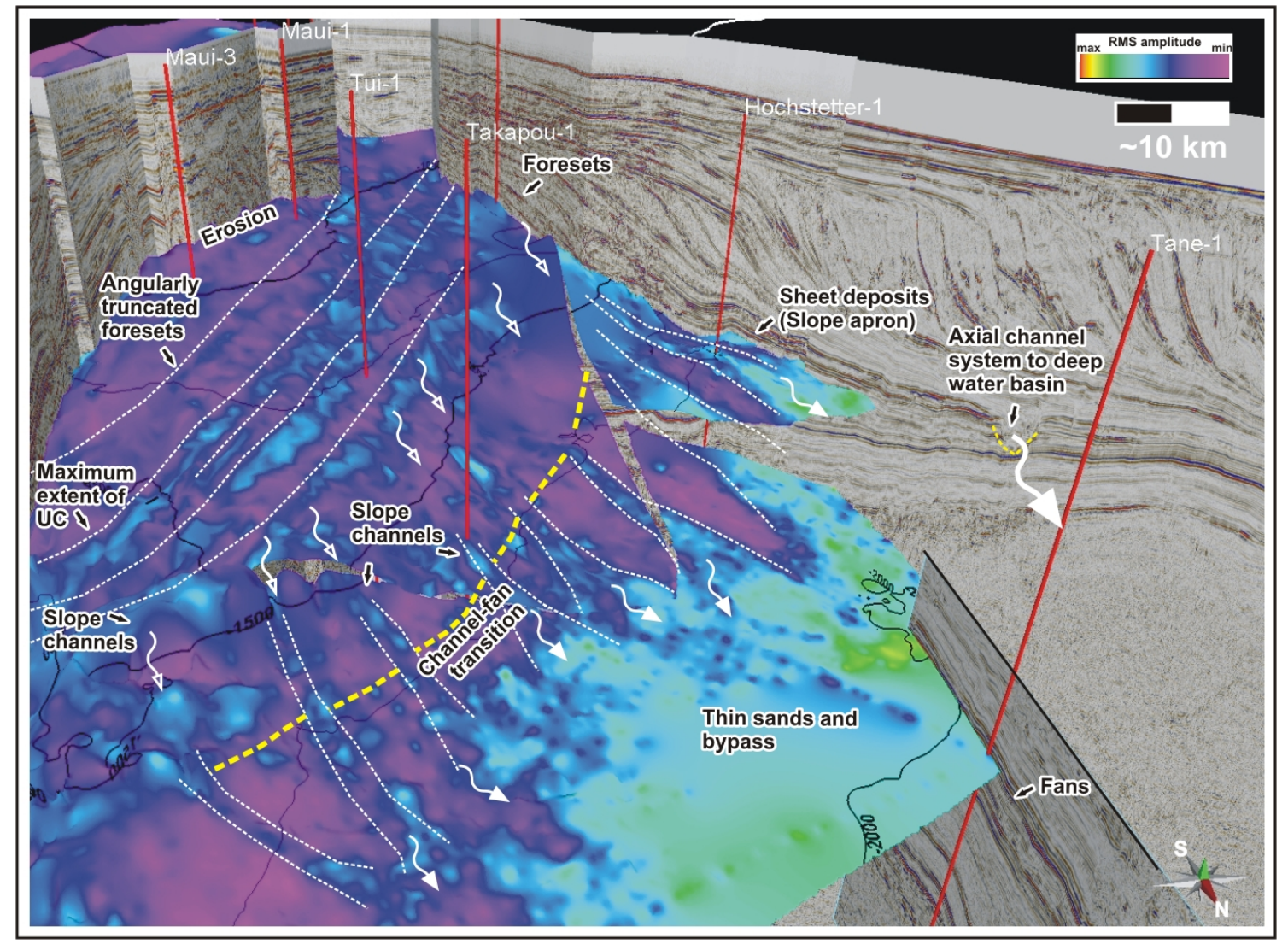

Figure 6.21 Upper Tongaporutuan- to Kapitean-aged depositional systems from the paleo-shelf to the intermediate base of slope shown in perspective view of attribute maps (also shown in Figure 6.20B) and seismic profiles. The attribute maps are draped over stratal surfaces that mark the bottom part of extraction window used for attribute map. Seismic facies interpretations are outlined and annotated and inferred sediment transport directions are indicated as white wavy arrows. Wells paths are shown in red. The black lines on surface show the depth of the stratal horizon in ms TWT.

\section{Kapitean to Opoitian (6-4.5 Ma, N50-N60)}

Following further progradation of the shelf margin system during the Late Tongaporutuan, relatively flat, continuous reflectors indicate the development of the shelf across the central basin area (Figure 6.20D). Attribute maps show small (0.05-0.2 $\mathrm{km}$ ), dendritic channel systems leading into 4-5 $\mathrm{km}$ wide valleys that trend north and then north-westward toward the inferred slope (Figure 6.20C). The character of these systems is analogous to incised valleys described in detail in other basins around the world (e.g., Nordfjord et al., 2006). Smaller erosional features of similar age can be mapped on the 3D data set further south, which are interpreted to represent small shelf contributories (Figure 6.15C).

Increasing aggradation of clinoform reflectors indicate dwindling in sediment supply to the western basin during the Kapitean (Figure 6.18). This decrease in sediment supply is also marked by an increasing dominance of continuous parallel reflectors and fewer 
channels incising into the slope. In the lower slope, medium- to high-amplitude continuous reflectors near the top of the Miocene sequence (Figure 6.19 \& Figure 6.20) show a correlation with the base of fine-grained hemipelagic mud and marls of the Ariki Fm in distal Western Platform wells (Tane-1). Decreasing clastic input to the western basin is coeval with southward onlap of medium- to high-amplitude strata onto the earlier unconformity in the eastern basin (Figure 6.17 and Figure 6.19C).

\section{Source to sink mapping of slope channel systems}

\section{Delineation of sediment pathways using meta-attributes}

The previous section has shown that submarine channel systems can be delineated from simple attribute extractions in areas of dense seismic data coverage. Imaging the basinward continuation of channels is increasingly difficult across the Western Platform and Deepwater Taranaki Basin due to a reduction in data density. While the channel systems are often marked by rapid lateral changes in the seismic signal, which makes them visible on seismic amplitude or coherency attributes, maps extracted from sparse 2D data do not sufficiently highlight the features to visualize their continuity. However, combinations of multiple attributes that capture specific facies characteristics (amplitude, frequency, lateral coherency) into facies meta-attributes, make it possible to highlight channel features enough to allow for map view visualization across the low spatial density seismic grid in the deep-water basin (10 km spacing).

An attribute map extracted from a 2D seismic data set with roughly $1.5 \mathrm{~km}$ grid spacing in the area of the Maui 3D survey (Figure 6.22A), shows the resolution of Waiauan-aged channel systems on facies meta-attributes. In this case, yellow to red colours reflect lowmedium amplitude, low-medium coherency facies and correlate well with the channels defined on 3D (Figure 6.22B). While information about detailed channel morphometrics, such as sinuosity, is lost on the $2 \mathrm{D}$ meta-attribute rendition, the pathways of these channel systems can be traced regionally across the grid of various seismic surveys and into areas where simple amplitude mapping does not suffice. Meta-attribute maps show the continuity of Waiauan channel systems towards the northeast-trending axial channel system on the Western Platform (Figure 6.22C) and further continuation into Deepwater Taranaki Basin (Figure 6.22D). 

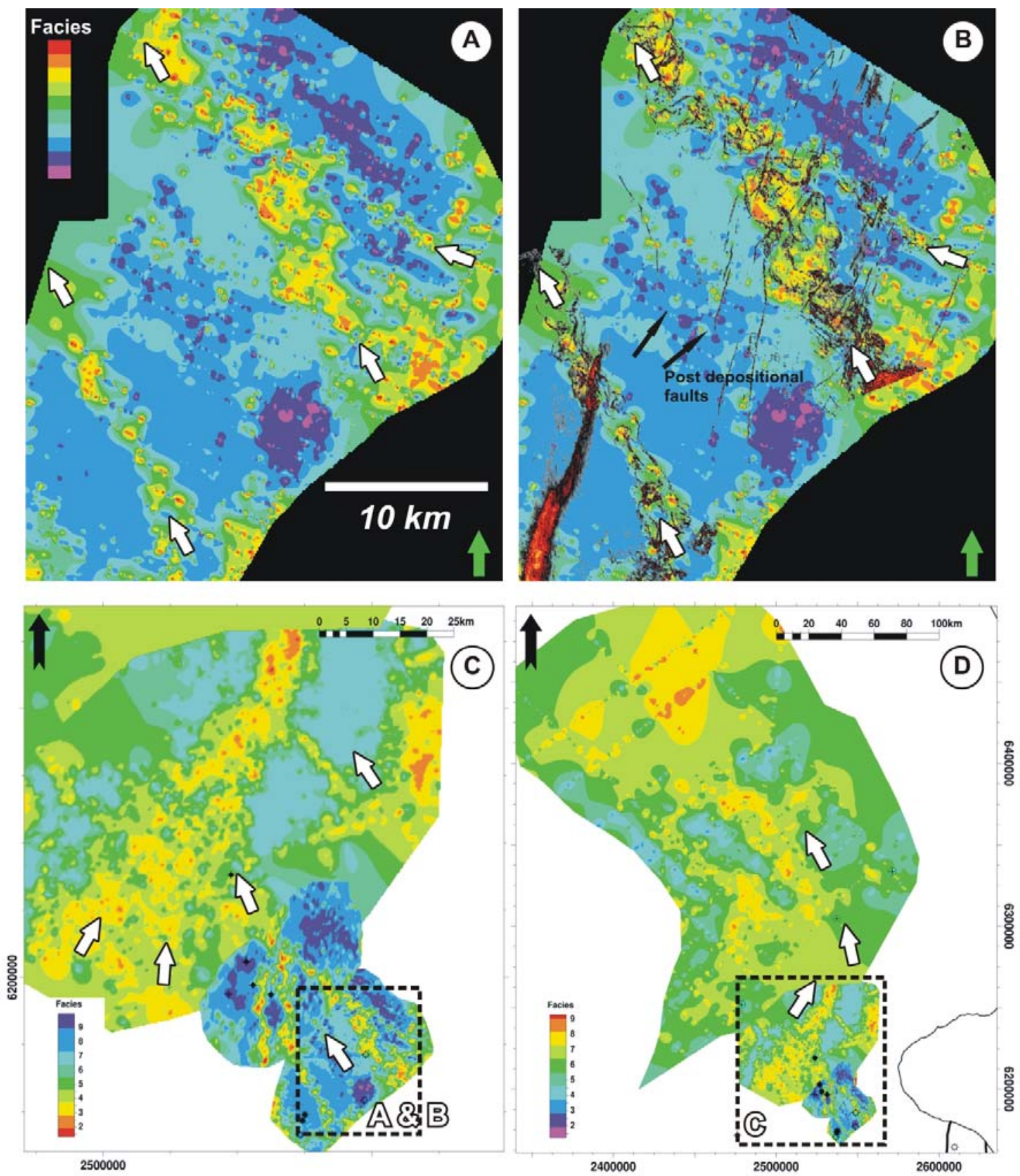

Figure 6.22 A) Attribute map extracted from meta-attribute volume of 2D survey 86MA in the central basin over Waiauan-aged interval shown in Figure 6.16B. B) Comparison of meta-attribute map shown in (A) with 3D variance attribute from the Maui3D survey (also shown in Figure 16B). C) Meta-attribute extractions from Western Platform 2D seismic surveys (STOS95, SUNZ91) at the stratigraphic interval shown in Figure 6.14B, outlining the basin-ward continuity of channel systems shown in (A) and (B) (indicated by black dashed rectangle). D) Composite metaattribute map showing channel continuity from the central to the deep-water basin (DTB01). Inferred sediment transport directions are shown as white arrows. 


\section{Slope channel mega-systems}

Large axial channel systems observed on seismic data during the late Middle Miocene (Figure 6.14) and Late Miocene and Early Pliocene (Figure 6.21) suggest significant bypass of sediment beyond the proximal Taranaki Basin and into the NCT. Combinations of meta-attribute maps in the distal, deep-water basin with simple amplitude maps in the proximal basin allow the visualisation the depositional systems during these two times from sediment source areas on the shelf to sediment sinks in deep water (Figure 6.23). The south-western upper reaches of the younger axial system are outside the study area and were thus not mapped. However, Thrasher and Cahill (1990) mapped channel systems of similar age on sparse seismic data further south-west than the extent of the current study area, and intuitively inferred the continuation of this network into the NCT. The combined display of attribute maps and their channel outlines shows good agreement and suggests sediment transport over a distance of more than $500 \mathrm{~km}$ across the basin. King and Thrasher (1996) suggested that the system became active in the Early Pliocene, but stratal geometries adjacent to this channel provide evidence that this system has started to develop during the Late Miocene (Figure 6.24C).

The two distributary mega-systems show a series of commonalities with respect to sediment dispersal pathways that yield information about the basin's paleogeomorphology and sedimentation style (Figure 6.23). Elements common to both systems include 1) shelf incision and slope channels oriented perpendicular to the prograding shelf margin, 2) axial channels oriented parallel to the base of the advancing slope, 3) deep-water channels that bend to the northwest to align with the axis of the NCT, and 4) fan lobe deposition in the NCT. The northwest translation of the Late Miocene system with respect to the Middle Miocene system reflects the advancement of the shelf edge and slope during the Late Miocene.

Northeast-trending axial channel systems originate from the west and northwest of the present-day South Island and appear to be guided along a bathymetric trough in the advancing slope and elevated topography on its eastern and western flanks, respectively (Figure 6.8). The trough evidently formed in a region of subsidence along the downthrown sides of the en-echelon Kahurangi, Whitiki, and Cape Egmont faults. To the west the system may have been guided along the structurally elevated Challenger 
Plateau. It is noted that the location of the Late Middle Miocene axial trough coincides with the eastern flank of the flexural forebulge inferred from palinspastic reconstructions (Chapter 3) and flexural modelling (Holt \& Stern, 1994), which may indicate the additional structural control on the channel pathway.

Channel systems can be traced through the present-day deep-water area covered by the DTB01 survey, but variable occurrence of high-amplitude, semi-continuous seismic reflections packages also indicates the deposition of sheet deposits in the area (Figure 6.24E). In the north-western survey large mounded gullwing structures are observed, indicating the presence of large channel-levee complexes and fan deposits (Figure 6.24F). The features are confined by a depression within the NCT (see also Figure 6.7A) and lateral switching indicates the compensational architecture of stacked fan, channel, and channel-levee deposits. The combination of channels and sheet deposits indicates that the systems successively built out into the NCT, and that sediment was increasingly being bypassed beyond the coverage of the deep-water seismic survey. While the channels are characterized by mostly low-amplitude, chaotic fill, differential compaction of sediment may indicate potentially coarse-grained channel fill (Figure 6.24F). Relatively well-developed levees observed within the Late Miocene to Pliocene depositional system suggest the availability of sufficient fine-grained sediment to build the channel walls. High amplitudes on the levee flanks may either indicate inter-bedded sand and silt sequences, condensed units, or ponded sands that lap back onto fine-grained levees. 

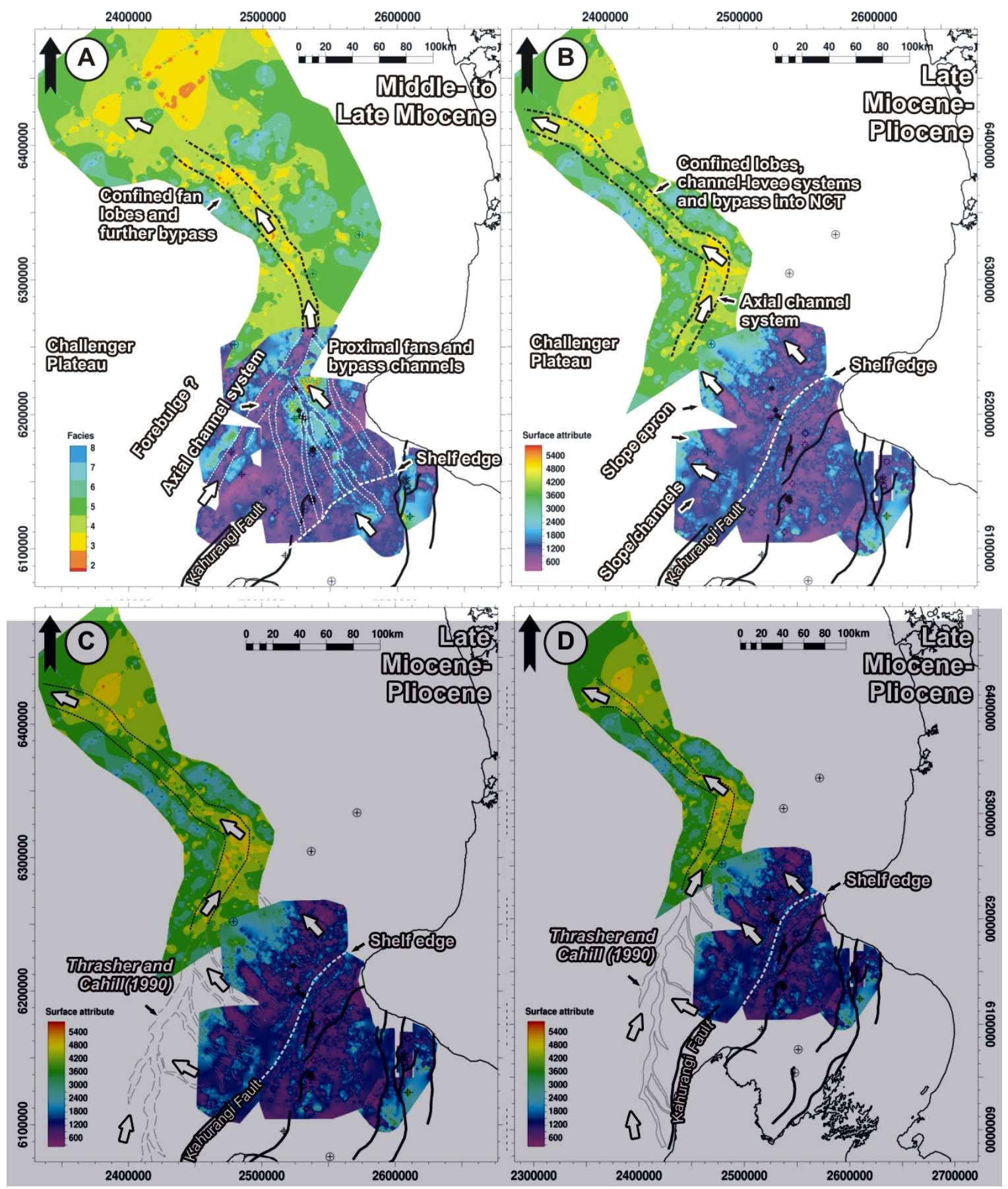

Figure 6.23 Composite attribute maps of RMS amplitude in the proximal basin and meta-attributes in the deep-water area, showing the character of Middle Miocene (A) and Late Miocene (B) slope channel mega-systems. C) Comparison of the Late Miocene system with channels mapped by Thrasher and Cahill (1990) (grey dashed lines) at the top of Miocene strata. D) Regional overview of the Late Miocene depositional system expanded to the south to include the complete channel network mapped by Thrasher and Cahill (1990). 

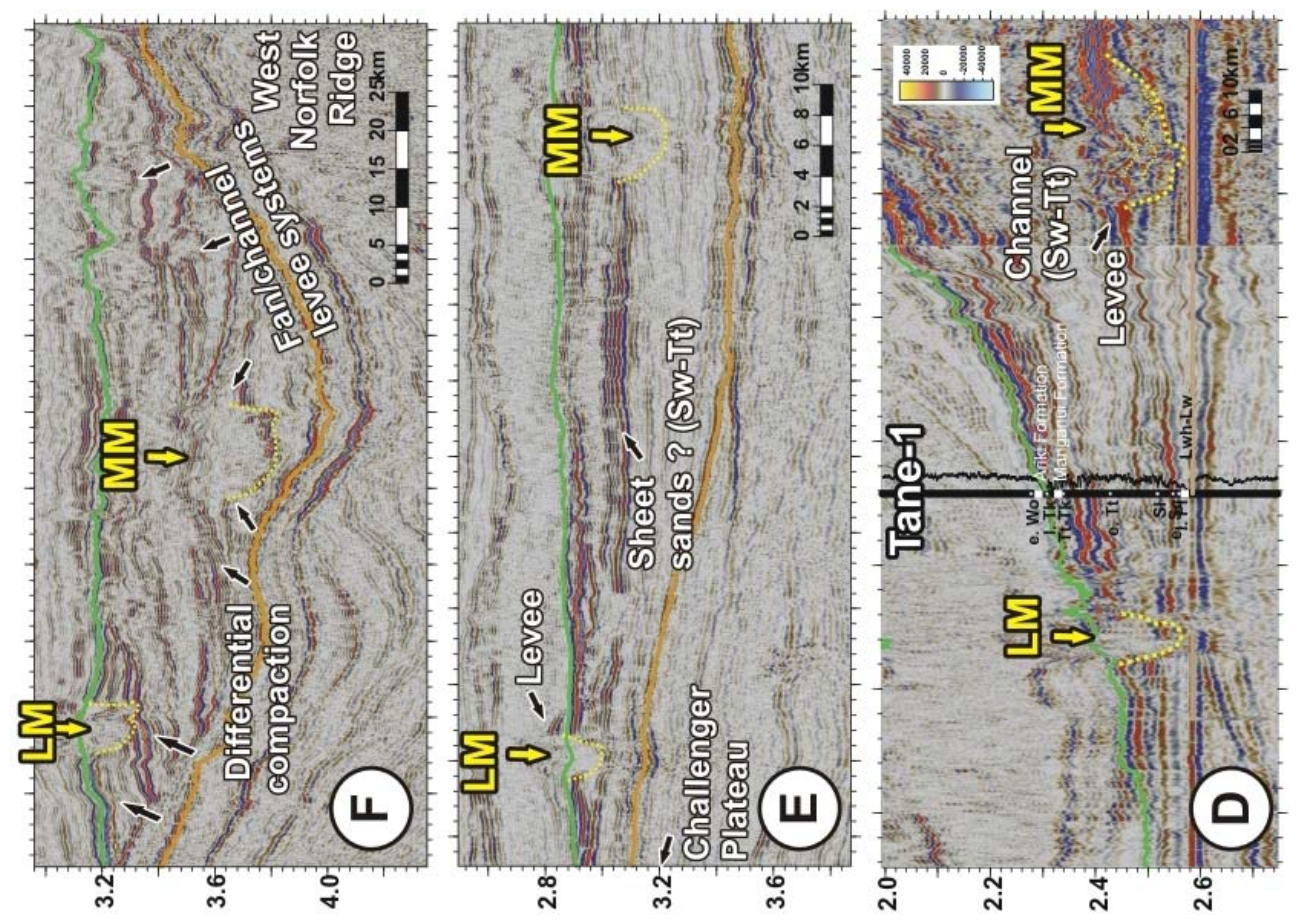

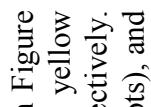

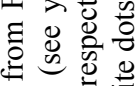

苍 है है

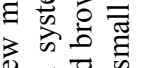

可 $\overline{0}$

ठั ฮ્

४.

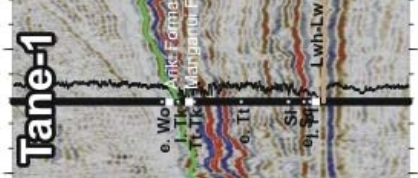

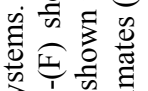

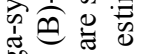

車 $\Xi$ 号 乌다

过造造

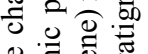

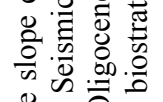

चु $\dot{0} \overrightarrow{0}$

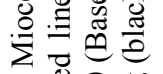

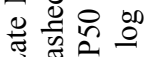

กอ
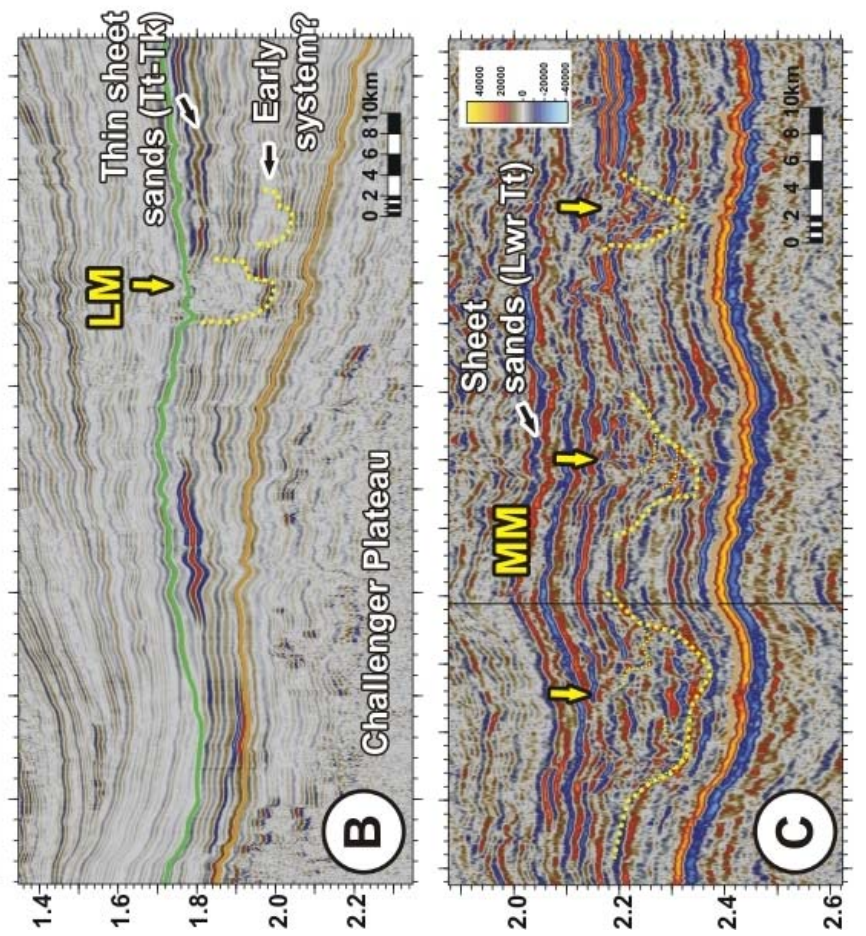

宅 它

㓬员

券㗪

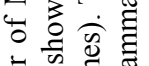

离公品㗊

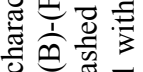

.

on oै

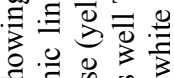

क

过卷 表

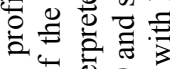

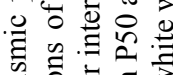

的. 毒

证寻

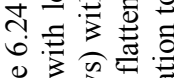

总 กิ 


\section{Paleobathymetry estimates from decompacted foreset heights}

As mentioned above, microfauna assemblages indicate widespread bathyal environments during the onset of Miocene regression through most of the central basin (e.g., Moki-1, Tui-1, Tane-1), shallowing toward slope and shelf conditions to the eastern, southeastern, and southern basin (e.g., Kupe area, Fresne-1). Bathyal depth estimates show large uncertainties (Figure 6.6), pertaining to the lack of susceptibility of bathyal microfauna to changes in bathymetry of anything less than several hundred metres $( \pm 500)$, and thus do not yield information about the detailed basin paleo-geomorphology.

In order to further constrain the paleobathymetry across the basin at respective time intervals, a series of clinoform heights were measured from seismic data. The clinoform measurements were made in areas inferred to be most representative for the overall depositional systems and the seismic lines were chosen to approximate the depositional dip as closely as possible. The vertical distance between the upper and lower clinoform rollover (Figure 6.25) was measured on seismic lines that were flattened on the base Oligocene horizon (P50), to establish first-order approximations for the difference between the shelf edge and the base of slope. Particular attention was given to avoid effects of flexural loading due to younger foresets. The measured heights in two-waytraveltime (TWT) were depth-converted using simple interval velocities that have been derived in previous studies (Stagpoole, 1998). The depth-converted heights were then decompacted with Taranaki Basin specific compaction coefficients (Funnell et al., 1996) using procedures outlined in Chapter 2 (Table 6.2). In order to establish first-order minimum water-depth estimates of the paleo-basin floor, a generic estimate of the paleowater depth at the shelf break was added to the calculated foreset heights, which was based on global average values of $150 \mathrm{~m}$ (Gross, 1982). 


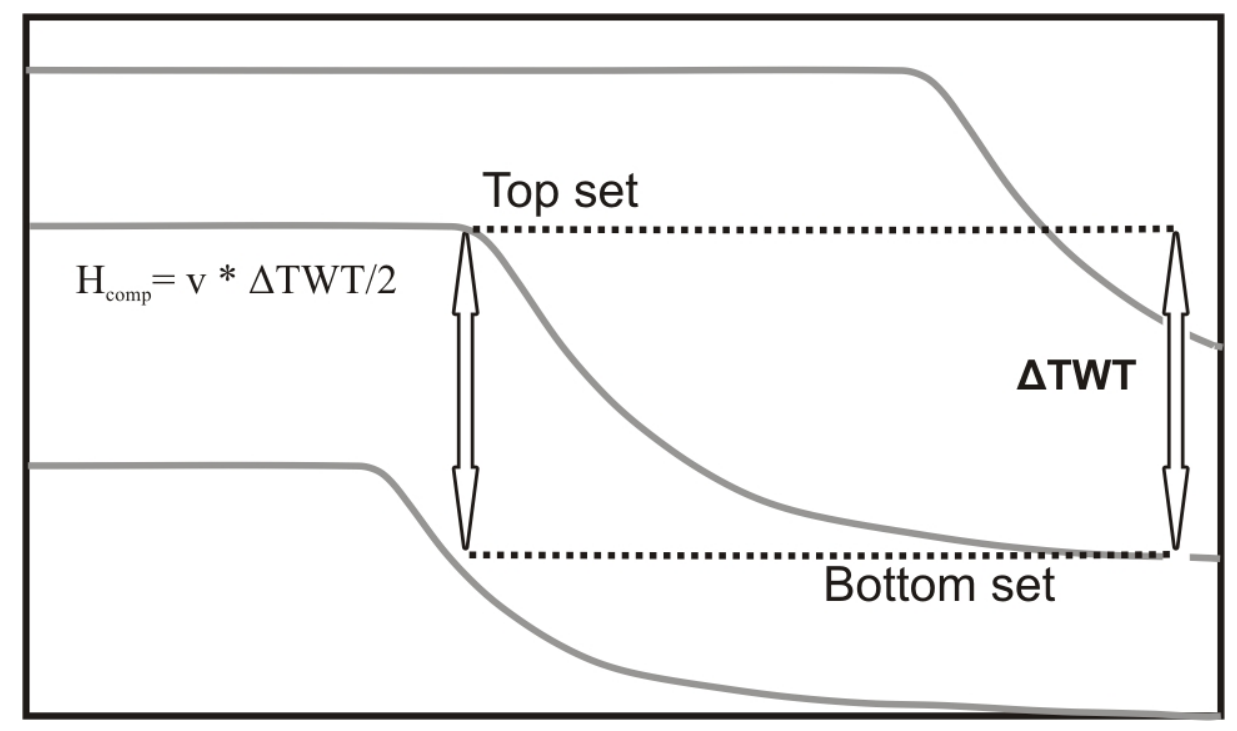

Figure 6.25 Schematic illustration of procedure to measure clinoform foreset heights. Measured foreset thicknesses in two-way-travel time ( $\triangle \mathrm{TWT}$ ) are depth converted using average interval velocities (v) from Stagpoole (1998). These thicknesses are decompacted using the approach of Sclater and Christie (1980) with compaction coefficients from Funnell et al. (1996).

Table 6.2 List of measured foresets, showing (from left to right): their inferred absolute age, New Zealand stage association from biostratigraphy, seismic line name on which the foreset was measured, depth of the topset-clinoform rollover and travel time difference with respect to the lower inclination point (in milliseconds two-way-travel time), minimum and maximum velocities used for depth conversion in $\mathrm{m} / \mathrm{sec}$ (after Stagpoole, 1998) and minimum, maximum and average values of decompacted foreset heights (in $\mathrm{km}$ ). Grey area shows measurements in the Pliocene Toru Trough sub-basin (see Chapter 7).

\begin{tabular}{|c|c|c|c|c|c|c|c|c|c|}
\hline $\begin{array}{l}\text { Age } \\
\text { [Ma] }\end{array}$ & $\begin{array}{c}\text { NZ } \\
\text { Stage }\end{array}$ & $\begin{array}{c}\text { Seismic line } \\
\text { name }\end{array}$ & $\begin{array}{l}\text { Top Set } \\
\text { (TWT) }\end{array}$ & $\Delta T W T$ & v_min & v_max & h_min & h_max & h_av \\
\hline $17-15$ & $\mathrm{Pl}$ & or03-003 & 2572 & 330 & 2800 & 3800 & 0.7 & 0.9 & 0.8 \\
\hline $15-13$ & $\mathrm{Sl}$ & or03-003 & 2422 & 300 & 2800 & 3800 & 0.6 & 0.8 & 0.7 \\
\hline $13-11$ & Sw & $\begin{array}{l}\text { or003-007, } \\
\text { HZT82a-115 }\end{array}$ & 1780 & 500 & 2800 & 3800 & 0.9 & 1.2 & 1.1 \\
\hline $11-9$ & $\mathrm{Tt}$ & $\begin{array}{c}\text { or003-007, } \\
\text { HZT82a-115 }\end{array}$ & 1850 & 600 & 2800 & 3800 & 1.1 & 1.5 & 1.3 \\
\hline $9-7$ & $\mathrm{Tt}$ & 86ma-054 & 1100 & 600 & 2800 & 3800 & 1.0 & 1.4 & 1.2 \\
\hline $7-5$ & Tk-Wo & stos95-234 & 1050 & 700 & 2500 & 3500 & 1.1 & 1.5 & 1.3 \\
\hline $4-3$ & $\begin{array}{l}\text { Wo- } \\
\text { Wm }\end{array}$ & hzt82a-120 & 1140 & 80 & 2500 & 3500 & 0.1 & 0.2 & 0.2 \\
\hline $3.5-3$ & $\begin{array}{l}\text { Wp- } \\
W m\end{array}$ & hzt82a-120 & 920 & 200 & 2500 & 3500 & 0.3 & 0.4 & 0.4 \\
\hline $3.5-3$ & $\begin{array}{l}\text { Wp- } \\
W m\end{array}$ & sk10-2664 & 900 & 150 & 2500 & 3500 & 0.2 & 0.3 & 0.3 \\
\hline 2 & $\mathrm{Wn}$ & DTB01-31 & 700 & 840 & 2200 & 2800 & 1.1 & 1.6 & 1.3 \\
\hline
\end{tabular}


Figure 6.26 shows the resulting Miocene to Recent foreset heights and inferred base of slope depths that were calculated along a southeast-northwest path within the basin (Figure 6.27). The calculated values show a trend of increasing clinoform heights from the Early Middle Miocene to the Late Miocene from about $0.8 \mathrm{~km}$ to $1.3 \mathrm{~km}$, indicating that younger foresets built out over deeper basin floor than older ones. Calculated values approach modern day foreset heights on the north-western part of the Western Platform (the modern slope margin to the NCT), whereas they are consistently higher than clinoforms bordering the present-day Challenger Plateau (Figure 6.26 and Figure 6.27).

The consistently greater height of Miocene clinoforms compared to foresets downlapping onto the present-day Challenger Plateau is interpreted as a manifestation of lower topography and greater available accommodation space within proximal basin and the southeast continuation of the NCT (Figure 6.27). The north-westward increase in foreset heights through time shows the overall gradient of the paleo-basin floor, and suggests that the proximal basin represented an extended slope into the NCT. The small decrease in foreset height between 16 and 14 Ma could be interpreted as a result of eastward dipping foreland morphology, which is also manifested by the containment of fan deposition along the axis of the proximal basin during most of the Middle Miocene (Figure 6.27). The continuous foreset height-increase from $11 \mathrm{Ma}$ is paralleled by the first occurrence of large axial channel bypass systems, suggesting that the foreland basin was filled to spill and the end of sedimentary confinement within the foredeep. The shallower morphology of the Challenger Plateau provided a barrier to westward sediment transport, leading to subtle ponding of sediment at the interim base of slope (foreset base), and successive northward deflection of channel systems down the steepest gradient towards the NCT. 


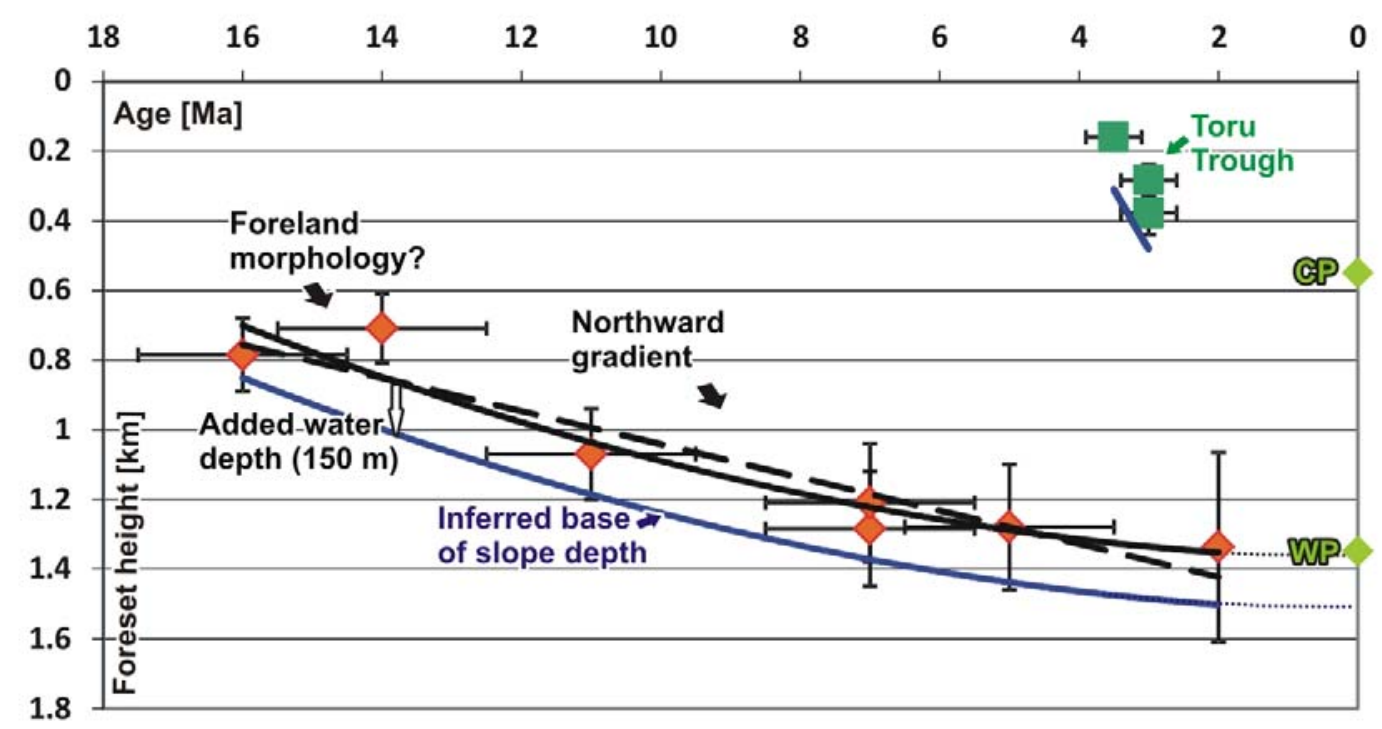

Figure 6.26 Decompacted heights of Miocene to Recent foresets. Orange diamonds show foreset heights of the prograding north-western continental margin through time, dark green squares show Pliocene foresets observed in the Toru Trough (eastern basin, Tangahoe Formation), and light green diamonds indicate foreset heights of the present-day shelf measured from bathymetric grids on the Challenger Plateau and the New Caledonia Trough. Linear and polynomial $\left(2^{\text {nd }}\right.$-order) trendlines for the western foresets are shown as black solid and dashed lines, respectively. The blue line shows the polynomial trend line with $150 \mathrm{~m}$ of inferred shelf break water depth added to approximate the total water depth of the base of slope. The locations of individual measurements are indicated in Figure 6.27.
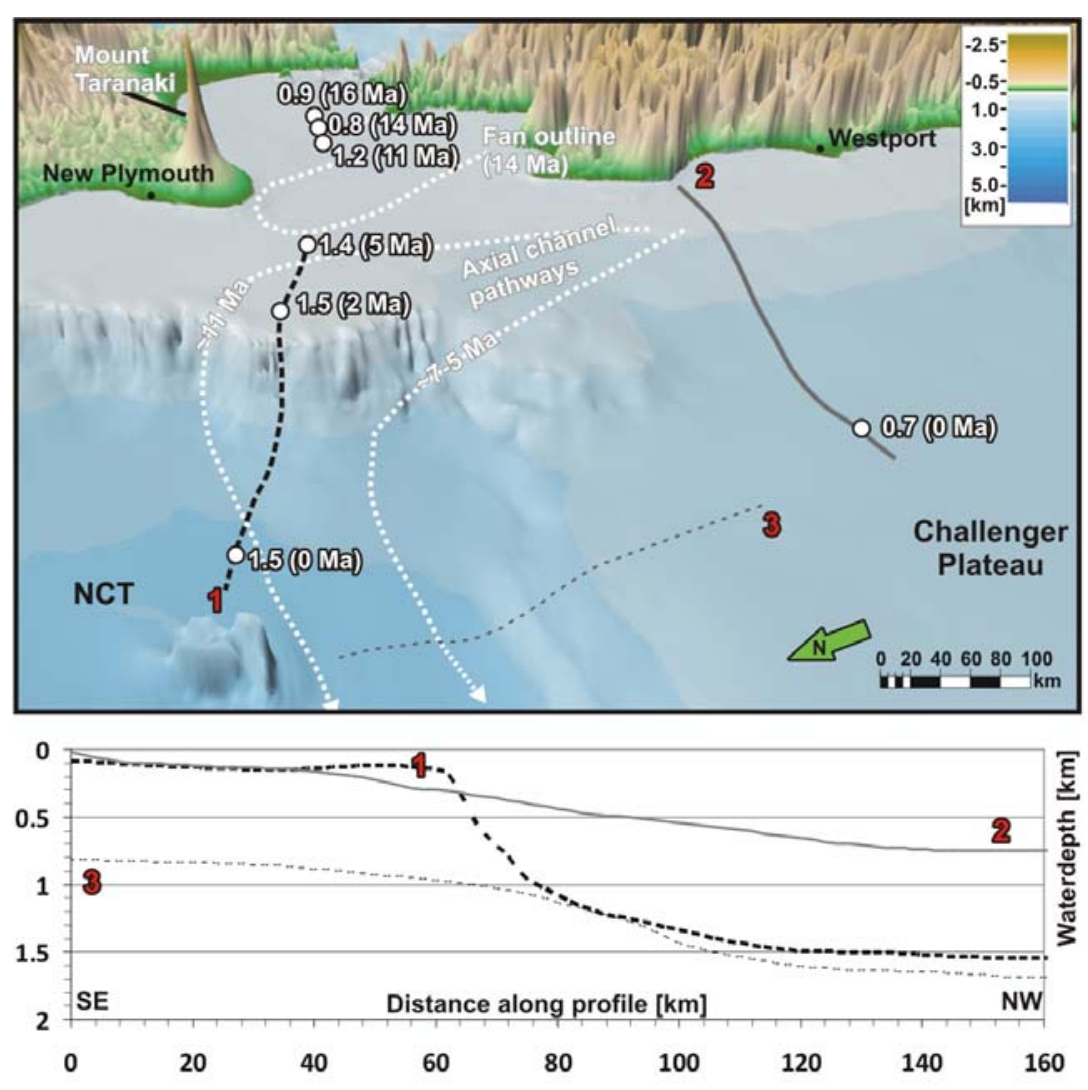

Figure 6.27 Top) Perspective view of digital topography model (DTM) in Taranaki Basin (vertical exaggeration=40) showing the location of clinoform measurements and inferred depth of the base of slope through time, as calculated from decompaction of foreset heights. Bottom) Present-day depth profiles extracted from DTM at locations shown as grey and black lines in top map. Note the difference in slope character and height of margins shown in profile 1 and 2, as well as the morphology on the northern slope of the Challenger Plateau that may have controlled the orientation of Miocene sediment bypass systems (white dashed lines). Colour scale refers to sub-aerial topographic elevation and submarine bathymetry (see legend on top right). 


\subsection{DISCUSSION}

\subsubsection{Characteristics of slope to basin floor channels}

\section{General channel characteristics from 3D data and lithostratigraphic association}

The seismic attribute maps derived here show channels from a large spectrum of bathymetric settings, each of which shows distinct morphometric character. Due to the progradational character of the Miocene sedimentary wedge, sediment conduits from each depositional environment have been imaged on the limited 3D data through time. The variable character of channel features in their respective environmental setting, as described in previous sections, is illustrated in Figure 6.28 by juxtaposing variance from different parts of the stratigraphic column. The images show the plan-view character of channel facies within different lithostratigraphic formations that have previously been described in sparse outcrop cross sections (e.g., Jordan, 1994; King \& Browne, 1994; Browne et al., 2000; King et al., 2007b).

The changing character of channels in varying environments is further illustrated by channel outlines that were mapped on seismic amplitude and variance maps in the Maui 3D survey (Figure 6.29). The channel specimens show the combined effects of tectonism and progradational advance of the slope through time. Early Middle Miocene (Sc-Sl) systems associated with fan lobes show distinct northward sediment transport, which changes toward a north-westerly orientation as the slope advanced in this direction during the Late Middle Micoene (Sw). Early Late Miocene lower to middle slope systems show a diversion in transport direction to more fault sub-parallel orientation (north-northeast), which is inferred to be associated with inception of convergent activity on the Cape Egmont and Whitiki Faults. Middle to upper slope channels of lower Tongaporutuan to Kapitean age show again the dominance of the gradient of the advancing slope to the northwest. The dominantly low-amplitude fill of middle to upper slope channels indicates that these features represent mostly sediment bypass conduits, although high amplitudes at their base indicate that they may have retained a coarsegrained lag deposits. In lower slope to basin floor environments, channel systems can be grossly subdivided into two groups: 1) lower-sinuosity channel with possibly coarsegrained high-amplitude fill and 2) sinuous channels with dominantly low amplitude (possibly fine- grained) fill and high-amplitude (possibly coarse-grained) lags. 


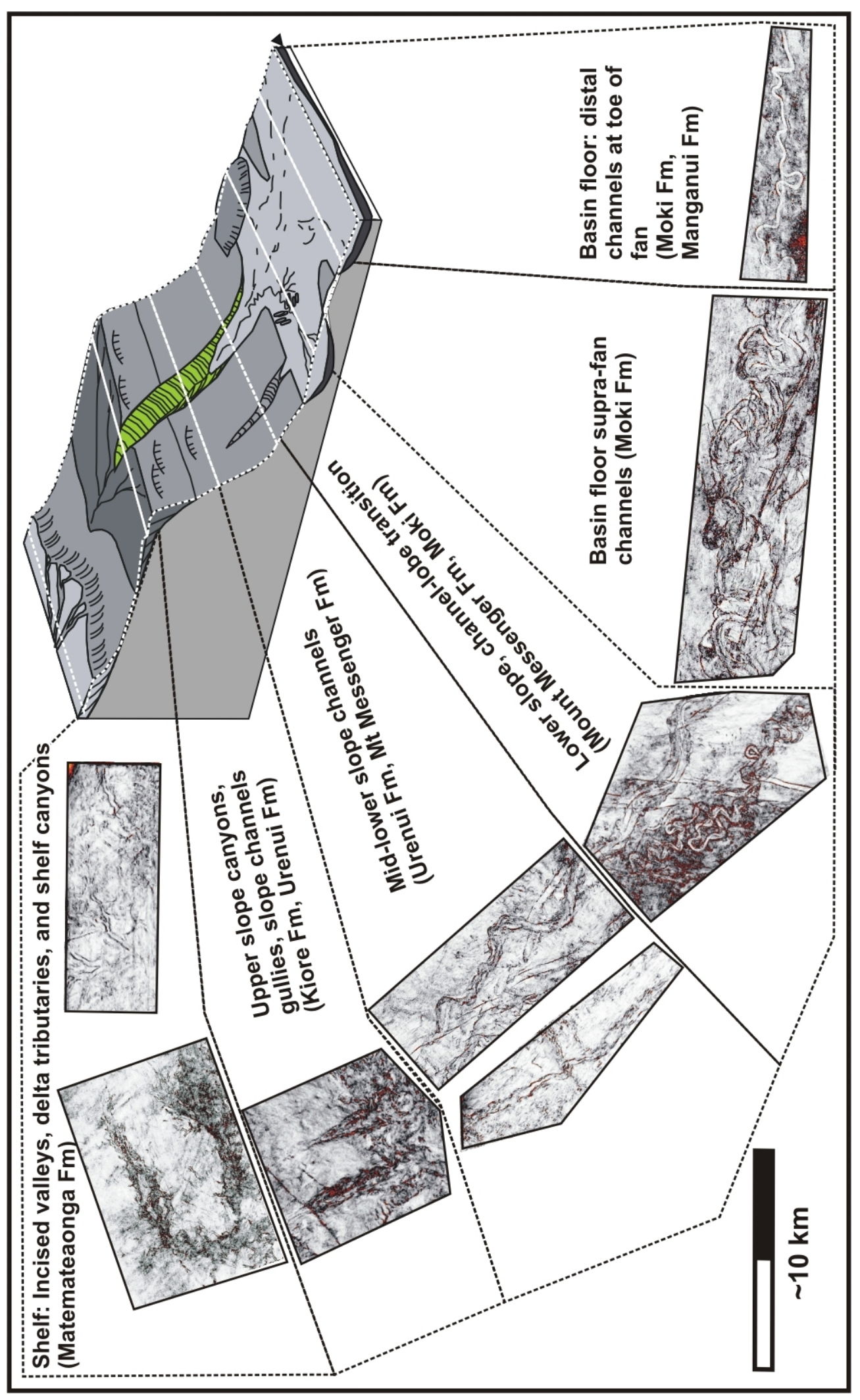

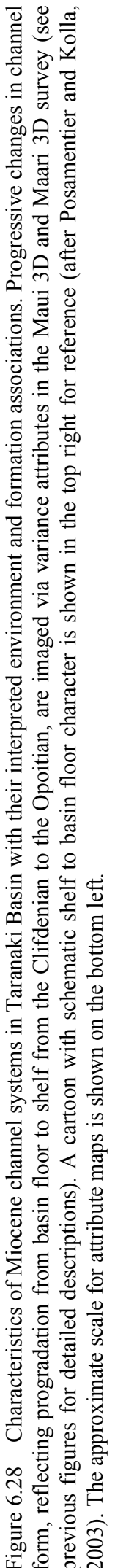



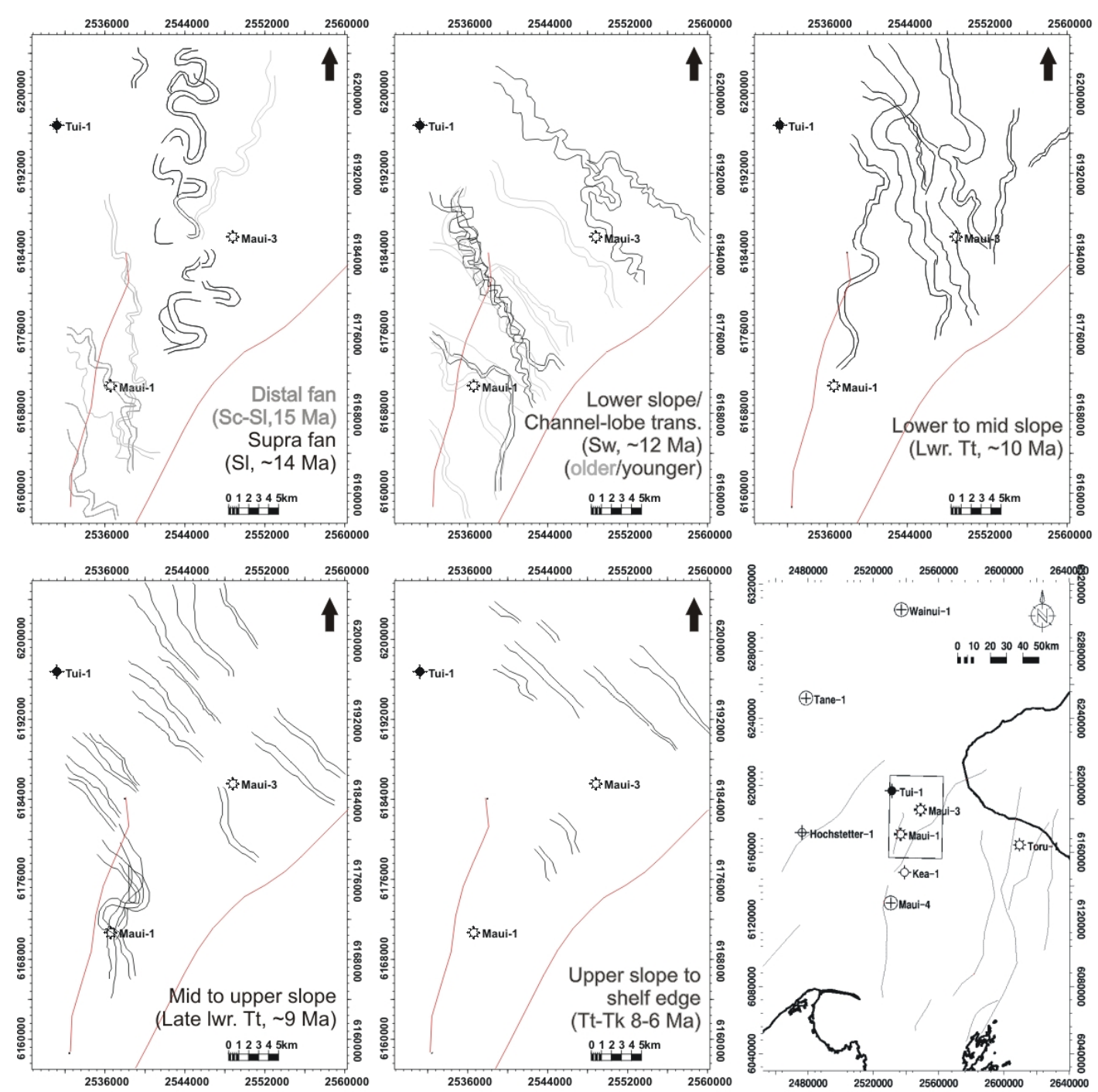

Figure 6.29 Outlines of Miocene channel systems (black and grey lines) mapped in the Maui 3D data set. Fault traces of the Cape Egmont and Whitiki faults are shown as red lines. Locations of wells are shown in black. Location of Maui 3D data set is shown in map on bottom right.

\section{Channel width and sinuosity}

In order to further characterize the observed channel systems with regards to their general environment, the width and sinuosity (line length) of channel segments were measured within Petrel and ArcMap (Hawth's tools), respectively. Sinuosity is quantified as the ratio between the line lengths of mapped channel margins and the channel lengths measured along the sediment transport direction in a straight line.

Channel widths are highly variable in respective depositional environments (Figure 6.30), but generally decrease down-slope from an average of about $580 \mathrm{~m}$ in the upper 
slope to about $370 \mathrm{~m}$ in the area of fan deposition. This trend may be more pronounced in earlier, Middle Miocene systems, which exhibit up to $10 \mathrm{~km}$ wide outer shelf to upper slope canyons (Figure 6.8). The distinct Waiauan channel generations show some slight differentiation in width, whereby the older, straight channels show a tendency to be somewhat narrower than the younger, sinuous channels (Figure 6.30). The average overall channel width shows an average of about $510 \mathrm{~m}$ and a median of about $430 \mathrm{~m}$. These values are considerably higher than the $206 \mathrm{~m}$ or $310 \mathrm{~m}$ average of channel elements observed from global seismic and outcrop examples, respectively (McHargue et al., 2011). The generally higher width values and large spread of measurements may indicate that the data set consists of a mix of master channels and individual channel elements, and data resolution does not always allow for distinguishing the latter. The general decrease of channel width in a down-slope direction is interpreted to be related to the energy of the flux and erosional capacity. While channels become narrower downslope, the meander belt width significantly decreases in more unconfined supra-fan settings $(5 \mathrm{~km})$.

Channel sinuosity increases down-slope, in concert with decreasing gradient. Highest sinuosity values of $>2$ are observed in the supra-fan setting, from which they decrease towards distal fan areas. Greatest variability in sinuosity (standard deviation 0.23) is observed in inferred lower slope or channel-lobe transition areas. The particular example of Waiauan aged lower slope channels shows a correlation between sinuosity and channel fill character proposed that has been documented in other settings (Posamentier \& Walker, 2006). Relatively older, lower-sinuosity channels (average $=1.2$, maximum=1.5) have dominantly high-amplitude fill, whereas younger, higher-sinuosity channels (average $=1.55$, maximum $=1.8$ ) have dominantly low-amplitude fill with highamplitude basal lag deposits. Channel sinuosity in middle slope to shelf environments are shown to be relatively straight, although some sinuosity is observed in structurally controlled areas (Figure 6.30), probably related to the varying gradient of the slope.

The clear negative correlation of inferred slope and sinuosity is commonly observed in channel systems around the world (Weimer, 2000; Weimer \& Slatt, 2004), but is in contrast to observations in fluvial systems (Schumm \& Khan, 1971) and other submarine settings (Wood \& Mize-Spansky, 2009). The observed variability in lower slope to basin floor areas hints at additional factors controlling channel sinuosity in deep-water settings. Additional factors controlling channel sinuosity could be related to the lithology 
(and thus friction) of the substrate into which the channel incises. For example, lower sinuosity, distal fan channel character is marked by high-amplitude fill (possibly sandy lithologies) incising into relatively bland strata (observed fine-grained silts and muds in wells), which is in contrast to observed highly sinuous supra-fan channels that develop wide meander belts through coarse-grained sandy material (Figure 6.12). Similarly, lower slope channels of Waiauan age show older, relatively straight channels developing through fine-grained bathyal mud and more sinuous channels that develop after the deposition of mixed mud-sand sheets (Figure 6.16). The differences in the latter example could also be explained in terms of base-level fluctuations and related energy of sediment flux (e.g., Posamentier et al., 2000). During the early lowstand and initially rapid baselevel fall, relatively straight channels incise into the slope and transport coarse-grained sediment to the basin floor, some of which gets deposited within confines of channel walls in the channel lobe transition zone (see also Mutti \& Normark, 1991). After deposition of fans during maximum lowstand, base-level rise results in a reduction of flow energy and delivery of coarse-grained sediment to the shelf edge. Consequently, more sinuous channel-levee systems develop, where little available sand is deposited at the channel base and fine-grained sedimentation predominates. 

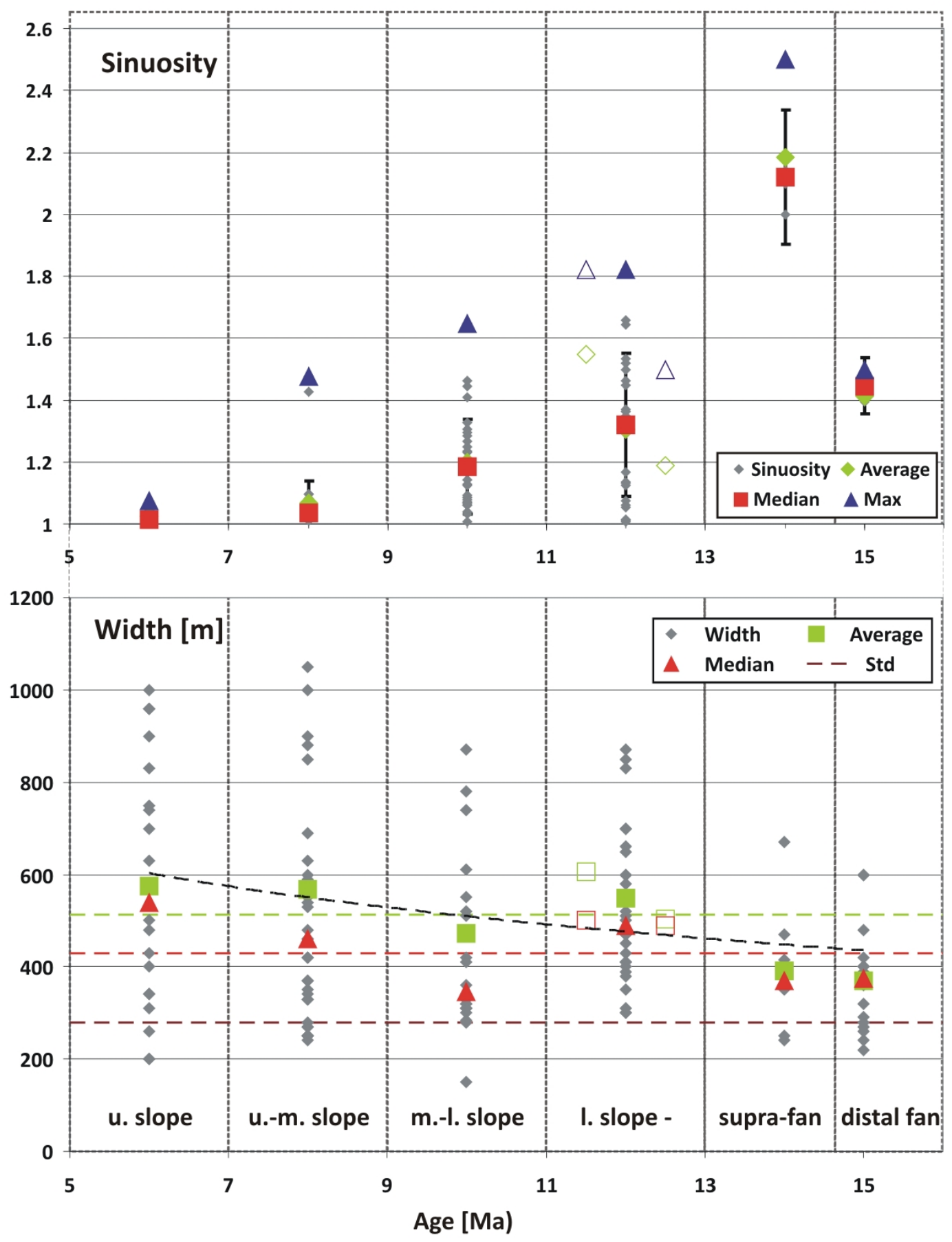

Figure 6.30 Sinuosity (top) and width (bottom) of Miocene channel systems imaged in the Maui 3D survey, and measured on a series of variance attribute maps created from the survey. The sinuosity is calculated as the ratio between total channel length and line length of mapped channel margins. Grey diamonds indicate individual measurements. The average, median and maximum values are calculated for each age group individually. The bottom plot shows the median, average and standard deviation of all measured channels (red, green, and brown dashed lines, respectively) and a polynomial trend is shown as a blacked dashed line. Waiauan (12Ma) channel systems were additionally grouped into older and younger components (open triangles, diamonds and squares) based on their stratigraphic relations, although their absolute age is not differentiated. 
The sedimentary characteristics and depositional elements constrained in the previous chapters were combined to reconstruct the paleogeographic development of the basin through the Miocene (Figure 6.31 to Figure 6.34). Location of the shelf, canyons and channels are shown where observed, while being generally inferred where not mapped in detail. In such areas, landscape geometries are inferred based on depositional elements mapped in their vicinity (e.g., shelf edges usually strike roughly perpendicular to interpreted upper slope channels nearby) and complemented by well and geological mapping where possible (e.g., Rattenbury et al., 1998b; Townsend et al., 2008). The outlines of the inner fan lobes are shown as constrained from amplitude mapping whereas distal fan areas are inferred from correlative downlapping reflector geometries. The intermediate base of slope is distinguished in a general sense from gradients descending further basin-ward into the axis of the NCT, in accordance with discussions of basin morphology above. The paleogeographic maps focus on phases of increased turbidite deposition which may be associated with intermittent relative base-level lowstands.

\section{Altonian}

The upper Altonian map shows the widespread bathyal conditions established during the Oligocene to Early Miocene (Figure 6.31). The distribution of inferred fan facies is interpreted to reflect deposition within a flexural foredeep west of and parallel to the Manaia/Flaxmore and Taranaki fault systems. The orientation of supra-fan channels of Altonian age indicates sediment transport from the east and southeast into this depocentre (Figure 6.9). Additional fan deposits are inferred from downlapping high-amplitude reflectors in the footwall of the Taranaki Fault, although their age association is uncertain. The orientation of the shelf edge and slope is constrained only in a few locations (e.g, Figure 6.8), and may vary locally. Terrestrial facies (coals) evidenced in well Surville-1 (Hayward et al., 1984) indicate the existence of low-lying, sub-aerially exposed areas to the south, while land masses in the southeast are only inferred due to the lack of contemporary sediment preservation. The reconstructed marine embayment and elevated topography in the south could represent a manifestation of active faulting on a southwest stepping thrust front as inferred by previous authors (Thrasher, 1989). 


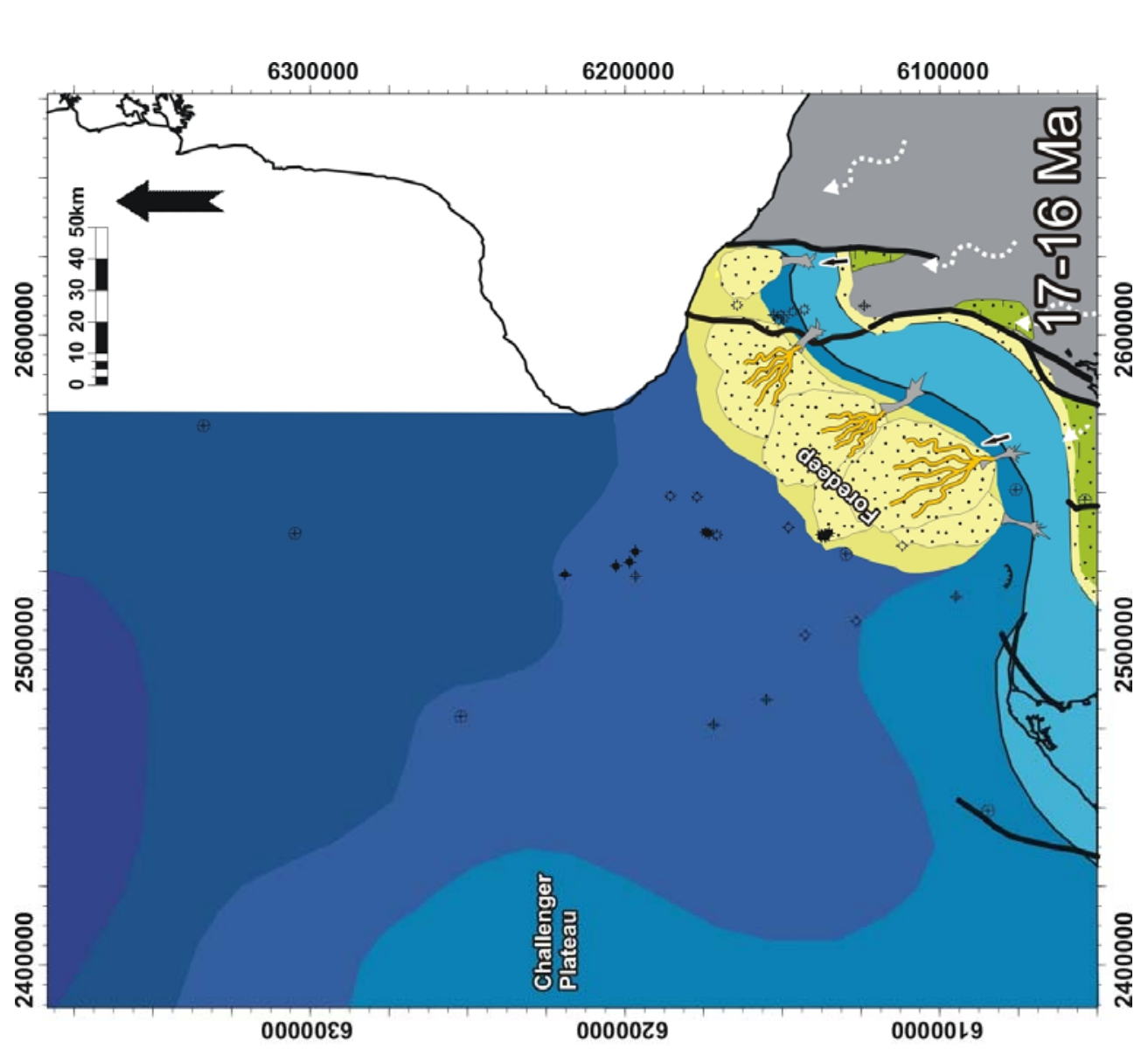

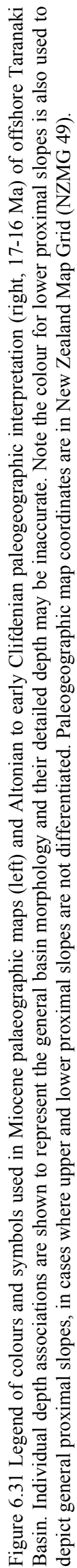

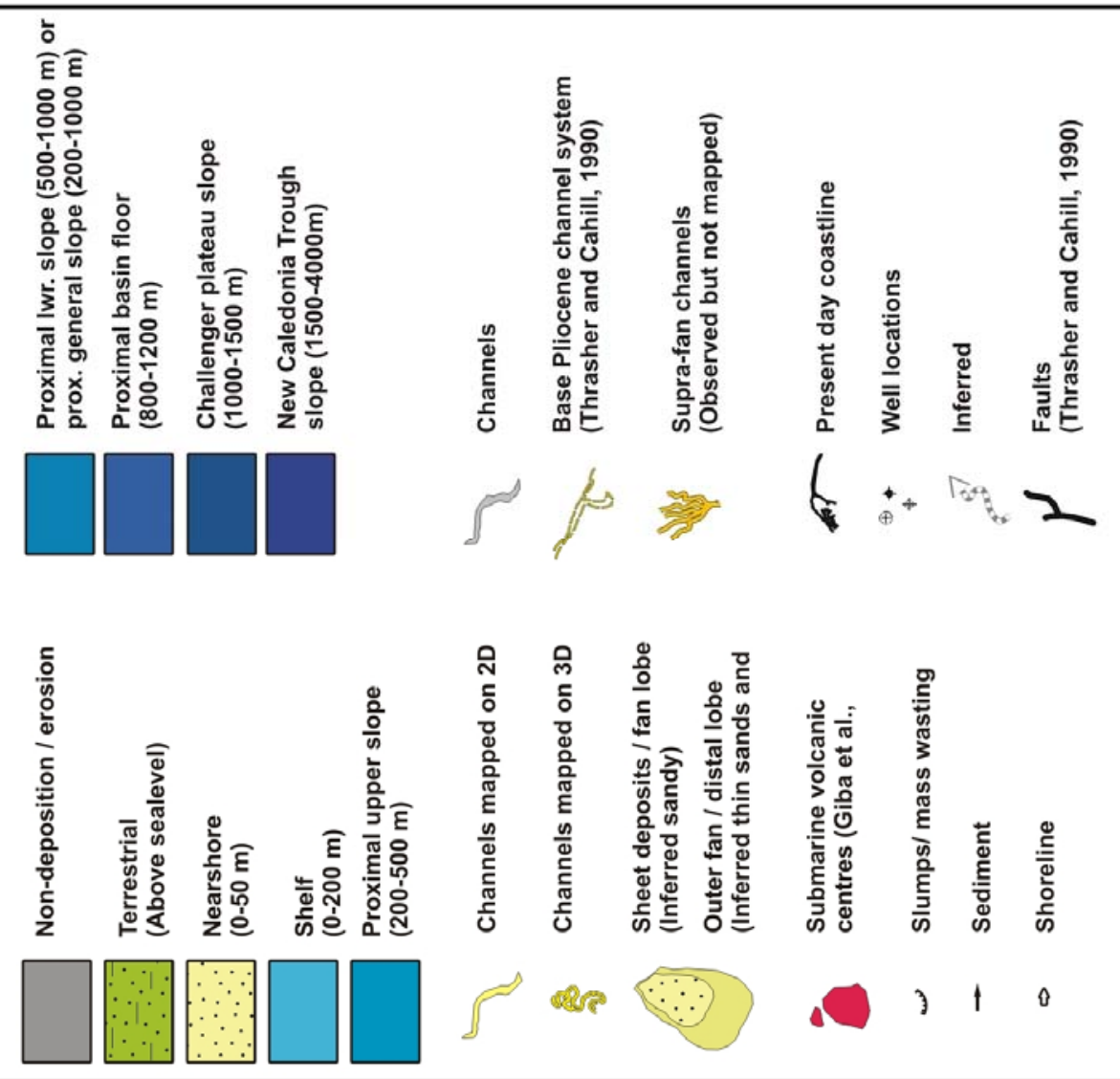




\section{Clifdenian to Lilburnian}

Clifdenian to Lillburnian depositional systems (Figure 6.32) are characterised by two distinct fan depocentres, with sediment input probably from a few separate point sources in the south and east. The separation into distinct depocentres may reflect local depressions adjacent to the Manaia-Flaxmore and Taranaki Fault systems, while Clifdenian deepening in the south (Figure 6.6) may be attributed to flexural subsidence adjacent to faults in the south Tasman Bay (Thrasher, 1989; King \& Thrasher, 1992). The longitudinal character of the $>100 \mathrm{~km}$ long, Lillburnian fan system in the central basin ( see Figure 6.10 and Figure 6.12) may reflect the structural controls of broadening flexural foredeep morphology, localized depressions adjacent to faults in the southwest, and a westward advancing slope in the east. Since fan facies of Clifdenian to Lillburnian age can be correlated across the Cape Egmont Fault in the central basin (Figure 6.11), active faulting was likely limited to shelf and slope areas in the south. The large extent of this sandy system suggests considerable sub-areal exposure and erosion of areas in the southern hinterland, in line with inferred uplift and convergent activity of the western South Island from about $24 \mathrm{Ma}$ (Kamp et al., 1996), and convergent faulting in Tasman Bay during the early Middle Miocene (Thrasher, 1989).

Although the detailed analysis of sediment feeder systems in the south is hampered by erosion and poor data quality, the general sediment transport directions indicate sourcing of sediment from the present-day area of the Moutere depression in the area of Nelson city and possibly areas to the west (Kahurangi Range) as inferred by Lock (1985). The interpreted depocentre of fan deposition (Moki Formation) however is further east than inferred by Lock (1985), and consistent with interpretations from de Bock (1994) shown in Figure 6.5.

Sediment routing from the south is consistent with previous studies (de Bock, 1994; Higgs, 2004) that point to plutonic and subordinate metamorphic sources, derived from erosion of the Seperation Point Granite Massif in Northwest Nelson. Sourcing from the southwest may involve metamorphic sequences of the Buller and Takaka Terrane (see Mortimer et al., 1997). Lithic-rich sandstones from the Kapuni-9 well in the eastern present-day onshore area suggest a dominantly meta-sedimentary source (Higgs, 2004), consistent with the interpretation of a distinct depocentre and routing system (e.g., Murihiku Supergroup). 


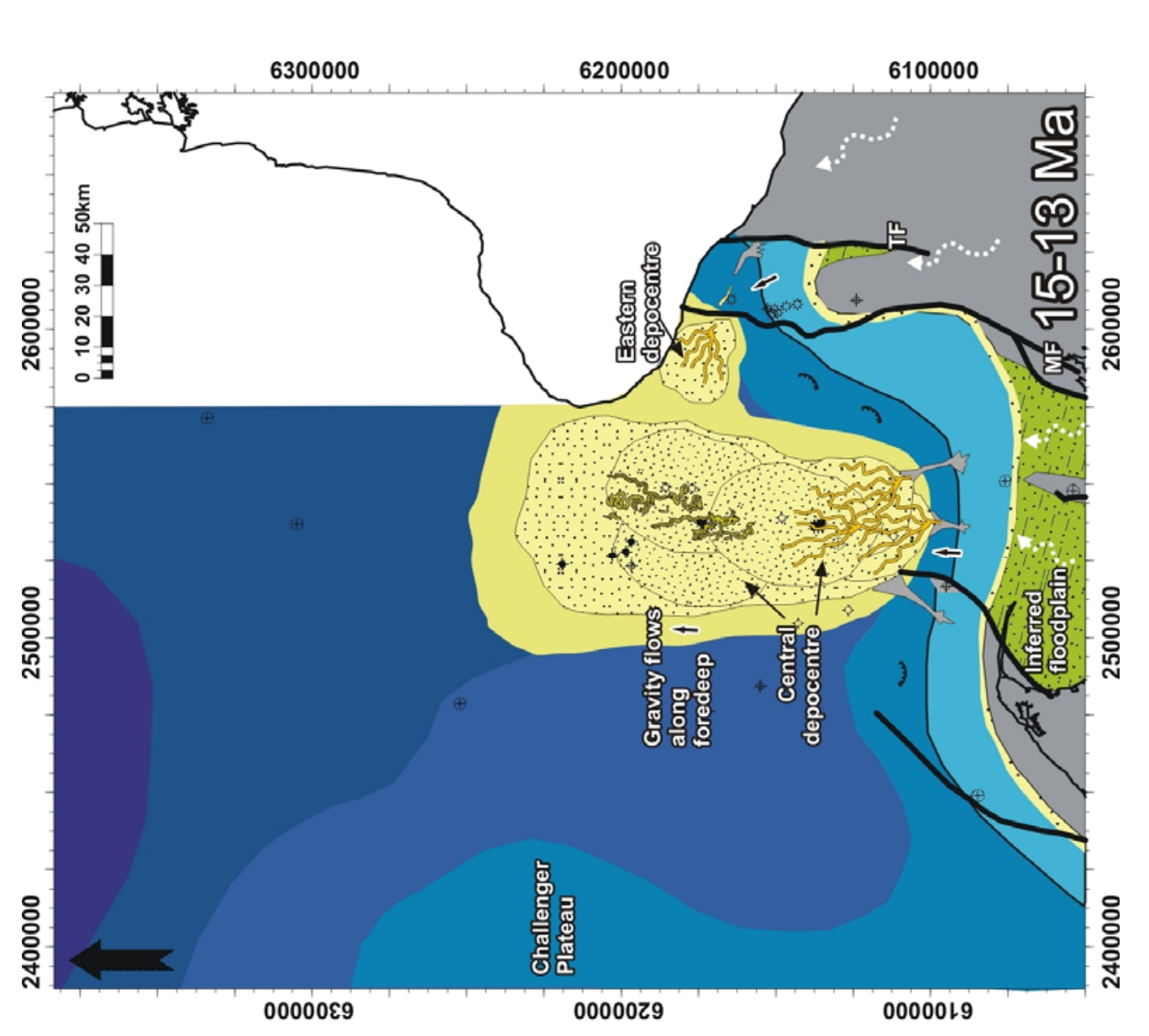

要
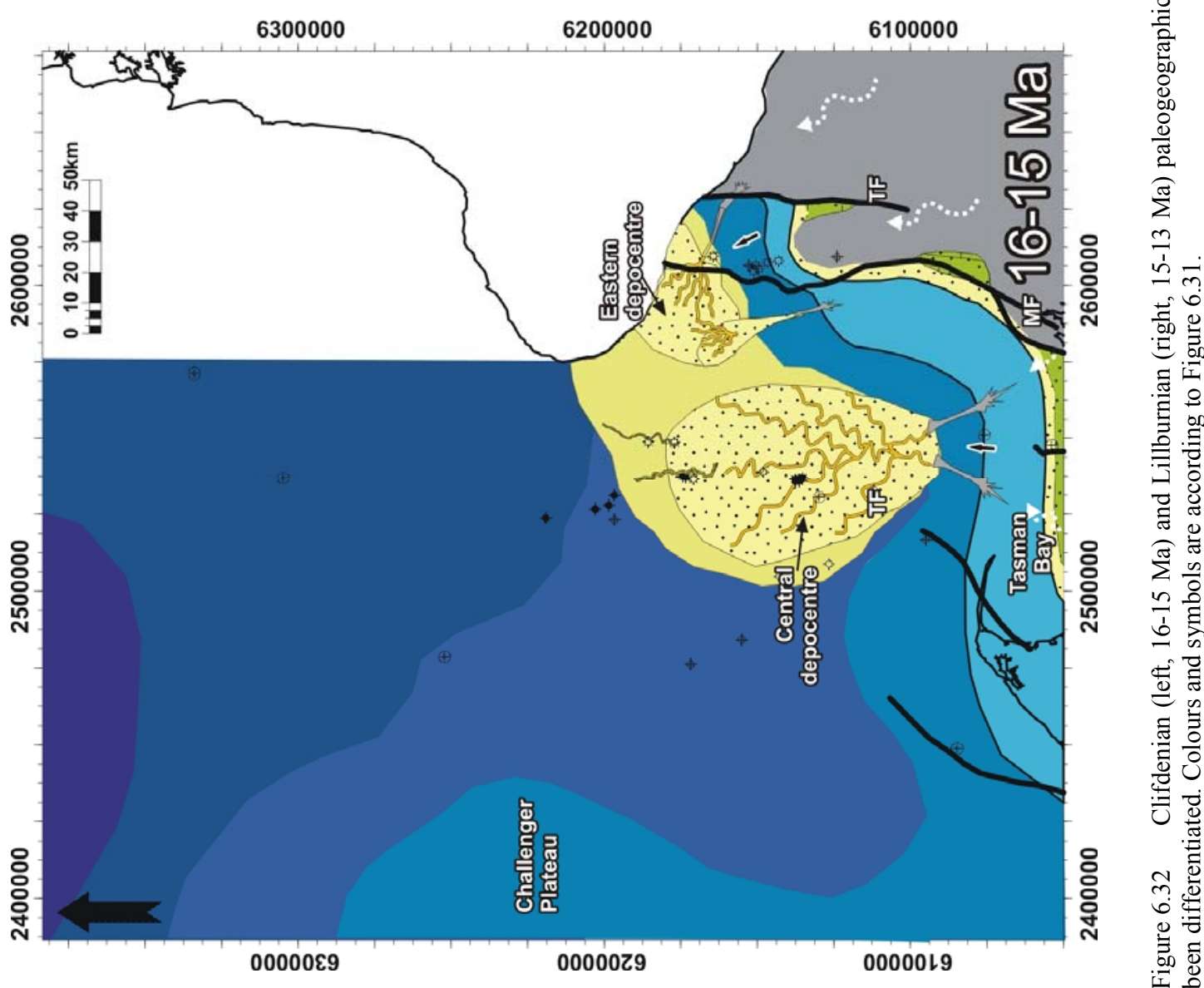


\section{Waiauan}

Incision of large shelf canyon systems and large channel networks indicate increased sediment input into the basin during the Waiauan (Figure 6.33). In the central basin, north-westward-trending channel systems suggest a change in dominant sediment transport direction, possibly related to further uplift of the south-eastern hinterland and development of the slope across the foreland depression. Large drainage systems with a northerly to north-westerly orientation in the western and south-western basin indicate sediment transport from areas in the north-western South Island. Northeast-oriented axial channel systems in the south-western basin suggest increasing sediment sourcing from the western proto-South Island during the late Middle Miocene.

Seismic facies distributions suggest the proximal locus of fan deposition was shifted from the southern Moki-Maari area the Tui area during this time. The distribution of fan inferred fan deposits corroborates a location near the intermediate base of slope as inferred by Bussell (1994). The development of a large axial bypass system suggests that coarse-grained sediment was successively drained from this area and fed fan systems into the head of the NCT. In addition, a channel system mapped on seismic data in the northeastern DTB survey documents the derivation of sediment from the north-eastern basin. This channel represents the only mapped evidence of clastic sediment input from northeastern Taranaki Basin towards the NCT during the Middle Miocene. The subsequent absence of channels in this area is possibly related to the actively-subsiding Northern Graben depression (Giba et al., 2010), which may have started to capture sediment derived from the north-eastern basin during this time. 


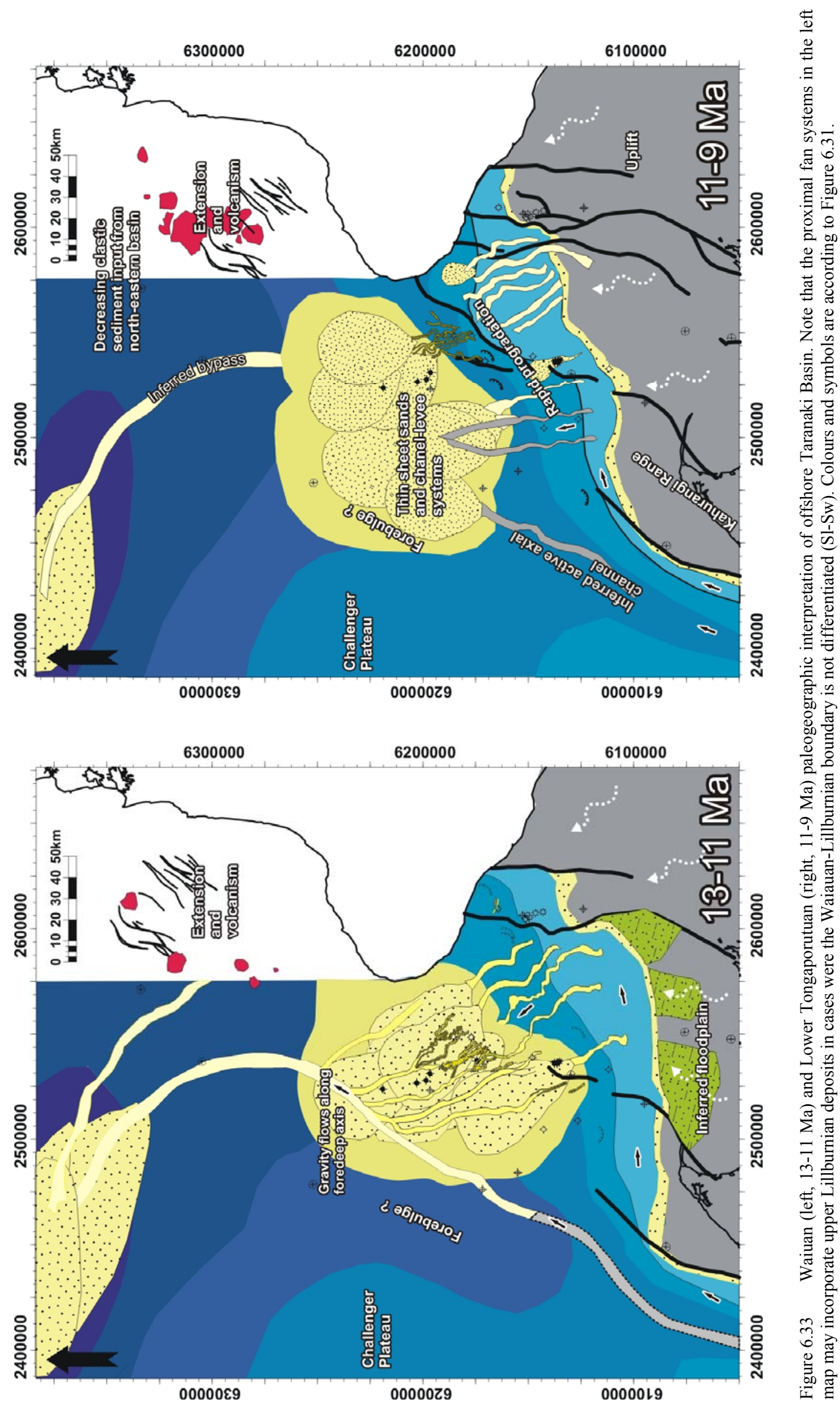




\section{Lower Tongaporutuan}

The lower Tongaporutuan map shows the rapid progradation of the shelf margin across the Eastern Mobile Belt (Figure 6.33). Intense incision and channelling in the shelf and slope indicate significant sediment transport into deep-water areas. The locus of fan deposition migrated westwards towards the Western Platform. Significant bypass beyond this area is considered likely due to the general increase in sediment supply (see Chapter 3 ) and the relatively thin expression of sandy fan lobe facies in Western Platform wells (e.g., $\sim 40 \mathrm{~m}$ in Takapou-1). Continued bypass of sediment into the area of the NCT is inferred through the lower reaches of the Waiauan axial channel system. Fan deposition higher on the slope appears to have been localised to restricted local depressions on the downthrown side of active reverse faults.

\section{Tongaporutuan to Kapitean}

During the upper Tongaporutuan to lower Kapitean (Figure 6.34), shelf margin progradation continued across the central basin and was accompanied by the development of a widespread unconformity in the southern and central basin (see also Vonk \& Kamp, 2008). During maximum regression, the shelf area depicted on the map may have been completely exposed, and the unconformity may have extended onto the present-day onshore area as inferred by Vonk and Kamp (2008). However, seismic data in the area just south of the present-day shoreline shows only subtle angular truncations, indicating that erosion further north may have been minor (Figure 6.17).

Widespread incision of the upper and lower slope during the Late Miocene indicates considerable transport of sediment into deeper water along frequently spaced channel systems. During this time another large axial bypass system is inferred to develop that transported sediment from this area and the western part of the uplifting South Island into the NCT, representing a westward migrated equivalent of the Waiauan axial system. Deposition of sandy facies in the down-dip direction occurred on the south-western side of the NCT in the study area. Occurrence of marl deposits of the Ariki Formation in well Wainui-1 and Ariki-1 (Shell BP Todd Oil Services Ltd., 1981b; 1984) document a decrease of clastic sediment supply to the north-western basin, indicating that sediment derived from east of this area was diverted into the opening Northern Graben. 
The widespread unconformity in the south and high sediment input into the deep basin in the north, as indicated by the large number of intervening slope channels, are together interpreted to be a manifestation of substantial tectonic activity that probably reached its peak during the Late Tongaporutuan. Due to the high density and close spacing of channel incision with relatively thin sands deposited on the intermediate base of slope the depositional system could be described as a line-source fed slope fan apron system in the sense of Reading and Richards (1994). While the inferred widespread exposure basement types suggests a varied extra-basinal provenance of sediments supplied to the basin, turbidite facies are inferred to contain increasing percentages of intra-basinal reworked sediment.

\section{Kapitean to Opoitian}

The latest Miocene to Early Pliocene is marked by a cessation of convergence on structures located south of the present-day Taranaki peninsula and subsidence and inundation of marine strata across the Toru Trough (Figure 6.34). Southward onlapping of shallow marine facies of the Matemateaonga Formation in the east (see also Vonk et al., 2002) was accompanied by decreasing sediment delivery to the western basin with minor outbuilding of the slope and deposition of fine-grained deposits in Western Platform wells. The decrease in sedimentation culminated in the deposition of Ariki Formation marls observed in well Tane-1 and is inferred to be linked to diversion of major drainage systems towards the subsiding Toru Trough and further into the Northern Graben. Sediment derived from the western South Island likely continued to be transported into the NCT through the large axial channel system west of the relatively starved slope. 


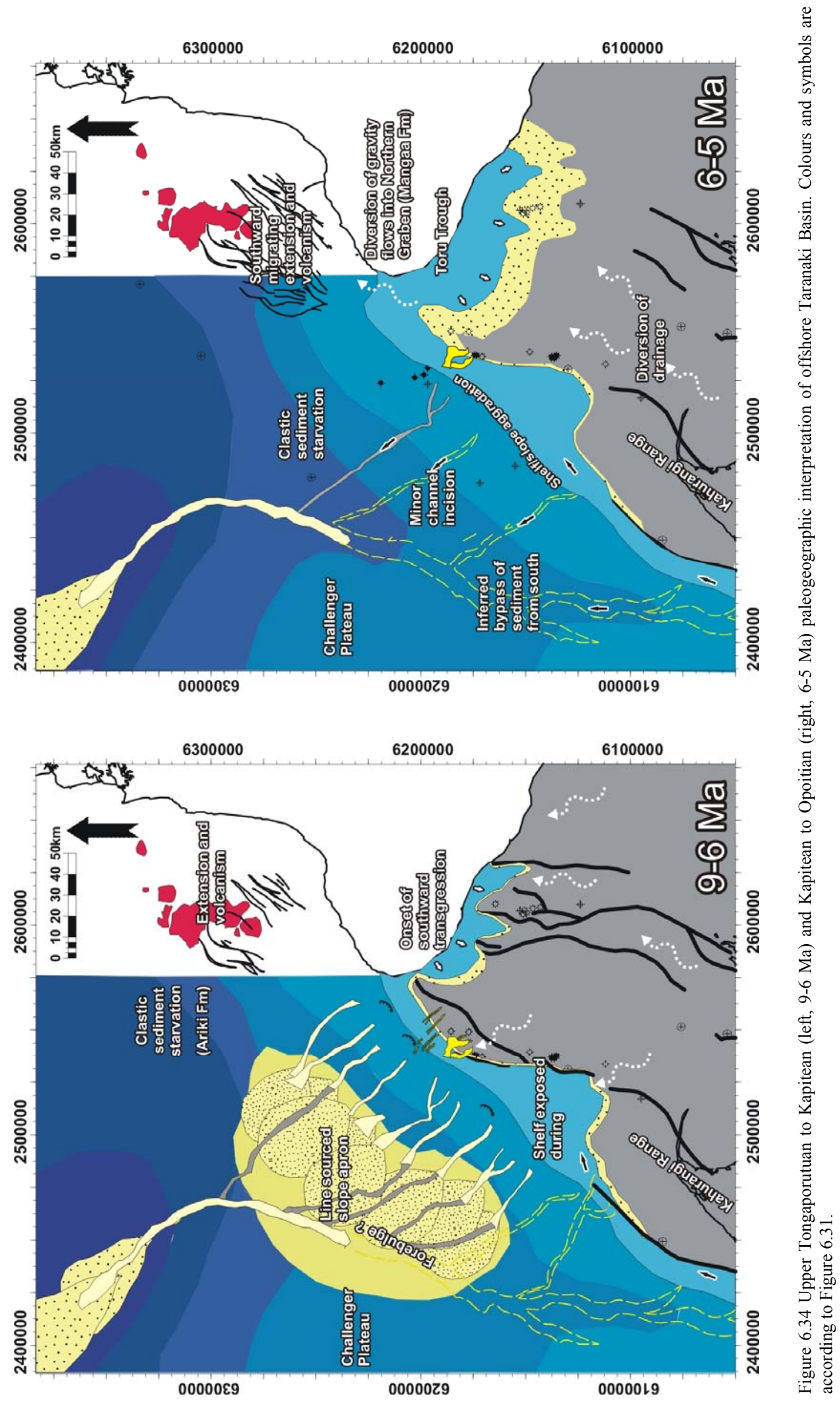




\subsubsection{Analogue depositional systems}

A modern analogue to the inferred basin morphology of Miocene systems and, in particular, Waiauan depositional systems observed in Taranaki Basin can be found within the Westcoast Basin offshore western South Island (Figure 6.35). A physiographic perspective view shows the morphological similarities between the southern part of the Challenger Plateau and the Taranaki Basin on the northern part (Figure 6.35A). The general evolution of this basin from early extension to compression is similar to Taranaki Basin, although foreland basin development was not pronounced until the Late Miocene and rapid sedimentation was delayed until the Pliocene (Sircombe \& Kamp, 1998). Within the Westcoast Basin, the Hokitika and Cook canyons are major sediment conduits between the uplifting Southern Alps, across the southern flanks of the Challenger Plateau and into the deep-water Tasman Sea (Figure 6.35B). This contributory system extends over $700 \mathrm{~km}$ and has a vertical drop of over $3000 \mathrm{~m}$. While the vertical drop of this system is likely to be higher and sediment sources more voluminous, multiple similarities with the Middle Miocene Taranaki Basin example can be established.

A profile across the basin from the shelf to abyssal plains shows how the slope flattens onto and across the Challenger Plateau and increases again towards the edge of this feature (Figure 6.35B). In the upper parts of this system, large canyons incise into the shelf and the upper slope. The canyons are between 6 and 10 kilometres wide and 500$1000 \mathrm{~m}$ deep, leading into 1-3 km wide sinuous upper slope chutes, comparable in size to Late Middle Miocene systems shown in Figure 6.13C. The gradient of the slope decreases from over $1.5^{\circ}$ to less than $0.2^{\circ}$ onto the Challenger Plateau. In this broad area, channels exhibit similar width and sinuosity as Late Middle Miocene systems imaged in the Maui 3D survey (Figure 6.16). About $120 \mathrm{~km}$ down the slope profile, a subtle bulge near the base of intermediate slope is interpreted as the expression of the frontal toe area of older fan lobe deposition (delimited by black dotted line in Figure 6.35B). Channels incise into this bulge and lead towards the southern flank of the Challenger Plateau, where channel widths increase to over $10 \mathrm{~km}$ and merge into a master channel that incises up to $1 \mathrm{~km}$ into the substratum, analogous to Miocene systems in Taranaki Basin (Figure 6.14). This master channel transports sediment over the southern edge of the Challenger Plateau to the base of the slope, in the opposite direction of Miocene Taranaki systems. Beyond this area, mounded structures on the basin floor indicate the deposition 
of fans, while deep-water channel systems transport sediment to the west into abyssal waters.

The varied fan deposition onto an intermediate slope and further bypass into deeper basin areas have been documented in other basins with access to extended slopes. One such example has been described in Messinian to Holocene strata on the Ebro continental margin in the Mediterranean Sea (Nelson, 1990; Nelson \& Maldonado, 1990). In this system, turbidites are deposited on the intermediate base of slope of the Ebro margin before being further bypassed and deflected northwards through the Valencia Valley into the Valencia Fan (Figure 6.35C). The "backstop" and reason for northward diversion into the lower-lying Valencia valley is provided by the opposing slope of the Balearic Islands, which is somewhat analogous to diversion along the Challenger Plateau in Taranaki Basin. 

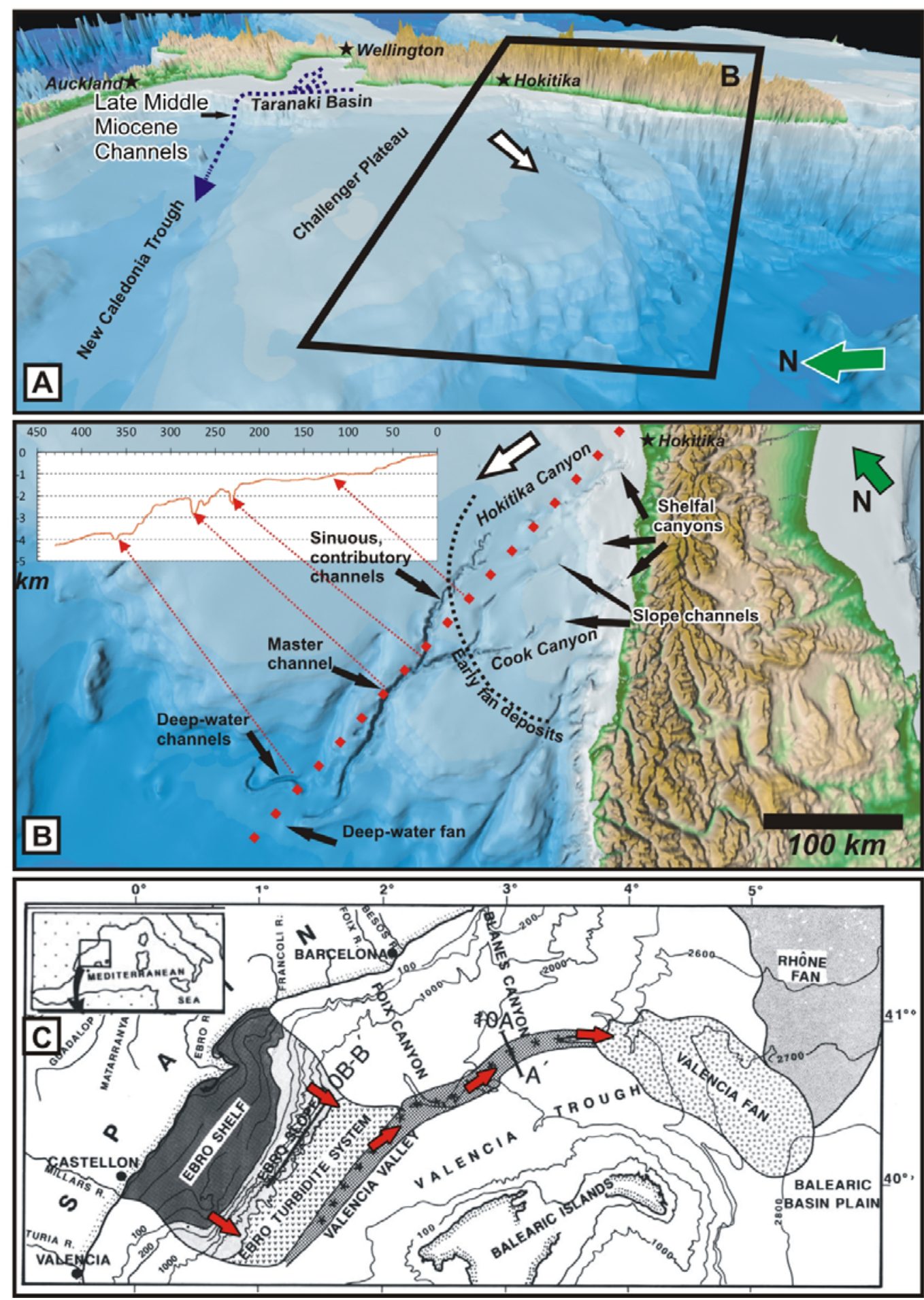

Figure 6.35 A) Physiographic perspective view of western New Zealand (topography and bathymetry, vertical exaggeration=40), showing the present-day offshore basin morphology and approximate pathways of late Middle Miocene channel systems (dashed blue lines). B) Map view of the Hokitika and Cook Canyon systems with bathymetric profile (extracted along the red dashed line). The location of this map is outlined by black rectangle in (A). Depositional components of the channel and canyon system are indicated with black arrows in B). The white arrow indicates the sediment transport direction. Colour scale is shown in Figure 6.28. C) Sedimentary systems and character of turbidite deposition and axial bypass channels of the Ebro margin (after Nelson \& Maldonado, 1990). The red arrows indicate the sediment transport direction and water-depth contours are shown in meters. 


\subsubsection{Fault evolution and structuring of the basin}

Based on the eastward-thickening wedge geometry and sediment thickness variations within this wedge (Figure 6.8 and Chapter 3), the Taranaki and Manaia faults are inferred to have been active since the Oligocene. In addition to successive westward stepping of the deformation front proposed by other studies (Muir et al., 2000) and constrained in Chapter 3 to occur during the Late Miocene, seismic facies and isochron thickness patterns indicate that there was a progressive south-to-north activation of structures in the central basin area. Lillburnian basin-floor fan facies in the central basin do not seem to be affected by active faulting, while convergent structuring of the hinterland is inferred from seismic mapping in Tasman Bay during Altonian and Lilburnian times (Thrasher, 1989). Convergence during the Waiauan across faults in the Maari 3D area has been inferred from seismic isopach maps (Dauzacker et al., 1996) and may be corroborated by oblique channel trajectories in this area (Figure 6.15). Signs for contemporary fault movement on the Cape Egmont Fault further north (Maui area) are lacking and not evidenced until the lower Tongaporutuan (Figure 6.20 and Chapter 3).

This northward propagation of convergent activity documented here is in apparent contrast with the inferred step-wise southward migration of backarc extension since 16$12 \mathrm{Ma}$ (Giba et al., 2010), but could be related to a general intensification of convergence and inversion in the southern and eastern hinterland during the late Middle to Late Miocene (Thrasher, 1989; Kamp \& Green, 1990; Kamp et al., 1996; Nicol et al., 2007). The lack of internal deformation within southward onlapping facies of Late Miocene to Early Pliocene age (Tk-Wo, Matemateaonga Formation in the eastern basin) indicate that the convergence across the Taranaki, Manaia and, Cape Egmont fault had ceased in the area just south of the peninsula before $5 \mathrm{Ma}$, while continuing in the far southern basin to the present-day. An inferred latest Miocene age for the maximum northward unconformity extent is in agreement with reconstructions of Vonk and Kamp (2008), although the culmination of convergent tectonism could be up to about one million years later than inferred by these authors ( $6.5 \mathrm{Ma}$ vs. $7.5 \mathrm{Ma})$. 


\subsubsection{Controls on sedimentation and turbidite deposition}

The character and timing of sedimentation and turbidite deposition is interpreted to mirror the combined effects of extra- and intra-basinal controls such as local and hinterland tectonism and sea-level fluctuations. A comparison of sedimentation patterns, phases of increased turbidite deposition, sea-level fluctuations (Haq et al., 1987), and a selection of local and hinterland tectonism inferred from this and previous studies show the chronologic relation between these factors (Figure 6.36). While there is a certain degree of uncertainty about timing and duration of turbidite deposition due to the limitations and variability in biostratigraphic age estimates across the basin, several phases of increased turbidite occurrence and fan deposition are observed from seismic and well data and inferred to reflect third-order cyclicity (0.5-3 Ma).

During the Early to Middle Miocene, phases of turbidite deposition are more distinct and appear to become more continuous during the Late Miocene, in concert with generally increasing sedimentation rates (Chapter 3, see also King \& Thrasher, 1992). Turbidites of Clifdenian and lower Lillburnian age roughly coincide in time with global sea-level lowstands at 16 and $15 \mathrm{Ma}$ (Haq et al., 1987), although the turbidite deposition lags up to 0.5 million years behind the eustatic minima. A general lowering trend in sea level from the Middle Miocene to the Late Miocene is accompanied by incision of big shelfal canyon systems and sediment bypass into the NCT, while Waiauan and lower Tongaporutuan turbidite deposition may correlate to specific punctuated sea-level falls at 13 and 10.5 Ma. While higher-order cyclicity can be inferred from alternating high and low amplitude packages in the upper slope during the Late Miocene (Figure 6.18 and Figure 6.21), and may indicate relative eustatic base-level modifications of depositional system, the long-lived duration of turbidite deposition is not allow for correlation with any distinct event on the sea-level curve.

Previous studies have pointed out distinct phases of increased convergence and uplift within the eastern and southern Taranaki Basin hinterland (Thrasher, 1989; Kamp \& Green, 1990; Kamp et al., 1996; Field et al., 1997; Kamp, 1999; Nicol et al., 2002; Nicol et al., 2007). These authors have emphasized distinct events in the respective study areas, but the frequent overlap of these events in time indicates a continuum of hinterland tectonism with general increase in deformation through the Miocene (Figure 6.36). Uplift of sediment source areas since 24 Ma can be inferred from inversion of areas in north- 
western South Island (Kamp et al., 1996) and contraction across the eastern North Island (e.g., Field et al., 1997). The early supply of sediment from the hinterland is reflected in the onset of clastic input (Taimana Formation, P60-N10) and early turbidite deposition (Kauri sandstone) into the eastern basin (see also King \& Thrasher, 1996). Early to Middle Miocene turbidite systems are deposited during early phases of local convergence in the southern basin (Thrasher, 1989) and could be tectonically forced. Deposition of Waiauan turbidite sands and development of large bypass channel systems from the western South Island follows the onset of a second inversion phase in the Buller Coal field in that general area (Kamp et al., 1996) and occurs during a phase of increased shortening in the eastern North Island (Field et al., 1997). Superposition of hinterland and local tectonism, including local uplift of structures in the southern basin (Thrasher, 1989; Kamp \& Green, 1990), are paralleled by increasing speed of progradation and protracted turbidite deposition. Decreasing sediment input into the western basin can be related to cessation of convergence across local faults and subsidence of the Toru Trough and Wanganui Basin (Anderton, 1981).

In summary, the increasing dominance of tectonism through the Miocene and uncertainty in timing of turbidite deposition makes a correlation with global sea-level curves highly uncertain. While Middle Miocene turbidite deposition may be related to eustatic sea-level changes, sedimentation appears to be dominantly a response to constant tectonic forcing. Especially during the Late Miocene increase in local tectonism, deep-water sediment transport and turbidite deposition is expected to have occurred throughout and independent of eustatic sea-level cycles, although it may have been accelerated during higher-order lowstands. 


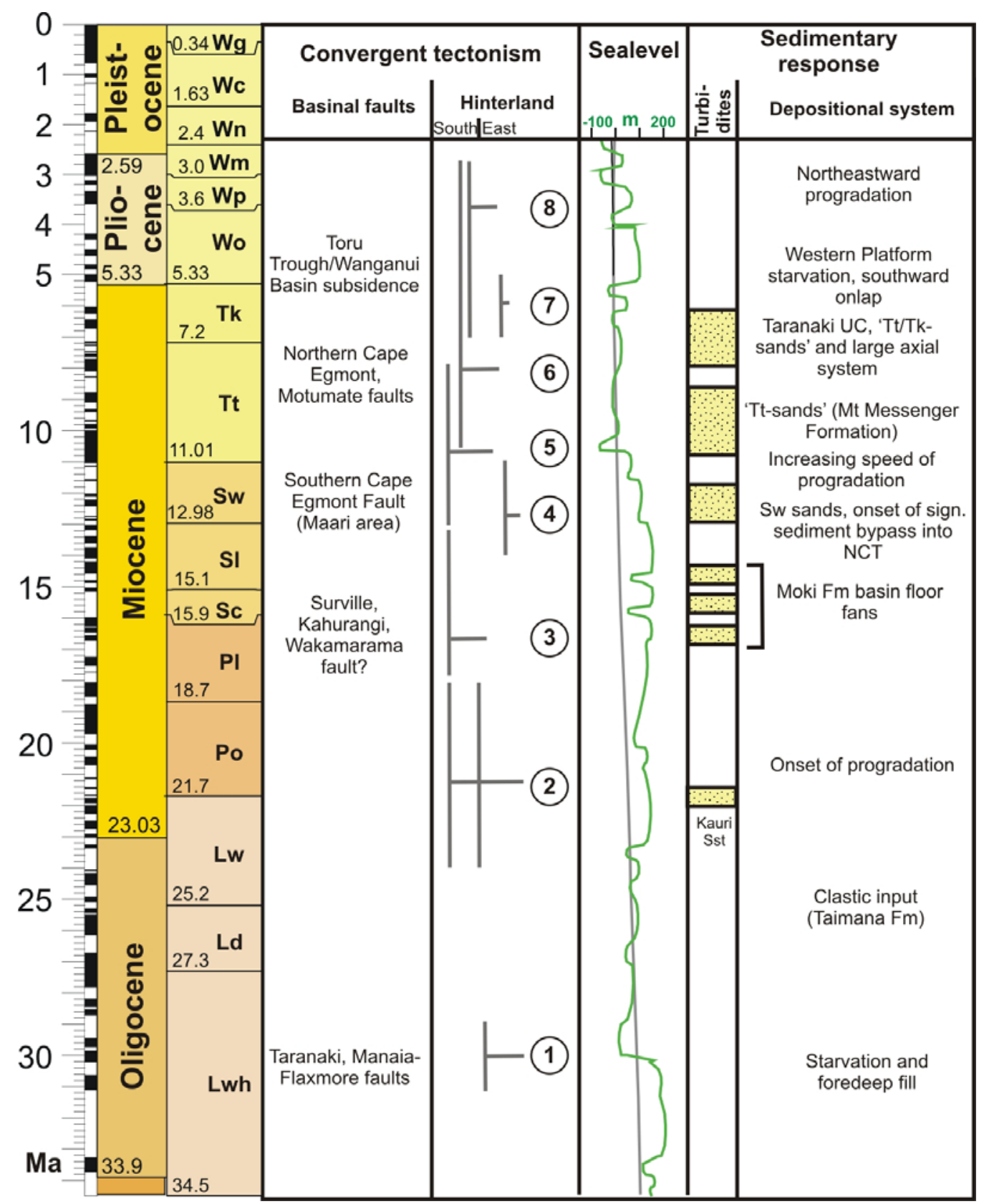

Figure 6.36 Summary panel of structural, eustatic and depositional events. Individual columns in the panel show the international epoch names and boundary ages, New Zealand stage abbreviations, local tectonic events inferred from seismic data, tectonic events in the hinterland from other studies (in eastern and southern hinterland), eustatic sea-level curve (after Haq et al., 1987), inferred turbidite ages and general depositional events are observed from analysis of seismic facies. Tectonic phases are selected from previous studies and numbered as: 1) Pacific plate subduction north of New Zealand (King, 2000b), 2) First phase of Buller coalfield inversion (western South Island, Kamp et al., 1996), onset of rapid Hikurangi subduction (Field et al., 1997; Kamp, 1999), 3) First phase of Tasman Bay convergence (Thrasher, 1989), 4) Increased North Island shortening (Field et al., 1997; Nicol et al., 2007), 5) Second phase of Buller coalfield inversion (Kamp et al., 1996), 6) Exhumation of southern Taranaki Basin (Kamp \& Green, 1990), 7) Rapid shortening on eastern North Island (Field et al., 1997), 8) Second phase of Tasman Bay convergence (Thrasher, 1989). 


\subsubsection{Filling the foreland}

The reconstruction of the Taranaki Miocene depositional systems show the characteristic interplay between convergent tectonism and sedimentation that is encountered in other foreland basins around the globe. The system shows the evolution from underfilled stage with the stratigraphic trinity of carbonates, hemipeliagic mud and flysch sequences (Sinclair, 1997a) to eventual overfilling and development of a widespread sub-aerial unconformity. The rapid subsidence and significant submarine submergence during the early phases of convergence in Taranaki Basin (Hayward \& Wood, 1989; King \& Thrasher, 1992; Stern \& Holt, 1994) make this basin somewhat unusual, as foreland basins are often bordered by shallow cratonic regions on either side (Allen \& Allen, 2005). The basin submergence led to good preservation of sedimentary sequences and a lack of an extensive forebulge unconformity that is commonly observed in other foreland basins (DeCelles \& Giles, 1996). Thick coarse-grained molasse sequences, as documented in the Himalayan and Alpine foreland basins (e.g., Sinclair et al., 1991; Sinclair, 1997b; Willett \& Schlunegger, 2010), are not observed in Taranaki Basin wells, although the advancing topset wedge could be interpreted as marine equivalent to such deposits.

The combination of sediment transport parallel and perpendicular to the deformation front demonstrates the competition between foreland subsidence, intra-basinal syndepositional thrusting, and rapid sedimentation. Segmentation of the foredeep by oblique-to-thrust front structures is inferred to control Early to Middle Miocene depocentres and their feeder systems in areas near the Taranaki and Manaia faults in the eastern basin, a process that is commonly observed in foreland settings (Burbank et al., 1986; Ricci Lucchi, 1990; Covault \& Graham, 2008; Covault et al., 2009). Early Miocene convergence on the Manaia Fault and incipient reverse faulting in the central basin during the Tongaporutuan suggests that the eastern basin areas were successively incorporated into the top of structural wedge and could be interpreted as piggy-back basins. Structured depocentres within the wedge-top may have controlled Early Miocene fan deposition in the footwall of the Taranaki Fault (Figure 6.9) and lower Tongaporutuan slope fan deposition in the Maari area (Figure 6.15B). However depositional systems were always in connection with the distal foredeep, and not 
separated for extended intervals as is observed in other foreland associated piggy-back basins (e.g., Sinclair \& Tomasso, 2002)

The longitudinal character of Lilburnian fan systems (Figure 6.32) indicates the confinement of basin-floor fan systems along the north-south-oriented foredeep. Waiauan fan systems appear to be confined in the west by the eastward dipping foreland basin geometry and topographically higher areas on the Challenger Plateau (Figure 6.33). Westward advance of sediment depocentres and bypass of sediment since the Waiauan shows that this confinement to the foredeep is outpaced by increasing sedimentation (see also Chapter 3), indicating the transition from an underfilled to an overfilled foreland basin (Sinclair, 1997a). This change in basin character differs from examples of the Alpine Molasse Foreland Basin in Austria (Puchkirchen Formation, De Ruig \& Hubbard, 2006), where sand deposition is primarily restricted to the foredeep.

Since the Late Middle Miocene, deep-water sedimentation style was separated into intermediate base of slope deposition in proximal Taranaki and sediment bypass into the lower-lying Deepwater Taranaki Basin via large channel or canyon systems. The combined attribute maps across the Taranaki Basin show the complete extent of axial foreland basin drainage systems that have previously been documented in outcrop (e.g., Mutti et al., 2009) or only partially mapped on seismic data (De Ruig \& Hubbard, 2006). The decrease in net sand in the Late Miocene turbidite systems, despite the general increase in sedimentation rates, may be partly attributed to the increasing bypass of coarse-grained material beyond the intermediate basin floor to the lower depocentre in the NCT.

Turbidite deposition within this foreland basin sequence can be summarized into five stages: 1) axial and transverse deposition into a broad foredeep (Early Miocene), 2) compartmentalization of fault related depocentres and development of a longitudinal fan system within the foredeep confines (Early Middle Miocene), 3) bypass of sediment into the lower-lying basin (NCT, late Middle Miocene), 4) shelf margin progradation across the foredeep with decreasing slope fan deposition near the intermediate base of slope, accompanied by further sediment bypass into the lower basin, and 5) blanketing of the intermediate base of slope by the prograding shelf margin complex. 


\subsubsection{Implications for hydrocarbon prospectivity}

\section{Provenance}

The basement structure of Taranaki Basin can be broadly subdivided into accreted terranes with NNW-SSE boundaries (Mortimer et al., 1997). Reservoir quality studies of the Moki Formation suggest that the variable basement provenances in the Taranaki Basin hinterland have significant impact on the reservoir properties of sedimentary facies (Higgs, 2004). Sediment sourced from plutonic rocks of the Separation Point granite suite in Northwest Nelson south of the basin have shown significantly better reservoir properties than rocks sourced from Median Tectonic Zone or Eastern Province metasediments located further east. Due to the delineation of feeder systems, Early to early Middle Miocene fan systems (Altonian-Lillburnian) can be associated with discrete easterly and southerly source areas (Figure 6.33), allowing inferences about their likely dominant provenance and therefore reservoir quality.

The separation of provenances of Waiauan and later systems is expected to be less distinct than Clifdenian and Lilburnian fans, as a more varied suite of basement areas was sub-aerially exposed and the general sediment transport in the proximal basin occurred at high angles to the structural grain. The north-westward sediment transport directions in the south-eastern basin and substantial topography observed under the present-day Wanganui Basin (Nicol, 2011) could indicate uplift of this area and a consequently increasing proportion of schistose rocks of the Haast Schist (Mortimer et al., 1997), which may in turn have adversely affected the reservoir quality. Similar regional changes in source area have been shown in other deep-water basins to adversely impact reservoir quality. In the North Sea, uplift of the dominantly schistose Norwegian mainland during early opening of the Atlantic has led to the deposition of mostly muddy sediment and poor Tertiary prospectivity (Richards et al., 1998).

With continued inversion of the basin, an increasing amount of previously deposited sediment was reworked into the sedimentary system, contributing to the fine-grained character and good sorting of Late Miocene slope to basin floor sequences (Browne et $a l ., 2005 b)$. Despite a general dominance of fine-grained facies in upper slope to shelf environments, sandstones of Lillburnian to Waiauan age observed in well Motueka-1 show that coarse-grained sediment was deposited in the shelf area and was available for 
re-deposition into the basin. While north-westward sediment transport directions may suggest an ongoing proportion of meta-sedimentary provenance in the Late Miocene, the large channel system emanating from the western part of the proto-South Island also suggests maintenance of sourcing from Paleozoic granitoids of the Western Province (Mortimer et al., 1997).

\section{Reservoir quality of turbidite deposits}

The reconstruction of depositional systems suggests that the number of sediment entry points increased through the Miocene. The continental margin developed from fan systems fed by single or few point sources in the Clifdenian and Lillburnian, to multiple large canyon feeder systems during the Waiauan, and to a line source with smaller canyons in the Tongaporutuan.

The combined development of depositional character and lithologic content can be classified as a mixed sand-mud submarine fan to ramp or slope apron setting sensu Reading and Richards (1994). Analysis of worldwide shelf margins suggests that reservoir geometry tends to be related to the number of feeder systems and that linesourced slope aprons show greater variability in terms of internal architecture and organisation (Richards \& Bowman, 1998; Richards et al., 1998). The reservoir quality and connectivity of facies deposited near the base of the intermediate slope is thus expected to decrease towards the Late Miocene. The architecture of Waiauan and later turbidites with their combined lobe-channel-levee architecture (Figure 6.18B) is interpreted to be analogous to Early Tongaporutuan slope fan facies observed in outcrop along the northern Taranaki coast (King et al., 1994b; Browne \& Slatt, 2002). These outcrop facies have been divided into (1) channel fill (siltstone and inter-bedded sandstone and siltstone), (2) proximal channel-levee and overbank units (alternating sandstones and siltstones) and 3) distal channel-levee and overbank units (siltstone and ripple-laminated sandstone), in which the best reservoir quality is predicted for the latter two facies (Browne et al., 2000; Browne \& Slatt, 2002). The decrease in connectivity of sand bodies in Late Miocene turbidite deposits (slope fans) compared to the basin-floor fans of the Moki Formation may have increased the potential for stratigraphic trapping.

While the quality of sandy reservoir facies deposited near the intermediate base of slope is likely to decrease, sorting of coarse-grained sediment may be improved in fan systems 
in the NCT, due to progressive loss of fine-grained sediment beyond the channel walls (flow-stripping, e.g., Posamentier \& Kolla, 2003).

\subsection{SUMMARY AND CONCLUSIONS}

The analysis of seismic facies and seismic attributes has allowed the reconstruction of the continental margin development and characterization of depositional systems through the Miocene, showing the varying controls of foreland basin subsidence, hinterland uplift, and rapid sedimentation.

Down-slope sediment supply to deep-water environments changed from initially a few sources to an increasing number of large canyon systems, and then to a line source of smaller, but closely-spaced contributory channels in the Late Miocene. Since the Late Middle Miocene, thin sheet sands were deposited near the intermediate base of slope located on the Western Platform, while large deep-water channel systems transported coarse-grained sediment from the proximal Taranaki Basin to fan systems in the New Caledonia Trough. This study has imaged these systems over a distance of more than 500 $\mathrm{km}$ and shows that channels previously imaged in the central area (Bussell, 1994) represent small parts of a much larger network. The channel networks appear to be collectively guided by the advancing sedimentary slope and the morphologies of the eastward dipping foreland basin, the Challenger Plateau, and the New Caledonia Trough, and are analogous to channel systems linking the slope of the Ebro Basin to the Valencia Fan (Nelson \& Maldonado, 1990).

While channel azimuths in the deep-water area indicate similar bypass from proximal areas of the northern Taranaki Basin in the late Middle Miocene, sediment supply from these areas was cut off due to subsidence of the Northern Graben during the Late Miocene. During the latest Miocene to early Pliocene, a decrease in clastic sediment input to the Western Platform margin marks the combined effects of southward opening of the Northern Graben (Giba et al., 2010) and subsidence of the Toru Trough and adjacent Wanganui Basin (Anderton, 1981).

Sediment isochron thicknesses, axial channel directions, and decompacted foreset heights suggest that the evolving paleo-basin morphology had significant impact on sediment dispersal characteristics. Detailed channel characteristics mapped on 3D data suggest that 
the slope gradient exerts the primary control on channel sinuosity, while factors such as underlying substrate and relative base level may be of additional importance.

Separate Middle Miocene sediment depocentres observed in the central and eastern basin explain the differences in provenance observed in the Moki Formation (Higgs, 2004). During the late Middle to Late Miocene, the uplift of basement terranes in the hinterland and exposure of previously deposited sediment is likely to have resulted in a more varied provenance of turbidite deposits. Despite a likely high proportion of meta-sedimentary and metamorphic components, derivation of sediment from the western South Island indicates that input from granitic sources was maintained through the Miocene.

Seismic facies and well data do not indicate the presence of thick Late Miocene aged turbidite sheet sands, but slope fans, channel levee systems, and axial bypass systems may contain considerable proportions of sand. Lateral accretion and aggradation of channel-levee systems in the slope and within axial channels suggest the compartmentalisation of sand bodies, which may increase the potential for stratigraphic trapping. Substantial sediment volumes are expected to have been transported in axial channel systems since the Middle Miocene, indicating that a significant proportion of coarse-grained sediment was bypassed to deep-water fans. Thus, the best late Middle to Late Miocene reservoir facies may be located in the southern New Caledonia Trough, in present-day water depth of more than $1.5 \mathrm{~km}$. 



\section{CHAPTER 7 TECTONIC AND EUSTATIC INFLUENCES ON SEDIMENT DEPOSITION IN A HIGH SEDIMENT FLUX BACKARC ENVIRONMENT - TARANAKI BASIN DURING THE PLIOCENE-PLEISTOCENE}

\subsection{INTRODUCTION}

Taranaki Basin's extensive shelf (Figure 7.1), which occupies an area of approximately $50,000 \mathrm{~km}^{2}$, is a direct result of enormous sediment volumes deposited in response to New Zealand's uplifting North and South Island since the Miocene (Adams, 1980; Kamp \& Green, 1990; Kamp et al., 2004; Pulford \& Stern, 2004; Wood \& Stagpoole, 2007). During the Plio-Pleistocene sedimentation across this vast area developed in discrete depocentres in two directions through north-westward outbuilding of the shelf in the west (Giant Foresets Formation, Shell BP Todd Oil Services Ltd., 1976; Beggs, 1990; King \& Thrasher, 1996) and subsidence of the eastern Taranaki (Toru Trough) and Wanganui basins in the east (Anderton, 1981; Stern et al., 1992; King \& Thrasher, 1996; Kamp et al., 2004; Proust et al., 2005). The latter subsidence resulted in the spread of sedimentary successions beyond the previous Taranaki Basin boundary towards the east into the Wanganui Basin, such that the Late Neogene history of the two basins is similar (Kamp et al., 2004).

Crustal deformation in eastern Taranaki and Wanganui Basin is intimately related with the dynamics of Australia-Pacific subduction, which shows a rapid change from extensional backarc tectonism ("Mariana-type") in the northern to mild compression ("Chile-type") in the south-western North Island (Walcott, 1987; Wallace et al., 2004; Stern et al., 2006). A north- to south progression of compressive to extensional crustal faulting, subsidence and uplift events has been documented along the Western North Island through geologic time (King \& Thrasher, 1992; Stern et al., 1992; Kamp, 1999; Stern et al., 2006; Giba et al., 2010). The stratigraphic record in southern offshore Taranaki Basin falls within this trend and provides an opportunity to study the sequential evolution of these backarc processes and their influences on the sedimentary system. 
Plio-Pleistocene sedimentary sequences, which were deposited as a response to pervasive basin subsidence in eastern Taranaki and Wanganui Basin, have been described as one of the most complete shallow marine stratigraphic records of Late Neogene climate and sealevel change (Abbott \& Carter, 1994; Naish \& Kamp, 1997; Vonk et al., 2002; Naish \& Wilson, 2009). Late stage uplift of the North Island (Kamp et al., 2004; Pulford \& Stern, 2004) has facilitated detailed studies of latest Miocene to Recent outcrop geology, but seismic stratigraphy and sequence stratigraphic investigations of the offshore sedimentary record have been limited to few studies that date back more than 15 years (Thrasher, 1988; Beggs, 1990; Ogilvie, 1993; Nodder, 1995). These sedimentary successions are of considerable economic importance as they contain potential shallow hydrocarbon reservoir targets and their deposition as overburden has influenced the timing of hydrocarbon maturation and migration in underlying strata (Armstrong et al., 1996; King \& Thrasher, 1996; McAlpine, 1999; McAlpine, 2000; Vonk et al., 2002).

This chapter investigates the latest Miocene to Recent development of Taranaki Basin and discusses the relative influences of tectonism and eustasy on the development of depositional systems. Through the combined analysis of updated biostratigraphy, tectonic subsidence, and seismic stratigraphy, this study aims to improve the understanding of the character of north-to-south successive depocentre formation in western New Zealand (Stern et al., 1992; Kamp, 1999; Pulford \& Stern, 2004; Stern et al., 2006), and provide further constraints for their geodynamic driving mechanisms.

The depositional development and sequence stratigraphic architecture of the western shelf is investigated to further constrain the signals of eustatic sea-level fluctuations in the offshore area. Information about subsidence, facies evolution, and sediment dispersal are combined to provide a paleogeographic synthesis of the basin evolution since $5 \mathrm{Ma}$.

The study provides evidence that the formation of the South Taranaki Bight cannot be explained by mere shallow crustal backarc extension, but points to the importance of whole-lithosphere dynamics during backarc evolution. It is contended that lithosphericscale depressions and extensional faulting exerted a major control on sediment dispersal within the basin, while higher frequency variations in sedimentation patterns are controlled by Milankovich-scale glacio-eustasy. 


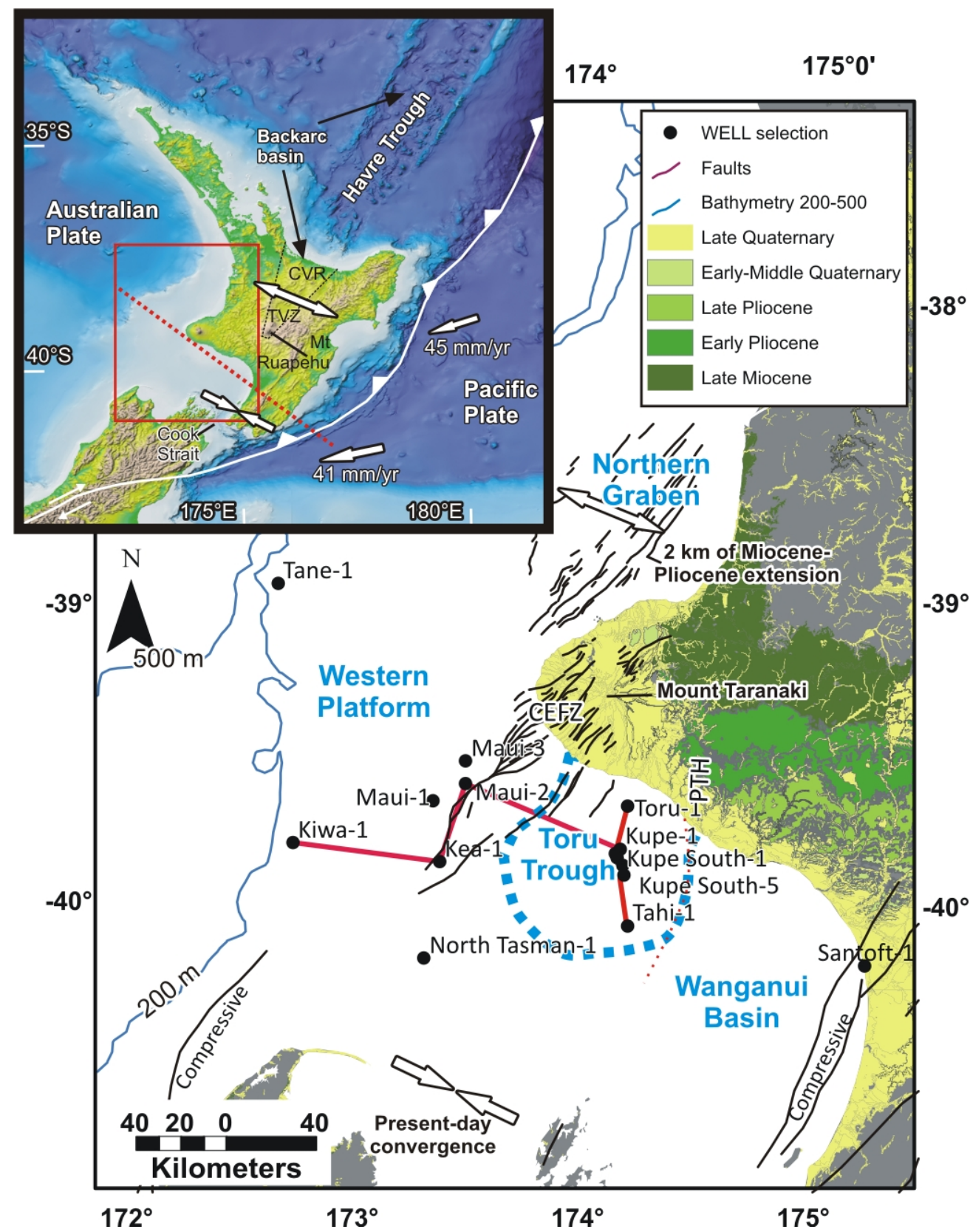

Figure 7.1 Overview map of Taranaki and Wanganui basins showing the study area and structural provinces discussed in this chapter. Selected wells discussed in this chapter are shown as black dots. Major Faults inferred to be active during the latest Miocene-to Pleistocene period are shown as black lines (after Thrasher and Cahill, 1990; Giba et al., 2010; Uruski, 1998). The distribution of Late Miocene to Quaternary onshore outcrop geology is shown in green to yellow, respectively (Rattenbury et al., 1998a; Townsend et al., 2008). The $200 \mathrm{~m}$ and $500 \mathrm{~m}$ bathymetry contour are shown to display the width of the present-day continental shelf. Red lines show the locations of well correlation panels shown in Figure 7.3. The Cape Egmont Fault Zone and the Patea-Tongaporutu high are annotated as CEFZ and PTH, respectively. The inset shows the location of the main map (red rectangle) within greater New Zealand and illustrates the location of the study area with respect to the modern Australia-Pacific plate boundary (white line). Relative Australia-Pacific convergence (after Beavan et al., 2002) and general areas of hinterland extension and compression are indicated by the white arrows. Areas of active arc extension are the Havre Trough, the Central Volcanic Region (CVR), and the Taupo Volcanic Zone (TVZ). The red dashed line shows the location of the profile in Figure 7.21 . 


\subsection{GEOLOGIC BACKGROUND}

\subsubsection{Structural setting and development}

The Plio-Pleistocene structural development of the eastern Taranaki Basin (Toru Trough) and Wanganui Basin is characterized by subsidence, marine flooding and ultimate formation of the Cook Strait (Figure 7.1). The subsidence is expressed as a series of roughly circular depocentres, which migrated eastward and southward from eastern Taranaki Basin to the southern Wanganui Basin from the latest Miocene-Early Pliocene to the present (Anderton, 1981). Plio-Pleistocene sub-basins in Wanganui Basin have been considered to be part of a 100-200 km wide locus of subsidence which has migrated progressively southward across the western part of the North Island at rates of $10 \mathrm{~mm} / \mathrm{my}$ since the onset of Australia-Pacific plate subduction in the Eocene-Oligocene (Stern et al., 1992; Kamp, 1999). Following subsidence of these basins, uplift of the North Island by up to $2 \mathrm{~km}$ since $5 \mathrm{Ma}$ tilted the older geology of the contiguous eastern Taranaki and Wanganui basins and induced a southwest dip of $2-4^{\circ}$ of the strata (King \& Thrasher, 1996; Kamp et al., 2004; Pulford \& Stern, 2004).

While the western Taranaki Basin remained tectonically quiescent during the Neogene, faulting patterns in the eastern basin represent the distal influence of Australia-Pacific plate boundary deformation. Following widespread convergence and foreland basin subsidence during the Oligocene and Miocene (King \& Thrasher, 1992; Holt \& Stern, 1994), northern Taranaki Basin recorded about $2 \mathrm{~km}$ of horizontal extension during the Late Miocene to Early Pliocene in the Northern Graben (King \& Thrasher, 1996; Giba et al., 2010). During the Pliocene the locus of extension is migrated southwards into South Taranaki Bight and is expressed as a return to normal fault displacement on the Cape Egmont and adjacent faults (see Chapter 3; King \& Thrasher, 1996; Funnell et al., 2004; Giba et al., 2010). Faulting patterns indicate that the southern Taranaki Basin and eastern parts of Wanganui Basin have remained under compression during this time (Bishop \& Buchanan, 1995; King \& Thrasher, 1996; Lamarche et al., 2005) and GPS data suggests presently mild convergence at shortening rates of about $4 \mathrm{~mm} / \mathrm{yr}$ (Wallace et al., 2004).

The southward propagation of extensional activity has been interpreted as a response to clock-wise rotation and southward migration of the Hikurangi subduction zone, possibly 
related to successive slab roll-back of the subducted Pacific plate (King \& Thrasher, 1992; 1996; Wallace et al., 2004; Giba et al., 2010). Although south-eastern Taranaki and Wanganui Basin have been variably referred to as backarc basins in the literature, there is no volcanic activity to their east, and the southernmost volcanic expression roughly coincides with the latitude of Mount Taranaki and Mount Ruapehu to the north (Figure 7.1). Moreover, geophysical characteristics of Wanganui Basin suggest a deviation from usual backarc basin formation via extensional faulting. These characteristics include a maximum crustal thickness of $40 \mathrm{~km}$ (Stern \& Davey, 1990), a $150 \mathrm{mGal}$ Bouguer/free-air/isostatic gravity low (Reilly, 1972), and relatively minor faulting (Anderton, 1981; Lamarche et al., 2005). Consequently, subsidence of the basin has been related to distributed flexure induced by high frictional shear between the subducted Pacific plate and the overriding Australian plate (Stern et al., 1992) or the early phases of detachment (Rayleigh-Taylor instability after Houseman \& Molnar, 1997) of the lithosphere, which has been thickened during previous convergence (Stern et al., 2006). Subsequent uplift of previous North Island depocentres has been attributed to asthenospheric upwelling, possibly related to slab roll-back or the catastrophic gravitational removal of the lithospheric mantle lid (Pulford \& Stern, 2004; Stern et al., 2006).

\subsubsection{Stratigraphy and depositional patterns}

Rapid sediment deposition resulted in a stratigraphic succession that is $>2 \mathrm{~km}$ thick on the Western Platform (Beggs, 1990) and up to $4 \mathrm{~km}$ east in the southern Wanganui Basin (Anderton, 1981). However, this period is represented by only a thin veneer of sediments in the southern Taranaki Basin (Hayward et al., 1984; Hayward \& Wood, 1989; King \& Thrasher, 1996).

Plio-Pleistocene strata in Taranaki Basin (Figure 7.2) have been combined into the Rotokare Group (King \& Robinson, 1988), which consists of the Matemateaonga-, Tangahoe, Mangaa and Giant Foresets formations (or its proximal equivalents, King \& Thrasher, 1996). The earliest sedimentary strata of the group is the latest Miocene to Early Pliocene (Tk-Wo) Matemateaonga Formation (Arnold, 1957) and seismic data indicate that correlative strata mark the base of the sedimentary succession in the adjacent Wanganui Basin (Uruski, 1998; Proust et al., 2005). In outcrop, this formation is characterised by cyclical repetition of coquina shell bed, siltstones, sandstones and minor 
coals, deposited in shallow shelfal to terrestrial environments (Vonk et al., 2002), with overall southward transgressive onlap (King \& Thrasher, 1996). Although thicknesses of $>1.4 \mathrm{~km}$ indicate substantial subsidence of the basin during the time of deposition, cyclical superposition of $6^{\text {th }}$-order glacio-eustatic sea-level oscillations within an overall shallow marine sedimentary record (Vonk et al., 2002) indicate that subsidence was roughly in balance with sediment deposition. On the Western Platform the MiocenePliocene boundary corresponds to a condensed interval of deep-water marls of the Ariki Formation (King, 1988b) that indicate starvation of clastic material (King \& Thrasher, 1996).

The Tangahoe Formation (Arnold, 1957) is distinguished from strata below and above by its dominantly fine-grained character and is composed of mudstones, siltstones and finegrained sandstones (Figure 7.2). The base of the formation is associated with an extensive flooding surface or paraconformity and glauconitic mudstone beds that indicate a paleo-bathymetric deepening of about 400 m (Hayton, 1998; Kamp et al., 2004). Frequent occurrence of rip-up clasts in outcropping sandstone beds indicate deposition via sediment gravity flows (Townsend et al., 2008), which are vertically succeeded by shallow shelf deposits (Naish et al., 2005).

Overlying strata comprise a series of shelf deposits, which have been grouped into the Whenuakura Group in the present-day onshore area (Fleming, 1953), but are otherwise referred to as undifferentiated in the offshore area due to the general lack of ability to further characterise these strata from limited wireline logs available in the shallow section of petroleum exploration boreholes (King \& Thrasher, 1996). Cyclothemic superposition of shelf to shoreface mudstones, siltstone, shell beds (limestones), and sandstones observed in outcrop have been interpreted as a result of fluctuating sea levels (Fleming, 1953; Beu \& Edwards, 1984; Abbott \& Carter, 1994; Naish, 1997; Saul et al., 1999b; Abbott et al., 2005), parts of which have been grouped into a series of transgressive, highstand and regressive systems tracts of $5^{\text {th }}-(100 \mathrm{ky})$ to $6^{\text {th }}$-order $(40 \mathrm{ky})$ cyclicity (e.g., Naish \& Kamp, 1997; Naish et al., 2005). Relative lowstand deposits are usually not preserved in shelfal outcrop facies, as sediment is mostly bypassed to the shelf margin (Beggs, 1990; Naish et al., 2005). Evidence for westward bypass comes from Pleistocene channel systems observed on limited high-frequency seismic data in the central basin (Nodder, 1995). 
The coeval shelf margin to basin floor facies, the Giant Foresets Formation, owes their name to their appearance as large progradational clinoform sequences on seismic reflection profiles (Shell BP Todd Oil Services Ltd., 1976; Pilaar \& Wakefield, 1979; Thrasher, 1988). Soenander (1992) and Hansen and Kamp (2004; 2006) suggested that the sequence prograded as a series of fan lobes that initially filled the Northern Graben depression during the Early Pliocene and continued to regress north-westwards along a linear front since the Mangapanian time (3.0-2.4 Ma) .

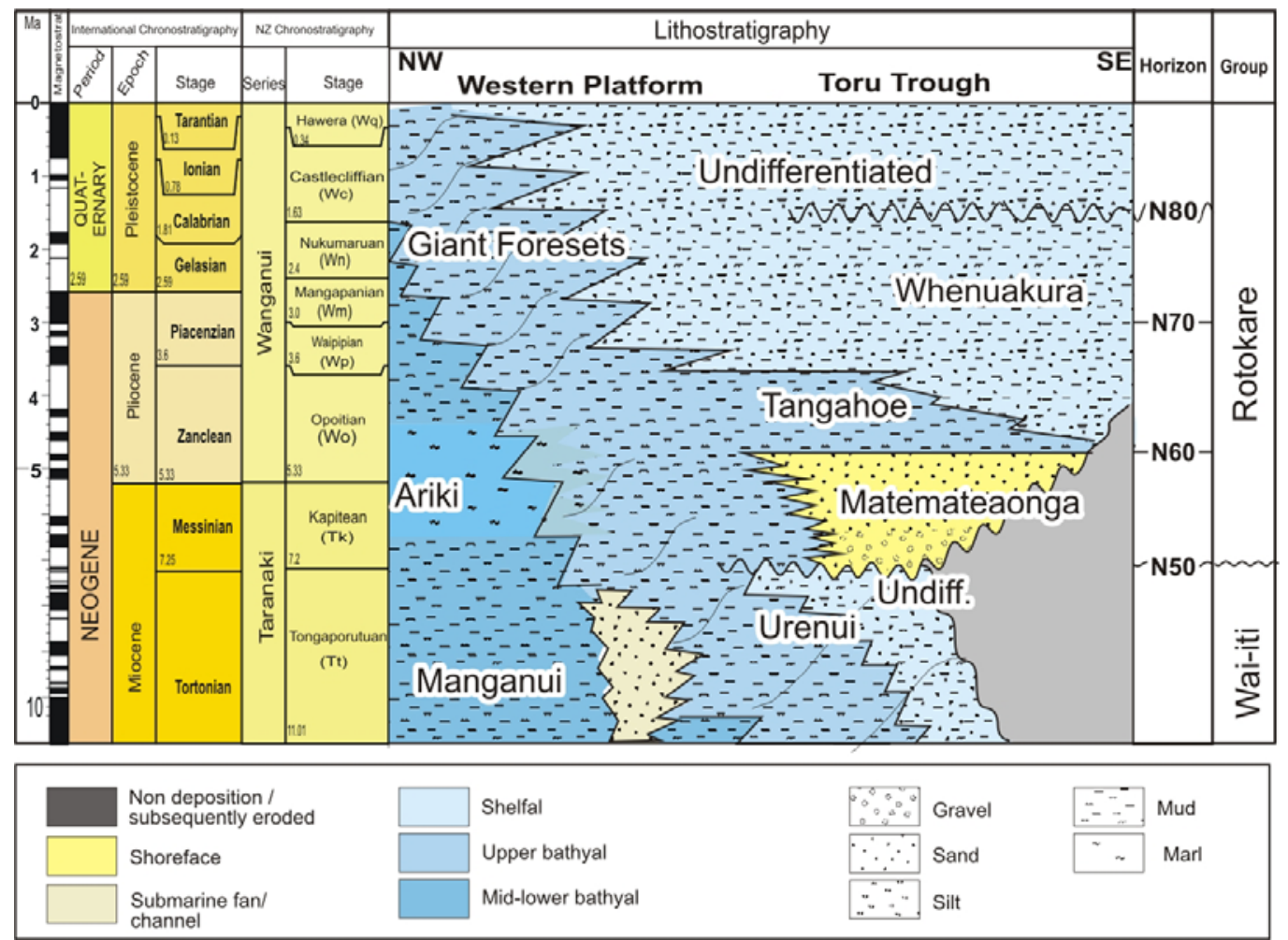

Figure 7.2 Chronostratigraphic panel of Late Miocene to Recent basin strata in the proximal Taranaki Basin (modified after King and Thrasher, 1996). Note the abbreviations of New Zealand stage names that are frequently used in the following discussion. The approximate age of seismic horizons used in the study is shown in the second column from the right. 


\subsubsection{Borehole and seismic data}

The borehole data used in this chapter consists of a selection of wells in representative regions within the study area (Figure 7.1). The well data have been compiled from petroleum exploration reports and formation boundaries and biostratigraphic data were reassessed by GNS Sciences 4D Taranaki project (e.g., Roncaglia et al., 2007; Roncaglia et al., 2008). In order to constrain the timing and magnitude of basin subsidence due to sediment loading and tectonic forcing, the stratigraphic record of ten boreholes was backstripped assuming Airy-isostatic compensation of the sedimentary load. Due to the uncertainty about the appropriate magnitude of sea-level fluctuations during the PlioPleistocene period in the literature (e.g., Haq et al., 1987; Miller et al., 2005; Naish \& Wilson, 2009), no water-depth corrections have been applied. The seismic data used in this chapter consists of a basin-wide 2D seismic data set as well as two 3D surveys $\left(\sim 1500 \mathrm{~km}^{2}\right)$ in the central basin (Maui 3D) and eastern basin (Kerry 3D). The well data, phase- and gain-matched seismic data, and calculation method for decompaction and tectonic subsidence are described in detail in Chapter 2 of this thesis.

\subsubsection{Seismic horizon interpretation}

A total of five seismic horizons were mapped on major sequence boundaries, facies changes, and age correlations, with an aim to approximate the subdivisions of: A) the Late Kapitean to Opoitian (Tk-Wo, $6-4.5 \mathrm{Ma}$ ) Matemateaonga Formation and time equivalents (N50-N60), B) the Opoitian to Waipipian or Mangapanian (Wo-Wp/Wm, 4.5-3 Ma) Tangahoe Formation and lateral time equivalents (N60-N70), and C) the Mangapanian to Recent (3.0-0 Ma) Giant Foresets and Whenuakura Formation (N70Seabed). In addition, a Late Pliocene/Pleistocene unconformity (N80) was mapped in the eastern basin.

All of the five horizons were interpreted across the south-eastern part of the basin east of the Cape Egmont Fault and the Toru Trough (Kupe area), whereas only three of these (N50, N60, Seabed) were mapped across the seismic grid west of this fault into the central basin area. Correlations of the remaining reflectors into western areas were made 
on selected lines to infer the approximate age of observed facies patterns. As already stated by previous authors (Hansen \& Kamp, 2006), it is noted that biostratigraphic age estimates in individual wells are frequently too variable to infer the exact age of reflectors. Therefore, age associations are interpreted with respect to the most dominant age occurrence and confidence about internal consistency is gained from the achievement of mapping closure across the seismic grid. Seismic horizon interpretations of the Top Miocene and Seabed in the deep-water basin from Uruski et al. (2002b) were used to show the regional sediment thickness of Plio-Pleistocene sediment on isochron maps.

Sequences between individual horizon interpretations were sub-divided via proportional and horizontal slicing (Zeng et al., 1998) to extract and display intra-formational seismic attribute and facies information from $2 \mathrm{D}$ and $3 \mathrm{D}$ data. The sequence stratigraphic interpretation system by DGB's Opendtect software (e.g., de Bruin et al., 2007; Brouwer et al., 2008) was used to automate the mapping of detailed reflector characteristics and develop a sequence stratigraphic model for the depositional evolution of the Giant Foresets Formation on the Western Platform. The details relating to this approach are discussed in Chapter 2.

Table 7.1 List of seismic horizon interpretations used in this chapter. The formation association represents the correlation with formation tops in wells and ages represent approximate estimates.

\begin{tabular}{|l|l|l|c|c|c|}
\hline Horizon ID & & Horizon & Formation association (Well tops) & NZ stage & Age [Ma] \\
\hline & & & & & \\
\hline Seabed & & Seabed & Seabed & Wq & 0 \\
\hline N80 & $\square$ & Plio-Pleis UC & Intra Whenuakura & Wn-Wc & $\sim 1.5$ \\
\hline N70 & $\square$ & Base Whenuakura & Top Tangahoe & Wp-Wm & $3-3.6$ \\
\hline N60 & $\square$ & Base Tangahoe & Matemateaonga & Wo & 4.5 \\
\hline N50 & $\square$ & Base Rotokare & Manganui, Kiore, Urenui & Tk & 6 \\
\hline
\end{tabular}

\subsection{RESUlts}

\subsubsection{Borehole stratigraphy}

The first-order Plio-Pleistocene depositional evolution is illustrated in thickness variations and facies distribution in the stratigraphic borehole record (Figure 7.3). In the area of the Toru Trough (Figure 7.3, top), the N50-N60 sequence (Matemateaonga Formation) sequence thins from $>1000 \mathrm{~m}$ in the north (Toru-1) to about $250 \mathrm{~m}$ in the south (Tahi-1). Cutting samples cover a range of lithofacies from coquina shell bed (limestone), siltstone, sandstone, and pebble- to cobble-sized conglomerate, resembling 
sedimentary patterns described from outcrops in the eastern Taranaki peninsula (Vonk et $a l .$, 2002). The gamma-ray wireline response is characterized by low counts and serrate patterns, whereas sonic and density $\operatorname{logs}$ show a blocky pattern whereby silt-and-sand units are separated by higher-density limestone beds (Roncaglia et al., 2008). Thicknesses decrease towards the west to less than $100 \mathrm{~m}$ (Maui-2), slightly increase westwards to 100-200 m (Kiwa-1, Tane-1), and are absent in the southern central basin (Kea-1). In the central basin (Maui-2), strata consist of interlayered clay and sandstone lithologies, whereas they consist of dominantly fine-grained lithologies with occasionally high calcareous content on the Western Platform (e.g., Ariki Formation in Tane-1).

The Tangahoe Formation and age equivalents (N60-N70) show a similar thickness distribution as the previous sequence. In the eastern basin, the sequence consists of dominantly fine-grained, clay and siltstone lithologies. Blocky gamma-ray signatures and borehole cuttings indicate localized sandstone packages, primarily at the base and the top of the formation. In the central basin the sequence thins to less than $100 \mathrm{~m}$ (Maui-2, Kea1) and consists of mixed fine-grained and coarse-grained sediment. While the sequence is similarly thin in well Kiwa-1, coarse-grained strata (sands) indicate increased clastic sedimentation on the Western Platform from the Waipipian to Mangapanian (3.6-3.0 Ma).

The Whenuakura/Giant Foresets interval has a relatively uniform thickness of about 800 $\mathrm{m}$ in eastern wells, where it consists of interlayered sand, silt and clay sequences. The interval is only about $250 \mathrm{~m}$ thick in the footwall of the Cape Egmont Fault (Maui-2), but has thicknesses of $>1000 \mathrm{~m}$ in the hanging wall of the southern Cape Egmont Fault zone (Kea-1) and on the Western Platform (Kiwa-1), respectively. Lithologies consist of frequent sand, silt and claystone inter-beds with serrate gamma-ray signatures. 


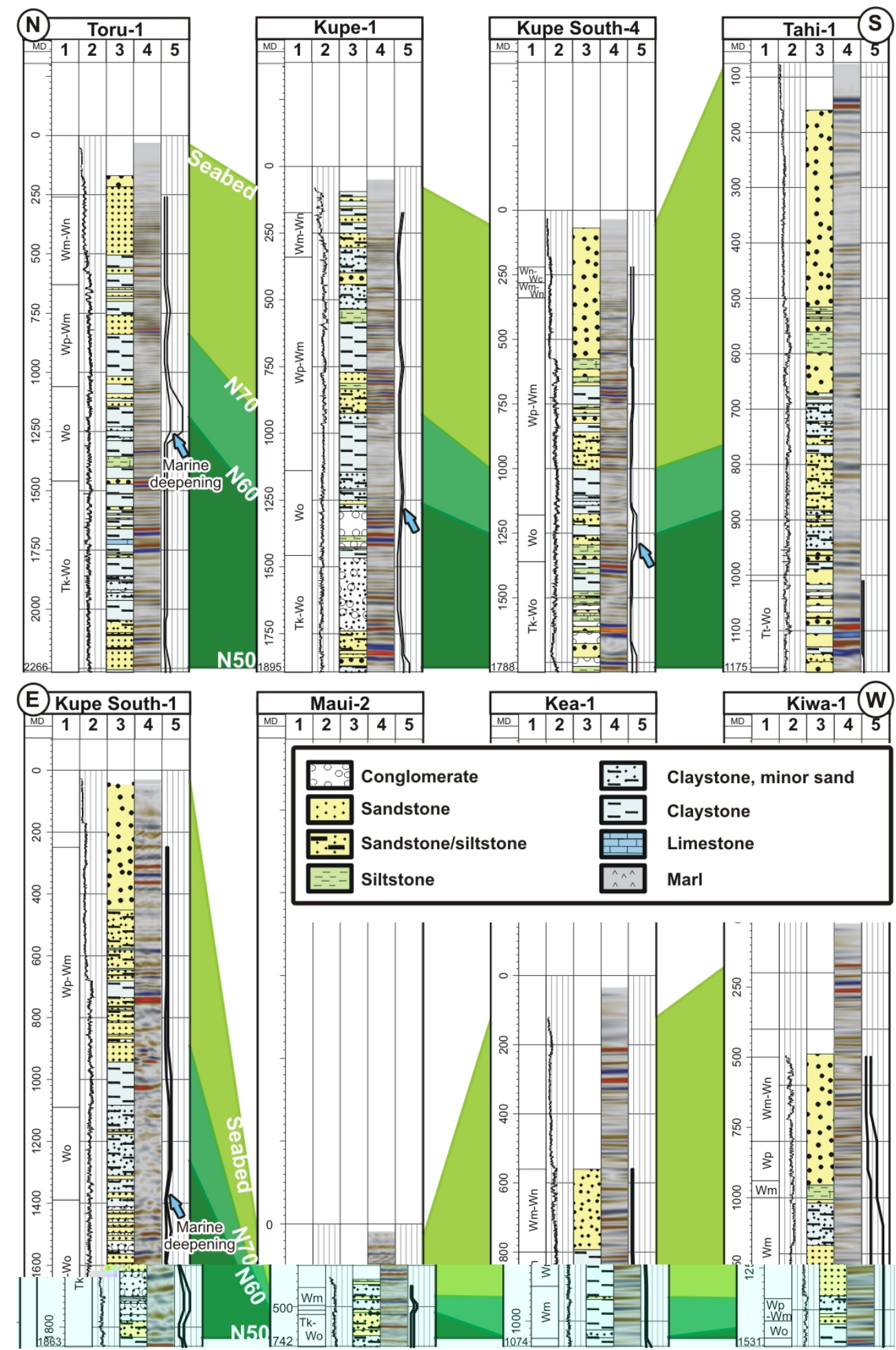

Figure 7.3 Well correlation panels showing selected boreholes with representative facies content and thickness distribution in a north-south direction across the Toru Trough (top) and east-west from the Toru Trough to the Western Platform (bottom, for location see Figure 7.1). Individual columns in each well show the 1) New Zealand stage acronym from biostratiographic age determination, 2) $\gamma$-ray $\log (0-150 \mathrm{cpl}), 3)$ mudlog/cuttings-derived lithology interpretation (code shown in legend), 4) seismic amplitude response (scaled from blue/negative to red/positive), 5) biostratigraphic minimum and maximum paleo-water-depth estimates $(-100-800 \mathrm{~m})$. The seismic amplitude responses represent extractions of ten traces from 2D seismic transect closest to the borehole. The colours between well locations represent chronostratigraphic sequence correlations as mapped on seismic data (dark green: N50-N60, Matemateaonga/Ariki Fm; green: N60-N70, Tangahoe Fm; light green: N70-Seabed, Whenuakura/Giant Foresets Fm) 


\subsubsection{Biostratigraphic water-depth estimates}

Paleo-environmental interpretations of microfaunal assemblages (Figure 7.3) indicate upper to lower bathyal water depths on the Western Platform during the Late Kapitean to Opoitian (400-800 $\mathrm{m}$ in Kiwa-1). Sedimentary strata of the time equivalent Matemateaonga Formation in the eastern and central basin suggest terrestrial, marginalmarine, and shelfal environments during the late Kapitean to lower Opoitian, with a gradational deepening observed in some wells. During the Opoitian, water depths rapidly increase by 200-500 $\mathrm{m}$ to outer shelf and bathyal conditions in the eastern basin (blue arrows, Figure 7.3), which is most pronounced in the north-eastern Toru Trough (Toru-1) with a deepening from $100 \mathrm{~m}$ to $400-600 \mathrm{~m}$. From the Opoitian to the Mangapanian ( 4.5-2.4 Ma) water depths decrease back to shelf and marginal marine depths in the area of the Toru Trough, while marine flooding and shallow marine conditions are indicated by wells further south (Kea-1, North Tasman-1). Wells on the Western Platform show a decrease in planktonic foraminifera suggestive of shallowing upwards and development of shelf conditions by the Manganpanian-Nukamuruan (3-1.6 Ma).

\subsubsection{Basin subsidence}

Total Plio-Pleistocene basin subsidence values (sediment and tectonic loading without water depth) since $6 \mathrm{Ma}$ vary from $<0.2$ to $1.8 \mathrm{~km}$. Highest amounts of subsidence are observed in the Toru Trough (Toru-1) and Western Platform, and lowest values in central (Maui-1, Maui-2) or southern wells (Kea-1, North Tasman-1), in which the Early Pliocene record is missing (Figure 7.4). Back-stripped subsidence values (tectonic subsidence including water depth) show that up to $700 \mathrm{~m}$ of subsidence in the Toru Trough can be attributed to tectonic forcing between 6-4 Ma. This subsidence event was localised in the northern Toru Trough with a gradual decrease towards the south (Kupe wells) and west (Maui wells). Incorporation of an additional stratigraphic marker that represents the uppermost shallow marine sample near the base of the Tangahoe Formation (N60) in well Toru-1 suggests that 70\% $(450 \mathrm{~m})$ of this initial tectonic subsidence occurred between 4.5-4 Ma at rates of about $1000 \mathrm{~m} / \mathrm{my}$. This initial subsidence is followed by $50-350 \mathrm{~m}$ of uplift over a similar area to the previous subsidence until $\sim 3 \mathrm{Ma}(>2.4 \mathrm{Ma})$, then by gradual subsidence until today. Total subsidence values suggest that this tectonic uplift was partly compensated by the 
sedimentary load. The lack of additional age and formation markers does not allow further constraints on the timing of change from tectonic uplift to subsidence.

Kea- 1 shows the highest total compacted sedimentation rates $(340 \mathrm{~m} / \mathrm{my}$ at $0 \%$ porosity) of all wells during the Late Pliocene-Pleistocene, indicating that this area was a major depocentre since the onset of its Plio-Pleistocene stratigraphic record at about 3 Ma. Tectonic subsidence values of $340 \mathrm{~m}$ indicate that about $30 \%$ of the total subsidence signal can be attributed to tectonics and is probably related to extensional activity on the adjacent Cape Egmont Fault Zone (Figure 7.1).

High total subsidence values in Kiwa-1 can be explained by sedimentary loading on the Western Platform, which increased since $3 \mathrm{Ma}$ with compacted sedimentation rates of $300 \mathrm{~m} / \mathrm{my}$. Tectonic subsidence in this area was negligible within the margin of error. Small negative subsidence values of $20-75 \mathrm{~m}$ in Kiwa-1 (i.e., uplift) are likely to be a calculation artefact, since the regional (flexural) compensation of the Plio-Pleistocene sediment load of the Giant Foresets Formation (see Holt \& Stern, 1991) is smaller than predicted by an Airy-isostatic assumption.

In summary, the tectonic history can be grouped into three components: 1) a Late Miocene-Early Pliocene subsidence event focused on the northern Toru Trough that is followed by subtle uplift, 2) gradual subsidence of the South Taranaki Bight during the Late Pliocene-Pleistocene, and 3) tectonic quiescence of the Western Platform. 

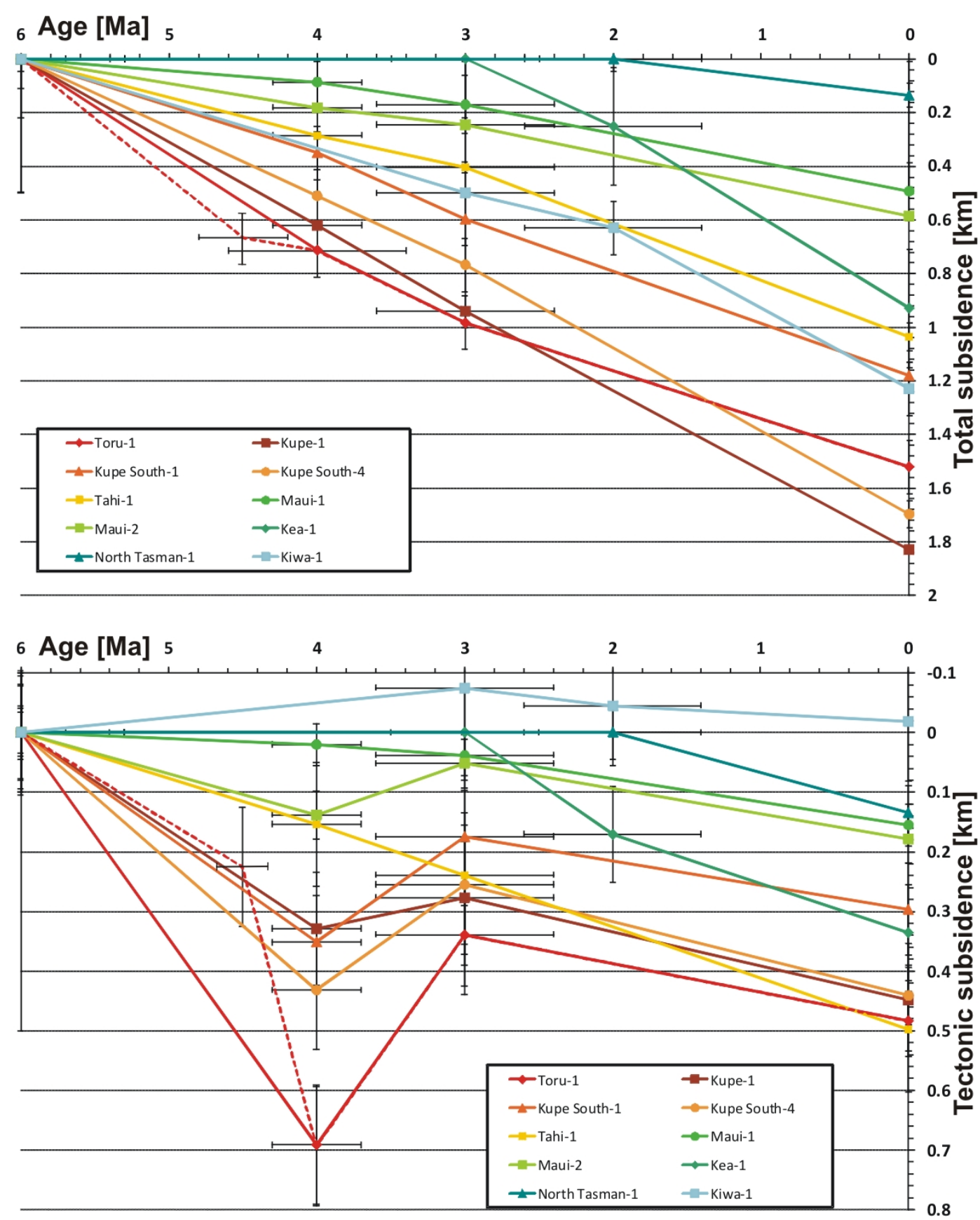

Figure 7.4 Subsidence histories of ten selected wells in offshore southern Taranaki Basin since $6 \mathrm{Ma}$, showing the different signatures of total subsidence (top) and tectonic component of subsidence (bottom). Well locations are shown in Figure 7.1 and curve colour changes from red to blue are from the northern Toru Trough to the west, respectively. Age and subsidence uncertainties based on biostratigraphic data are shown as black bars. 


\subsubsection{Structural basin evolution from seismic isochron maps}

The regional structural evolution of the offshore Taranaki Basin since the latest Miocene can be deduced from isochron maps that were calculated from $2 \mathrm{D}$ seismic horizon interpretations (Figure 7.5). Regional isochron maps show the two main depocentres during the latest Miocene to Recent interval: 1) an eastern depocentre with a roughly NW-SE orientation that terminates to the west with thickest strata of up to $2.3 \mathrm{~s}$ TWT in the hanging wall of the Cape Egmont Fault (Figure 7.5, top left), and 2) a western NE$\mathrm{SW}$-oriented depocentre with total thickness of $>1.75 \mathrm{~s}$ TWT that thins into distal areas of the southern New Caledonia Trough (NCT) and onto the Challenger Plateau. Using basic interval velocities for Miocene-Pliocene strata of 2.5-3 km/s, (Stagpoole, 1998), simplified maximum sediment thickness estimates are 2.9-3.4 km and 2.2-2.6 km for each depocentre, respectively.

Subdivisions of the total sequence show the differential evolution of these depocentres during the Early Pliocene and Late Pliocene-Pleistocene periods. The latest Miocene to Early Pliocene (N50-N60, Tk-Wo) isochron map (Figure 7.5, centre left) outlines development of the sub-circular Toru Trough, which formed a major depocentre with a thickness up to $0.7 \mathrm{~s}$ TWT $(0.9-1 \mathrm{~km})$. Sediment thicknesses of generally less than $0.6 \mathrm{~s}$ (TWT) indicate limited westward sediment dispersal on the northwest-facing shelf margin. The two depocentres thin to the south and are divided by an elevated area that has been referred to as the Tasman Nose or Farewell Rise (Nodder, 1995).

The late Early Pliocene to seabed isochron (4.5-0.0 Ma) indicates increased sediment accumulation ( $>1.2 \mathrm{~s}$ TWT) and north-westward outbuilding of the shelf margin. In the east, the isochron shows a southward expansion of the sedimentary depocentre, while the development of thick strata in the hanging wall of the Cape Egmont Fault ( $>2 \mathrm{~s}$ TWT) suggests initiation of extensional activity. Time-thickness distribution calculated over the N60-N70 sequence (Figure 7.5, centre right; Tangahoe Fm, 4.5-3.0 Ma) and N80Seabed (Figure 7.5, bottom right; $\sim 1.6-0.0 \mathrm{Ma}$ ) show that initiation of extension on the Cape Egmont Fault post-dated the deposition of the Tangahoe Formation and continued during the Quaternary. An area of thinner strata that parallels the trend of the present-day shoreline of the southern Taranaki peninsula evident on the N60-seabed and N80-seabed isochrons indicate the location of post-depositional tilting and erosion $(\sim 300 \mathrm{~m})$. 

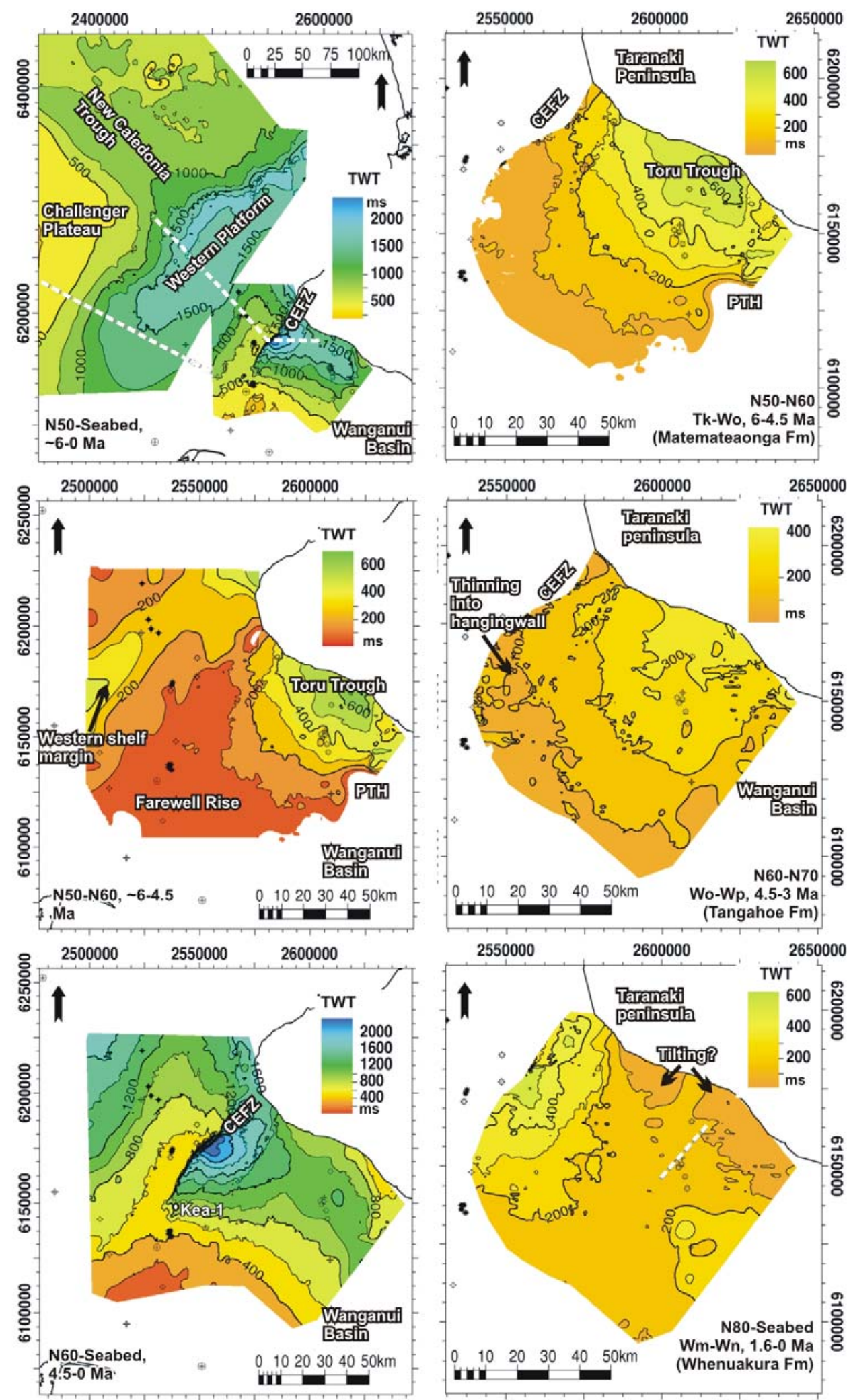

Figure 7.5 Isochron maps calculated from gridded seismic horizon interpretations across the greater basin (top left), the central offshore basin (centre left and bottom left), and the Toru Trough (right). Reflectors, NZ stage associations, and inferred absolute ages are annotated in black. Structural features and provinces are annotated in white (CEFZ-Cape Egmont Fault Zone, PTH-Patea-Tongaporutu High). The locations of seismic lines and attribute maps shown in Figure 7.6 and Figure 7.7 are delineated as white dashed lines in top left and bottom right panel, respectively. Note that these isochrons represent smoothed versions of the original seismic interpretation and structural expressions of smaller latest Pliocene-Pleistocene faults in the central Toru Trough are not visible. 


\subsubsection{Seismic facies overview and lithology interpretation}

The seismic facies character of the Plio-Pleistocene succession can be broadly subdivided by the dominance of relatively flat-lying top set facies in the eastern basin and progradational foreset and bottomset facies in the west (Figure 7.6).

\section{Eastern basin}

Topset facies are distinguished from basinal facies by the dominance of relatively flat, semi-to continuous parallel reflectors and are associated with the Late Miocene to Early Pliocene Matemateaonga and the Late Pliocene to Pleistocene Whenuakura Formation (Figure 7.2). The seismic facies character of these formations can be further subdivided into at least four groups:

1) Semicontinuous to continuous, medium- to high-amplitude, low- to mediumfrequency, parallel reflectors

2) Semicontinuous to continuous, low- to medium-amplitude, medium-frequency, parallel reflectors

3) Discontinuous to semicontinuous, medium-amplitude, contorted/chaotic reflectors

4) Discontinuous, high-amplitude, contorted/chaotic reflectors

These facies vary rapidly along respective reflector timelines as well as vertically and internal reflector onlaps and downlaps indicate the dynamic development of these facies during fluctuating base levels. Correlations between lithology and seismic facies are highly variable (Figure 7.3 and Figure 7.7), and seismic reflections may represent the composite signal of a combination of stacked lithologies and diagenetic effects. Despite these differences interpretations can be made based on tendencies of associations between seismic and lithofacies.

Seismic facies (1) frequently correlate with sandstones, conglomerates and/or limestone and may be associated with sandy shoreface units and shell bed horizons. The relatively higher amplitudes may be associated with high impedance contrasts of cemented shell beds and lower impedance of the sands with respect to the surrounding finer-grained 
strata. Facies (2) often corresponds with dominant fine-grained silt and clay units. In some instances, facies (3) correlates with the increased occurrence of mud, sand and conglomerate inter-beds. Facies (4) similarly correlates with sand, conglomerate and silt inter-beds, but their restricted lateral extent of generally only 100-250 m may suggest that these facies represent marine and/or terrestrial channel systems. Relatively highamplitude facies (1) are not commonly observed in the younger N70-Seabed (Whenuakura) sequence, probably owing to the lack of cemented shell beds and less well developed shoreface facies as evident in well data.

The Tangahoe Formation (N60-N70), is easily distinguished from strata above (Whenuakura Fm, N70-Seabed) and below (Matemateaonga Fm, N50-N60) by its overall more bland character and off-lapping reflector geometries over wide areas (Figure 7.7). The dominant seismic facies consists of low- to medium-amplitude, semi- to discontinuous, contorted to offlapping reflectors interpreted as shelf, outer shelf, and slope clay- and siltstones. Relatively continuous, off-lapping reflectors with medium to high amplitudes periodically subdivide these reflectors and show clear clinoform geometries with north-easterly dip that have previously been noted by Ogilvie (1993). Discontinuous medium- to high-amplitude facies frequently incise into these higher amplitude reflectors and are interpreted as channel facies. The flat-lying clinoform bottomsets have commonly medium to high amplitudes that grade into low to medium amplitudes in a distal direction, and correlate with fine-grained sediment and sand, respectively (Figure 7.7). 

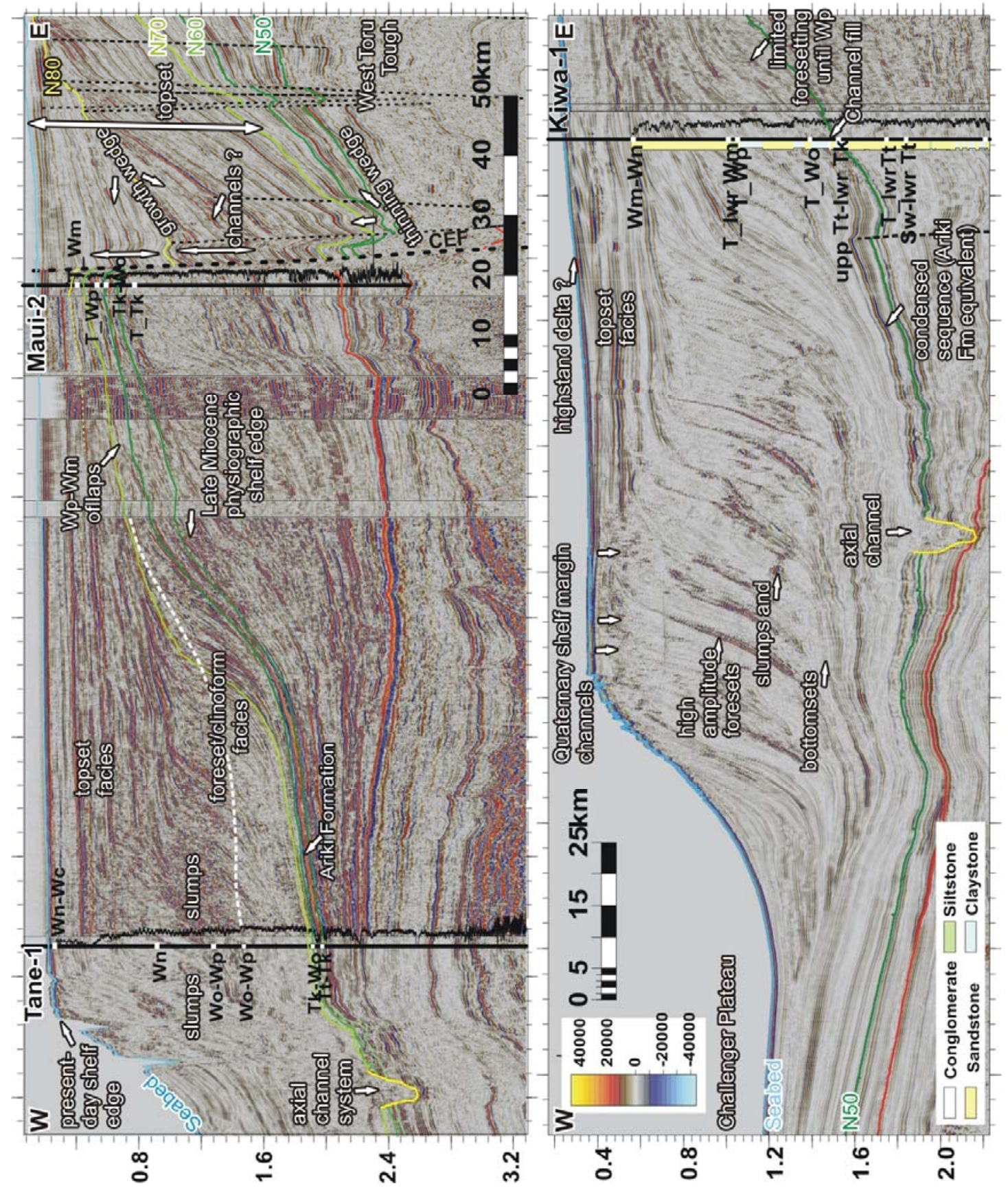

Figure 7.6 Regional EW-seismic composite profiles across the central Western Platform and the eastern Toru Trough (top) and southern Western Platform (bottom) showing the character of latest Miocene to Recent strata (general facies patterns are annotated) and faulting (black dashed lines). Well tracks of three wells are shown (thick black lines) with gamma-ray logs (thin black lines), biostratigraphic age markers with New Zealand stage abbreviations (white squares, see Figure 7.2 for absolute age) and lithology interpretations from well cuttings. Interpreted horizons are annotated and colour-coded as shown in Table 7.1. The base Oligocene horizon is shown for general reference (red). See for profile locations. Approximate attribute extraction level used for the delineation of Plio-Pleistocene slope clinoform geometry (Figure 7.13A) is shown as a white dashed line. Seismic profiles here and in subsequent figures are shown in seconds two-way-travel time (TWT). 


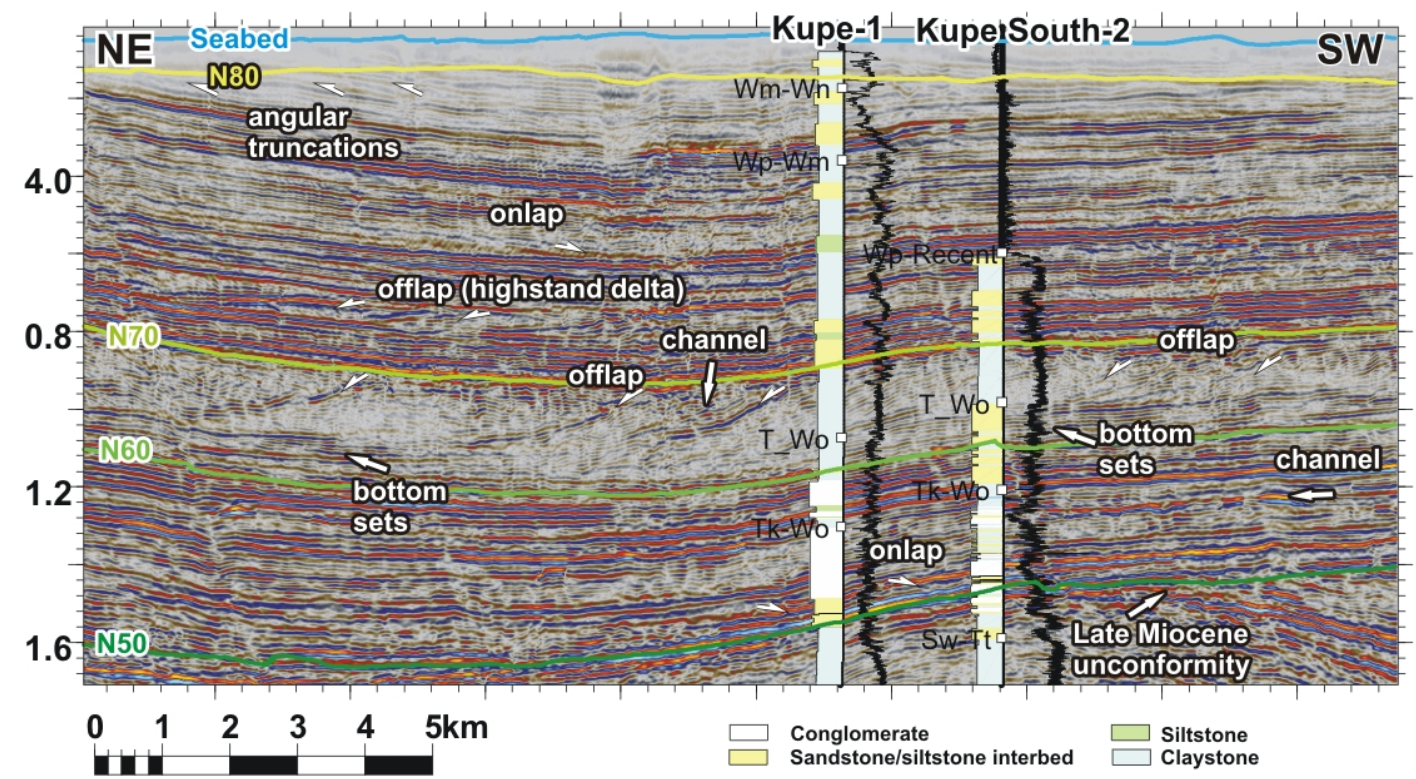

Figure 7.7 Seismic profile from the Kerry 3D survey showing the character of Late Miocene to Recent strata in the Toru Trough (see Figure 7.5 for location). Note the similarity of shelf facies of the Matemateaonga (N50-N60) and Whenuakura formations (N70-Seabed), the different character of the intervening Tangahoe Formation (N60-70), and southwest to northeast increase in clinoform height in this formation. Well tracks of two wells are shown with gammaray logs (thin black lines), biostratigraphic age markers with New Zealand stage abbreviations (white squares, see Figure 7.2 for absolute age), and lithology interpretation from borehole cuttings (see legend at bottom for colour code).

\section{Western basin}

Seismic reflection patterns of the Giant Foresets Formation in the western basin are characterised by large westward progradational clinoforms, which grade eastward into flat-lying top set facies (Figure 7.6) (see also Pilaar \& Wakefield, 1979; Thrasher, 1988; Beggs, 1990; Hansen \& Kamp, 2004; 2006). The clinoforms are between 0.5-1.0 s TWT high between their upper and lower inclination points which, if de-compacted, equates approximately $\sim 0.7-1.5 \mathrm{~km}$ of relief. The clinoforms show several characteristics that have been noted by previous authors based on more limited data: 1) foreset sequences show a cyclic character of progradation, degradation with slumping and channelling (Beggs, 1990), 2) individual sequences of lower continuity and amplitude are divided by semi-continuous, high-amplitude reflectors (King \& Thrasher, 1996), and 3) repetitive steepening and collapse of the slope, the critical angle of which is inferred from seismic reflector dip and assumption of an average formation velocity of $2.5 \mathrm{~km} / \mathrm{s}$ to be about $3^{\circ}$ (see also Beggs, 1990). The overall lithology is dominated by mudstones and finegrained siltstones, while degradational sequences show heterogeneous lithologies of sporadic sandstone and conglomerate beds (e.g., Kiwa-1, Tane-1). 
Regional investigation of this sequence shows several commonalities and differences in shelf margin architecture across the area from the southwest to the northwest. The base of the sequence (Late Miocene- Early Pliocene) is comparatively thin, shows only minor progradation compared to older and younger sequence and subtle aggradation of shelf margin reflectors. These reflectors grade basin-ward into thin high-amplitude reflectors that correlate with the base of Ariki Formation marls in well Tane-1 (Figure 7.6), and indicate limited downslope sediment dispersal. Increasing clinoform progradation above the N60 horizon suggests the renewed outbuilding of the shelf. The north-western shelf margin is distinguished from the southwest by having frequently higher clinoforms $(\sim>1$ $\mathrm{km}$ ), a greater component of shelf aggradation and topset preservation, and greater occurrence of channels and slumps (Figure 7.6). These architectural differences may be attributed to the underlying morphology of the Challenger Plateau and the NCT (see Chapter 6), with the latter providing significantly more accommodation space. In addition, persistent north-eastward longshore drift (Beggs, 1990) may have transported sediment past the south-western area and to the northwest, in turn leading to increased progradation rates and more unstable shelf margin architecture.

\subsubsection{Seismic facies distribution and development of depositional systems}

\section{N50-N60 ( 6-4.5 Ma)}

The gross regional facies distribution of latest Miocene to Early Pliocene strata can be inferred from interval attribute extraction over the upper part of the N50-N60 sequence (Figure 7.8). This map shows the high-amplitude character of the condensed outer slope facies consisting of cemented mudstone and marls of the Ariki Formation as well as the dominantly high amplitudes of shelfal strata associated with the Matemateaonga Formation (Figure 7.8).

Seismic facies landward of the approximate shelf break and in the area of the central structural high (Figure 7.5 and Figure 7.6) show subtle offlaps that are succeeded by patterns of onlap, drape, and truncation (Figure 7.9E). This combination of facies indicates variable sediment deposition and erosion and relatively shallow marine paleoenvironment. Attribute maps extracted within the offlapping sequence reveal several 100-200 m wide, low-sinuosity channel systems and outline the overall northwestward sediment transport directions (Figure 7.9A). 
Widespread southward onlap observed in the eastern basin (Figure 7.10) mirrors effects of gradual basin subsidence of the Toru Trough and the Wanganui Basin (Figure 7.4). Reflectors onlap and thin onto the Farewell Rise in the southwest and the PateaTongaporutu High in the southeast (Figure 7.10), and subsequently drape over the latter without significant thickness or facies variations. More pronounced thinning southward along this trend may suggest increased topography of the basement high in line with interpretations of the paleo-topography in the adjacent area (Nicol, 2011), but the relative continuity of facies suggests non-activity of the Taranaki Fault.

RMS amplitudes extracted over stratal intervals near the base of this sequence show south-westward convex high-amplitude areas near the reflector onlaps, which may outline the distribution of calcareous shell beds or shoreface sands (Figure 7.8B). Highamplitude facies evident on 3D attribute maps (Figure 7.8C) may resemble eastwardtrending channel systems, but their limited continuity makes a detailed interpretation difficult. The lack of continuity may be attributed a low paleo-relief and frequent trajectory changes during intermittent base-level fluctuations. 

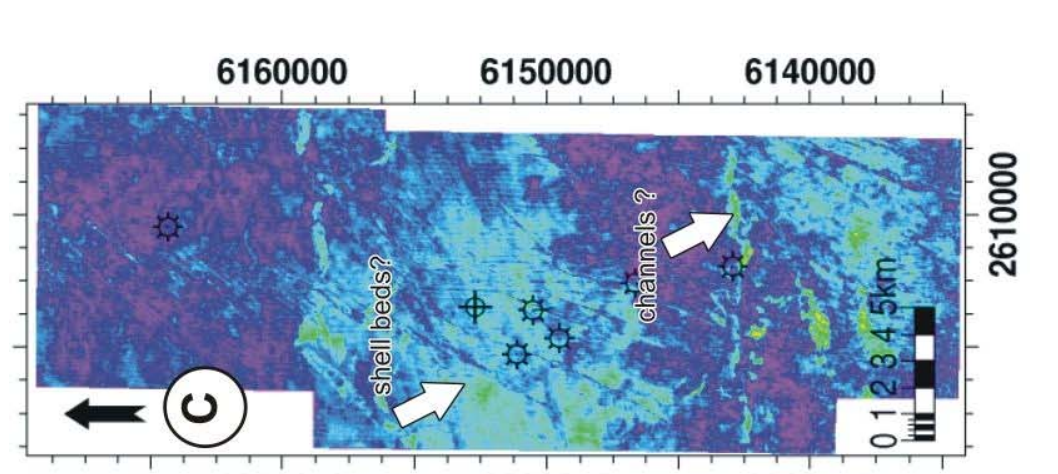

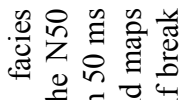
记

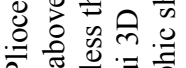

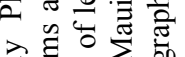
的苛

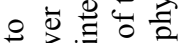

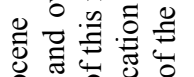
o

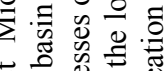

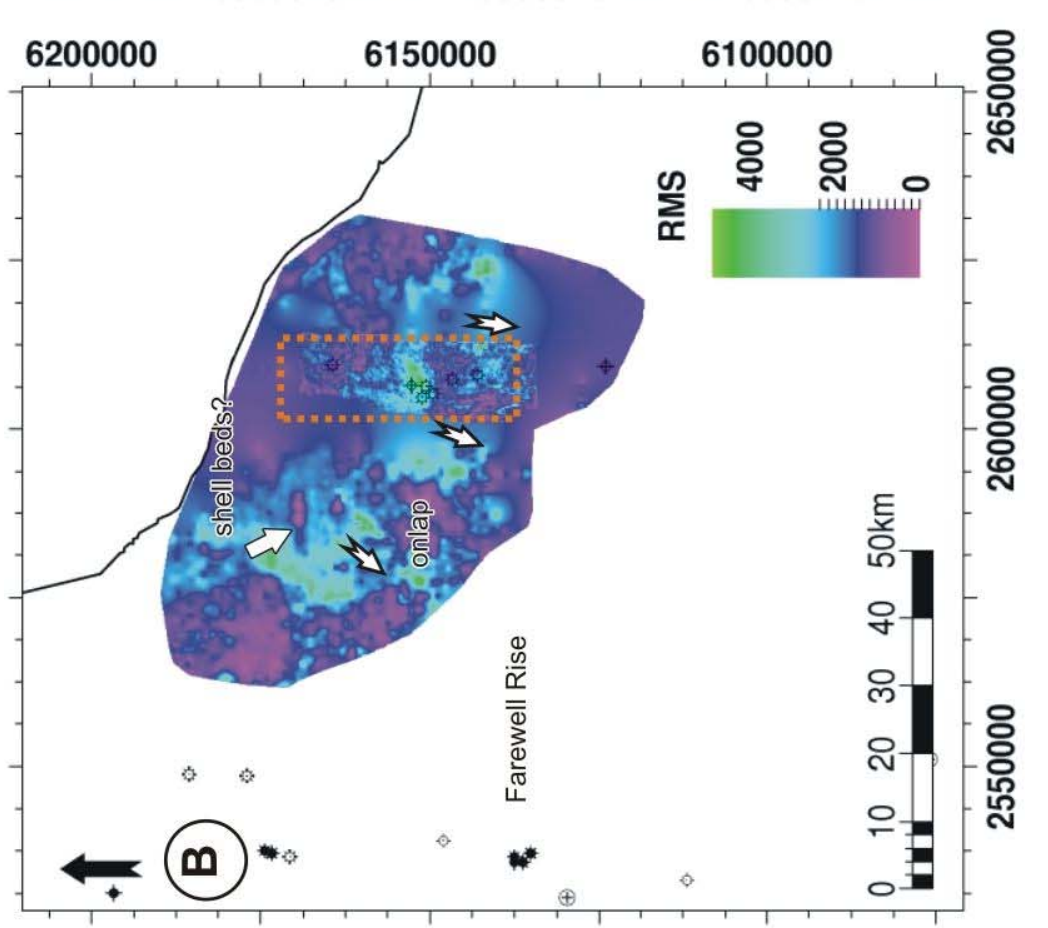
过

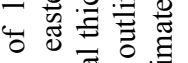

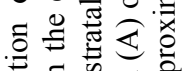

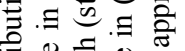
焉 记 물

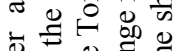

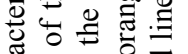

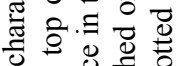
o on 过星 क

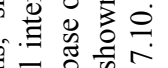
过 的焉 은

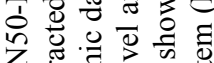

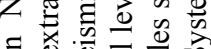

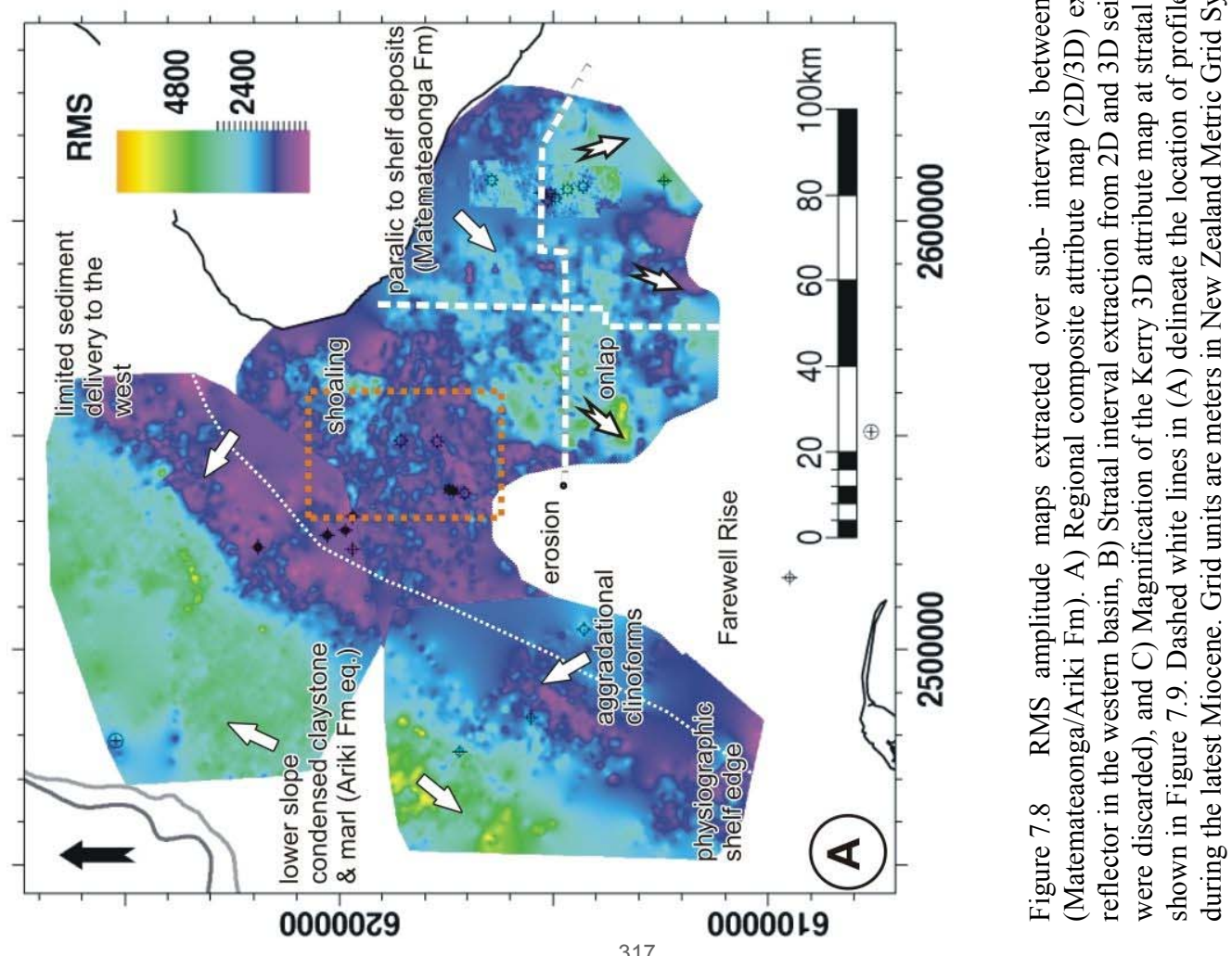



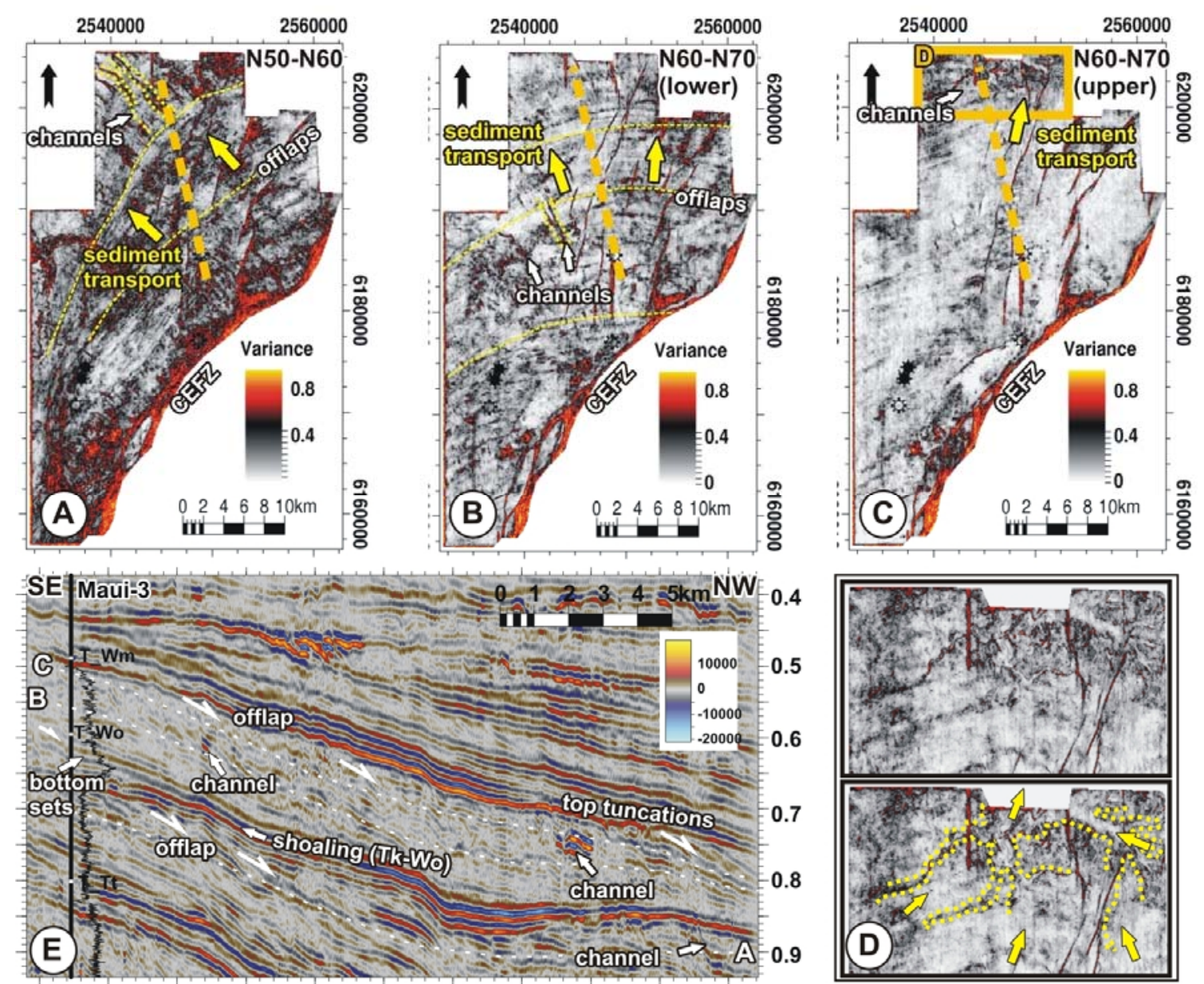

Figure 7.9 Variance attribute maps and seismic sections from the Maui 3D survey showing seismic facies patterns and changing sediment transport directions of the A) lower Matemateaonga Fm equivalent (latest Miocene-Early Pliocene), (B) lower part of the Tangahoe Fm equivalent (late Early-Late Pliocene), and C) upper Tangahoe Fm equivalent (Late Pliocene). D) Magnified view of channels in the northern part of attribute map shown in (C) depicting the diversion of sediment towards the north (location shown as orange rectangle). The yellow dashed lines indicate the clinoform strike at respective intervals. E) Seismic profile from the Maui 3D (at location shown as dashed orange line in attribute maps above) showing facies character and attribute extraction levels (white dotted lines). Well track of Maui-3 (thick black line) is shown with gamma-ray wireline log (thin black line) and biostratigraphic age markers (white rectangles). The location of attribute maps is shown in Figure 7.8. 

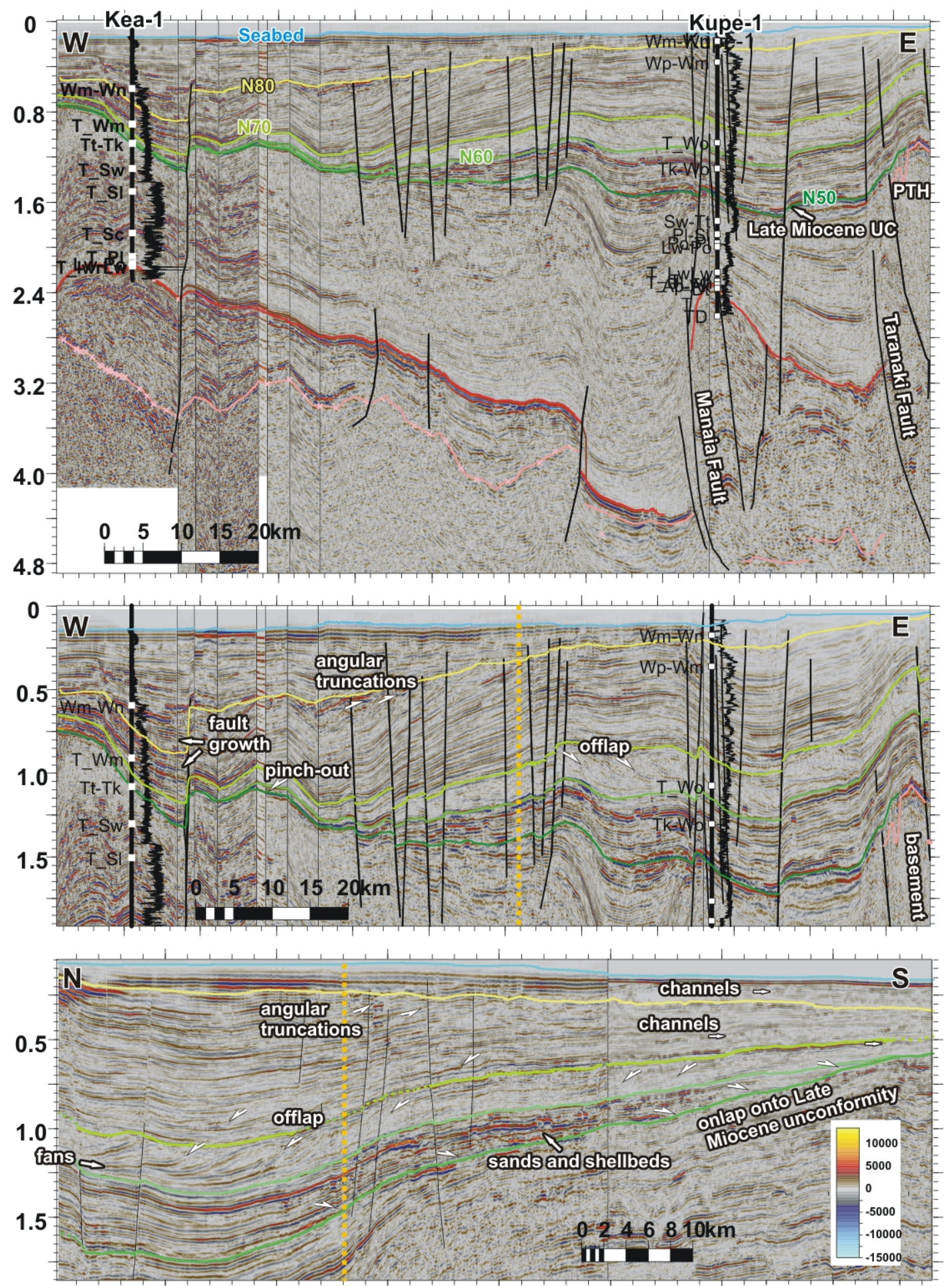

Figure 7.10 Seismic composite profiles showing the character of Late Miocene to Recent strata and faulting (black lines) in the Toru Trough. The top panel shows an east-west seismic line from the Taranaki Fault in the east to well Kea-1 in the west. The centre panel shows a magnification of the same line to emphasise the late basin strata. Note the continuity of latest Miocene and younger strata across the Taranaki Fault (N50-N60). The bottom panel shows a northsouth seismic composite profile across the Toru Trough. The intersection of the two lines is shown as orange dashed line in the centre and bottom panel, respectively. Well tracks are shown (thick black lines) with gamma-ray logs (thin black lines) and biostratigraphic age markers with New Zealand stage abbreviations (white squares, see Figure 7.2 for absolute age). The base Oligocene and basement horizons are shown for general reference in red and pink, respectively. See Figure 7.8A for location of seismic lines. 
Rapid tectonic subsidence and bathymetric deepening at about 4.5 $\mathrm{Ma}$ in the Toru Trough (Figure 7.4) was succeeded by north-eastward outbuilding of a local shelf margin (Tangahoe Formation), in a counter direction to the general Miocene north-westward depositional trend (Figure 7.8). Proportional interval attribute maps show laterally continuous high-amplitude foreset reflectors (Figure 7.11), which outline the detailed geometry of this north-eastward-convex shelf margin. A north-eastward increase in decompacted clinoform heights from 160m (80 ms TWT) in the south to $380 \mathrm{~m}(200 \mathrm{~ms}$ TWT) just north of well Toru-1, documents the deepening of the sub-basin in that direction (Figure 7.7, see also Figure 6.26). The topset reflectors extend onto the Farewell Rise in the southwest, and frequent toplap truncations indicate variable deposition and erosion in that area (Figure 7.10). Low- to moderate-sinuosity channels (Figure 7.11) document the downslope sediment transport into the local trough. Small shelf edge canyons ( $\sim 1 \mathrm{~km}$ wide, 70-90 ms TWT deep) and slope channels (100-300 m and $50 \mathrm{~ms}$ TWT deep) lead towards mounded, sandy bottomsets (Figure 7.7 and Figure 7.11 bottom). In the Kupe South-1 well, one of the channels has been penetrated close to the upper clinoform rollover and, based on cutting and wireline log data, is interpreted as $\sim 55 \mathrm{~m}$ of fine sandstone and siltstone (Matthews \& Bennett, 1987).

Correlation of a clinoform-bottomset pair with the Opoitian-Waipipian stage boundary suggests that this local shelf margin had prograded to about the central Kupe Field area by 3.6 Ma. Offlapping facies suggest further progradation to the northeast, east and southeast across the Patea-Tongaporutu High during the Waipipian (Figure 7.10 and Figure 7.11), and subsequently to the north across the central area (Maui 3D) during the Waipipian-Mangapanian (Figure 7.9E). Clinoforms in the central basin are smaller ( 50 ms TWT, $<100 \mathrm{~m}$ ) than observed in the Toru Trough, which may be a manifestation of smaller subsidence in that area (Figure 7.4). Late Waipipian to Mangapanian aged channels show a significant azimuthal deviation from older, northwest-trending channel systems and merge from the east, south, and southwest in the northern survey (Figure 7.9C), suggestive of a changing paleo-relief and further bypass of sediment into the Northern Graben. On the Western Platform, sandy channel fill of upper OpoitianWaipipian age (4-3 Ma) observed in Kiwa-1 (Figure 7.6) may indicate the reactivation of the nearby axial channel systems as clinoform regression advanced toward the Late Miocene physiographic shelf margin (Figure 7.6 and Figure 7.12). 

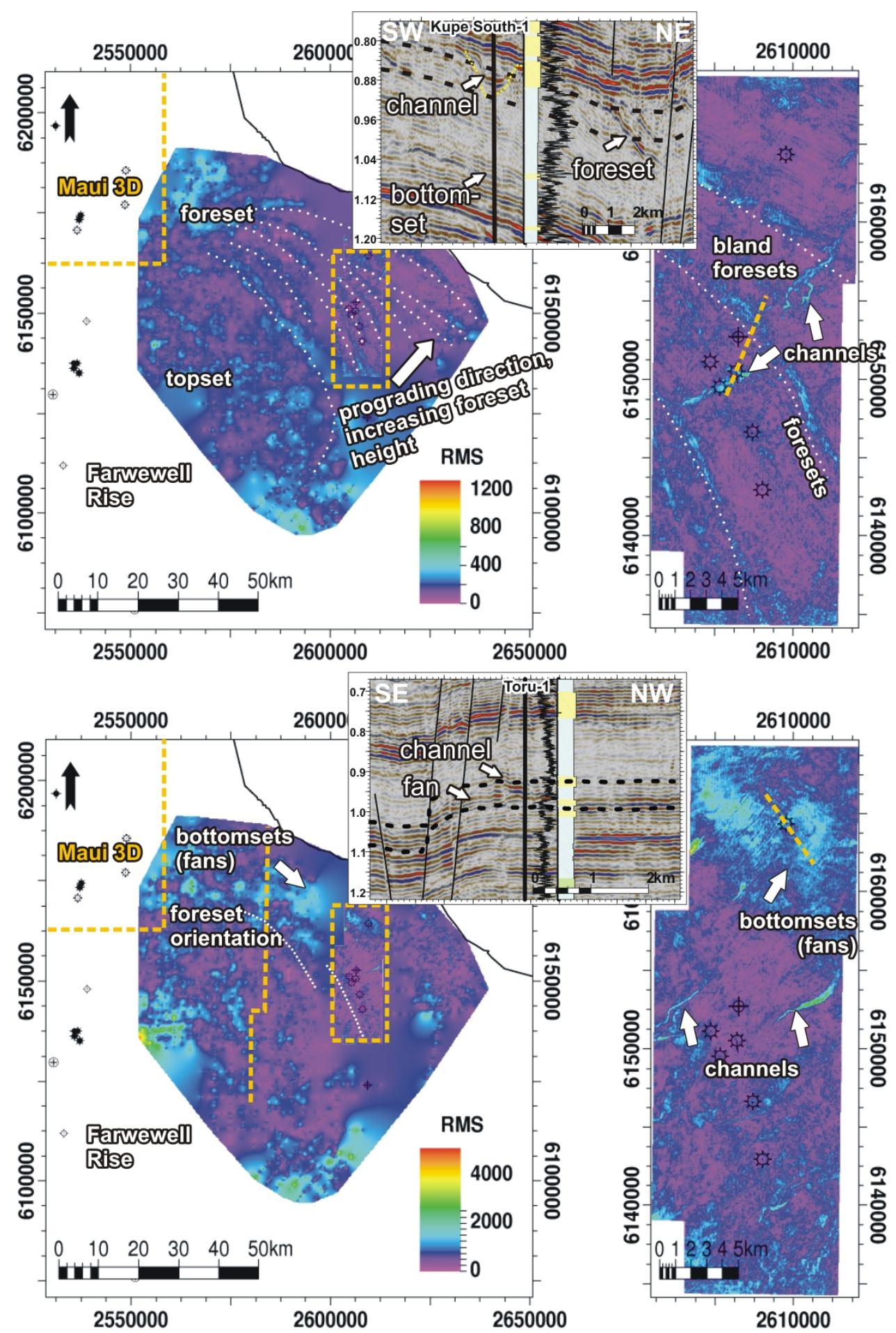

Figure 7.11 RMS amplitude maps extracted over stratal intervals between N60-N70 horizons and seismic lines from the Kerry 3D survey, showing the character and distribution of latest Early to Late Pliocene facies (Tangahoe Fm) in the Toru Trough. The top and bottom panels show composite 2D/3D attributes (left), representative seismic lines (middle), and magnification of the 3D attribute map (right) extracted from near the top and the bottom of the N60-N70 interval, respectively. Location of seismic lines and 3D attribute maps are shown as orange dashed lines and polygons, respectively. Seismic lines show well tracks (thick black lines) with gamma-ray wireline logs (thin serrate black line) and lithology interpretation from well cuttings, respectively (see Figure 7.7 for colour code). Extraction window used for attribute maps is shown as black dashed line and faults are shown as thin black lines. 
From the Mangapanian, shelf margin progradation was again focused on the western shelf (Figure 7.12). Attribute maps extracted across the prograding sequence highlight high-amplitude clinoforms and show the slope geometry during outbuilding of the shelf margin (Figure 7.13A). In plan-view, the north-western slope has a convex shape, whereas the southern part is relatively linear (NE-SW-trending). This north- to south variation in slope geometry is maintained through to the present, as observed on bathymetry contours (Figure 7.13A top left), and indicates more rapid margin progradation in the northwest probably in response to the higher sedimentation rates in that area (Beggs, 1990). Despite the overall rapid westward progradation of the shelf margin, a north-eastward downlapping delta system of upper Waipipian to Mangapanian age (3.0-2.4 Ma) in the eastern basin (Figure 7.7 and Figure 7.13B) suggests that sediment was transported northward from the uplifting South Island during relative baselevel highstands.

Thickening of strata in the hanging wall of the Cape Egmont Fault (Figure 7.6) shows that onset of renewed extension significantly post-dated the deposition of the Tangahoe Formation (N60-N70, Figure 7.6). Facies patterns in the hanging wall are similar to areas in the east, suggestive of only minor seabed topographic expression of the fault and balance between sedimentation and fault displacement. Increased occurrence of discontinuous facies within the lower part of the thickening sequence, however, points to the temporary localisation of channel systems in the hangingwall of the Cape Egmont Fault (Figure 7.6). Angular truncations of previous off-lapping strata and stacked patterns of varying amplitude facies in the footwall of the Cape Egmont Fault (Maui 3D) suggest variable erosion and deposition during the Pleistocene (Figure 7.6 and Figure 7.9). Multiple erosion and truncation surfaces are cut by 1-5 km wide, 50-150 ms TWT thick, medium- to high-amplitude channel systems with highly sinuous margins and northwest orientation (Figure 7.13C). The channel character and orientation is identical to features described from shallow, high frequency $(3.5 \mathrm{kHz}) 2 \mathrm{D}$ seismic data east of the fault (Nodder, 1995). In accordance with Nodder's (1995) earlier interpretations, it is considered likely that these systems represent paralic or terrestrial channels that transport sediment across the faults towards the contemporary shelf during relative base-level lowstands. 


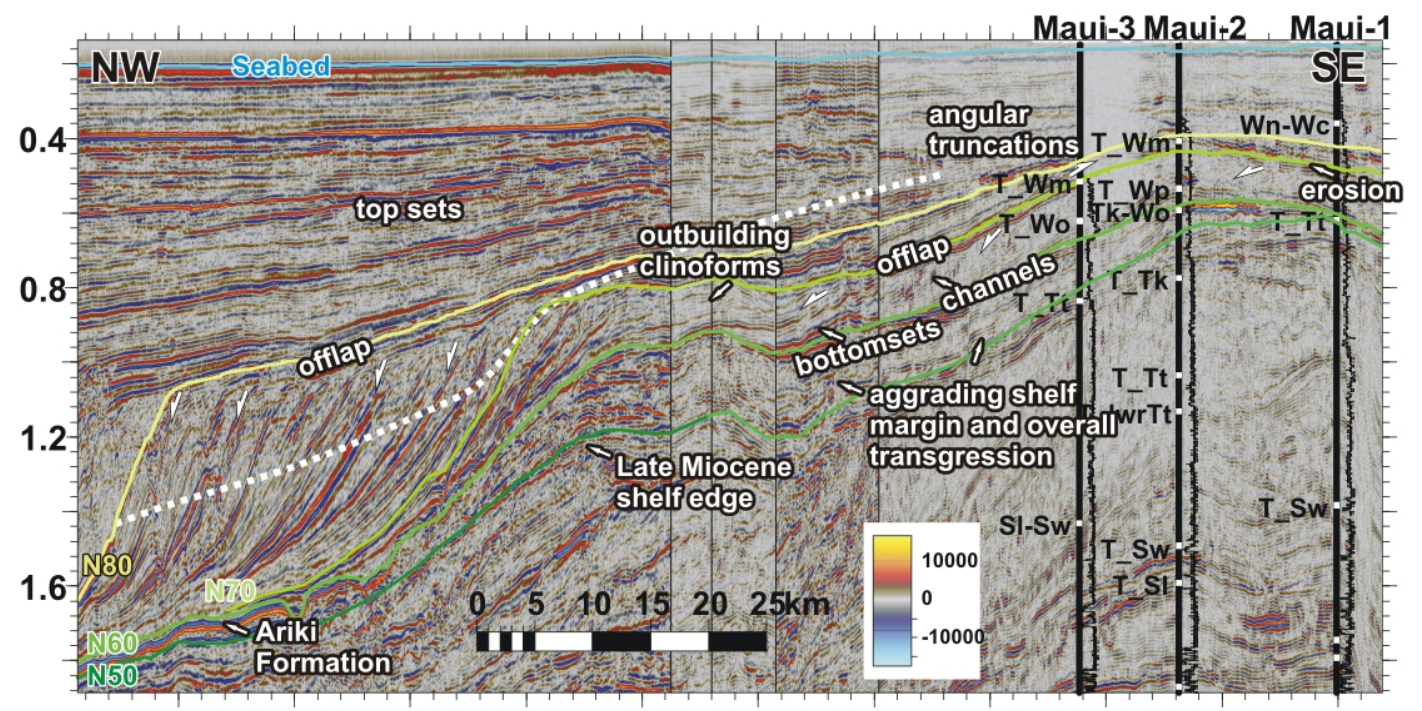

Figure 7.12 Seismic composite profile from the Maui 3D survey to the Western Platform showing the character of Late Miocene to Recent strata and development of the Giant Foresets Formation. Note the increase in foreset height from the Opoitian (Wo) to Mangapanian (Wm) strata. Well tracks of two wells are shown (thick black lines) with gamma-ray logs (thin black lines) and biostratigraphic age markers with New Zealand stage abbreviations (white squares, see Figure 7.2 for absolute age). Note that only the lower two horizons and the seabed reflector are regionally tied, whereas the remaining two are only locally interpreted to show the approximate age correlations of foresets. See Figure 7.13 for profile location. Approximate attribute extraction level used for the delineation of Plio-Pleistocene clinoform geometry (Figure 7.13A) is shown as a white dashed line. 

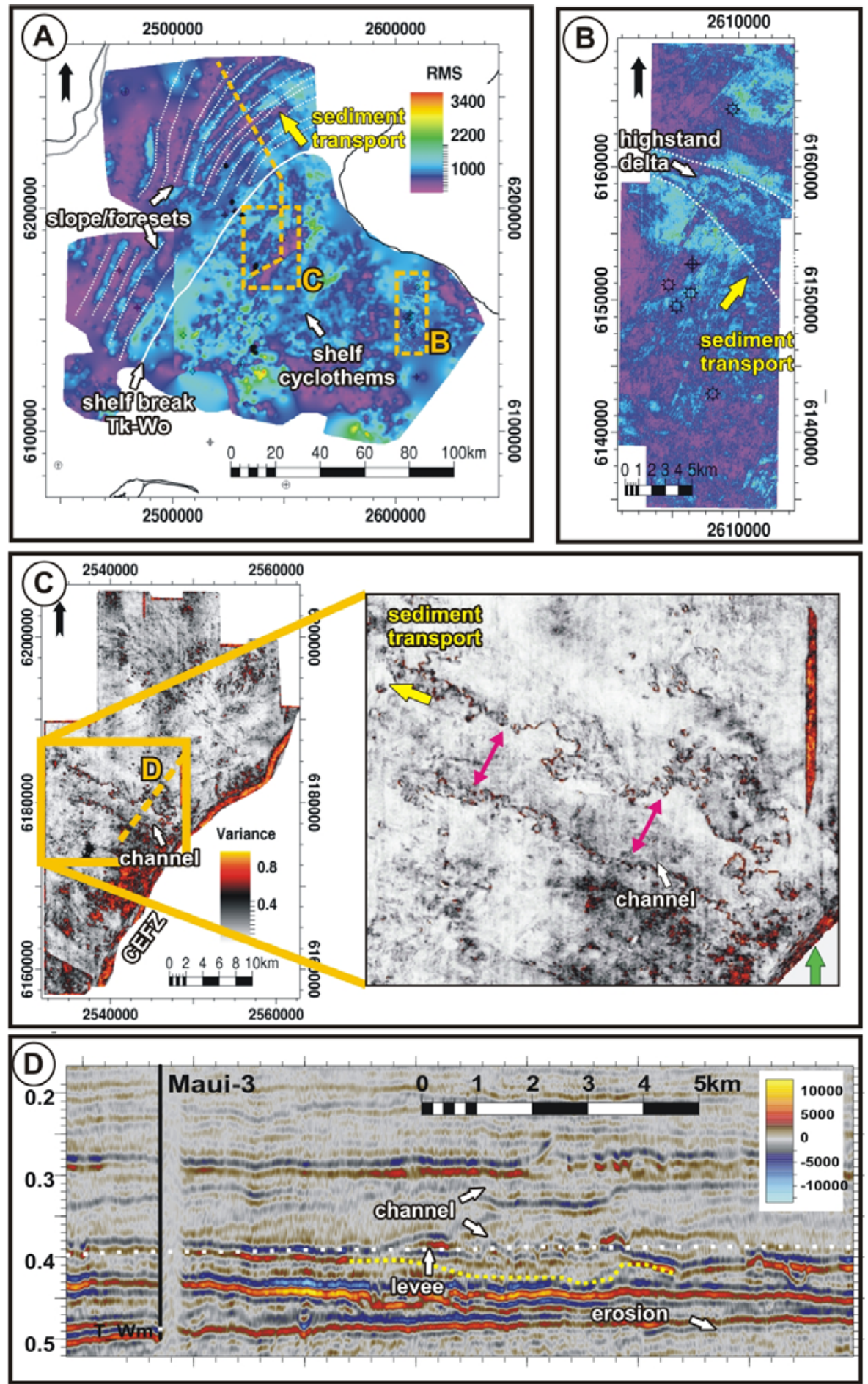

Figure 7.13 Facies characteristics and distribution of Late Pliocene-Pleistocene deposits (Giant Foresets Fm, Whenuakura Fm). A) Regional composite RMS interval attribute maps extracted over $50 \mathrm{~ms}$ above and below the marker indicated in Figure 7.6 and Figure 7.12, showing the general facies distribution and foreset orientations (white dotted lines). The phantom horizon was derived by proportional sub-division of the N50-Seabed interval. B) RMS interval attribute map from the Kerry 3D data set showing the orientation and sediment transport direction of Late Pliocene downlaps (highstand-delta, Wp-Wm shown in Figure 7.7). C) Variance attribute map extracted from the Maui 3D showing the outline of Quaternary channels $(\mathrm{Wn}-\mathrm{Wc})$. The channel interior is indicated by pink double arrows. D) Seismic profile from the Maui 3D survey showing the cross section character of the channel magnified in (C) with well path of Maui-3 (black line) with youngest available biostratigraphic marker (white rectangle). Locations of maps in (B) and (C) and seismic profile in (D) and Figure 7.12 are shown as orange dashed rectangles and lines in (A) and (C), respectively. Note that, despite the general westward-oriented sediment transport, north-eastward sediment transport occurred locally at least during Late Pliocene-Early Pleistocene relative base-level highstands (B). 


\subsubsection{Chronostratigraphy and sequence stratigraphy of Plio-Pleistocene clinoform sequences}

The architecture of the exceptionally well-imaged clinoform sequences on the Western Platform was further investigated via mapping of additional reflectors and automatically tracked horizons (Figure 7.14). Manually mapped and auto-tracked horizons on the DTB01-31 seismic line on the Western Platform were used to derive a pseudochronostratigraphic model, in which seismic reflectors are sequentially numbered and coloured from oldest to youngest, starting at the thickest part of individual sequences (Figure 7.15). A flattened version of these reflectors (Figure 7.15, centre) shows the overall east to west progradation of the depositional system in relative geologic time. The time markers show relatively muted clinoform progradation during the period between 63.6 Ma (Tk-Wo), which is followed by filling of a large axial slope channel and a slight increase in progradation until $3 \mathrm{Ma}(\mathrm{Wp})$, and thereafter rapid progradation of the shelf margin of more than $70 \mathrm{~km}$ to the present-day.

The character of topset and bottomset reflections is shown to the right and left of the overall progradational trend in Figure 6.15 and there are frequent alternations between relatively continuous (long traces) and discontinuous reflectors (short traces). The number of slope- and bottomset reflectors (left) is significantly greater than the number of mappable topset reflectors (right), suggesting a poor preservation of strata on the shelf. The oblique clinoform character and poor topset preservation are common characteristics of rapidly prograding shelf margins (e.g., Mitchum R.M \& Vail, 1977), and indicate a lack of accommodation space on the shelf during progradation. Due to the lack of vertical aggradation of clinoform reflectors, frequent down-stepping of the shelf edge, and overall depositional duration ( $\sim 3-5 \mathrm{my})$, the sequence is interpreted as an overall $3^{\text {rd }}$-order forced regression, which may have started during the Waipipian, as indicated by increasing toplap truncations in Tangahoe Formation clinoforms to the east (Figure 7.7 and Figure 7.9). On the south-western part of the Western Platform, the lack of accommodation space may be related to the distal effects of South Island uplift (Adams, 1980; Bishop \& Buchanan, 1995; Tippett \& Kamp, 1995).

Higher-order depositional periodicity is clearly evident from regularly occurring facies changes. A detailed sequence stratigraphic interpretation was derived based on reflector 
terminations and character within the framework of the chrono-stratigraphic horizon set (Figure 7.16). For simplicity, stratigraphic sequences were subdivided into early lowstand (fan), late lowstand (wedge), transgressive and highstand systems tracts (after Posamentier \& Vail, 1988) although it is realized that other schemes can be applied (see Catuneanu et al., 2010 for summary). A total of 21 sequences were identified between the latest Miocene ( 6.0 Ma) and present, of which 19 are observed since the Waipipian (3.0 Ma). Although the earlier phase (6-3 Ma) is relatively condensed in this area, facies variations observed within the north-eastward prograding shelf margin complex during the Opoitian and Waipipian (4.5-3 Ma, Tangahoe Formation, Figure 7.7 and Figure 7.11) suggest the presence of at least 8-10 additional cycles of similar periodicity.

As previously proposed by Beggs (1990), this sequence interpretation suggests that shelf margin/slope sedimentation and progradation occurs primarily during relative base-level lowstands. The boundary between the early and late lowstand is often not distinct (Figure 7.16), classic fan geometries are frequently absent, and numerous channel facies indicate bypass of sediment into the NCT. In the shelf to upper slope, lowstands are often marked by slumps and small channels, whereas deeply incising outer shelf channels are mostly limited to the last few cycles of the sequence. Sedimentation during transgression and relative highstands is focused on the shelf, whereas associated slope deposition is amalgamated into few medium- to high-amplitude, semi-continuous reflectors, which are interpreted as condensed sequences and can be laterally correlated across the seismic grid (Figure 7.11 and Figure 7.13A).

Transgressive systems tracts are mostly picked on the basis of a landward shift of reflectors with respect to the underlying lowstand deposits and stratal onlaps are only observed in some instances. In addition to flat-lying topset facies, occasional offlapping geometries indicate the development of deltas during relative highstands, and the top of the succession indicates the development of one such system during the current highstand. Due to the lack of accommodation space on the shelf, highstand deposits are frequently eroded during subsequent lowstand events, leading to the low preservation of shelf facies and incision and slumping in the slope. Erosion and bypass of sediment in shelf areas is consistent with the lack of lowstand deposits in coeval shelf deposits in outcrop (Naish \& Kamp, 1997; Naish et al., 2005). 


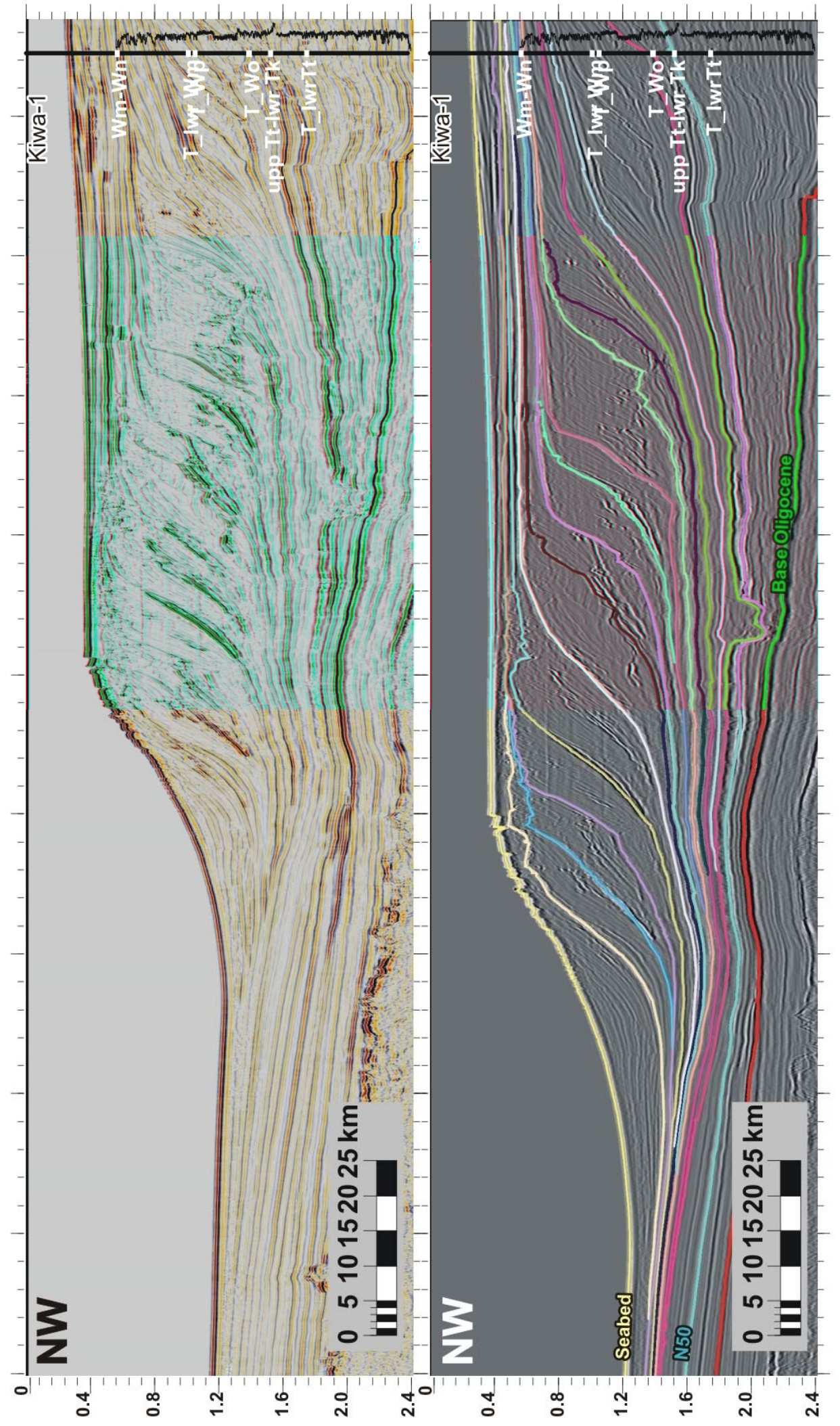

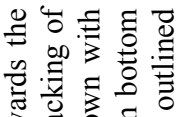

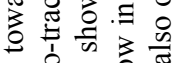

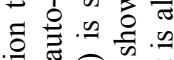

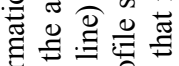

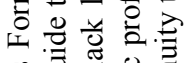

음

웅 응 흥

讨造

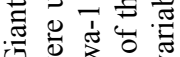

记菏

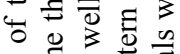

흐영

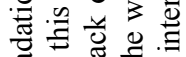

证

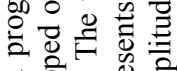

宛 高

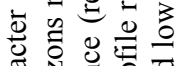

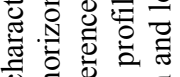

워ㅇㅝㅠ.

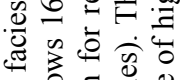

和 है

on $\overline{0}$ 至

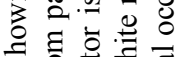

क 월

E.

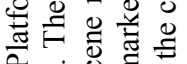

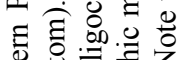

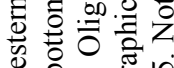

过荡 n

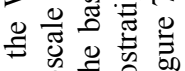

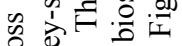

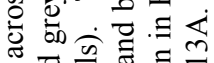

- 踏至

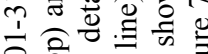

के 원.

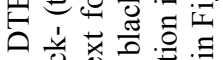

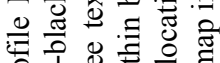

잉

讨

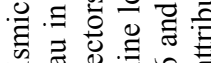

足

类交。

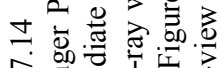

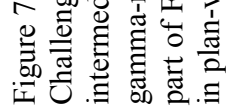



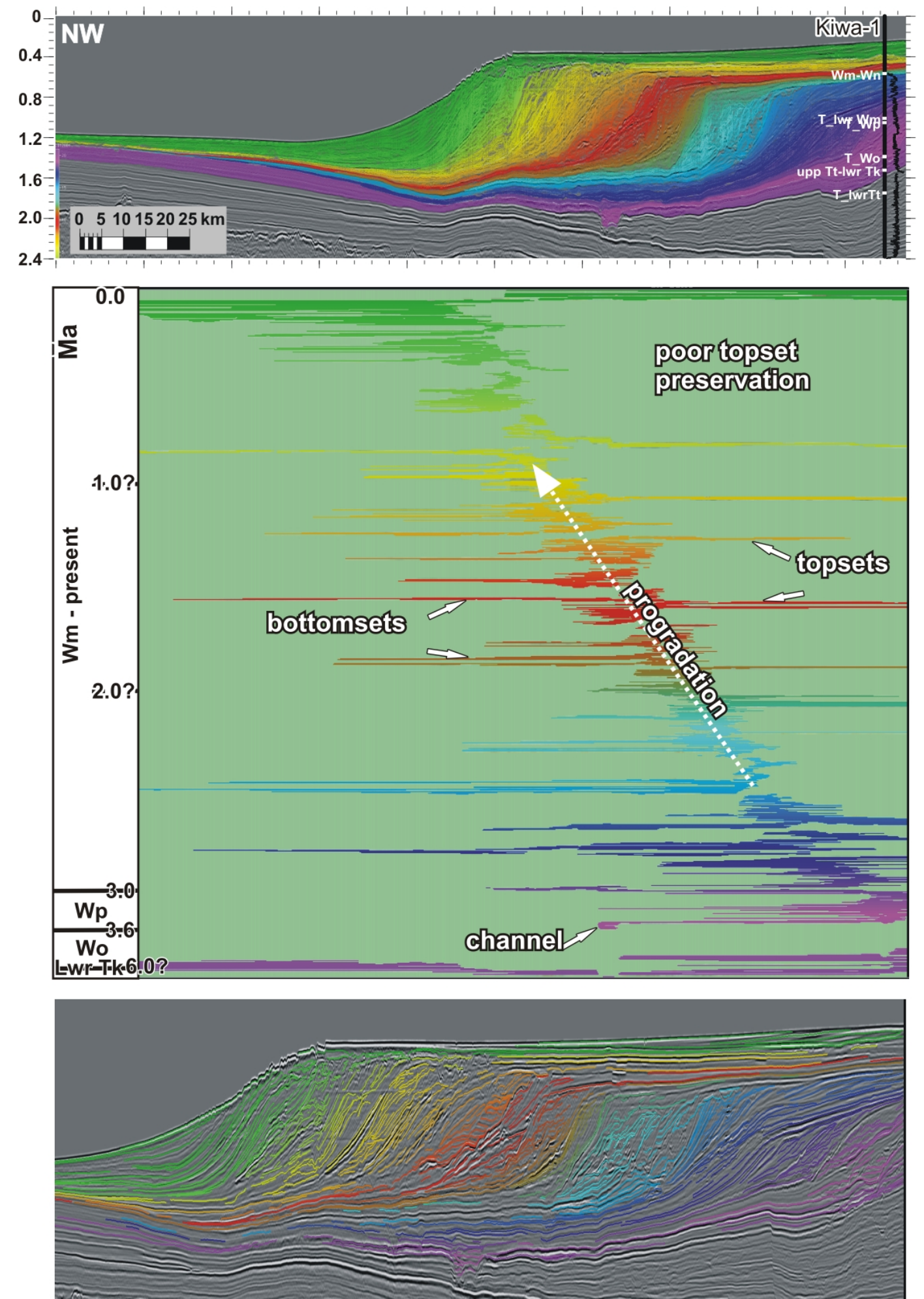

Figure 7.15 Depositional development of the Giant Foresets Formation derived by dip-steered auto-tracking of seismic reflectors on line DTB01-31. Top) seismic profile DTB01-31 with auto-tracked horizons coloured from oldest (purple) to youngest (green). The path of well Kiwa-1 (thick black line) is shown with gamma-ray wireline log (thin black line) and biostratigraphic markers (white rectangles). Centre) flattened and vertically stacked version of horizons shown in top panel (pseudo-chronostratigraphy, with colours as above). Time constraints from biostratigraphic data are shown on left together with simple linear approximation of timing from 3.0-0.0 Ma. Bottom) magnified version of line DTB01-31 with sparser selection of auto-tracked horizons, showing the good fit of seismic reflections and their terminations with auto-tracked horizons. 

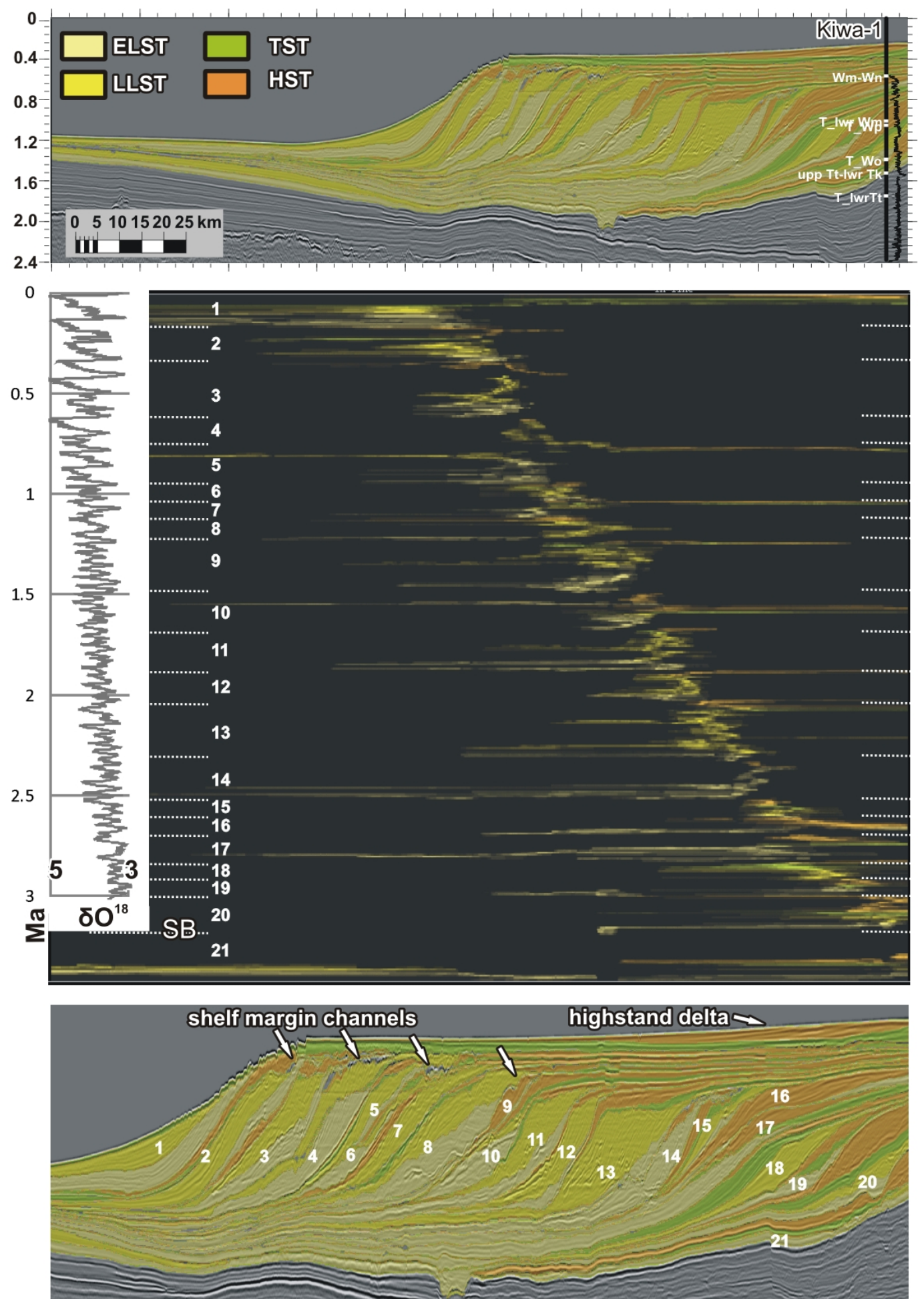

Figure 7.16 Sequence stratigraphic interpretation of the Giant Foresets Formation on line DTB01-31, based on auto-tracked horizons shown in Figure 7.15. Top) seismic profile with auto-tracked horizons coloured according to systems tract interpretation indicated in legend (ELST/LLST-early/late lowstand systems tract, TST/HSTtransgressive/highstand systems tract). The path of well Kiwa-1 (thick black line) is shown with gamma-ray wireline $\log$ (thin black line) and biostratigraphic markers (white rectangles). Centre) flattened and vertically stacked version of auto-tracked horizons shown in top panel (pseudo-chronostratigraphy), coloured according to systems tract interpretation. Sequence boundaries (base of lowstand) are shown as stippled line on the left and right and are sequentially numbered. The graph on the left shows an oxygen isotope curve derived from global benthic $\delta \mathrm{O}^{18}$ records (Lisiecki and Raymo, 2005) from 3.0-0.0 Ma for reference. Note the dominance of higher frequency signal (41 ky) and lower frequency signal (100 ky) before and after $\sim 9.9 \mathrm{Ma}$, respectively. Bottom) magnified version of line DTB01-31 with sequence stratigraphic interpretation and numbered sequences according to centre panel. 


\subsubsection{Paleogeographic synthesis}

The sedimentary characteristics, facies development and fault evolution constrained in the previous sections are combined to reconstruct the paleogeographic development of the basin from the latest Miocene (Figure 7.17-Figure 7.20).

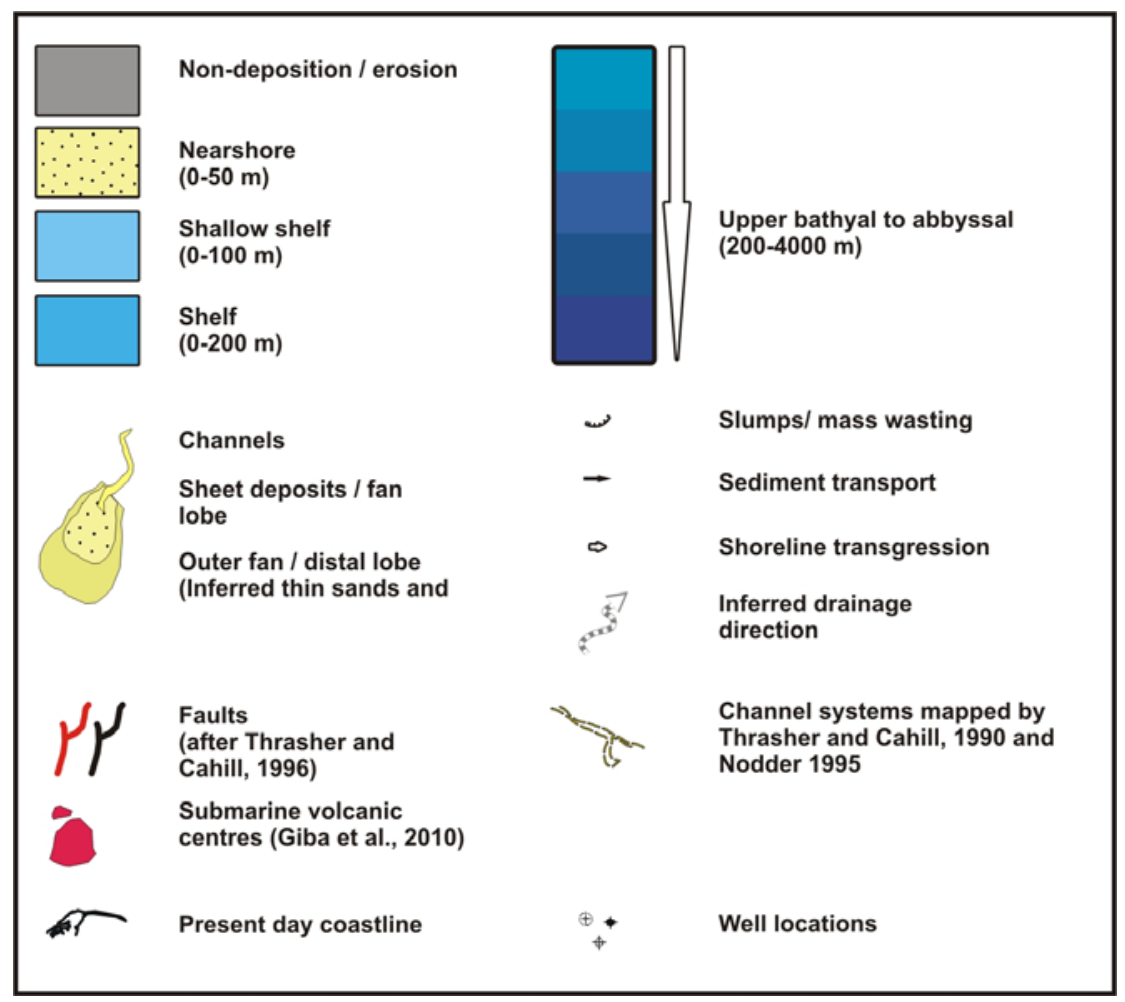

Figure 7.17 Legend for palaeographic maps. Individual water-depth associations are shown to represent the general basin morphology and their detailed bathymetry may be inaccurate.

\section{Latest Miocene to Early Pliocene}

Gradual subsidence of a semi-circular depocentre in the eastern basin (Toru Trough) began during the Late Miocene and led to southward onlap of shallow marine facies. These onlapping facies are considered to be analogous to onshore facies of the Matemateaonga Formation (Fleming, 1953; Vonk et al., 2002). Convergent activity ceased before the end of the Miocene in the South Taranaki Bight and subsidence was not fault controlled. The location of this depocentre agrees with the early Pliocene depocentre of Anderton (1981) and marks the area of early flooding in the Wanganui Basin. Subsidence of this area led to the diversion of drainage systems from the South 
Island towards the east and basin-ward sediment transport and deposition of basin-floor fans (Mangaa Formation) was focused on the actively extending and subsiding Northern Graben (Hansen \& Kamp, 2004; 2006; Giba et al., 2010). Sediment delivery to the western basin was additionally hampered by the remnant structural high in the central basin (Farewell Rise), which is expressed by subdued westward progradation of the shelf until the Waipipian-Mangapanian and limited clastic input downslope resulting in deposition of marls of the Ariki Formation (e.g., in well Tane-1).

\section{Late Early to early Late Pliocene}

Rapid tectonic basement subsidence of up to $500 \mathrm{~m}$ during the Opoititan ( 4.5 Ma) and associated tilting of adjacent areas resulted in further flooding of the Farewell Rise and southern Wanganui Basin (Figure 7.18). This rapid subsidence event agrees well with outcrop geology in the present-day onshore area, where it is expressed by a change from shoreface facies to bathyal glauconitic mudstone layers (Hayton, 1998; Kamp et al., 2004). The subsidence emphasised the eastward diversion of sediment drainage from the South Island, while progradation on the western margin remained subdued. The deposition of sandy basin-floor fan facies in the eastern basin indicates the formation of a semi-enclosed basin and entrapment of sediment, which substantiates earlier speculations that renewed deposition of marls of the Ariki Formation in the Northern Graben until the Waipipian can be related to subsidence in the Wanganui Basin (Hansen \& Kamp, 2004; Kamp et al., 2004). The progradation of the shelf edge across the now buried PateaTongaporutu high (basement high associated with the Taranaki Fault) calls into question the interpretation of two contemporary margin wedges east and west of this structure (Kamp et al., 2004), but suggests that the main divide was represented by the Farewell Rise.

During the Waipipian (Figure 7.19), most of the accommodation space in the eastern offshore area was backfilled to shallow shelfal environments. Sandy gravity flows were deposited towards the northeast in the present-day onshore area (Kamp et al., 2004; Townsend et al., 2008) and western clinoforms subsequently prograded towards the main physiographic shelf margin in the northwest. While parts of the large axial bypass channel system mapped in Chapter 6 may have been active during the early Pliocene, it is considered likely that the system was rejuvenated after depocentres in the east were infilled and outbuilding clinoforms approached the physiographic shelf edge in the west. 


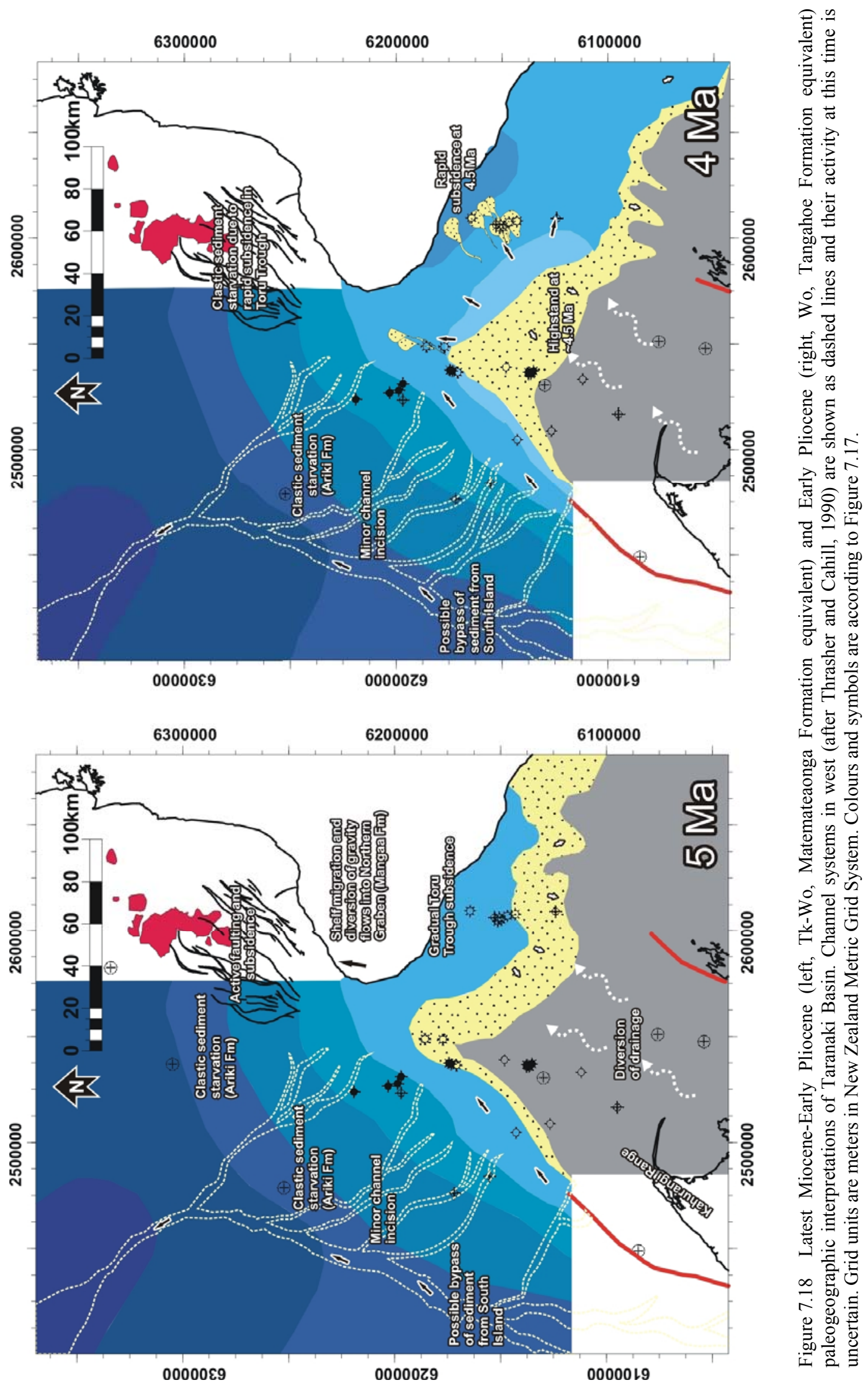




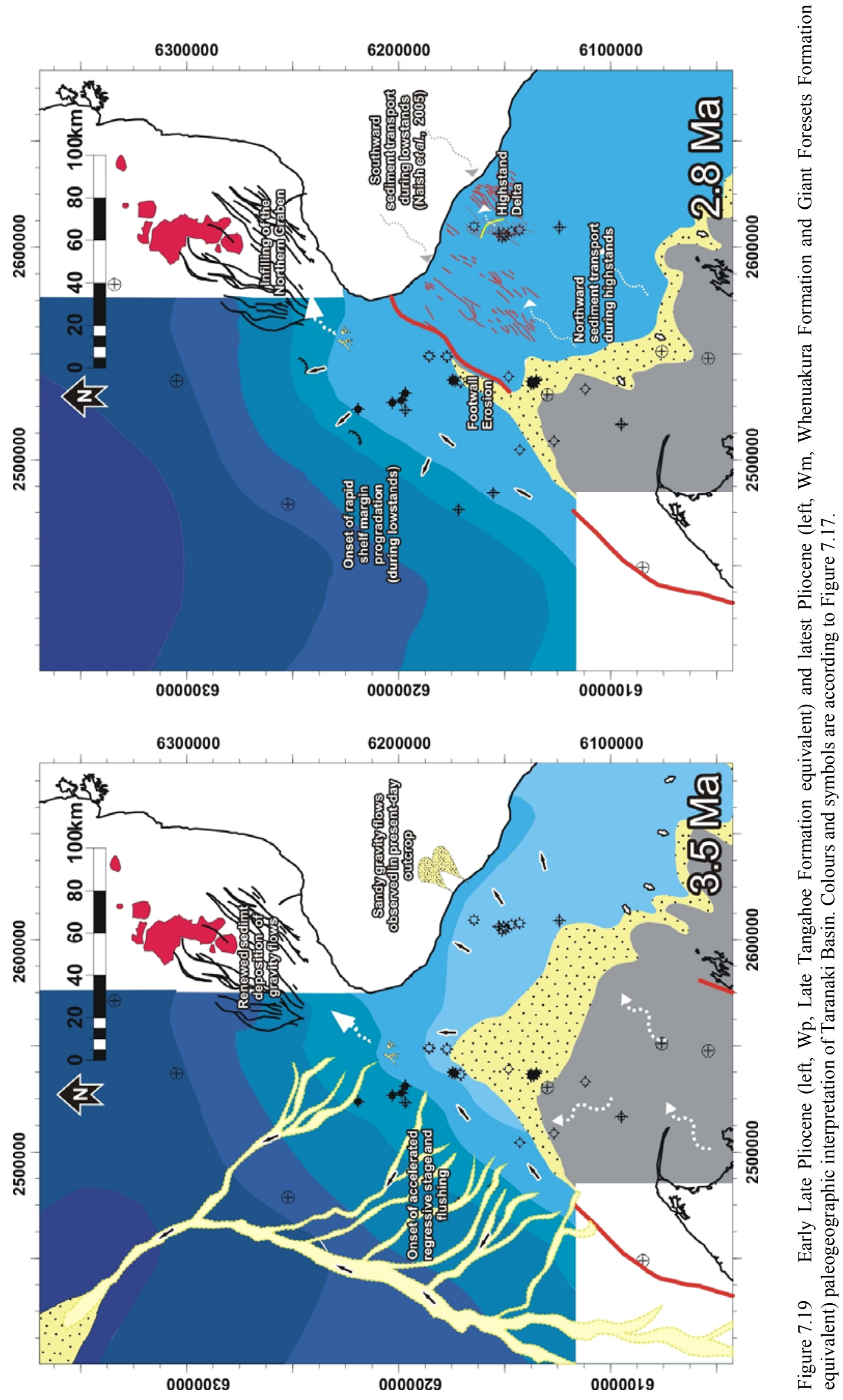




\section{Onset of extensional faulting in the South Taranaki Bight}

Diverted channel orientations in the northern Maui 3D survey (Figure 7.9C) indicate that extensional systems of the Northern Graben were encroaching upon the southern Taranaki Basin by the late Waipipian to early Mangapanian ( 3.3-2.7 Ma). Onset of extension on the southern Cape Egmont Fault is inferred to have commenced at $\sim 3.0 \mathrm{Ma}$ (Figure 7.19, right), which is indicated by sedimentary growth in the hanging wall above the Tangahoe Formation (Figure 7.6). Rapid fault offset of more than $1 \mathrm{~km}$ during the Pliocene (see Chapter 3) may have temporarily localized sediment transport in the hangingwall of the Cape Egmont Fault, while sedimentation generally kept pace with high displacement rates. Truncated strata on the western side of the fault may be an expression of footwall uplift and minor erosion near or above the erosional wave base. A series of smaller, northeast-southwest-oriented faults developed probably at a later stage as indicated by the structural restoration shown in Chapter 3 .

\section{Late Pliocene to Pleistocene}

Shelf progradation was focused on the western margin since the Mangapanian ( 3.0 Ma, Figure 7.19 , right). The timing of rapid westward progradation is consistent with infilling of accommodation space in the Northern Graben (Hansen \& Kamp, 2004) and was probably influenced by coeval hinterland uplift of northern parts of the North Island (Stagpoole, 1998; Pulford \& Stern, 2004). In the Toru Trough, deposition of shelf cyclothems indicate that the basin continued to gradually subside, although back-stripped well data suggests that tectonic uplift may have reduced the amount of subsidence caused by sediment loading (Figure 7.4). North-eastward-oriented sediment transport in shelf delta systems during Late Pliocene highstands (Figure 7.7 and Figure 7.13B), corresponds well with provenance studies of coastal outcrop sections, in which transgressive facies suggest sourcing from northern North Island volcanoes, whereas highstand facies imply sourcing from the South Island (Naish et al., 2005). Due to the limited age resolution $(\mathrm{Wp}-\mathrm{Wm})$ it is unclear how long this pattern persisted, but increased dominance of northern sourcing is likely due to the increased uplift of the North Island land mass (Kamp et al., 2004; Pulford \& Stern, 2004). 
Tilting and erosion of strata in the northern Toru Trough parallel to the present-day coastline may indicate that the eastern basin area was affected by this uplift during the Pleistocene (Figure 7.20). Youngest strata sub-cropping at this unconformity are of Mangapanian-Nukumaruan age, which suggests an age of less than 1.6 Ma. While potentially several hundred meters of missing strata are indicated by seismic reflector truncation (see Chapter 3), paralic and shallow marine strata in the present-day onshore area (Abbott et al., 2005; Townsend et al., 2008) suggest that the area was not substantially sub-aerially exposed. Fluvial or paralic channel systems observed west (Figure 7.13) and east of the Cape Egmont Fault (Nodder, 1995) indicate the development of westward-oriented drainage systems and periodic exposure of large parts of this shelfal area during relative base-level lowstands (Figure 7.13C). 


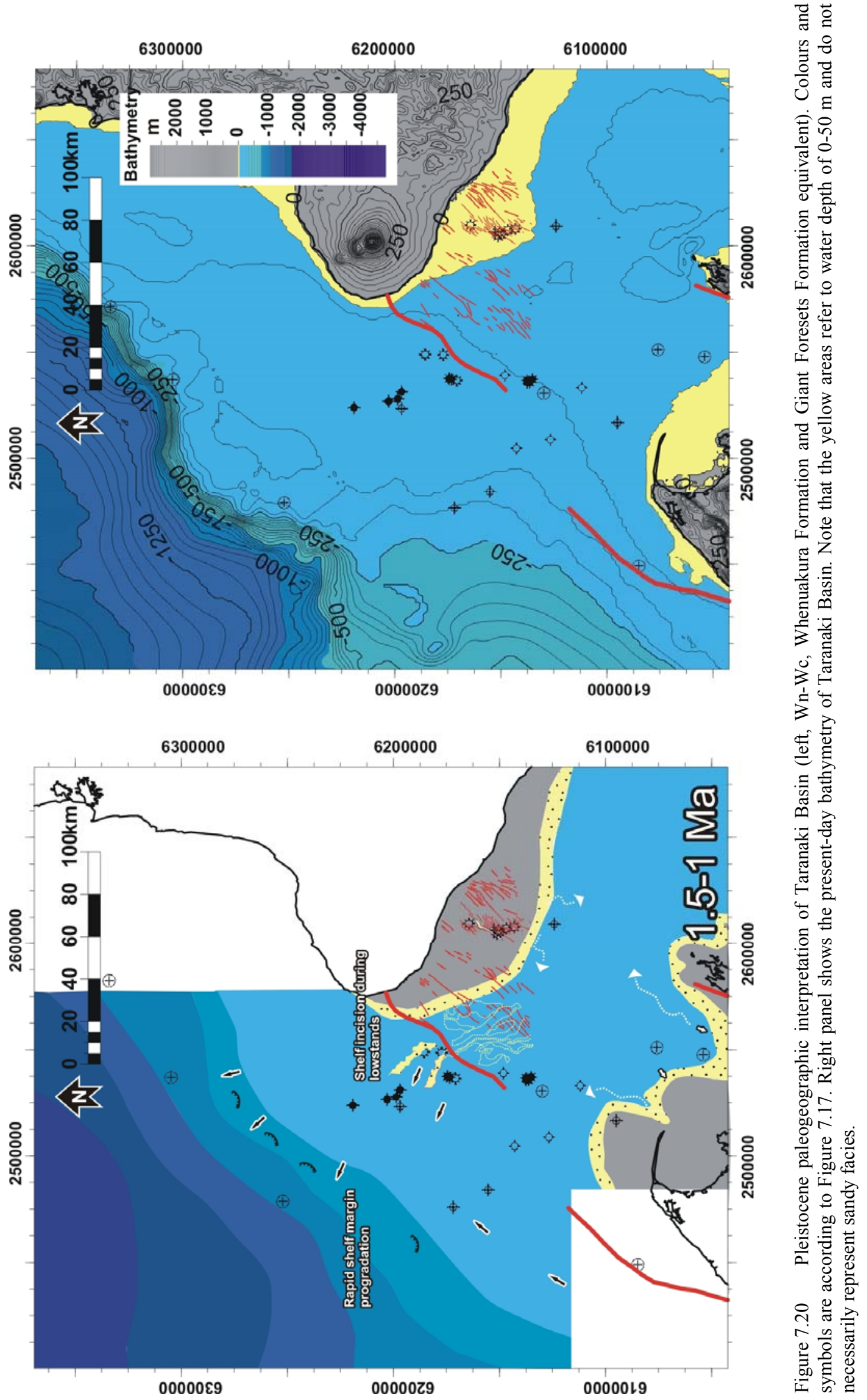




\subsubsection{Characteristics of backarc basin formation}

Previous authors have recognized that parts of the Taranaki Basin developed from a compressional retroarc foreland basin into an extensional basin and that the formation of the Toru Trough and western Wanganui Basin formed in association with a incipient backarc activity (King \& Thrasher, 1996; Lamarche et al., 2005; Proust et al., 2005; Giba et al., 2010). While its location nearby or within a magmatic arc in the hinterland of a convergent plate boundary (Figure 7.21) would classify Taranaki Basin as an intra- or backarc basin (Taylor \& Karner, 1983; Marsaglia, 1995), faulting and subsidence history show unusual patterns of basin development that mark the transition from between compressional and extensional regimes.

Sedimentary thickness distributions and faulting patterns evident on seismic data suggest that local convergence in the South Taranaki Bight ceased before the end of the Miocene (7-5 Ma), and was since limited to structures in the vicinity of northern South Island (e.g., Thrasher, 1989). Considerable normal displacement on the Cape Egmont Fault (Figure 7.6) and across the Toru Trough (Figure 7.10) since about $3 \mathrm{Ma}$ illustrate that extensional activity has migrated southward from its earlier position in the northern Taranaki Basin, in line with interpretations by previous authors (King \& Thrasher, 1996; Giba et al., 2010). The majority of observed Plio-Pleistocene tectonic subsidence in the Toru Trough (and contiguous Wanganui Basin) however occurred during the intervening time between significant compressional and extensional faulting, and thus cannot be attributed to shallow crustal faulting and classic backarc basin formation along divergent faults (Uyeda, 1981; Taylor \& Karner, 1983).

The wavelength of latest Miocene to Early Pliocene subsidence of 100-200 km indicated by seismic isochron maps (Figure 7.5) is comparable to the dimensions of the gravity low observed in the present Wanganui Basin (Figure 7.21) (Reilly, 1972) and agrees with eastward and southward migration of subsidence locus through time (Anderton, 1981). The magnitude of tectonic subsidence in the Toru Trough $(700 \mathrm{~m})$ is similar to values determined in the Wanganui Basin (Stern et al., 1992), but indicates a phase of rapid subsidence at rates of up to $1000 \mathrm{~m} / \mathrm{my}$ and subsequent tectonic uplift (Figure 7.4). While the observed uplift signal may be overestimated due to regional (flexural) compensation of the sedimentary load, high confidence is put on the rapid tectonic subsidence, which is substantiated by the good agreement between biostratigraphic depth markers and 
clinoform heights (Figure 7.3 and Figure 7.7). Since faulting cannot explain the observed subsidence patterns, any alternative mechanism proposed for the tectonic evolution has to honour the characteristics of transient subsidence, uplift and, sequential timing of fault activity.

The transient nature, magnitude, and rate of subsidence are defining characteristics of surface deflections resulting from viscous downward drag by subduction induced asthenospheric mantle flow (Mitrovica et al., 1989; Gurnis, 1992). However modelled wavelengths of such effects are an order of magnitude greater than observed for the PlioPleistocene Taranaki and Wanganui depocentres (Burgess \& Moresi, 1999). The wavelength of subsidence and subsequent uplift in absence of significant upper crustal faulting requires a driving mechanism localized with the lithospheric mantle. Due to the substantial distance $(>200 \mathrm{~km})$ with respect to the plate boundary (Figure 7.21), circular nature of subsidence, and depth of the Benioff zone more than hundred kilometres beneath the Toru Trough (Anderson \& Webb, 1994), it is unlikely that the subsidence can be entirely related to high friction on the plate interface. This is because shearstresses would have had to be unusually high (>170 MPa, Stern et al., 1992). A model of lithospheric instability however, as proposed by Stern et al. (2006), would provide a necessary mechanism to rapidly deflect the crust on the observed wavelength, although extensional faults mostly postdate the deflection and do not satisfy the contemporary extension predicted in the periphery of such instabilities (Houseman \& Molnar, 1997). The chronologic offset of subsidence and extension in the Toru Trough and Cape Egmont Fault suggests that faults are not purely related to crustal bending as predicted by flexural models (Stern et al., 1992), and may be linked to backarc extension.

Backarc extension is frequently associated with roll-back of the subducted slab and onset of asthenospheric mantle flow (e.g., Uyeda, 1981; Sdrolias \& Müller, 2006). It is considered possible that the subsidence, eastward stepping of depocentres, and subsequent development of extension may be an early expression of slab rollback of the underlying Pacific plate. The following uplift and extension could indicate the initial stages of asthenospheric wedge development and backarc formation. Seismological observations suggest a lack of mantle flow in the area south of Mount Ruapehu on the central North Island (Reyners et al., 2006), which may indicate that the backarc is in its very early stages and not fully developed. Slab rollback has been inferred for northern areas of Taranaki Basin (Wallace et al., 2004) and would present a mechanism to explain 
the north-south propagation of depocentres in western North Island observed by previous authors (Kamp, 1999; Stern et al., 2006). While lateral crustal motions are frequently observed in backarc environments (Uyeda, 1981; Schellart et al., 2006), lithospheric depression associated during the early phases of backarc basin evolution have not been widely documented in the literature. However, observations of rapidly drowning carbonate bodies in similar tectonic environments of the South China Sea (Dorobek, 2008), for example, may suggest that such processes are a characteristic feature of backarc initiation. The validity of such a mechanism would have to be proven numerically, and is beyond the scope of this study.
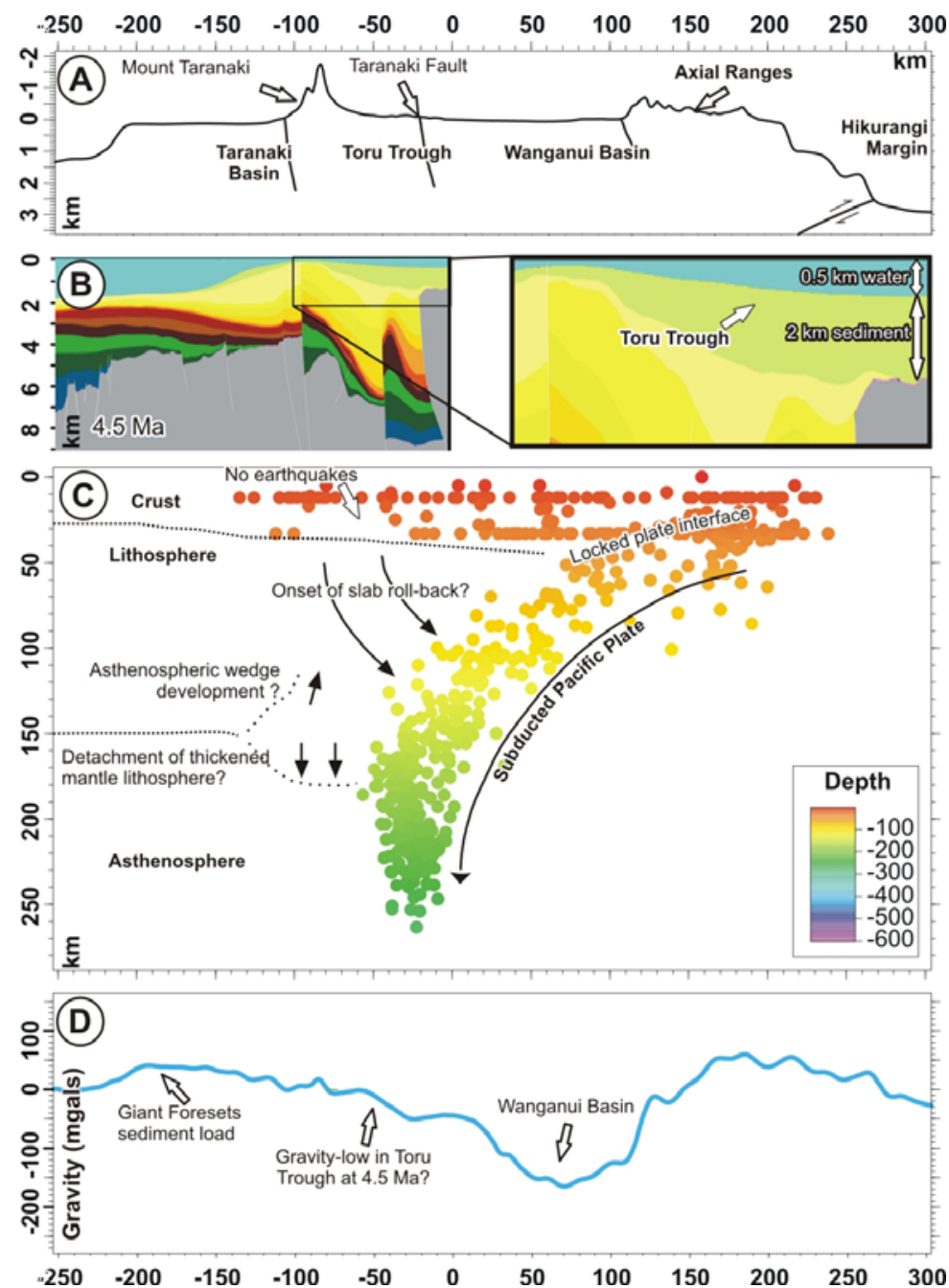

Figure 7.21 Profiles across the North Island, Wanganui, and Taranaki Basin (see Figure 7.1for location). A) Present-day topography and bathymetry extracted along a digital elevation model $50 \mathrm{~km}$ north of the offshore study area for reference. B) Palinspastic reconstruction across Taranaki Basin, showing the depression of the Toru Trough after deposition of the Matemateaonga Fm and rapid subsidence at $\sim 4.5 \mathrm{Ma}$ (see magnified view on right). C) Hypocentre locations of earthquakes $\mathrm{M}>4.5$ since 1950 located by the Geonet seismic network (www.geonet.org.nz) projected over an area $\pm 50 \mathrm{~km}$ north and south onto the profile. Hypocentres show the crustal seismicity and the Benioff zone of the subducted Pacific slab, which is observed to be rapidly steepening under the study area. The Moho and lithosphere/asthenosphere boundary are schematically depicted (stippled line) and possible mechanisms for subsidence are annotated. D) Satellite gravity profile (Wood \& Woodward, 2002), showing the present-day -150 mgal gravity low in the area of the Wanganui Basin and gravity high on the Western Platform attributed to the Giant Foresets sediment load (see also Stern et al., 1992). 
Stratigraphic patterns observed from seismic data show a cyclic hierarchy of depositional changes reflecting the varying controls of tectonism, sediment supply and eustasy (Figure 7.22). The sedimentary sequences described above show a change in dominant stratal terminations from onlap (Matemateaonga Formation), to offlap (Tangahoe Formation) to rapid progradation of the shelf (offlap and downlap, late Tangahoe and Giant Foresets formations). Consequently, these sequences can be interpreted in terms of third-order (0.5-5 Ma) transgressive, highstand, and falling stage/regressive elements of a secondorder megasequence (5-50 Ma). The onset of the regressive phase may have started during the Waipipian (3.6-3.0 Ma), as indicated by increasing topset erosion in the Toru Trough (Figure 7.7 and Figure 7.10), suggesting that the rate of base-level fall may have out-paced subsidence. The onset of regression coincides with a general lowering trend in in global sea level since the Late Pliocene (Haq et al., 1987), which may be influenced by the growth of southern and, later, northern hemisphere ice sheets (e.g., Shackleton et al., 1984; Naish et al., 2005). However, it is considered unlikely that rapid water-depth increases in the Toru Trough of up to $500 \mathrm{~m}$ over timespans less than $1 \mathrm{Ma}$ are of paleoclimatic origin, as fluctuations in global sea levels are expected to be limited to amplitudes of $<100 \mathrm{~m}$ (Naish \& Wilson, 2009). Thus, the differentiation of large-scale sedimentation patterns is considered to be largely controlled by tectonic events as noted by previous authors (King \& Thrasher, 1996) and continuously increasing sediment input from the rising South and North Island land masses.

The repetitive occurrence of seismic facies patterns clearly shows the superposition of higher-order cycles. While higher-order cyclicity is evident in shelf strata by the repetitive backwards- and forwards-stepping of seismic facies, changes in stratal terminations (Figure 7.7), and bypass channels (Figure 7.13C), constraining these sequences is difficult due to the limited resolution of generic seismic reflection data $(>10$ m) and often poor lateral preservation of shelfal highstand facies during lowstand erosion. Shelf margin, slope, and basin-floor fan facies of the Tangahoe and Giant Foresets Formation, on the other hand, have a more constrainable expression of cyclic superposition on seismic reflection data. The sequences mapped within the Giant Foresets Formation suggest the periodic differentiation of sedimentation loci landward and basin-ward of the shelf edge. Foreset sequences constrain the cyclicity of slope to 
basin floor sedimentation during relative base-level lowstands, a signal which is frequently missing in onshore outcrop (e.g., Naish \& Kamp, 1997; Naish et al., 2005).

The 19-21 cycles mapped within the Giant Foresets Formation on the Western Platform (Figure 7.16 and Figure 7.22 ) indicate a periodicity of $150-280 \mathrm{ky}$ and thus $4^{\text {th }}$ - to $5^{\text {th }}$ order cyclicity, respectively (e.g., Vail et al., 1977a; Catuneanu et al., 2010). Similarly, assuming duration of Tangahoe shelf margin progradation in the offshore Toru Trough of about 1 my ( 4.3-3.3 Ma), the $>10$ recognized highstand-lowstand sequences (relatively higher amplitude foresets, Figure 7.11) would suggest a $100 \mathrm{ky}$ recurrence time. The repetitive sequence architecture is strongly suggestive of cyclical sea-level fluctuations, possibly reflecting the influences of orbital eccentricity on sea-level heights $\left(5^{\text {th }}\right.$-order Milankovich cycles).

While it is widely acknowledged that Late Pliocene to Pleistocene sea-level changes were controlled by orbitally influenced variations in the size of Northern Hemisphere continental ice sheets (e.g, Shackleton et al., 1984), ice volumes are generally considered to have been too small to cause sea-level changes of $>5 \mathrm{~m}$ until expansion of the Greenland ice-sheet towards Asia and North America at 3.0 Ma. Thus, cyclic variations in sedimentation pattern during the late Early-early Late Pliocene (Tangahoe Formation) are likely to reflect the dynamics of ice sheets in the Southern Hemisphere as suggested by Naish et al. (2005). While changing sea level is the likely driver for the observed sedimentary stacking patterns, additional research is required to constrain the absolute magnitude of sea-level changes.

Facies variations on the orders observed here $(\sim 100 \mathrm{ky})$ have been documented in outcrop and high resolution seismic reflection data in Taranaki sequences in Miocene to Pleistocene sequences (e.g., King et al., 1994a; Nodder, 1995). However, variations of Pliocene shelf sequences described in outcrop have shown the dominance of $41 \mathrm{ky}$ periodicity $\left(6^{\text {th }}\right.$-order), while $5^{\text {th }}$-order cycles are subdued until the Middle Pleistocene (Abbott \& Carter, 1994; Naish \& Kamp, 1997; Carter \& Naish, 1998; Naish et al., 2005). This change from smaller-amplitude, higher-frequency events to higher-amplitude, lower-frequency events is reflected in benthic oxygen isotope records (e.g., Lisiecki \& Raymo, 2005), from which water-depth fluctuations on the order of 10-30 m and $120 \mathrm{~m}$ are derived for the Pliocene-Early Pleistocene and Middle to Late Pleistocene, respectively (Naish \& Wilson, 2009). This leaves two possibilities for the interpretation 
of observed cyclicity in Taranaki Basin sedimentary sequences. Cyclic repetition of foreset sequences mapped in the Tangahoe and Giant Foresets formations could represent stacks of multiple $41 \mathrm{ky}$ cycles that produce composite foreset sequences. Large channel systems that incise into the strata near the contemporary shelf margin observed during the last eight sequences mapped in Figure 7.16 may be a manifestation of higheramplitude sea-level fluctuations associated with Quaternary glacial cycles, during which the coastline would have migrated to within a few tens of kilometres of the shelf edge. On the other hand, it is considered possible that obliquity-paced $\left(6^{\text {th }}\right.$-order $)$ sea-level variations have little effect on shelf margin dynamics and that shelf margins respond to cyclic signals not observed in the benthic oxygen isotope records. Since poor age resolution of strata in petroleum exploration wells hampers the correlation between observed depositional events and detailed isotope and eustatic proxy curves, further sampling is needed to constrain the eustatic influences on shelf margin development in New Zealand. 


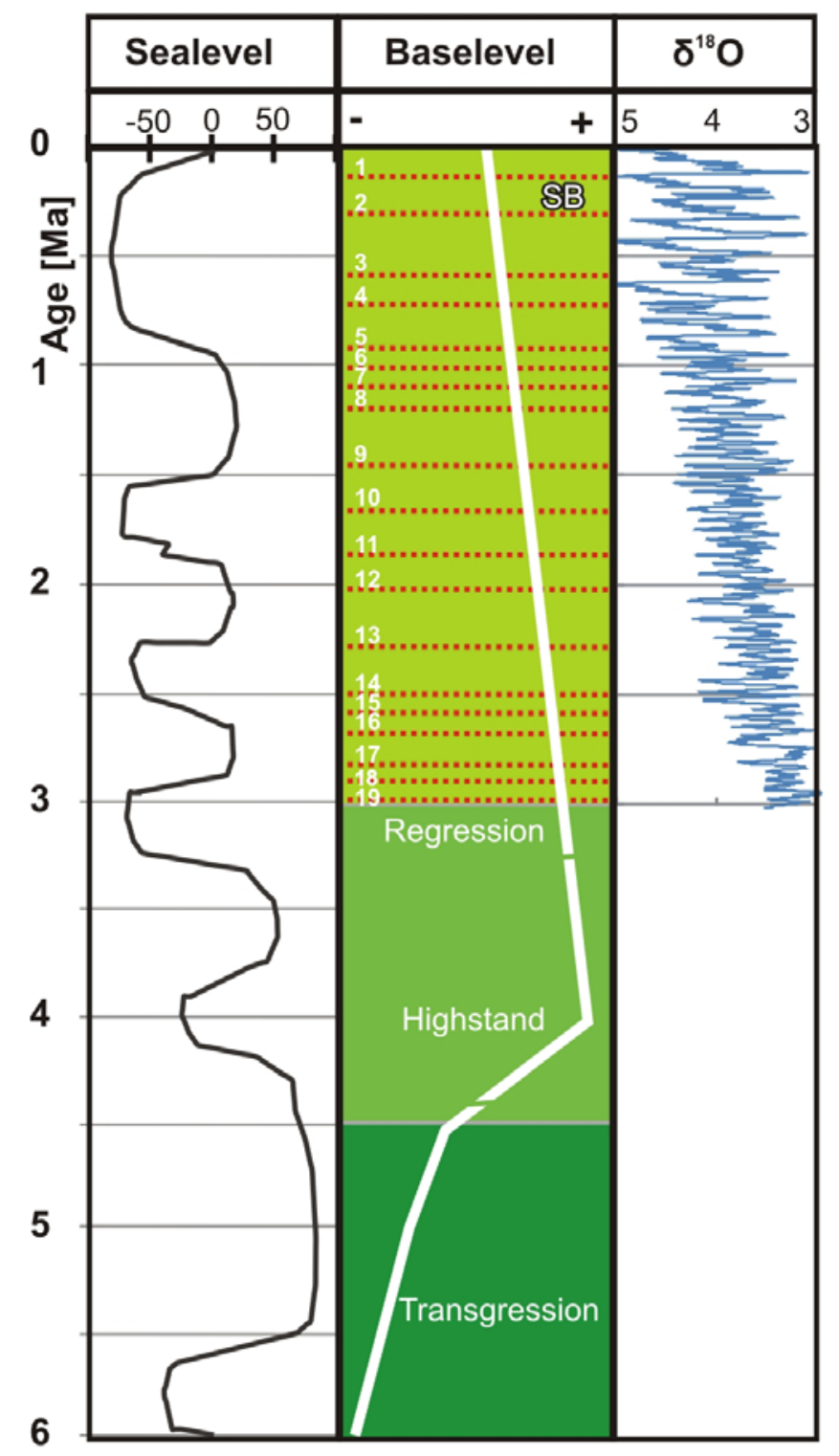

Figure 7.22 Summary of global sea-level estimates and base-level changes in Taranaki Basin. The left column shows the sea-level curve from the Haq et al. (1987) since 6 Ma. The centre column shows the inferred base-level changes in Taranaki Basin observed from seismic data (white line). The background colour indicates the broad formation subdivision (N60-N60, N60-70, N70-N80). Red dashed lines mark the sequence boundaries observed within the Giant Foresets Formation assuming constant sedimentation (Figure 7.16). The right column shows an oxygen isotope curve derived from global benthic $\delta^{18} \mathrm{O}$ records (Lisiecki and Raymo, 2005) since 3.0 Ma. 
The analysis of borehole stratigraphy and seismic facies patterns has provided further constraints on the latest Miocene to Recent paleographic evolution of southern Taranaki Basin and its characteristics during development from a compressive foreland to an extensional backarc basin.

Late Miocene to Early Pliocene subsidence patterns and sub-basin formation cannot be explained by shallow crustal faulting, but observed wavelengths of crustal deflection $(100-200 \mathrm{~km})$ imply geodynamic processes that are localised within the mantle lithosphere. Displacements of more than $2 \mathrm{~km}$ on the Cape Egmont Fault and formation of normal faults across the Toru Trough since 3 Ma suggest the South Taranaki Bight has developed into a young (proto-) backarc basin. The transient nature of subsidence that preceded normal faulting may indicate the development of instabilities in the previously over-thickened lithosphere as proposed by Stern et al. (2006) or may represent the precursors to roll-back of the subducted Pacific plate.

The combined analysis of tectonic subsidence and seismic facies patterns has shown a rare example of the effects of subduction-related mantle dynamics on sediment dispersal. These medium-wavelength vertical crustal motions controlled the distribution of sandy shallow marine sequences (Matemateaonga Formation) and turbidite deposition (Tangahoe Formation). Together with crustal faulting in the Northern Graben, these vertical motions may explain the temporary muting of clastic sediment delivery (Ariki Formation) to the western and northern basin despite the generally large sediment volumes delivered to the basin (Stagpoole et al., 2002; Wood \& Stagpoole, 2007).

In addition to the tectonically-controlled, $2^{\text {nd }}$ - to $3^{\text {rd }}$-order base-level fluctuations, the cyclical superposition of shelf margin sequences since the early Late Pliocene (4.5 Ma) are suggestive of sea-level changes at the pace of orbital eccentricity (100 ky) or, possibly, obliquity (40 ky). Analysis of clinoform sequences complement sequence stratigraphic studies of onshore strata (e.g., Saul et al., 1999a; Naish et al., 2005) and shows that shelf margin growth occurred primarily during relative base-level lowstands. 


\section{CHAPTER 8 SYNOPSIS}

This thesis has presented the first integrated seismic mapping study of the greater offshore Taranaki Basin, covering an area equivalent to about one third of New Zealand's emerged continental landmass. It has demonstrated how seismic geomorphology workflows can be applied to large and heterogeneous data sets to study the regional facies distribution of strata within a sedimentary basin. Through the combined analysis of seismic facies, crustal deformation, and subsidence history the study has developed a refined picture of the tectono-sedimentary evolution of Late Cretaceous to Recent rift, passive margin, foreland basin, and backarc basin sequences. The following paragraphs summarize some general conclusions of regional seismic attribute analysis and basin history established in the individual chapters of this thesis.

\subsection{SEISMIC GEOMORPHOLOGY AND ATTRIBUTE ANALYSIS}

Seismic attributes have provided a semi-quantitative basis for facies interpretation and enabled the delineation and characterisation of regional facies belts and sediment transport directions. The study has shown that the insightful plan-view imaging of depositional systems characteristics is primarily dependent on the density of seismic data coverage, the dimensions of a given depositional element, and the ability to isolate a given facies signature from the background seismic signal. Simple interval amplitude statistics and proportional horizon slicing have proved to be the most effective means of delineating seismic facies. Multi-attribute analysis based on a small number of seismic attributes has aided in isolating specific seismic facies from the background seismic response and improved the plan-view imaging in areas of sparse data coverage. However, complications resulting from unresolved amplitude normalisation of heterogeneously processed data sets, gridding of attribute extractions from sparse 2D data, or phantom horizon-reflector cross-cutting, make it essential to frequently validate and calibrate attribute data with seismic profiles and borehole data. Notwithstanding the obvious limitations due to lateral resolution, attribute analysis of 2D seismic data sets has proven an effective way to interpret and delineate seismic facies over large geographic areas. Such analysis should be considered as a general tool for basin screening and quality control of seismic horizon interpretation and may help to improve the understanding of basin development and petroleum prospectivity. 


\subsection{TARANAKI BASIN DEVELOPMENT}

The Late Cretaceous to Recent history of the greater Taranaki Basin is a record of more or less contiguous basin fills, initially within two rift systems of differing age and orientation, and later within a variety of superimposed sub-basins of differing structural origin (Figure 8.1).

The present-day deep-water part of the Taranaki Basin was initiated as a failed rift that formed prior to New Zealand's breakup from Gondwana ( $>85 \mathrm{Ma}$ ). Proximal Taranaki Basin formed as a result of minor intra-continental stretching $(\beta<1.5)$ during Tasman Sea spreading (85-55 Ma). The basin morphology that resulted from variable stretching and subsidence in these juxtaposed rift systems exerted principal control on the distribution and character of early sedimentary sequences. Due to the overall low crustal stretching, terrestrial to shallow marine sedimentary sequences are well developed in both basin areas, but particularly so in the proximal basin. Late Cretaceous depositional systems in the present-day deep-water area are analogous to Paleogene sequences in the proximal basin, and may contain similarly good petroleum source and reservoir rocks.

Post-rift thermal subsidence and passive margin development ensued in both parts of Taranaki Basin. However, contrary to previous interpretations that passive margin subsidence carried on to eventually provide the modern bathymetric expression of the Deepwater Taranaki Basin, stratigraphic restorations in this study suggest that northern parts of this region, and possibly the $2000 \mathrm{~km}$-long New Caledonia basin system, were modified in the Middle to Late Eocene by minor reverse faulting and increasingly significant subsidence. This crustal deformation is attributed to early Australia-Pacific plate convergence and initiation of southwest-directed subduction northwest of New Zealand. As well as causing the outer Taranaki Basin to founder to bathyal water depths, the onset and southward migration of subduction also subsequently led to $>1 \mathrm{~km}$ of rapid subsidence of the greater Taranaki area during the Oligocene (Figure 8.1). Although discrete pre-Oligocene convergent faulting in the proximal basin has not been ascertained, southern Taranaki Basin may have been subjected to long-wavelength tilting and uplift in the Late Eocene during the early phases of convergence. The timing and regional scale of these events suggest that Middle Cenozoic basin modification was related to changes in asthenospheric flow or lithospheric delamination during subduction initiation. Both of these processes provide mechanisms to explain the widespread 
development of unconformities at the base of Oligocene strata and rapid regional subsidence.

Regional drowning and local foreland basin subsidence along the eastern basin margins caused the supply of clastic sediment to the distal basin to be muted during the Oligocene and Early Miocene. Conversely, thick turbidite sequences filled the foredeep depression until it was finally overfilled during the late Middle Miocene, as marked by the development of large-scale slope channel networks that bypassed sediment to distal basin areas. Between the late Middle Miocene and Early Pliocene, large axial drainage systems, similar to modern day examples such as the Cook, Hokitika, or Hikurangi canyons, have transported sediments from the western South Island and southern Taranaki Basin over hundreds of kilometres into deep-water environments of the New Caledonia Trough. Progressively increasing intra- and extra- basinal uplift within a broad convergent fold and thrust belt resulted in greater sediment input and a change in downslope sedimentation character from large canyon point-sources to a slope apron line-source. The combination of regularly-spaced sediment input and large-scale sediment bypass provide explanations for the lack of thick sandy turbidite accumulations on the Western Platform. On the other hand, late Middle to Late Miocene sandy turbidite facies in the southern New Caledonia Trough are expected to be well developed, due to improved sorting and stripping of fine-grained sediment from turbidity flows during long-distance sediment transport.

Following cessation of convergence in the Taranaki foreland fold and thrust belt, a $\sim 100$ $200 \mathrm{~km}$-wide contiguous depocentre formed during the latest Miocene and Early Pliocene (6-4 Ma) across the south-eastern Taranaki Basin and the, no longer active, Taranaki Fault. This depocentre subsided at rates of up to $\sim 1000 \mathrm{~m} / \mathrm{my}$, without any upper crustal faulting. Subsidence resulted in maximum water depths of $\sim 500 \mathrm{~m}$ and temporarily diverted sediment transport towards the more easterly located Wanganui Basin, thereby subduing the westward advance of the shelf margin until $\sim 3$ Ma. Deposition of the Giant Foresets Formation occurred predominantly after infilling of eastern depocentres and the slope advanced rapidly to its present-day location during eustatically-controlled base-level lowstands of $4^{\text {th }}-6^{\text {th }}$-order cyclicity. Some minor horizontal crustal extension $(1-1.5 \mathrm{~km})$ developed in the eastern basin over the last 3 million years, and may indicate the early stages of extensional back-arc basin formation. The sequence of crustal subsidence and extension in southeast Taranaki Basin is part of a 
southward migrating continuum of sub-basin development in western North Island during the Neogene, associated with plate boundary tectonic processes. This study provides new constraints on the geodynamic character of the crustal subsidence that have not been well constrained in areas further north.

The two periods (late Paleogene and late Neogene) of somewhat unusual subsidence in the wider Taranaki area, as deduced from stratigraphic evidence, are both characterised by large vertical crustal deflections $(>0.5-1 \mathrm{~km})$, rapid subsidence rates $(>100-1000$ $\mathrm{m} / \mathrm{my})$, and pervasive expression over large distances $(\sim 100->1000 \mathrm{~km})$, with only minor or no accompanying crustal faulting. The two subsidence events are both of lithospheric to asthenospheric scale; the former appears to relate to subduction initiation and the latter appears to be a precursor to backarc development as subduction matures. Collectively, they emphasize the importance of large-scale mantle dynamics in the formation of sedimentary basins behind a convergent plate boundary. These deflections may be directly linked to the interaction of the subducting slab with the overriding lithosphere (e.g., lithospheric instabilities, delamination) or induced asthenosphere dynamics (e.g., convection, slab roll-back, and viscous drag). Passive indicators of subduction-induced subsidence or uplift may be expressed as sudden diversion of sediment pathways, starvation of clastic sediment, or development of unconformities. While in Taranaki Basin crustal faulting or post-rift thermal cooling is clearly not able to explain sudden subsidence events, faulting may have masked the recognition of such large-scale modifications in other basins behind convergent margins (e.g., Mediterranean, South China Sea). Due to their potential impact on the thermal history and fluid migration within a basin, the recognition and characterisation of such processes may be economically significant and the study thus emphasises the importance of integrating stratigraphic, subsidence, and structural analysis at regional scales. 

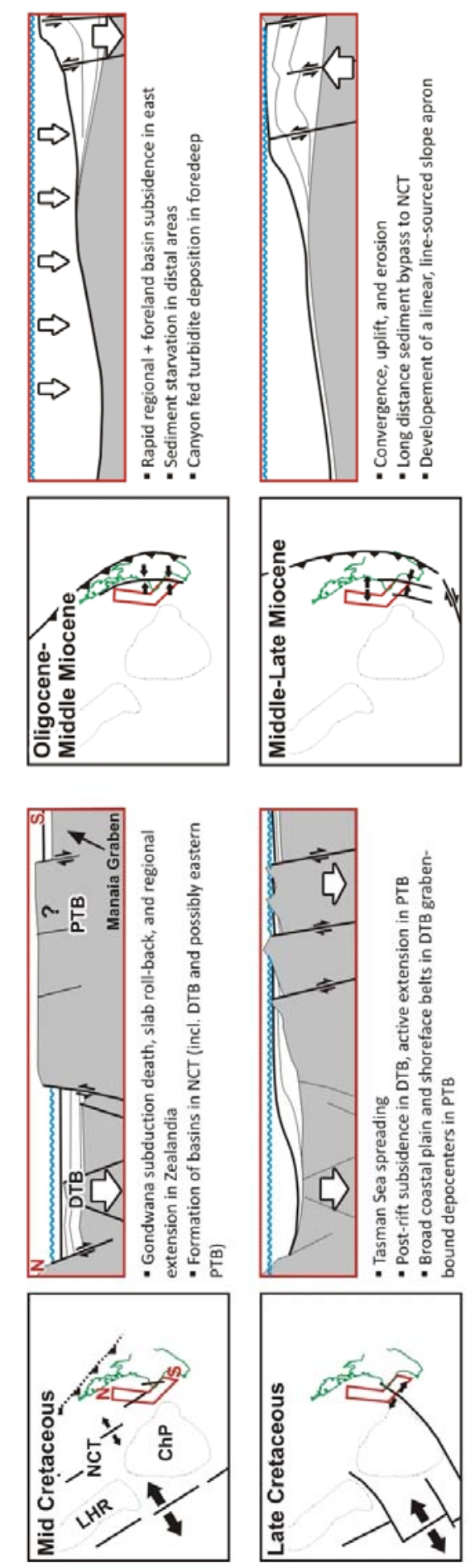
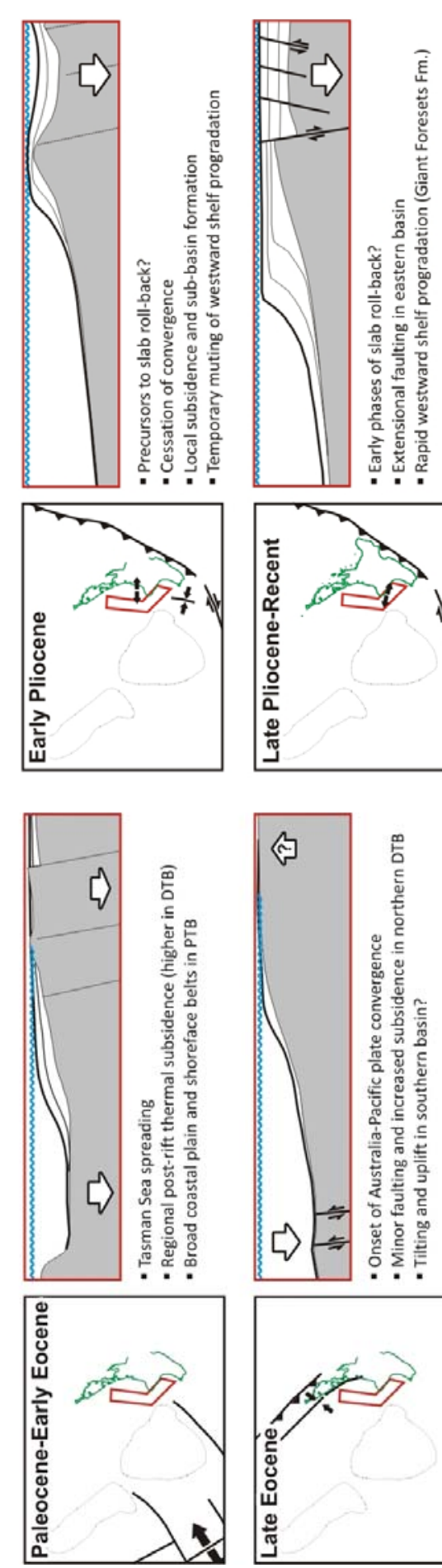
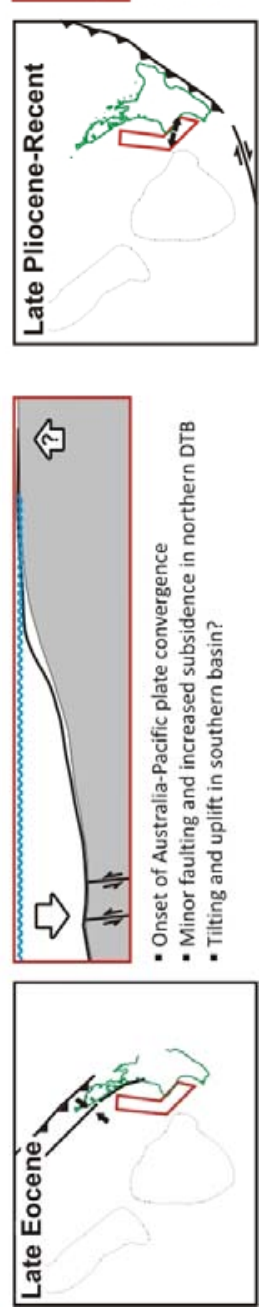

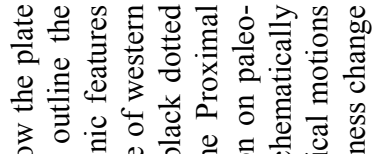

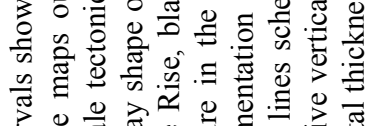

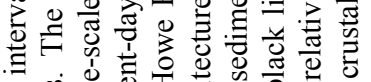

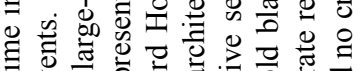

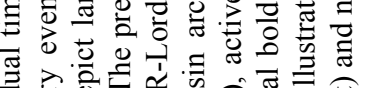
훙 可

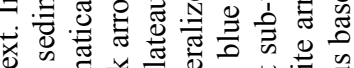
言类

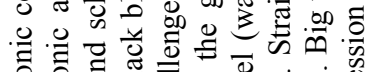
部亭

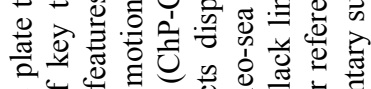

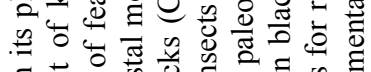

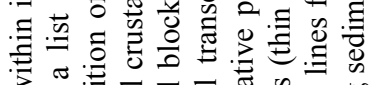

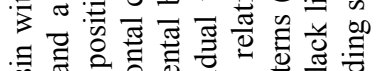

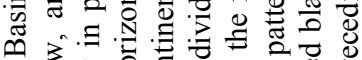

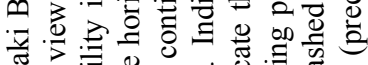

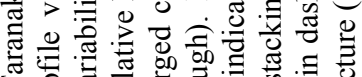

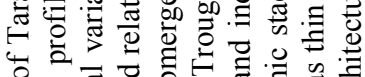

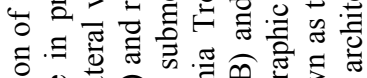

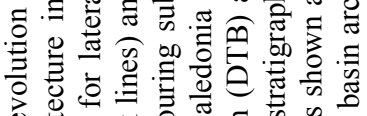
ठ

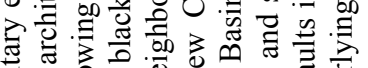

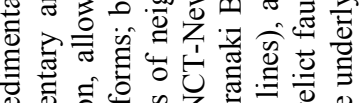

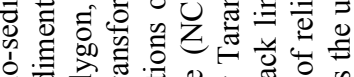
o

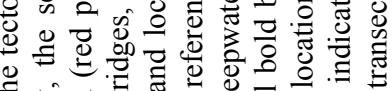

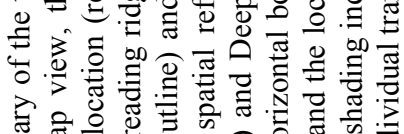

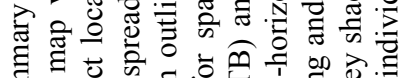

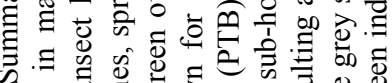

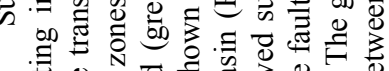

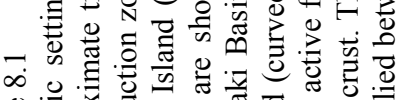

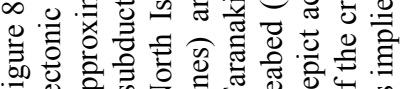





\section{REFERENCES}

ABBotT, S.T. \& CARTER, R.M. (1994) The Sequence Architecture of Mid-Pleistocene (C.1.1-0.4 Ma) Cyclothems from New Zealand: Facies Development During a Period of Orbital Control on Sea-Level Cyclicity. Orbital forcing and cyclic sequences, 367-394.

AbBott, S.T., NAish, T.R., CARTER, R.M. \& Pillans, B.J. (2005) Sequence Stratigraphy of the Nukumaruan Stratotype (Pliocene-Pleistocene, C.208-1.63 Ma), Wanganui Basin, New Zealand. Journal of the Royal Society of New Zealand, 35(1/2), 123-150.

Abreu, V., Sullivan, M., Pirmez, C. \& Mohrig, D. (2003) Lateral Accretion Packages (Laps): An Important Reservoir Element in Deep Water Sinuous Channels. Marine and Petroleum Geology, 20, 631-648.

AdAMS, J. (1980) Contemporary Uplift and Erosion of the Southern Alps, New Zealand: Summary. Geological Society of America Bulletin, 91, 2-4.

Aitchison, J.C., Clarke, G.L., Mefrre, S. \& Cluzel, D. (1995) Eocene Arc-Continent Collision in New Caledonia and Implications for Regional Southwest Pacific Tectonic Evolution. Geology, 23, 161-164.

Allen, P.A. \& Allen, J.R. (1990) Basin Analysis: Principles and Applications. Blackwell Scientific Publications, Cambridge.

Allen, P.A. \& Allen, J.R. (2005) Basin Analysis - Principles and Applications. Blackwell Publishing, 560.

Aminzadeh, F. \& De Groot, P. (2004) Soft Computing for Qualitative and Quantitative Seismic Object and Reservoir Property Prediction Part 1: Neural Network Applications. First Break, 22, 49-54.

Anderson, H. \& WeBB, T. (1994) New Zealand Seismicity: Patterns Revealed by the Upgraded National Seismograph Network. New Zealand Journal of Geology \& Geophysics, 37, 477-493.

ANDERTON, P.W. (1981) Structure and Evolution of the South Wanganui Basin, New Zealand. New Zealand journal of geology and geophysics, 24(1), 39-63.

Angevine, C.L., Heller, P.L. \& PaOla, C. (1990) Quantitative Sedimentary Basin Modeling. American Association of Petroleum Geologists, Tulsa, Oklahoma.

Armstrong, P.A., Chapman, D.S., Funnell, R.H., Allis, R.G. \& Kamp, P.J.J. (1996) Thermal Modeling and Hydrocarbon Generation in an Active-Margin Basin; Taranaki Basin, New Zealand. AAPG Bulletin, 80, 1216-1241.

ARNOLD, H.C. (1957) Pliocene Stratigraphy of South Taranaki. New Zealand Unpublished Openfile Petroleum Report, 414, 19 p 15 Fiche 17 Enclosures.

ARnot, M.J., Browne, G.H. \& KING, P.R. (2007) Thick-Bedded Sandstone Facies in a Middle Basin-Floor Fan Setting, Mount Messenger Formation, Mohakatino Beach, New Zealand. In: Atlas of Deep-Water Outcrops. Aapg Studies in Geology. 56 (Ed. by T. H. Nilsen, R. D. Shew, G. S. Steffens \& J. R. J. Studlick), Aapg Studies in Geology. 56, 241-244 (chapter 261). American Association of Petroleum Geologists, Tulsa, Okla.

AWE NeW Zealand, P.-L. (2010) Hoki-1 Well Completion Report. New Zealand Unpublished Openfile Petroleum Report 4169, 582.

BaAske, U.P., Mutti, M., Baioni, F., Bertozzi, G. \& NAini, M.A. (2007) Using MultiAttribute Neural Networks Classification for Seismic Carbonate Facies Mapping: A Workflow Example from Mid-Cretaceous Persian Gulf Deposits, 105-120.

BAHORICH, M. \& FARMER, S. (1995) 3-D Seismic Discontinuity for Faults and Stratigraphic Features; the Coherence Cube. The Leading Edge, 14, 1053-1058.

BAHORICH, M.S., BRIDGES, S.R. \& ANONYMOUS (1992) Seismic Sequence Attribute Map (Ssam). SEG Annual Meeting Expanded Technical Program Abstracts with Biographies, 62, 227-230.

BAL, A. \& LEWIS, D.W. (1994) A Cretaceous - Early Tertiary Macrotidal Estuarine-Fluvial Succession : Puponga Coal Measures in Whanganui Inlet, Onshore Pakawau Sub-Basin, Northwest Nelson, New Zealand. New Zealand journal of geology and geophysics, 37(3), 287-307. 
Ballance, P.F. (1976) Evolution of the Upper Cenozoic Magmatic Arc and Plate Boundary in Northern New Zealand. Earth and Planetary Science Letters, 28, 356-370.

BALlance, P.F., HAYWARD, B.W. \& BROOK, F.J. (1985) Subduction Regression of Volcanism in New Zealand - Matters Arising. Nature, 313(6005), 820.

BARNES, A.E. (1996) Theory of 2-D Complex Seismic Trace Analysis. Geophysics, 61, 264-272. BARNES, A.E. (2007) Redundant and Useless Seismic Attributes. Geophysics, 72, P33-38.

BAur, J., King, P., STERn, T. \& Leitner, B. (2010) Development and Seismic Geomorphology of a Miocene Slope Channel Mega-System, Taranaki Basin, New Zealand. Seismic Imaging of Depositional and Geomorphic Systems, SEPM Foundation, Gulf Coast Section, 30th Annual Research Conference. L. Wood, Simo, T. and Rosen, N. . Houston, 618-649.

Baur, J., Sutherland, R. \& Stern, T. (in prep.) Anomalous Passive Subsidence of DeepWater Sedimentary Basins: An Example from the Southern New Caledonia Trough and Taranaki, New Zealand.

Beaubouef, R.T. \& FriedmanN, S.J. (2000) High Resolution Seismic/Sequence Stratigraphic Framework for the Evolution of Pleistocene Intra Slope Basins, Western Gulf of Mexico. Depositional models and reservoir analogs: SEPM Gulf Coast Section Research Conference Program and Abstracts, SEPM. Houston, Texas. 20, 40-60.

Beaumont, C. (1981) Foreland Basins. Geophysical Journal, Royal Astronomical Society, 65, 291-329.

Beavan, J., Tregoning, P., Bevis, M., Kato, T. \& Meertens, C. (2002) Motion and Rigidity of the Pacific Plate and Implications for Plate Boundary Deformation. Journal of Geophysical Research B: Solid Earth, 107, ETG 19-11 - 19-15.

BegGS, J.M. (1990) Seismic Stratigraphy of the Plio-Pleistocene Giant Foresets, Western Platform, Taranaki Basin. New Zealand Oil Exploration Conference (1989 : Queenstown, NZ), 201-207.

BegGs, J.M. \& PockNALL, D.T. (1992) Sequence Stratigraphic Controls on Reservoir Architecture, Lower Eocene Kapuni Group, Maui Field, Taranaki Basin, New Zealand, DSIR Geology \& Geophysics, 34.

BEU, A.G. \& EDWARDS, A.R. (1984) New Zealand Pleistocene and Late Pliocene Glacio-Eustatic Cycles. Palaeogeography, Palaeoclimatology, Palaeoecology, 46(1-3), 119-142.

BILlen, M.I., GuRnis, M. \& SimOnS, M. (2003) Multiscale Dynamics of the Tonga-Kermadec Subduction Zone. Geophysical Journal International, 153, 359-388.

Bishop, D.J. \& BuchANAN, P.G. (1995) Development of Structurally Inverted Basins: A Case Study from the West Coast, South Island, New Zealand. Basin inversion, 549-585.

Bland, K.J., Strogen, D.P., Fohrmann, M. \& Kroeger, K.F. (2010) Cretaceous-Recent Lithostratigraphy of the Kupe Mapping Area (4d Taranaki Project), Southeastern Taranaki Basin. GNS Science, Lower Hutt.

Boggs, S. (2001) Principles of Sedimentology and Stratigraphy, 3rd edn. Prentice Hall International.

BotT, M.H.P. (1979) Subsidence Mechanisms at Passive Continental Margins. American Association of Petroleum Geologists, Memoir 29, 8-19.

Bouma, A.H. (1962) Sedimentology of Some Flysch Deposits; a Graphic Approach to Facies Interpretations. Elsevier Amsterdam.

Brouwer, F., De Bruin, G., De Groot, P. \& Connolly, D. (2008) Interpretation of Seismic Data in the Wheeler Domain: Integration with Well Logs, Regional Geology and Analogs. 27, 2786-2790.

BRowne, G.H. \& SlatT, R.M. (1999) An Integrated Outcrop and Behind Outcrop Study of Slope Fan (Channel-Levee) Lithofacies, Taranaki, New Zealand, and Their Implications to Thin-Bedded Reservoirs. AAPG bulletin / American Association of Petroleum Geologists. 83(8), 1303.

Browne, G.H., SlatT, R.M. \& King, P.R. (2000) Contrasting Styles of Basin-Floor Fan and Slope Fan Deposition : Mount Messenger Formation, New Zealand. In: Fine-Grained Turbidite Systems. Aapg Memoir. $72 \sim$ Special Publication / Society for Sedimentary Geology. 68 (Ed. by A. H. Bouma \& C. G. Stone), Aapg Memoir. $72 \sim$ Special 
Publication / Society for Sedimentary Geology. 68, 142-152. American Association of Petroleum Geologists and Society for Sedimentary Geology, Tulsa, Okla.

BRowne, G.H. \& SLATT, R.M. (2002) Outcrop and Behind-Outcrop Characterization of a Late Miocene Slope Fan System, Mt. Messenger Formation, New Zealand. American Association of Petroleum Geologists Bulletin, 86, 841-862.

Browne, G.H., King, P.R., Higgs, K.E. \& Slatt, R.M. (2005a) Grain Size Characteristics for Distinguishing Basin Floor Fan and Slope Fan Depositional Settings : Outcrop and Subsurface Examples from the Late Miocene Mount Messenger Formation, New Zealand. New Zealand journal of geology and geophysics, 48(2), 213-227.

Browne, G.H., KING, P.R., HigGS, K.E. \& SLATT, R.M. (2005b) Grain-Size Characteristics for Distinguishing Basin Floor Fan and Slope Fan Depositional Settings: Outcrop and Subsurface Examples from the Late Miocene Mount Messenger Formation, New Zealand. New Zealand journal of geology and geophysics, 48, 213-227.

Browne, G.H., King, P.R., ARnot, M.J. \& Helle, K. (2007a) A Complete Middle-to-Inner Basin-Floor-Fan Cycle, Mount Messenger Formation, Tongaporutu, New Zealand. American Association of Petroleum Geologists, Tulsa, Okla.

Browne, G.H., King, P.R., ARNOT, M.J. \& SlatT, R.M. (2007b) Architecture of Base-of-Slope Fans, Mount Messenger Formation, Pukearuhe Beach, New Zealand (Ed. by, 257-261 (chapter 264).

Browne, G.H., Kennedy, E.M., Constable, R.M., Raine, J.I., Crouch, E.M. \& Sykes, R. (2008) An Outcrop-Based Study of the Economically Significant Late Cretaceous Rakopi Formation, Northwest Nelson, Taranaki Basin, New Zealand. New Zealand journal of geology and geophysics, 51(4), 295-315.

Bryant, I.D., Marshall, M.G., Greenstreet, C.W., Voggenreiter, W.R., Choen, J.M. \& Stroemmen, J.F. (1994). Integrated Geological Reservoir Modelling of the Maui Field, Taranaki Basin, New Zealand. 1994 New Zealand Petroleum Conference Proceeding, Wellington, New Zealand, Crown Minerals Operations Group, Energy and Resources Division, Ministry of Commerce.

BRYANT, I.D., GREENSTREET, C.W. \& VOGGENREITER, W.R. (1995) Integrated 3-D Geological Modeling of the C1 Sands Reservoir, Maui Field, Offshore New Zealand. AAPG bulletin, 79(3), 351-374.

Burbank, D.W., RAYNolds, R.G.H. \& Johnson, G.D. (1986) Late Cenozoic Tectonics and Sedimentation in the North-Western Himalayan Foredeep: Ii. Eastern Limb of the Northwest Syntaxis and Regional Synthesis ( India, Pakistan). Foreland basins, 293-306.

Burgess, P.M., GuRnis, M. \& MORESI, L. (1997) Formation of Sequences in the Cratonic Interior of North America by Interaction between Mantle, Eustatic, and Stratigraphic Processes. Bulletin of the Geological Society of America, 109, 1515-1535.

BURGESS, P.M. \& MORESI, L.N. (1999) Modelling Rates and Distribution of Subsidence Due to Dynamic Topography over Subducting Slabs: Is It Possible to Identify Dynamic Topography from Ancient Strata? Basin research, 11, 305-314.

BuRns, R.E. \& ANDREwS, J.E. (1973) Regional Aspects of Deep Sea Drilling in the Southwest Pacific. Initial Rep. Deep Sea Drill.Proj., 21, 897-906.

BURTON, D. \& WoOD, L.J. (2010) Seismic Geomorphology and Tectonostratigraphic Fill of Half Grabens, West Natuna Basin, Indonesia. American Association of Petroleum Geologists. International Conference \& Exhibition (2000 : Bali, Indonesia), 94, 1695-1712.

BusSELL, M.R. (1994) Seismic Interpretation of the Moki Formation on the Maui 3d Survey, Taranaki Basin. 1994 New Zealand Petroleum Conference Proceedings, Crown Minerals Operations Group, Energy and Resources Division, Ministry of Commerce. Wellington, New Zealand, 240-255.

Calvert, A., Sandvol, E., Seber, D., Barazangi, M., Roecker, S., Mourabit, T., Vidal, F., Alguacil, G. \& JABOUR, N. (2000) Geodynamic Evolution of the Lithosphere and Upper Mantle beneath the Alboran Region of the Western Mediterranean: Constraints from Travel Time Tomography. Journal of Geophysical Research B: Solid Earth, 105, 10871-10898.

CANDE, S.C. \& STOCK, J.M. (2004) Pacific-Antarctic-Australia Motion and the Formation of the Macquarie Plate. Geophysical Journal International, 157, 399-414. 
CARTER, D.C. (2003) 3-D Seismic Geomorphology: Insights into Fluvial Reservoir Deposition and Performance, Widuri Field, Java Sea. American Association of Petroleum Geologists. International Conference \& Exhibition (2000 : Bali, Indonesia), 87, 909-934.

CARTER, R.M. (1985) The Mid-Oligocene Marshall Paraconformity, New Zealand : Coincidence with Global Eustatic Sea-Level Fall or Rise? Journal of geology, 93(3), 359-371.

CARTER, R.M., CARTER, L. \& DAVY, B. (1994) Seismic Stratigraphy of the Bounty Trough, South-West Pacific Ocean. Marine and Petroleum Geology, 11, 79-93.

CARTER, R.M. \& NAISH, T.R. (1998) A Review of Wanganui Basin, New Zealand : Global Reference Section for Shallow Marine, Plio-Pleistocene (2.5-0 Ma) Cyclostratigraphy. Sedimentary Geology, 122(1/4), 37-52.

Catuneanu, O., Bhattacharya, J.P., Blum, M.D., Dalrymple, R.W., Eriksson, P.G., Fielding, C.R., Fisher, W.L., Galloway, W.E., Gianolla, P., Gibling, M.R., GileS, K.A., HolbrooK, J.M., Jordan, R., Kendall, C.G.S.C., Macurda, B., Martinsen, O.J., Miall, A.D., Nummedal, D., Posamentier, H.W., Pratt, B.R., Shanley, K.W., SteEl, R.J., STRASSER, A. \& TUCKer, M.E. (2010) Sequence Stratigraphy: Common Ground after Three Decades of Development. First Break, 28, 41-54.

CHANIER, F. \& FerRIERE, J. (1989) On the Existence of Major Tangential Movements in the East Coast Range of New Zealand: Their Significance within the Framework of Pacific Plate Subduction. Sur l'existence de mouvements tangentiels majeurs dans la chaine cotiere orientale de Nouvelle-Zelande; signification dans le cadre de la subduction de la plaque pacifique, 308, 1645-1650.

Chanier, F. \& Ferriere, J. (1991) From a Passive to an Active Margin: Tectonic and Sedimentary Processes Linked to the Birth of an Accretionary Prism (Hikurangi Margin, New Zealand). Bulletin - Societe Geologique de France, 162, 649-660.

ChOpra, S. \& MARfurt, K.J. (2007) Seismic Attributes for Prospect Identification and Reservoir Characterization. Soc of Exploration Geophysicists.

Cluzel, D., Aitchison, J.C. \& PiCARD, C. (2001) Tectonic Accretion and Underplating Mafic Terranes in the Late Eocene Intraoceanic Fore-Arc of New Caledonia (Southwest Pacific): Geodynamic Implications. International Union of Geodesy and Geophysics, 18th general assembly, interdisciplinary symposium No. 1, 340, 23-59.

Cluzel, D., Mefrre, S., Maurizot, P. \& Crawford, A.J. (2006) Earliest Eocene (53 Ma) Convergence in the Southwest Pacific: Evidence from Pre-Obduction Dikes in the Ophiolite of New Caledonia. Terra Nova, 18, 395-402.

COAKLEY, B. \& Gurnis, M. (1995) Far-Field Tilting of Laurentia During the Ordovician and Constraints on the Evolution of a Slab under an Ancient Continent. Journal of geophysical research, 100, 6313-6327.

COAKLEY, B.J. \& WATTS, A.B. (1991) Tectonic Controls of the Development of Unconformities: The North Slope, Alaska. Tectonics, 10, 101-130.

Collot, J., Geli, L., Lafoy, Y., Vially, R., Cluzel, D., Klingelhoefer, F. \& Nouzé, H. (2008) Tectonic History of Northern New Caledonian Basin from Deep Offshore Seismic Reflection: Relation to Late Eocene Obduction in New Caledonian, Southwest Pacific. Tectonics, 27.

Collot, J., Herzer, R., LAfoy, Y. \& GÉLI, L. (2009) Mesozoic History of the Fairway-Aotea Basin: Implications for the Early Stages of Gondwana Fragmentation. Geochemistry, Geophysics, Geosystems, 10.

Compagnie Generale De, G. (2001) Pep38737 Reprocessing Report. Ministry of Economic Development unpublished petroleum report. 2664, Ministry of Economic Development. Wellington, 44p.

CoOPer, M. \& WARren, M.J. (2010) The Geometric Characteristics, Genesis and Petroleum Significance of Inversion Structures, 827-846.

Cooper, R.A., Crampton, J.S., Raine, J.I., Gradstein, F.M., Morgans, H.E.G., Sadler, P.M., STRONG, C.P., WAGHORN, D. \& WILSON, G.J. (2001) Quantitative Biostratigraphy of the Taranaki Basin, New Zealand: A Deterministic and Probabilistic Approach. American Association of Petroleum Geologists bulletin, 85, 1469-1498.

COOPER, R.A. (2004) The New Zealand Geological Timescale. Institute of Geological \& Nuclear Sciences Limited, Lower Hutt. 
Covault, J.A. \& GRAham, S.A. (2008) Turbidite Architecture in Proximal Foreland BasinSystem Deep-Water Depocenters: Insights from the Cenozoic of Western Europe. Austrian Journal of Earth Sciences, 101, 36-51.

COVAult, J.A., HubBard, S.M., Graham, S.A., Hinsch, R. \& LinZER, H.G. (2009) TurbiditeReservoir Architecture in Complex Foredeep-Margin and Wedge-Top Depocenters, Tertiary Molasse Foreland Basin System, Austria. Marine and Petroleum Geology, 26, 379-396.

CoveY, M. (1986) The Evolution of Foreland Basins to Steady State: Evidence from the Western Taiwan Foreland Basin. Foreland basins, 77-90.

Cowie, P.A., VAnneste, C. \& Sornette, D. (1993) Statistical Physics Model for the Spatiotemporal Evolution of Faults. Journal of geophysical research, 98, 21,809821,821 .

Cowie, P.A., GuPTA, S. \& DAwERS, N.H. (2000) Implications of Fault Array Evolution for Synrift Depocentre Development: Insights from a Numerical Fault Growth Model. Basin research, 12, 241-261.

Crawford, A.J., MefFre, S. \& Symonds, P.A. (2003) 120 to 0 Ma Tectonic Evolution of the Southwest Pacific and Analogous Geological Evolution of the 600 to 220 Ma Tasman Fold Belt System. Geological Society of America Special Papers, 372, 383-403.

Crocker, S. (1991) Toru-1 Well Completion Report Ppl 38116. Ministry of Economic Development unpublished petroleum report. 1668, Ministry of Economic Development. Wellington, 1438p., 1420 enclosures.

Crosby, A.G., McKenzie, D. \& Sclater, J.G. (2006) The Relationship between Depth, Age and Gravity in the Oceans. Geophysical Journal International, 166, 553-573.

Cross, N.E., Cunningham, A., CoOK, R.J., TAHA, A., Esmaie, E., El Swidan, N., HadlerJACOBSEN, F., GARDNER, M.H. \& BORER, J.M. (2009) Three-Dimensional Seismic Geomorphology of a Deep-Water Slope-Channel System: The Sequoia Field, Offshore West Nile Delta, Egypt Seismic Stratigraphic and Geomorphic Analysis of Deep-Marine Deposition Along the West African Continental Margin. American Association of Petroleum Geologists. International Conference \& Exhibition (2000 : Bali, Indonesia), 93, 1063-1086.

Crowley, J., Way, C.J. \& Purcell, D. (1989) Kupe South-4 Well Completion Report. Ppl38116. Ministry of Economic Development unpublished petroleum report. 1483, Ministry of Economic Development. Wellington, 1089p., 1015 enclosures.

Crown-Minerals (2010) New Zealand Petroleum Basins. Crown Minerals, Ministry of Economic Development, Wellington.

DauZacker, M.V., Yang, J.S., Pomilio, G.A. \& Till, V.S. (1996) A New Exploratory Approach to the Moki-Manaia Oil Discoveries. 1996 New Zealand Petroleum Conference Proceedings, New Zealand Crown Minerals, Ministry of Commerce. Wellington, New Zealand, 86-104.

Davy, B., Hoernle, K. \& Werner, R. (2008) Hikurangi Plateau: Crustal Structure, Rifted Formation, and Gondwana Subduction History. Geochemistry, Geophysics, Geosystems, 9.

DE BocK, J.F. (1994) Moki Formation, a Miocene Reservoir Sequence, Its Facies' Distribution and Source in Offshore Southern Taranaki Basin. 1994 New Zealand Petroleum Conference, Ministry of Commerce. Wellington. Proceedings, 155-167.

DE Bruin, G., Hemstra, N. \& Pouwel, A. (2007) Stratigraphic Surfaces in the Depositional and Chronostratigraphic (Wheeler-Transformed) Domain. The Leading Edge, 26, 883-886.

DE RoolJ, M. \& TINGDAHL, K. (2002) Meta-Attributes--the Key to Multivolume, Multiattribute Interpretation. The Leading Edge, 21, 1050-1053.

De Ruig, M.J. \& HubBard, S.M. (2006) Seismic Facies and Reservoir Characteristics of a Deep-Marine Channel Belt in the Molasse Foreland Basin, Puchkirchen Formation, Austria. American Association of Petroleum Geologists Bulletin, 90, 735-752.

DeCELles, P.G. \& GILES, K.A. (1996) Foreland Basin Systems. Basin research, 8, 105-123.

DEweY, J.F. (1982) Plate Tectonics and the Evolution of the British Isles (Thirty- Fifth William Smith Lecture). Journal of the Geological Society, 139, 371-412. 
DiCAPRIO, L., GURNIS, M. \& MÜLlER, R.D. (2009a) Long-Wavelength Tilting of the Australian Continent since the Late Cretaceous. Earth and Planetary Science Letters, 278, 175-185.

DiCAPriO, L., MÜlLER, R.D., GURNIS, M. \& GONCHAROV, A. (2009b) Linking Active Margin Dynamics to Overriding Plate Deformation: Synthesizing Geophysical Images with Geological Data from the Norfolk Basin. Geochemistry, Geophysics, Geosystems, 10.

DiCKInSON, W.R. (1976) Plate Tectonic Evolution of Sedimentary Basins. American Association of Petroleum Geologists, Tulsa, Oklahoma.

DOCHERTY, J.I.C. \& BANDA, E. (1992) A Note on the Subsidence History of the Northern Margin of the Alboran Basin. Geo-Marine Letters, 12, 82-87.

DorobeK, S.L. (2008) Carbonate-Platform Facies in Volcanic-Arc Settings: Characteristics and Controls on Deposition and Stratigraphic Development. Special Paper of the Geological Society of America, 436, 55-90.

Egan, S.S., Kane, S., Buddin, T.S., Williams, G.D. \& HodgetTS, D. (1999) Computer Modelling and Visualisation of the Structural Deformation Caused by Movement Along Geological Faults. Computers and Geosciences, 25, 283-297.

EMmel, F.J. \& CURRAY, J.R. (1984) The Bengal Submarine Fan, Northeastern Indian Ocean. Geo-Marine Letters, 3, 119-124.

Falvey, D.A. (1974) The Development of Continental Margins in Plate-Tectonic Theory. Journal of Australian Petroleum Exploration Association, 14, 95-106.

Field, B.D., Uruski, C.I., Beu, A.G., Browne, G.H., Crampton, J.S., Funnell, R.H., Killops, S.D., Laird, M., MAZEngarb, C., Morgans, H.E.G., Rait, G.J., SMale, D. \& Strong, C.P. (1997) Cretaceous-Cenozoic Geology and Petroleum Systems of the East Coast Region, New Zealand, Institute of Geological \& Nuclear Sciences. Lower Hutt. 19, 2 v.

Fleming, C.A. (1953) The Geology of Wanganui Subdivision; Waverley and Wanganui Sheet Districts (N137 and N138). New Zealand Geological Survey bulletin. 52. N. Z. G. S. L. H. DSIR, $361 \mathrm{p}$.

Flores, R.M., Browne, G.H. \& SyKeS, R. (1998) Lithofacies, Depositional Setting and Reservoir Characteristics of the Farewell Formation, Kupe South Field, Taranaki Basin, New Zealand. New Zealand's basins of opportunity : 1998 New Zealand Petroleum Conference : proceedings., Ministry of Commerce. Wellington, NZ, 499-512.

Flores, R.M., BEgGS, J.M., KING, P.R. (1993) Sedimentology of Tide-Dominated Reservoir Sandstones in the Eocene Kapuni Group, Taranaki Basin, New Zealand. American Association of Petroleum Geologists 1993 annual convention abstracts, 102.

FunNell, R.H., ChapMan, D., Allis, R.G. \& ARMSTRONG, P. (1996) Thermal State of the Taranaki Basin, New Zealand. Journal of geophysical research, 101(B11), 25197-25215.

FunNell, R.H., Stagpoole, V.M., Nicol, A., McCormack, N. \& ReYeS, A.G. (2004) Petroleum Generation and Implications for Migration : A Maui Field Charge Study, Taranaki Basin. New Zealand Petroleum Conference (2004: Auckland), 9.

FURLONG, K.P. \& KAMP, P.J.J. (2009) The Lithospheric Geodynamics of Plate Boundary Transpression in New Zealand: Initiating and Emplacing Subduction Along the Hikurangi Margin, and the Tectonic Evolution of the Alpine Fault System. International Union of Geodesy and Geophysics, 18th general assembly, interdisciplinary symposium No. 1, 474, 449-462.

Gaina, C., MÜller, D.R., Royer, J.-Y., Stock, J., Hardebeck, J. \& Symonds, P. (1998) The Tectonic History of the Tasman Sea: A Puzzle with 13 Pieces. J. Geophys. Res., 103.

GArven, G. \& FreEzE, R.A. (1984) Theoretical Analysis of the Role of Groundwater Flow in the Genesis of Stratabound Ore Deposits. 1. Mathematical and Numerical Model. American Journal of Science, 284, 1085-1124.

GAwTHORPE, R.L. \& LEEDER, M.R. (2000) Tectono-Sedimentary Evolution of Active Extensional Basins. Basin research, 12, 195-218.

GAYER, R., GARVEN, G. \& RiCKARD, D. (1998) Fluid Migration and Coal-Rank Development in Foreland Basins. Geology, 26, 679-682.

GECO-PRAKLA (1991) 1991 Seismic Survey, Ppl38422 Ppl38443 Ppl38444. Ministry of Economic Development unpublished petroleum report. 1948, Ministry of Economic Development. Wellington. 1948, 168p., 135 enclosures. 
GeCO, P. (1991) 1991 Seismic Survey, Ppl38422 Ppl38443 Ppl38444. Ministry of Economic Development unpublished petroleum report. 1948, Ministry of Economic Development. Wellington, 168p., 135 enclosures.

GiBA, M., NiCOL, A. \& WALSH, J.J. (2010) Evolution of Faulting and Volcanism in a Back-Arc Basin and Its Implications for Subduction Processes. Tectonics, 29.

GöGuS, O.H. \& PYSKLYWEC, R.N. (2008) Near-Surface Diagnostics of Dripping or Delaminating Lithosphere. Journal of Geophysical Research B: Solid Earth, 113.

GRAIN, S.L. (2008) Palaeogeography of a Mid Miocene Turbidite Complex, Moki Formation, Taranaki Basin, New Zealand, Victoria University of Wellington, Wellington.

GrESKO, M.J., JORDAN, D.W. \& THOMPSON, P.R. (1992) Sequence Stratigraphic Analysis of the Tangaroa Sandstone, Northern Taranaki Basin, New Zealand. New Zealand Oil Exploration Conference (1991 : Christchurch, NZ), 234-244.

Gross, M.G. (1982) Oceanography: A View of the Earth 3rd edn. Prentice Hall International.

GuRNIS, M. \& HAGER, B.H. (1988) Controls of the Structure of Subducted Slabs. Nature, 335, 317-321.

GuRnIS, M. (1990) Plate-Mantle Coupling and Continental Flooding. Geophysical Research Letters, 17, 623-626.

GURNIS, M. (1992) Rapid Continental Subsidence Following the Initiation and Evolution of Subduction. Science, 255, 1556-1558.

GuRNIS, M. (1993) Depressed Continental Hypsometry Behind Oceanic Trenches: A Clue to Subduction Controls on Sea-Level Change. Geology, 21, 29-32.

Gurnis, M., Hall, C. \& LAVIER, L. (2004) Evolving Force Balance During Incipient Subduction. Geochemistry, Geophysics, Geosystems, $\mathbf{5}$.

HAdler-Jacobsen, F., Gardner, M.H. \& BoreR, J.M. (2007) Seismic Stratigraphic and Geomorphic Analysis of Deep-Marine Deposition Along the West African Continental Margin. Geological Society Special Publications, 277, 47-84.

HALL, R. \& SPAKMAN, W. (2002) Subducted Slabs beneath the Eastern Indonesia-Tonga Region: Insights from Tomography. Earth and Planetary Science Letters, 201, 321-336.

HANSEN, R.J. \& KAMP, P.J.J. (2004) Late Miocene to Early Pliocene Stratigraphic Record in Northern Taranaki Basin: Condensed Sedimentation Ahead of Northern Graben Extension and Progradation of the Modern Continental Margin. New Zealand journal of geology and geophysics, 47, 645-662.

HANSEN, R.J. \& KAMP, P.J.J. (2006) An Integrated Biostratigraphy and Seismic Stratigraphy for the Late Neogene Continental Margin Succession in Northern Taranaki Basin, New Zealand. New Zealand journal of geology and geophysics, 49, 39-56.

HAQ, B.U., HARDENBOL, J. \& VAIL, P.R. (1987) Chronology of Fluctuating Sea Levels since the Triassic. Science, 235, 1156-1167.

HART, B.S. (2008) Channel Detection in 3-D Seismic Data Using Sweetness. American Association of Petroleum Geologists. International Conference \& Exhibition (2000 : Bali, Indonesia), 92, 733-742.

HASKell, N.L., NiSSEN, S.E., LOPEZ, J.A. \& BAHORICH, M.S. (1995) 3-D Seismic Coherency and the Imaging of Sedimentological Features. Sequence stratigraphy - concepts and applications, 197-214.

HAYKIN, S. (1994) Neural Networks: A Comprehensive Foundation. New York: Maxwell MacMillian College Pub.

HAYton, S.H. (1998) Sequence Stratigraphic, Paleoenvironmental, and Chronological Analysis of the Late Neogene Wanganui River Section, Wanganui Basin, University of Waikato, Hamilton.

HAYWARD, B.W., Mildenhall, D.C. \& BeU, A.G. (1984) Biostratigraphy of Surville-1 Offshore Well Tasman Bay. Ppl 38125 Note: See Also Completion Report Pr 677. Ministry of Economic Development unpublished petroleum report. 1058, Ministry of Economic Development. Wellington, 24.

HAYWARD, B.W. (1985a) Foraminiferal Biostratigraphy of Kiwa-1 Offshore Well, South Taranaki Basin. Ppl 38114. New Zealand Unpublished Openfile Petroleum Report, 1117, $36 \mathrm{p} 31$ Fiche. 
HAYWARD, B.W. (1985b) Foraminiferal Biostratigraphy of Tangaroa-1 Offshore Well, North West Taranaki Ppl 38048. Ministry of Economic Development unpublished petroleum report. 1079, Ministry of Economic Development. Wellington, 32pp.

HAYWARD, B.W. (1986) Foraminiferal Biostratigraphy and Paleobathymetry of Ariki-1 Offshore Well, North West Taranaki Ppl 38048. Ministry of Economic Development, Wellington.

Hayward, B.W. \& NEW Zealand Geological Survey (1986) A Guide to Paleoenvironmental Assessment Using New Zealand Cenozoic Foraminiferal Faunas. New Zealand Geological Survey, Lower Hutt.

HAYWARD, B.W. \& KING, P.R. (1987) Paleogeography and Tectonic History of Taranaki Basin. (Abstract). Geological Society of New Zealand annual conference (1987 : Dunedin), 53.

HAYWARD, B.W. \& WOOD, R.A. (1989) Computer-Generated Geohistory Plots for Taranaki Drillhole Sequences. New Zealand Geological Survey Report PAL, 147, 73.

Hayward, B.W., Grenfell, H.R., SABAA, A.T., NeIL, H.L. \& BUZAS, M.A. (2010) Recent New Zealand Deep-Water Benthic Foraminifera : Taxonomy, Ecologic Distribution, Biogeography, and Use in Paleoenvironmental Assessment. GNS Science, Lower Hutt.

Hendrie, D.B., KuszNiR, N.J., Morley, C.K. \& EBINGER, C.J. (1994) Cenozoic Extension in Northern Kenya: A Quantitative Model of Rift Basin Development in the Turkana Region. International Union of Geodesy and Geophysics, 18th general assembly, interdisciplinary symposium No. 1, 236, 409-438.

Herzer, R.H. (1995) Seismic Stratigraphy of a Buried Volcanic Arc, Northland, New Zealand and Implications for Neogene Subduction. Marine and Petroleum Geology, 12, 511-531.

Herzer, R.H., DAvy, B.W., MorTimer, N., Quilty, P.G., Chaproniere, G.C.H., JONES, C.M., CRAWFord, A.J. \& Hollis, C.J. (2009) Seismic Stratigraphy and Structure of the Northland Plateau and the Development of the Vening Meinesz Transform Margin, Sw Pacific Ocean. Marine Geophysical Researches, 30, 21-60.

HigGS, K.E. (2004) A Petrographic and Reservoir Quality Study of the Moki Formation, Taranaki Basin. Ministry of Economic Development unpublished petroleum report. 3005, Ministry of Economic Development. Wellington, 188p.; 181 enclosure.

Higgs, K.E., ARNOT, M.J., BROWNE, G.H. \& KenNEDY, E.M. (2010) Reservoir Potential of Late Cretaceous Terrestrial to Shallow Marine Sandstones, Taranaki Basin, New Zealand. Marine and Petroleum Geology, 27(9), 1849-1871; doi:1810.1016/j.marpetgeo.2010.1808.1002.

Hollis, C.J., Beu, A.G., Crampton, J.S., Crundwell, M.P., Morgans, H.E.G., Raine, J.I., JONES, C.M. \& BOYES, A.F. (2010) Calibration of the New Zealand CretaceousCenozoic Timescale to Gts2004. GNS Science, Lower Hutt.

HOLT, W.E. \& STERN, T.A. (1991) Sediment Loading on the Western Platform of the New Zealand Continent: Implications for the Strength of a Continental Margin. Earth and Planetary Science Letters, 107, 523-538.

HOLT, W.E. \& STERn, T.A. (1994) Subduction, Platform Subsidence, and Foreland Thrust Loading: The Late Tertiary Development of Taranaki Basin New Zealand. Tectonics, 13, 1068-1092.

Houseman, G.A. \& MolnaR, P. (1997) Gravitational (Rayleigh-Taylor) Instability of a Layer with Non-Linear Viscosity and Convective Thinning of Continental Lithosphere. Geophysical Journal International, 128, 125-150.

Hubbard, S.M., Romans, B.W. \& Graham, S.A. (2008) Deep-Water Foreland Basin Deposits of the Cerro Toro Formation, Magallanes Basin, Chile: Architectural Elements of a Sinuous Basin Axial Channel Belt. Sedimentology, 55, 1333-1359.

Hubbard, S.M., DE Ruig, M.J. \& Graham, S.A. (2009) Confined Channel-Levee Complex Development in an Elongate Depo-Center: Deep-Water Tertiary Strata of the Austrian Molasse Basin. Marine and Petroleum Geology, 26, 85-112.

IsAACS, M.J. (1994) Cretaceous and Cenozoic Sedimentary Basins of Northland Nz: Supplementary Information. Ministry of Economic Development, Wellington.

JoRDAN, D.W., SCHUltZ, D.J., CHERnG, J.A. (1994) Facies Architecture and Reservoir Quality of Miocene Mt Messenger Deep-Water Deposits, Taranaki Peninsula, New Zealand. Submarine fans and turbidite systems: sequence stratigraphy, reservoir architecture and production characteristics, Gulf of Mexico and international. P. Weimer, Bouma, A.H., 
Perkins, B., Gulf Coast Section, Society of Economic Paleontologists and Mineralogists Foundation. Houston, 151-166.

Juniper, Z., Arnot, M.J., Zhu, H., Griffin, A.G. \& Jones, C.M. (2010) Depth-Twt Calibrations for 7 Selected Southern Offshore Taranaki Wells. GNS Science data series, GNS Science (NZ), 1 CD.

KAMP, P.J.J. (1986) Late Cretaceous-Cenozoic Tectonic Development of the Southwest Pacific Region. International Union of Geodesy and Geophysics, 18th general assembly, interdisciplinary symposium No. 1, 121, 225-251.

KAMP, P.J.J. \& GREen, P.F. (1990) Thermal and Tectonic History of Selected Taranaki Basin (New Zealand) Wells Assessed by Apatite Fission Track Analysis. American Association of Petroleum Geologists bulletin, 74, 1401-1419.

KAMP, P.J.J., WeBSTER, K.S. \& NATHAN, S. (1996) Thermal History Analysis by Integrated Modelling of Apatite Fission Track and Vitrinite Reflectance Data : Application to an Inverted Basin (Buller Coalfield, New Zealand). Basin research, 8(4), 383-402.

KAMP, P.J.J. (1999) Tracking Crustal Processes by Ft Thermochronology in a Forearc High (Hikurangi Margin, New Zealand) Involving Cretaceous Subduction Termination and Mid-Cenozoic Subduction Initiation. International Union of Geodesy and Geophysics, 18th general assembly, interdisciplinary symposium No. 1, 307, 313-343.

Kamp, P.J.J., Vonk, A.J., Bland, K.J., HANSEn, R.J., Hendy, A.J.W., McIntyre, A.P., Ngatai, M., Cartwright, S.J., Hayton, S. \& Nelson, C.S. (2004) Neogene Stratigraphic Architecture and Tectonic Evolution of Wanganui, King Country, and Eastern Taranaki Basins, New Zealand. New Zealand journal of geology and geophysics, 47, 625-644.

Killops, S.D., Woolhouse, A.D., Weston, R.J. \& CooK, R.A. (1994) A Geochemical Appraisal of Oil Generation in the Taranaki Basin, New Zealand. American Association of Petroleum Geologists bulletin, 78(10), 1560-1585.

KING, P.R. (1988a) Well Summary Sheets Onshore Taranaki. New Zealand Geological Survey Report $G, 125,14$.

KING, P.R. (1988b) Well Summary Sheets Offshore Taranaki. New Zealand Geological Survey Report $G, \mathbf{1 2 7}, 18$.

KING, P.R. \& RoBINSON, P.H. (1988) An Overview of Taranaki Region Geology, New Zealand. New Zealand Oil Exploration Conference (1987: Wairakei), 6(2), 213-232.

KING, P.R. \& Thrasher, G.P. (1992) Post-Eocene Development of the Taranaki Basin, New Zealand : Convergent Overprint of a Passive Margin. AAPG.

King, P.R., BRowne, G.H. \& SlATt, R.M. (1994a) Sequence Architecture of Exposed Late Miocene Basin Floor Fan and Channel-Levee Complexes (Mount Messenger Formation), Taranaki Basin, New Zealand. In: Submarine Fans and Turbidite Systems: Sequence Stratigraphy, Reservoir Architecture and Production Characteristics Gulf of Mexico and International. (Ed. by P. Weimer, Bouma, A.H., Perkins, B.F.), 177-192. Gulf Coast Section, Society of Economic Paleontologists and Mineralogists Foundation, Houston.

King, P.R., BRowne, G.H. \& Slatt, R.M. (1994b) Sequence Architecture of Exposed Late Miocene Basin Floor Fan and Channel-Levee Complexes (Mount Messenger Formation), Taranaki Basin, New Zealand. Submarine fans and turbidite systems : sequence stratigraphy, reservoir architecture and production characteristics Gulf of Mexico and international. P. Weimer, A. H. Bouma \& B. F. Perkins, Gulf Coast Section. Houston, TX, 177-192.

King, P.R. \& Browne, G.H., Slatt, R.M. (1994) Sequence Architecture of Exposed Late Miocene Basin Floor Fan and Channel-Levee Complexes (Mount Messenger Formation), Taranaki Basin, New Zealand. In: Society of Economic Paleontologists and Mineralogists Foundation. Gulf Coast Section. Annual Research Conference (15th : 1994 : Houston, Texas) (Ed. by, 177-192.

King, P.R. \& THRASHER, G.P. (1996) Cretaceous-Cenozoic Geology and Petroleum Systems of the Taranaki Basin, New Zealand. Institute of Geological \& Nuclear Sciences monograph 13, Institute of Geological \& Nuclear Sciences. Lower Hutt, 243. 
King, P.R., NAish, T.R., Browne, G.H., Field, B.D. \& EDbrooKe, S.W. (1999) Cretaceous to Recent Sedimentary Patterns in New Zealand. Institute of Geological \& Nuclear Sciences folio series, $\mathbf{1}, 1 \mathrm{v}$.

KING, P.R. (2000a) New Zealand's Changing Configuration in the Last 100 Million Years : Plate Tectonics, Basin Development, and Depositional Setting. New Zealand Petroleum Conference (2000 : Christchurch, NZ), 131-145.

KING, P.R. (2000b) Tectonic Reconstructions of New Zealand 40 Ma to the Present. New Zealand journal of geology and geophysics, 43(4), 611-638.

King, P.R., Browne, G.H., Arnot, M.J., Slatt, R.M., Helle, K. \& Stromsoyen, I. (2007a) An Overview of the Miocene Mount Messenger-Urenui Formations, New Zealand : A 2D, Oblique-Dip Outcrop Transect through an Entire Third-Order, Progradational, DeepWater Clastic Succession. In: Atlas of Deep-Water Outcrops. Aapg Studies in Geology. 56 (Ed. by T. H. Nilsen, R. D. Shew, G. S. Steffens \& J. R. J. Studlick), Aapg Studies in Geology. 56, 238-240 (chapter 260). American Association of Petroleum Geologists, Tulsa, Okla.

King, P.R., Browne, G.H., ARnot, M.J. \& Stromsoyen, I. (2007b) Slope Feeder Channels, Urenui Formation, Wai-Iti and Mimi Beaches, New Zealand (Ed. by, 262-264 (chapter 265).

KLEMPERER, S.L. (1988) Crustal Thinning and Nature of Extension in the Northern North Sea from Deep Seismic Reflection Profiling. Tectonics, 7, 803-821.

Klingelhoefer, F., Lafoy, Y., Collot, J., Cosquer, E., GÉli, L., NouzÉ, H. \& Vially, R. (2007) Crustal Structure of the Basin and Ridge System West of New Caledonia (Southwest Pacific) from Wide-Angle and Reflection Seismic Data. Journal of Geophysical Research B: Solid Earth, 112.

KNOX, G.J. (1982) Taranaki Basin, Structural Style and Tectonic Setting. New Zealand Journal of Geology \& Geophysics, 25, 125-140.

KomInZ, M.A. (1984) Oceanic Ridge Volumes and Sea Level Change - an Error Analysis. Interregional Unconformities and Hydrocarbon Accumulation, 36, 109-127.

KusZNiR, N.J., MARSDEN, G. \& EGAN, S.S. (1991) A Flexural-Cantilever Simple-Shear/PureShear Model of Continental Lithosphere Extension: Applications to the Jeanne D'arc Basin, Grand Banks and Viking Graben, North Sea. The geometry of normal faults, 4160 .

LAfoy, Y., Brodien, I., Vially, R. \& EXON, N.F. (2005) Structure of the Basin and Ridge System West of New Caledonia (Southwest Pacific): A Synthesis. Marine Geophysical Researches, 26, 37-50.

LAIRD, M.G. (1981) The Late Mesozoic Fragmentation of the New Zealand Segment of Gondwana. Gondwana Five: selected papers and abstracts, fifth Gondwana symposium, 311-318.

LAIRD, M.G. \& BRAdShaW, J.D. (2004) The Break-up of a Long-Term Relationship: The Cretaceous Separation of New Zealand from Gondwana. Gondwana Research, 7, 273286.

Lamarche, G., Collot, J.Y., Wood, R.A., Sosson, M., Sutherland, R. \& Delteil, J. (1997) The Oligocene-Miocene Pacific-Australia Plate Boundary, South of New Zealand: Evolution from Oceanic Spreading to Strike-Slip Faulting. Earth and Planetary Science Letters, 148, 129-139.

Lamarche, G., Proust, J.N. \& Nodder, S.D. (2005) Long-Term Slip Rates and Fault Interactions under Low Contractional Strain, Wanganui Basin, New Zealand. Tectonics, 24, 1-30.

LE PICHON, X. \& SiBueT, J.-C. (1981) Passive Margins; a Model of Formation. Journal of Geophysical Research, 86, 3708-3720.

LEASK, W.E. (1980) Basin Analysis of Tertiary Strata in Golden Bay, Nelson, Victoria University of Wellington.

LEASK, W.L. (1993) Brunner Coal Measures at Golden Bay, Nelson : An Eocene FluvialEstuarine Deposit. New Zealand journal of geology and geophysics, 36(1), 37-50.

LEwIS, K.B. \& BARNES, P.M. (1999) Kaikoura Canyon, New Zealand: Active Conduit from near-Shore Sediment Zones to Trench-Axis Channel. Marine Geology, 162, 39-69. 
LEWIS, K.B. \& PANTIN, H.M. (2002) Channel-Axis, Overbank and Drift Sediment Waves in the Southern Hikurangi Trough, New Zealand. Marine Geology, 192, 123-151.

LISIECKI, L.E. \& RAYMO, M.E. (2005) A Pliocene-Pleistocene Stack of 57 Globally Distributed Benthic $\Delta 180$ Records. Paleoceanography, 20, 1-17.

Lister, G.S., ETheridge, M.A. \& SYMONDS, P.A. (1986) Detachment Faulting and the Evolution of Passive Continental Margins. Geology, 14, 246-250.

Lister, G.S., ETHERIDGE, M.A. \& SYMONDS, P.A. (1991) Detachment Models for the Formation of Passive Continental Margins. Tectonics, 10, 1038-1064.

LOCK, R. \& ADAMS, E.A. (1980) Mckee-1 Well Completion Report, Ppl 38034. Ministry of Economic Development unpublished petroleum report, Ministry of Economic Development. Wellington. PR786, 424p., 425 enclosures.

Lock, R. (1985) The Distribution, Sedimentology, and Petroleum Prospects of the Moki Formation, Taranaki Basinm Nz, Ppl 38114. New Zealand unpublished Openfile Petroleum Report, Ministry of Commerce. Wellington. 1187.

LowE, D.R. (1982) Sediment Gravity Flows: Ii. Depositional Models with Special Reference to the Deposits of High-Density Turbidity Currents. Journal of Sedimentary Petrology, 52, 279-297.

LOwELL, J.D. (1995) Mechanics of Basin Inversion from Worldwide Examples. Basin inversion, 39-57.

Lyon-CAen, H. \& Molnar, P. (1985) Gravity Anomalies, Flexure of the Indian Plate, and the Structure, Support and Evolution of the Himalaya and Ganga Basin. Tectonics, 4, 513538.

MARFURT, K.J., KIRLIN, R.L., FARMER, S.L. \& BAHORICH, M.S. (1998) 3-D Seismic Attributes Using a Semblance-Based Coherency Algorithm. Geophysics, 63, 1150-1165.

Marsaglia, K.M. (1995) Interarc and Backarc Basins. Tectonics of Sedimentary Basins, 299329.

Masini, M., Bulnes, M. \& Poblet, J. Cross-Section Restoration: A Tool to Simulate Deformation. Application to a Fault-Propagation Fold from the Cantabrian Fold and Thrust Belt, Nw Iberian Peninsula. Journal of Structural Geology, 32, 172-183.

MatschKe, G. \& Weber, J. (1979) Marine Seismic Survey Ppl 682. Report on Digital Data Processing. Ministry of Economic Development unpublished petroleum report. 627, Ministry of Economic Development. Wellington, 37p., 216 enclosures.

MATtHEws, E. (2000). Offshore Taranaki Exploration. 2000 New Zealand Petroleum Conference Proceedings, Christchurch, Wellington, New Zealand, Crown Minerals, Ministry of Economic Development.

MATTHEWS, E. (2002). Implications of Neogene Structural Development on Hydrocarbon Prospectivity of the Tui-Maui Area, Offshore Taranaki, New Zealand. 2002 New Zealand Petroleum Conference Proceedings, Auckland, New Zealand, Crown Minerals, Ministry of Economic Development.

MatTHEWs, E. (2008). Awe Taranaki Exploration. 2008 New Zealand Petroleum Conference Proceedings, Auckland, New Zealand, Crown Minerals, Ministry of Economic Development.

Matthews, E. (2010). Tui Update. New Zealand Petroleum Conference Proceedings, Auckland, Ministry of Economic Development.

Matthews, E.R. \& BenNeTt, D.J. (1987) Kupe South-1 Well Completion Report Ppl 38116. Ministry of Economic Development unpublished petroleum report. 1284, Ministry of Economic Development. Wellington, 982p., 985 enclosures.

Matthews, E.R., BRAND, R.P., Buchan, R.J., JAMiEson, W.A., Jones, N.T. \& Mills, K.L. (1998). Exploration of the Area West of the Maui Field, Offshore Taranaki Basin. 1998 New Zealand Petroleum Conference Proceedings, Wellington, New Zealand, Crown Minerals, Ministry of Commerce.

MCALPINE, A. (1999) Maturation \& Migration Modelling: Pep 38462, Offshore Taranaki, New Zealand. Ministry of Economic Development unpublished petroleum report. 2454, Ministry of Economic Development. Wellington, 184p., 110 enclosures.

MCAlpine, A. (2000) Basin Modelling of Oil Plays Northwest of Maui : Results, Constraints and Calibrations. New Zealand Petroleum Conference (2000 : Christchurch, NZ), 59-67. 
Mchargue, T., Pyrcz, M.J., Sullivan, M.D., Clark, J.D., Fildani, A., Romans, B.W., Covault, J.A., Levy, M., Posamentier, H.W. \& Drinkwater, N.J. (2011) Architecture of Turbidite Channel Systems on the Continental Slope: Patterns and Predictions. Marine and Petroleum Geology, 28, 728-743.

McKenzIE, D. (1978) Some Remarks on the Development of Sedimentary Basins. Earth and Planetary Science Letters, 40, 25-32.

MCKenZIE, D.P. (1969) Speculations on the Consequences and Causes of Plate Motions*. Geophysical journal of the Royal Astronomical Society, 18, 1-32.

Meldahl, P., Heggland, R., De Groot, P.F.M. \& BRIL, A.H. (2004) Method of Combining Directional Seismic Attributes Using a Supervised Learning Approach.

Mildenhall, D.C., Wilson, G.J. \& NeW Zealand Geological, S. (1982) Palynology of Wainui-1 Offshore Well, 3000 M-3894 M. New Zealand Geological Survey report PAL. 50, New Zealand Geological Survey. Lower Hutt, $22 \mathrm{p}$.

Miller, K.G., Kominz, M.A., Browning, J.V., Wright, J.D., Mountain, G.S., KatZ, M.E., Sugarman, P.J., Cramer, B.S., Christie-Blick, N. \& Pekar, S.F. (2005) The Phanerozoic Record of Global Sea-Level Change. Science, 310, 1293-1298.

MiLls, K. (2000) Hochstetter-1 Well Completion Report. Pep 38460. Offshore Taranaki Basin. Ministry of Economic Development unpublished petroleum report. 2524, Ministry of Economic Development. Wellington, 517p., 516 enclosures.

Milne, A. \& QuicK, R. (1999) Waka Nui-1 Well Completion Report. Pep 38602. Ministry of Economic Development unpublished petroleum report. 2436, Ministry of Economic Development. Wellington. 2436, 922p., 924 enclosures.

Milner, M., MASSEY, M., JONES, C.M. \& VISKOVIC, G.P.D. (2010) Offshore Taranaki Phaseand Datum- Shifted Seismic Database, GNS Science (NZ), Database.

Ministry of ECONOMIC DeVelopment New Zealand (2010) New Zealand Petroleum Basins. Crown Minerals, Ministry of Economic Development, Wellington.

MitchUm R.M, JR. \& VAIL, P.R. (1977) Seismic Stratigraphy and Global Changes of Sea Level, Part 7: Seismic Stratigraphic Interpretation Procedure. AAPG Memoir, 26, 135-143.

Mitchum, R.M., VAIL, P.R. \& SANGREE, J.B. (1977a) Seismic Stratigraphy and Global Changes of Sea Level, Part 6: Stratigraphic Interpretation of Seismic Reflection Patterns in Depositional Sequences. Seismic Stratigraphy - Applications to Hydrocarbon Exploration, 26, 117-133.

Mitchum, R.M., VAIL, P.R. \& THOMPSON, S. (1977b) Seismic Stratigraphy and Global Changes of Sea Level; Part 2, the Depositional Sequence as a Basic Unit for Stratigraphic Analysis. Memoir - American Association of Petroleum Geologists, 53-62.

Mitrovica, J.X., BEAumont, C. \& JARVIS, G.T. (1989) Tilting of Continental Interiors by the Dynamical Effects of Subduction. Tectonics, 8, 1079-1094.

MoBIL, I.O.C. (1972) Seismic Profiles Offshore Nz. Ministry of Economic Development unpublished petroleum report, Ministry of Economic Development. Wellington. PR587, 26p., 934 enclosures.

MoBIL, I.O.C. (1979) Reprocessed Mobil Lines (Original Survey 1972 Pr587 ). Ministry of Economic Development unpublished petroleum report, Ministry of Economic Development. Wellington. PR738, 11p., 495 enclosures.

MogG, W.G., Aurisch, K., O'LeARY, R. \& PASS, G.P. (2008) Offshore Canterbury Basin : Beyond the Shelf Edge. 2008 New Zealand Petroleum Conference proceedings : beyond 08., Ministry of Economic Development. Wellington, 26 p.

Moore, P.R. \& New Zealand Geological, S. (1989) Stratigraphy of the Waipawa Black Shale (Paleocene), Eastern North Island, New Zealand. New Zealand Geological Survey, Lower Hutt.

Mortimer, N., TUlloch, A.J. \& IRELAND, T.R. (1997) Basement Geology of Taranaki and Wanganui Basins, New Zealand. New Zealand journal of geology and geophysics, 40, 223-236.

Mortimer, N. (2004a) Basement Gabbro from the Lord Howe Rise. New Zealand journal of geology and geophysics, 47, 501-507.

Mortimer, N. (2004b) New Zealand's Geological Foundations. Gondwana Research, 7, 261272. 
Moscardelli, L. \& Wood, L. (2008) New Classification System for Mass Transport Complexes in Offshore Trinidad. Basin research, 20, 73-98.

Mouslopoulou, V., Walsh, J.J. \& Nicol, A. (2009) Fault Displacement Rates on a Range of Timescales. Earth and Planetary Science Letters, 278, 186-197.

Muir, R.J., BradShAW, J.D., WEAVER, S.D. \& LAIRD, M.G. (2000) The Influence of Basement Structure on the Evolution of the Taranaki Basin, New Zealand. Journal of the Geological Society, 157, 1179-1185.

Mulder, T., SYVITSKI, J.P.M. \& Skene, K.I. (1998) Modeling of Erosion and Deposition by Turbidity Currents Generated at River Mouths. Journal of sedimentary research, 68, 124-137.

MutTI, E. (1985) Turbidite Systems and Their Relations to Depositional Sequences ( Gravity Flows). Provenance of arenites. Proc. Cetraro, Cosenza, 1984, 65-93.

MUTTI, E. \& NORMARK, W.R. (1991) An Integrated Approach to the Study of Turbidite Systems. Seismic Facies and Sedimentary Processes of Submarine Fans and Turbidite Systems, 75-106.

Mutti, E., Tinterri, R., Benevelli, G., Biase, D.D. \& Cavanna, G. (2003) Deltaic, Mixed and Turbidite Sedimentation of Ancient Foreland Basins. Marine and Petroleum Geology, 20, 733-755.

MutTi, E., Bernoulli, D., LuCChi, F.R. \& TINTERRI, R. (2009) Turbidites and Turbidity Currents from Alpine 'Flysch' to the Exploration of Continental Margins. Sedimentology, 56, 267-318.

NAISH, T. (1997) Constraints on the Amplitude of Late Pliocene Eustatic Sea-Level Fluctuations: New Evidence from the New Zealand Shallow-Marine Sediment Record. Geology, 25, 1139-1142.

NAISH, T. \& KAMP, P.J.J. (1997) Sequence Stratigraphy of Sixth-Order (41 K.Y.) PliocenePleistocene Cyclothems, Wanganui Basin, New Zealand : A Case for the Regressive Systems Tract. Geological Society of America Bulletin, 109(8), 978-999.

Naish, T.R., Wehland, F., Wilson, G.S., Browne, G.H., CoOK, R.A., Morgans, H.E.G., Rosenberg, M., King, P.R., Smale, D., Nelson, C.S., KAMP, P.J.J. \& RicketTs, B. (2005) An Integrated Sequence Stratigraphic, Palaeoenvironmental, and Chronostratigraphic Analysis of the Tangahoe Formation, Southern Taranaki Coast, with Implications for Mid-Pliocene (C. 3.4-3.0 Ma) Glacio-Eustatic Sea-Level Changes. Journal of the Royal Society of New Zealand, 35, 151-196.

NAISH, T.R. \& WILSON, G.S. (2009) Constraints on the Amplitude of Mid-Pliocene (3.6-2.4ma) Eustatic Sea-Level Fluctuations from the New Zealand Shallow-Marine Sediment Record. Philosophical Transactions of the Royal Society A: Mathematical, Physical and Engineering Sciences, 367, 169-187.

Nelson, C.H. (1990) Estimated Post-Messinian Sediment Supply and Sedimentation Rates on the Ebro Continental Margin, Spain. Marine Geology, 95, 395-418.

Nelson, C.H. \& MALDONADO, A. (1990) Factors Controlling Late Cenozoic Continental Margin Growth from the Ebro Delta to the Western Mediterranean Deep Sea. Marine Geology, 95, 419-440.

New Zealand Overseas Petroleum LtD. (2004) Pukeko-1 Well Completion Report. Ministry of Economic Development unpublished petroleum report. 2928, Ministry of Economic Development. Wellington, 1826p., 1822 enclosures.

Nicol, A., Van Dissen, R., Vella, P., Alloway, B. \& Melhuish, A. (2002) Growth of Contractional Structures During the Last 10 M.Y. At the Southern End of the Emergent Hikurangi Forearc Basin, New Zealand. New Zealand journal of geology and geophysics, 45, 365-385.

Nicol, A., Stagpoole, V.M. \& Maslen, G. (2004) Structure and Petroleum Potential of the Taranaki Fault Play. New Zealand Petroleum Conference (2004: Auckland), 9.

Nicol, A., Mazengarb, C., Chanier, F., Rait, G., Uruski, C. \& Wallace, L. (2007) Tectonic Evolution of the Active Hikurangi Subduction Margin, New Zealand, since the Oligocene. Tectonics, 26. 
Nicol, A., Walsh, J.J., Villamor, P., Seebeck, H. \& Berryman, K.R. (2010) Normal Fault Interactions, Paleoearthquakes and Growth in an Active Rift. Journal of Structural Geology, 32.

NiCOL, A. (2011) Landscape History of the Marlborough Sounds, New Zealand. New Zealand Journal of Geology and Geophysics, 53, 1-14.

NODDER, S.D. (1995) Late Quaternary Transgressive/Regressive Sequences from Taranaki Continental Shelf, Western New Zealand. Marine Geology, 123, 187-214.

NordfJord, S., GofF, J.A., Austin, J.A. \& Gulick, S.P.S. (2006) Seismic Facies of IncisedValley Fills, New Jersey Continental Shelf: Implications for Erosion and Preservation Processes Acting During Latest Pleistocene-Holocene Transgression. Journal of sedimentary research, 76, 1284-1303.

Normark, W.R. (1970) Growth Patterns of Deep- Sea Fans. American Association of Petroleum Geologists bulletin, 54, 2170-2195.

OGILVIE, M.J. (1993) The Pliocene-Pleistocene Seismic Stratigraphy of Part of the Offshore South Taranaki and South Wanganui Basins, Victoria University, Wellington.

OLIVER, J. (1986) Fluids Expelled Tectonically from Orogenic Belts: Their Role in Hydrocarbon Migration and Other Geologic Phenomena. Geology, 14, 99-102.

OMV NeW ZEALAND, L. (2002) Pep38472 2002 Reprocessing. Ministry of Economic Development unpublished petroleum report. 2992, Ministry of Economic Development. Wellington, 3p., 59 enclosures.

OMV NEW ZEALAND LTD. (2002) Pep38472 2002 Reprocessing. Ministry of Economic Development unpublished petroleum report, Ministry of Economic Development. Wellington. PR2992, 3p., 71 enclosures.

PALMER, J. (1985) Pre-Miocene Lithostratigraphy of Taranaki Basin, New Zealand. New Zealand journal of geology and geophysics, 28(2), 197-216.

PALMER, J.A. \& ANDREWS, P.B. (1993) Cretaceous-Tertiary Sedimentation and Implied Tectonic Controls on the Structural Evolution of Taranaki Basin, New Zealand. In: South Pacific Sedimentary Basins (Ed. by P. F. Ballance), 309-328. Elsevier Science Publishers, Amsterdam.

PARsons, B. \& Sclater, J.G. (1977) An Analysis of the Variation of Ocean Floor Bathymetry and Heat Flow with Age. J. Geophys. Res., 82, 803-827.

PETROCORP (1995) Offshore 2d Seismic Survey, 1995/1996. P95 Lines. Ppl38455, Ppl38456, Pp138457, Ppl38458, Pp138459. Ministry of Economic Development unpublished petroleum report. 2261, Ministry of Economic Development. Wellington, 723p., 315 enclosures.

PILAAR, W.F.H. \& WAKEFIELD, L.L. (1978) Structural and Stratigraphic Evolution of the Taranaki Basin, Offshore North Island, New Zealand. APEA journal, 18, 93-101.

PILAAR, W.F.H. \& WAKEFIELD, L.L. (1979) Structural, Stratigraphic Evolution of Taranaki Basin. Oil Gas $J, 77,100-104$.

PILAAR, W.F.H. \& WAKEFIELD, L.L.F. (1984) Hydrocarbon Generation in the Taranaki Basin, New Zealand. In: Petroleum Geochemistry and Basin Evaluation (Ed. by A. Demaisan \& R. J. Murris), 405-423. American Association of Petroleum Geologists, Tulsa.

PIPER, D.J.W. \& NORMARK, W.R. (2001) Sandy Fans-from Amazon to Hueneme and Beyond. American Association of Petroleum Geologists Bulletin, 85, 1407-1438.

PIRMEZ, C. \& FLOOD, R.D. (1995) Morphology and Structure of Amazon Channel. Initial Reports of the Ocean Drilling Program. R. D. Flood et al. College Station, Texas, Ocean Drilling Program. v. 155, p. 23-45.

Pocknall, D.T. \& BegGS, J.M. (1990) Palynofacies as a Tool for the Interpretation of Depositional Environments in the Waikato and Taranaki Basins, New Zealand. New Zealand Oil Exploration Conference (1989 : Queenstown, NZ), Ministry of Commerce, 250-258.

Pollock, R.M. \& CROUCH, E.M. (2005) Correlation of Paleocene to Eocene Sediments between Tui-1 and the Maui Field, Offshore Taranaki, New Zealand. Institute of Geological \& Nuclear Sciences client report. 2005/25, 43 p. - plus map.

Posamentier, H.W. \& VAIL, P.R. (1988) Eustatic Controls on Clastic Deposition Ii Sequence and Systems Tract Models. 
Posamentier, H.W., Meizarwin, Wisman, P.S. \& Plawman, T. (2000) Deep-Water Depositional Systems - Ultra-Deep Makassar Strait, Indonesia. GCSSEPM Research Conference, Houston, TX, Proceedings Volume, p. 806-816.

Posamentier, H.W. \& Kolla, V. (2003) Seismic Geomorphology and Stratigraphy of Depositional Elements in Deep-Water Settings. Journal of sedimentary research, 73, 367-388.

Posamentier, H.W. \& WAlKer, R.G. (2006) Facies Models Revisited. SEPM, Special Publication, 84, 531.

Posamentier, H.W., Davies, R.J., CARTwright, J.A. \& Wood, L.J. (2007) Seismic Geomorphology; an Overview. Geological Society Special Publications, 277, 1-14.

Pratson, L., ImRan, J., PARKer, G., SyVitski, J.P.M. \& HutTON, E. (2000) Debris Flow Vs. Turbidity Currents: A Modeling Comparison of Their Dynamics and Deposits. FineGrained Turbidite Systems, 68, 72-75.

Prins, M.A., Postma, G., Cleveringa, J., Cramp, A. \& Kenyon, N.H. (2000) Controls on Terrigenous Sediment Supply to the Arabian Sea During the Late Quaternary: The Indus Fan. Marine Geology, 169, 327-349.

Prosser, S. (1993) Rift-Related Linked Depositional Systems and Their Seismic Expression. Tectonics and seismic sequence stratigraphy, 35-66.

Proust, J.N., LAMARChE, G., NODDER, S. \& KAMP, P.J.J. (2005) Sedimentary Architecture of a Plio-Pleistocene Proto-Back-Arc Basin: Wanganui Basin, New Zealand. Sedimentary Geology, 181, 107-145.

Pulford, A. \& STERN, T. (2004) Pliocene Exhumation and Landscape Evolution of Central North Island, New Zealand: The Role of the Upper Mantle. J. Geophys. Res., 109, F01016.

RADOVICH, B.J. \& OLIVEROS, R.B. (1998) 3-D Sequence Interpretation of Seismic Instantaneous Attributes from the Gorgon Field. The Leading Edge, 17, 1286-1293.

Rait, G., Chanier, F. \& WATERS, D.W. (1991) Landward- and Seaward-Directed Thrusting Accompanying the Onset of Subduction beneath New Zealand. Geology, 19, 230-233.

RANGEL, H.D., GUIMARAİFES, P.D.T.M. \& SPADINI, A.R. (2005) Barracuda and Roncador Giant Oil Fields, Deep-Water Campos Basin, Brazil. AAPG Memoir, 123-127.

Rattenbury, M.S., CoOper, R.A., Johnston, M.R., Geological, I.o. \& Sciences, N. (1998a) Geology of the Nelson Area : Scale 1:250,000, Institute of Geological \& Nuclear Sciences Limited. Lower Hutt. 9, 67 p. + fold. map.

RATtenbury, M.S., COOPER, R.A., Johnston, M.R., Institute OF, G. \& NuClear, S. (1998b) Geology of the Nelson Area : Scale 1:250,000. Institute of Geological \& Nuclear Sciences Limited, Lower Hutt.

REAding, H.G. \& RichardS, M. (1994) Turbidite Systems in Deep-Water Basin Margins Classified by Grain Size and Feeder System. American Association of Petroleum Geologists bulletin, 78, 792-822.

ReILly, W.I. (1972) New Zealand Gravity Map Series. New Zealand Journal of Geology and Geophysics, 15, 3-15.

Reyners, M., Eberhart-Phillips, D., Stuart, G. \& Nishimura, Y. (2006) Imaging Subduction from the Trench to $300 \mathrm{Km}$ Depth beneath the Central North Island, New Zealand, with Vp and Vp/Vs. Geophysical Journal International, 165, 565-583.

RICCI LUCCHI, F. (1990) Turbidites in Foreland and on-Thrust Basins of the Northern Apennines. Palaeogeography, Palaeoclimatology, Palaeoecology, 77, 51-66.

Richards, M. \& Bowman, M. (1998) Submarine Fans and Related Depositional Systems Ii: Variability in Reservoir Architecture and Wireline Log Character. Marine and Petroleum Geology, 15, 821-839.

Richards, M., BOWMAN, M. \& REAdING, H. (1998) Submarine-Fan Systems I: Characterization and Stratigraphic Prediction. Marine and Petroleum Geology, 15, 689-717.

RIJKS, E.J.H. \& JAUFFRED, J.C.E.M. (1991) Seismic Interpretation 29; Attribute Extraction; an Important Application in Any Detailed 3-D Interpretation Study. The Leading Edge, 10, 11-19. 
Roberts, A.M., Yielding, G., Kusznir, N.J., WALKer, I.M. \& DORN- LoPeZ, D. (1995) Quantitative Analysis of Triassic Extension in the Northern Viking Graben. Journal Geological Society (London), 152, 15-26.

Robertson-ReSEARCH (1997) Tui/Toke 1997 Seismic Reprocessing, Pep38460 (Stos95 Lines). Ministry of Economic Development unpublished petroleum report. 2403, Ministry of Economic Development. Wellington. 2403, 3p., 1 enclosures.

Robertson, R. (1997) Tui/Toke 1997 Seismic Reprocessing, Pep38460 (Stos95 Lines). Ministry of Economic Development unpublished petroleum report. 2403, Ministry of Economic Development. Wellington, 3p., 1 enclosures.

Robinson, P.H., Thompson, B., King, P.R., Hayward, B.W., Raine, J.I. \& ScotT, G.H. (1986) Preliminary Diagrams on the Depositional History of Late Eocene to Oligocene Sediments, Taranaki Basin, New Zealand. New Zealand Geological Survey, Lower Hutt.

RoBINSON, P.H. \& KING, P.R. (1988) Hydrocarbon Reservoir Potential of the Taranaki Basin, Western New Zealand. New Zealand Oil Exploration Conference (1987 : Wairakei), 6(2), 248-262.

Rogers, B.A., Adams, S.A., Holstege, G.C.J., NAzzer, C.A., Viets, T.O. \& Young, I.M. (2000) Maari-1/1a - Results and Implications for Development. 2000 New Zealand Petroleum Conference Proceedings, Christchurch, Crown Minerals, Ministry of Economic Development. Wellington, New Zealand, 173-181.

Roncaglia, L., MiLner, M. \& BAuR, J. (2007) Maari-1, Maari-2 and Moki 2-a Well Sheets, Insitute of Geological and Nuclear Sciences. 2007/253, 3 figs.

Roncaglia, L., Morgans, H.E.G., Arnot, M.J., Baur, J., Zhu, H., Bushe, H., Jones, C.M., KInG, P.R. \& Milner, M. (2008) Stratigraphy, Well Correlation and Seismic-to-Well Tie in the Upper Cretaceous to Pliocene Interval in the Kupe Region, Taranaki Basin, New Zealand : Introduction to the Stratigraphic Database in Petrel. GNS Science, Lower Hutt.

Roncaglia, L. (2010) Well Summary Sheets from Taranaki Basin, New Zealand : Selected Wells from the Kupe and Maari Field Areas, GNS Science (NZ), 1 CD.

Roncaglia, L., Milner, M., Baur, J.R., Fohrmann, M., Kroeger, K.F., Strogen, D.P., Zhu, H., ARnOt, M.J., Bland, K.J., Bushe, H., FunNell, R.H., Ilg, B.R., HiLl, M.G., Jones, C.M., King, P.R., LeITNER, B., Morgans, H.E.G. \& ReID, E. (2010) Procedures and Metadata Protocols Used in Modelling Taranaki Basin Petroleum Systems : Guidelines from a Pilot Case Study in the Kupe Area. GNS Science, Lower Hutt.

Ronen, S., Schultz, P.S., Hattori, M. \& Corbett, C. (1994) Seismic-Guided Estimation of Log Properties; Part 2, Using Artificial Neural Networks for Nonlinear Attribute Calibration. The Leading Edge, 13, 674-678.

Rowley, D.B. \& SAHAgian, D. (1986) Depth-Dependent Stretching: A Different Approach. Geology, 14, 32-35.

Russell, B., HAMPSOn, D., Schuelke, J. \& Quirein, J. (1997) Multiattribute Seismic Analysis. The Leading Edge, 16, 1439-1443.

SANGREE, J.B. \& WIDMIER, J.M. (1979) Interpretation of Depositional Facies from Seismic Data. Geophysics, 44, 131-160.

SARKAR, S., MARFurT, K.J. \& Slatt, R.M. (2010) Generation of Sea-Level Curves from Depositional Pattern as Seen through Seismic Attributes-Seismic Geomorphology Analysis of an Mtc-Rich Shallow Sediment Column, Northern Gulf of Mexico. The Leading Edge, 29, 1084-1091.

Saul, G., Naish, T.R., ABbotT, S.T. \& CARTER, R.M. (1999a) Sedimentary Cyclicity in the Marine Pliocene-Pleistocene of the Wanganui Basin (New Zealand); Sequence Stratigraphic Motifs Characteristic of the Past 2.5 M.Y. Geological Society of America Bulletin, 111(4), 524-537.

Saul, G., NAish, T.R., ABbott, S.T. \& CARTER, R.M. (1999b) Sedimentary Cyclicity in the Marine Pliocene-Pleistocene of the Wanganui Basin (New Zealand): Sequence Stratigraphic Motifs Characteristic of the Past 2.5 M.Y. Bulletin of the Geological Society of America, 111, 524-537. 
SAvage, H.M. \& CooKe, M.L. (2003) Can Flat-Ramp-Flat Fault Geometry Be Inferred from Fold Shape?: A Comparison of Kinematic and Mechanical Folds. Journal of Structural Geology, 25, 2023-2034.

SCHEllart, W.P., Lister, G.S. \& TOY, V.G. (2006) A Late Cretaceous and Cenozoic Reconstruction of the Southwest Pacific Region: Tectonics Controlled by Subduction and Slab Rollback Processes. Earth-Science Reviews, 76, 191-233.

Schiøler, P., Rogers, K., Sykes, R., Hollis, C.J., Ilg, B., Meadows, D., Roncaglia, L. \& URUSKI, C. (2010) Palynofacies, Organic Geochemistry and Depositional Environment of the Tartan Formation (Late Paleocene), a Potential Source Rock in the Great South Basin, New Zealand. Marine and Petroleum Geology, 27, 351-369.

SCHMidT, D.S. \& RoBInson, P.H. (1990). The Structural Setting and Depositional History for the Kupe South Field, Taranaki Basin. 1989 New Zealand Oil Exploration Conference Proceedings, Wellington, New Zealand, Petroleum and Geothermal Unit, Energy and Resources Division, Ministry of Commerce.

Schultz, P.S., Ronen, S., HATTORI, M. \& CORBETt, C. (1994) Seismic-Guided Estimation of Log Properties; Part 1, a Data-Driven Interpretation Methodology. The Leading Edge, 13, 305-315.

Schumm, S.A. \& KHAn, H.R. (1971) Experimental Study of Channel Patterns. Nature, 233, 407409.

SClater, J.G. \& Christie, P.A.F. (1980) Continental Stretching; an Explanation of the PostMid-Cretaceous Subsidence of the Central North Sea Basin. Journal of Geophysical Research, 85, 3711-3739.

ScotT, G.H., KING, P.R. \& CRUNDwell, M.P. (2004) Recognition and Interpretation of Depositional Units in a Late Neogene Progradational Shelf Margin Complex, Taranaki Basin, New Zealand : Foraminiferal Data Compared with Seismic Facies and Wireline Logs. Sedimentary Geology, 164(1/2), 55-74.

SDROLIAS, M. \& MÜLLER, R.D. (2006) Controls on Back-Arc Basin Formation. Geochemistry, Geophysics, Geosystems, 7.

Shackleton, N.J., BACKMAN, J., Zimmerman, H., Kent, D.V., HALl, M.A., Roberts, D.G., Schnitker, D., Baldauf, J.G., Desprairies, A., Homrighausen, R., Huddlestun, P., KeEne, J.B., KAltenbaCK, A.J., KrumsieK, K.A.O., Morton, A.C., MurRay, J.W. \& Westberg-Smith, J. (1984) Oxygen Isotope Calibration of the Onset of Ice-Rafting and History of Glaciation in the North Atlantic Region. Nature, 307, 620-623.

Shanmugam, G. (2006) Deep-Water Processes and Facies Models: Implications for Sandstone Petroleum Reservoirs. Elsevier Amsterdam.

SHELL-BP-TODD (1976) Well Resume, Tane-1 (Offshore). Crown Minerals Open File Petroleum Report, 698

SHell BP TODD Oil Services LtD. (1969) Maui-1 Well Resume. Ministry of Economic Development unpublished petroleum report. 540, Ministry of Economic Development. Wellington, 224p., 222 enclosures.

SHELl BP TODD OIL SERVICES LTD. (1970a) Well Resume Maui-4. Ministry of Economic Development unpublished petroleum report. 543, Ministry of Economic Development. Wellington, 248p., 246 enclosures.

Shell BP TODD OIL SERVICES LTD. (1970b) Well Resume Maui-2. Ministry of Economic Development unpublished petroleum report. 541, Ministry of Economic Development. Wellington, 143p., 111 enclosures.

Shell BP TODD OIL SeRvices LTD. (1973) Kapuni Field Seismic Survey Data. Ministry of Economic Development unpublished petroleum report, Ministry of Economic Development. Wellington. PR624, 70p., 35 enclosures.

SHELl BP TODD OIL SERVICES LTD. (1976) Well Resume, Tane-1 (Offshore). Crown Minerals Open File Petroleum Report, 698.

SHELl BP TODD OIL SERVICES LTD. (1981a) Well Resume - Tangaroa-1 Ppl 38048 Offshore Taranaki. Ministry of Economic Development unpublished petroleum report. 793, Ministry of Economic Development. Wellington, 349p., 346 enclosures. 
Shell BP Todd Oil Services LTD. (1981b) Well Resume, Wainui-1. Crown Minerals PPL 38049 Open File Pet. Report 869.

SHell BP TODD OIL SeRviceS LTD. (1984) Well Completion Report Ariki-1. Ppl 38048, Exploration, Department Ministry of Economic Development. Wellington. 1038, 179p., 145 enclosures.

SHELl BP TodD Oil Services LTD. (1986) Well Resume Te Ranga-1, Ppl 38107 Taranaki New Plymouth. Ministry of Economic Development unpublished petroleum report. 1197, Ministry of Economic Development. Wellington, 809p., 818 enclosures.

Shell Oil COMPANY (1987) Seismic Sequences as Applied to Basin-Fill Analysis: Taranaki Basin, New Zealand. In: Atlas of Seismic Stratigraphy (Ed. by A. W. Bally), 1. American Association of Petroleum Geologists, Tulsa, Okla.

SHERIFF, R.E., TANER, M.T. \& RAO, K. (1978) Seismic Attribute Measurements in Offshore Production. Proceedings of the Annual Offshore Technology Conference, 2, 1103-1108.

Sinclair, H.D., CoAKley, B.J., Allen, P.A. \& WATTS, A.B. (1991) Simulation of Foreland Basin Stratigraphy Using a Diffusion Model of Mountain Belt Uplift and Erosion: An Example from the Central Alps, Switzerland. Tectonics, 10, 599-620.

SINCLAIR, H.D. (1997a) Tectonostratigraphic Model for Underfilled Peripheral Foreland Basins: An Alpine Perspective. Bulletin of the Geological Society of America, 109, 324-346.

SINCLAIR, H.D. (1997b) Flysch to Molasse Transition in Peripheral Foreland Basins: The Role of the Passive Margin Versus Slab Breakoff. Geology, 25, 1123-1126.

Sinclair, H.D. \& TOMASsO, M. (2002) Depositional Evolution of Confined Turbidite Basins. Journal of sedimentary research, 72, 451-456.

SiRCOMBE, K.N. \& KAMP, P.J.J. (1998) The South Westland Basin: Seismic Stratigraphy, Basin Geometry and Evolution of a Foreland Basin within the Southern Alps Collision Zone, New Zealand. International Union of Geodesy and Geophysics, 18th general assembly, interdisciplinary symposium No. 1, 300, 359-387.

SoENANDER, H.B. (1992) Seismic Stratigraphy of the Giant Foresets Formation, Offshore North Taranaki Western Platform. New Zealand Oil Exploration Conference (1991 : Christchurch, NZ), 207-233.

Sonneland, L., Olsen, M. \& INGE BARKVED, O. (1989) Application of Wavefield Attributes in 3d Seismic Interpretation. Technical Programme and Abstracts of Papers - European Association of Exploration Geophysicists, 51, 37-38.

SPAsojeVIC, S., LiU, L. \& GuRNis, M. (2009) Adjoint Models of Mantle Convection with Seismic, Plate Motion, and Stratigraphic Constraints: North America since the Late Cretaceous. Geochemistry, Geophysics, Geosystems, 10.

Srivastava, A.K., Samanta, B.G., Singh, V. \& Sen, G. (2004) Utilization of Seismic Attributes for Reservoir Mapping: A Case Study from the Cambay Basin, India. First Break, 22, 31-37.

Stagpoole, V. \& Nicol, A. (2008) Regional Structure and Kinematic History of a Large Subduction Back Thrust: Taranaki Fault, New Zealand. J. Geophys. Res., 113.

Stagpoole, V.M. (1998) A Geophysical Study of the Northern Taranaki Basin, New Zealand. $\mathrm{PhD}$ Thesis, Victoria University of Wellington.

Stagpoole, V.M., Hill, M., Thornton, S., Wood, R.A. \& Funnell, R.H. (2002) New Zealand Basin Development and Depositional Systems Evolution : Quantification and Visualisation. New Zealand Petroleum Conference (2002 : Auckland, NZ). 2002, 351362.

STECKLER, M.S. \& WATTS, A.B. (1978) Subsidence of the Atlantic-Type Continental Margin Off New York. Earth and Planetary Science Letters, 41, 1-13.

STECKler, M.S., ReYNoldS, D.J., COAKLEY, B.J., SwIFT, B.A. \& JARRARD, R. (1993) Modelling Passive Margin Sequence Stratigraphy. Sequence stratigraphy and facies associations, 19-41.

Steckler, M.S., Mountain, G.S., Miller, K.G. \& Christie-Blick, N. (1999) Reconstruction of Tertiary Progradation and Clinoform Development on the New Jersey Passive Margin by 2-D Backstripping. Marine Geology, 154, 399-420.

Stein, C.A. \& SteIn, S. (1992) A Model for the Global Variation in Oceanic Depth and Heat Flow with Lithospheric Age. Nature, 359, 123-129. 
Stern, T.A. \& DAVEy, F.J. (1990) Deep Seismic Expression of a Foreland Basin : Taranaki Basin, New Zealand. Geology, 18(10), 979-982.

Stern, T.A., Quinlan, G.M. \& HolT, W.E. (1992) Basin Formation Behind an Active Subduction Zone : Three-Dimensional Flexural Modelling of Wanganui Basin, New Zealand. Basin research, 4, 197-214.

Stern, T.A. \& Holt, W.E. (1994) Platform Subsidence Behind an Active Subduction Zone. Nature, 368(6468), 233-236.

Stern, T.A., StratFord, W.R. \& SAlmon, M.L. (2006) Subduction Evolution and Mantle Dynamics at a Continental Margin: Central North Island, New Zealand. Reviews of Geophysics, 44.

Strogen, D.P., Bland, K.J., BAUR, J.R. \& KING, P.R. (2010) Updated Regional Paleogeographies for the Taranaki Basin. 2010 New Zealand Petroleum Conference : conference proceedings : transformation., Crown Minerals, Ministry of Economic Development. Wellington, Poster P15.

Strogen, D.P., BAuR, J.R. \& Bland, K.J. (2011) Updated Regional Paleogeographies for the Taranaki Basin. GNS Science, Lower Hutt.

SuPPE, J. (1983) Geometry and Kinematics of Fault-Bend Folding. American Journal of Science, 283, 684-721.

Sutherland, R. (1995) The Australia-Pacific Boundary and Cenozoic Plate Motions in the Sw Pacific: Some Constraints from Geosat Data. Tectonics, 14, 819-831.

Sutherland, R., King, P.R. \& WoOD, R.A. (2001) Tectonic Evolution of Cretaceous Rift Basins in South-Eastern Australia and New Zealand : Implications for Exploration Risk Assessment. Eastern Australasian Basins Symposium, 25-28 November 2001, Melbourne, Victoria. Special publication / Petroleum Exploration Society of Australia. K. C. Hill \& T. Bernecker, Australasian Institute of Mining and Metallurgy. Carlton, Vic., 3-13.

Sutherland, R., Collot, J., Lafoy, Y., Logan, G.A., Hackney, R., Stagpoole, V., Uruski, C., Hashimoto, T., Higgins, K., Herzer, R.H., Wood, R., Mortimer, N. \& Rollet, N. (2010a) Lithosphere Delamination with Foundering of Lower Crust and Mantle Caused Permanent Subsidence of New Caledonia Trough and Transient Uplift of Lord Howe Rise During Eocene and Oligocene Initiation of Tonga-Kermadec Subduction, Western Pacific. Tectonics, 29.

Sutherland, R., SPAsojevic, S. \& GuRnis, M. (2010b) Mantle Upwelling after Gondwana Subduction Death Explains Anomalous Topography and Subsidence Histories of Eastern New Zealand and West Antarctica. Geology, 38, 155-158.

Swift, B.A., SAwYer, D.S., Grow, J.A. \& KLITGORD, K.D. (1987) Subsidence, Crustal Structure, and Thermal Evolution of the Georges Bank Basin. American Association of Petroleum Geologists bulletin, 71, 702-718.

Sykes, R., Bartram, K.R., Dow, M.J. \& SugGate, R.P. (1999) Enhanced Petroleum Potential of Marine-Influenced Coals in Mangahewa Formation, Taranaki Basin. Sixteenth annual meeting of the Society for Organic Petrology : abstracts and program : Snowbird, Utah, U.S.A., 1999. Abstracts and program / Society for Organic Petrology. 16, [Society for Organic Petrology]. [s.1.], 41-45.

SyKes, R. \& Dow, M. (2000). Petroleum Source Rock Potential of North Cape Formation (Late Cretaceous) Coaly Sediments, Taranaki Basin. 2000 New Zealand Petroleum Conference Proceedings, Christchurch, Wellington, New Zealand, Crown Minerals, Ministry of Economic Development.

SYKeS, R. (2001). Depositional and Rank Controls on the Petroleum Potential of Coaly Source Rocks. 2001 PESA Eastern Australian Basins Symposium Proceedings, Petroleum Exploration Society of Australia Special Publication, Carlton, Victoria, Australia, The Australasian Institute of Mining and Metallurgy.

SYKES, R., ZINK, K.-G. \& FUNNELL, R.H. (2010) Chemometric Analysis of Oil Families and OilSource Rock Correlations in New Zealand Basins : Implications for Source Kitchens and Migration Pathways. 2010 New Zealand Petroleum Conference : conference proceedings : transformation., Crown Minerals, Ministry of Economic Development. Wellington, 20. 
Taner, M.T., Koehler, F. \& Sheriff, R.E. (1979) Complex Seismic Trace Analysis. Geophysics, 44, 1041-1063.

TANNER, D.C., Behrmann, J.H., ONCKen, O. \& WeBER, K. (1998) Three-Dimensional RetroModelling of Transpression on a Linked Fault System: The Upper Cretaceous Deformation on the Western Border of the Bohemian Massif, Germany, 275-287.

TANNER, D.C., BEHRMANN, J.H. \& DRESMANN, H. (2003) Three-Dimensional RetroDeformation of the Lechtal Nappe, Northern Calcareous Alps. Journal of Structural Geology, 25, 737-748.

TANNER, D.C., BENSE, F.A. \& ERTL, G. (2011) Kinematic Retro-Modelling of a Cross-Section through a Thrust-and-Fold Belt: The Western Irish Namurian Basin, 61-76.

TAYLOR, B. \& KARNER, G.D. (1983) On the Evolution of Marginal Basins. Reviews of Geophysics \& Space Physics, 21, 1727-1741.

TGS-NOPEC (2001) Astrolabe Seismic Survey. Ministry of Economic Development unpublished petroleum report. 2847, Ministry of Economic Development. Wellington, 301p.

Thomas, W.A. \& BAyonA, G. (2002) Palinspastic Restoration of the Anniston Transverse Zone in the Appalachian Thrust Belt, Alabama. Journal of Structural Geology, 24, 797-826.

THRASHER, G. (1992) Late Cretaceous Geology of Taranaki Basin. PhD Thesis, Victoria University of Wellington.

THRASHER, G.P. (1988) The Interpretation of Seismic Reflection Data from the Western Platform Region of Taranaki Basin. New Zealand Oil Exploration Conference (1987 : Wairakei), 6(2), 136-150.

Thrasher, G.P. (1989) Miocene Faulting in Tasman Bay, Nelson, New Zealand, DSIR, New Zealand Geological Survey. Lower Hutt, 49-55.

Thrasher, G.P. (1990a) The Maui Field and the Exploration Potential of Southern Taranaki; a Few Unanswered Questions. Petroleum exploration in New Zealand news, 25, 26-30.

ThrASHer, G.P. (1990b) Late Cretaceous Sediments of Taranaki Basin. Seminar: Recent Developments in New Zealand Basin Studies (1990 : Lower Hutt), 13-14.

THRASHER, G.P. (1990c) Tectonics of the Taranaki Rift. 1989 New Zealand Oil Exploration Conference, Ministry of Commerce. Wellington, 124-133.

THRASHER, G.P. \& CAHILL, J.P. (1990) Subsurface Maps of the Taranaki Basin Region, New Zealand. New Zealand Geological Survey report G. 142. DSIR New Zealand Geological Survey. Lower Hutt, New Zealand Geological Survey. Lower Hutt.

THRASHER, G.P. (1991a). Late Cretaceous Source Rocks of Taranaki Basin. 1991 New Zealand Oil Exploration Conference Proceedings, Christchurch, Wellington, New Zealand, Ministry of Commerce.

THRASHER, G.P. (1991b) Evolution of the Cape Egmont Fault Zone, Taranaki Basin, New Zealand. Australian Society of Exploration Geophysicists Conference and Exhibition, Exploration in a Changing Environment (1991: Sydney), 174-175.

Thrasher, G.P. (1991c) Geology and Petroleum Potential of the Pakawau Basin Ppl 38411. DSIR Geology and Geophysics contract report. 1991/59.

Thrasher, G.P., KING, P.R. \& COOK, R.A. (1995) Taranaki Basin Petroleum Atlas. Institute of Geological \& Nuclear Sciences, Lower Hutt.

TingdaHL, K.M., BRIL, A.H. \& DE GROOT, P.F. (2001) Improving Seismic Chimney Detection Using Directional Attributes. Journal of Petroleum Science and Engineering, 29, 205211.

Tingdahl, K.M. \& De Groot, P.F.M. (2003) Post-Stack-Dip- and Azimuth Processing. Journal of Seismic Exploration, 12, 113-126.

TIPPETT, J.M. \& KAMP, P.J.J. (1995) Geomorphic Evolution of the Southern Alps, New Zealand. Earth Surface Processes \& Landforms, 20, 177-192.

TitHERIDGE, D.G. (1977) Stratigraphy and Sedimentology of the Upper Pakawau and Lower Westhaven Groups (Upper Cretaceous-Oligocene), Nw Nelson. MSc Thesis, University of Canterbury.

Titheridge, D.G. (1992) New Zealand Thesis in Earth Sciences : [the Geological and Depositional Setting of the Brunner Coal Measures, New Zealand, and the Influence of These Factors on Seam Thickness and Petrological Characteristics of Brunner Coals]. New Zealand journal of geology and geophysics, 35(3), 389. 
Townsend, D.B., Vonk, A. \& KAMP, P.J.J. (2008) Geology of the Taranaki Area : Scale 1:250,000, GNS Science. Lower Hutt. 7, 77 p. +71 folded map.

Tricentrol ExPloration Overseas, L.T.D. (1984) Well Completion Report Moki-1 Ppl 38114. Ministry of Economic Development unpublished petroleum report. 987, Ministry of Economic Development. Wellington, 488p., 486 enclosures.

Tricentrol EXPlORATION OVERSEAS LTD. (1985) Well Completion Report Kea-1 Ppl 38114. Ministry of Economic Development unpublished petroleum report. 1089, Ministry of Economic Development. Wellington, 618p., 612 enclosures.

Uruski, C. \& WooD, R. (1991) A New Look at the New Caledonia Basin, an Extension of the Taranaki Basin, Offshore North Island, New Zealand. Marine and petroleum geology, 8 , 379-391.

URUSKI, C.I. (1998) Wanganui Basin Seismic Maps. Institute of Geological \& Nuclear Sciences client report. 54767A.12, 16 p. + maps.

Uruski, C.I., StagPoole, V.M. \& BAillie, P. (2002a) Deepwater Taranaki Basin : Exploring a New Zealand Frontier. Oil and gas journal, 100(48), 28-32.

Uruski, C.I., Stagpoole, V.M., IsaAc, M.J., King, P.R. \& Maslen, G. (2002b) Seismic Interpretation Report - Astrolabe Survey Taranaki Basin, New Zealand, Ministry of Economic Development. Wellington. 3072, 192p., 129 enclosures.

URUSKi, C.I. \& StagPoole, V.M. (2004) Wakanui-1, Independent Well Summary. Institute of Geological \& Nuclear Sciences client report. 2004/06, Institute of Geological \& Nuclear Sciences. 2004/06, 21 p. - plus map in folder.

URUSKI, C.I. (2008) Deepwater Taranaki, New Zealand : Structural Development and Petroleum Potential. Exploration geophysics. 39(2), 94-107.

Uruski, C.I. (2010) New Zealand's Deepwater Frontier. Marine and Petroleum Geology, 27, 2005-2026.

UYEDA, S. (1981) Subduction Zones and Back Arc Basins - a Review. Geologische Rundschau, 70, 552-569.

VaIL, P.R. \& SAngree, J.B. (1971) Time Stratigraphy from Seismic Data. The American Association of Petroleum Geologists Bulletin, 55, 367-368.

VAil, P.R., Mitchum R.M, JR. \& THOMPSON, S. (1977a) Seismic Stratigraphy and Global Change of Sea Level, Part 4. Global Cycles or Relative Changes of Sea Level. American Association Petroleum Geolologists Bulletin, 23, 1-18.

VAIL, P.R., MitchUM, R.M. \& THOMPSON, S. (1977b) Seismic Stratigraphy and Global Changes of Sea Level; Part 3, Relative Changes of Sea Level from Coastal Onlap. Memoir American Association of Petroleum Geologists, 63-81.

VAIL, P.R., TODD, R.G. \& SANGREE, J.B. (1977c) Seismic Stratigraphy and Global Changes of Sea Level; Part 5, Chronostratigraphic Significance of Seismic Reflections. Memoir American Association of Petroleum Geologists, 99-116.

VAIL, P.R. (1987) Seismic Stratigraphy Interpretation Using Sequence Stratigraphy: Part 1: Seismic Stratigraphy Interpretation Procedure, 1-10. Atlas of seismic stratigraphy: AAPG Studies in Geology no. 27.

VAN BemMel, P.P. \& PEPPER, R.E.F. (2002) Seismic Signal Processing Method and Apparatus for Generating a Cube of Variance Values.

VAN DER Lingen, G.J. \& SMALE, D. (1990). Porosity Evaluation of an Upper Cretaceous Marine Sandstone, Tane-1 Offshore Oil Exploration Well, Taranaki Basin, New Zealand. 1989 New Zealand Oil Exploration Conference Proceedings, Wellington, New Zealand, Petroleum and Geothermal Unit, Energy and Resources Division, Ministry of Commerce.

Van Wagoner, J.C., Mitchum, R.M., Posamentier, H.W. \& Vail, P.R. (1987) Key Definitions of Sequence Stratigraphy. Atlas of Seismic Stratigraphy, 27, 11-14.

VeEvers, J.J. (2000) Change of Tectono-Stratigraphic Regime in the Australian Plate During the $99 \mathrm{Ma}$ (Mid-Cretaceous) and $43 \mathrm{Ma}$ (Mid Eocene) Swerves of the Pacific. Geology, 28, 47-50.

Voggenreiter, W.R. (1992) Kapuni 3d Interpretation - Imaging Eocene Paleogeography. 1991 New Zealand Oil Exploration Conference Proceedings, Ministry of Commerce. Wellington, New Zealand, 287-298. 
VogGenReITER, W.R. (1993) Structure and Evolution of the Kapuni Anticline, Taranaki Basin, New Zealand : Evidence from the Kapuni 3d Seismic Survey. New Zealand journal of geology and geophysics, 36(1), 77-94.

Vonk, A.J., KAMP, P.J.J. \& HendY, A.J.W. (2002) Outcrop to Subcrop Correlations of Late Miocene-Pliocene Strata, Eastern Taranaki Peninsula. New Zealand Petroleum Conference (2002: Auckland), 234-255.

VonK, A.J. \& KAMP, P.J.J. (2008) The Late Miocene Southern and Central Taranaki Inversion Phase (Sctip) and Related Sequence Stratigraphy and Paleogeography. 2008 New Zealand Petroleum Conference proceedings : beyond 08., Ministry of Economic Development. Auckland, New Zealand, 17

WalcotT, R.I. (1987) Geodetic Strain and the Deformational History of the North Island of New Zealand During the Late Cainozoic. Philosophical Transactions of the Royal Society of London, 321, 162-181.

WalKer, R.G. (1978) Deep-Water Sandstone Facies and Ancient Submarine Fans: Models for Exploration for Stratigraphic Traps. AAPG Bulletin (American Association of Petroleum Geologists), 62, 932-966.

Wallace, L.M., Beavan, J., McCaffrey, R. \& Darby, D. (2004) Subduction Zone Coupling and Tectonic Block Rotations in the North Island, New Zealand. Journal of Geophysical Research B: Solid Earth, 109, 1-21.

WATTS, A.B. \& RYAN, W.B.F. (1976) Flexure of the Lithosphere and Continental Margin Basins. International Union of Geodesy and Geophysics, 18th general assembly, interdisciplinary symposium No. 1, 36, 25-44.

WATTS, A.B. (1992) The Effective Elastic Thickness of the Lithosphere and the Evolution of Foreland Basins. Basin research, 4, 169-178.

Weimer, P. (2000) Deep-Water Reservoirs of the World : Papers Presented at the the Twentieth Annual Bob F. Perkins Research Conference, 2000. Gulf Coast Section Society of Economic Paleontologists and Mineralogists Foundation Bob F. Perkins Research Conference (20th : 2000 : Houston, Tex.), Society of Economic Paleontologists and Mineralogists, Gulf Coast Section Foundation. [Houston, Tex.], 1 computer laser optical disk.

Weimer, P. \& Slatt, R.M. (2004) The Petroleum Systems of Deep-Water Settings, Seg Distinguished Instructor Short Course Notes.

WERNICKE, B. \& BURCHFIEL, B.C. (1982) Modes of Extensional Tectonics. Journal of Structural Geology, 4, 105-115.

WeSTERn GeOPHYSICAL, C. (1986) Final Report of Operation and Field Work in Prospect Area Taranaki, Maui Pm1381012. Ministry of Economic Development unpublished petroleum report. 1219, Ministry of Economic Development. Wellington, 495p., 257 enclosures.

Western Geophysical COMPANy (1986) Final Report of Operation and Field Work in Prospect Area Taranaki, Maui Pm1381012. Ministry of Economic Development unpublished petroleum report. 1219, Ministry of Economic Development. Wellington. 1219, 495p., 257 enclosures.

WESTERN GeOPHYSICAL COMPANY (1996) Reprocessed Seismic Lines, Offshore Southern Taranaki Basin, Pep38455. Ministry of Economic Development unpublished petroleum report. 2304, Ministry of Economic Development. Wellington, 47p., 44 enclosures.

WHEELER, P. \& WHITE, N. (2000) Quest for Dynamic Topography: Observations from Southeast Asia. Geology, 28, 963-966.

White, N. \& MCKenZIE, D. (1988) Formation of the "Steer's Head" Geometry of Sedimentary Basins by Differential Stretching of the Crust and Mantle. Geology, 16, 250-253.

White, R. (1991) Properties of Instantaneous Seismic Attributes. The Leading Edge, 10, 26-32.

Willett, S.D. \& Schlunegger, F. (2010) The Last Phase of Deposition in the Swiss Molasse Basin: From Foredeep to Negative-Alpha Basin. Basin research, 22, 623-639.

Wizevich, M.C., Thrasher, G.P., Bussell, M.R., Wilson, G.J. \& Collen, J.D. (1992) Evidence for Marine Deposition in the Late Cretaceous Pakawau Group, Northwest Nelson. New Zealand Journal of Geology \& Geophysics, 35, 363-369.

Wizevich, M.C. (1994) Sedimentary Evolution of the Onshore Pakawau Sub-Basin: Rift Sediments of the Taranaki Basin Deposited During Tasman Sea Spreading. In: Evolution 
of the Tasman Sea Basin (Ed. by G. J. van der Lingen, Swanson, K.M., Muir, R.J.), Proceedings of the Tasman Sea Conference Christchurch, New Zealand, 27-30 November 1992, 83-104. Balkema, Rotterdam.

Wood, L.J. (2007) Quantitative Seismic Geomorphology of Pliocene and Miocene Fluvial Systems in the Northern Gulf of Mexico, U.S.A. Journal of sedimentary research, 77, 713-730.

WoOD, L.J. \& MIZE-SpANSKY, K.L. (2009) Quantitative Seismic Geomorphology of a Quaternary Leveed-Channel System, Offshore Eastern Trinidad and Tobago Northeastern South America. American Association of Petroleum Geologists Bulletin, 93, 101-125.

Wood, R., Lamarche, G., Herzer, R., Delteil, J. \& Davy, B. (1996) Paleogene Seafloor Spreading in the Southeast Tasman Sea. Tectonics, 15, 966-975.

Wood, R.A. \& WoOdWARD, D.J. (1999) Sediment Thickness and Crustal Structure of Western New Zealand. In: Geological Society of New Zealand. Conference (1999 : Massey University) (Ed. by, 175.

WoOD, R.A. \& WOODWARD, D.J. (2002) Sediment Thickness and Crustal Structure of Offshore Western New Zealand from 3d Gravity Modelling. New Zealand journal of geology and geophysics, 45(2), 243-255.

Wood, R.A. \& Stagpoole, V. (2007) Validation of Tectonic Reconstructions by Crustal Volume Balance: New Zealand through the Cenozoic. Geological Society of America Bulletin, 119, 933-943.

XIE, X. \& HelleR, P.L. (2009) Plate Tectonics and Basin Subsidence History. Bulletin of the Geological Society of America, 121, 55-64.

Zachos, J., Pagani, H., Sloan, L., Thomas, E. \& Billups, K. (2001) Trends, Rhythms, and Aberrations in Global Climate 65 Ma to Present. Science, 292, 686-693.

Zeng, H., BACKus, M.M., BARrow, K.T. \& TYler, N. (1998) Stratal Slicing, Part I: Realistic 3D Seismic Model. Geophysics, 63, 502-513.

ZENG, H. (2004) Seismic Geomorphology-Based Facies Classification. The Leading Edge, 23, 644-645.

ZhU, H.A., M.; Jones, C.; JuniPer, Z.; Viskovic. P. (2010) Depth-Twt Calibrations for 35 Selected Offshore Taranaki Wells. GNS Data Series $2 a$. 
Supplements to:

REGIONAL SEISMIC ATTRIBUTE ANALYSIS AND TECTONOSTRATIGRAPHY OF OFFSHORE SOUTH-WESTERN TARANAKI BASIN, NEW ZEALAND

by

Jan Robert Baur

A thesis

submitted to the Victoria University of Wellington in fulfilment of the requirements for the degree of Doctor of Philosophy in Geophysics

Victoria University of Wellington 


\section{CONTENTS}

Supplement 1 Summary of seismic and well information..............................................................

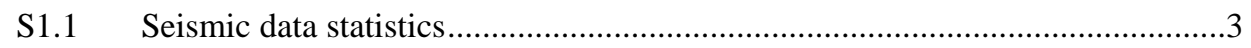

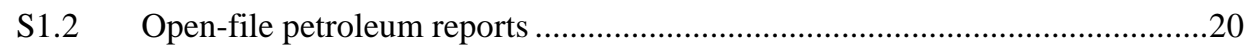

Supplement 2 Tectonic subsidence calculations........................................................................25

Supplement 3 Basin structure and development ........................................................................33

S3.1 Basement to Late Cretaceous (Basement-K85)......................................................33

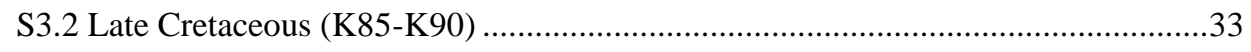

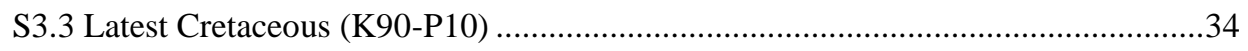

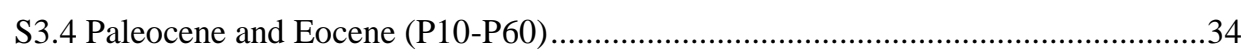

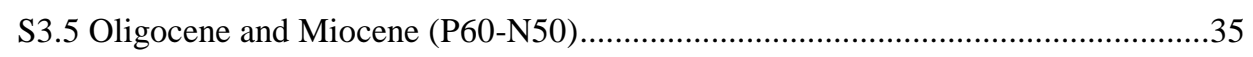

S3.6 Reconstruction of the Late Miocene unconformity ..................................................36

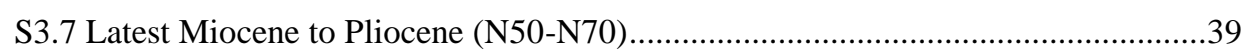

S3.8 Late Pliocene to Pleistocene (N70-Seabed) …………………………………........39 


\section{SUPPLEMENT 1 SUMMARY OF SEISMIC AND WELL INFORMATION}

The following sections list the seismic data statistics and open-file petroleum report references for seismic and borehole data used in this study.

\section{S1.1 Seismic data statistics}

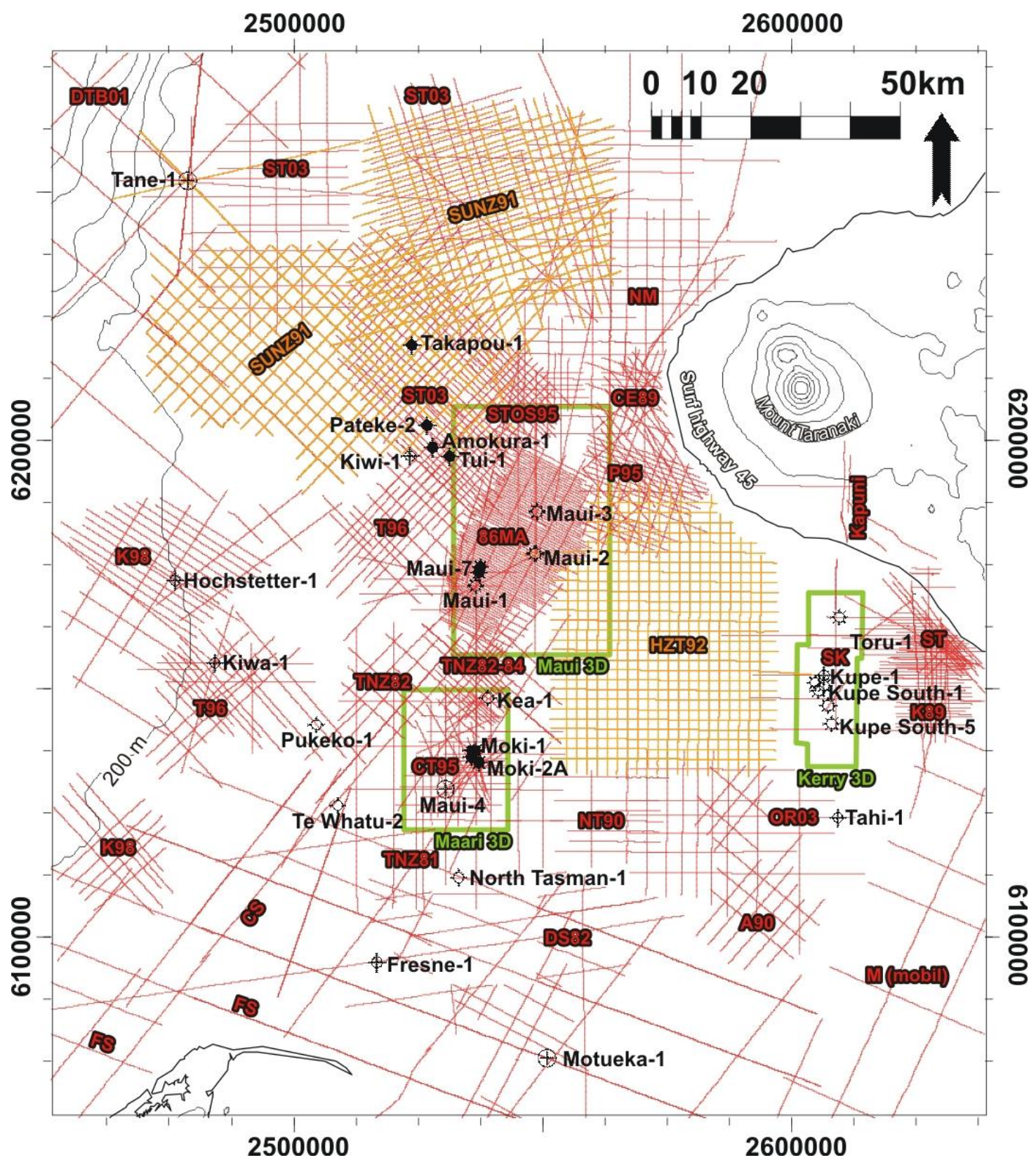

Figure S 1.1 Overview of seismic data sets used in this study. 2D and 3D seismic surveys are shown as red/orange lines and green polygons, respectively. Orange lines were used as the reference surveys for phase-matching the data set (see chapter 2 for details). The survey names of major surveys are annotated. Wells used in this area are shown by black symbols. 
Table S1 Statistics of seismic data used in this study. The columns show: seismic line names (survey name and lines number), type of data (2D or 3D), minimum (min) and maximum (max) longitude (X) and latitude (Y), maximum time ( $\mathrm{T}$ in $\mathrm{ms}$ TWT), and petroleum report number (PR) of the associated processing report. Seismic lines without petroleum report number have been provided to the 4D-Taranaki project through confidential data sharing agreements.

\begin{tabular}{|c|c|c|c|c|c|c|c|}
\hline Name & Type & $\mathbf{X} \min$ & $X$ max & $Y$ min & $Y$ max & $\mathbf{T} \max$ & PR \\
\hline $80 e-100-1662$ & $2 \mathrm{D}$ & 2477411 & 2487838 & 6133063 & 6166836 & 5036 & 1662 \\
\hline $80 e-101-1662$ & $2 \mathrm{D}$ & 2466174 & 2489405 & 6163441 & 6178201 & 5028 & 1662 \\
\hline 80e-102-1662 & $2 \mathrm{D}$ & 2465042 & 2486607 & 6157018 & 6189958 & 5052 & 1662 \\
\hline 80ma-101-2308 & $2 \mathrm{D}$ & 2529259 & 2530822 & 6165241 & 6178690 & 5020 & 2308 \\
\hline 80ma-102-2308 & $2 \mathrm{D}$ & 2524270 & 2541843 & 6170637 & 6170718 & 5020 & 2308 \\
\hline 80ma-103-2308 & $2 \mathrm{D}$ & 2531507 & 2534139 & 6162581 & 6181396 & 5020 & 2308 \\
\hline 80ma-104-2308 & $2 \mathrm{D}$ & 2527310 & 2544743 & 6173268 & 6173343 & 5020 & 2308 \\
\hline 80ma-105-scan & $2 \mathrm{D}$ & 2533170 & 2537919 & 6177745 & 6192217 & 4012 & 2308 \\
\hline 80ma-107_1-scan & $2 \mathrm{D}$ & 2538352 & 2545228 & 6186687 & 6215991 & 4708 & 2308 \\
\hline 80ma-107_2-scan & $2 \mathrm{D}$ & 2534462 & 2539964 & 6170865 & 6193842 & 4000 & 2308 \\
\hline 80ma-108-2308 & $2 \mathrm{D}$ & 2526587 & 2541839 & 6184848 & 6201915 & 5020 & 2308 \\
\hline 86ma-001 & $2 \mathrm{D}$ & 2529475 & 2543095 & 6157060 & 6164047 & 5028 & 1219 \\
\hline 86ma-002 & $2 \mathrm{D}$ & 2529534 & 2538836 & 6159784 & 6164520 & 5028 & 1219 \\
\hline 86ma-004 & $2 \mathrm{D}$ & 2529655 & 2543804 & 6158308 & 6165601 & 5028 & 1219 \\
\hline 86ma-005 & $2 \mathrm{D}$ & 2529770 & 2539632 & 6161013 & 6166119 & 5028 & 1219 \\
\hline 86ma-006 & $2 \mathrm{D}$ & 2530714 & 2540707 & 6161028 & 6166189 & 5028 & 1219 \\
\hline 86ma-007 & $2 \mathrm{D}$ & 2529962 & 2544592 & 6159673 & 6167109 & 5028 & 1219 \\
\hline 86ma-008 & $2 \mathrm{D}$ & 2530002 & 2540369 & 6162332 & 6167665 & 5028 & 1219 \\
\hline 86ma-009 & $2 \mathrm{D}$ & 2530925 & 2541505 & 6162414 & 6167738 & 5028 & 1219 \\
\hline $86 m a-010$ & $2 \mathrm{D}$ & 2530997 & 2546221 & 6160507 & 6168273 & 5028 & 1219 \\
\hline 86ma-011 & $2 \mathrm{D}$ & 2530249 & 2541151 & 6163557 & 6169225 & 5028 & 1219 \\
\hline 86ma-012 & $2 \mathrm{D}$ & 2530332 & 2541384 & 6164076 & 6169731 & 5028 & 1219 \\
\hline 86ma-013 & $2 \mathrm{D}$ & 2531234 & 2547012 & 6161803 & 6169842 & 5028 & 1219 \\
\hline 86ma-014 & $2 \mathrm{D}$ & 2531345 & 2542774 & 6164434 & 6170363 & 5028 & 1219 \\
\hline 86ma-015 & $2 \mathrm{D}$ & 2530564 & 2542175 & 6165361 & 6171299 & 5028 & 1219 \\
\hline 86ma-016 & $2 \mathrm{D}$ & 2530606 & 2546890 & 6163502 & 6171840 & 5028 & 1219 \\
\hline 86ma-017 & $2 \mathrm{D}$ & 2530672 & 2543559 & 6165751 & 6172335 & 5028 & 1219 \\
\hline 86ma-018 & $2 \mathrm{D}$ & 2530833 & 2543811 & 6166186 & 6172816 & 5028 & 1219 \\
\hline 86ma-019 & $2 \mathrm{D}$ & 2531698 & 2548501 & 6164246 & 6172988 & 5028 & 1219 \\
\hline $86 m a-020$ & $2 \mathrm{D}$ & 2531813 & 2545208 & 6166584 & 6173478 & 5028 & 1219 \\
\hline $86 m a-021$ & $2 \mathrm{D}$ & 2531915 & 2545429 & 6167121 & 6173991 & 5028 & 1219 \\
\hline $86 m a-022$ & $2 \mathrm{D}$ & 2531096 & 2550703 & 6164904 & 6174943 & 5028 & 1219 \\
\hline $86 \mathrm{ma}-023$ & $2 \mathrm{D}$ & 2531180 & 2548671 & 6166461 & 6175433 & 5028 & 1219 \\
\hline $86 m a-024$ & $2 \mathrm{D}$ & 2531262 & 2548962 & 6166928 & 6176038 & 5028 & 1219 \\
\hline $86 m a-025$ & $2 \mathrm{D}$ & 2532151 & 2550085 & 6167010 & 6176067 & 5028 & 1219 \\
\hline 86ma-026 & $2 \mathrm{D}$ & 2531417 & 2551736 & 6166661 & 6176976 & 5028 & 1219 \\
\hline $86 m a-027$ & $2 \mathrm{D}$ & 2532318 & 2550561 & 6167747 & 6177150 & 5028 & 1219 \\
\hline $86 m a-028$ & $2 \mathrm{D}$ & 2531570 & 2550004 & 6168621 & 6178043 & 5028 & 1219 \\
\hline 86ma-029 & $2 \mathrm{D}$ & 2531654 & 2550216 & 6169044 & 6178624 & 5028 & 1219 \\
\hline $86 m a-030$ & $2 \mathrm{D}$ & 2531784 & 2552894 & 6168242 & 6179039 & 5028 & 1219 \\
\hline $86 m a-031$ & $2 \mathrm{D}$ & 2532801 & 2551601 & 6169443 & 6179102 & 5028 & 1219 \\
\hline 86ma-032 & $2 \mathrm{D}$ & 2533078 & 2551852 & 6169909 & 6179521 & 5028 & 1219 \\
\hline 86ma-033 & $2 \mathrm{D}$ & 2532508 & 2551269 & 6170783 & 6180348 & 5028 & 1219 \\
\hline 86ma-034 & $2 \mathrm{D}$ & 2533643 & 2554723 & 6169559 & 6180374 & 5028 & 1219 \\
\hline 86ma-035 & $2 \mathrm{D}$ & 2533305 & 2552595 & 6171199 & 6181121 & 5028 & 1219 \\
\hline 86ma-036 & $2 \mathrm{D}$ & 2533298 & 2552005 & 6172124 & 6181639 & 5028 & 1219 \\
\hline 86ma-037 & $2 \mathrm{D}$ & 2534502 & 2553176 & 6172073 & 6181628 & 5028 & 1219 \\
\hline 86ma-038 & $2 \mathrm{D}$ & 2533928 & 2554995 & 6171726 & 6182460 & 5028 & 1219 \\
\hline 86ma-039 & $2 \mathrm{D}$ & 2532784 & 2553016 & 6173282 & 6183625 & 5028 & 1219 \\
\hline $86 m a-040$ & $2 \mathrm{D}$ & 2534494 & 2553416 & 6173589 & 6183319 & 5028 & 1219 \\
\hline $86 m a-041$ & $2 \mathrm{D}$ & 2535627 & 2554806 & 6173580 & 6183267 & 5028 & 1219 \\
\hline
\end{tabular}




\begin{tabular}{|c|c|c|c|c|c|c|c|}
\hline Name & Type & $X$ min & $X \max$ & $Y$ min & $Y \max$ & $T \max$ & PR \\
\hline $86 m a-042$ & $2 \mathrm{D}$ & 2535899 & 2556873 & 6173046 & 6183676 & 5028 & 1219 \\
\hline 86ma-043 & $2 \mathrm{D}$ & 2533780 & 2554809 & 6174614 & 6185325 & 5028 & 1219 \\
\hline 86ma-044a & $2 \mathrm{D}$ & 2540921 & 2555285 & 6174967 & 6182257 & 5028 & 1219 \\
\hline 86ma-045 & $2 \mathrm{D}$ & 2535837 & 2555700 & 6175283 & 6185388 & 5028 & 1219 \\
\hline $86 m a-046$ & $2 \mathrm{D}$ & 2536206 & 2557526 & 6174887 & 6185823 & 5028 & 1219 \\
\hline $86 m a-047$ & $2 \mathrm{D}$ & 2534822 & 2557530 & 6175550 & 6187066 & 5028 & 1219 \\
\hline $86 m a-048$ & $2 \mathrm{D}$ & 2537555 & 2557946 & 6175877 & 6186175 & 5028 & 1219 \\
\hline 86ma-049 & $2 \mathrm{D}$ & 2537039 & 2557579 & 6176609 & 6187004 & 5028 & 1219 \\
\hline $86 m a-050$ & $2 \mathrm{D}$ & 2538165 & 2558642 & 6176705 & 6186974 & 5028 & 1219 \\
\hline $86 m a-051$ & $2 \mathrm{D}$ & 2536133 & 2558661 & 6177154 & 6188575 & 5028 & 1219 \\
\hline $86 m a-052$ & $2 \mathrm{D}$ & 2537893 & 2557846 & 6178121 & 6188300 & 5028 & 1219 \\
\hline $86 m a-053$ & $2 \mathrm{D}$ & 2538951 & 2558698 & 6178169 & 6188294 & 5028 & 1219 \\
\hline $86 m a-054$ & $2 \mathrm{D}$ & 2538420 & 2559759 & 6178233 & 6189130 & 5028 & 1219 \\
\hline $86 m a-055$ & $2 \mathrm{D}$ & 2537228 & 2558661 & 6179424 & 6190274 & 5028 & 1219 \\
\hline $86 m a-056$ & $2 \mathrm{D}$ & 2538954 & 2557834 & 6180405 & 6189864 & 5028 & 1219 \\
\hline $86 \mathrm{ma}-057$ & $2 \mathrm{D}$ & 2539288 & 2557847 & 6180862 & 6190366 & 5028 & 1219 \\
\hline $86 m a-058$ & $2 \mathrm{D}$ & 2540427 & 2562664 & 6178980 & 6190362 & 5028 & 1219 \\
\hline $86 m a-059$ & $2 \mathrm{D}$ & 2539331 & 2558697 & 6181625 & 6191526 & 5028 & 1219 \\
\hline $86 m a-060$ & $2 \mathrm{D}$ & 2540166 & 2557854 & 6182661 & 6191661 & 5028 & 1219 \\
\hline $86 m a-061$ & $2 \mathrm{D}$ & 2540453 & 2557840 & 6183158 & 6191988 & 5028 & 1219 \\
\hline $86 m a-062$ & $2 \mathrm{D}$ & 2540712 & 2561789 & 6181668 & 6192475 & 5028 & 1219 \\
\hline $86 m a-063$ & $2 \mathrm{D}$ & 2540075 & 2558725 & 6183786 & 6193366 & 5028 & 1219 \\
\hline 86ma-064 & $2 \mathrm{D}$ & 2542167 & 2558659 & 6184468 & 6192852 & 5028 & 1219 \\
\hline $86 m a-065$ & $2 \mathrm{D}$ & 2542412 & 2558728 & 6184981 & 6193219 & 5028 & 1219 \\
\hline $86 m a-066$ & $2 \mathrm{D}$ & 2541933 & 2561880 & 6183940 & 6194093 & 5028 & 1219 \\
\hline $86 m a-067$ & $2 \mathrm{D}$ & 2540602 & 2557909 & 6186488 & 6195317 & 5028 & 1219 \\
\hline $86 m a-068$ & $2 \mathrm{D}$ & 2542440 & 2557876 & 6187058 & 6194944 & 5028 & 1219 \\
\hline $86 m a-069$ & $2 \mathrm{D}$ & 2539079 & 2557846 & 6187669 & 6197138 & 5028 & 1219 \\
\hline $86 \mathrm{ma}-070$ & $2 \mathrm{D}$ & 2543834 & 2562791 & 6185642 & 6195319 & 5028 & 1219 \\
\hline $86 m a-071$ & $2 \mathrm{D}$ & 2539248 & 2558725 & 6188348 & 6198195 & 5028 & 1219 \\
\hline $86 m a-072$ & $2 \mathrm{D}$ & 2544408 & 2558680 & 6188902 & 6196195 & 5028 & 1219 \\
\hline 86ma-073 & $2 \mathrm{D}$ & 2539375 & 2558709 & 6189357 & 6199258 & 5028 & 1219 \\
\hline $86 m a-074$ & $2 \mathrm{D}$ & 2544129 & 2561919 & 6188329 & 6197417 & 5028 & 1219 \\
\hline $86 m a-075$ & $2 \mathrm{D}$ & 2538628 & 2557871 & 6191020 & 6200804 & 5028 & 1219 \\
\hline 86ma-076 & $2 \mathrm{D}$ & 2544676 & 2557878 & 6191525 & 6198276 & 5028 & 1219 \\
\hline 86ma-077 & $2 \mathrm{D}$ & 2540286 & 2558751 & 6191606 & 6201135 & 5028 & 1219 \\
\hline $86 m a-079$ & $2 \mathrm{D}$ & 2540101 & 2559124 & 6192563 & 6202261 & 5028 & 1219 \\
\hline $86 m a-081$ & $2 \mathrm{D}$ & 2540942 & 2550402 & 6198135 & 6202986 & 5028 & 1219 \\
\hline $86 m a-083$ & $2 \mathrm{D}$ & 2542521 & 2550849 & 6198969 & 6203372 & 5028 & 1219 \\
\hline 86ma-101 & $2 \mathrm{D}$ & 2531344 & 2548117 & 6169068 & 6202687 & 5028 & 1219 \\
\hline $86 m a-102$ & $2 \mathrm{D}$ & 2531812 & 2550180 & 6161058 & 6197899 & 5028 & 1219 \\
\hline 86ma-103 & $2 \mathrm{D}$ & 2542543 & 2554618 & 6173050 & 6197082 & 5028 & 1219 \\
\hline 86ma-103a & $2 \mathrm{D}$ & 2535042 & 2542574 & 6158203 & 6173111 & 5028 & 1219 \\
\hline 86ma-104 & $2 \mathrm{D}$ & 2538826 & 2558473 & 6157992 & 6196285 & 5028 & 1219 \\
\hline 86ma-105 & $2 \mathrm{D}$ & 2550373 & 2560031 & 6172336 & 6191167 & 5028 & 1219 \\
\hline 91 ce-003-2306 & $2 \mathrm{D}$ & 2560218 & 2568473 & 6184163 & 6190133 & 3536 & 2306 \\
\hline a90-01 & $2 \mathrm{D}$ & 2583572 & 2595676 & 6123962 & 6134248 & 6016 & 2992 \\
\hline a90-02 & $2 \mathrm{D}$ & 2580978 & 2593158 & 6117655 & 6128422 & 6016 & 2992 \\
\hline a90-03 & $2 \mathrm{D}$ & 2580573 & 2590687 & 6122437 & 6134557 & 6016 & 2992 \\
\hline a90-04 & $2 \mathrm{D}$ & 2582907 & 2594817 & 6120444 & 6134673 & 6016 & 2992 \\
\hline a90-05 & $2 \mathrm{D}$ & 2584329 & 2596092 & 6117348 & 6131556 & 6016 & 2992 \\
\hline a90-06 & $2 \mathrm{D}$ & 2584116 & 2605506 & 6102327 & 6120062 & 6016 & 2992 \\
\hline a90-07 & $2 \mathrm{D}$ & 2584933 & 2602739 & 6099166 & 6113984 & 6016 & 2992 \\
\hline a90-08 & $2 \mathrm{D}$ & 2583667 & 2600430 & 6095662 & 6109625 & 6016 & 2992 \\
\hline a90-09 & $2 \mathrm{D}$ & 2580736 & 2593842 & 6100318 & 6115732 & 6016 & 2992 \\
\hline a90-10 & $2 \mathrm{D}$ & 2583146 & 2602064 & 6098547 & 6120630 & 6016 & 2992 \\
\hline
\end{tabular}




\begin{tabular}{|c|c|c|c|c|c|c|c|}
\hline Name & Type & $X \min$ & $X \max$ & $Y$ min & $Y \max$ & $T$ max & PR \\
\hline a90-11 & $2 \mathrm{D}$ & 2585584 & 2600276 & 6097079 & 6114105 & 6016 & 2992 \\
\hline a90-12 & $2 \mathrm{D}$ & 2587257 & 2601187 & 6094706 & 6110690 & 6016 & 2992 \\
\hline a90-13 & $2 \mathrm{D}$ & 2590368 & 2602455 & 6093466 & 6107561 & 6016 & 2992 \\
\hline a90-14 & $2 \mathrm{D}$ & 2594976 & 2606476 & 6094152 & 6107663 & 6016 & 2992 \\
\hline ar90445-103r & $2 \mathrm{D}$ & 2535068 & 2558790 & 6256406 & 6308776 & 7020 & $1629 ?$ \\
\hline $\mathrm{c} 4 \mathrm{ext}$ & $2 \mathrm{D}$ & 2513682 & 2524788 & 6166995 & 6170152 & 4976 & $1629 ?$ \\
\hline ce89-02-2306 & $2 \mathrm{D}$ & 2560438 & 2573953 & 6201997 & 6214032 & 5012 & 2306 \\
\hline ce89-03 & $2 \mathrm{D}$ & 2568001 & 2574051 & 6210628 & 6217767 & 5020 & 2306 \\
\hline ce89-04 & $2 \mathrm{D}$ & 2557759 & 2571889 & 6193999 & 6206323 & 5020 & 2306 \\
\hline ce89-05 & $2 \mathrm{D}$ & 2567034 & 2574839 & 6207207 & 6216845 & 5020 & 2306 \\
\hline ce89-07 & $2 \mathrm{D}$ & 2565729 & 2575045 & 6204760 & 6215792 & 5020 & 2306 \\
\hline ce89-08 & $2 \mathrm{D}$ & 2560621 & 2570933 & 6179178 & 6187938 & 5020 & 2306 \\
\hline ce89-09 & $2 \mathrm{D}$ & 2565472 & 2576298 & 6200636 & 6215467 & 5020 & 2306 \\
\hline ce89-11 & $2 \mathrm{D}$ & 2563570 & 2576967 & 6197714 & 6213872 & 5020 & 2306 \\
\hline ce89-13 & $2 \mathrm{D}$ & 2562310 & 2576903 & 6195200 & 6212895 & 5020 & 2306 \\
\hline ce89-15 & $2 \mathrm{D}$ & 2562419 & 2575948 & 6193952 & 6210356 & 5020 & 2306 \\
\hline ce89-19 & $2 \mathrm{D}$ & 2560811 & 2574101 & 6191515 & 6207697 & 5020 & 2306 \\
\hline ce89-21 & $2 \mathrm{D}$ & 2560955 & 2574165 & 6189102 & 6205017 & 5020 & 2306 \\
\hline ce89-23-2306 & $2 \mathrm{D}$ & 2561644 & 2573148 & 6188378 & 6202188 & 5016 & 2306 \\
\hline ce89-25 & $2 \mathrm{D}$ & 2561100 & 2572623 & 6186607 & 6200517 & 5020 & 2306 \\
\hline ce89-27 & $2 \mathrm{D}$ & 2558774 & 2572398 & 6182495 & 6198587 & 5020 & 2306 \\
\hline ce89-29 & $2 \mathrm{D}$ & 2557940 & 2569815 & 6180317 & 6194435 & 5020 & 2306 \\
\hline ce89-31 & $2 \mathrm{D}$ & 2560698 & 2566970 & 6179041 & 6186725 & 5020 & 2306 \\
\hline cs-05a-3254 & $2 \mathrm{D}$ & 2510314 & 2540023 & 6086047 & 6090440 & 5132 & $3074 ?$ \\
\hline cs-05b-3254 & $2 \mathrm{D}$ & 2548756 & 2567707 & 6091748 & 6094674 & 5116 & $3074 ?$ \\
\hline cs-07a-3254 & $2 \mathrm{D}$ & 2522899 & 2527679 & 6100092 & 6100825 & 5112 & $3074 ?$ \\
\hline cs-07b-3254 & $2 \mathrm{D}$ & 2548762 & 2570037 & 6104103 & 6107295 & 5136 & $3074 ?$ \\
\hline cs-08a-3254 & $2 \mathrm{D}$ & 2548858 & 2562525 & 6108044 & 6110070 & 5136 & $3074 ?$ \\
\hline cs-08b-3254 & $2 \mathrm{D}$ & 2514988 & 2527867 & 6103010 & 6104898 & 5104 & $3074 ?$ \\
\hline cs-09a-3254 & $2 \mathrm{D}$ & 2516412 & 2527802 & 6107592 & 6109100 & 5128 & $3074 ?$ \\
\hline cs-09b-3254 & $2 \mathrm{D}$ & 2548765 & 2554682 & 6112264 & 6113149 & 5136 & $3074 ?$ \\
\hline cs-12a-3254 & $2 \mathrm{D}$ & 2484181 & 2528384 & 6115235 & 6121775 & 5160 & $3074 ?$ \\
\hline cs-16-3254 & $2 \mathrm{D}$ & 2494101 & 2520818 & 6107053 & 6117434 & 5140 & $3074 ?$ \\
\hline cs17_1 & $2 \mathrm{D}$ & 2478840 & 2489459 & 6102258 & 6115846 & 6016 & 2115 \\
\hline cs17_2 & $2 \mathrm{D}$ & 2494474 & 2503473 & 6122216 & 6133725 & 6016 & 2115 \\
\hline cs-17-fugro & $2 \mathrm{D}$ & 2466276 & 2503355 & 6085919 & 6133588 & 5136 & 2115 \\
\hline cs-18-3254 & $2 \mathrm{D}$ & 2496746 & 2511352 & 6087955 & 6130005 & 5148 & $3074 ?$ \\
\hline cs-18-fugro & $2 \mathrm{D}$ & 2496743 & 2511345 & 6087957 & 6130010 & 5136 & $3074 ?$ \\
\hline cs-20a-3254 & $2 \mathrm{D}$ & 2531585 & 2532601 & 6080564 & 6090483 & 5080 & $3074 ?$ \\
\hline cs-20b-3254 & $2 \mathrm{D}$ & 2527690 & 2527780 & 6122584 & 6123317 & 5136 & $3074 ?$ \\
\hline cs-21 & $2 \mathrm{D}$ & 2557905 & 2558776 & 6062446 & 6112425 & 4956 & $3074 ?$ \\
\hline cs-6-fugro & $2 \mathrm{D}$ & 2439552 & 2578477 & 6083781 & 6104432 & 5136 & $3074 ?$ \\
\hline cs-7 & $2 \mathrm{D}$ & 2524729 & 2573048 & 6100383 & 6108062 & 4956 & $3074 ?$ \\
\hline ct95-01-2125 & $2 \mathrm{D}$ & 2524948 & 2542172 & 6139455 & 6139592 & 6028 & 2125 \\
\hline ct95-03-2125 & $2 \mathrm{D}$ & 2524549 & 2542772 & 6135941 & 6136197 & 6028 & 2125 \\
\hline ct95-04-2125 & $2 \mathrm{D}$ & 2524300 & 2542525 & 6134605 & 6134673 & 6028 & 2125 \\
\hline ct95-05-2125 & $2 \mathrm{D}$ & 2523446 & 2542171 & 6133126 & 6133191 & 6028 & 2125 \\
\hline ct95-06-2125 & $2 \mathrm{D}$ & 2531947 & 2543671 & 6130879 & 6131016 & 6028 & 2125 \\
\hline ct95-07-2125 & $2 \mathrm{D}$ & 2521123 & 2533735 & 6130113 & 6130247 & 6028 & 2125 \\
\hline ct95-08-2125 & $2 \mathrm{D}$ & 2527424 & 2527614 & 6132266 & 6147429 & 6028 & 2125 \\
\hline ct95-09-2125 & $2 \mathrm{D}$ & 2524628 & 2539367 & 6136998 & 6143732 & 6028 & 2125 \\
\hline ct95-10-2125 & $2 \mathrm{D}$ & 2520959 & 2536261 & 6125617 & 6147788 & 6028 & 2125 \\
\hline ct95-11-2125 & $2 \mathrm{D}$ & 2531749 & 2540719 & 6131305 & 6140350 & 6028 & 2125 \\
\hline ct95-12-2125 & $2 \mathrm{D}$ & 2524529 & 2542998 & 6124814 & 6139045 & 6028 & 2125 \\
\hline ct95-13-2125 & $2 \mathrm{D}$ & 2531418 & 2541947 & 6128964 & 6137008 & 6028 & 2125 \\
\hline ct95-14-2125 & $2 \mathrm{D}$ & 2530205 & 2539321 & 6121171 & 6140673 & 6028 & 2125 \\
\hline
\end{tabular}




\begin{tabular}{|c|c|c|c|c|c|c|c|}
\hline Name & Type & $\mathbf{X} \min$ & $X$ max & $Y$ min & $Y \max$ & $T \max$ & PR \\
\hline ct95-15-2125 & $2 \mathrm{D}$ & 2531106 & 2537692 & 6112922 & 6127757 & 6028 & 2125 \\
\hline ct95-16-2125 & $2 \mathrm{D}$ & 2535576 & 2538344 & 6128373 & 6143286 & 6028 & 2125 \\
\hline ct95-17-2125 & $2 \mathrm{D}$ & 2531272 & 2542261 & 6132481 & 6140822 & 6028 & 2125 \\
\hline ct95-18-2125 & $2 \mathrm{D}$ & 2530517 & 2539251 & 6126637 & 6146083 & 6028 & 2125 \\
\hline ct95-19-2125 & $2 \mathrm{D}$ & 2526666 & 2539345 & 6125087 & 6146851 & 6028 & 2125 \\
\hline ds2-82-01a-3254 & $2 \mathrm{D}$ & 2520685 & 2527788 & 6094966 & 6108590 & 6160 & 1526 \\
\hline ds2-82-03a-3254 & $2 \mathrm{D}$ & 2527620 & 2527800 & 6095485 & 6095811 & 6160 & 1526 \\
\hline ds2-82-06-3254 & $2 \mathrm{D}$ & 2537500 & 2553430 & 6059540 & 6068065 & 6160 & 1526 \\
\hline ds2-82-07-aa-3254 & $2 \mathrm{D}$ & 2532719 & 2535298 & 6085628 & 6090500 & 6160 & 1526 \\
\hline ds2-82-09a-3254 & $2 \mathrm{D}$ & 2536907 & 2540758 & 6083431 & 6090489 & 6160 & 1526 \\
\hline ds2-82-09b-3254 & $2 \mathrm{D}$ & 2548786 & 2550613 & 6105204 & 6108549 & 6160 & 1526 \\
\hline ds2-82-11-aa-3254 & $2 \mathrm{D}$ & 2548779 & 2556113 & 6091836 & 6105558 & 6160 & 1526 \\
\hline ds2-82-11-ab-3254 & $2 \mathrm{D}$ & 2532222 & 2548072 & 6060847 & 6090499 & 6160 & 1526 \\
\hline ds2-82-13-3254 & $2 \mathrm{D}$ & 2544635 & 2554854 & 6075246 & 6094718 & 6160 & 1526 \\
\hline ds2-82-13b-3254 & $2 \mathrm{D}$ & 2536201 & 2544931 & 6058650 & 6075404 & 6160 & 1526 \\
\hline ds2-82-18-3254 & $2 \mathrm{D}$ & 2532156 & 2559065 & 6073166 & 6087434 & 6160 & 1526 \\
\hline ds2-82-20a-3254 & $2 \mathrm{D}$ & 2531918 & 2557326 & 6076841 & 6090494 & 6160 & 1526 \\
\hline ds2-82-20b-3254 & $2 \mathrm{D}$ & 2520155 & 2527790 & 6092711 & 6096805 & 6160 & 1526 \\
\hline ds2-82-24a-3254 & $2 \mathrm{D}$ & 2522616 & 2527784 & 6098254 & 6101065 & 6160 & 1526 \\
\hline ds2-82-24b-3254 & $2 \mathrm{D}$ & 2542251 & 2556308 & 6082970 & 6090504 & 6160 & 1526 \\
\hline ds2-82-28a-3254 & $2 \mathrm{D}$ & 2524974 & 2527789 & 6103877 & 6105382 & 6160 & 1526 \\
\hline ds2-82-28b-3254 & $2 \mathrm{D}$ & 2548777 & 2553877 & 6090030 & 6092736 & 6160 & 1526 \\
\hline dtb01-01 & $2 \mathrm{D}$ & 2407524 & 2577151 & 6327037 & 6517694 & 8000 & 2847 \\
\hline dtb01-03 & $2 \mathrm{D}$ & 2568452 & 2588198 & 6309076 & 6337702 & 8004 & 2847 \\
\hline dtb01-04 & $2 \mathrm{D}$ & 2335865 & 2511977 & 6395075 & 6523953 & 8000 & 2847 \\
\hline dtb01-05 & $2 \mathrm{D}$ & 2477531 & 2572501 & 6318862 & 6414905 & 8000 & 2847 \\
\hline dtb01-06 & $2 \mathrm{D}$ & 2334424 & 2469532 & 6357438 & 6461327 & 8000 & 2847 \\
\hline dtb01-07 & $2 \mathrm{D}$ & 2468541 & 2553719 & 6319368 & 6406146 & 8000 & 2847 \\
\hline dtb01-08 & $2 \mathrm{D}$ & 2375007 & 2492675 & 6349856 & 6439333 & 8000 & 2847 \\
\hline dtb01-09 & $2 \mathrm{D}$ & 2372454 & 2543653 & 6313475 & 6492478 & 8000 & 2847 \\
\hline dtb01-11 & $2 \mathrm{D}$ & 2451191 & 2543536 & 6298236 & 6392039 & 8000 & 2847 \\
\hline dtb01-12 & $2 \mathrm{D}$ & 2336310 & 2502940 & 6282148 & 6422459 & 8000 & 2847 \\
\hline dtb01-13 & $2 \mathrm{D}$ & 2439249 & 2519660 & 6306391 & 6387269 & 8000 & 2847 \\
\hline dtb01-14 & $2 \mathrm{D}$ & 2336194 & 2512862 & 6268943 & 6415778 & 8000 & 2847 \\
\hline dtb01-15 & $2 \mathrm{D}$ & 2430762 & 2508660 & 6300720 & 6376193 & 8000 & 2847 \\
\hline dtb01-16 & $2 \mathrm{D}$ & 2334367 & 2516111 & 6252441 & 6406864 & 8000 & 2847 \\
\hline dtb01-17 & $2 \mathrm{D}$ & 2332419 & 2508634 & 6285689 & 6453025 & 8000 & 2847 \\
\hline dtb01-18 & $2 \mathrm{D}$ & 2337265 & 2524910 & 6239268 & 6401160 & 8000 & 2847 \\
\hline dtb01-19 & $2 \mathrm{D}$ & 2399993 & 2502262 & 6274602 & 6370168 & 8000 & 2847 \\
\hline dtb01-20 & $2 \mathrm{D}$ & 2360572 & 2528859 & 6245663 & 6390947 & 8000 & 2847 \\
\hline dtb01-21 & $2 \mathrm{D}$ & 2387339 & 2498937 & 6258720 & 6361086 & 8000 & 2847 \\
\hline dtb01-22 & $2 \mathrm{D}$ & 2374960 & 2536450 & 6240580 & 6386464 & 8000 & 2847 \\
\hline dtb01-23 & $2 \mathrm{D}$ & 2370886 & 2481931 & 6249121 & 6349102 & 8000 & 2847 \\
\hline dtb01-24 & $2 \mathrm{D}$ & 2335620 & 2540961 & 6186840 & 6375400 & 8000 & 2847 \\
\hline dtb01-25 & $2 \mathrm{D}$ & 2358728 & 2484221 & 6229796 & 6340591 & 8000 & 2847 \\
\hline dtb01-26 & $2 \mathrm{D}$ & 2393723 & 2547078 & 6221955 & 6368076 & 8000 & 2847 \\
\hline dtb01-27 & $2 \mathrm{D}$ & 2334923 & 2486935 & 6210672 & 6337491 & 8000 & 2847 \\
\hline dtb01-28 & $2 \mathrm{D}$ & 2339095 & 2553102 & 6155970 & 6360499 & 8000 & 2847 \\
\hline dtb01-29 & $2 \mathrm{D}$ & 2335316 & 2484528 & 6187625 & 6313777 & 8000 & 2847 \\
\hline dtb01-30a & $2 \mathrm{D}$ & 2388610 & 2427017 & 6186834 & 6224332 & 8000 & 2847 \\
\hline $\mathrm{dtb} 01-30 \mathrm{~b}$ & $2 \mathrm{D}$ & 2479256 & 2564012 & 6275453 & 6358192 & 8000 & 2847 \\
\hline dtb01-31 & $2 \mathrm{D}$ & 2336326 & 2488115 & 6152027 & 6272837 & 8000 & 2847 \\
\hline dtb01-32 & $2 \mathrm{D}$ & 2363871 & 2577335 & 6132788 & 6355833 & 8008 & 2847 \\
\hline dtb01-33 & $2 \mathrm{D}$ & 2337679 & 2449563 & 6136749 & 6232002 & 8000 & 2847 \\
\hline dtb01-34 & $2 \mathrm{D}$ & 2556801 & 2578795 & 6319333 & 6341039 & 8000 & 2847 \\
\hline dtb01-35 & $2 \mathrm{D}$ & 2473660 & 2538952 & 6247557 & 6252354 & 8000 & 2847 \\
\hline
\end{tabular}




\begin{tabular}{|c|c|c|c|c|c|c|c|}
\hline Name & Type & $\mathbf{X} \min$ & $X \max$ & $Y$ min & $Y \max$ & $T \max$ & PR \\
\hline dtb01-36 & $2 \mathrm{D}$ & 2563036 & 2591494 & 6332410 & 6336602 & 8000 & 2847 \\
\hline dtb01-38 & $2 \mathrm{D}$ & 2441785 & 2484376 & 6190975 & 6242856 & 8000 & 2847 \\
\hline dtb01-40 & $2 \mathrm{D}$ & 2476649 & 2509002 & 6232849 & 6525854 & 8000 & 2847 \\
\hline e6 & $2 \mathrm{D}$ & 2468548 & 2481649 & 6153770 & 6153997 & 4968 & 1662 \\
\hline f-02_r03 & $2 \mathrm{D}$ & 2518682 & 2555619 & 6206931 & 6241711 & 5000 & 1662 \\
\hline fs-01b-3254 & $2 \mathrm{D}$ & 2548716 & 2605082 & 6084618 & 6106138 & 6060 & $1104(3074)$ \\
\hline fs-02b-3254 & $2 \mathrm{D}$ & 2548841 & 2566344 & 6092240 & 6099164 & 6016 & $1104(3074)$ \\
\hline fs- $03 a-3254$ & $2 \mathrm{D}$ & 2548820 & 2605777 & 6070012 & 6091180 & 6028 & 1104(3074) \\
\hline fs- $03 b-3254$ & $2 \mathrm{D}$ & 2466496 & 2527584 & 6099171 & 6122490 & 6004 & $1104(3074)$ \\
\hline fs-04-3254 & $2 \mathrm{D}$ & 2481507 & 2590267 & 6061042 & 6101975 & 6048 & $1104(3074)$ \\
\hline fs- $04 w-3254$ & $2 \mathrm{D}$ & 2451062 & 2483860 & 6100774 & 6113894 & 6020 & $1104(3074)$ \\
\hline fs-05-3254 & $2 \mathrm{D}$ & 2479878 & 2576984 & 6051351 & 6087778 & 6016 & $1104(3074)$ \\
\hline fs- $05 w-3254$ & $2 \mathrm{D}$ & 2442284 & 2481962 & 6087032 & 6102487 & 6004 & $1104(3074)$ \\
\hline fs-06-3254 & $2 \mathrm{D}$ & 2449692 & 2473559 & 6082358 & 6091562 & 5176 & 1104(3074) \\
\hline fs- $08-3254$ & $2 \mathrm{D}$ & 2439772 & 2471563 & 6072691 & 6085042 & 5148 & $1104(3074)$ \\
\hline fs 15 & $2 \mathrm{D}$ & 2452507 & 2467339 & 6095331 & 6113845 & 4980 & $1104(3074)$ \\
\hline fs-17-3254 & $2 \mathrm{D}$ & 2434946 & 2469152 & 6054303 & 6093670 & 5140 & $1104(3074)$ \\
\hline fs- $18-1-3254$ & $2 \mathrm{D}$ & 2449055 & 2483170 & 6053761 & 6096774 & 6024 & $1104(3074)$ \\
\hline fs- $18-2-3254$ & $2 \mathrm{D}$ & 2481189 & 2508138 & 6094874 & 6127845 & 6012 & $1104(3074)$ \\
\hline fs-19a-3254 & $2 \mathrm{D}$ & 2497918 & 2527831 & 6079822 & 6120130 & 6064 & $1104(3074)$ \\
\hline fs-1-fugro & $2 \mathrm{D}$ & 2479059 & 2605080 & 6084619 & 6134166 & 6016 & $1104(3074)$ \\
\hline fs $2 \_1$ & $2 \mathrm{D}$ & 2515122 & 2527506 & 6107137 & 6111686 & 5020 & $1104(3074)$ \\
\hline $\mathrm{fs} 2 \_2$ & $2 \mathrm{D}$ & 2527639 & 2545331 & 6100505 & 6106883 & 5020 & $1104(3074)$ \\
\hline fs-21-1-fugro & $2 \mathrm{D}$ & 2503500 & 2527553 & 6048143 & 6077871 & 6016 & $1104(3074)$ \\
\hline fs-21-2-fugro & $2 \mathrm{D}$ & 2526293 & 2555181 & 6076807 & 6112789 & 6016 & $1104(3074)$ \\
\hline fs-22-s $1-3254$ & $2 \mathrm{D}$ & 2527783 & 2574052 & 6045230 & 6104221 & 6004 & $1104(3074)$ \\
\hline fs-22-s2-3254 & $2 \mathrm{D}$ & 2517352 & 2528567 & 6031978 & 6046008 & 5136 & $1104(3074)$ \\
\hline fs-23-fugro & $2 \mathrm{D}$ & 2520236 & 2552258 & 6009363 & 6049965 & 5136 & $1104(3074)$ \\
\hline fs-24-1-fugro & $2 \mathrm{D}$ & 2559794 & 2602026 & 6039018 & 6092447 & 6016 & $1104(3074)$ \\
\hline fs-24-2-fugro & $2 \mathrm{D}$ & 2529219 & 2560841 & 6000555 & 6040593 & 5136 & $1104(3074)$ \\
\hline fs-3-fugro & $2 \mathrm{D}$ & 2466495 & 2605781 & 6070017 & 6122493 & 6016 & $1104(3074)$ \\
\hline fs-4-fugro & $2 \mathrm{D}$ & 2481503 & 2590261 & 6061044 & 6101978 & 6016 & $1104(3074)$ \\
\hline fs-5-fugro & $2 \mathrm{D}$ & 2479875 & 2576668 & 6051688 & 6087780 & 6016 & $1104(3074)$ \\
\hline g2-2992 & $2 \mathrm{D}$ & 2585927 & 2614254 & 6160678 & 6160762 & 6020 & $1104(3074)$ \\
\hline h-02a-3254 & $2 \mathrm{D}$ & 2531286 & 2555361 & 6127630 & 6164812 & 5136 & $1104(3074)$ \\
\hline h-04a-3254 & $2 \mathrm{D}$ & 2543592 & 2551550 & 6127533 & 6139311 & 5136 & $1104(3074)$ \\
\hline h-13a-3254 & $2 \mathrm{D}$ & 2524372 & 2531493 & 6127527 & 6143706 & 5136 & $1104(3074)$ \\
\hline hzt82a-100 & $2 \mathrm{D}$ & 2551534 & 2596856 & 6135689 & 6136083 & 6016 & 2992 \\
\hline hzt82a-101 & $2 \mathrm{D}$ & 2554736 & 2554999 & 6132681 & 6175886 & 6016 & 2992 \\
\hline hzt82a-102 & $2 \mathrm{D}$ & 2551333 & 2596820 & 6137637 & 6138051 & 6016 & 2992 \\
\hline hzt82a-103 & $2 \mathrm{D}$ & 2556762 & 2557044 & 6132874 & 6176142 & 6016 & 2992 \\
\hline hzt82a-104 & $2 \mathrm{D}$ & 2551366 & 2596695 & 6139641 & 6140038 & 6016 & 2992 \\
\hline hzt82a-105 & $2 \mathrm{D}$ & 2558802 & 2559125 & 6132850 & 6179727 & 6016 & 2992 \\
\hline hzt82a-106 & $2 \mathrm{D}$ & 2551577 & 2596927 & 6141628 & 6142035 & 6016 & 2992 \\
\hline hzt82a-107 & $2 \mathrm{D}$ & 2560824 & 2561256 & 6132641 & 6191336 & 6016 & 2992 \\
\hline hzt82a-108 & $2 \mathrm{D}$ & 2551432 & 2596724 & 6143607 & 6144001 & 6016 & 2992 \\
\hline hzt82a-109 & $2 \mathrm{D}$ & 2562838 & 2563313 & 6132626 & 6191331 & 6016 & 2992 \\
\hline hzt82a-110 & $2 \mathrm{D}$ & 2551664 & 2596985 & 6145617 & 6145987 & 6016 & 2992 \\
\hline hzt82a-111 & $2 \mathrm{D}$ & 2564898 & 2565371 & 6132808 & 6191549 & 6016 & 2992 \\
\hline hzt82a-112 & $2 \mathrm{D}$ & 2551409 & 2596769 & 6147657 & 6148043 & 6016 & 2992 \\
\hline hzt82a-113 & $2 \mathrm{D}$ & 2566919 & 2567385 & 6132574 & 6191297 & 6016 & 2992 \\
\hline hzt82a-114 & $2 \mathrm{D}$ & 2551678 & 2597032 & 6149592 & 6149951 & 6016 & 2992 \\
\hline hzt82a-115 & $2 \mathrm{D}$ & 2568954 & 2569448 & 6132776 & 6191442 & 6016 & 2992 \\
\hline hzt82a-116 & $2 \mathrm{D}$ & 2551673 & 2597073 & 6151528 & 6151939 & 6016 & 2992 \\
\hline hzt82a-117 & $2 \mathrm{D}$ & 2570983 & 2571461 & 6132538 & 6191254 & 6016 & 2992 \\
\hline hzt82a-118 & $2 \mathrm{D}$ & 2551468 & 2606674 & 6152662 & 6153928 & 6016 & 2992 \\
\hline
\end{tabular}




\begin{tabular}{|c|c|c|c|c|c|c|c|}
\hline Name & Type & $X \min$ & $X \max$ & $Y$ min & $Y \max$ & $T \max$ & PR \\
\hline hzt82a-119 & $2 \mathrm{D}$ & 2573035 & 2573519 & 6132742 & 6191482 & 6016 & 2992 \\
\hline hzt82a-120 & $2 \mathrm{D}$ & 2551442 & 2595545 & 6155511 & 6155928 & 6016 & 2992 \\
\hline hzt82a-121 & $2 \mathrm{D}$ & 2575065 & 2575584 & 6132522 & 6191199 & 6016 & 2992 \\
\hline hzt82a-122 & $2 \mathrm{D}$ & 2551741 & 2597140 & 6157479 & 6157877 & 6016 & 2992 \\
\hline hzt82a-123 & $2 \mathrm{D}$ & 2577098 & 2577656 & 6132706 & 6191445 & 6016 & 2992 \\
\hline hzt82a-124 & $2 \mathrm{D}$ & 2551464 & 2596875 & 6159472 & 6159844 & 6016 & 2992 \\
\hline hzt82a-125 & $2 \mathrm{D}$ & 2579102 & 2579620 & 6132478 & 6185900 & 6016 & 2992 \\
\hline hzt82a-126 & $2 \mathrm{D}$ & 2551769 & 2597213 & 6161465 & 6161854 & 6016 & 2992 \\
\hline hzt82a-127 & $2 \mathrm{D}$ & 2581129 & 2581632 & 6132703 & 6182782 & 6016 & 2992 \\
\hline hzt82a-128 & $2 \mathrm{D}$ & 2551488 & 2596921 & 6163432 & 6163843 & 6016 & 2992 \\
\hline hzt82a-129 & $2 \mathrm{D}$ & 2583180 & 2583751 & 6132444 & 6189132 & 6016 & 2992 \\
\hline hzt82a-130 & $2 \mathrm{D}$ & 2551775 & 2597236 & 6165404 & 6165806 & 6016 & 2992 \\
\hline hzt82a-131 & $2 \mathrm{D}$ & 2585218 & 2585756 & 6132695 & 6185125 & 6016 & 2992 \\
\hline hzt82a-132 & $2 \mathrm{D}$ & 2551511 & 2596951 & 6167393 & 6167779 & 6016 & 2992 \\
\hline hzt82a-133 & $2 \mathrm{D}$ & 2587265 & 2587795 & 6132385 & 6183566 & 6016 & 2992 \\
\hline hzt82a-134 & $2 \mathrm{D}$ & 2551807 & 2597271 & 6169395 & 6169781 & 6016 & 2992 \\
\hline hzt82a-135 & $2 \mathrm{D}$ & 2589317 & 2589806 & 6132707 & 6180403 & 6016 & 2992 \\
\hline hzt82a-136 & $2 \mathrm{D}$ & 2551651 & 2597021 & 6171347 & 6171758 & 6016 & 2992 \\
\hline hzt82a-137 & $2 \mathrm{D}$ & 2591337 & 2591855 & 6132341 & 6179519 & 6016 & 2992 \\
\hline hzt82a-138 & $2 \mathrm{D}$ & 2551839 & 2596862 & 6173314 & 6173745 & 6016 & 2992 \\
\hline hzt82a-139 & $2 \mathrm{D}$ & 2593362 & 2593846 & 6132563 & 6176768 & 6016 & 2992 \\
\hline hzt82a-140 & $2 \mathrm{D}$ & 2555645 & 2597101 & 6175319 & 6175708 & 6016 & 2992 \\
\hline hzt82a-142 & $2 \mathrm{D}$ & 2545915 & 2594633 & 6176921 & 6177674 & 6016 & 2992 \\
\hline hzt82a-144 & $2 \mathrm{D}$ & 2558728 & 2593025 & 6179316 & 6179634 & 6016 & 2992 \\
\hline hzt82a-146 & $2 \mathrm{D}$ & 2558949 & 2588722 & 6181355 & 6181638 & 6016 & 2992 \\
\hline hzt82a-148 & $2 \mathrm{D}$ & 2558764 & 2588064 & 6183326 & 6183628 & 6016 & 2992 \\
\hline hzt82a-150 & $2 \mathrm{D}$ & 2559002 & 2584884 & 6185348 & 6185602 & 6016 & 2992 \\
\hline hzt82a-152 & $2 \mathrm{D}$ & 2558800 & 2584964 & 6187324 & 6187568 & 6016 & 2992 \\
\hline k89-1007-2664 & $2 \mathrm{D}$ & 2617815 & 2630162 & 6163857 & 6163908 & 6016 & 2664 \\
\hline k89-1008-2664 & $2 \mathrm{D}$ & 2617769 & 2630535 & 6162504 & 6162660 & 6016 & 2664 \\
\hline k89-1009-2664 & $2 \mathrm{D}$ & 2612709 & 2631775 & 6161846 & 6162106 & 6016 & 2664 \\
\hline k89-1010-2664 & $2 \mathrm{D}$ & 2603576 & 2631787 & 6160467 & 6160936 & 6012 & 2664 \\
\hline k89-1011-2664 & $2 \mathrm{D}$ & 2610042 & 2631820 & 6159866 & 6160149 & 6016 & 2664 \\
\hline k89-1012-2664 & $2 \mathrm{D}$ & 2614489 & 2635069 & 6158695 & 6158997 & 6016 & 2664 \\
\hline k89-1013-2664 & $2 \mathrm{D}$ & 2603213 & 2634743 & 6157842 & 6158171 & 6008 & 2664 \\
\hline k89-1014-2664 & $2 \mathrm{D}$ & 2614401 & 2636342 & 6156629 & 6156944 & 6028 & 2664 \\
\hline k89-1015-2664 & $2 \mathrm{D}$ & 2620520 & 2636260 & 6155766 & 6156019 & 6016 & 2664 \\
\hline k89-1016-2664 & $2 \mathrm{D}$ & 2620810 & 2636229 & 6154485 & 6154820 & 6024 & 2664 \\
\hline k89-1017-2664 & $2 \mathrm{D}$ & 2620761 & 2636188 & 6154215 & 6154399 & 6016 & 2664 \\
\hline k89-1018-2664 & $2 \mathrm{D}$ & 2626066 & 2633923 & 6157629 & 6168531 & 6016 & 2664 \\
\hline k89-1019-2664 & $2 \mathrm{D}$ & 2620873 & 2636318 & 6151908 & 6152276 & 6016 & 2664 \\
\hline k89-1020-2664 & $2 \mathrm{D}$ & 2618575 & 2635943 & 6150343 & 6150656 & 6016 & 2664 \\
\hline k89-1021-2664 & $2 \mathrm{D}$ & 2620743 & 2636118 & 6149057 & 6149155 & 6016 & 2664 \\
\hline k89-1022-2664 & $2 \mathrm{D}$ & 2620981 & 2636325 & 6148368 & 6148688 & 6016 & 2664 \\
\hline k89-1023-2664 & $2 \mathrm{D}$ & 2620977 & 2636196 & 6146954 & 6147269 & 6016 & 2664 \\
\hline k89-1024-2664 & $2 \mathrm{D}$ & 2620608 & 2635876 & 6146257 & 6146407 & 6016 & 2664 \\
\hline k89-1025-2664 & $2 \mathrm{D}$ & 2620724 & 2635967 & 6144797 & 6145006 & 6016 & 2664 \\
\hline k89-1026-2664 & $2 \mathrm{D}$ & 2621002 & 2636221 & 6144224 & 6144309 & 6016 & 2664 \\
\hline k89-1027-2664 & $2 \mathrm{D}$ & 2620949 & 2636254 & 6142828 & 6143022 & 6016 & 2664 \\
\hline k89-1028-2664 & $2 \mathrm{D}$ & 2620746 & 2635941 & 6142157 & 6142419 & 6016 & 2664 \\
\hline k89-1036-2304 & $2 \mathrm{D}$ & 2626631 & 2628147 & 6140674 & 6163081 & 6016 & 2304 \\
\hline k89-1037-2304 & $2 \mathrm{D}$ & 2623939 & 2626812 & 6133020 & 6171832 & 6020 & 2304 \\
\hline k98-1 & $2 \mathrm{D}$ & 2451797 & 2471872 & 6104643 & 6126096 & 4872 & 2366 \\
\hline k98-10 & $2 \mathrm{D}$ & 2452361 & 2470197 & 6111636 & 6127846 & 4872 & 2366 \\
\hline k98-11 & $2 \mathrm{D}$ & 2453373 & 2478838 & 6149826 & 6165699 & 4872 & 2366 \\
\hline k98-13 & $2 \mathrm{D}$ & 2456939 & 2480977 & 6154156 & 6169587 & 4872 & 2366 \\
\hline
\end{tabular}




\begin{tabular}{|c|c|c|c|c|c|c|c|}
\hline Name & Type & $X \min$ & $X \max$ & $Y$ min & $Y \max$ & $T$ max & PR \\
\hline k98-16 & $2 \mathrm{D}$ & 2456131 & 2479167 & 6150290 & 6186924 & 4872 & 2366 \\
\hline k98-18 & $2 \mathrm{D}$ & 2454315 & 2470508 & 6162016 & 6188324 & 4872 & 2366 \\
\hline k98-19 & $2 \mathrm{D}$ & 2458285 & 2480666 & 6160121 & 6174601 & 4872 & 2366 \\
\hline k98-2 & $2 \mathrm{D}$ & 2459933 & 2474342 & 6105422 & 6118155 & 4872 & 2366 \\
\hline k98-20 & $2 \mathrm{D}$ & 2477256 & 2509596 & 6163748 & 6187362 & 4872 & 2366 \\
\hline k98-21 & $2 \mathrm{D}$ & 2454687 & 2480494 & 6162305 & 6179414 & 4832 & 2366 \\
\hline k98-22 & $2 \mathrm{D}$ & 2472435 & 2501594 & 6166867 & 6190000 & 4872 & 2366 \\
\hline k98-23 & $2 \mathrm{D}$ & 2455173 & 2481938 & 6163256 & 6180527 & 4872 & 2366 \\
\hline k98-24 & $2 \mathrm{D}$ & 2480594 & 2492365 & 6145670 & 6153350 & 4832 & 2366 \\
\hline k98-25 & $2 \mathrm{D}$ & 2453248 & 2483613 & 6164165 & 6183544 & 4832 & 2366 \\
\hline k98-27 & $2 \mathrm{D}$ & 2457620 & 2483731 & 6165996 & 6182949 & 4872 & 2366 \\
\hline k98-29 & $2 \mathrm{D}$ & 2458047 & 2485064 & 6167028 & 6184576 & 4832 & 2366 \\
\hline k98-3 & $2 \mathrm{D}$ & 2453568 & 2473763 & 6105938 & 6128471 & 4872 & 2366 \\
\hline k98-31 & $2 \mathrm{D}$ & 2458357 & 2486591 & 6168226 & 6186198 & 4872 & 2366 \\
\hline k98-33 & $2 \mathrm{D}$ & 2462088 & 2487704 & 6169190 & 6185770 & 4832 & 2366 \\
\hline k98-35 & $2 \mathrm{D}$ & 2463716 & 2489338 & 6170310 & 6186766 & 4872 & 2366 \\
\hline k98-37 & $2 \mathrm{D}$ & 2466077 & 2490817 & 6171381 & 6187279 & 4836 & 2366 \\
\hline k98-39 & $2 \mathrm{D}$ & 2468447 & 2492511 & 6172392 & 6187594 & 4872 & 2366 \\
\hline k98-4 & $2 \mathrm{D}$ & 2458027 & 2474095 & 6107362 & 6122301 & 4872 & 2366 \\
\hline k98-41 & $2 \mathrm{D}$ & 2472038 & 2493451 & 6173460 & 6187076 & 4836 & 2366 \\
\hline k98-43 & $2 \mathrm{D}$ & 2473127 & 2495219 & 6174749 & 6188365 & 4872 & 2366 \\
\hline k98-45 & $2 \mathrm{D}$ & 2486862 & 2493817 & 6179318 & 6185620 & 4872 & 2366 \\
\hline k98-47 & $2 \mathrm{D}$ & 2493055 & 2501701 & 6177663 & 6187141 & 4872 & 2366 \\
\hline k98-5 & $2 \mathrm{D}$ & 2454986 & 2473382 & 6109842 & 6130948 & 4872 & 2366 \\
\hline k98-6 & $2 \mathrm{D}$ & 2456911 & 2473543 & 6108756 & 6124637 & 4872 & 2366 \\
\hline k98-7 & $2 \mathrm{D}$ & 2456436 & 2473698 & 6113355 & 6133047 & 4872 & 2366 \\
\hline k98-8 & $2 \mathrm{D}$ & 2455317 & 2471391 & 6110162 & 6125449 & 4872 & 2366 \\
\hline k98-9 & $2 \mathrm{D}$ & 2455566 & 2474760 & 6140564 & 6152574 & 4872 & 2366 \\
\hline kapuni-d_med & $2 \mathrm{D}$ & 2610013 & 2610657 & 6183794 & 6199670 & 5816 & 624 \\
\hline kapuni-1_med & $2 \mathrm{D}$ & 2611382 & 2611712 & 6185364 & 6196961 & 4464 & 624 \\
\hline Kerry3D_repro & $3 \mathrm{D}$ & 2599337 & 2614153 & 6134252 & 6169439 & 4996 & 1556 \\
\hline m101-1985 & $2 \mathrm{D}$ & 2623659 & 2630935 & 6123902 & 6151440 & 5016 & 1985 \\
\hline m101a-1985 & $2 \mathrm{D}$ & 2597093 & 2606152 & 6063821 & 6083695 & 5016 & 1985 \\
\hline m102-1985 & $2 \mathrm{D}$ & 2627725 & 2638069 & 6147442 & 6148729 & 5016 & 1985 \\
\hline m109-1985 & $2 \mathrm{D}$ & 2606033 & 2646966 & 6059531 & 6147310 & 5016 & 1985 \\
\hline m112-1985 & $2 \mathrm{D}$ & 2626192 & 2691050 & 6114595 & 6142910 & 5016 & 1985 \\
\hline m117-1985 & $2 \mathrm{D}$ & 2610741 & 2656990 & 6043590 & 6142594 & 5016 & 1985 \\
\hline m118-1985 & $2 \mathrm{D}$ & 2624623 & 2694068 & 6103993 & 6134519 & 5016 & 1985 \\
\hline m128-1985 & $2 \mathrm{D}$ & 2650863 & 2691283 & 6091540 & 6109415 & 5016 & 1985 \\
\hline m131n-1985 & $2 \mathrm{D}$ & 2621004 & 2659244 & 6015344 & 6110647 & 5016 & 1985 \\
\hline m132-1985 & $2 \mathrm{D}$ & 2619266 & 2662601 & 6099755 & 6119471 & 5016 & 1985 \\
\hline m133-1985 & $2 \mathrm{D}$ & 2660864 & 2674283 & 6106815 & 6136236 & 5016 & 1985 \\
\hline m137-1985 & $2 \mathrm{D}$ & 2659232 & 2667442 & 6081969 & 6107956 & 5016 & 1985 \\
\hline m138-1985 & $2 \mathrm{D}$ & 2615405 & 2657718 & 6092622 & 6111126 & 5016 & 1985 \\
\hline m140-1985 & $2 \mathrm{D}$ & 2644737 & 2685809 & 6077395 & 6094320 & 5016 & 1985 \\
\hline m141-1985 & $2 \mathrm{D}$ & 2637933 & 2681264 & 6020906 & 6129449 & 5016 & 1985 \\
\hline m152-1985 & $2 \mathrm{D}$ & 2607571 & 2682913 & 6060972 & 6094089 & 5016 & 1985 \\
\hline m155-1985 & $2 \mathrm{D}$ & 2668886 & 2689128 & 6050482 & 6097859 & 5016 & 1985 \\
\hline m172-1985 & $2 \mathrm{D}$ & 2598315 & 2664299 & 6042099 & 6071858 & 5016 & 1985 \\
\hline Maui 3D & $3 \mathrm{D}$ & 2532055 & 2563329 & 6156751 & 6206754 & 5499 & 2546 \\
\hline Maari 3D & $3 \mathrm{D}$ & 2522092 & 2543067 & 6121712 & 6149874 & 6000 & 2598 \\
\hline n1685-001-2304 & $2 \mathrm{D}$ & 2620405 & 2626824 & 6165076 & 6165163 & 6020 & 2304 \\
\hline n1685-002-2664 & $2 \mathrm{D}$ & 2619294 & 2628875 & 6163158 & 6163401 & 6016 & 2304 \\
\hline n1685-003-2664 & $2 \mathrm{D}$ & 2621040 & 2629470 & 6161239 & 6161344 & 6016 & 2304 \\
\hline n1685-004-2664 & $2 \mathrm{D}$ & 2620873 & 2632418 & 6159259 & 6159405 & 6016 & 2304 \\
\hline n1685-005-2664 & $2 \mathrm{D}$ & 2621013 & 2633437 & 6157120 & 6157424 & 6016 & 2304 \\
\hline
\end{tabular}




\begin{tabular}{|c|c|c|c|c|c|c|c|}
\hline Name & Type & $X \min$ & $X \max$ & $Y$ min & $Y \max$ & $T \max$ & PR \\
\hline n1685-006-2664 & $2 \mathrm{D}$ & 2621933 & 2637882 & 6155058 & 6155281 & 6016 & 2304 \\
\hline n1685-007-2304 & $2 \mathrm{D}$ & 2623244 & 2634274 & 6153652 & 6153828 & 6024 & 2304 \\
\hline n1685-008-2304 & $2 \mathrm{D}$ & 2625007 & 2634362 & 6151096 & 6151225 & 6024 & 2304 \\
\hline n1685-009-2664 & $2 \mathrm{D}$ & 2622296 & 2634872 & 6149686 & 6149997 & 6016 & 2304 \\
\hline n1685-010-2664 & $2 \mathrm{D}$ & 2623395 & 2634843 & 6145503 & 6145796 & 6016 & 2304 \\
\hline n1685-101-2304 & $2 \mathrm{D}$ & 2627428 & 2629040 & 6141613 & 6165113 & 6024 & 2304 \\
\hline n1685-102-2304 & $2 \mathrm{D}$ & 2630815 & 2631775 & 6143764 & 6159640 & 6024 & 2304 \\
\hline nm-01_r03 & $2 \mathrm{D}$ & 2525412 & 2597048 & 6239872 & 6240548 & 6008 & 2708 \\
\hline $\mathrm{nm}-100 \mathrm{r}$ & $2 \mathrm{D}$ & 2512521 & 2526749 & 6201593 & 6215394 & 5020 & 2708 \\
\hline$n m-10-1-2708$ & $2 \mathrm{D}$ & 2564302 & 2574782 & 6219459 & 6219775 & 4988 & 2708 \\
\hline $\mathrm{nm}-10-2-2708$ & $2 \mathrm{D}$ & 2544372 & 2567734 & 6219691 & 6219879 & 4996 & 2708 \\
\hline$n m-104 r$ & $2 \mathrm{D}$ & 2527263 & 2540908 & 6216241 & 6229986 & 5024 & 2708 \\
\hline $\mathrm{nm}-12-1-2708$ & $2 \mathrm{D}$ & 2558326 & 2583752 & 6229968 & 6230239 & 4988 & 2708 \\
\hline $\mathrm{nm}-12-2-2708$ & $2 \mathrm{D}$ & 2543260 & 2561623 & 6230107 & 6230242 & 4960 & 2708 \\
\hline nm-13-2708 & $2 \mathrm{D}$ & 2555838 & 2590466 & 6234902 & 6237245 & 4984 & 2708 \\
\hline$n m-16-2708$ & $2 \mathrm{D}$ & 2524217 & 2621590 & 6261469 & 6262651 & 4988 & 2708 \\
\hline nm-19-1-2708 & $2 \mathrm{D}$ & 2577515 & 2577663 & 6224671 & 6240177 & 4972 & 2708 \\
\hline$n m-19-2-2708$ & $2 \mathrm{D}$ & 2577611 & 2578049 & 6236757 & 6285012 & 4968 & 2708 \\
\hline$n m-20-1-2708$ & $2 \mathrm{D}$ & 2566027 & 2567642 & 6213032 & 6285211 & 4976 & 2708 \\
\hline$n m-2-0-2708$ & $2 \mathrm{D}$ & 2542000 & 2597548 & 6256150 & 6256782 & 4972 & 2708 \\
\hline$n m-2-1-2708$ & $2 \mathrm{D}$ & 2522408 & 2545172 & 6256746 & 6256880 & 4968 & 2708 \\
\hline $\mathrm{nm}-30-2708$ & $2 \mathrm{D}$ & 2546767 & 2580223 & 6253824 & 6254159 & 4980 & 2708 \\
\hline$n m-31-2708$ & $2 \mathrm{D}$ & 2546533 & 2580074 & 6259252 & 6259541 & 4984 & 2708 \\
\hline$n m-35-2708$ & $2 \mathrm{D}$ & 2546446 & 2579926 & 6248354 & 6248796 & 4992 & 2708 \\
\hline nt89-03-3254 & $2 \mathrm{D}$ & 2551407 & 2574072 & 6123311 & 6123600 & 6160 & 1807 \\
\hline nt89-04-3254 & $2 \mathrm{D}$ & 2559724 & 2559848 & 6114102 & 6133778 & 6160 & 1807 \\
\hline nt89-05-3254 & $2 \mathrm{D}$ & 2552500 & 2575226 & 6117058 & 6117406 & 6160 & 1807 \\
\hline nt90-1-3254 & $2 \mathrm{D}$ & 2548293 & 2575297 & 6132150 & 6132407 & 6160 & 1816 \\
\hline nt90-2-3254 & $2 \mathrm{D}$ & 2552252 & 2573384 & 6127478 & 6127632 & 6160 & 1816 \\
\hline nt90-3-3254 & $2 \mathrm{D}$ & 2560681 & 2573557 & 6125440 & 6125564 & 6160 & 1816 \\
\hline nt90-4-3254 & $2 \mathrm{D}$ & 2555013 & 2573324 & 6121312 & 6121476 & 6160 & 1816 \\
\hline nt90-5-3254 & $2 \mathrm{D}$ & 2555268 & 2573605 & 6119221 & 6119292 & 6160 & 1816 \\
\hline nt90-6-3254 & $2 \mathrm{D}$ & 2566871 & 2566985 & 6114740 & 6135591 & 6160 & 1816 \\
\hline or03-001 & $2 \mathrm{D}$ & 2567586 & 2600561 & 6133665 & 6133999 & 6160 & 2794 \\
\hline or03-002 & $2 \mathrm{D}$ & 2567221 & 2608623 & 6127573 & 6127626 & 6160 & 2794 \\
\hline or03-003 & $2 \mathrm{D}$ & 2567493 & 2612980 & 6124043 & 6124714 & 6160 & 2794 \\
\hline or03-004 & $2 \mathrm{D}$ & 2567083 & 2608606 & 6120974 & 6121023 & 6160 & 2794 \\
\hline or03-005 & $2 \mathrm{D}$ & 2570987 & 2600925 & 6117090 & 6117264 & 6160 & 2794 \\
\hline or03-006 & $2 \mathrm{D}$ & 2567437 & 2614839 & 6112682 & 6112974 & 6160 & 2794 \\
\hline or03-007 & $2 \mathrm{D}$ & 2570717 & 2570989 & 6108601 & 6137744 & 6160 & 2794 \\
\hline or03-008 & $2 \mathrm{D}$ & 2574738 & 2575076 & 6108235 & 6137320 & 6160 & 2794 \\
\hline or03-009 & $2 \mathrm{D}$ & 2577810 & 2578346 & 6108464 & 6137511 & 6160 & 2794 \\
\hline or03-010 & $2 \mathrm{D}$ & 2580866 & 2581171 & 6108099 & 6137236 & 6160 & 2794 \\
\hline or03-011 & $2 \mathrm{D}$ & 2583820 & 2584216 & 6106443 & 6137517 & 6160 & 2794 \\
\hline or03-012 & $2 \mathrm{D}$ & 2586983 & 2587252 & 6104152 & 6137206 & 6160 & 2794 \\
\hline or03-013 & $2 \mathrm{D}$ & 2592979 & 2593373 & 6104243 & 6137333 & 6160 & 2794 \\
\hline or03-014 & $2 \mathrm{D}$ & 2601585 & 2601621 & 6096652 & 6130781 & 6160 & 2794 \\
\hline p116-81-04-2992 & $2 \mathrm{D}$ & 2591209 & 2639537 & 6147545 & 6148210 & 6016 & 2992 \\
\hline p116-81-07-2992 & $2 \mathrm{D}$ & 2595396 & 2625916 & 6141562 & 6141954 & 6016 & 2992 \\
\hline P95_400-2261 & $2 \mathrm{D}$ & 2561894 & 2573844 & 6212399 & 6216596 & 6020 & 2261 \\
\hline P95_401-2261 & $2 \mathrm{D}$ & 2562928 & 2569467 & 6200306 & 6218178 & 6020 & 2261 \\
\hline P95_402-2261 & $2 \mathrm{D}$ & 2558505 & 2573999 & 6210172 & 6215718 & 6020 & 2261 \\
\hline P95_403-2261 & $2 \mathrm{D}$ & 2566680 & 2573153 & 6200212 & 6218086 & 6020 & 2261 \\
\hline P95_405-2261 & $2 \mathrm{D}$ & 2561058 & 2574693 & 6179816 & 6218034 & 6028 & 2261 \\
\hline P95_406-2261 & $2 \mathrm{D}$ & 2558637 & 2573969 & 6205852 & 6211386 & 6020 & 2261 \\
\hline P95_407-2261 & $2 \mathrm{D}$ & 2566566 & 2575085 & 6176962 & 6201509 & 6024 & 2261 \\
\hline
\end{tabular}




\begin{tabular}{|c|c|c|c|c|c|c|c|}
\hline Name & Type & $X \min$ & $X \max$ & $Y$ min & $Y \max$ & $T$ max & PR \\
\hline P95_408-2261 & $2 \mathrm{D}$ & 2558573 & 2575867 & 6201187 & 6207379 & 6020 & 2261 \\
\hline P95_409-2261 & $2 \mathrm{D}$ & 2570012 & 2576751 & 6177016 & 6197271 & 6032 & 2261 \\
\hline P95_411-2261 & $2 \mathrm{D}$ & 2572779 & 2579289 & 6176405 & 6195219 & 6032 & 2261 \\
\hline P95_412-2261 & $2 \mathrm{D}$ & 2559131 & 2581618 & 6192477 & 6201092 & 6020 & 2261 \\
\hline P95_414-2261 & $2 \mathrm{D}$ & 2558946 & 2582682 & 6191207 & 6200029 & 6020 & 2261 \\
\hline P95_416-2261 & $2 \mathrm{D}$ & 2558804 & 2583355 & 6190030 & 6198917 & 6020 & 2261 \\
\hline P95_418-2261 & $2 \mathrm{D}$ & 2558835 & 2583413 & 6188971 & 6197847 & 6020 & 2261 \\
\hline P95_420-2261 & $2 \mathrm{D}$ & 2558011 & 2581998 & 6188382 & 6197309 & 6056 & 2261 \\
\hline P95_422-2261 & $2 \mathrm{D}$ & 2559487 & 2581110 & 6187558 & 6195683 & 6020 & 2261 \\
\hline P95_424-2261 & $2 \mathrm{D}$ & 2559042 & 2581610 & 6186205 & 6194742 & 6024 & 2261 \\
\hline P95_426-2261 & $2 \mathrm{D}$ & 2557998 & 2579614 & 6185924 & 6193898 & 6044 & 2261 \\
\hline P95_428-2261 & $2 \mathrm{D}$ & 2558145 & 2579809 & 6184774 & 6192923 & 6032 & 2261 \\
\hline P95_430-2261 & $2 \mathrm{D}$ & 2558324 & 2583072 & 6181462 & 6191145 & 6028 & 2261 \\
\hline P95_434-2261 & $2 \mathrm{D}$ & 2560549 & 2573700 & 6181665 & 6186774 & 6028 & 2261 \\
\hline P95_436-2261 & $2 \mathrm{D}$ & 2557176 & 2577984 & 6179294 & 6186810 & 6028 & 2261 \\
\hline P95_438-2261 & $2 \mathrm{D}$ & 2560124 & 2573330 & 6179679 & 6184740 & 6032 & 2261 \\
\hline P95_440-2261 & $2 \mathrm{D}$ & 2557494 & 2575316 & 6177696 & 6184533 & 6036 & 2261 \\
\hline P95_442-2261 & $2 \mathrm{D}$ & 2557374 & 2572420 & 6177868 & 6183514 & 6028 & 2261 \\
\hline P95_444c-2261 & $2 \mathrm{D}$ & 2568376 & 2580122 & 6194166 & 6198382 & 6020 & 2261 \\
\hline P95_445c-2261 & $2 \mathrm{D}$ & 2561305 & 2567923 & 6176975 & 6193842 & 6028 & 2261 \\
\hline P95_450-2261 & $2 \mathrm{D}$ & 2570458 & 2579682 & 6179704 & 6202203 & 6028 & 2261 \\
\hline p95-001a-2708 & $2 \mathrm{D}$ & 2586906 & 2620828 & 6242100 & 6356524 & 7176 & 2261 \\
\hline p95-001e-2708 & $2 \mathrm{D}$ & 2569665 & 2588399 & 6214593 & 6245825 & 7176 & 2261 \\
\hline p95-001s-2708 & $2 \mathrm{D}$ & 2557894 & 2571424 & 6180526 & 6218086 & 7176 & 2261 \\
\hline p95-500-2664 & $2 \mathrm{D}$ & 2606932 & 2627444 & 6164217 & 6164487 & 6016 & 2261 \\
\hline p95-501-2261 & $2 \mathrm{D}$ & 2626584 & 2626937 & 6140075 & 6165910 & 6020 & 2261 \\
\hline p95-502-2261 & $2 \mathrm{D}$ & 2621611 & 2633546 & 6157334 & 6157732 & 6028 & 2261 \\
\hline p95-503-2261 & $2 \mathrm{D}$ & 2627803 & 2628187 & 6138876 & 6163680 & 6020 & 2261 \\
\hline p95-504-2261 & $2 \mathrm{D}$ & 2620045 & 2634031 & 6156027 & 6156371 & 6024 & 2261 \\
\hline p95-505-2261 & $2 \mathrm{D}$ & 2628838 & 2628969 & 6139024 & 6161587 & 6020 & 2261 \\
\hline p95-506-2261 & $2 \mathrm{D}$ & 2617676 & 2635667 & 6155062 & 6155459 & 6104 & 2261 \\
\hline p95-507-2261 & $2 \mathrm{D}$ & 2630821 & 2630976 & 6139192 & 6159632 & 6020 & 2261 \\
\hline p95-508-2261 & $2 \mathrm{D}$ & 2617582 & 2635595 & 6153892 & 6154143 & 6020 & 2261 \\
\hline p95-509-2664 & $2 \mathrm{D}$ & 2620170 & 2634894 & 6154511 & 6171597 & 6016 & 2261 \\
\hline p95-510-2664 & $2 \mathrm{D}$ & 2616693 & 2635666 & 6153238 & 6153344 & 6016 & 2261 \\
\hline pc94-16 & $2 \mathrm{D}$ & 2591967 & 2612004 & 6190605 & 6190895 & 5520 & 2261 \\
\hline phm01-2664 & $2 \mathrm{D}$ & 2618086 & 2640360 & 6147357 & 6172156 & 5016 & 2664 \\
\hline phm02-2664 & $2 \mathrm{D}$ & 2610684 & 2641773 & 6152662 & 6168662 & 5016 & 2664 \\
\hline phm03-2304 & $2 \mathrm{D}$ & 2613674 & 2624175 & 6159891 & 6167933 & 5020 & 2664 \\
\hline pr84-88-210-me & $2 \mathrm{D}$ & 2611105 & 2629122 & 6176213 & 6187821 & 5820 & 2677 \\
\hline pr84-88-211_a & $2 \mathrm{D}$ & 2610002 & 2610988 & 6179399 & 6185599 & 6020 & 2677 \\
\hline pr84-88-211-me & $2 \mathrm{D}$ & 2609996 & 2610991 & 6179423 & 6185611 & 5672 & 2677 \\
\hline pr84-88-212_a & $2 \mathrm{D}$ & 2615568 & 2618935 & 6177819 & 6180423 & 6020 & 2677 \\
\hline pr84-88-213-me & $2 \mathrm{D}$ & 2624113 & 2630098 & 6174094 & 6174228 & 5816 & 2677 \\
\hline pr84-88-215 & $2 \mathrm{D}$ & 2623888 & 2629712 & 6173063 & 6173303 & 5816 & 2677 \\
\hline pr84-88-215-me & $2 \mathrm{D}$ & 2623888 & 2629687 & 6173063 & 6173303 & 5816 & 2677 \\
\hline s1382-001-2708 & $2 \mathrm{D}$ & 2544714 & 2583452 & 6244475 & 6244785 & 5028 & 2708 \\
\hline s1382-003-2708 & $2 \mathrm{D}$ & 2544912 & 2587293 & 6232220 & 6232558 & 5016 & 2708 \\
\hline s1382-004-2708 & $2 \mathrm{D}$ & 2544667 & 2581274 & 6227282 & 6227560 & 4260 & 2708 \\
\hline s1382-005-2708 & $2 \mathrm{D}$ & 2554334 & 2568562 & 6224719 & 6224832 & 5008 & 2708 \\
\hline s1382-006-2708 & $2 \mathrm{D}$ & 2544760 & 2576245 & 6222161 & 6222379 & 5028 & 2708 \\
\hline s1382-007-2708 & $2 \mathrm{D}$ & 2544722 & 2574215 & 6217186 & 6217536 & 5024 & 2708 \\
\hline s1382-008a & $2 \mathrm{D}$ & 2550003 & 2572741 & 6212206 & 6212358 & 6008 & 2308 \\
\hline s1382-009 & $2 \mathrm{D}$ & 2544531 & 2558434 & 6210053 & 6210143 & 5008 & 2308 \\
\hline s1382-010 & $2 \mathrm{D}$ & 2544515 & 2563447 & 6207260 & 6207406 & 5000 & 2308 \\
\hline s1382-011 & $2 \mathrm{D}$ & 2544650 & 2563410 & 6204695 & 6205126 & 5008 & 2308 \\
\hline
\end{tabular}




\begin{tabular}{|c|c|c|c|c|c|c|c|}
\hline Name & Type & $X \min$ & $X$ max & $Y$ min & $Y \max$ & $T \max$ & PR \\
\hline s1382-012 & $2 \mathrm{D}$ & 2550494 & 2567879 & 6201320 & 6201443 & 5020 & 2308 \\
\hline s1382-014 & $2 \mathrm{D}$ & 2557521 & 2583188 & 6189498 & 6189710 & 6028 & 2308 \\
\hline s1382-015-2708 & $2 \mathrm{D}$ & 2543775 & 2583395 & 6238741 & 6238983 & 5032 & 2708 \\
\hline s1382-101 & $2 \mathrm{D}$ & 2546225 & 2546376 & 6201133 & 6228880 & 5008 & 2308 \\
\hline s1382-102 & $2 \mathrm{D}$ & 2548661 & 2548738 & 6200611 & 6214058 & 5004 & 2308 \\
\hline s1382-103 & $2 \mathrm{D}$ & 2550844 & 2551105 & 6201321 & 6224996 & 5008 & 2308 \\
\hline s1382-104 & $2 \mathrm{D}$ & 2553618 & 2553798 & 6195605 & 6224428 & 5016 & 2308 \\
\hline s1382-105-2708 & $2 \mathrm{D}$ & 2552273 & 2560141 & 6187881 & 6246234 & 5012 & 2708 \\
\hline s1382-105a & $2 \mathrm{D}$ & 2559847 & 2561126 & 6191385 & 6228973 & 5008 & 2308 \\
\hline s1382-106-2708 & $2 \mathrm{D}$ & 2563170 & 2563728 & 6187741 & 6246469 & 5020 & 2708 \\
\hline s1382-106b & $2 \mathrm{D}$ & 2563171 & 2563729 & 6187743 & 6246481 & 6020 & 2308 \\
\hline s1382-107-2708 & $2 \mathrm{D}$ & 2566607 & 2566810 & 6205486 & 6221589 & 5020 & 2708 \\
\hline s1382-108-2708 & $2 \mathrm{D}$ & 2570339 & 2570917 & 6187729 & 6246121 & 5032 & 2708 \\
\hline s1382-109-2708 & $2 \mathrm{D}$ & 2574004 & 2574275 & 6217559 & 6246388 & 5012 & 2708 \\
\hline s1382-110-2708 & $2 \mathrm{D}$ & 2581119 & 2581322 & 6227845 & 6246231 & 4984 & 2708 \\
\hline s1382-111-2708 & $2 \mathrm{D}$ & 2584594 & 2584651 & 6230441 & 6236801 & 5024 & 2708 \\
\hline s1382-113 & $2 \mathrm{D}$ & 2570922 & 2578575 & 6188087 & 6202729 & 6020 & 2308 \\
\hline s1383-209a & $2 \mathrm{D}$ & 2549242 & 2558167 & 6213552 & 6213634 & 3996 & 2308 \\
\hline s1383-209b & $2 \mathrm{D}$ & 2561899 & 2573278 & 6213463 & 6213548 & 5144 & 2308 \\
\hline s1383-210a & $2 \mathrm{D}$ & 2549527 & 2558053 & 6211046 & 6211102 & 4004 & 2308 \\
\hline $\mathrm{s} 1383-210 \mathrm{~b}$ & $2 \mathrm{D}$ & 2561770 & 2573222 & 6210928 & 6211176 & 5140 & 2308 \\
\hline s1383-211 & $2 \mathrm{D}$ & 2549218 & 2559319 & 6208591 & 6208661 & 4020 & 2308 \\
\hline s1383-306 & $2 \mathrm{D}$ & 2552369 & 2552436 & 6205796 & 6217741 & 3988 & 2308 \\
\hline s1383-307 & $2 \mathrm{D}$ & 2555061 & 2555137 & 6205813 & 6216462 & 3992 & 2308 \\
\hline s1383-308 & $2 \mathrm{D}$ & 2568611 & 2568723 & 6205715 & 6218861 & 5140 & 2308 \\
\hline s1383-311 & $2 \mathrm{D}$ & 2571396 & 2581990 & 6188193 & 6206676 & 5140 & 2308 \\
\hline s1383-312-2708 & $2 \mathrm{D}$ & 2571208 & 2588693 & 6218345 & 6236421 & 5012 & 2308 \\
\hline s1685-501-2664 & $2 \mathrm{D}$ & 2619608 & 2637453 & 6152552 & 6173509 & 6020 & 2664 \\
\hline sk-10-2664 & $2 \mathrm{D}$ & 2592188 & 2635693 & 6152610 & 6152842 & 5012 & 2664 \\
\hline $\mathrm{sk} 13 \mathrm{e}$ & $2 \mathrm{D}$ & 2608745 & 2608930 & 6142402 & 6168457 & 6016 & 2664 \\
\hline sk13n & $2 \mathrm{D}$ & 2608870 & 2608961 & 6166050 & 6175877 & 6016 & 2664 \\
\hline sk-13n_austral & $2 \mathrm{D}$ & 2608865 & 2608973 & 6166195 & 6176075 & 5140 & 2664 \\
\hline st03-101 & $2 \mathrm{D}$ & 2517934 & 2564669 & 6199316 & 6249534 & 6032 & - \\
\hline st03-102 & $2 \mathrm{D}$ & 2515481 & 2540321 & 6201600 & 6227809 & 6028 & - \\
\hline st03-103 & $2 \mathrm{D}$ & 2511853 & 2539943 & 6202304 & 6232367 & 6028 & - \\
\hline st03-104 & $2 \mathrm{D}$ & 2513430 & 2540130 & 6207880 & 6236000 & 6028 & - \\
\hline st03-105 & $2 \mathrm{D}$ & 2511511 & 2537926 & 6210017 & 6238410 & 6028 & - \\
\hline st03-106 & $2 \mathrm{D}$ & 2511042 & 2536017 & 6214357 & 6240825 & 6028 & - \\
\hline st03-107 & $2 \mathrm{D}$ & 2510905 & 2534200 & 6218772 & 6243563 & 6028 & - \\
\hline st03-108 & $2 \mathrm{D}$ & 2510794 & 2531593 & 6223133 & 6245366 & 6028 & - \\
\hline st03-109 & $2 \mathrm{D}$ & 2510915 & 2528838 & 6227358 & 6246593 & 6028 & - \\
\hline st03-110 & $2 \mathrm{D}$ & 2508930 & 2525166 & 6200786 & 6216460 & 6032 & - \\
\hline st03-111 & $2 \mathrm{D}$ & 2508555 & 2527260 & 6202958 & 6221207 & 6028 & - \\
\hline st03-112 & $2 \mathrm{D}$ & 2510384 & 2529150 & 6204919 & 6223116 & 6028 & - \\
\hline st03-113 & $2 \mathrm{D}$ & 2507614 & 2533934 & 6204580 & 6229824 & 6028 & - \\
\hline st03-114 & $2 \mathrm{D}$ & 2511335 & 2533632 & 6209593 & 6231615 & 6040 & - \\
\hline st03-115 & $2 \mathrm{D}$ & 2510828 & 2536844 & 6213496 & 6238828 & 6028 & - \\
\hline st03-116 & $2 \mathrm{D}$ & 2511812 & 2538278 & 6214809 & 6239851 & 6028 & - \\
\hline st03-117 & $2 \mathrm{D}$ & 2512989 & 2539256 & 6215437 & 6240733 & 6028 & - \\
\hline st03-118 & $2 \mathrm{D}$ & 2515201 & 2541549 & 6217822 & 6243022 & 6028 & - \\
\hline st03-201 & $2 \mathrm{D}$ & 2481028 & 2512387 & 6226593 & 6226890 & 6028 & - \\
\hline st03-202 & $2 \mathrm{D}$ & 2480728 & 2512123 & 6230836 & 6231059 & 6028 & - \\
\hline st03-203 & $2 \mathrm{D}$ & 2480944 & 2512336 & 6234624 & 6234977 & 6028 & - \\
\hline st03-204 & $2 \mathrm{D}$ & 2479548 & 2510946 & 6238018 & 6238268 & 6028 & - \\
\hline st03-205 & $2 \mathrm{D}$ & 2477554 & 2511166 & 6241376 & 6242148 & 6028 & - \\
\hline st03-206 & $2 \mathrm{D}$ & 2484544 & 2510914 & 6243301 & 6243401 & 6028 & - \\
\hline
\end{tabular}




\begin{tabular}{|c|c|c|c|c|c|c|c|}
\hline Name & Type & $X$ min & $X \max$ & $Y$ min & $Y \max$ & $T$ max & PR \\
\hline st03-207 & $2 \mathrm{D}$ & 2484783 & 2511126 & 6246910 & 6247426 & 6020 & - \\
\hline st03-208 & $2 \mathrm{D}$ & 2469426 & 2510874 & 6248881 & 6249303 & 6024 & - \\
\hline st03-209 & $2 \mathrm{D}$ & 2464667 & 2511088 & 6252052 & 6252926 & 6032 & - \\
\hline st03-210 & $2 \mathrm{D}$ & 2484551 & 2510819 & 6254687 & 6255118 & 6036 & - \\
\hline st03-211 & $2 \mathrm{D}$ & 2462361 & 2512941 & 6257949 & 6258261 & 6028 & - \\
\hline st03-212 & $2 \mathrm{D}$ & 2486851 & 2513137 & 6260050 & 6260347 & 6024 & - \\
\hline st03-213 & $2 \mathrm{D}$ & 2486334 & 2517858 & 6263524 & 6263737 & 6032 & - \\
\hline st03-214 & $2 \mathrm{D}$ & 2479321 & 2479700 & 6233710 & 6265122 & 6028 & - \\
\hline st03-215 & $2 \mathrm{D}$ & 2491085 & 2491319 & 6220970 & 6266495 & 6032 & - \\
\hline st03-216 & $2 \mathrm{D}$ & 2496352 & 2496639 & 6221260 & 6268179 & 6028 & - \\
\hline st03-217 & $2 \mathrm{D}$ & 2501147 & 2501630 & 6221066 & 6282610 & 6024 & - \\
\hline st03-218 & $2 \mathrm{D}$ & 2506531 & 2506998 & 6243458 & 6282869 & 6028 & - \\
\hline st03-301 & $2 \mathrm{D}$ & 2521456 & 2568248 & 6235926 & 6250352 & 6028 & - \\
\hline st03-302 & $2 \mathrm{D}$ & 2521027 & 2546063 & 6238105 & 6245801 & 6032 & - \\
\hline st03-303 & $2 \mathrm{D}$ & 2520162 & 2545195 & 6240099 & 6247738 & 6028 & - \\
\hline st03-304 & $2 \mathrm{D}$ & 2521197 & 2565504 & 6243012 & 6256194 & 6028 & - \\
\hline st03-305 & $2 \mathrm{D}$ & 2517330 & 2547420 & 6243416 & 6252506 & 6028 & - \\
\hline st03-306 & $2 \mathrm{D}$ & 2517375 & 2547289 & 6245326 & 6254479 & 6032 & - \\
\hline st03-307 & $2 \mathrm{D}$ & 2516987 & 2546885 & 6247726 & 6256555 & 6032 & - \\
\hline st03-308 & $2 \mathrm{D}$ & 2516314 & 2546086 & 6249271 & 6258343 & 6028 & - \\
\hline st03-309 & $2 \mathrm{D}$ & 2516511 & 2546430 & 6251486 & 6260601 & 6024 & - \\
\hline st03-310 & $2 \mathrm{D}$ & 2516007 & 2545968 & 6253979 & 6262948 & 6028 & - \\
\hline st03-311 & $2 \mathrm{D}$ & 2515508 & 2545352 & 6255536 & 6264934 & 6028 & - \\
\hline st03-312 & $2 \mathrm{D}$ & 2515885 & 2544480 & 6257813 & 6266827 & 6028 & - \\
\hline st03-313 & $2 \mathrm{D}$ & 2514256 & 2544229 & 6259663 & 6268560 & 6032 & - \\
\hline st03-314 & $2 \mathrm{D}$ & 2515754 & 2545672 & 6261788 & 6270942 & 6024 & - \\
\hline st03-315 & $2 \mathrm{D}$ & 2520166 & 2532476 & 6231834 & 6271279 & 6028 & - \\
\hline st03-316 & $2 \mathrm{D}$ & 2523432 & 2536028 & 6232703 & 6272040 & 6028 & - \\
\hline st03-317 & $2 \mathrm{D}$ & 2527624 & 2539587 & 6234108 & 6273617 & 6028 & - \\
\hline st03-318 & $2 \mathrm{D}$ & 2532147 & 2544403 & 6233471 & 6272918 & 6028 & - \\
\hline st03-319 & $2 \mathrm{D}$ & 2545712 & 2556215 & 6223511 & 6258310 & 6028 & - \\
\hline st03-320 & $2 \mathrm{D}$ & 2546105 & 2560094 & 6224987 & 6268846 & 6028 & - \\
\hline st03-321 & $2 \mathrm{D}$ & 2550179 & 2563796 & 6225899 & 6269845 & 6028 & - \\
\hline st03-401 & $2 \mathrm{D}$ & 2522824 & 2561117 & 6223677 & 6257663 & 6028 & - \\
\hline st03-402 & $2 \mathrm{D}$ & 2549618 & 2557956 & 6224311 & 6266354 & 6032 & - \\
\hline st301-2664 & $2 \mathrm{D}$ & 2623330 & 2631672 & 6157457 & 6157502 & 5508 & - \\
\hline st303-2664 & $2 \mathrm{D}$ & 2627078 & 2634540 & 6153685 & 6161122 & 5512 & - \\
\hline st304-2664 & $2 \mathrm{D}$ & 2627781 & 2634676 & 6154311 & 6161114 & 5516 & - \\
\hline st305-2664 & $2 \mathrm{D}$ & 2628505 & 2634989 & 6154663 & 6161095 & 5520 & - \\
\hline st306-2664 & $2 \mathrm{D}$ & 2629238 & 2635309 & 6155055 & 6161078 & 5520 & - \\
\hline st307-2664 & $2 \mathrm{D}$ & 2619370 & 2635509 & 6155780 & 6156075 & 5516 & - \\
\hline st308-2664 & $2 \mathrm{D}$ & 2617955 & 2634605 & 6154599 & 6154815 & 5512 & - \\
\hline st309-2664 & $2 \mathrm{D}$ & 2619878 & 2636222 & 6151924 & 6152153 & 5516 & - \\
\hline st310-2664 & $2 \mathrm{D}$ & 2626366 & 2634441 & 6153005 & 6161123 & 5516 & - \\
\hline stos95-100 & $2 \mathrm{D}$ & 2527648 & 2543068 & 6181819 & 6198307 & 5024 & 2403 \\
\hline stos $95-102$ & $2 \mathrm{D}$ & 2514845 & 2551979 & 6170409 & 6210167 & 5024 & 2403 \\
\hline stos95-104 & $2 \mathrm{D}$ & 2513892 & 2551593 & 6171457 & 6211828 & 5024 & 2403 \\
\hline stos95-106 & $2 \mathrm{D}$ & 2527263 & 2551137 & 6188483 & 6213514 & 5024 & 2403 \\
\hline stos95-108 & $2 \mathrm{D}$ & 2512954 & 2550096 & 6174984 & 6214686 & 5024 & 2403 \\
\hline stos $95-110$ & $2 \mathrm{D}$ & 2525972 & 2548915 & 6191144 & 6215615 & 5024 & 2403 \\
\hline stos95-112 & $2 \mathrm{D}$ & 2521219 & 2548014 & 6188241 & 6216660 & 5024 & 2403 \\
\hline stos95-114 & $2 \mathrm{D}$ & 2523022 & 2547386 & 6192532 & 6218416 & 5024 & 2403 \\
\hline stos95-116 & $2 \mathrm{D}$ & 2518319 & 2546356 & 6189593 & 6219649 & 5024 & 2403 \\
\hline stos95-190 & $2 \mathrm{D}$ & 2517488 & 2534785 & 6179479 & 6195902 & 5024 & 2403 \\
\hline stos95-194 & $2 \mathrm{D}$ & 2518775 & 2534546 & 6182370 & 6197509 & 5024 & 2403 \\
\hline stos $95-200$ & $2 \mathrm{D}$ & 2520151 & 2536621 & 6184487 & 6200265 & 5024 & 2403 \\
\hline
\end{tabular}




\begin{tabular}{|c|c|c|c|c|c|c|c|}
\hline Name & Type & $X \min$ & $X \max$ & $Y$ min & $Y \max$ & $T \max$ & PR \\
\hline stos95-202 & $2 \mathrm{D}$ & 2520832 & 2537240 & 6185532 & 6200980 & 5024 & 2403 \\
\hline stos95-204 & $2 \mathrm{D}$ & 2521370 & 2538752 & 6185514 & 6201783 & 5024 & 2403 \\
\hline stos95-206 & $2 \mathrm{D}$ & 2522221 & 2539190 & 6186182 & 6202546 & 5024 & 2403 \\
\hline stos95-208 & $2 \mathrm{D}$ & 2522825 & 2540145 & 6186520 & 6203287 & 5024 & 2403 \\
\hline stos95-212 & $2 \mathrm{D}$ & 2524266 & 2541609 & 6188305 & 6204582 & 5024 & 2403 \\
\hline stos95-214 & $2 \mathrm{D}$ & 2525077 & 2539308 & 6191676 & 6205594 & 5024 & 2403 \\
\hline stos95-216 & $2 \mathrm{D}$ & 2531258 & 2541757 & 6190782 & 6200924 & 5024 & 2403 \\
\hline stos95-218 & $2 \mathrm{D}$ & 2526398 & 2542409 & 6191784 & 6206844 & 5024 & 2403 \\
\hline stos $95-220$ & $2 \mathrm{D}$ & 2527006 & 2542819 & 6192373 & 6207542 & 5024 & 2403 \\
\hline stos95-224 & $2 \mathrm{D}$ & 2528368 & 2543928 & 6194269 & 6208897 & 5024 & 2403 \\
\hline stos $95-226$ & $2 \mathrm{D}$ & 2528890 & 2543908 & 6195696 & 6209693 & 5024 & 2403 \\
\hline stos95-230 & $2 \mathrm{D}$ & 2530439 & 2545320 & 6197184 & 6211313 & 5024 & 2403 \\
\hline stos95-234 & $2 \mathrm{D}$ & 2531813 & 2546760 & 6198910 & 6212648 & 5024 & 2403 \\
\hline stos $95-238$ & $2 \mathrm{D}$ & 2533184 & 2548080 & 6200374 & 6214127 & 5024 & 2403 \\
\hline stos95-242 & $2 \mathrm{D}$ & 2534728 & 2550876 & 6200272 & 6215462 & 5024 & 2403 \\
\hline stos95-244 & $2 \mathrm{D}$ & 2535307 & 2551486 & 6200606 & 6216379 & 5024 & 2403 \\
\hline stos $95-246$ & $2 \mathrm{D}$ & 2536122 & 2552674 & 6200703 & 6217036 & 5024 & 2403 \\
\hline stos $95-248$ & $2 \mathrm{D}$ & 2536646 & 2552478 & 6202117 & 6217946 & 5024 & 2403 \\
\hline stos $95-250$ & $2 \mathrm{D}$ & 2537637 & 2552817 & 6203231 & 6218372 & 5024 & 2403 \\
\hline stos $95-252$ & $2 \mathrm{D}$ & 2538619 & 2553629 & 6204021 & 6218858 & 5024 & 2403 \\
\hline stos $95-254$ & $2 \mathrm{D}$ & 2539507 & 2552687 & 6206323 & 6219348 & 5024 & 2403 \\
\hline stos95-256 & $2 \mathrm{D}$ & 2540619 & 2552541 & 6208186 & 6219595 & 5024 & 2403 \\
\hline stos $95-300$ & $2 \mathrm{D}$ & 2544906 & 2545121 & 6179750 & 6219575 & 5024 & 2403 \\
\hline stos95-301 & $2 \mathrm{D}$ & 2512214 & 2534031 & 6171921 & 6176692 & 5024 & 2403 \\
\hline sunz91-101-1948 & $2 \mathrm{D}$ & 2463604 & 2534665 & 6248507 & 6266638 & 6012 & 1948 \\
\hline sunz91-102-1948 & $2 \mathrm{D}$ & 2513816 & 2539877 & 6258100 & 6266149 & 6012 & 1948 \\
\hline sunz91-103-1948 & $2 \mathrm{D}$ & 2513753 & 2543593 & 6256021 & 6265129 & 6012 & 1948 \\
\hline sunz91-104-1948 & $2 \mathrm{D}$ & 2513803 & 2551804 & 6253857 & 6265595 & 6012 & 1948 \\
\hline sunz91-105-1948 & $2 \mathrm{D}$ & 2509428 & 2558401 & 6250417 & 6265524 & 6012 & 1948 \\
\hline sunz91-106-1948 & $2 \mathrm{D}$ & 2513606 & 2561889 & 6249632 & 6264626 & 6016 & 1948 \\
\hline sunz91-107-1948 & $2 \mathrm{D}$ & 2513833 & 2564394 & 6247460 & 6263270 & 6016 & 1948 \\
\hline sunz91-108-1948 & $2 \mathrm{D}$ & 2511841 & 2564214 & 6244730 & 6260993 & 6012 & 1948 \\
\hline sunz91-109-1948 & $2 \mathrm{D}$ & 2513634 & 2563970 & 6243169 & 6258787 & 6012 & 1948 \\
\hline sunz91-110-1948 & $2 \mathrm{D}$ & 2513613 & 2563269 & 6240903 & 6256467 & 6016 & 1948 \\
\hline sunz91-111-1948 & $2 \mathrm{D}$ & 2513859 & 2564146 & 6239099 & 6254593 & 6016 & 1948 \\
\hline sunz91-112-1948 & $2 \mathrm{D}$ & 2511074 & 2564794 & 6236060 & 6252809 & 6012 & 1948 \\
\hline sunz91-113_r03 & $2 \mathrm{D}$ & 2510958 & 2562858 & 6233717 & 6250077 & 6016 & 1948 \\
\hline sunz91-113-1948 & $2 \mathrm{D}$ & 2511042 & 2564044 & 6233747 & 6250453 & 6012 & 1948 \\
\hline sunz91-114_r03 & $2 \mathrm{D}$ & 2510600 & 2565073 & 6231693 & 6248648 & 6012 & 1948 \\
\hline sunz91-114-1948 & $2 \mathrm{D}$ & 2510478 & 2564979 & 6231656 & 6248620 & 6012 & 1948 \\
\hline sunz91-115_r03 & $2 \mathrm{D}$ & 2513491 & 2564721 & 6230583 & 6246404 & 6016 & 1948 \\
\hline sunz91-115-1948 & $2 \mathrm{D}$ & 2513588 & 2564838 & 6230615 & 6246442 & 6012 & 1948 \\
\hline sunz91-116_r03 & $2 \mathrm{D}$ & 2513996 & 2564173 & 6228568 & 6244046 & 6016 & 1948 \\
\hline sunz91-116-1948 & $2 \mathrm{D}$ & 2513879 & 2564077 & 6228531 & 6244017 & 6012 & 1948 \\
\hline sunz91-117_r03 & $2 \mathrm{D}$ & 2514008 & 2564023 & 6226498 & 6241838 & 6016 & 1948 \\
\hline sunz91-117-1948 & $2 \mathrm{D}$ & 2513892 & 2563939 & 6226464 & 6241815 & 6012 & 1948 \\
\hline sunz91-118_r03 & $2 \mathrm{D}$ & 2513579 & 2563750 & 6224252 & 6239725 & 6016 & 1948 \\
\hline sunz91-118-1948 & $2 \mathrm{D}$ & 2513667 & 2563869 & 6224280 & 6239753 & 6012 & 1948 \\
\hline sunz91-119_r03 & $2 \mathrm{D}$ & 2507444 & 2564561 & 6218968 & 6236577 & 6016 & 1948 \\
\hline sunz91-119-1948 & $2 \mathrm{D}$ & 2507321 & 2564405 & 6218927 & 6236559 & 6020 & 1948 \\
\hline sunz91-120_r03 & $2 \mathrm{D}$ & 2529987 & 2565658 & 6222928 & 6233959 & 6016 & 1948 \\
\hline sunz91-120-1948 & $2 \mathrm{D}$ & 2530085 & 2565777 & 6222965 & 6234001 & 6012 & 1948 \\
\hline sunz91-121_r03 & $2 \mathrm{D}$ & 2554993 & 2562627 & 6242747 & 6266864 & 6008 & 1948 \\
\hline sunz91-121-1948 & $2 \mathrm{D}$ & 2554953 & 2562598 & 6242841 & 6266985 & 6012 & 1948 \\
\hline sunz91-122-1948 & $2 \mathrm{D}$ & 2552736 & 2564176 & 6231146 & 6267439 & 6012 & 1948 \\
\hline sunz91-123-1948 & $2 \mathrm{D}$ & 2548084 & 2561839 & 6225352 & 6268813 & 6016 & 1948 \\
\hline
\end{tabular}




\begin{tabular}{|c|c|c|c|c|c|c|c|}
\hline Name & Type & $X \min$ & $X \max$ & $Y$ min & $Y \max$ & $T$ max & PR \\
\hline sunz91-124-1948 & $2 \mathrm{D}$ & 2544296 & 2558547 & 6222604 & 6267494 & 6016 & 1948 \\
\hline sunz91-125-1948 & $2 \mathrm{D}$ & 2539871 & 2552784 & 6227277 & 6268388 & 6016 & 1948 \\
\hline sunz91-126-1948 & $2 \mathrm{D}$ & 2535926 & 2550156 & 6222118 & 6267442 & 6012 & 1948 \\
\hline sunz91-127-1948 & $2 \mathrm{D}$ & 2531438 & 2547585 & 6216879 & 6268212 & 6012 & 1948 \\
\hline sunz91-128-1948 & $2 \mathrm{D}$ & 2536613 & 2543479 & 6216857 & 6238170 & 6012 & 1948 \\
\hline sunz91-129-1948 & $2 \mathrm{D}$ & 2523380 & 2542245 & 6206830 & 6267139 & 6012 & 1948 \\
\hline sunz91-130-1948 & $2 \mathrm{D}$ & 2519178 & 2533571 & 6221300 & 6267011 & 6012 & 1948 \\
\hline sunz91-131-1948 & $2 \mathrm{D}$ & 2514866 & 2529858 & 6219973 & 6267462 & 6012 & 1948 \\
\hline sunz91-132_r03 & $2 \mathrm{D}$ & 2513335 & 2538878 & 6210283 & 6234606 & 6016 & 1948 \\
\hline sunz91-133_r03 & $2 \mathrm{D}$ & 2504884 & 2535312 & 6210868 & 6239877 & 6012 & 1948 \\
\hline sunz91-133-1948 & $2 \mathrm{D}$ & 2504793 & 2544372 & 6202241 & 6239963 & 6012 & 1948 \\
\hline sunz91-134_r03 & $2 \mathrm{D}$ & 2499719 & 2531924 & 6208473 & 6239316 & 6016 & 1948 \\
\hline sunz91-134-1948 & $2 \mathrm{D}$ & 2499770 & 2542759 & 6198098 & 6239268 & 6012 & 1948 \\
\hline sunz91-135_r03 & $2 \mathrm{D}$ & 2495707 & 2531122 & 6205126 & 6238908 & 6016 & 1948 \\
\hline sunz91-135-1948 & $2 \mathrm{D}$ & 2495618 & 2538444 & 6198123 & 6238998 & 6012 & 1948 \\
\hline sunz91-136_r03 & $2 \mathrm{D}$ & 2468980 & 2528986 & 6203060 & 6262243 & 6016 & 1948 \\
\hline sunz91-136-1948 & $2 \mathrm{D}$ & 2469052 & 2534278 & 6198000 & 6262169 & 6012 & 1948 \\
\hline sunz91-137-1948 & $2 \mathrm{D}$ & 2487045 & 2519190 & 6208012 & 6238889 & 6012 & 1948 \\
\hline sunz91-138 & $2 \mathrm{D}$ & 2482098 & 2525579 & 6197716 & 6239510 & 6016 & 1948 \\
\hline sunz91-138-1948 & $2 \mathrm{D}$ & 2482103 & 2502646 & 6219745 & 6239476 & 6016 & 1948 \\
\hline sunz91-139-1948 & $2 \mathrm{D}$ & 2478970 & 2521505 & 6197426 & 6238475 & 6012 & 1948 \\
\hline sunz91-140-1948 & $2 \mathrm{D}$ & 2473919 & 2517915 & 6196471 & 6239156 & 6012 & 1948 \\
\hline sunz91-141-1948 & $2 \mathrm{D}$ & 2471243 & 2513590 & 6196472 & 6237591 & 6012 & 1948 \\
\hline sunz91-142-1948 & $2 \mathrm{D}$ & 2471419 & 2512776 & 6192830 & 6233222 & 6012 & 1948 \\
\hline sunz91-143-1948 & $2 \mathrm{D}$ & 2471322 & 2510005 & 6191275 & 6229139 & 6012 & 1948 \\
\hline sunz91-144-1948 & $2 \mathrm{D}$ & 2470543 & 2495782 & 6200930 & 6225543 & 6012 & 1948 \\
\hline sunz91-145-1948 & $2 \mathrm{D}$ & 2470427 & 2489000 & 6203318 & 6221568 & 6012 & 1948 \\
\hline sunz91-146-1948 & $2 \mathrm{D}$ & 2470629 & 2485701 & 6202534 & 6216873 & 6012 & 1948 \\
\hline sunz91-147-1948 & $2 \mathrm{D}$ & 2470504 & 2486421 & 6221849 & 6238626 & 6012 & 1948 \\
\hline sunz91-148-1948 & $2 \mathrm{D}$ & 2470868 & 2490841 & 6217595 & 6238900 & 6012 & 1948 \\
\hline sunz91-149-1948 & $2 \mathrm{D}$ & 2470438 & 2495337 & 6212898 & 6239341 & 6012 & 1948 \\
\hline sunz91-150-1948 & $2 \mathrm{D}$ & 2471766 & 2499226 & 6209683 & 6239189 & 6012 & 1948 \\
\hline sunz91-151-1948 & $2 \mathrm{D}$ & 2471909 & 2503488 & 6205551 & 6239289 & 6012 & 1948 \\
\hline sunz91-152-1948 & $2 \mathrm{D}$ & 2476111 & 2508614 & 6205668 & 6240272 & 6012 & 1948 \\
\hline sunz91-153-1948 & $2 \mathrm{D}$ & 2479406 & 2511806 & 6204819 & 6239526 & 6016 & 1948 \\
\hline sunz91-154-1948 & $2 \mathrm{D}$ & 2481354 & 2518802 & 6202553 & 6242652 & 6012 & 1948 \\
\hline sunz91-155_r03 & $2 \mathrm{D}$ & 2503975 & 2521398 & 6222271 & 6240814 & 6016 & 1948 \\
\hline sunz91-155-1948 & $2 \mathrm{D}$ & 2485448 & 2521331 & 6202579 & 6240742 & 6012 & 1948 \\
\hline sunz91-156_r03 & $2 \mathrm{D}$ & 2504126 & 2524152 & 6217999 & 6239381 & 6012 & 1948 \\
\hline sunz91-156-1948 & $2 \mathrm{D}$ & 2489431 & 2524091 & 6202294 & 6239316 & 6012 & 1948 \\
\hline sunz91-157_r03 & $2 \mathrm{D}$ & 2513829 & 2527276 & 6223877 & 6238230 & 6012 & 1948 \\
\hline sunz91-157-1948 & $2 \mathrm{D}$ & 2492251 & 2527216 & 6200804 & 6238168 & 6012 & 1948 \\
\hline sunz91-158_r03 & $2 \mathrm{D}$ & 2510988 & 2527330 & 6216495 & 6234092 & 6016 & 1948 \\
\hline sunz91-158-1948 & $2 \mathrm{D}$ & 2498561 & 2527607 & 6203163 & 6234385 & 6012 & 1948 \\
\hline sunz91-159_r03 & $2 \mathrm{D}$ & 2512934 & 2530172 & 6214053 & 6232569 & 6012 & 1948 \\
\hline sunz91-159-1948 & $2 \mathrm{D}$ & 2500899 & 2530110 & 6201107 & 6232504 & 6012 & 1948 \\
\hline sunz91-160_r03 & $2 \mathrm{D}$ & 2500546 & 2532269 & 6196246 & 6230085 & 6016 & 1948 \\
\hline sunz91-160-1948 & $2 \mathrm{D}$ & 2500618 & 2533438 & 6196329 & 6231685 & 6012 & 1948 \\
\hline sunz91-161_r03 & $2 \mathrm{D}$ & 2500537 & 2537303 & 6192002 & 6231282 & 6016 & 1948 \\
\hline sunz91-161-1948 & $2 \mathrm{D}$ & 2500435 & 2537232 & 6191890 & 6231205 & 6016 & 1948 \\
\hline sunz91-162_r03 & $2 \mathrm{D}$ & 2511835 & 2542087 & 6199901 & 6231771 & 6016 & 1948 \\
\hline sunz91-162-1948 & $2 \mathrm{D}$ & 2501661 & 2531890 & 6189142 & 6221029 & 6016 & 1948 \\
\hline sunz91-163_r03 & $2 \mathrm{D}$ & 2519088 & 2547093 & 6203171 & 6232702 & 6016 & 1948 \\
\hline sunz91-163-1948 & $2 \mathrm{D}$ & 2515692 & 2547030 & 6199600 & 6232635 & 6012 & 1948 \\
\hline sunz91-164-1948 & $2 \mathrm{D}$ & 2517605 & 2557306 & 6197443 & 6239073 & 6016 & 1948 \\
\hline sunz91-165-1948 & $2 \mathrm{D}$ & 2521897 & 2555645 & 6197363 & 6232763 & 6012 & 1948 \\
\hline
\end{tabular}




\begin{tabular}{|c|c|c|c|c|c|c|c|}
\hline Name & Type & $X \min$ & $X$ max & $Y$ min & $Y \max$ & $T \max$ & PR \\
\hline sunz91-166-1948 & $2 \mathrm{D}$ & 2539230 & 2550130 & 6211278 & 6222731 & 6016 & 1948 \\
\hline sunz91-167-1948 & $2 \mathrm{D}$ & 2530531 & 2544262 & 6197640 & 6212179 & 6012 & 1948 \\
\hline swift-arb1_ks-4 & $2 \mathrm{D}$ & 2606555 & 2627418 & 6145380 & 6174524 & 5004 & 2442 \\
\hline swift-arb2_rb-1 & $2 \mathrm{D}$ & 2624025 & 2634156 & 6152288 & 6170362 & 4816 & 2442 \\
\hline t96-01 & $2 \mathrm{D}$ & 2516690 & 2533729 & 6174803 & 6191413 & 5072 & 2307 \\
\hline t96-02 & $2 \mathrm{D}$ & 2508184 & 2520439 & 6178868 & 6191856 & 5080 & 2307 \\
\hline t96-03 & $2 \mathrm{D}$ & 2514702 & 2533999 & 6169260 & 6189189 & 5064 & 2307 \\
\hline t96-04 & $2 \mathrm{D}$ & 2508991 & 2521170 & 6177460 & 6190640 & 5032 & 2307 \\
\hline t96-05 & $2 \mathrm{D}$ & 2511973 & 2523956 & 6174754 & 6186768 & 5068 & 2307 \\
\hline t96-06 & $2 \mathrm{D}$ & 2507651 & 2523504 & 6173686 & 6190681 & 5028 & 2307 \\
\hline t96-07 & $2 \mathrm{D}$ & 2511134 & 2527821 & 6168730 & 6185562 & 5068 & 2307 \\
\hline t96-08 & $2 \mathrm{D}$ & 2506441 & 2529470 & 6170415 & 6195126 & 5072 & 2307 \\
\hline t96-09 & $2 \mathrm{D}$ & 2505763 & 2515699 & 6178626 & 6188804 & 5080 & 2307 \\
\hline $\mathrm{t} 96-10$ & $2 \mathrm{D}$ & 2508633 & 2531635 & 6168132 & 6192733 & 5068 & 2307 \\
\hline t96-11 & $2 \mathrm{D}$ & 2507226 & 2525377 & 6167162 & 6185123 & 5068 & 2307 \\
\hline t96-13 & $2 \mathrm{D}$ & 2515974 & 2534104 & 6172049 & 6172183 & 5080 & 2307 \\
\hline t96-14 & $2 \mathrm{D}$ & 2510095 & 2534239 & 6159721 & 6185917 & 5072 & 2307 \\
\hline t96-15 & $2 \mathrm{D}$ & 2513211 & 2534083 & 6169118 & 6169152 & 5080 & 2307 \\
\hline t96-16 & $2 \mathrm{D}$ & 2531210 & 2531314 & 6161921 & 6175975 & 5072 & 2307 \\
\hline t96-17 & $2 \mathrm{D}$ & 2523377 & 2534400 & 6165889 & 6165996 & 5080 & 2307 \\
\hline t96-18 & $2 \mathrm{D}$ & 2476404 & 2490907 & 6147897 & 6161425 & 5080 & 2307 \\
\hline t96-19 & $2 \mathrm{D}$ & 2488294 & 2514466 & 6134726 & 6165522 & 5076 & 2307 \\
\hline t96-21 & $2 \mathrm{D}$ & 2492005 & 2510463 & 6136076 & 6156972 & 5080 & 2307 \\
\hline t96-22 & $2 \mathrm{D}$ & 2470289 & 2496126 & 6136303 & 6160381 & 5032 & 2307 \\
\hline t96-23 & $2 \mathrm{D}$ & 2484491 & 2493648 & 6151448 & 6162021 & 5032 & 2307 \\
\hline t96-24 & $2 \mathrm{D}$ & 2472447 & 2496512 & 6134746 & 6157263 & 5080 & 2307 \\
\hline t96-25 & $2 \mathrm{D}$ & 2485045 & 2505793 & 6135509 & 6159274 & 5080 & 2307 \\
\hline t96-26 & $2 \mathrm{D}$ & 2472917 & 2501192 & 6131884 & 6158225 & 5032 & 2307 \\
\hline t96-27 & $2 \mathrm{D}$ & 2480882 & 2498418 & 6142165 & 6162026 & 5032 & 2307 \\
\hline t96-29 & $2 \mathrm{D}$ & 2477043 & 2497764 & 6137240 & 6160488 & 5080 & 2307 \\
\hline t96-30 & $2 \mathrm{D}$ & 2502194 & 2514368 & 6135614 & 6147049 & 5076 & 2307 \\
\hline t96-31 & $2 \mathrm{D}$ & 2476679 & 2493388 & 6140250 & 6158791 & 5028 & 2307 \\
\hline t96-32 & $2 \mathrm{D}$ & 2491432 & 2491651 & 6137171 & 6159054 & 5080 & 2307 \\
\hline t96-33 & $2 \mathrm{D}$ & 2476687 & 2493632 & 6138026 & 6157070 & 5080 & 2307 \\
\hline $\mathrm{t} 96-35$ & $2 \mathrm{D}$ & 2474639 & 2487936 & 6142632 & 6157224 & 5032 & 2307 \\
\hline t96-37 & $2 \mathrm{D}$ & 2473402 & 2487938 & 6140553 & 6156819 & 5080 & 2307 \\
\hline t96-39 & $2 \mathrm{D}$ & 2474521 & 2486078 & 6140940 & 6153674 & 5032 & 2307 \\
\hline t96-41 & $2 \mathrm{D}$ & 2474275 & 2481708 & 6143458 & 6151591 & 5032 & 2307 \\
\hline t96-43 & $2 \mathrm{D}$ & 2472161 & 2482375 & 6139146 & 6150255 & 5080 & 2307 \\
\hline t96-45 & $2 \mathrm{D}$ & 2472188 & 2485629 & 6130042 & 6144594 & 5080 & 2307 \\
\hline $\mathrm{t} 96-47$ & $2 \mathrm{D}$ & 2467553 & 2475690 & 6108989 & 6118508 & 5020 & 2307 \\
\hline t96-49 & $2 \mathrm{D}$ & 2472500 & 2504027 & 6155094 & 6155215 & 5080 & 2307 \\
\hline t96-51 & $2 \mathrm{D}$ & 2474088 & 2504357 & 6151357 & 6151435 & 5032 & 2307 \\
\hline tnz81-601-2115 & $2 \mathrm{D}$ & 2508904 & 2542534 & 6147389 & 6147529 & 4724 & 2115 \\
\hline tnz81-603-852 & $2 \mathrm{D}$ & 2525463 & 2542374 & 6144377 & 6144483 & 5024 & 852 \\
\hline tnz81-604-3254 & $2 \mathrm{D}$ & 2526000 & 2526086 & 6105677 & 6136620 & 5136 & 1812 \\
\hline tnz81-605-2115 & $2 \mathrm{D}$ & 2526519 & 2542685 & 6141338 & 6141461 & 4724 & 2115 \\
\hline tnz81-607-2115 & $2 \mathrm{D}$ & 2508693 & 2541224 & 6138401 & 6138438 & 4724 & 2115 \\
\hline tnz81-609-852 & $2 \mathrm{D}$ & 2529941 & 2542627 & 6136959 & 6137002 & 5024 & 1987 \\
\hline tnz81-610a-3254 & $2 \mathrm{D}$ & 2530549 & 2530617 & 6127494 & 6150954 & 5136 & 1812 \\
\hline tnz81-610p-2115 & $2 \mathrm{D}$ & 2530508 & 2530611 & 6110483 & 6150490 & 4724 & 2115 \\
\hline tnz81-611-3254 & $2 \mathrm{D}$ & 2525596 & 2542281 & 6135475 & 6135500 & 5136 & 1812 \\
\hline tnz81-611-852 & $2 \mathrm{D}$ & 2525482 & 2542164 & 6135470 & 6135494 & 5084 & 852 \\
\hline $\operatorname{tnz} 81-612-1812$ & $2 \mathrm{D}$ & 2532006 & 2532022 & 6124500 & 6139130 & 5024 & 1812 \\
\hline tnz81-613-2115 & $2 \mathrm{D}$ & 2528556 & 2542407 & 6134043 & 6134091 & 4724 & 2115 \\
\hline tnz81-614-2115 & $2 \mathrm{D}$ & 2533059 & 2533186 & 6122409 & 6149957 & 4724 & 2115 \\
\hline
\end{tabular}




\begin{tabular}{|c|c|c|c|c|c|c|c|}
\hline Name & Type & $X \min$ & $X \max$ & $Y$ min & $Y \max$ & $T$ max & PR \\
\hline tnz81-615p-2115 & $2 \mathrm{D}$ & 2522049 & 2542576 & 6132511 & 6132631 & 4724 & 2115 \\
\hline tnz81-618-2338 & $2 \mathrm{D}$ & 2536535 & 2536690 & 6127378 & 6175069 & 5024 & 2338 \\
\hline tnz81-618a-3254 & $2 \mathrm{D}$ & 2536606 & 2536671 & 6132515 & 6173716 & 5136 & 2338 \\
\hline tnz81-618p-1987 & $2 \mathrm{D}$ & 2536619 & 2536638 & 6105848 & 6118741 & 4724 & 1987 \\
\hline tnz81-618p-2115 & $2 \mathrm{D}$ & 2536620 & 2536664 & 6122510 & 6149966 & 4724 & 2115 \\
\hline tnz81-619-2115 & $2 \mathrm{D}$ & 2510026 & 2542512 & 6129747 & 6129790 & 4724 & 2115 \\
\hline tnz81-621-852 & $2 \mathrm{D}$ & 2525535 & 2537476 & 6128103 & 6128294 & 5084 & 852 \\
\hline tnz81-622p-2115 & $2 \mathrm{D}$ & 2539560 & 2539584 & 6120538 & 6148691 & 4724 & 2115 \\
\hline tnz81-623-2115 & $2 \mathrm{D}$ & 2520562 & 2541936 & 6126529 & 6126594 & 4724 & 2115 \\
\hline tnz81-624-2115 & $2 \mathrm{D}$ & 2512500 & 2512718 & 6105103 & 6162536 & 4724 & 2115 \\
\hline tnz81-625-852 & $2 \mathrm{D}$ & 2525771 & 2536709 & 6125015 & 6125066 & 5084 & 852 \\
\hline tnz81-626-2115 & $2 \mathrm{D}$ & 2519920 & 2520106 & 6105976 & 6163374 & 4728 & 2115 \\
\hline tnz81-627-2115 & $2 \mathrm{D}$ & 2518271 & 2545673 & 6123491 & 6123766 & 4724 & 2115 \\
\hline tnz81-630a-2338 & $2 \mathrm{D}$ & 2525615 & 2553572 & 6139058 & 6163117 & 5024 & 2338 \\
\hline tnz81-630a-3254 & $2 \mathrm{D}$ & 2525760 & 2553726 & 6138935 & 6163040 & 5160 & 1812 \\
\hline tnz81-632-3254 & $2 \mathrm{D}$ & 2537515 & 2553842 & 6146751 & 6161019 & 5128 & 1812 \\
\hline tnz81-635a-3254 & $2 \mathrm{D}$ & 2518299 & 2527802 & 6117648 & 6117702 & 5136 & 1812 \\
\hline tnz81-639a-3254 & $2 \mathrm{D}$ & 2519282 & 2527788 & 6114644 & 6114725 & 5136 & 1812 \\
\hline tnz81-641p-1987 & $2 \mathrm{D}$ & 2531352 & 2542631 & 6111802 & 6111877 & 4724 & 1987 \\
\hline tnz81-643p-1987 & $2 \mathrm{D}$ & 2527984 & 2542141 & 6108647 & 6108833 & 4724 & 1987 \\
\hline tnz81-645-2308 & $2 \mathrm{D}$ & 2508938 & 2528101 & 6143608 & 6162868 & 5024 & 2308 \\
\hline $\operatorname{tnz} 81-645 \mathrm{dl}-852$ & $2 \mathrm{D}$ & 2527234 & 2536597 & 6161999 & 6170585 & 4028 & 852 \\
\hline tnz81-651-852 & $2 \mathrm{D}$ & 2546460 & 2552224 & 6143857 & 6150267 & 4024 & 852 \\
\hline tnz82-400-943 & $2 \mathrm{D}$ & 2509496 & 2522204 & 6139947 & 6151394 & 5012 & 2338 \\
\hline tnz82-401-943 & $2 \mathrm{D}$ & 2509841 & 2521815 & 6148697 & 6161214 & 5008 & 2338 \\
\hline tnz82-402-943 & $2 \mathrm{D}$ & 2510690 & 2524483 & 6141971 & 6154584 & 5012 & 2338 \\
\hline tnz82-403-943 & $2 \mathrm{D}$ & 2511090 & 2529160 & 6140137 & 6160354 & 5012 & 2338 \\
\hline tnz82-404-943 & $2 \mathrm{D}$ & 2511049 & 2526350 & 6144388 & 6158255 & 5008 & 2338 \\
\hline tnz82-405_2115 & $2 \mathrm{D}$ & 2504342 & 2533243 & 6126902 & 6160107 & 6020 & 2115 \\
\hline tnz82-405-943 & $2 \mathrm{D}$ & 2505151 & 2534042 & 6127789 & 6160990 & 5008 & 2338 \\
\hline tnz82-406-943 & $2 \mathrm{D}$ & 2519781 & 2527608 & 6147414 & 6154486 & 4016 & 2338 \\
\hline tnz82-407-2338 & $2 \mathrm{D}$ & 2507266 & 2539193 & 6125989 & 6162504 & 5028 & 2338 \\
\hline tnz82-408-2338 & $2 \mathrm{D}$ & 2518338 & 2538100 & 6143329 & 6161063 & 5020 & 2338 \\
\hline tnz82-409-2338 & $2 \mathrm{D}$ & 2529199 & 2545276 & 6146720 & 6165444 & 5020 & 2338 \\
\hline tnz82-410-2338 & $2 \mathrm{D}$ & 2528483 & 2540595 & 6143008 & 6153620 & 5024 & 2338 \\
\hline tnz82-411-2338 & $2 \mathrm{D}$ & 2530251 & 2542200 & 6145962 & 6159485 & 5020 & 2338 \\
\hline tnz82-412-2338 & $2 \mathrm{D}$ & 2529086 & 2541167 & 6143971 & 6154510 & 5016 & 2338 \\
\hline tnz82-413-2338 & $2 \mathrm{D}$ & 2534252 & 2547894 & 6143795 & 6159194 & 5020 & 2338 \\
\hline tnz82-414-2338 & $2 \mathrm{D}$ & 2530092 & 2542279 & 6145184 & 6155914 & 6028 & 2338 \\
\hline tnz82-416-2338 & $2 \mathrm{D}$ & 2526014 & 2543291 & 6145515 & 6160580 & 5024 & 2338 \\
\hline tnz82-418-2338 & $2 \mathrm{D}$ & 2531463 & 2538789 & 6150739 & 6157049 & 5024 & 2338 \\
\hline tnz82-418a-2338 & $2 \mathrm{D}$ & 2538798 & 2543608 & 6146546 & 6150734 & 5024 & 2338 \\
\hline tnz82-420-2338 & $2 \mathrm{D}$ & 2532529 & 2542308 & 6149825 & 6158245 & 5020 & 2338 \\
\hline tnz82-422-2338 & $2 \mathrm{D}$ & 2530620 & 2545359 & 6148205 & 6160815 & 5020 & 2338 \\
\hline tnz82-424-2338 & $2 \mathrm{D}$ & 2533963 & 2546466 & 6149263 & 6159910 & 5016 & 2338 \\
\hline tnz82-426-2338 & $2 \mathrm{D}$ & 2541885 & 2544842 & 6152741 & 6155236 & 5020 & 2338 \\
\hline tnz82-426a-2338 & $2 \mathrm{D}$ & 2534966 & 2541877 & 6155250 & 6161244 & 5020 & 2338 \\
\hline tnz82-428-2338 & $2 \mathrm{D}$ & 2540445 & 2550133 & 6153705 & 6162562 & 5012 & 2338 \\
\hline tnz82-430_2115 & $2 \mathrm{D}$ & 2537120 & 2538619 & 6129092 & 6135402 & 6016 & 2115 \\
\hline tnz82-430a_2115 & $2 \mathrm{D}$ & 2536281 & 2537828 & 6132503 & 6138918 & 6016 & 2115 \\
\hline tnz84-500-2338 & $2 \mathrm{D}$ & 2528702 & 2537201 & 6140200 & 6147937 & 4120 & 2338 \\
\hline tnz84-501-2338 & $2 \mathrm{D}$ & 2535365 & 2540901 & 6152772 & 6159092 & 5020 & 2338 \\
\hline tnz84-503-2338 & $2 \mathrm{D}$ & 2536498 & 2542054 & 6151839 & 6158176 & 5016 & 2338 \\
\hline tnz84-504-2338 & $2 \mathrm{D}$ & 2529101 & 2538304 & 6141797 & 6150145 & 4124 & 2338 \\
\hline tnz84-505-2338 & $2 \mathrm{D}$ & 2530243 & 2538917 & 6143234 & 6149547 & 5020 & 2338 \\
\hline tnz84-506-2338 & $2 \mathrm{D}$ & 2533675 & 2539920 & 6142635 & 6148206 & 5016 & 2338 \\
\hline
\end{tabular}




\begin{tabular}{llllllll} 
Name & Type & $\mathbf{X ~ m i n}$ & $\mathbf{X ~ m a x}$ & $\mathbf{Y ~ m i n}$ & $\mathbf{Y ~} \mathbf{m a x}$ & $\mathbf{T ~ m a x}$ & PR \\
\hline \hline tnz84-507-2338 & 2D & 2530268 & 2544268 & 6141425 & 6151718 & 4128 & 2338 \\
tnz84-508-2338 & 2D & 2534819 & 2541337 & 6143087 & 6148971 & 5024 & 2338 \\
tnz84-509-2338 & 2D & 2538836 & 2554179 & 6141308 & 6141356 & 5028 & 2338 \\
tnz84-510-2338 & 2D & 2535182 & 2541446 & 6144090 & 6149678 & 5016 & 2338 \\
tnz84-511-2338 & 2D & 2538836 & 2554249 & 6136919 & 6137012 & 5016 & 2338 \\
tnz84-512-2338 & 2D & 2535677 & 2541509 & 6152500 & 6157560 & 5024 & 2338 \\
tnz84-513-2338 & 2D & 2538787 & 2554151 & 6129611 & 6129773 & 5008 & 2338 \\
tnz84-514-2338 & 2D & 2536675 & 2542279 & 6153789 & 6158687 & 5020 & 2338 \\
tnz84-515-2338 & 2D & 2540802 & 2554181 & 6123420 & 6123526 & 5008 & 2338 \\
tnz84-516-2338 & 2D & 2545115 & 2545153 & 6112299 & 6136037 & 4008 & 2338 \\
tnz84-518-2338 & 2D & 2550002 & 2550031 & 6114038 & 6135895 & 5008 & 2338 \\
tnz84-519_1987 & 2D & 2538811 & 2546138 & 6111776 & 6111807 & 5040 & 1987 \\
tnz84-522_2115 & 2D & 2534853 & 2539419 & 6127706 & 6140320 & 4120 & 2115 \\
tnz84-524-2338 & 2D & 2529356 & 2536648 & 6128221 & 6137517 & 4016 & 2338 \\
tnz86-101_2115 & 2D & 2497419 & 2509435 & 6114188 & 6134041 & 6024 & 2115 \\
tz-01-2681 & 2D & 2624203 & 2633223 & 6160792 & 6160795 & 7176 & 2681 \\
tz-02-2681 & 2D & 2622102 & 2633905 & 6160195 & 6160199 & 7188 & 2681 \\
tz-03-2681 & 2D & 2622002 & 2634546 & 6159599 & 6159601 & 7192 & 2681 \\
tz-04-2681 & 2D & 2621496 & 2635587 & 6158997 & 6159007 & 7192 & 2681 \\
tz-05-2681 & 2D & 2621506 & 2636914 & 6158214 & 6158231 & 7184 & 2681 \\
tz-06-2681 & 2D & 2623028 & 2638229 & 6157479 & 6157483 & 7180 & 2681 \\
tz-07-2681 & 2D & 2629994 & 2630010 & 6150224 & 6164451 & 7184 & 2681 \\
tz-10-2681 & 2D & 2625801 & 2633286 & 6153527 & 6160782 & 7180 & 2681 \\
tz-11-2681 & 2D & 2626885 & 2634517 & 6152334 & 6159727 & 7180 & 2681 \\
tz-13-2681 & 2D & 2629933 & 2638168 & 6154983 & 6163211 & 7184 & 2681 \\
tz-14-2681 & 2D & 2629538 & 2637764 & 6154666 & 6162899 & 7188 & 2681 \\
tz-16-2681 & 2D & 2628746 & 2636944 & 6154080 & 6162271 & 7184 & 2681
\end{tabular}


Seismic acquisition, processing, and reprosessing reports

ARCO Petroleum New Zealand InC. (1990) 1990 Seismic Survey Ppl38446, Offshore Taranaki, New Zealand. (Ar90 Survey). Ministry of Economic Development unpublished petroleum report, Ministry of Economic Development. Wellington. PR1629, 11p., 19 enclosures. Compagnie Generale De GeophysiQue (2001) Pep38737 Reprocessing Report. Ministry of Economic Development unpublished petroleum report. 2664, Ministry of Economic Development. Wellington. 2664, 44p.

Digicon Geophysical LtD. (1997) Kiwa Seismic Reprocessing, Pep 38460. Ministry of Economic Development unpublished petroleum report. 2308, Ministry of Economic Development. Wellington. 2308, 145p., 141 enclosures.

Digital EXPloration LTD. (1994) Pep 38413 Seismic Reprocessing Program. Seismic Data Processing Report, Taranaki Basin. Ministry of Economic Development unpublished petroleum report. 2115, Ministry of Economic Development. Wellington. 2115, 113p., 164 enclosures.

EXPlORE Digicon / GeCO-PRAKLA (1995) 1995 Seismic Survey, Pike Area. Pep38413. (Ct95 Lines). Ministry of Economic Development unpublished petroleum report. 2125, Ministry of Economic Development. Wellington. 2125, 248p., 238 enclosures.

FRIED, J. (1992) Ppl38708, Ppl38709 Reprocessing Program, South Wanganui Basin. Ministry of Economic Development unpublished petroleum report. 1985, Ministry of Economic Development. Wellington. 1985, 156p., 190 enclosures.

GECO-PRAKLA (1990) 1990 Seismic Survey Ppl38409 (Nt90 Lines). Ministry of Economic Development unpublished petroleum report, Ministry of Economic Development. Wellington. PR1816, 15p., 13 enclosures.

GECO-PRAKLA (1991a) 1991 Seismic Survey, Ppl38422 Ppl38443 Ppl38444. Ministry of Economic Development unpublished petroleum report. 1948, Ministry of Economic Development. Wellington. 1948, 168p., 135 enclosures.

GECO-PRAKLA (1991b) Pml38144/145 Moki / Maui-4 1991 Reprocessing. Ministry of Economic Development unpublished petroleum report. 1812, Ministry of Economic Development. Wellington. 1812, 50p., 47 enclosures.

GeCo-PRAKLA, S. (1999) Maari 3d Seismic Survey. Ministry of Economic Development unpublished petroleum report. 2598, Ministry of Economic Development. Wellington. 2598, $573 \mathrm{p}$.

GECO NEw ZEALAND (1988) Offshore Taranaki Ppl38418 Reprocessing. Ministry of Economic Development unpublished petroleum report. 1662, Ministry of Economic Development. Wellington. 1662, 74p., 71 enclosures.

GeOPHYSICAL SERVICE INC. (1985) Operations Report Marine Seismic Survey Ppl 38083 Taranaki Bight. Ministry of Economic Development unpublished petroleum report, Ministry of Economic Development. Wellington. PR1104, 49p., 43 enclosures.

JoNeS, N. \& BuCHAN, R. (1998) Kate 2d Marine Seismic Survey, Pep38460 and Pep38466, K98 Lines. Ministry of Economic Development unpublished petroleum report. 2366, Ministry of Economic Development. Wellington. 2366, 761p., 114 enclosures.

KenMORE GeOPHYSICAL (2001) Reprocessing of Seismic Lines Pr84-88-213, Pr84-88-214 \& Pr84-88-215. Ministry of Economic Development unpublished petroleum report, Ministry of Economic Development. Wellington. PR2677, 13p., 19 enclosures.

LimiteD, D.G. (1996) Tory Marine Seismic Survey, Pep 38460. (T96 Lines). Ministry of Economic Development unpublished petroleum report. 2307, Ministry of Economic Development. Wellington. 2307, 857p., 884 enclosures.

Multiwave Geophysical Company (2003) Pep38472 2003 Ray 2d Seismic Survey. Ministry of Economic Development unpublished petroleum report. 2794, Ministry of Economic Development. Wellington. 2794, 43p., 14 enclosures. 
New Zealand Overseas Petroleum LtD. (2004) Pep38460 Scanned and Vectorized Seismic Data. Ministry of Economic Development unpublished petroleum report, Ministry of Economic Development. Wellington. PR3074.

OMV NeW ZEALAND LTD. (2002) Pep38472 2002 Reprocessing. Ministry of Economic Development unpublished petroleum report, Ministry of Economic Development. Wellington. PR2992, 3p., 71 enclosures.

PeTrOCORP (1995) Offshore 2d Seismic Survey, 1995/1996. P95 Lines. Ppl38455, Ppl38456, Ppl38457, Ppl38458, Ppl38459. Ministry of Economic Development unpublished petroleum report. 2261, Ministry of Economic Development. Wellington. 2261, 723p., 315 enclosures.

Robertson RESEARCH (1997) Tui/Toke 1997 Seismic Reprocessing, Pep38460 (Stos95 Lines). Ministry of Economic Development unpublished petroleum report, Ministry of Economic Development. Wellington. PR2403, 3p., 1 enclosures.

SHell BP TodD OIL SeRvices LTD. (1973) Kapuni Field Seismic Survey Data. Ministry of Economic Development unpublished petroleum report, Ministry of Economic Development. Wellington. PR624, 70p., 35 enclosures.

Shell Petroleum Mining - EXPloration Consultancy Group (2002) Licence Pep 38474 Technical Evaluation. Ministry of Economic Development unpublished petroleum report. 2708, Ministry of Economic Development. Wellington. 2708, 64p., 68 enclosures.

SHELl TODD OIL SERVICES LTD. (1999) Maui 3d Reprocessing 1999. Ministry of Economic Development unpublished petroleum report. 2546, Ministry of Economic Development. Wellington. 2546.

SHELl TODD OIL SERVICES LTD. (2002) Kaheru 2d Transition Zone Seismic Survey. Ministry of Economic Development unpublished petroleum report. 2681, Ministry of Economic Development. Wellington. 2681, 114p., 113 enclosures.

SimOn-Horizon Australia (1992) 1992 Seismic Reprocessing Ppl 38406 Ppl 38407. Ministry of Economic Development unpublished petroleum report. 1987, Ministry of Economic Development. Wellington. 1987, 26p., 24 enclosures.

StIRling Petroleum NL (1989) Reprocessing Report Ppl38406. Ministry of Economic Development unpublished petroleum report, Ministry of Economic Development. Wellington. PR1526, 47p., 44 enclosures.

TGS-NOPEC (2001) Astrolabe Seismic Survey. Ministry of Economic Development unpublished petroleum report. 2847, Ministry of Economic Development. Wellington, 301p.

ToOMATH, A. (1991) Ppl38409 Offshore Taranaki, Seismic Interpretation Report. Ministry of Economic Development unpublished petroleum report, Ministry of Economic Development. Wellington. PR1807, 26p., 10 enclosures.

TRICENTROL OIL COMPANY LTD. (1981) Marine Seismic Survey Ppl38114 Offshore Taranaki. Ministry of Economic Development unpublished petroleum report. 852, Ministry of Economic Development. Wellington. 852, 4p., 104 enclosures.

WESTERN GEOPHYSICAL (1996) Reprocessed Seismic Lines, Offshore Southern Taranaki Basin, Pep38456. Ministry of Economic Development unpublished petroleum report, Ministry of Economic Development. Wellington. PR2306, 71p., 68 enclosures.

WESTERN GEOPHYSICAL COMPANY (1986) Final Report of Operation and Field Work in Prospect Area Taranaki, Maui Pml381012. Ministry of Economic Development unpublished petroleum report. 1219, Ministry of Economic Development. Wellington. 1219, 495p., 257 enclosures.

Western Geophysical Company (1996) Reprocessed Seismic Lines, Offshore Southern Taranaki Basin, Pep38455. Ministry of Economic Development unpublished petroleum report. 2304, Ministry of Economic Development. Wellington. 2304, 47p., 44 enclosures.

WeSteRn Mining CoRPORATION (1996) The 1996 Kerry 3d Marine Seismic Survey, Pml38146. Ministry of Economic Development unpublished petroleum report. 1556, Ministry of Economic Development. Wellington. 1556, 987p., 983 enclosures.

WoODWARD, D.J. (1997) Reprocessing of Data from Pep38460 Offshore Taranaki. Ministry of Economic Development unpublished petroleum report. 2338, Ministry of Economic Development. Wellington. 2338, 98p., 71 enclosures. 


\section{Well completion reports}

Brophy, F. \& Falloon, A. (1979) North Tasman-1 Well Completion Report. Ministry of Economic Development unpublished petroleum report. 736, Ministry of Economic Development. Wellington, 243p., 247 enclosures.

CROCKER, S. (1991) Toru-1 Well Completion Report Ppl 38116. Ministry of Economic Development unpublished petroleum report. 1668, Ministry of Economic Development. Wellington, 1438p., 1420 enclosures.

Crowley, J., Way, C.J. \& Purcell, D. (1989) Kupe South-4 Well Completion Report. Ppl38116. Ministry of Economic Development unpublished petroleum report. 1483, Ministry of Economic Development. Wellington, 1089p., 1015 enclosures.

DePARTMENT, E. (1984) Well Completion Report Moki-2, Moki-2a Ppl 38114 Offshore Taranaki. Ministry of Economic Development unpublished petroleum report. 1100, Ministry of Economic Development. Wellington. 1100, 353p., 353 enclosures.

Donaldson, I.F., WAY, C.J. \& WellensieK, J.A. (1987) Kupe South-2 Well Completion Report Ppl 38116. Ministry of Economic Development unpublished petroleum report. 1285, Ministry of Economic Development. Wellington, 2198p., 2124 enclosures.

Donaldson, I.F., WAY, C.J. \& EVERETT, T. (1988) Kupe South-3, Kupe South-3a, Kupe South3b, Well Completion Report Ppl 38116. Ministry of Economic Development unpublished petroleum report. 1368, Ministry of Economic Development. Wellington. 1368, 2169p., 2120 enclosures.

DufF, S., Elliot, C., Morgans, H.E.G. \& Pocknall, D.T. (1991) Kupe South-5, Well Completion Report. Pp138116. Ministry of Economic Development unpublished petroleum report. 1678, Ministry of Economic Development. Wellington, 1595p., 1519 enclosures.

HALliburton Australia PTy LTD. (1999) Maari-1 \& 1a Well Completion Report, Ppl 38413. Ministry of Economic Development unpublished petroleum report. 1572, Ministry of Economic Development. Wellington. 1572, 626p., 645 enclosures.

Matthews, E.R. \& BenNeTt, D.J. (1987) Kupe South-1 Well Completion Report Ppl 38116. Ministry of Economic Development unpublished petroleum report. 1284, Ministry of Economic Development. Wellington, 982p., 985 enclosures.

MiLlS, K. (2000) Hochstetter-1 Well Completion Report. Pep 38460. Offshore Taranaki Basin. Ministry of Economic Development unpublished petroleum report. 2524, Ministry of Economic Development. Wellington, 517p., 516 enclosures.

Milne, A. \& QuicK, R. (1999) Waka Nui-1 Well Completion Report. Pep 38602. Ministry of Economic Development unpublished petroleum report. 2436, Ministry of Economic Development. Wellington. 2436, 922p., 924 enclosures.

MorRISON, W.K. \& RIVERS, T.L. (1991) Final Geological Report Motueka-1. Ppl38406. Ministry of Economic Development unpublished petroleum report. 1685, Ministry of Economic Development. Wellington. 1685, 130p., 138 enclosures.

New Zealand Overseas Petroleum LtD. (2004a) Pukeko-1 Well Completion Report. Ministry of Economic Development unpublished petroleum report. 2928, Ministry of Economic Development. Wellington, 1826p., 1822 enclosures.

New ZEAland OverSEas Petroleum LTD. (2004b) Kiwi-1 Well Completion Report. Ministry of Economic Development unpublished petroleum report. 2995, Ministry of Economic Development. Wellington, 991p., 994 Enclosures.

Nz Aquitaine Petroleum, L.T.D. (1976) Well Completion Report Fresne-1. Ministry of Economic Development unpublished petroleum report. 674, Ministry of Economic Development. Wellington, $157 \mathrm{p}$.

NZ Aquitaine Petroleum LTD. (1976) Well Completion Report Surville-1. Ministry of Economic Development unpublished petroleum report. 677, Ministry of Economic Development. Wellington, 141p., 146 enclosures.

OMV NeW ZEALAND LTD. (2003) Maari-2 Well Completion Report. Ministry of Economic Development unpublished petroleum report. 2772, Ministry of Economic Development. Wellington. 2772, 1135p. 
Palmer, J. (1984) Tahi-1 Well Completion Report. Ppl 38116. Ministry of Economic Development unpublished petroleum report. 1030, Ministry of Economic Development. Wellington, 1186p., 1184 enclosures.

SHELl BP TODD OIL SERVICES LTD. (1969) Maui-1 Well Resume. Ministry of Economic Development unpublished petroleum report. 540, Ministry of Economic Development. Wellington, 224p., 222 enclosures.

SHELl BP TODD OIL SERVICES LTD. (1970a) Well Resume Maui-3. Ministry of Economic Development unpublished petroleum report. 542, Ministry of Economic Development. Wellington, 120p., 129 enclosures.

SHELl BP TODD OIL SERVICES LTD. (1970b) Well Resume Maui-4. Ministry of Economic Development unpublished petroleum report. 543, Ministry of Economic Development. Wellington, 248p., 246 enclosures.

SHELl BP TODD OIL SERVICES LTD. (1970c) Well Resume Maui-2. Ministry of Economic Development unpublished petroleum report. 541, Ministry of Economic Development. Wellington, 143p., 111 enclosures.

SHELl BP TODD OIL SERVICES LTD. (1976a) Well Resume Kupe-1. Ministry of Economic Development unpublished petroleum report. 662, Ministry of Economic Development. Wellington, 252p., 256 enclosures.

SHELl BP TODD OIL SERVICES LTD. (1976b) Well Resume, Tane-1 (Offshore). Crown Minerals Open File Petroleum Report, 698.

SHELl BP TOdD OIL SERvices LTD. (1981) Well Resume, Wainui-1. Crown Minerals PPL 38049 Open File Pet. Report 869.

SHELl BP TODD OIL SERVICES LTD. (1982) Well Resume Kiwa-1 Ppl 38055. Ministry of Economic Development unpublished petroleum report. 880, Ministry of Economic Development. Wellington, 310p., 314 enclosures.

SHell BP TODD OIL SERVICES LTD. (1984) Well Completion Report Ariki-1. Ppl 38048, Exploration, Department Ministry of Economic Development. Wellington. 1038, 179p., 145 enclosures.

SHELl BP TOdD OIL SERVICES LTD. (1987) Well Resume Maui-7 Petroleum Mining Licence 381012 Taranaki, New Zealand. Ministry of Economic Development unpublished petroleum report. 1218, Ministry of Economic Development. Wellington. 1218, 297p., 216 enclosures.

SHELl TODD OIL SERVICES LTD. (1994) Mb-P(8) Well Completion Report, Maui B Field, Pml 381012. Offshore Taranaki Basin. Ministry of Economic Development unpublished petroleum report. 2018, Ministry of Economic Development. Wellington. 2018, 1153p., 1151 enclosures.

SHELl TODD OIL SERVICES LTD. (2004) Takapou-1 Well Completion Report. Ministry of Economic Development unpublished petroleum report. 3032, Ministry of Economic Development. Wellington, 562p., 565 Enclosures.

T. STROUd, D.M. \& LEASK, B. (2004) Amokura-1 Well Completion Report. Ministry of Economic Development unpublished petroleum report. 2920, Ministry of Economic Development. Wellington, 1296p., 1293 Enclosures.

T. STROUd, D.M.L.F.S.W.K.M. (2003) Tui-1 Well Completion Report. Ministry of Economic Development unpublished petroleum report. 2784, Ministry of Economic Development. Wellington, 1737p., 1731 enclosures.

Tricentrol Exploration Overseas, L.T.D. (1984) Well Completion Report Moki-1 Ppl 38114. Ministry of Economic Development unpublished petroleum report. 987, Ministry of Economic Development. Wellington, 488p., 486 enclosures.

TRICENTROL EXPLORATION OVERSEAS LTD. (1985) Well Completion Report Kea-1 Ppl 38114. Ministry of Economic Development unpublished petroleum report. 1089, Ministry of Economic Development. Wellington, 618p., 612 enclosures.

VAN OYen, F.H. \& BRAnger, J. (1970) Cook-1 Well Completion Report. Ppl693. Ministry of Economic Development unpublished petroleum report. 513, Ministry of Economic Development. Wellington, 406p., 416 enclosures.

Webster, M. \& RAINEY, S. (1988) Te Whatu-1, Te Whatu-2 Well Completion Report, Ppl38114. Ministry of Economic Development unpublished petroleum report. 1345, Ministry of Economic Development. Wellington, 334p., 339 enclosures. 

The following tables show input parameters and results from back-stripping of Taranaki Basin borehole strata. The locations of these wells are plotted in Figure S1.1 and Figure 2.2. The results are discussed in individual chapters in the main body of the thesis. Individual wells are shown with columns indicating (from left to right): age (Ma) at the top of the respective formation, stratigraphic formation names from petroleum reports and reassessment by the 4D- Taranaki project (Formation), depth of the formation top $(\mathrm{Zt})$ and base $(\mathrm{Zb})$ in kilometres, paleobathymetry estimate at the top of the formation (Wdt), average grain density (rho) in $\mathrm{kg} / \mathrm{m}^{3}$, average compaction coefficient (c) in $\mathrm{km}^{-1}$, surface porosity (phi) in \%, total subsidence with compacted sediment in $\mathrm{km}$, total subsidence with decompacted sediment in $\mathrm{km}$, and tectonic subsidence in $\mathrm{km}$.

Amokoura-1
\begin{tabular}{|l|l|l|l|l|l|l|l|l|l|l|}
\hline Age & Formation & Zb & $\mathbf{Z t}$ & Wdt & rho & $\mathbf{c}$ & phi & Comp & Total & Tectonic \\
\hline 65 & North_Cape_Fm & 3.953 & 3.909 & 0.1 & 2650 & 0.33 & 45 & 0.04 & 0.07 & 0.14 \\
\hline 55 & Farewell_Fm_F1_sand & 3.909 & 3.649 & 0.05 & 2650 & 0.33 & 45 & 0.30 & 0.45 & 0.31 \\
\hline 53 & Turi_Fm & 3.649 & 3.472 & 0.05 & 2720 & 0.5 & 54 & 0.48 & 0.74 & 0.48 \\
\hline 45 & Kaimiro_D_sand & 3.472 & 3.306 & 0.05 & 2650 & 0.33 & 45 & 0.65 & 0.94 & 0.58 \\
\hline 34 & Turi_Fm & 3.306 & 3.024 & 0.1 & 2720 & 0.5 & 54 & 0.93 & 1.33 & 0.84 \\
\hline 30 & Otaraoa_Fm & 3.024 & 3.001 & 1.2 & 2720 & 0.5 & 54 & 0.95 & 1.36 & 1.95 \\
\hline 25 & Tikorangi_Fm & 3.001 & 2.952 & 1.2 & 2710 & 0.7 & 70 & 1.00 & 1.45 & 2.01 \\
\hline 19 & Taimana_Fm & 2.952 & 2.923 & 1.2 & 2720 & 0.5 & 54 & 1.03 & 1.49 & 2.02 \\
\hline 15 & Lower_Manganui_Fm & 2.923 & 2.773 & 1.2 & 2720 & 0.5 & 54 & 1.18 & 1.65 & 2.09 \\
\hline 13 & Moki_Fm & 2.773 & 2.662 & 1.2 & 2650 & 0.33 & 45 & 1.29 & 1.75 & 2.13 \\
\hline 11 & Mid_Manganui_Fm & 2.662 & 2.581 & 1 & 2720 & 0.5 & 54 & 1.37 & 1.84 & 1.97 \\
\hline 10 & Moki_2A_sand_Fm & 2.581 & 2.57 & 1 & 2650 & 0.5 & 45 & 1.38 & 1.86 & 1.97 \\
\hline 8 & Mid_Manganui_Fm & 2.57 & 2.527 & 1 & 2720 & 0.5 & 54 & 1.43 & 1.90 & 2.00 \\
\hline 7 & Tt_sand_1 & 2.527 & 2.427 & 0.8 & 2650 & 0.33 & 45 & 1.53 & 1.99 & 1.83 \\
\hline 6 & Upper_Manganui_Fm & 2.427 & 2.321 & 0.8 & 2720 & 0.5 & 54 & 1.63 & 2.11 & 1.88 \\
\hline 5 & Tt_sand_2 & 2.321 & 2.294 & 0.8 & 2650 & 0.5 & 45 & 1.66 & 2.13 & 1.89 \\
\hline 4 & Upper_Manganui_Fm & 2.294 & 1.85 & 0.6 & 2720 & 0.5 & 54 & 2.10 & 2.58 & 1.86 \\
\hline 0 & GiantForesets & 1.85 & 0.123 & 0.123 & 2720 & 0.5 & 54 & 3.83 & 3.83 & 1.82 \\
\hline
\end{tabular}


Ariki-1

\begin{tabular}{|l|l|l|l|l|l|l|l|l|l|l|}
\hline Age & Formation & Zb & $\mathbf{Z t}$ & Wdt & rho & $\mathbf{c}$ & phi & Comp & Total & Tectonic \\
\hline 65 & North_Cape_Fm & 4.762 & 4.319 & 0.05 & 2600 & 0.4 & 54 & 0.44 & 0.75 & 0.52 \\
\hline 55 & Turi_Paleocene & 4.319 & 4.09 & 0.2 & 2600 & 0.4 & 54 & 0.67 & 1.08 & 0.86 \\
\hline 38 & Turi_Eocene & 4.09 & 3.724 & 0.4 & 2600 & 0.4 & 54 & 1.04 & 1.55 & 1.30 \\
\hline 34 & Tangaroa_Fm & 3.724 & 3.611 & 0.6 & 2670 & 0.35 & 45 & 1.15 & 1.66 & 1.55 \\
\hline 28 & Tikorangi_Fm & 3.611 & 3.385 & 1.5 & 2700 & 0.4 & 48 & 1.38 & 1.91 & 2.55 \\
\hline 25 & Taimana_Fm & 3.385 & 3.347 & 1.5 & 2700 & 0.7 & 70 & 1.42 & 1.98 & 2.59 \\
\hline 22 & LwManganui_Fm & 3.347 & 2.916 & 1.5 & 2700 & 0.5 & 54 & 1.85 & 2.44 & 2.78 \\
\hline 16 & Moki_Fm_equiv. & 2.916 & 2.565 & 1.5 & 2700 & 0.5 & 54 & 2.20 & 2.79 & 2.91 \\
\hline 10 & Mohakatino_Fm & 2.565 & 2.39 & 1.5 & 2700 & 0.6 & 70 & 2.37 & 3.01 & 3.03 \\
\hline 5 & Moh_Manganui_Fm & 2.39 & 2.256 & 1.2 & 2700 & 0.5 & 54 & 2.51 & 3.12 & 2.75 \\
\hline 4 & Ariki_Fm & 2.256 & 2.147 & 0.6 & 2700 & 0.5 & 54 & 2.62 & 3.21 & 2.18 \\
\hline 0 & Giant_Foresets_Fm & 2.147 & 0.25 & 0.25 & 2700 & 0.5 & 54 & 4.51 & 4.51 & 2.22 \\
\hline
\end{tabular}

Cook-1

\begin{tabular}{|l|l|l|l|l|l|l|l|l|l|l|}
\hline Age & Formation & Zb & Zt & Wdt & rho & c & phi & Comp & Total & Tectonic \\
\hline 70 & Rakopi_Fm & 2.654 & 2.217 & 0 & 2500 & 0.5 & 54 & 0.44 & 0.67 & 0.43 \\
\hline 65 & North_Cape_Fm & 2.217 & 1.38 & 0.02 & 2650 & 0.33 & 45 & 1.27 & 1.51 & 0.85 \\
\hline 34 & Farewell_Fm & 1.38 & 0.616 & 0 & 2650 & 0.33 & 45 & 2.04 & 2.16 & 1.12 \\
\hline 28 & Abel_Head_Fm & 0.616 & 0.545 & 0.4 & 2720 & 0.5 & 54 & 2.11 & 2.22 & 1.55 \\
\hline 24 & Takaka_Fm & 0.545 & 0.511 & 1 & 2710 & 0.7 & 70 & 2.14 & 2.26 & 2.18 \\
\hline 19 & Kaipuke_Fm & 0.511 & 0.499 & 1 & 2720 & 0.5 & 54 & 2.16 & 2.26 & 2.18 \\
\hline 4 & Manganui_Fm & 0.499 & 0.225 & 0.4 & 2720 & 0.5 & 54 & 2.43 & 2.45 & 1.66 \\
\hline 0 & GF & 0.225 & 0.16 & 0.16 & 2720 & 0.5 & 54 & 2.49 & 2.49 & 1.44 \\
\hline
\end{tabular}

Fresne-1

\begin{tabular}{|l|l|l|l|l|l|l|l|l|l|l|}
\hline Age & Formation & Zb & Zt & Wdt & rho & c & phi & Comp & Total & Tectonic \\
\hline 70 & North_Cape_Fm_Eq & 2.494 & 1.221 & 0.05 & 2650 & 0.33 & 45 & 1.27 & 1.48 & 0.85 \\
\hline 65 & Puponga_Mbr & 1.221 & 0.914 & 0 & 2500 & 0.5 & 54 & 1.58 & 1.80 & 0.98 \\
\hline 34 & Farewell_Fm & 0.914 & 0.399 & 0.02 & 2650 & 0.33 & 45 & 2.10 & 2.19 & 1.16 \\
\hline 28 & Abel_Head_Fm & 0.399 & 0.377 & 0.4 & 2720 & 0.5 & 54 & 2.12 & 2.21 & 1.55 \\
\hline 24 & Takaka_Fm & 0.377 & 0.314 & 0.8 & 2710 & 0.7 & 70 & 2.18 & 2.27 & 1.99 \\
\hline 19 & Kaipuke_Fm & 0.314 & 0.228 & 1 & 2720 & 0.5 & 54 & 2.27 & 2.32 & 2.21 \\
\hline 4 & Manganui_Fm & 0.228 & 0.172 & 0.4 & 2720 & 0.5 & 54 & 2.32 & 2.36 & 1.63 \\
\hline 0 & G_Fore & 0.172 & 0.074 & 0.074 & 2600 & 0.5 & 54 & 2.42 & 2.42 & 1.33 \\
\hline
\end{tabular}


Kea-1

\begin{tabular}{|l|l|l|l|l|l|l|l|l|l|l|}
\hline Age & Formation & Zb & Zt & Wdt & rho & c & phi & Comp & Total & Tectonic \\
\hline 55 & Undiff_Kapuni_Grp & 3.115 & 2.96 & 0.02 & 2600 & 0.3 & 50 & 0.16 & 0.24 & 0.17 \\
\hline 50 & Mangahewa_C_sand & 2.96 & 2.943 & 0.05 & 2600 & 0.3 & 50 & 0.17 & 0.26 & 0.22 \\
\hline 45 & Mangahewa_C_shale & 2.943 & 2.929 & 0.05 & 2700 & 0.5 & 54 & 0.19 & 0.29 & 0.23 \\
\hline 42 & Turi_Fm & 2.929 & 2.905 & 0.05 & 2680 & 0.4 & 49 & 0.21 & 0.32 & 0.26 \\
\hline 38 & Otaraoa_Fm & 2.905 & 2.881 & 0.3 & 2700 & 0.5 & 54 & 0.23 & 0.36 & 0.53 \\
\hline 34 & Tikorangi_Fm & 2.881 & 2.785 & 0.8 & 2710 & 0.7 & 70 & 0.33 & 0.58 & 1.18 \\
\hline 25 & Taimana_Fm & 2.785 & 2.723 & 1.2 & 2700 & 0.5 & 54 & 0.39 & 0.66 & 1.62 \\
\hline 16 & Lwr_Manganui_Fm & 2.723 & 2.554 & 1.2 & 270 & 0.5 & 54 & 0.56 & 0.88 & 1.88 \\
\hline 15 & Moki_Fm & 2.554 & 2.188 & 1.2 & 2700 & 0.5 & 54 & 0.93 & 1.31 & 2.09 \\
\hline 14 & Mid_Manganui_Fm & 2.188 & 2.146 & 1.2 & 2700 & 0.5 & 54 & 0.97 & 1.35 & 2.11 \\
\hline 13.5 & M2A_sand & 2.146 & 2.13 & 1.2 & 2690 & 0.45 & 50 & 0.99 & 1.37 & 2.12 \\
\hline 13 & M_Manganui_Fm & 2.13 & 2.063 & 1.2 & 2680 & 0.4 & 49 & 1.05 & 1.43 & 2.15 \\
\hline 12 & Upp_Manganui_Fm & 2.063 & 1.669 & 1.2 & 2660 & 0.4 & 45 & 1.45 & 1.79 & 2.29 \\
\hline 11 & Sw_sand & 1.669 & 1.65 & 0.8 & 2700 & 0.45 & 49 & 1.47 & 1.81 & 1.89 \\
\hline 7 & Upp_Manganui_Fm & 1.65 & 1.03 & 0 & 2680 & 0.45 & 45 & 2.09 & 2.35 & 1.29 \\
\hline 3 & Hiatus & 1.03 & 1.03 & 0 & 2700 & 0 & 0 & 2.09 & 2.35 & 1.29 \\
\hline 2 & Wm & 1.03 & 0.78 & 0.1 & 2680 & 0.45 & 45 & 2.34 & 2.54 & 1.47 \\
\hline 0 & Wm-Wn & 0.78 & 0.1 & 0.1 & 2680 & 0.45 & 45 & 3.02 & 3.01 & 1.63 \\
\hline
\end{tabular}

\section{Kiwa-1}

\begin{tabular}{|l|l|l|l|l|l|l|l|l|l|l|}
\hline Age & Formation & Zb & Zt & Wdt & rho & c & phi & Comp & Total & Tectonic \\
\hline 75 & Basement & 3.698 & 3.679 & 0 & 2650 & 0.33 & 40 & 0.02 & 0.03 & 0.02 \\
\hline 65 & NorthCapeFm & 3.679 & 3.528 & 0 & 2700 & 0.55 & 60 & 0.17 & 0.33 & 0.22 \\
\hline 45 & KaimiroFm & 3.528 & 3.046 & 0.05 & 2700 & 0.5 & 54 & 0.65 & 1.02 & 0.64 \\
\hline 34 & TuriFm & 3.046 & 2.866 & 0.1 & 2700 & 0.5 & 54 & 0.83 & 1.24 & 0.79 \\
\hline 25 & TikorangiFm & 2.866 & 2.84 & 1 & 2690 & 0.6 & 60 & 0.86 & 1.28 & 1.71 \\
\hline 22 & TaimanaFm & 2.84 & 2.79 & 1 & 2660 & 0.4 & 45 & 0.91 & 1.32 & 1.73 \\
\hline 6 & ManganuiFm & 2.79 & 1.39 & 0.5 & 2700 & 0.45 & 49 & 2.31 & 2.67 & 1.76 \\
\hline 3 & WoWp & 1.39 & 0.89 & 0.4 & 2680 & 0.45 & 45 & 2.81 & 3.05 & 1.78 \\
\hline 2 & Wm & 0.89 & 0.76 & 0.3 & 2680 & 0.45 & 45 & 2.94 & 3.15 & 1.71 \\
\hline 0 & Wm-Wn & 0.76 & 0.16 & 0.2 & 2680 & 0.45 & 45 & 3.54 & 3.54 & 1.74 \\
\hline
\end{tabular}

Kupe-1

\begin{tabular}{|l|l|l|l|l|l|l|l|l|l|l|}
\hline Age & Formation & Zb & Zt & Wdt & rho & c & phi & Comp & Total & Tectonic \\
\hline 34 & Farewell_Fm & 3.67 & 3.18 & 0 & 2680 & 0.4 & 49 & 0.49 & 0.74 & 0.43 \\
\hline 22 & Otaraoa_Fm & 3.18 & 2.92 & 0.6 & 2700 & 0.55 & 60 & 0.75 & 1.15 & 1.27 \\
\hline 19 & Taimana_Fm & 2.92 & 2.77 & 0.3 & 2700 & 0.5 & 54 & 0.90 & 1.33 & 1.05 \\
\hline 15 & L_Manganui_Fm & 2.77 & 2.37 & 0.2 & 2700 & 0.5 & 54 & 1.30 & 1.78 & 1.15 \\
\hline 8 & U_Manganui_Fm & 2.37 & 1.97 & 0.3 & 2690 & 0.45 & 50 & 1.70 & 2.16 & 1.40 \\
\hline 6 & Kiore_Fm_Eq & 1.97 & 1.86 & 0.05 & 2680 & 0.4 & 49 & 1.81 & 2.26 & 1.18 \\
\hline 4 & Matemateaonga_Fm & 1.86 & 1.24 & 0.2 & 2660 & 0.4 & 45 & 2.43 & 2.78 & 1.51 \\
\hline 3 & Tangahoe_Fm & 1.24 & 0.92 & 0.05 & 2700 & 0.45 & 49 & 2.75 & 3.04 & 1.46 \\
\hline 0 & Giant_Foresets_Fm & 0.92 & 0.03 & 0.03 & 2680 & 0.45 & 45 & 3.64 & 3.64 & 1.63 \\
\hline
\end{tabular}


Kupe South-2

\begin{tabular}{|l|l|l|l|l|l|l|l|l|l|l|}
\hline Age & Formation & Zb & Zt & Wdt & rho & $\mathbf{c}$ & phi & Comp & Total & Tectonic \\
\hline 34 & Farewell_Fm & 3.054 & 2.82 & 0 & 2680 & 0.4 & 49 & 0.23 & 0.36 & 0.22 \\
\hline 22 & Otaraoa_Fm & 2.82 & 2.745 & 0.6 & 2700 & 0.55 & 60 & 0.31 & 0.50 & 0.91 \\
\hline 19 & Taimana_Fm & 2.745 & 2.495 & 0.5 & 2700 & 0.5 & 54 & 0.56 & 0.85 & 1.00 \\
\hline 15 & L_Manganui_Fm & 2.495 & 1.964 & 0.2 & 2700 & 0.5 & 54 & 1.09 & 1.48 & 1.01 \\
\hline 8 & U_Manganui_Fm & 1.964 & 1.783 & 0.2 & 2690 & 0.45 & 50 & 1.27 & 1.66 & 1.08 \\
\hline 6 & Kiore_Fm & 1.783 & 1.22 & 0.05 & 2680 & 0.4 & 49 & 1.83 & 2.16 & 1.13 \\
\hline 4 & Matemateaonga_Fm & 1.22 & 0.87 & 0.3 & 2660 & 0.4 & 45 & 2.18 & 2.43 & 1.48 \\
\hline 3 & Tangahoe_Fm & 0.87 & 0.624 & 0.05 & 2700 & 0.45 & 49 & 2.43 & 2.63 & 1.31 \\
\hline 0 & Giant_Foresets_Fm & 0.624 & 0.04 & 0.04 & 2680 & 0.45 & 45 & 3.01 & 3.01 & 1.43 \\
\hline
\end{tabular}

\section{Kupe South-4}

\begin{tabular}{|l|l|l|l|l|l|l|l|l|l|l|}
\hline Age & Formation & Zb & $\mathbf{Z t}$ & Wdt & rho & $\mathbf{c}$ & phi & Comp & Total & Tectonic \\
\hline 65 & North_Cape_Fm & 3.77 & 3.57 & 0 & 2680 & 0.45 & 50 & 0.20 & 0.34 & 0.21 \\
\hline 34 & Farewell_Fm & 3.57 & 3.023 & 0 & 2680 & 0.4 & 49 & 0.75 & 1.08 & 0.61 \\
\hline 32 & Matapo_Mb & 3.023 & 3.018 & 0.2 & 2650 & 0.33 & 40 & 0.75 & 1.09 & 0.81 \\
\hline 22 & Otaraoa_Fm & 3.018 & 2.79 & 0.6 & 2700 & 0.55 & 60 & 0.98 & 1.42 & 1.39 \\
\hline 19 & Taimana_Fm_equiv & 2.79 & 2.534 & 0.2 & 2700 & 0.5 & 54 & 1.24 & 1.71 & 1.12 \\
\hline 15 & L_Manganui_Fm & 2.534 & 2.038 & 0.2 & 2700 & 0.5 & 54 & 1.73 & 2.23 & 1.33 \\
\hline 6 & U_Manganui_Fm & 2.038 & 1.738 & 0 & 2690 & 0.45 & 50 & 2.03 & 2.49 & 1.23 \\
\hline 4 & Matemateaonga_Fm & 1.738 & 1.227 & 0.3 & 2660 & 0.4 & 45 & 2.54 & 2.90 & 1.66 \\
\hline 3 & Tangahoe_Fm & 1.227 & 0.97 & 0.05 & 2700 & 0.45 & 49 & 2.80 & 3.11 & 1.48 \\
\hline 0 & Giant_Foresets_Fm & 0.97 & 0.04 & 0.04 & 2680 & 0.45 & 45 & 3.73 & 3.73 & 1.67 \\
\hline
\end{tabular}

Maui-1

\begin{tabular}{|l|l|l|l|l|l|l|l|l|l|l|}
\hline Age & Formation & Zb & $\mathbf{Z t}$ & Wdt & rho & c & phi & Comp & Total & Tectonic \\
\hline 65 & North_Cape_Fm & 3.502 & 3.423 & 0 & 2600 & 0.3 & 50 & 0.08 & 0.13 & 0.08 \\
\hline 55 & Farewell_Fm_G_sand & 3.423 & 3.167 & 0.02 & 2600 & 0.3 & 50 & 0.34 & 0.51 & 0.34 \\
\hline 50 & Kaimiro_Fm_D_sand & 3.167 & 2.983 & 0.05 & 2600 & 0.3 & 50 & 0.52 & 0.76 & 0.52 \\
\hline 45 & L_Turi_Fm_D_shale & 2.983 & 2.977 & 0.05 & 2700 & 0.5 & 54 & 0.53 & 0.77 & 0.52 \\
\hline 42 & Mangahewa_C_sand & 2.977 & 2.681 & 0.05 & 2680 & 0.4 & 49 & 0.82 & 1.15 & 0.72 \\
\hline 38 & Mangahewa_C_shale & 2.681 & 2.669 & 0.05 & 2700 & 0.5 & 54 & 0.83 & 1.16 & 0.73 \\
\hline 34 & Turi_Fm & 2.669 & 2.619 & 0.01 & 2700 & 0.5 & 54 & 0.88 & 1.23 & 0.73 \\
\hline 25 & Otaraoa_Fm & 2.619 & 2.593 & 1.2 & 2700 & 0.5 & 54 & 0.91 & 1.27 & 1.94 \\
\hline 20 & Tikorangi_Fm & 2.593 & 2.529 & 1.2 & 2710 & 0.7 & 70 & 0.97 & 1.39 & 2.01 \\
\hline 19 & Taimana_Fm & 2.529 & 2.49 & 1.2 & 2700 & 0.5 & 54 & 1.01 & 1.43 & 2.03 \\
\hline 16 & L_Manganui_Fm & 2.49 & 2.37 & 1.2 & 2700 & 0.5 & 54 & 1.13 & 1.56 & 2.09 \\
\hline 15 & Moki_Fm_ & 2.37 & 2.119 & 1 & 2690 & 0.45 & 50 & 1.38 & 1.81 & 1.99 \\
\hline 14 & Mid_Manganui_Fm & 2.119 & 1.984 & 1 & 2680 & 0.4 & 49 & 1.52 & 1.94 & 2.04 \\
\hline 13 & M2A_sand & 1.984 & 1.961 & 0.8 & 2660 & 0.4 & 45 & 1.54 & 1.96 & 1.85 \\
\hline 12 & Mid_Manganui_Fm & 1.961 & 1.671 & 0.8 & 2700 & 0.45 & 49 & 1.83 & 2.23 & 1.96 \\
\hline 11 & Sw_sand & 1.671 & 1.65 & 0.3 & 2680 & 0.45 & 45 & 1.85 & 2.25 & 1.46 \\
\hline 6 & U_Manganui_Fm & 1.65 & 0.604 & 0.05 & 2680 & 0.45 & 45 & 2.90 & 3.07 & 1.49 \\
\hline 4 & Wo & 0.604 & 0.517 & 0.05 & 2680 & 0.45 & 45 & 2.99 & 3.13 & 1.51 \\
\hline 3 & Wo-Wp & 0.517 & 0.435 & 0.05 & 2680 & 0.45 & 45 & 3.07 & 3.19 & 1.53 \\
\hline 0 & Wn-Wc & 0.435 & 0.11 & 0.1 & 2680 & 0.45 & 45 & 3.39 & 3.39 & 1.65 \\
\hline
\end{tabular}

\section{Maui-2}




\begin{tabular}{|l|l|l|l|l|l|l|l|l|l|l|}
\hline Age & Formation & $\mathbf{Z b}$ & $\mathbf{Z t}$ & $\mathbf{W d t}$ & rho & $\mathbf{c}$ & phi & Comp & Total & Tectonic \\
\hline 55 & Farewell_Fm & 3.451 & 3.237 & 0 & 2680 & 0.4 & 49 & 0.30 & 0.43 & 0.23 \\
\hline 50 & Kaimiro_Fm & 3.237 & 3.076 & 0 & 2600 & 0.3 & 50 & 0.46 & 0.65 & 0.36 \\
\hline 45 & Turi_Fm & 3.076 & 3.058 & 0.05 & 2700 & 0.5 & 54 & 0.48 & 0.68 & 0.43 \\
\hline 38 & Mangahewa_Fm & 3.058 & 2.756 & 0.05 & 2680 & 0.4 & 49 & 0.78 & 1.08 & 0.64 \\
\hline 34 & Turi_Fm & 2.756 & 2.679 & 1 & 2700 & 0.5 & 54 & 0.86 & 1.19 & 1.65 \\
\hline 22 & Tikorangi_Fm & 2.679 & 2.561 & 1 & 2710 & 0.7 & 70 & 0.98 & 1.40 & 1.79 \\
\hline 19 & Taimana_Fm & 2.561 & 2.526 & 1 & 2700 & 0.5 & 54 & 1.01 & 1.44 & 1.80 \\
\hline 15 & Manganui_Fm & 2.526 & 2.383 & 1 & 2700 & 0.5 & 54 & 1.15 & 1.59 & 1.86 \\
\hline 14 & Moki_Fm & 2.383 & 2.067 & 1 & 2690 & 0.45 & 50 & 1.47 & 1.90 & 1.99 \\
\hline 13 & Manganui_Fm & 2.067 & 1.846 & 1 & 2680 & 0.4 & 49 & 1.69 & 2.10 & 2.07 \\
\hline 11 & Mount_Mess_Fm_eq & 1.846 & 1.636 & 0.2 & 2660 & 0.4 & 45 & 1.90 & 2.28 & 1.33 \\
\hline 6 & Manganui_Fm & 1.636 & 0.685 & 0.05 & 2700 & 0.45 & 49 & 2.85 & 3.06 & 1.47 \\
\hline 4 & Wo-Tk & 0.685 & 0.505 & 0.15 & 2680 & 0.45 & 45 & 3.03 & 3.18 & 1.61 \\
\hline 3 & Wp & 0.505 & 0.44 & 0.05 & 2680 & 0.45 & 45 & 3.10 & 3.22 & 1.52 \\
\hline 0 & Wm & 0.44 & 0.1 & 0.11 & 2680 & 0.45 & 45 & 3.44 & 3.43 & 1.65 \\
\hline
\end{tabular}

\section{Maui-4}

\begin{tabular}{|l|l|l|l|l|l|l|l|l|l|l|}
\hline Age & Formation & Zb & Zt & Wdt & rho & c & phi & Comp & Total & Tectonic \\
\hline 75 & Rakopi_Fm & 3.805 & 3.201 & 0 & 2500 & 0.5 & 50 & 0.60 & 0.92 & 0.56 \\
\hline 65 & North_Cape_Fm & 3.201 & 2.755 & 0.05 & 2650 & 0.33 & 45 & 1.05 & 1.41 & 0.84 \\
\hline 55 & Farewell_Fm & 2.755 & 2.165 & 0 & 2650 & 0.33 & 45 & 1.64 & 2.02 & 1.06 \\
\hline 38 & Mangahewa_Fm & 2.165 & 1.996 & 0.02 & 2650 & 0.33 & 45 & 1.81 & 2.18 & 1.15 \\
\hline 34 & Turi_Fm & 1.996 & 1.974 & 0.05 & 2720 & 0.54 & 54 & 1.83 & 2.21 & 1.20 \\
\hline 22 & Otaraoa_Fm & 1.974 & 1.856 & 1 & 2720 & 0.54 & 54 & 1.95 & 2.35 & 2.21 \\
\hline 19 & Lower_Manganui_Fm & 1.856 & 1.673 & 1 & 2720 & 0.54 & 54 & 2.13 & 2.54 & 2.30 \\
\hline 11 & Moki_Fm & 1.673 & 1.295 & 1 & 2650 & 0.33 & 45 & 2.51 & 2.84 & 2.41 \\
\hline 4 & Upper_Manganui_Fm & 1.295 & 0.388 & 0.6 & 2720 & 0.54 & 54 & 3.42 & 3.54 & 2.28 \\
\hline 0 & Giant_Foresets_Fm & 0.388 & 0.104 & 0.104 & 2720 & 0.54 & 54 & 3.70 & 3.70 & 1.83 \\
\hline
\end{tabular}


North Tasman-1

\begin{tabular}{|l|l|l|l|l|l|l|l|l|l|l|}
\hline Age & Formation & Zb & $\mathbf{Z t}$ & Wdt & rho & c & phi & Comp & Total & Tectonic \\
\hline 75 & Ncape & 2.697 & 2.639 & 0 & 2700 & 0 & 0 & 0.06 & 0.06 & 0.00 \\
\hline 70 & Wainui_Mbr & 2.639 & 2.399 & 0.02 & 2600 & 0.3 & 50 & 0.30 & 0.41 & 0.26 \\
\hline 65 & North_Cape_Fm & 2.399 & 2.218 & 0.02 & 2600 & 0.3 & 50 & 0.48 & 0.64 & 0.40 \\
\hline 55 & Farewell_Fm_E_sand & 2.218 & 2.092 & 0.02 & 2600 & 0.3 & 50 & 0.61 & 0.80 & 0.49 \\
\hline 40 & Mangahewa_C_sand & 2.092 & 1.98 & 0.05 & 2600 & 0.3 & 50 & 0.72 & 0.93 & 0.60 \\
\hline 34 & Turi_Fm & 1.98 & 1.961 & 0.1 & 2700 & 0.5 & 54 & 0.74 & 0.96 & 0.66 \\
\hline 30 & Otaraoa_Fm & 1.961 & 1.945 & 0.2 & 2680 & 0.4 & 49 & 0.75 & 0.98 & 0.77 \\
\hline 28 & Otaraoa_glauc_bed & 1.945 & 1.94 & 0.3 & 2700 & 0.5 & 54 & 0.76 & 0.99 & 0.88 \\
\hline 22 & Otaraoa_Fm & 1.94 & 1.909 & 1.2 & 2710 & 0.7 & 70 & 0.79 & 1.05 & 1.82 \\
\hline 20 & Taimana_Fm & 1.909 & 1.791 & 1.2 & 2700 & 0.5 & 54 & 0.91 & 1.19 & 1.90 \\
\hline 16 & L_Manganui_Fm & 1.791 & 1.537 & 1.2 & 270 & 0.5 & 54 & 1.16 & 1.47 & 2.24 \\
\hline 15 & Moki_Fm & 1.537 & 1.252 & 1.2 & 2700 & 0.5 & 54 & 1.45 & 1.75 & 2.37 \\
\hline 14 & Mid_Manganui_Fm & 1.252 & 1.184 & 1.2 & 2700 & 0.5 & 54 & 1.51 & 1.81 & 2.40 \\
\hline 13 & M2A_sand_ & 1.184 & 1.167 & 1.2 & 2690 & 0.45 & 50 & 1.53 & 1.83 & 2.40 \\
\hline 12 & Mid_Manganui_Fm & 1.167 & 0.661 & 1.2 & 2680 & 0.4 & 49 & 2.04 & 2.22 & 2.56 \\
\hline 11 & Sw_sand & 0.661 & 0.615 & 1.2 & 2660 & 0.4 & 45 & 2.08 & 2.25 & 2.57 \\
\hline 7 & U_Manganui_Fm & 0.615 & 0.263 & 0 & 2700 & 0.45 & 49 & 2.43 & 2.50 & 1.46 \\
\hline 2 & Hiatus & 0.263 & 0.263 & 0 & 2680 & 0 & 0 & 2.43 & 2.50 & 1.46 \\
\hline 0 & Wn-Wc & 0.263 & 0.1 & 0.1 & 2680 & 0.45 & 45 & 2.60 & 2.60 & 1.59 \\
\hline
\end{tabular}

Pukeko-1

\begin{tabular}{|l|l|l|l|l|l|l|l|l|l|l|}
\hline Age & Formation & Zb & Zt & Wdt & rho & c & phi & Comp & Total & Tectonic \\
\hline 65 & North_Cape_Fm & 4.153 & 3.993 & 0.02 & 2650 & 0.33 & 45 & 0.16 & 0.25 & 0.17 \\
\hline 58 & Farewell_Fm_E_sand & 3.993 & 3.633 & 0.02 & 2650 & 0.33 & 45 & 0.52 & 0.75 & 0.45 \\
\hline 55 & Farewell_Fm_E_shale & 3.633 & 3.53 & 0.02 & 2720 & 0.54 & 54 & 0.62 & 0.92 & 0.54 \\
\hline 43 & Kaimiro_Fm_D_sand & 3.53 & 3.487 & 0.04 & 2650 & 0.33 & 45 & 0.67 & 0.97 & 0.59 \\
\hline 40 & Mangahewa_C_sand & 3.487 & 3.266 & 0.04 & 2650 & 0.33 & 45 & 0.89 & 1.23 & 0.72 \\
\hline 38 & Mangahewa_C_shale & 3.266 & 3.251 & 0.06 & 2720 & 0.54 & 54 & 0.90 & 1.25 & 0.75 \\
\hline 34 & Turi_Fm & 3.251 & 3.223 & 0.1 & 2720 & 0.54 & 54 & 0.93 & 1.29 & 0.81 \\
\hline 32 & Otaraoa_Fm & 3.223 & 3.208 & 0.1 & 2720 & 0.54 & 54 & 0.95 & 1.32 & 0.82 \\
\hline 30 & Otaraoa_glaucbed & 3.208 & 3.204 & 1 & 2720 & 0.54 & 54 & 0.95 & 1.32 & 1.72 \\
\hline 28 & Otaraoa_Fm & 3.204 & 3.175 & 1 & 2720 & 0.54 & 54 & 0.98 & 1.36 & 1.75 \\
\hline 25 & Tikorangi_Fm & 3.175 & 3.13 & 1 & 2710 & 0.71 & 70 & 1.02 & 1.45 & 1.81 \\
\hline 19 & Lower_Manganui_Fm & 3.13 & 3.074 & 1 & 2720 & 0.54 & 54 & 1.08 & 1.52 & 1.84 \\
\hline 17 & Moki_Fm_equiv & 3.074 & 2.942 & 1 & 2650 & 0.33 & 45 & 1.21 & 1.65 & 1.89 \\
\hline 15 & Mid_Manganui_Fm & 2.942 & 2.885 & 1 & 2720 & 0.54 & 54 & 1.27 & 1.72 & 1.92 \\
\hline 13 & M2A_sand & 2.885 & 2.848 & 1 & 2650 & 0.33 & 45 & 1.31 & 1.76 & 1.93 \\
\hline 11 & Mid_Manganui_Fm & 2.848 & 2.556 & 0.8 & 2720 & 0.54 & 54 & 1.60 & 2.09 & 1.88 \\
\hline 10 & Sw_sand & 2.556 & 2.506 & 0.8 & 2650 & 0.33 & 45 & 1.65 & 2.14 & 1.90 \\
\hline 8 & Mid_Manganui_Fm & 2.506 & 2.431 & 0.8 & 2720 & 0.54 & 54 & 1.72 & 2.22 & 1.93 \\
\hline 7 & T_sand & 2.431 & 2.417 & 0.6 & 2650 & 0.33 & 45 & 1.74 & 2.23 & 1.74 \\
\hline 4 & Upper_Manganui_Fm & 2.417 & 0.85 & 0.4 & 2720 & 0.54 & 54 & 3.30 & 3.59 & 2.02 \\
\hline 0 & Giant_Foresets & 0.85 & 0.132 & 0.132 & 2720 & 0.8 & 65 & 4.02 & 4.02 & 1.90 \\
\hline & & & & & & \\
\hline
\end{tabular}


Tahi-1

\begin{tabular}{|l|l|l|l|l|l|l|l|l|l|l|}
\hline Age & Formation & Zb & Zt & Wdt & rho & c & phi & Comp & Total & Tectonic \\
\hline 75 & Rakopi_Fm & 1.746 & 1.361 & 0 & 2680 & 0.45 & 50 & 0.39 & 0.51 & 0.31 \\
\hline 65 & North_Cape_Fm & 1.361 & 1.137 & 0 & 2680 & 0.4 & 49 & 0.61 & 0.76 & 0.44 \\
\hline 6 & Pause & 1.137 & 1.137 & 0 & 1000 & 0 & 0 & 0.61 & 0.76 & 0.44 \\
\hline 4 & Matemateonga_Fm & 1.137 & 0.853 & 0.02 & 2660 & 0.4 & 45 & 0.89 & 1.03 & 0.59 \\
\hline 3 & Tangahoe_Fm & 0.853 & 0.734 & 0.05 & 2700 & 0.45 & 49 & 1.01 & 1.15 & 0.68 \\
\hline 0 & Giant_Foresets_Fm & 0.734 & 0.1 & 0.09 & 2680 & 0.45 & 45 & 1.65 & 1.65 & 0.94 \\
\hline
\end{tabular}

Takapou-1

\begin{tabular}{|l|l|l|l|l|l|l|l|l|l|l|}
\hline Age & Formation & Zb & Zt & Wdt & rho & c & phi & Comp & Total & Tectonic \\
\hline 68 & Wainui_Mbr & 4.133 & 4.037 & 0 & 2500 & 0.54 & 54 & 0.10 & 0.19 & 0.13 \\
\hline 65 & North_Cape_Fm & 4.037 & 3.963 & 0.02 & 2700 & 0.45 & 45 & 0.17 & 0.30 & 0.21 \\
\hline 55 & Turi_Fm & 3.963 & 3.699 & 0.05 & 2500 & 0.49 & 49 & 0.43 & 0.69 & 0.47 \\
\hline 43 & Kaimiro_D_sand & 3.699 & 3.658 & 0.02 & 2700 & 0.45 & 45 & 0.48 & 0.74 & 0.47 \\
\hline 34 & Turi_Fm & 3.658 & 2.943 & 0.1 & 2600 & 0.5 & 54 & 1.19 & 1.67 & 1.03 \\
\hline 28 & Otaraoa_Fm & 2.943 & 2.928 & 1 & 2710 & 0.7 & 70 & 1.21 & 1.70 & 1.95 \\
\hline 25 & Tikorangi_Fm & 2.928 & 2.878 & 1.2 & 2710 & 0.7 & 70 & 1.26 & 1.78 & 2.20 \\
\hline 21 & Taimana_Fm & 2.878 & 2.849 & 1.2 & 2000 & 0.5 & 54 & 1.28 & 1.81 & 2.22 \\
\hline 18 & Lower_Manganui_Fm & 2.849 & 2.818 & 1.2 & 2000 & 0.5 & 54 & 1.32 & 1.84 & 2.24 \\
\hline 15 & Moki_Fm & 2.818 & 2.688 & 1.2 & 2700 & 0.33 & 45 & 1.45 & 1.95 & 2.27 \\
\hline 13 & Mid_Manganu_Fm & 2.688 & 2.571 & 1.2 & 2000 & 0.5 & 54 & 1.56 & 2.07 & 2.35 \\
\hline 11 & M2A_sand & 2.571 & 2.56 & 1.2 & 2700 & 0.33 & 45 & 1.57 & 2.08 & 2.35 \\
\hline 9 & Mid_Manganui_Fm & 2.56 & 2.526 & 1.2 & 2000 & 0.5 & 54 & 1.61 & 2.12 & 2.37 \\
\hline 8 & Tt_sand_1 & 2.526 & 2.51 & 1.2 & 2700 & 0.33 & 45 & 1.62 & 2.13 & 2.38 \\
\hline 7 & Upper_Manganui_Fm & 2.51 & 2.314 & 1.2 & 2000 & 0.5 & 54 & 1.82 & 2.33 & 2.51 \\
\hline 6 & Tt_sand_2 & 2.314 & 2.274 & 1.2 & 2700 & 0.33 & 45 & 1.86 & 2.36 & 2.52 \\
\hline 4 & Upper_Manganui_Fm & 2.274 & 1.289 & 1 & 2700 & 0.5 & 54 & 2.84 & 3.24 & 2.64 \\
\hline 0 & Giant_Foresets & 1.289 & 0.152 & 0.15 & 2000 & 0.8 & 70 & 3.98 & 3.98 & 2.27 \\
\hline & & & & & & & & \\
\hline
\end{tabular}

Tane-1

\begin{tabular}{|l|l|l|l|l|l|l|l|l|l|l|}
\hline Age & Formation & $\mathbf{Z b}$ & $\mathbf{Z t}$ & Wdt & rho & $\mathbf{c}$ & phi & Comp & Total & Tectonic \\
\hline 75 & Rakopi_Fm & 4.475 & 4 & 0 & 2600 & 0.4 & 54 & 0.48 & 0.79 & 0.50 \\
\hline 70 & Wainui_Mbr & 4 & 3.638 & 0 & 2600 & 0.4 & 54 & 0.84 & 1.28 & 0.77 \\
\hline 65 & North_Cape_Fm & 3.638 & 3.492 & 0.02 & 2670 & 0.5 & 54 & 0.98 & 1.47 & 0.88 \\
\hline 55 & Paleocene & 3.492 & 3.25 & 0.07 & 2700 & 0.5 & 54 & 1.23 & 1.76 & 1.06 \\
\hline 34 & Turi_Fm & 3.25 & 2.633 & 0.15 & 2700 & 0.4 & 50 & 1.84 & 2.38 & 1.39 \\
\hline 25 & Tikorangi_Fm & 2.633 & 2.61 & 1.5 & 2700 & 0.7 & 70 & 1.87 & 2.42 & 2.76 \\
\hline 22 & Taimana_Fm & 2.61 & 2.547 & 1.5 & 2700 & 0.5 & 54 & 1.93 & 2.48 & 2.79 \\
\hline 5 & Manganui_Fm & 2.547 & 2.209 & 1.5 & 2700 & 0.5 & 54 & 2.27 & 2.81 & 2.91 \\
\hline 4 & Ariki_Fm & 2.209 & 2.141 & 1 & 2700 & 0.6 & 70 & 2.33 & 2.90 & 2.46 \\
\hline 0 & Giant_Foresets_Fm & 2.141 & 0.236 & 0.236 & 2700 & 0.5 & 54 & 4.24 & 4.24 & 2.13 \\
\hline
\end{tabular}


Toru-1

\begin{tabular}{|l|l|l|l|l|l|l|l|l|l|l|}
\hline Age & Formation & Zb & Zt & Wdt & rho & c & phi & Comp & Total & Tectonic \\
\hline 55 & Farewell_Fm & 4.13 & 3.9 & 0 & 2680 & 0.4 & 49 & 0.23 & 0.38 & 0.23 \\
\hline 34 & Kaimiro_Fm & 3.9 & 3.74 & 0 & 2680 & 0.4 & 49 & 0.39 & 0.62 & 0.36 \\
\hline 32 & Matapo_Sandstone & 3.74 & 3.74 & 0.3 & 2650 & 0.33 & 40 & 0.39 & 0.62 & 0.66 \\
\hline 22 & Otaraoa_Fm & 3.74 & 3.52 & 0.6 & 2700 & 0.55 & 60 & 0.61 & 0.99 & 1.18 \\
\hline 19 & Taimana_Fm & 3.52 & 3.22 & 0.2 & 2700 & 0.5 & 54 & 0.91 & 1.37 & 0.97 \\
\hline 15 & L_Manganui_Fm & 3.22 & 2.91 & 0.8 & 2700 & 0.5 & 54 & 1.22 & 1.73 & 1.73 \\
\hline 8 & U_Manganui_Fm & 2.91 & 2.22 & 0.2 & 2690 & 0.45 & 50 & 1.91 & 2.42 & 1.39 \\
\hline 6 & Kiore_Fm & 2.22 & 2.02 & 0.05 & 2680 & 0.4 & 49 & 2.11 & 2.61 & 1.31 \\
\hline 4.5 & Matemateaonga_Fm & 2.02 & 1.22 & 0.05 & 2660 & 0.4 & 45 & 2.91 & 3.27 & 1.53 \\
\hline 4 & Matemateaonga & 1.22 & 1.16 & 0.5 & 2700 & 0.45 & 49 & 2.97 & 3.32 & 2.00 \\
\hline 3 & Tangahoe_Fm & 1.16 & 0.82 & 0.05 & 2700 & 0.45 & 49 & 3.31 & 3.59 & 1.65 \\
\hline 0 & Giant_Foresets_Fm & 0.82 & 0 & 0.03 & 2680 & 0.45 & 45 & 4.13 & 4.13 & 1.79 \\
\hline
\end{tabular}

Wainui-1

\begin{tabular}{|l|l|l|l|l|l|l|l|l|l|l|}
\hline Age & Formation & Zb & $\mathbf{Z t}$ & Wdt & rho & $\mathbf{c}$ & phi & Comp & Total & Tectonic \\
\hline 70 & Wainui_Mbr & 3.875 & 3.762 & 0 & 2600 & 0.5 & 0 & 0.11 & 0.11 & 0.03 \\
\hline 65 & North_Cape_Fm & 3.762 & 3.718 & 0.1 & 2650 & 0.54 & 54 & 0.16 & 0.20 & 0.19 \\
\hline 34 & Turi_Fm & 3.718 & 3.022 & 0.4 & 2700 & 0.54 & 54 & 0.85 & 1.22 & 1.06 \\
\hline 25 & Tikorangi_Fm & 3.022 & 2.968 & 1.5 & 2700 & 0.7 & 70 & 0.91 & 1.32 & 2.22 \\
\hline 22 & Taimana_Fm & 2.968 & 2.931 & 1.5 & 2650 & 0.6 & 54 & 0.94 & 1.36 & 2.24 \\
\hline 18 & Lower_Manganui_Fm & 2.931 & 2.739 & 1.5 & 2700 & 0.54 & 54 & 1.14 & 1.57 & 2.32 \\
\hline 16 & Moki_Fm_equiv & 2.739 & 2.612 & 1.5 & 2700 & 0.54 & 54 & 1.26 & 1.70 & 2.38 \\
\hline 5 & Mohakatino_Fm & 2.612 & 2.307 & 1.2 & 2700 & 0.54 & 65 & 1.57 & 2.06 & 2.27 \\
\hline 4 & Ariki_Fm & 2.307 & 2.215 & 1 & 2700 & 0.6 & 60 & 1.66 & 2.15 & 2.10 \\
\hline 0 & Giant_Foresets_Fm & 2.215 & 0.459 & 0.2 & 2700 & 0.5 & 54 & 3.42 & 3.42 & 1.73 \\
\hline
\end{tabular}

\section{Waka Nui-1}

\begin{tabular}{|l|l|l|l|l|l|l|l|l|l|l|}
\hline Age & Formation & Zb & $\mathbf{Z t}$ & Wdt & rho & c & phi & Comp & Total & Tectonic \\
\hline 62 & Kapuni_base & 3.545 & 3.464 & 0.02 & 2670 & 0.35 & 54 & 0.08 & 0.11 & 0.10 \\
\hline 60 & lower_Turi_Fm & 3.464 & 3.118 & 0.2 & 2700 & 0.4 & 54 & 0.43 & 0.55 & 0.54 \\
\hline 55 & Waipawa_Black_Shale & 3.118 & 3.092 & 0.4 & 2700 & 0.7 & 54 & 0.45 & 0.58 & 0.76 \\
\hline 50 & upper_Turi_Fm & 3.092 & 2.951 & 0.8 & 2700 & 0.5 & 54 & 0.59 & 0.74 & 1.25 \\
\hline 38 & Turi_marl & 2.951 & 2.823 & 1.5 & 2700 & 0.5 & 65 & 0.72 & 0.88 & 2.04 \\
\hline 34 & Tangaroa_equiv & 2.823 & 2.764 & 1.5 & 2700 & 0.5 & 70 & 0.78 & 0.94 & 2.08 \\
\hline 25 & Tikorangi_Fm & 2.764 & 2.579 & 1.5 & 2700 & 0.5 & 70 & 0.97 & 1.11 & 2.19 \\
\hline 18 & Taimana_Fm & 2.579 & 2.427 & 1.5 & 2700 & 0.6 & 54 & 1.12 & 1.22 & 2.23 \\
\hline 6 & Manganui_Fm & 2.427 & 2.357 & 1.5 & 2700 & 0.5 & 54 & 1.19 & 1.27 & 2.25 \\
\hline 5 & Mohakatino_Fm & 2.357 & 2.214 & 1.5 & 2700 & 0.2 & 0 & 1.33 & 1.35 & 2.23 \\
\hline 4 & Ariki_Fm & 2.214 & 2.171 & 1.5 & 2700 & 0.5 & 54 & 1.37 & 1.38 & 2.25 \\
\hline 0 & Plio-Pleistocene & 2.171 & 2.152 & 1.5 & 2700 & 0.5 & 54 & 1.39 & 1.39 & 2.25 \\
\hline
\end{tabular}


The following sections describe the details that relate to the palinspastic restoration shown in Chapter 3, including reconstructed formation thickness, deformational styles, and approaches taken to estimate eroded sediment.

\section{S3.1 Basement to Late Cretaceous (Basement-K85)}

The distribution of the earliest sequence (Basement-K85) is limited to the Manaia Graben in the east and graben systems in the NCT in the west (Figure 3.5). The timing and depositional nature of this sequence is not well constrained, since no borehole has penetrated this formation. Previous authors have suggested that these strata could be time equivalents of the Murihiku or Taniwha Formations (King \& Thrasher, 1996; Uruski et al., 2002b). Maximum decompacted sediment thicknesses and fault throws in these areas are $\sim 1.5 \mathrm{~km}$ and up to $2.5 \mathrm{~km}$, respectively (Figure 3.5). Normal faults offset basement by up to $1 \mathrm{~km}$ in the west and the amount of graben fill in the east indicates considerable early activity on the Manaia Fault. The graben-bound geographic distribution of this formation suggests that most of the formation was deposited during active extension, although the lack of displacement of the K85 horizon suggests waning of extension in the deep water area before the end of this time interval. Although poorly resolved below the tip of the Taranaki Fault on seismic data, apparently constant thickness of this package towards could indicate that this formation was more widespread towards the east before inversion.

\section{S3.2 Late Cretaceous (K85-K90)}

The Rakopi Formation (85-75 Ma) and time equivalents are widely distributed across the section, but are not present in the area of the Maui High (Figure 3.5). The sequence is up to $2.5 \mathrm{~km}$ thick in the present-day deep water area and thins onto the Western Platform. On the Western Platform, the section shows two half-graben structures in which the formation thickens up to $500 \mathrm{~m}$. In the eastern part of the profile, the main depocentres are located within the Manaia Graben and adjacent to the Cape Egmont Fault and have sediment thicknesses of up to $1.5 \mathrm{~km}$. The presence of the formation immediately west of the Manaia Fault is uncertain due to poor imaging on the seismic line, but thicknesses 
could be up to $500 \mathrm{~m}$. The roughness of the basement surface is indicative of small fault systems not included in the profile.

\section{S3.3 Latest Cretaceous (K90-P10)}

The North Cape Formation and time equivalents (75-65 Ma) exhibit a more uniform geographic distribution than previous formations. In three areas, the Manaia Graben, the hanging wall of the Cape Egmont Fault, and the NCT, maximum sediment thicknesses are between 1.2-1.4 km. While thicker hanging wall-strata in half-grabens and fault offsets indicate some syn-sedimentary fault activity (Figure 3.5), the generally more widespread distribution than older formations suggests waning control of fault structures on sediment deposition. Increased onlap of strata onto the Maui High indicates a general rise in base-level.

\section{S3.4 Paleocene and Eocene (P10-P60)}

The Paleocene (P10-P20) sequence is widely distributed and covers all previously remaining basement highs along the cross-section (Figure 3.5). The Manaia Graben represents a prominent depocentre, with sediment thicknesses of over $1.8 \mathrm{~km}$. Growth strata in the hanging wall of the Manaia Fault and eastward thinning of strata suggests syn-sedimentary fault activity. Subtle thickening of Paleocene strata on the Maui High may indicate normal displacement on the Whitiki Fault, but fault offsets are too small to be constrained and were likely on the order of $100 \mathrm{~m}$. Continuous sediment cover across the Cape Egmont Fault indicates waning of extensional activity. The sedimentary distribution is more uniform in the western part of the cross-section, with thicknesses of less than $700 \mathrm{~m}$ and gradual thinning towards the Maui area basement high and the NCT. Small offset of older strata across the Kiwa Fault indicates minor extensional activity, while the rest of the western part of the basin appears to be tectonically quiescent.

The Eocene sequence is relatively thin in the eastern part of cross-section, indicating that the Manaia Graben ceased to be a significant depocentre. Greatest Early to Middle Eocene (P20-P30, 55-40 Ma) sediment thicknesses $(>600 \mathrm{~m})$ are observed on the Western Platform, from which the sequence gradually thins to the east, where it onlaps onto the foot wall of the Manaia Fault. The Middle-Late Eocene (40-34 Ma) extends across the footwall of the Manaia Fault, indicative of further base-level rise and marine 
transgression. While the sequence does not exhibit any fault movement during the Eocene, angular reflector truncations bounding the top of the Eocene sequence on seismic indicate erosion in the area of Toru-1. Maximum decompacted thicknesses on the flanks of the Manaia structure suggests that erosion was on the order of $100 \mathrm{~m}$. Because of this relatively small amount of erosion and lack of clear indicators of original thickness, no restoration of missing section was attempted.

\section{S3.5 Oligocene and Miocene (P60-N50)}

This interval comprises five horizons (P60, N10, N30, N45, N48 and N50) that encompass the time from 34-5 Ma (Figure 3.6, Figure 3.7). Oligocene microfauna (34-24 $\mathrm{Ma}$ ) in well samples indicate significant water depth increase to over $600 \mathrm{~m}$ in the east of the basin and more than $1 \mathrm{~km}$ in the central and western parts. Decompacted strata form a westward thinning sedimentary wedge with thickest strata of over $800 \mathrm{~m}$ adjacent to the Taranaki Fault. Although correlative reference strata in the up-thrown side of the Taranaki Fault are missing, the distinct wedge geometry indicates convergent activity and flexural depression on this basin-bounding fault. In addition, slight thinning of Oligocene strata across the Manaia Anticline could indicate minor activity on the Manaia Fault. A thin blanket of Oligocene strata is evident across the western part of the crosssection.

The Early Miocene package (24-19 Ma) exhibits similar wedge geometry with maximum sediment thicknesses of about $1.5 \mathrm{~km}$ in the east, thinning westward towards the Western Platform. Thinning of strata onto the Manaia Anticline and offset older strata indicate reverse movement on the associated Manaia Fault.

The early Middle Miocene sequence geometry (19-14 Ma) indicates a basin-ward translation of the sediment wedge, with up to $1.5 \mathrm{~km}$ thick strata west of the Manaia Fault (Figure 3.6). Strata are thinning onto the Manaia Anticline $(500 \mathrm{~m})$ and slightly thicken towards the Taranaki Fault $(800 \mathrm{~m})$. The variations in sediment thickness and displacement of older strata across the Manaia Fault indicate considerable convergence (and inversion of the structure). Biostratigraphic water depth estimates samples indicate the development of upper slope to shelf environments in the eastern part of the basin, while remaining bathyal in the western parts (Shell BP Todd Oil Services Ltd., 1969; Roncaglia et al., 2008b). 
Middle Miocene (11-14 Ma) stratal patterns and well data indicate further westward progradation of the continental slope (Figure 3.6). The sediment package is thickest west of the Manaia Anticline $(\sim 1.9 \mathrm{~km})$, thins to about $800 \mathrm{~m}$ across the associated high and thickens again eastwards to about $1.3 \mathrm{~km}$ west of the Taranaki Fault. Minor offset of strata could indicate onset of convergent activity across the Cape Egmont Fault, but displacements are close to the limits of uncertainty $(<150 \mathrm{~m})$. The decompacted crosssection reveals a broad up-ward convex bulge of sediment on the Western Platform, which appears to have migrated westward between 14-11 Ma and is be interpreted as a flexural forebulge formed due to tectonic loading in the east.

The Late Miocene sequence (11-7 Ma) shows broad shelf development across the eastern and central part of the basin (Figure 3.7, centre panel). Folding and offset of strata suggests convergent activity on the Cape Egmont and Whitiki Fault, while strata across the Manaia Fault indicate a change from faulting to folding. The eastern part of the crosssection is widely marked by seismic angular truncations, indicative of widespread erosion. Eastward truncation of the additionally mapped Late Miocene reflector (N48) against overthrust basement indicates reverse activity on the Taranaki Fault at least until $8 \mathrm{Ma}$. Decompaction of the Late Miocene sequence in the area of west of the Taranaki Fault resulted in relatively flat geometry, suggesting that compressive activity ceased shortly thereafter, possibly around 7-6 Ma.

\section{S3.6 Reconstruction of the Late Miocene unconformity}

The top of the N50 sequence is marked by angular seismic reflector truncations of variable character over most of the eastern part of the section (Figure S3.1). East of the Cape Egmont Fault, sub-cropping reflector packages are relatively parallel over wide areas and are interpreted as shelfal topset facies, whereas reflectors west of the fault are interpreted as top-truncated progradational shelf margin foresets. West of the Whitiki Fault, reflectors sub-cropping the N50 horizon are relatively conformable, suggesting that the western limit of erosion was located less than $10 \mathrm{~km}$ west of this fault. The down-stepping of mounded and clinoformal reflectors surface west of this area with respect to the unconformal surface in the east is interpreted as a forced regressive strata deposited during uplift and erosion of the sediments in the eastern basin. 
Biostratigraphic paleobathymetry estimates from wells on the Maui High suggest water depth associations in sub-cropping strata of 200-700 m (Shell BP Todd Oil Services Ltd., 1969; 1970a). Based on these depth estimates and assuming an average outer shelf water depth of $\sim 150-200 \mathrm{~m}$, minimum erosion estimates range from $50-550 \mathrm{~m}$ on the Maui High. To estimate the amount of erosion in this area from seismic data, possible shelf margin geometries before erosion and re-deposition of strata were reconstructed by mapping the westernmost truncated reflector and extrapolating possible slope profiles eastward across the Maui area (Figure S3.1). Three possible shelf margin geometries were drawn and a likely maximum value of $\sim 400 \mathrm{~m}( \pm 100 \mathrm{~m})$ estimated. Depending on activity of the Whitiki Fault, the eroded thickness could be few hundred metres higher, but was likely $<600 \mathrm{~m}$ in total.

In the eastern part the profile, points of no erosion were estimated from conformable reflectors below the N50 horizon, which are found west of the Taranaki Fault and the syncline west of the Manaia Fault. From the latter syncline, reflector packages above the N48 horizon ( 9-8 Ma) thin eastwards towards and are parallel towards the west, indicating active folding on the Manaia Anticline and post-depositional uplift near the Cape Egmont Fault. Higher in the sequence, reflector packages below the N50 horizon show thinning to the east and to the west, indicating increased tilting and late stage activity on the Cape Egmont structure. The boundary between these two packages was mapped in the east an extrapolated westward parallel to the N48 horizon. This horizon is considered a minimum erosion estimate, since it assumes that no strata were deposited above the parallel package before erosion. A high erosion estimate is derived by upward translating the mapped reflector to match the deepest part of this sequence to the estimated point of no erosion west of the Manaia Anticline. This erosion estimate is corrected downwards to approximate the thinning of sediments towards the structural highs of the Cape Egmont and Manaia faults, giving likely maximum erosion estimates immediately east of the Cape Egmont Fault of $\sim 600 \mathrm{~m}( \pm 100 \mathrm{~m})$. Since reflectors are relatively conformal across the Manaia Anticline and biostratigraphic markers in wells indicate approximately shelfal values, it is not clear if erosion occurred on top of the structure during the Late Miocene. Non-erosion on the top of the structure may indicate cessation of activity on this fault considerably before the end of the Miocene. However, angular truncations observed during the Middle-Late Miocene (N30-N45) suggest erosion at multiple times in the and thus Miocene erosion values of $\sim 150$ m estimated for the crest of the Manaia anticline in this area. 


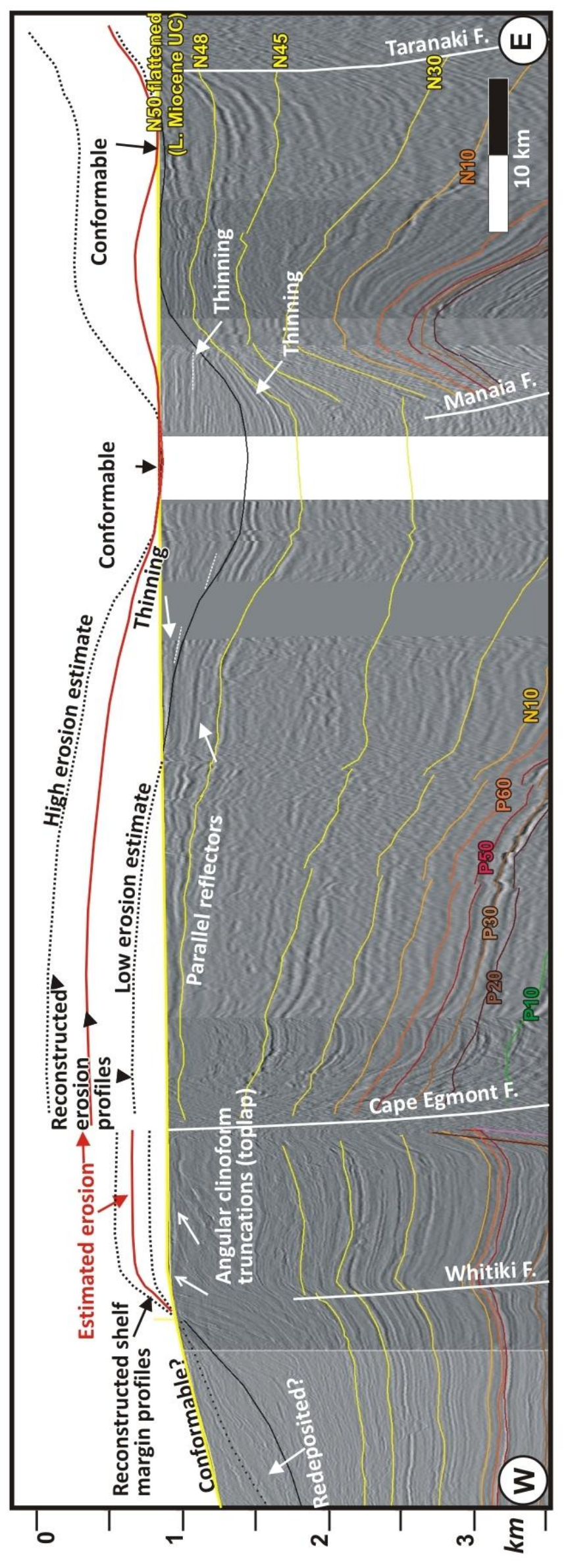

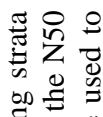

을

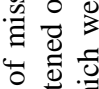

흔

㮫

氮卷

溇

Ð

o.

范

क

亲

요

ส

㓂 㝎

융.

芯. ప్

ญ्ष

这

雳

ㄷ․․

30 ป

윰

空实

澏

哥

路

कo

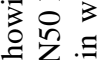

记

궁 궁

范

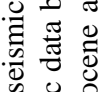

品

.

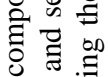

棺苛官

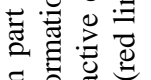

투웡

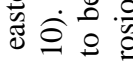

에

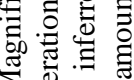

$\sum \mathbb{D}_{00} \triangleq$

的芯志

थิ ฮี

诖递串 


\section{S3.7 Latest Miocene to Pliocene (N50-N70)}

This interval spans the time between 7-3 Ma, comprising the Matemateaonga and Tangahoe Formations in the eastern part of the section and upper Manganui to Ariki Formation in the west (Figure 3.7, Figure 3.8). In the eastern basin, oldest strata above the N50 horizon consist of shallow marine ( $<100 \mathrm{~m}$ water depth) sandstones, siltstones and gravels of the Matemateaonga Formation with an estimated age of 5-6 Ma, while biostratigraphic data indicates water depth increase to about $400-500 \mathrm{~m}$ at the base of the Tangahoe Formation (4.5-4 Ma) in the eastern part of the section (Roncaglia et al., 2008a). Relatively flat reflector geometries at the base of the Tangahoe Formation suggest that the deepening occurred over a wide area in the eastern basin, while westward thinning strata and contemporary shallow marine conditions in Maui wells point to a decline of this subsidence towards the west. Thickness variations along the cross-section suggest that the eastern part received most of the sediment between 6-3 Ma (>1400 m). Comparatively little sediment was deposited west of the Cape Egmont Fault $(<600 \mathrm{~m})$, possibly as a result of the eastward depocentre formation. Besides small amount of extensional fault displacement east of the Taranaki Fault between 3-4 Ma (<100 m), no faulting is observed within Taranaki Basin.

\section{S3.8 Late Pliocene to Pleistocene (N70-Seabed)}

The Late Pliocene to Pleistocene interval ( 3-0 Ma) encompasses most of the Giant Foresets Formation on the Western Platform and shelf to shallow marine age equivalent in the east (Figure 3.8). Seismic stratal patterns suggest rapid westward progradation of the shelf margin (oblique clinoforms) and significant extensional activity on the Cape Egmont Fault (hanging wall growth strata). Greatest sediment thicknesses of about $2 \mathrm{~km}$ are found in the hanging wall of this fault as well as clinoforms on the Western Platform (Figure 3.8). Growth geometry of strata above the N70 (Tangahoe Formation) in the hanging-wall of the Cape Egmont Fault suggests the onset of extensional activity at about $3 \mathrm{Ma}$, with an estimated uncertainty of \pm 0.5 my based on the variability of age correlations with the N70 horizon in wells in the area of the Manaia Fault (Roncaglia et al., 2008a). Despite significant activity of the Cape Egmont Fault between the N70 and N80 reflectors (>1.4 km vertical displacement), contemporary displacement on smaller 
faults across the eastern basin is relatively small, increasing in activity after the time of the N80 horizon $(<2-1.5 \mathrm{Ma})$.

The N80 horizon represents an unconformable horizon with angular sup-cropping reflectors in the eastern part of the cross-section (Figure S3.2). Parallel reflectors below this unconformity indicate deposition in a relatively flat-lying environment over most of the Central Graben before uplift, tilting, and erosion. In the east, thinning of strata in the area of the Taranaki Fault indicates onset of uplift between $3 \mathrm{Ma}$ and 1.5 Ma. Although angular truncations are observed in the hanging wall of the Cape Egmont Fault, angularity could be associated with fault growth (i.e., differential subsidence or downthrow), so no restoration of eroded strata was made in this area. Missing strata further east was restored by first extrapolating non-thinning strata parallel to the underlying N70 horizon and then extrapolating the trajectories of thinning strata onto an inferred high in the east. The reconstructed package suggests eastward increasing erosion, with values of up to $800 \mathrm{~m}$ of missing strata at the eastern end of the profile.

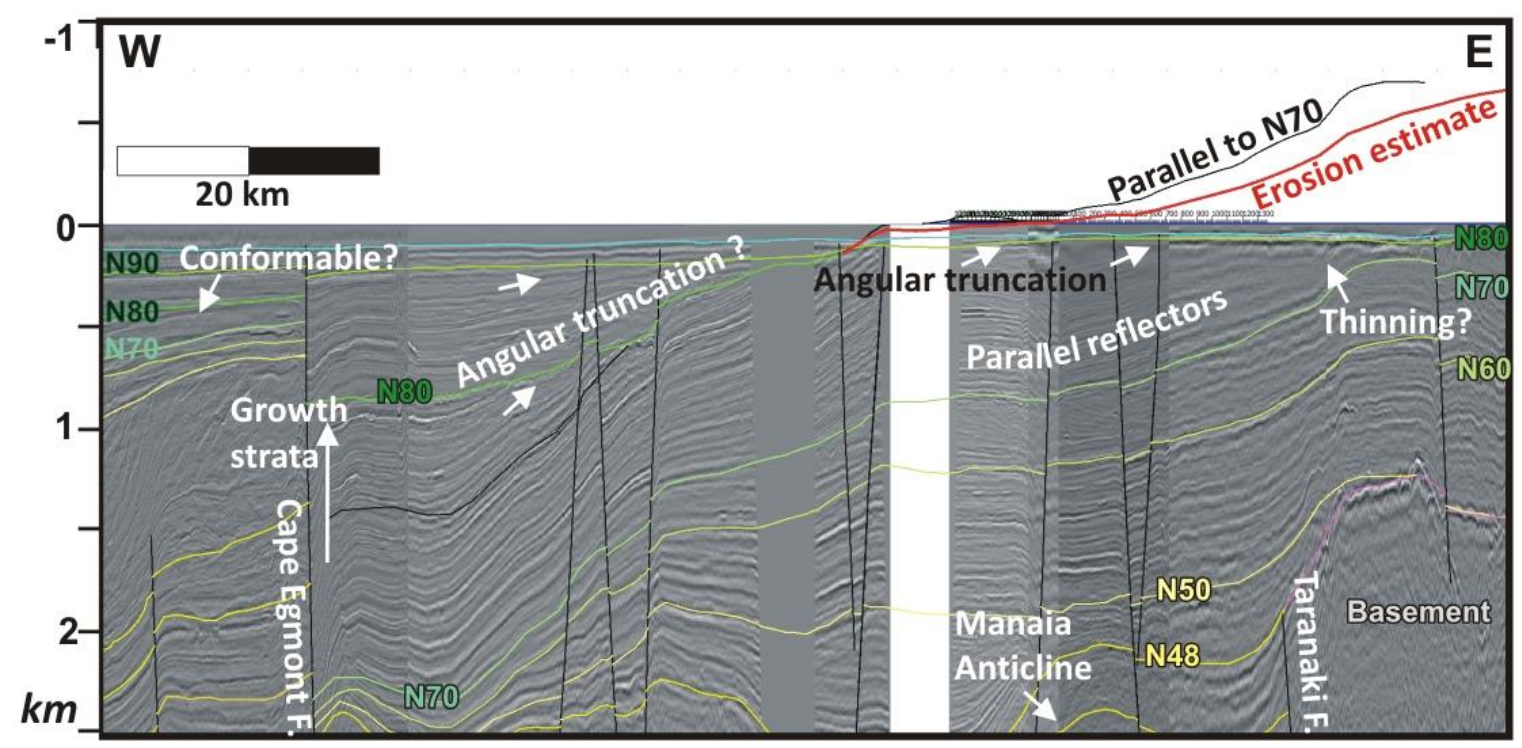

Figure S 3.1 Magnified seismic data of the eastern part of the composite cross-section, showing stratal patterns below the Plio-Pleistocene unconformity and markers used for the reconstruction of missing section (vertical exaggeration $=15$ ). Note the angularly truncated parallel reflector packages that subcrop the N80 reflector and the subparallel character of strata west of the Cape Egmont Fault. 